\title{
FUNCTIONAL CHARACTERIZATION AND EXPRESSION OF MOLLUSCAN DETOXIFICATION ENZYMES AND TRANSPORTERS INVOLVED IN DIETARY ALLELOCHEMICAL RESISTANCE
}

\author{
By \\ Kristen Elizabeth Whalen \\ Bachelor of Science, University of North Carolina, Wilmington, 2001 \\ Submitted in partial fulfillment of the requirements for the degree of \\ Doctor of Philosophy \\ at the \\ MASSACHUSETTS INSTITUTE OF TECHNOLOGY \\ and the \\ WOODS HOLE OCEANOGRAPHIC INSTITUTION
}

June 2008

(C)2008 Kristen E. Whalen

All rights reserved.

The author hereby grants to MIT and WHOI permission to reproduce paper and electronic copies of this thesis in whole or in part and to distribute them publicly.

Signature of Author

Joint Program in Oceanography/ Applied Ocean Science and Engineering Massachusetts Institute of Technology and Woods Hole Oceanographic Institution

May 16, 2008

Certified by

Mark E. Hahn

Thesis Supervisor

Accepted by

Edward F. DeLong

Chair, Joint Committee for Biological Oceanography Massachusetts Institute of Technology and Woods Hole Oceanographic Institution 
This thesis is dedicated in loving memory of my sister,

Meredith L. Whalen (1978 - 2001),

for always believing in me 


\title{
FUNCTIONAL CHARACTERIZATION AND EXPRESSION OF MOLLUSCAN DETOXIFICATION ENZYMES AND TRANSPORTERS INVOLVED IN DIETARY ALLELOCHEMICAL RESISTANCE
}

\author{
by \\ Kristen Elizabeth Whalen \\ Submitted in partial fulfillment of the requirements for the degree of \\ Doctor of Philosophy
}

\section{BRIEF ABSTRACT}

Understanding how organisms deal with potentially toxic or fitness-reducing allelochemicals is important for understanding patterns of predation and herbivory in the marine environment. The ability of marine consumers to tolerate dietary toxins may involve biochemical resistance mechanisms, which increase the hydrophilicity of compounds and facilitate their active efflux out of sensitive cells and tissues. While several allelochemical-responsive detoxification enzymes have been sequenced and functionally characterized in terrestrial invertebrates feeding on chemically defended host plants, there is virtually no information concerning the role of these biotransformation enzymes that may mediate feeding tolerance in marine invertebrates. The objective of this research was to assess the diversity and dietary regulation of cytochrome P450s (CYP), glutathione $S$-transferases (GST) and ABC transporters in the generalist marine gastropod Cyphoma gibbosum feeding on a variety of chemically defended gorgonian corals, and to identify those dietary natural products that act as substrates for these proteins.

Molecular and proteomic techniques identified both allelochemically-responsive CYPs, and constitutively expressed GSTs and transporters in Cyphoma digestive glands. Inhibition of Cyphoma GST activity by gorgonian extracts and selected allelochemicals (i.e., prostaglandins) indicated that gorgonian diets are likely to contain substrates for molluscan detoxification enzymes. In vitro metabolism studies with recombinant CYPs suggested those Cyphoma enzymes most closely related to vertebrate fatty acid hydroxylating enzymes may contribute to the detoxification of ichthyodeterrent cyclopentenone prostaglandins found in abundance in selected gorgonian species. Finally, the presence and activity of multixenobiotic resistance transporters in Cyphoma and the co-occuring specialist nudibranch, Tritonia hamnerorum, suggests these efflux transporters could function as a first line of defense against dietary intoxication. Together, these results suggest marine consumers that regularly exploit allelochemicalrich prey have evolved both general (GST and ABC transporters) and allelochemicalspecific (CYP) detoxification mechanisms to tolerate prey chemical defenses.

Thesis Supervisor: Mark E. Hahn

Title: Senior Scientist, Biology Department, WHOI 


\section{COMPLETE ABSTRACT}

Intense consumer pressure in tropical marine ecosystems not only structures the organization and functioning of marine communities, but has a profound effect on the phenotype of resident organisms. In order to persist in the midst of extreme predation and herbivory, sessile benthic marine organisms, afforded with no means of escape, often produce chemical defenses, termed allelochemicals, which render their tissues unpalatable or toxic to most potential consumers. Despite the fitness-reducing consequences of consuming noxious/toxic prey, less mobile consumers, frequently drawn to their hosts by the chemical refugia they provide, are able to tolerate the toxicological challenges posed by their prey/hosts. The processes underlying dietary allelochemical tolerance are likely mediated, in part, by biochemical resistance mechanisms that have evolved under the selective pressure of host chemical defenses. Although many have invoked this hypothesis to explain the variation in marine consumer tolerance, few studies have examined the enzymatic diversity and corresponding metabolism of dietary allelochemicals.

The shallow Caribbean reefs of the western Atlantic provide an ideal model system with which to investigate marine consumer detoxification and transport-mediated resistance to dietary allelochemicals. The ovulid gastropod Cyphoma gibbosum is considered a trophic generalist, feeding upon at least three families of allelochemicallyrich gorgonian corals. By virtue of its polyphagous diet, $C$. gibbosum is exposed to a broad and unpredictable array of gorgonian defenses likely necessitating an equally diverse set of counterdefense mechanisms. Using a combination of molecular, proteomic and biochemical approaches, I characterized the diversity and dietary regulation of three families of xenobiotic resistance proteins and examined the potential of gorgonian natural products as substrates for these proteins.

Cloning of multiple cytochrome P450 monooxygenases (CYP4) cDNAs revealed that Cyphoma digestive gland tissues expressed a total of twelve new molluscan CYPs grouped within three subfamilies, designated CYP4V10, CYP4BK, and CYP4BL. Expression of CYP4BK and CYP4BL group transcripts was significantly induced in snails feeding on the gorgonian diet Plexaura homomalla, (known to contain high concentrations of ichthyodeterrent cyclopentenone prostaglandins), compared to a control diet devoid of gorgonian chemistry. Both CYP4BK and CYP4BL subfamilies form a monophyletic clade sharing extensive sequence identity, and in some cases key active residues, with vertebrate prostaglandin-hydroxylating CYP4A and CYP4F subfamilies, suggesting that allelochemically responsive Cyphoma CYP4s may have evolved from an ancestral gene encoding an eicosanoid-metabolizing enzyme. Heterologous expression of select Cyphoma CYP4s indicated a possible role in eicosanoid metabolism, providing further evidence of the putative role of Cyphoma P450s in the detoxification of dietary prostaglandins and supporting the hypothesis that interactions between Cyphoma and its allelochemical-rich prey have contributed to the diversification of some P450 families.

Enzymatic analysis provided evidence for high, constitutive expression of glutathione $S$-transferase (GST) activity in the digestive gland homogenates from snails feeding on all seven allelochemically diverse gorgonian diets. A proteomic approach (HPLC coupled with LC-MS/MS) identified two major GST mu forms and one minor GST theta form - the latter being the first identified from a molluscan source - that were 
consistently expressed in the same relative proportion in all snail digestive glands examined. Gorgonian extracts were screened using a bioassay-guided fractionation approach for their ability to inhibit GST activity; all moderately hydrophobic extracts contained putative substrates or inhibitors for Cyphoma GSTs, suggesting that the constitutive expression of catalytically versatile enzymes may provide a competitive advantage for generalists that encounter a tremendous diversity of gorgonian defense compounds.

To further determine whether specific gorgonian allelochemicals could be substrates for consumer GSTs, I examined the prostaglandin-mediated inhibition of Cyphoma CDNB-conjugating GST activity. Enzymatic analysis indicated that prostaglandin $\mathrm{A}_{2}$, the series found in the highest concentration (ave. $2 \%$ dry weight) in gorgonian tissues, is a competitive inhibitor - and therefore likely a substrate - of affinity-purified Cyphoma GSTs. Conservative estimates of the in vivo concentration of prostaglandins indicate that GSTs would be operating at or near their physiological capacity in Cyphoma digestive gland tissues, and thus may represent effective mechanisms for prostaglandin deactivation and metabolism.

Finally, the presence and function of multixenobiotic resistance (MXR) mechanisms were demonstrated in the generalist Cyphoma gibbosum, and a co-occurring specialist nudibranch, Tritonia hamnerorum, which consumes a single species of gorgonian coral and sequesters its host's dietary defenses for its own protection. MXR expression was compared between consumers using immunochemical approaches and this analysis revealed that $\mathrm{P}$-glycoprotein was expressed in the nudibranch tissues localized to areas with the highest exposure to gorgonian allelochemicals (i.e., gut lumen and epidermis) - consistent with a role in dietary xenobiotic efflux, while comparable expression was absent in Cyphoma. A competitive-based dye efflux assay demonstrated significant MXR-mediated efflux activity in live Tritonia, suggesting that the use of transport mechanisms may provide protection against dietary toxins. In the present study, eight partial sequences belonging to both $\mathrm{ABCB}$ and $\mathrm{ABCC}$ subfamilies were cloned and characterized from Cyphoma and Tritonia tissues. Predicted protein structure and phylogenetic analyses indicate shared homologies and possible shared function with characterized vertebrate xenobiotic resistance efflux proteins. Quantitative estimates of the expression of the putative glutathione-conjugate efflux protein, MRP-1, indicated constitutive expression of this transcript in the digestive gland of Cyphoma individuals feeding on multiple gorgonian diets. The universal expression of MRP transporters in Cyphoma digestive tissues may facilitate the efflux of putative glutathione-conjugates of prostaglandin and other lipophilic gorgonian compounds.

The studies described in this thesis provide the most comprehensive investigation thus far of the three phases of detoxification and transport that may protect marine consumers from their chemically defended prey. These data indicate that both general and allelochemical-specific multixenobiotic resistance mechanisms operate in marine consumers to confer resistance to gorgonian allelochemicals. These findings will undoubtedly help provide a framework for understanding the profound variation of consumer tolerance for their chemically rich prey, and more broadly, hold great significance for understanding patterns of predation and herbivory in marine ecosystems. 


\section{Acknowledgements}

The universe is full of magical things, patiently waiting for our wits to grow sharper.

--Eden Phillpotts

Mount Everest is very high and very cold. Many people are not crazy enough to tackle the icy and desolate cliff faces of such a formidable peak. The journey to the top can be fraught with perilous mishaps that test your resolve and make you wonder why you embarked on the journey in the first place. If that weren't enticing enough, of those who do set out to reach the summit, only one in four will actually make it.

There is a clear parallel here to getting a $\mathrm{PhD}$. It requires persistence, sacrifice and copious amounts of hard work to make it to the finish. It can be a lonely soulsearching endeavor, thankfully punctuated by beautiful moments of grandeur along the way that remind you why it was that you began this epic trek. However, it is the support and encouragement of a great number of people during my journey that has allowed me to reach the summit, and made me the scientist and person I am today.

First and foremost, my sincerest gratitude to my advisor, Mark Hahn, who was the guiding force behind my success. I consider myself extremely fortunate to have had the privilege of working with such a great mentor that afforded me opportunities to pursue my passions, provided me with unwavering support, and always greeted me with an open mind and a listening ear. Thank you.

I would like to thank my committee members for their insights and thought provoking discussions over the years, including Peter Dedon, David Epel, Christopher Reddy, John Stegeman, and especially Julia Kubanek. Thank you Julia, for helping me realize my potential early on in my academic career and for being a role model, friend and colleague all at the same time.

Special thanks to my dive buddies, Carly Gaebe, Ann Tarrant and Terry Rioux, who willingly donned damp wetsuits, consumed inedible pink cake, and spent long hours in the field all in the name of science, for which I am truly grateful.

I have had the great fortune of working with some wonderful colleagues and friends during my tenure at WHOI: Sibel Karchner, Diana Franks, Matt Jenny, Rebeka Merson, Joy Lapseritis, Eric Montie, Ellen Bailey, Bruce Woodin, Jed Goldstone, Celine Godard, Marsha Gomes, Julia Westwater, and Melissa Soule; all of which lended a hand, an ear - and in some cases - a much needed glass of spirits to the cause.

Heartfelt thanks goes to Vicke Starczak for being generous with her time and sharing her statistical prowess with me. Thank you to Dexter Morin and Ching-Yu Lin for making my time out West incredibly productive and fun! Also, many thanks to David Stressor and colleagues for offering assistance when it was needed the most.

One key to success, whether you're scaling Mount Everest or toiling away at your $\mathrm{PhD}$, is to surround yourself with good people and I have benefited immensely from the generosity, advice, and love of my friends and family. My labmates, Eric and Joy, welcomed me into the Hahn lab with open arms and were always quick with words of encouragement. I will always be indebted to my fellow Redfielders: Dreux, Lou Dawg, Erin, Katie, Bucky, Annette, KT-80, and Lizzard for providing me with constant 
entertainment and a welcomed distraction from my experiments. To all, I will cherish our friendships forever.

Finally, I thank my mom for her faith in me, her patience, and reminding me that I make her proud everyday. She was my base camp, my late night proposal spell-checker, and my constant cheerleader. I could not have done this without you.

Financial support for this research was provided by the following organizations and individuals:

National Science Foundation Graduate Research Fellowship

Tropical Research Initiative Grant - Ocean Life Institute (WHOI)

Ocean Ventures Fund (WHOI)

National Undersea Research Center - Caribbean Marine Research Center, Program

Development Proposal (CMRC-03-PRMN-01-03A)

Seaspace Student Scholarship

Conchologists of America Student Award

NOAA National Sea Grant College Program (Grant No. NA16RG2273)

Woods Hole Oceanographic Institution - Sea Grant (Project No. R/P-66)

A grant from Walter A. and Hope Noyes Smith supported proteomic work at the University of California, Davis - Proteomics Center

Academic Programs Office, Woods Hole Oceanographic Institution 


\section{TABLE OF CONTENTS}

Dedication

Brief Abstract

Complete Abstract

Acknowledgements

List of Figures

List of Tables

Chapter I Introduction

Background 20

Gorgonian chemical defenses $\quad 22$

Allelochemical biotransformation and transport 25

Mechanisms of detoxification and transport 28

Phase I 29

Phase II $\quad 39$

Phase III 44

Rationale

Chapter II Proteomic identification, cDNA cloning, and enzymatic activity of glutathione $S$-transferases from the generalist marine gastropod, Cyphoma gibbosum

Abstract

Introduction

Methods

Results

Discussion

Chapter III Gorgonian host-inducible cytochrome P450s from Cyphoma gibbosum: molecular cloning, diversity and function

Abstract

Introduction

Methods

Results

Discussion 
Chapter IV Influence of gorgonian diet on the activity and expression of Cyphoma gibbosum glutathione $S$-transferases: evidence that ecologically relevant prostaglandins are substrates for molluscan GSTs
Abstract
Introduction
Methods
Results
230
Discussion

Chapter V The role of multixenobiotic transporters in generalist and specialist molluscan predators as counter-defense mechanisms against dietary chemical stress
Abstract
Introduction
Methods
Results
Discussion 


\section{LIST OF FIGURES}

\section{Chapter I}

Figure 1. Overview of allelochemical metabolism and transport

\section{Chapter II}

Figure 1. Purification of cytosolic GSTs from C. gibbosum digestive gland 106

Figure 2. SDS-PAGE of affinity purified GSTs from C. gibbosum digestive gland

Figure 3. Representative HPLC spectrum of GST subunits

Figure 4. SDS-PAGE of HPLC separated GST subunits

Figure 5. Multiple alignment of deduced amino acid sequences of CgGSTM1 and CgGSTM2 with homologous peptide fragment identification by LC-MS/MS

Figure 6. Multiple alignment of theta-class GSTs from fish species with homologous peptide fragment identification by LC-MS/MS

Figure 7. Phylogenetic tree depicting the relationship of C. gibbosum mu-class

GSTs with other invertebrate and vertebrate GSTs

\section{Chapter III}

Figure 1. Cyphoma gibbosum and gorgonian sampling location in the Exuma Keys, Bahamas

Figure 2. Feeding assay experimental design for snails used for RNA isolation

Figure 3. Feeding assay experimental design for snails used for protein isolation

Figure 4. Quantifying relative yield of a target gene by real-time quantitative PCR versus input poly(A)+ RNA concentration

Figure 5. Percent identity matrix for comparison of C. gibbosum CYP4 nucleotide and amino acid sequences 
Figure 6. Cluster analysis of CYP4-1 clones visualized by an unrooted maximum parsimony tree

Figure 7. Nucleotide alignment of full-length C. gibbosum CYP4-1v1 and CYP4$1 \mathrm{v} 2$.

Figure 8. Cluster analysis of CYP4-2 clones visualized by an unrooted maximum parsimony tree

Figure 9. Nucleotide alignment of full-length C. gibbosum CYP4-2a and CYP4$2 \mathrm{~b}$

Figure 10. Cluster analysis of CYP4-3 clones visualized by an unrooted maximum parsimony tree

Figure 11. Nucleotide alignment of eleven full-length C. gibbosum CYP4-3 cDNA sequences

Figure 12. Deduced amino acid alignment of $C$. gibbosum CYP4-1, CYP-4-2, and CYP4-3 consensus sequences

Figure 13. Phylogenetic relationships of C. gibbosum CYP4 proteins with other invertebrate and vertebrate CYP4s

Figure 14. Phylogenetic relationships among C. gibbosum CYP4-3 proteins

Figure 15. Maximum parsimony trees depicting transcripts recognized by CYP4$3_{\text {(sub A) }}$ and CYP4-3 $3_{\text {(sub B) }}$ quantitative RT-PCR primers

Figure 16. Mean CYP4 gene expression among C. gibbosum feeding on gorgonian and control diets for four days

Figure 17. Induction of CYP4 gene expression in C. gibbosum feeding on the gorgonian Plexaura homomalla compared to diet controls

Figure 18. Comparing CYP4 expression levels among time-zero and $4 \mathrm{~d}$ controlfed C. gibbosum snails collected from five reefs

Figure 19. Comparison of CYP4 gene expression in snails feeding on control or $P$. homomalla diet for $4 \mathrm{~d}$ or greater

Figure 20. Amino acid alignment for defining putative residues involved in substrate recognition and catalytic activity in allelochemically-responsive Cyphoma CYP4-2 and CYP4-3 deduced amino acid sequences 
Figure 21. Cyphoma CYP4-2 and CYP4-3 clones selected for heterologous expression in yeast

Figure 22. Recombinant expression of selected C. gibbosum CYP4s in Saccharomyces cerevisiae

Figure 23. HPLC chromatograms of leukotriene $\mathrm{B}_{4}$ metabolites formed by recombinant yeast expressing $C$. gibbosum CYP4 proteins

\section{Chapter IV}

Figure 1. GST activity levels from digestive gland cytosolic preparations of $C$. gibbosum feeding either on a control diet or six gorgonian diets in controlled $4 \mathrm{~d}$ feeding assays

Figure 2. Representative HPLC separation of affinity-purified GST subunits from a C. gibbosum digestive gland

Figure 3. Average GST subunit percent composition as a function of snail diet

Figure 4. Peak area normalized to the amount of affinity-purified GST sample applied to the HPLC column

Figure 5. Inhibition of C. gibbosum GST activity by gorgonian crude and semipurified extracts

Figure 6. Inhibition of $C$. gibbosum GST activity by the chloroform-soluble HPLC fractions from eight gorgonian species

Figure 7. LC-MS identification of $\mathrm{PGA}_{2}$ in $P$. homomalla chloroform extracts

Figure 8. Comparison of ${ }^{1} \mathrm{H}$ NMR spectra from the $\mathrm{PGA}_{2}$ standard and the chloroform-soluble fraction 1 from $P$. homomalla

Figure 9. Effect of prostaglandin A, E, and F series on cytosolic C. gibbosum GST activity

Figure 10. Inhibition of $C$. gibbosum affinity-purified GST activity by selected prostaglandins (15(R)-15-methyl $\mathrm{PGA}_{2}, 15(\mathrm{~S})-\mathrm{PGA}_{2}, 15(\mathrm{~S})-\mathrm{PGE}_{2}$ and 15(S)$\mathrm{PGF}_{2 \alpha}$ ) 
Figure 11. Lineweaver-Burke plots showing mixed inhibition of Cyphoma GSTs toward CDNB by $15(\mathrm{~S})-\mathrm{PGA}_{2}$

\section{Chapter V}

Figure 1. Partial nucleotide and deduced amino acid sequence of Cyphoma MRP$1 \mathrm{cDNA}$

Figure 2. Partial nucleotide and deduced amino acid sequence of Cyphoma MRP2 cDNA

Figure 3. Partial nucleotide and deduced amino acid sequence Tritonia MRP-1 cDNA

Figure 4. Partial nucleotide and deduced amino acid sequence Tritonia MRP-2 cDNA

Figure 5. Alignment of deduced amino acid sequences of Cyphoma and Tritonia MRP proteins

Figure 6. Partial nucleotide and deduced amino acid sequence of Cyphoma Pgp-1 cDNA

Figure 7. Partial nucleotide and deduced amino acid sequence of Cyphoma Pgp-2 cDNA

Figure 8. Partial nucleotide and deduced amino acid sequence of Tritonia Pgp-1 cDNA

Figure 9. Partial nucleotide and deduced amino acid sequence of Tritonia Pgp-2 cDNA

Figure 10. Alignment of deduced amino acid and sequences of Cyphoma and Tritonia Pgp proteins with Mouse ABCB1a

Figure 11. Comparison of molluscan and human MRP hydropathy profiles 335

Figure 12. Comparison of molluscan and mouse Pgp hydropathy profiles 337

Figure 13. Phylogenetic relationships among Cyphoma, Tritonia and human ABC transporters

Figure 14. Phylogenetic relationships among Cyphoma, Tritonia and human $\mathrm{ABCB}$ and $\mathrm{ABCC}$ protein subfamilies 
Figure 15. Detecting Pgp expression in molluscan tissue homogenates

Figure 16. Immunolocalization of Pgp in T. hamnerorum tissues

Figure 17. Immunolocalization of Pgp in T. hamnerorum tissues cont.

Figure 18. Change in intracellular fluorescence in T. hamnerorum incubated with MRP (MK571) and Pgp (verapamil) inhibitors compared to untreated controls

Figure 19. Mean MRP-1 transcript expression among $C$. gibbosum individuals feeding on a gorgonian or control diet for four days

Figure 20. Mean MRP-1 transcript expression among time-zero and four day control diet fed C. gibbosum collected from five reefs 


\section{LIST OF TABLES}

\section{Chapter I}

Table 1. Biochemical and molecular evidence for molluscan CYPs

Table 2. Biochemical and molecular evidence for molluscan ABC transporters

\section{Chapter II}

Table 1. Oligonucleotide primers used in the present study

Table 2. Specific activities and protein fold purification from a representative GST purification from Cyphoma gibbosum digestive gland

Table 3. Homologous sequences identified from the partial tryptic digests of affinity-purified GSTs from C. gibbosum separated by HPLC

\section{Chapter III}

Table 1. Summary of digestive gland RNA and protein samples collected during January 2006 feeding assays

Table 2. Degenerate and specific oligonucleotide primers used in the present study

Table 3. Quantitative PCR primers used in the present study

Table 4. Oligonucleotide primers used for recombinant C. gibbosum CYP4 expression in yeast

Table 5. Summary of $C$. gibbosum cytochrome $\mathrm{P} 450$ nomenclature

Table 6. Results of a two-way MANOVA investigating differences in digestive gland CYP4 gene expression in C. gibbosum feeding on control versus gorgonian diets

Table 7. Results of ANOVA comparisons of diet- and reef-specific mean CYP4 gene expression in C. gibbosum feeding on control vs. gorgonian diets

Table 8. Results of a one-way MANOVA investigating CYP4 gene expression variability among reefs for time-zero and control-fed $C$. gibbosum 
Table 9. Comparison of amino acid residues lining the substrate binding channel in CYP102 (BM3), CYP4A11 and C. gibbosum CYP4-2 and CYP4-3 proteins

Table 10. Leukotriene $\mathrm{B}_{4}$ hydroxylase activity of recombinant $C$. gibbosum CYP4 proteins

Table 11. Leukotriene $\mathrm{B}_{4}$ hydroxylase activity in Cyphoma microsomes

\section{Chapter IV}

Table 1. Effect of prostaglandin inhibitors on Cyphoma gibbosum affinitypurified GSTs

Table 2. Apparent Michaelis-Menten constants $\left(\mathrm{K}_{\mathrm{m}}\right.$ and $\left.\mathrm{V}_{\max }\right)$ for Cyphoma gibbosum affinity-purified GSTs with 1-chloro-2,4-dinitrobenzene

Table 3. Comparing models of $15(\mathrm{~S})-\mathrm{PGA}_{2}$ inhibition of $C$. gibbosum affinitypurified GSTs by extra-sum-of-squares ( $F$-test)

Table 4. Comparing models of $15(\mathrm{~S})-\mathrm{PGA}_{2}$ inhibition of $C$. gibbosum affinitypurified GSTs using Akaike information criterion

Table 5. Kinetic constants for C. gibbosum affinity-purified GSTs with 15(S)$\mathrm{PGA}_{2}$ obtained by fitting to the competitive inhibition equation

\section{Chapter V}

Table 1. Primers used in the present study

Table 2. Summary of ABC transporter cDNAs obtained from Cyphoma gibbosum and Tritonia hamnerorum

Table 3. Results of a two-way ANOVA investigating differences in MRP-1 gene expression in C. gibbosum feeding on control versus gorgonian diets

Table 4. Results of a one-way ANOVA investigating reef-dependent MRP-1 gene expression in time-zero and four day control fed C. gibbosum 
Chapter I

Introduction 


\section{Background}

In marine communities, predation plays a pivotal role in affecting the phenotype of organisms as well as community organization (Duffy \& Hay 2001). The intensity of consumer pressure on coral reefs exerts strong selection on prey to avoid being eaten. Prey species unable to physically escape or tolerate consumers often produce noxious compounds, termed allelochemicals, as a mechanism of defense against predation (Paul 1992). Chemically defended prey are often noxious or toxic to most large, mobile consumers, yet appear to be the target of evolutionary opportunity for smaller, more specialized consumers (Hay 1991, Faulkner 1992). However, the physiological and biochemical mechanisms that allow these more specialized marine consumers to tolerate (i.e., consume, manipulate, and/or detoxify) dietary allelochemicals are largely unknown (Sotka \& Whalen 2008).

In the field of chemical ecology, rarely have specific adaptive traits been identified down to the biochemical or genetic level (Berenbaum 2002). Examining how chemical interactions at the cellular and molecular level shape the behavior of organisms is paramount in ultimately understanding how chemicals affect the distribution and abundance of organisms in communities. In terrestrial ecology the success of insects is due, in part, to their use of sophisticated detoxification systems to overcome the chemical defenses of their plants (Li et al. 2007). Chemical defenses in general are thought to be an evolutionary driving force behind the development of detoxification genes (Gonzalez \& Nebert 1990). Therefore, understanding the role of these genes in allelochemical resistance in marine organisms holds potential significance for understanding patterns of 
predation and herbivory in marine systems. While several allelochemical-responsive CYPs and GSTs genes have been sequenced and functionally characterized in insects feeding on chemically defended plants, there is virtually no information concerning the role of these biotransformation enzymes and multixenobiotic transporters in marine invertebrates that also feed on allelochemically-rich prey.

\section{Introduction}

\section{Marine Chemical Ecology}

The field of marine chemical ecology examines the role chemicals play in mediating a diverse array of interactions among marine organisms. With well over 7,000 natural products, termed secondary metabolites, isolated thus far from marine species (Harper et al. 2001), chemical ecologists are working to elucidate the ecological roles of these compounds in marine systems. Taking cues from their terrestrial counterparts, which had laid the groundwork some thirty years before, marine chemists and ecologists entered into productive collaborations and began exploring how secondary metabolites mediated marine consumer-prey interactions (Pawlik 2000). Research in this field has advanced significantly since the early studies in the 1980's. Laboratory and field based behavioral studies have begun to classify compounds as attractants, protectants or deterrents; however, more recently others have begun to address the physiological and biochemical mechanisms underlying these responses (Targett \& Arnold 2001).

Chemical defenses against predation have been a major focus in marine chemical ecology, as evidenced by the number of pertinent reviews (Bakus et al. 1986, Hay \& 
Fenical 1988, Pawlik et al. 1995, Hay 1996, Paul et al. 2001, Paul \& Puglisi 2004). The existence of chemical defenses in marine organisms and their importance in mediating predator-prey and plant-herbivore interactions have been well established. Many sessile benthic invertebrates lack the means to escape consumers and, therefore, have evolved chemical deterrents to ensure their survival (Faulkner \& Ghiselin 1983, Faulkner 1992, Stachowicz 2001, O'Neal \& Pawlik 2002). Although chemical defenses limit predation and herbivory in tropical marine ecosystems, some consumers still regularly feed on allelochemically rich organisms. The consequences of consuming defensive metabolites can be severe and range from reduced growth and reproductive fitness to decreased survival (Hay 1992, Targett \& Arnold 2001). However, for those consumers that consistently feed on chemically defended prey, behavioral adaptations (e.g. avoidance), physiological tolerance (e.g. sequestration, membrane impermeability, rapid excretion) and biochemical resistance mechanisms (e.g. detoxification enzymes) may explain the ability of these consumers to tolerate dietary allelochemicals (Brattsten 1992a). While the first two strategies have been documented in the marine environment (Targett 1979, Targett et al. 1986, Gerhart 1991, Slattery et al. 1998), few studies have investigated natural product detoxification mechanisms in marine invertebrates as a means of coping with noxious dietary compounds.

\section{Gorgonian chemical defenses}

Gorgonian corals (Phylum: Cnidaria; Subclass: Octocorallia; Order: Gorgonacea) 
are the most conspicuous group of invertebrates on Caribbean coral reefs (Lasker \& Coffroth 1983), reaching densities of up to 25 colonies $\mathrm{m}^{-2}$ (Goldberg 1973); however, they are consumed by only a limited number of specialized grazers despite their abundance and the intense predation in these ecosystems (O'Neal \& Pawlik 2002). Gorgonians, also referred to as octocorals, of the West Indian region (Gulf of Mexico, Antilles, Bahamas, Florida Keys, Bermuda, South America, Caribbean) represent 38\% of the known fauna with over 195 species documented (Bayer 1961). The dominance of these invertebrates can be attributed, in part, to the variety of metabolites they produce, collectively known as allelochemicals, which are known potent feeding deterrents (Rodriguez 1995). Numerous feeding studies (Fenical \& Pawlik 1991, Pawlik \& Fenical 1992, Paul \& Puglisi 2004) with crude organic extracts and pure compounds from gorgonians have shown that, with the exception of a few, small mesograzers (Lasker 1985, Lasker et al. 1988, Vreeland \& Lasker 1989), more mobile, larger grazers, such as fishes and invertebrates, do not readily consume octocorals. Field-based surveys assessing the palatability of gorgonians found that the majority of lipid-soluble gorgonian extracts deterred reef fish at concentrations an order of magnitude lower than those found in the soft tissues of the corresponding gorgonians (Pawlik et al. 1987).

As of 2001, the subclass Octocorallia accounted for $87 \%$ ( 1300 compounds) of all reported cnidarian metabolites, with nearly 500 coming from the order Gorgonacea alone (Harper et al. 2001). The majority of these compounds are terpenoids, representing over twenty different skeletal classes with unique substitution patterns and functionalities (Rodriguez 1995). Diterpenoid metabolites ( $\mathrm{C}_{20}$ compounds) represent the largest 
percentage of natural products isolated from gorgonians $(\sim 73 \%)$, while sesquiterpenoids $\left(\mathrm{C}_{15}\right.$ compounds) rank second (14\%). Two sesquiterpenes - curcuhydroquinone and curcuquinone - isolated from the octocoral Pseudopterogorgia rigida, are extremely active as fish feeding deterrents at low concentrations (Harvell et al. 1988). Similar compounds are well known as secondary metabolites of terrestrial plants and as defensive compounds of insects in terrestrial systems (Aneshansley et al. 1969, Eisner 1970, Thomson 1971). The ubiquity of these terpenoid compounds, coupled with their demonstration of potent feeding deterrence in the marine environment, make them interesting targets for further investigation (Harvell et al. 1988, Coll 1992).

Acetogenins, prostanoids, and highly functionalized steroids have also been reported from gorgonians (Rodriguez 1995). Among the most interesting are the prostanoids, which are produced in large quantities solely in the Caribbean octocoral Plexaura homomalla (Gerhart 1984, 1986). Feeding assays in the laboratory and on the reef with prostaglandins isolated from $P$. homomalla (e.g. 15-PGA 2 and their hydrolyzed derivatives), resulted in vomiting or learned aversion to these compounds in fish (Gerhart 1984). Additionally, many interesting sterols have been isolated from gorgonians; however, information on their defensive function is lacking.

Although these chemical defenses limit predation by most potential consumers, some relatively sedentary species such as the ovulid gastropod Cyphoma gibbosum, regularly feed on allelochemically rich octocorals (Harvell \& Suchanek 1987, Lasker et al. 1988, Ruesink \& Harvell 1990, Nowlis 1993). Cyphoma gibbosum exclusively feeds on gorgonians and is considered a trophic generalist, because most available species in 
several gorgonian families are included in its diet (Lasker et al. 1988). Additionally, it appears that $C$. gibbosum's tissues do not mirror the chemical composition of its octocoral prey (Cronin et al. 1995), suggesting the possibility that $C$. gibbosum can either efficiently excrete these compounds or biotransform their dietary allelochemicals to less toxic metabolites.

\section{Allelochemical biotransformation and transport}

Little is known about the role of allelochemical biotransformation in marine organisms (Kuhajek \& Schlenk 2003). In comparison, insect-plant allelochemical interactions are well understood and may provide a conceptual framework for research to elucidate the role of biotransformation enzymes in the chemical ecology of marine invertebrates. In both systems, terrestrial and marine invertebrates must contend with dietary allelochemicals that can have deleterious effects on their growth, reproduction and survival (Feeny 1992). Insects that feed on toxin-containing plants possess biotransformation mechanisms that allow them to exploit a specific subset of chemically defended plants. Berenbaum and colleagues (Berenbaum 1978, Berenbaum \& Feeny 1981) were the first to report that xanthotoxin, a linear furanocoumarin produced from umbelliferous plants, was toxic to southern armyworms but harmless to the larvae of black swallowtails. Cohen et al. (Cohen et al. 1989, 1990) later demonstrated that xanthotoxin resistance in swallowtail larvae was conferred by a suite of cytochrome P450 monooxygenases selectively induced upon exposure to xanthotoxin, and responsible for the subsequent oxidation of the furanocoumarin. While the dietary allelochemicals may 
be quite different between terrestrial and marine systems, Cyphoma gibbosum may have similar detoxification mechanisms to that of insects, allowing this molluscan predator to take advantage of an abundant, energy-rich food source not available to most other consumers likely lacking such biochemical resistance mechanisms. Despite the significance of allelochemicals in the evolution of biotransformation enzymes (Gonzalez $\&$ Nebert 1990) and the importance of these enzymes in the detoxification of anthropogenic xenobiotics (Omura 1999), little attention has been paid to the role of biotransformation enzymes in the metabolism of the wealth of dietary allelochemicals from marine organisms.

Biotransformation reactions are just one mechanism by which marine organisms can defend themselves against allelochemicals. A second approach involves multixenobiotic transporters (MXT) that may prevent putative toxins from accumulating in the cell in the first place (Epel 1998). The ability of marine natural products to modulate transporter activity has been assessed only recently using invertebrate models. Several extracts from seaweed and phytoplankton species were found to contain potent substrates/modulators of mussel and sea urchin multixenobiotic transporter activity (Eufemia et al. 2002). Subsequent crude fractionation of the extracts traced the compounds responsible for the inhibition of transporter activity in mussel cells to the moderately hydrophobic fractions. Interestingly, most known substrates for xenobiotic transporters are moderately hydrophobic, amphipathic, low molecular weight, planar molecules (Bard 2000). Exposure to these compounds would most likely occur via ingestion as the mussels actively filter particulate matter from the water column. To combat compound 
accumulation, MXT are highly expressed in the gills of bivalves (Minier et al. 1993, Smital \& Kurelec 1997), one of the primary routes of tissue exposure to dietary compounds. The tissue distribution (e.g. liver, kidney, digestive tract) of these proteins in other marine organisms also suggests a parallel role in protection from diet-derived toxins (Bard 2000). Marine consumers may use similar multixenobiotic transporters to prevent dietary accumulation of noxious gorgonian compounds in concert with other detoxification enzymes.

Much of the diversity of biotransformation enzymes in insects may be the result of co-evolution of prey chemical defenses and predator detoxification mechanisms (Gonzalez \& Nebert 1990, Li et al. 2003). I hypothesize that some marine invertebrates may have undergone a similar diversification of detoxification enzymes to combat the continuous barrage of defensive compounds produced by their prey (David et al. 2003). Marine generalists, like Cyphoma gibbosum, may have evolved an array of functional enzymes based on different selective forces associated with the biochemical defense profiles of their hosts. Alternatively, selection for resistance to diverse metabolites among marine generalists may have resulted in the development of an enzyme/transporter with broad substrate specificities (Li et al. 2003, Smital et al. 2004). Consequently, understanding the role of allelochemical detoxification and transport in marine organisms will allow us to determine how predators respond biochemically to dietary metabolites, and will contribute to a more general understanding of dietary preferences and patterns of predation on the reef. 


\section{Mechanisms of detoxification and transport}

The detoxification and excretion of xenobiotics, which can broadly be described by three phases, involve highly complex processes that are able to respond to an organism's chemical environment. Biotransformation is the process by which nonpolar compounds are converted to more water-soluble chemicals that are more easily excreted from the body (Figure 1).

Figure 1. Overview of allelochemical metabolism and transport (reproduced from Sotka \& Whalen 2008)

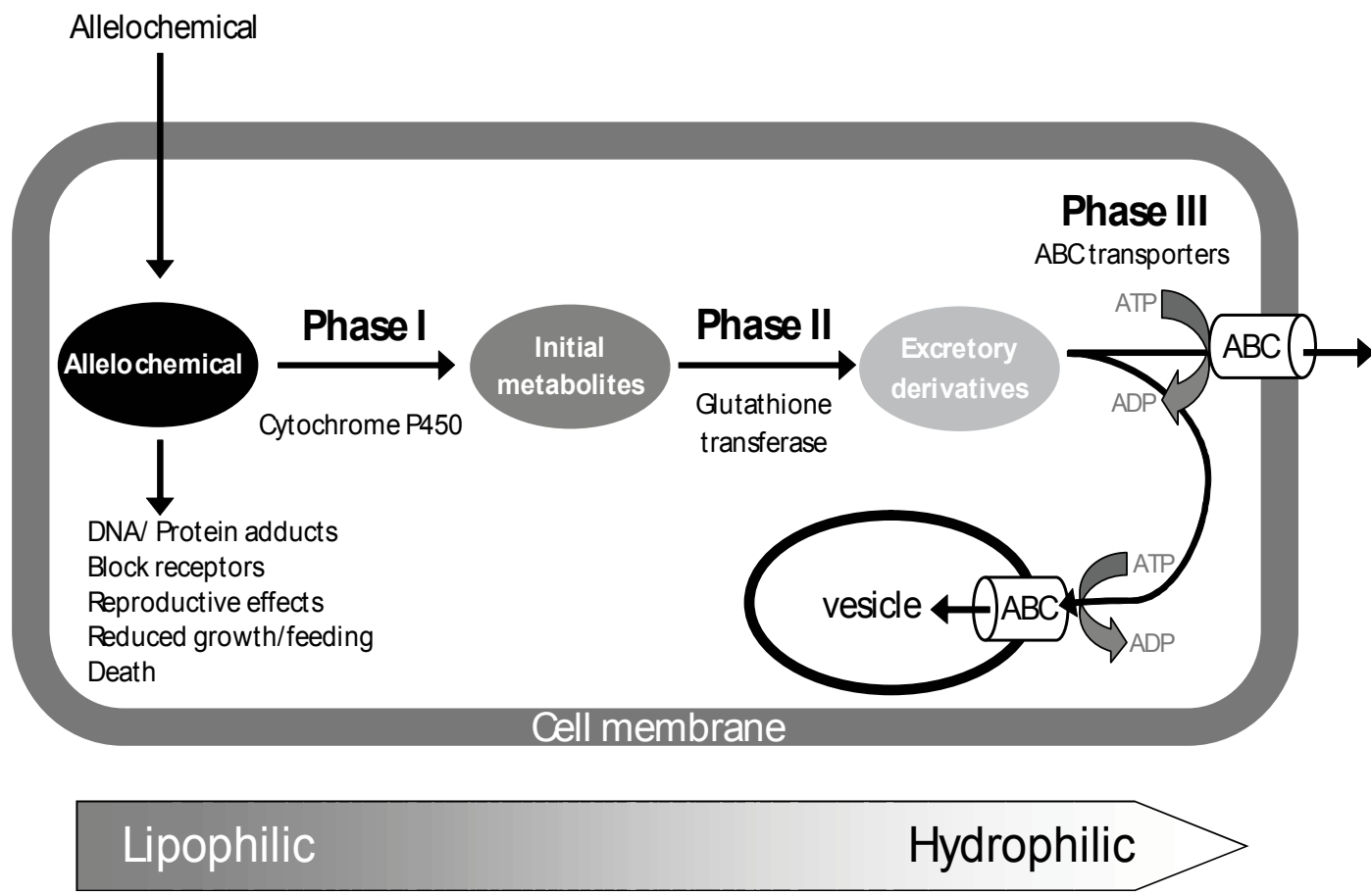

In general, the biotransformation of xenobiotic compounds is accomplished by a limited number of enzymes with broad substrate specificities. The reactions catalyzed by these 
enzymes can be divided into phase I and phase II (Williams 1959). Phase III processes involve the energy-dependent transport of multiple structurally and functionally unrelated xenobiotics across a variety of cellular membranes (Litman et al. 2001). Select phase III transport proteins prevent the retention of toxicants in cells and tissues and are complementary to both phase I and II reactions in minimizing xenobiotic toxicity. All three phases have previously been studied in marine invertebrates; however, these studies have focused primarily on their role in the metabolism and transport of anthropogenic compounds (e.g. polycyclic aromatic hydrocarbons (PAHs), polychlorinated biphenyls (PCBs), pesticides; reviewed in (Galgani et al. 1996, Eufemia \& Epel 2000, Snyder 2000). The participation of detoxification enzymes in the metabolism of dietary

allelochemicals in terrestrial systems has been extensively documented (Scott et al. 1998, Li et al. 2007) and I hypothesize that these enzymes may have similar functions in marine organisms.

\section{Phase I - Cytochrome P450}

The most familiar phase I reactions involve the addition of a polar functional group (e.g. hydroxyl) onto a compound to increase its hydrophilicity and facilitate excretion. These reactions are accomplished primarily by a suite of inducible enzymes collectively termed cytochrome P450 monooxygenases (CYPs) (Parkinson 2001) found in terrestrial and aquatic organisms ranging from bacteria to vertebrates (Omura 1999). CYPs comprise a large superfamily of heme-thiolate proteins that metabolize a wide range of endogenous and exogenous hydrophobic compounds. Embedded in the 
endoplasmic reticulum (ER), the cytochrome P450 enzyme can insert one oxygen atom from molecular oxygen, $\mathrm{O}_{2}$, onto the substrate as it is held at the active site by lipid interaction. The combination of a relatively non-specific and loose lipid interaction to bind a substrate and an activated oxygen radical to oxidize it makes the reaction mechanism of cytochrome P450 extremely powerful (Brattsten 1992a). In addition to hydroxylation reactions, CYPs catalyze several other types of oxidation reactions including: epoxidation of double bonds, heteroatom (S-, N-, and I-) oxygenation and Nhydroxylation; heteroatom (O-, S-, and N-) dealkylation; ester cleavage; and dehydrogenation (Parkinson 2001).

Each functional gene appears to encode a unique enzyme (Nelson et al. 1993) roughly 500 amino acid residues in length (Omura 1999). Different cytochrome P450 genes are assigned to different families according to their degree of sequence identity (families share $>40 \%$ identity; subfamilies share $>55 \%$ identity) (Nelson et al. 1993). A comparison of all eukaryotic CYPs found minimal conservation of residues with the exception of amino acids involved in structural conservation in the core of the protein around the heme (Werck-Reichhart \& Feyereisen 2000). The heme binding loop, considered to be the "P450 fingerprint region", contains the most characteristic P450 consensus sequence, including the absolutely conserved cysteine that serves as the fifth coordinating ligand to the heme iron. Other conserved sequences include the Glu-X-XArg motif in helix K, which participates in core structure stabilization, and the oxygen binding pocket in the I helix involved in oxygen activation and transfer of protons to the active site (Werck-Reichhart \& Feyereisen 2000). Microsomal P450 binding and 
insertion into the membrane is mediated by a hydrophobic amino-terminal sequence ("signal anchor sequence"), leaving the bulk of the enzyme exposed to the cytoplasmic side of the ER. Adjacent and down stream to the anchor sequence is a proline-rich/basic region that may serve to join the membrane-binding $\mathrm{N}$-terminus to the globular region of the P450 (Graham-Lorence \& Peterson 1996). Variable regions throughout the gene are associated with substrate binding and recognition and are often referred to as substraterecognition sites or SRSs (Werck-Reichhart \& Feyereisen 2000). The flexibility of SRS regions allows for structurally variable substrate binding and catalysis.

As of February 2008, there are a total of 7232 known CYP sequences, excluding variants and pseudogenes, representing 781 families (designated by number) (http://drnelson.utmem.edu/CytochromeP450.html). In animals alone, 110 P450 families have been described encompassing 2565 named sequences. The broad substrate specificity and inducible nature of many CYPs are consistent with their proposed central role in feeding habits, since generalist consumers can be expected to encounter a broad array of allelochemicals in their diet. The enormous metabolic diversity of the P450dependent monooxygenase system provides a comprehensive protective mechanism against a wide variety of xenobiotics (e.g. chemical defenses, hydrocarbons, etc) for organisms challenged with these compounds on a daily basis (Simpson 1997, Mansuy 1998).

For many invertebrates, the true number of P450 genes is unknown. However, sequencing of insect genomes shows extensive proliferation and divergence in both Drosophila melanogaster and Anopheles gambiae resulting in 90 and 100 annotated P450 
genes (http://p450.antibes.inra.fr) representing 5 families: CYP4, CYP6, CYP9, CYP18 and CYP 28. The extreme diversification of P450 forms and the acquisition of new gene functions are believed to have occurred via gene duplication events (Berenbaum 2002). To fully understand the evolutionary diversification of P450s, research has focused on identifying individual isoforms that metabolize specific dietary compounds (Berenbaum 1983, 1991, Cohen et al. 1992, Petersen et al. 2001), which may have acted as selective agents to promote $\mathrm{P} 450$ diversification. For example, furanocoumarin-containing host plants are all but ignored except by a few lepidopterans in the genus Papilio. The molecular basis of furanocoumarin resistance in P. polyxenes has been attributed to the constitutive expression of CYP6B1v1 and CYP6B1v2, which encode furanocoumarinmetabolizing P450s (Cohen et al. 1992, Ma et al. 1994) and contain a highly conserved furanocoumarin-responsive xenobiotic response element required for basal transcription and inducibility (Petersen et al. 2003). Additionally, specific expression of furanocoumarin-metabolizing CYPs is only detected in larval feeding stages and not in adults, eggs, or pupae, suggesting a function consistent with the dietary metabolism of toxic furanocoumarins (Harrison et al. 2001).

The polyphagous lepidopteran Helicoverpa zea also feeds on furanocoumarincontaining plants, but consumes more than 100 different host plant families with vastly different chemistry (Kogan et al. 1978). It has been suggested that this insect generalist can cope with a variety of plant chemical defenses because of the greater diversity, structural flexibility and functional versatility of its CYP6B genes in comparison to the specialist $P$. polyxenes (Li et al. 2004). The cost of increased flexibility, resulting in a 
less efficient metabolism of furanocoumarins, is balanced by the acceptance of a wider variety of allelochemicals at the catalytic site. C. gibbosum's CYPs may have similar biochemical traits which may allow this consumer to be an equally successful marine generalist.

Many terpenoids isolated from plants, including monoterpenes from Eucalyptus spp., have been shown to limit feeding by herbivores (Boyle et al. 1999). Marsupials that fed exclusively on eucalypt leaves containing the monoterpenes p-cymene and 1,8cineole use CYP2 and/or CYP3 enzymes to detoxify these natural products (Pass \& McLean 2002). Inhibition of 1,8-cineole metabolism by p-cymene metabolites and other plant secondary metabolites may impose a significant constraint on foliage consumption in these generalist marsupials. Inhibitory interactions among dietary compounds may explain obligatory browsing by generalist herbivores. Likewise, C. gibbosum feeds on many gorgonians that contain high concentrations of terpenoid compounds, and the production of these compounds is further increased in response to elevated predation by this mollusc (Thornton \& Kerr 2002). The mobility of C. gibbosum (Birkeland \& Gregory 1975) and the variety of gorgonian corals included in its diet may be explained by the need for diet mixing in this species (Harvell \& Suchanek 1987). It is believed that consumers are better able to tolerate particular compounds by limiting their residence time on any one species (Snyder et al. 1998). This mollusc may use similar strategies and CYPs to detoxify the range of gorgonian terpenes. 


\section{Molluscan Cytochrome P450s}

Among eukaryotes the phylum Mollusca ranks second in species diversity after Arthropoda, yet the diversity of molluscan CYP isoforms is poorly understood in comparison to that of insects. This discrepancy results in part from the lack of a fully sequenced molluscan genome, although there are species in the pipeline. Nevertheless, biochemical and molecular studies have provided some information about the diversity of molluscan CYPs.

There is biochemical evidence suggesting that some of the P450s responsible for biotransformation in mammals are present in marine invertebrates in general and molluscs in particular (Snyder 2000). Northern, Southern and Western blot techniques suggest that multiple CYPs (i.e., 1A, 2B, 2E, and 3A-like enzymes) may be expressed in the digestive glands of some molluscs after treatment with prototypical inducers of vertebrate CYPs (Wootton et al. 1995, Wootton et al. 1996, Peters et al. 1998b, a) (Table 1). However, some of this biochemical evidence is equivocal, and the presence of these CYPs has yet to be confirmed with a gene or cDNA sequence.

A few molluscan CYP cDNAs have been cloned and sequenced (Table 1). Both arthropods and molluscs share the CYP4 gene family and in both phyla this family accounts for the majority of known P450s (Rewitz et al. 2006, Strode et al. 2008). To date, multiple CYP4 isoforms have been identified in both freshwater and marine molluscs including Mytilus galloprovincialis (Mediterranean mussel), Haliotis rufescens (red abalone), Unio tumidus (freshwater mussel), Mytella strigata (mussel) and Perna viridis (Asian green mussel) (Snyder 1998, Chaty et al. 2004). A CYP4 sequence 
identified from $U$. tumidus shares high amino acid sequence identity with CYP4C sequences in lobster and Anopheles (59-61\%) and CYP4V sequences in mouse and trout (54\% identity) (Chaty et al. 2004). The ubiquity of CYP4 genes in mammals, bony fishes and invertebrates (Nelson 1998) suggests this gene family arose at least 1.25 billion years ago (Simpson 1997). While substantial information is lacking as to the physiological role and substrate specificity of these CYP4 enzymes in marine invertebrate systems, studies

\section{Table 1. Biochemical and molecular evidence for molluscan CYPs}

\begin{tabular}{|c|c|c|c|}
\hline Proposed CYP Classification $^{\mathrm{a}}$ & Species & Evidence & Literature or GenBank Reference \\
\hline \multirow[t]{5}{*}{ CYP1A } & Crassostrea gigas & Sequence & Boutet et al. 2004 \\
\hline & Mytilus edulis & Western blot & Peters et al. 1998a, Shaw et al. 2000 \\
\hline & & & Livingstone et al. 1997, Canova et al. 1998, \\
\hline & Mytilus galloprovincialis & Western blot & Peters et al. 1998a,b \\
\hline & Mytilus edulis & Northern blot & Wootton et al. 1995, Wootton et al. 1996 \\
\hline \multirow[t]{2}{*}{ CYP2 } & Crassostrea rhizophorae & Sequence & Rebelo \& Moreira 2003 \\
\hline & Mytilus edulis & Western blot & Jonsson et al. 2004 \\
\hline CYP2B & Mytilus galloprovincialis & Western blot & Peters et al. 1998a \\
\hline \multirow{2}{*}{ CYP2E } & Mytilus edulis & Western blot & Shaw et al. 2000 \\
\hline & Mytilus galloprovincialis & Western blot & Peters et al. 1998b \\
\hline \multirow[t]{3}{*}{ CYP3A } & Cryptochiton stelleri & Western blot & DeBusk et al. 2000 \\
\hline & Mytilus edulis & Southern & Wootton et al. 1995 \\
\hline & Mytilus galloprovincialis & Western blot & Peters et al. 1998a \\
\hline \multirow[t]{4}{*}{$\overline{\text { CYP4 }}$} & Mytella strigata & Sequence & GenBank \# DQ310714 \\
\hline & Mytilus edulis & Western blot & Jonsson et al. 2004 \\
\hline & Perna viridis & Sequence & GenBank \# EU429566 \\
\hline & Unio tumidus & Sequence & Chaty et al. 2004 \\
\hline \multirow[t]{3}{*}{$\overline{\text { CYP4A }}$} & Mytilus edulis & Northern blot & Wootton et al. 1995 \\
\hline & Mytilus edulis & Semi-quantitative RT-PCR & Luedeking \& Kohler 2002 \\
\hline & Mytilus galloprovincialis & Western blot & Peters et al. 1998a, b \\
\hline CYP4V13 (previously CYP4C17) & Haliotis rufescens & Sequence & Snyder 1998 \\
\hline CYP4Y1 & Mytilus galloprovincialis & Sequence & Snyder 1998 \\
\hline$\overline{\text { CYP10 }}$ & Lymnaea stagnalis & Sequence & Teunissen et al. 1992 \\
\hline CYP11A & Mytilus edulis & Southern blot & Wootton et al. 1995 \\
\hline CYP30 & Mercenaria mercenaria & Sequence & Brown et al. 1998 \\
\hline CYP320A1 & Biomphalaria glabrata & Sequence & GenBank \# AY922309 \\
\hline CYP322A1 & Perna canaliculus & Sequence & $\begin{array}{l}\text { K. Herron (submitted to P450 nomenclature } \\
\text { committee in 2001) }\end{array}$ \\
\hline$\overline{C Y P 356 A 1}$ & Crassostrea gigas & Sequence & Toledo-Silva et al. 2008 \\
\hline
\end{tabular}

in vertebrate systems indicate these enzymes regulate the biosynthesis and metabolism of fatty acids involved in cell signaling processes (Okita \& Okita 2001, Kikuta et al. 2002). 
CYP4 genes encode several P450 enzymes capable of hydroxylating saturated and unsaturated fatty acids (e.g. palmitate, arachidonic acid and various prostaglandins) (Yamamoto et al. 1984, Matsubara et al. 1987, Sharma et al. 1989) in vertebrates. Prostaglandins are unsaturated carboxylic acids consisting of a twenty carbon skeleton, including a five membered ring, and are synthesized from the precursor arachidonic acid. Surprisingly, the highest concentrations of prostaglandins in nature have been isolated from the Caribbean gorgonians (Weinheimer \& Spraggins 1969), where they function as feeding deterrents (Gerhart 1986, Pawlik \& Fenical 1989, Gerhart 1991). Prostaglandin esters comprise up to $3 \%$ of the dry weight of the gorgonian Plexaura homomalla (Weinheimer \& Spraggins 1969), with the hydroxy-methyl ester and hydroxy acid of 15(R)-prostaglandin $A_{2}$ contributing to the bulk of the chemical defense (Pawlik \& Fenical 1989). Cyphoma gibbosum can tolerate prostaglandins produced by Plexaura homomalla (Gerhart 1986) and actually prefers to reside on this species of gorgonian (Chiappone et al. 2003). It seems plausible - even likely - that Cyphoma may use members of the CYP4 family to detoxify the prostaglandins it encounters in its diet.

While the role of the CYP4 family in fatty acid metabolism in vertebrates has been studied extensively (reviewed in Simpson 1997), additional work in terrestrial invertebrates has suggested that CYP4 isoforms may contribute to toxin metabolism. Drosophilid CYP4 isoforms have been shown to be involved in the metabolism of defensive alkaloid plant compounds (Danielson et al. 1997), illustrating that CYP4 gene functions are more diverse than mammalian functions would suggest. In contrast to most housekeeping genes, P450s involved in xenobiotic metabolism are often transcriptionally 
inducible by substrates upon which they act (Whitlock 1986). Detoxification enzymes involved in allelochemical resistance should, therefore, exhibit a marked increase in expression following toxin exposure. Using a PCR-based cloning strategy, Danielson et al. (1997) was able to identify 15 novel CYPs from an isoquinoline alkaloid-resistant drosophilid. Six of these sequences displayed increased mRNA levels following exposure to isoquinoline alkaloids, while CYP4D10 was the only P450 that was strongly and specifically induced following exposure to primary host plant alkaloids but not to similar alkaloids of a rarely utilized host plant. The substrate specificity and induction response of CYP4D10 makes this detoxification enzyme the primary candidate for the observed alkaloid resistance in Drosophila mettleri. Other P450s that were induced to a lesser degree may still aid in allelochemical resistance through a cooperative action among multiple P450s (possibly within the same family), by allowing this generalist drosophilid to exploit a broader range of plants with chemically similar compounds. Although C. gibbosum is carnivorous, the association with its prey is analogous to plantinsect interactions. A generalist like $C$. gibbosum may possess an assortment of CYPs, whose expression may depend on the presence of inducers (e.g. gorgonian speciesspecific suite of allelochemicals) specific to each of those CYPs.

Exclusive to the molluscan genome are the CYP30 and CYP10 families (Teunissen et al. 1992, Brown et al. 1998). CYP30, originally isolated in Mercenaria mercenaria, is most closely related to the CYP3 family, followed by the insect CYP6, CYP9 and CYP25 families (Brown et al. 1998, Nelson 1998). While the substrate specificity of the CYP30 protein is unknown, members of the closely-related CYP3 
family are involved in steroid metabolism. Steroids have consistently been isolated from many gorgonian species (Block 1974, Cimino et al. 1979, Cimino et al. 1984, Coll 1992, Rodriguez 1995, Rho et al. 2000, Tanaka et al. 2002) and may have influenced the evolution of CYPs responsible for their metabolism in molluscs. CYP10 is most closely related to mitochondrial CYP families involved in steroid synthesis (CYP24, CYP11, CYP27) (Teunissen et al. 1992). The physiological functions of CYP10 are unknown; however, it is expressed exclusively in the female gonadotropic hormone producing dorsal bodies of Lynmaea stagnalis (Teunissen et al. 1992).

The importance of cytochrome P450 enzymes in the metabolism of dietary plant compounds and other xenobiotics has been studied for over thirty years (Gonzalez 1989). While the primary function of P450 enzymes is to convert hydrophobic, lipid-soluble organic xenobiotics to water-soluble excretable metabolites, the phase II biotransformation enzymes such as the glutathione S-transferases also facilitate the elimination of dietary compounds from the body. Studies investigating specific activities of phase I enzymes have noted that in fish and crustaceans total P450 content is an order of magnitude greater than in molluscs. However, this trend is reversed when examining glutathione S-transferases (reviewed in Livingstone 1998). Glutathione S-transferases, in addition to P450s, have increasingly been identified in molluscs (Lee 1988, Lee et al. 1988, Fitzpatrick et al. 1995, Fitzpatrick et al. 1997, Stien et al. 1998, Kaaya et al. 1999, Vidal \& Narbonne 2000, Hoarau et al. 2001, Khessiba et al. 2001, Hoarau et al. 2002, Petushok et al. 2002, Yang et al. 2002, Blanchette \& Singh 2003, Le Pennec \& Le Pennec 2003, Yang et al. 2004, Doyen et al. 2005, Hoarau et al. 2006, Blanchette et al. 
2007, Myrnes \& Nilsen 2007, Vasconcelos et al. 2007, Doyen et al. 2008) and may prove to be an equally vital adaptive response mechanism against allelochemicals in the marine environment.

\section{Phase II - Glutathione S-transferase}

Phase II biotransformation reactions involve the conjugation of a hydrophobic compound or modified metabolite from phase I with a cofactor that increases the molecular weight and polarity of the compound and facilitates excretion (Parkinson 2001). Glutathione S-transferases (GSTs) aid in this process by catalyzing the nucleophilic attack of reduced glutathione (GSH: $\gamma$-Glu-Cys-Gly) on nonpolar compounds that contain an electrophilic carbon, nitrogen, or sulphur atom, including those metabolites formed by P450 oxidation (Hayes et al. 2005). GSTs form a multigene family that encode cytosolic enzymes that are found in most aerobic eukaryotes and some prokaryotes and exhibit differing, but often overlapping, substrate specificities for both endogenous and exogenous compounds. Possible GST substrates include chemotherapeutic agents, insecticides, carcinogens, oxidative stress by-products and natural products (Sheehan et al. 2001, Hayes et al. 2005). Large scale genome sequencing projects have estimated the total number of GST genes for Caenorhabditis elegans (57), Drosophila melanogaster (43), and Homo sapiens (40) (Ding et al. 2003). To date, seven soluble cytosolic GST classes, encoding proteins of approximately 200 amino acids in length, have been identified in metazoans (e.g. Alpha, Mu, Pi, Theta, Sigma, Zeta and Omega) (Sheehan et al. 2001). Beta-class GSTs have only been 
described in bacteria (Vuilleumier 1997), while the delta and epsilon classes remain insect-specific (Zhou \& Syvanen 1997, Sheehan et al. 2001, Sawicki et al. 2003). GSTs within the same class share greater than $40-60 \%$ amino acid identity while those between classes typically share less than $25 \%$ identity, with the majority of the similarity at the Nterminus (Sheehan et al. 2001). In the past, various mammalian GSTs have been classified based on substrate specificity and inhibitor sensitivity; however, these techniques tend to result in overlapping values between GST classes and have proven less effective for classifying non-mammalian GSTs (Francis et al. 2001, Sheehan et al. 2001). Thus, to avoid confusion, amino acid sequences should be used for comparison between GST classes.

Each functional GST is composed of two subunits, either identical (homodimeric) or non-identical (heterodimeric) (Doyen et al. 2005). GST subunits in mammalian systems range from 199-244 amino acids in length (Hayes et al. 2005) and are also known to have two distinct binding sites: an N-terminal $\mathrm{G}$ site which binds glutathione, and a $\mathrm{C}$-terminal $\mathrm{H}$ site which binds the substrate. The highly conserved $\mathrm{N}$-terminal region contains a catalytically essential tyrosine, serine or cysteine residue that interacts with the thiol group of GSH. In contrast, the $\mathrm{H}$ site has a highly variable structure which can accommodate a wide range of substrates (Ortelli et al. 2003). The detection of alternative spliced products and the formation of heterodimers allows for the development of novel GST enzymes, which presumably increases the pool of potential substrates (Sheehan et al. 2001). 
GSTs involvement in the detoxification of dietary secondary metabolites in invertebrates has been known for some time (Yu 1982, 1989, Brattsten 1992b). Many plant allelochemicals and marine natural products contain the appropriate functional groups that can be directly conjugated with GSH (Schlenk \& Buhler 1988, Brattsten 1992b). Overexpression of GSTs has been suggested as a protective mechanism that invertebrates use to cope with, and adapt to, dietary allelochemicals. Various species of insects have shown 2 to 40 -fold induction of GSTs upon changes in host plant diet or when exposed to plant compounds in artificial diets (Yu 1982, Brattsten et al. 1984, Yu 1984, Snyder et al. 1995). Allelochemicals such as xanthotoxin, indole derivatives, flavones, and allyl glucosinolates that induce cytochrome P450s in insects often also induce GST activity (Yu 1983, 1984, 1986, 1992). However, GSTs and P450s are not always coordinately induced. For example, plant monoterpene menthols and pinenes are known P450 inducers in the fall armyworm, yet they do not induce GST activity (Yu 1982). In contrast, in the southern armyworm coumarin is a weak P450 inducer, but strongly induces GST activity (Brattsten et al. 1984). Thus, studies intent on characterizing the responses of a single type of detoxification enzyme may miss critical information. Additionally, studies investigating GST isoforms in five different species of lepidoptera established that the degree of polyphagy was positively correlated with the number of GST isoforms found. Specialist species had only one isoform, while generalist species showed multiple forms, presumably to detoxify a broader range of metabolites (Yu 1989). In light of the variety of compounds to which Cyphoma can be 
exposed, it will be interesting to characterize both the overall GST diversity and the differences in expression patterns among animals feeding on different gorgonian species.

\section{Molluscan Glutathione S-transferases}

GSTs have been identified with some frequency in many molluscan species (Fitzpatrick \& Sheehan 1993, Fitzpatrick et al. 1995, Blanchette \& Singh 1999, Vidal \& Narbonne 2000, Yang et al. 2004, Doyen et al. 2005, Blanchette et al. 2007, Doyen et al. 2008). Immunoblot analysis has suggested the presence of alpha, mu and pi GST-like classes from the clam Ruditapes decussatus (Hoarau et al. 2002). It is now accepted that $\mathrm{mu}$, alpha, and pi mammalian GST classes have a common precursor, the alpha/pi/mu class, which probably arose from theta gene duplication (Pemble \& Taylor 1992). Recently, four complete cDNA sequences encoding GSTs from the pi, mu, omega, and sigma classes have been cloned from the Pacific oyster, Crassostrea gigas (Boutet et al. 2004). The expression of select oyster GST classes was found to be tissue-specific, as well as time- and treatment- (hydrocarbon or pesticide) dependent. Currently, many of the known molluscan GST enzymes are found within the pi class with representatives from squid, octopus, and five species of bivalves (Tomarev et al. 1991, Tomarev et al. 1993, Doyen et al. 2005); GenBank Accession \# AF527010, AF227977 and EF520700).

The endogenous function of pi GSTs in molluscs has yet to be defined; however, studies in mammalian systems indicate that pi GSTs (GSTP1) are effective in the detoxification of electrophilic $\alpha, \beta$-unsaturated carbonyl compounds produced by radical reactions, lipid peroxidation and metabolism of drugs (Berhane et al. 1994). 
Additionally, prostaglandins have been found to substantially induce mammalian GST pi (GSTP1) gene transcription, mediated by a prostaglandin response element localized in the enhancer region of GSTP1 (Kawamoto et al. 2000). The cyclopentenone-type prostaglandins (e.g. $\mathrm{PGA}_{2}, \mathrm{PGJ}_{2}$ ) and metabolites of $\mathrm{PGD}_{2}$, including 15-deoxy- $\Delta^{12,14}$ prostaglandin $\mathrm{J}_{2}$ are potent inducers of GSTP1. Both the prostaglandin A and J series contain $\alpha, \beta$-unsaturated ketones, which are very susceptible to nucleophilic addition reactions with thiols like GSH. Similar studies have confirmed the role of pi GSTs in prostaglandin conjugation (Bogaards et al. 1997). It is possible that upon ingestion of $\mathrm{PGA}_{2}$ from its gorgonian diet, Cyphoma gibbosum may experience a related induction of putative prostaglandin conjugating GSTs.

While considerable attention has been focused on the role of GST in the detoxification of anthropogenic xenobiotics (Cheung et al. 2001, Hoarau et al. 2001, Blanchette \& Singh 2002, Gowlan et al. 2002), there is increasing interest in molluscan detoxification of plant chemical defenses (DeBusk et al. 2000, Kuhajek \& Schlenk 2003). The red alga Odonthalia floccossa contains a suite of brominated phenolics capable of deterring feeding in several molluscan herbivores (Kurata \& Taniguchii 1997), yet it is a staple in the diet of the marine chiton, Cryptochiton stelleri. Biotransformation enzymes, including GSTs, were hypothesized to aid this herbivorous mollusc in utilizing $O$. floccossa as a food source despite the high concentration of brominated aromatic compounds (DeBusk et al. 2000). The elevated presence of GST in C. stelleri may protect the chiton against dietary metabolites while also conferring a selective advantage over other herbivores that avoid chemically defended algae. 


\section{Phase III - ABC transporters}

Originally discovered for their role in chemotherapeutic drug resistance in tumor cells, the ATP Binding Cassette (ABC) transporters affect the adsorption, distribution and excretion of numerous xenobiotics. $\mathrm{ABC}$ transporters are a large superfamily of proteins found in bacteria to humans and are involved in the trafficking of molecules across cell membranes (Litman et al. 2001). This ATP-dependent process involves the unidirectional translocation of sugars, lipids, amino acids, peptides, metals, inorganic ions, natural products, glutathione conjugates and toxins (Croop 1998). In eukaryotes the typical structure of an $\mathrm{ABC}$ protein consists of two membrane-embedded transmembrane domains (TMD) and two highly conserved ATP binding domains (NBD: nucleotide binding domain) consisting of the Walker A and Walker B motifs and a signature C domain (Allikmets \& Dean 1998). Sequence similarity surrounding the ATP binding site can range as high as 30\% identical residues between prokaryotic and eukaryotes (Croop 1998). The TMDs contain 6 -11 membrane spanning $\alpha$-helices and determine substrate specificity, while the NBDs transfer the energy released during ATP hydrolysis to the transport of the substrate across the membrane (Dean 2002). ABC transporters can be divided into seven subfamilies based on gene structure, domain order and sequence homology. Below I will describe two of these subfamilies $(\mathrm{ABCB}, \mathrm{ABCC})$ and present evidence for their involvement in xenobiotic resistance.

The first $\mathrm{ABC}$ transporter, permeability-glycoprotein or Pgp (a.k.a., ABCB, MDR), was identified in Chinese hamster ovary cells and has subsequently been linked to the multi-drug resistance phenotype (Juliano \& Ling 1976). Since this time, P-gp-like 
proteins have been described in a variety of invertebrates including sponges, mussels, oysters, clams, worms, and insects (Bard 2000). The full length P-gp gene is approximately 1280 amino acids. Each protein has two TMD consisting of six transmembrane regions and two cytoplasmic ATP binding sites (Croop 1998). Pglycoproteins are expressed in tissues instrumental in xenobiotic disposition (liver and kidney), in tissues acting as xenobiotic barriers (colon, pancreas, blood-brain barrier) and in hormone producing tissues in vertebrates (Endicott \& Ling 1989). Localization of Pgp to the apical (luminal) surface of epithelial cells in various tissues support the involvement of this protein in the transport and secretion of xenobiotics (Thiebaut et al. 1987). P-glycoprotein mRNA and protein expression has been shown to increase in animals and cell cultures dosed with substrate (e.g. verapamil) (Collett et al. 2004), suggesting that this pump can act as an inducible defense and therefore aid in the protection of cells, tissues, and organisms against toxic chemicals.

Substrates for P-gp are diverse but are generally moderately hydrophobic, low molecular weight molecules with a basic nitrogen atom, cationic or neutral but never anionic. This list includes natural products, colchicines, vinca alkaloids (e.g. vinblastine, vincristine), anthracyclines (e.g. doxorubicin), verapamil, steroids (cortisol, aldosterone) and many many more (see Litman et al. 2001). Interestingly, many P-gp substrates are also substrates for cytochrome $\mathrm{P} 450$ and both proteins have been found to be coexpressed in tissues involved in xenobiotic absorption, such as the small intestine and liver (Watkins 1997). Several marine natural products from algae (okadaic acid, calyculin A, caulerpin), tunicates (patellamide $\mathrm{D}$, lamelarins), sea hares (dolastatins), and gorgonians 
(polyoxygenated steroids) have also been identified as putative substrates for P-gp (Suganuma et al. 1988, Chambers et al. 1993, Williams \& Jacobs 1993, Aherne et al. 1996, Quesada et al. 1996, Schroder et al. 1998, Tanaka et al. 2002). The original role of multixenobiotic transport proteins remains unclear; however, the expression of P-gp in non-cancerous tissues and its distribution in vertebrate systems suggests a protective role against dietary secondary metabolites and environmental xenobiotics (Epel 1998).

For several years, P-gp was considered the only ABC transport protein associated with xenobiotic resistance. This all changed when a second drug-resistance-related $\mathrm{ABC}$ transporter, the multidrug resistance-associated protein (MRP; family ABCC), was discovered and found to share $15 \%$ amino acid identity to P-gp. In addition to the 12 transmembrane segments characterizing P-gp, the majority of MRP proteins have an additional $\mathrm{N}$-terminal transmembrane domain composed of five helices and an intracellular loop making MRP roughly 1500 amino acids in length. Therefore, MRP can be thought of as having an N-terminal hydrophobic domain linked to a P-gp-like core. The tissue distribution of MRP is similar to that of P-gp, with protein expression found in the liver, kidney, gut, pancreas, bladder and tumor cell lines (Borst et al. 2000). However, unlike P-gp, the majority of MRP proteins are basolateral transporters whose operation results in the movement of compounds away from luminal surfaces into tissues or blood vessels that lie beneath the basement membrane (Evers et al. 1996).

Despite the overlap of drug resistance profiles between both transporters, the substrate selectivities of the pumps differ markedly, in that P-gp substrates are neutral or mildly positive lipophilic compounds, while MRP is able to transport neutral and anionic 
lipophilic compounds and products of phase II cellular detoxification processes including glutathione conjugated compounds (Litman et al. 2001). The actual mechanism of transport, as with all $\mathrm{ABC}$ transporters, is not fully understood. Studies able to block intracellular GSH synthesis with BSO (buthionine sulfoximine) were able to sensitize cells to natural product anticancer compounds; however, the formation of glutathione conjugates was never detected, suggesting that conjugation may not be required to transport compounds. This led some to hypothesize a model for MRP which includes cotransport of GSH without actual GSH conjugation. Support for this model is convincing; however, it is not known to what extent MRP substrates are conjugated or cotransported (Rappa et al. 1997, Loe et al. 1998, Hipfner et al. 1999).

\section{ABC transporter-mediated sequestration}

For the most part, multixenobiotic transporters (MXT), P-gp and MRP, have been described with respect to their role in transporting compounds from the inside of the cell to the outside. However, some reports suggest that both transporters may concentrate large amounts of compounds within the cytoplasmic compartment in endocytic vesicles, effectively sequestering rather than excreting toxic compounds. The ability to sequester xenobiotics may be an alternative protective mechanism that organisms use to partition compounds away from the rest of the cell. One study investigating P-gp-mediated okadaic acid (OA) resistance in the common mussel, Mytilus edulis, found mussel blood cells to be highly resistant to the cytotoxic effects of OA (Svensson et al. 2003). The authors immediately suspected P-gp's involvement because of earlier reports that had 
provided convincing evidence that OA was a P-gp substrate in a MDR cell line (Tohda et al. 1994, Ritz et al. 1997). However, upon measuring the accumulation in mussel blood cells of a well described P-gp substrate (vincristine) in the presence of a P-gp inhibitor (verapamil), the authors found a puzzling result. Instead of increasing the concentration of vincristine (i.e. preventing P-gp-mediated cell efflux of vincristine) as seen in gill tissue, the inhibitor actually reduced the accumulation of vincristine in mussel blood cells. Microscopy studies with the fluorescent P-gp substrate Rhodamine B confirmed the accumulation of the fluorescent dye within lysosomes and the subsequent decrease in lysosome fluorescence when incubated with verapamil. When blood cells were exposed to OA, vincristine accumulation was not significantly affected. Nevertheless, when the volume of the lysosomal compartment was measured in cells pre-exposed to OA, a significant increase was detected compared with control cells, suggesting OA sequestration within lysosomes. P-gp lysosomal sequestration of toxic pollutants has also been confirmed in F/B cells of the digestive gland in the crab Carcinus maenas (Kohler et al. 1998).

Sequestration of xenobiotics by $\mathrm{ABC}$ transporters may function as a protective mechanism against cytotoxicity; but more than this, accumulation of toxic compounds may provide protection against predation. Sequestration of dietary allelochemicals in marine invertebrates has been extensively documented (Faulkner 1992, Pennings \& Paul 1993, Proksch 1994). Specialist molluscan predators, such as nudibranchs, actively take up defensive compounds from their diet (sponges or gorgonians) and use these chemicals for their own protection (Cronin et al. 1995, Avila \& Paul 1997). It is not unreasonable 
to hypothesize that P-gp and/or MRP may be involved in the accumulation of dietary allelochemicals in these marine predators.

\section{Molluscan ABC transporters}

For many years, molluscs (bivalves in particular) have been used in studies as indicator species to assess the health of the aquatic environment ( $\mathrm{O}^{\prime}$ Connor 2002). Research soon focused on the role of $\mathrm{ABC}$ transporters and their function in mediating xenobiotic resistance in marine invertebrates. Immunohistochemical studies, isolation of homologous genes, and in vivo/membrane vesicle activity assays all confirmed the presence of $\mathrm{ABC}$ transporters in molluscs (Table 2). MXT expression and activity has been detected in the gills, hepatopancreas, intestine and other tissues of aquatic invertebrates exposed to environmental chemicals (Smital et al. 2004). In addition, significant induction and subsequent return to basal levels of P-gp transport activity in bivalves exposed to pollutants in the field has been shown to occur within a 4-day period (Smital et al. 2003). This suggests that the induction of these energy-requiring defense mechanisms is tightly controlled.

Natural products of a marine origin have also been shown to modulate multixenobiotic transport activity in molluscs. A study in Mytilus californianus found several extracts from seaweed and phytoplankton species, mainly those of a moderately hydrophobic nature, enhanced the accumulation of a known fluorescent P-gp substrate, suggesting algal secondary metabolites may act as P-gp substrates (Eufemia et al. 2002). 
Additionally, extracts from an invasive green alga species, Caulerpa taxifolia, caused the accumulation of fluorescent MXT substrates in the gills of exposed bivalves and

Table 2. Biochemical and molecular evidence for molluscan ABC transporters

\begin{tabular}{|c|c|c|c|}
\hline ABC subfamily designation & Species & Evidence & Reference \\
\hline \multirow{15}{*}{$\begin{array}{l}\text { ABCB subfamily or } \\
\text { P-glycoprotein (Pgp) }\end{array}$} & Anodonta cygnea & Western blot, Fluorescent dye assay & Smital et al. 2000 \\
\hline & Brachidontes pharaonis & Sequence & GenBank \# AJ972911, Feldstein et al. 2006 \\
\hline & Corbicula fluminea & $\begin{array}{l}\text { Western blot, }{ }^{3} \mathrm{H} \text {-vincristine accumulation } \\
\text { assay }\end{array}$ & Waldmann et al. 1995, Achard et al. 2004 \\
\hline & Crassostrea gigas & Sequence, Western blot, Southern blot & $\begin{array}{l}\text { GenBank \# AJ422120; EU073425, Minier et al. } \\
1993\end{array}$ \\
\hline & Crassostrea virginica & $\begin{array}{l}\text { Fluorescent dye assay, Western blot, } \\
\text { Sequence }\end{array}$ & $\begin{array}{l}\text { GenBank \# AY319412, Keppler \& Ringwood } \\
2001\end{array}$ \\
\hline & Dreissena polymorpha & Sequence, Fluorescent dye assay & $\begin{array}{l}\text { GenBank \# AJ506742, Smital et al. 2000, Smital } \\
\text { et al. } 2003\end{array}$ \\
\hline & Monodonta turbinata & Western blot, Fluorescent dye assay & Smital et al. 2000 \\
\hline & Mytilus californianus & $\begin{array}{l}\text { Western blot, Fluorescent dye assay, } \\
\text { Sequence }\end{array}$ & $\begin{array}{l}\text { Cronwall et al. 1995, Eufemia \& Epel 2000, } \\
\text { Luckenbach \& Epel } 2008\end{array}$ \\
\hline & Mytilus edulis & $\begin{array}{l}\text { Western blot, Sequence, Fluorescent dye } \\
\text { assay }\end{array}$ & $\begin{array}{l}\text { GenBank \# AF159717, Minier et al. 1993, Minier } \\
\text { \& Moore 1996, Luedeking \& Kohler 2002, } \\
\text { Svensson et al. } 2003\end{array}$ \\
\hline & Mytilus galloprovincialis & $\begin{array}{l}\text { Western blot, Fluorescent dye assay, }{ }^{3} \mathrm{H}- \\
\text { vincristine accumulation assay, Sequence }\end{array}$ & $\begin{array}{l}\text { Kurelec 1995, Galgani et al. 1996, Smital et al. } \\
2000 \text {, Smital et al. 2003, Franzellitti \& Fabbri } \\
2006\end{array}$ \\
\hline & Patella lusitanica & Fluorescent dye assay & Smital et al. 2000 \\
\hline & Perna perna & $\begin{array}{l}\text { Fluorescent dye assay, Western blot, } \\
\text { Sequence }\end{array}$ & GenBank \# AF150878, Franco et al. 2006 \\
\hline & Saccostrea forskali & $\begin{array}{l}\text { Western blot, Fluorescent dye assay, } \\
\text { Sequence }\end{array}$ & Kingtong et al. 2007 \\
\hline & Viviparus viviparus & Fluorescent dye assay & Smital et al. 2000 \\
\hline & Unio pictorum & Sequence & GenBank \# AY857552 \\
\hline \multirow{5}{*}{$\begin{array}{l}\text { ABCC subfamily or } \\
\text { Multidrug resistance- } \\
\text { associated protein (MRP) }\end{array}$} & Crassostrea gigas & Sequence & GenBank \# AJ438990 \\
\hline & Mytilus californianus & Fluorescent dye assay, Sequence & Luckenbach \& Epel 2008 \\
\hline & Mytilus edulis & Sequence, Northern blot & GenBank \# AF397142-3, Luedeking et al. 2005 \\
\hline & Mytilus galloprovincialis & Sequence & Franzellitti \& Fabbri 2006 \\
\hline & Saccostrea forskali & $\begin{array}{l}\text { Western blot, Fluorescent dye assay, } \\
\text { Sequence }\end{array}$ & Kingtong et al. 2007 \\
\hline
\end{tabular}

subsequent inhibition of multixenobiotic resistance (Smital et al. 2004). Evidence also suggests that glutathione-conjugated natural products may be transported by molluscan MRPs. Human MRP1 is known to transport the glutathione conjugate of prostaglandin $\mathrm{A}_{2}($ GS-PGA $)$ (Evers et al. 1997, Ishikawa et al. 1998). In gorgonians, $\mathrm{PGA}_{2}$ and derivatives are potent feeding deterrents and have been isolated in high concentrations (Gerhart 1984). Upon their ingestion these compounds may inhibit the inherent multixenobiotic transporter defenses of potential consumers and make them more susceptible to these and other gorgonian chemical defenses. Interestingly, molluscan 
predators like C. gibbosum, which feed exclusively on gorgonians, do not seem affected by gorgonian chemistry and may have evolved sophisticated MXT to avoid cytotoxicity and exploit an abundant food source untouched by other reef predators.

\section{Rationale}

Understanding how organisms deal with potentially toxic or fitness-reducing allelochemicals has significance for understanding patterns of predation and herbivory in the marine environment. Cytochrome P450 and glutathione $S$-transferase enzymatic activity has been extensively documented in many marine invertebrates (Snyder 2000, Le Pennec \& Le Pennec 2003, Rewitz et al. 2006); however, as yet, no genes specifically involved in the detoxification of dietary allelochemicals have been sequenced. Similarly, little is known about dietary allelochemicals that act as substrates for P-glycoprotein or multidrug resistance protein in marine invertebrates. The focus of this research was to characterize the diversity and dietary regulation of cytochrome P450s, glutathione $S$ transferases, and multixenobiotic transporters in two marine molluscs and to identify dietary natural products that act as substrates for these proteins.

Chapter 2 describes a proteomic approach used to identify the diversity and phylogenetic relatedness of GSTs in Cyphoma. Chapter 3 investigates the diversity of putative CYP allelochemical metabolizing genes, their transcriptional responsiveness to host-gorgonian allelochemicals and their enzymatic activity toward allelochemical analogs. Chapter 4 explores the biochemical interactions among gorgonian extracts/pure compounds with Cyphoma GSTs, further relating physiological enzyme activity with 
ecologically relevant concentrations of gorgonian natural products. Finally, Chapter 5 examines the distribution and activity of two diverse subfamilies of multixenobiotic resistance proteins in both generalist and specialist molluscs to assess the potential importance of these efflux proteins in mediating allelochemical transport.

\section{References}

Achard M, Baudrimont M, Boudou A, Bourdineaud JP (2004) Induction of a multixenobiotic resistance protein (MXR) in the Asiatic clam Corbicula fluminea after heavy metals exposure. Aquatic Toxicology 67:347-357

Aherne GW, Hardcastle A, Valenti M, Bryant A, Rogers P, Pettit GR, Srirangam JK, Kelland LR (1996) Antitumour evaluation of dolastatins 10 and 15 and their measurement in plasma by radioimmunoassay. Chemother Pharmacol 38:225-232

Allikmets R, Dean M (1998) Cloning of novel ABC transporter genes. Methods in Enzymology 292:116-130

Aneshansley DJ, Eisner T, Widom JM, Widom B (1969) Biochemistry at 100 degrees C: explosive secretory discharge of bombardier beetles. Science 165:61-63

Avila C, Paul VJ (1997) Chemical ecology of the nudibranch Glossodoris pallida: is the location of diet-derived metabolites important for defense? Marine Ecology Progress Series 150:171-180

Bakus GJ, Targett NM, Schulte B (1986) Chemical ecology of marine organisms: an overview. J Chem Ecol 12:951-987

Bard SM (2000) Multixenobiotic resistance as a cellular defense mechanism in aquatic organisms. Aquatic Toxicology 48:357-389

Bayer FM (1961) The Shallow-Water Octocorallia of the West Indian Region, The Hague

Berenbaum M (1978) Toxicity of a furanocoumarin to armyworms: a case of biosynthetic escape from insect herbivores. Science 201:532-534

Berenbaum M, Feeny P (1981) Toxicity of angular furanocoumarins to swallowtail butterflies: escalation in a coevolutionary arms race? Science 212:927-929 
Berenbaum MR (1983) Coumarins and caterpillars: a case for coevolution. Evolution 37:163-179

Berenbaum MR (1991) Coumarins. In: Rosenthal G, Berenbaum MR (eds) Herbivores: Their interactions with secondary plant metabolites, Vol 1. Academic Press, New York, p 221-249

Berenbaum MR (2002) Postgenomic chemical ecology: from genetic code to ecological interactions. Journal of Chemical Ecology 28:873-896

Berhane K, Widersten M, Engstrom A, Kozarich JW, Mannervik B (1994) Detoxication of base propenals and other $\alpha, \beta$-unsaturated aldehyde products of radical reactions and lipid peroxidation by human glutathione transferases. PNAS 91:1480-1484

Birkeland C, Gregory B (1975) Foraging behavior and rates of feeding of the gastropod, Cyphoma gibbosum. Bull Nat Hist Mus Los Angeles Co 20:57-67

Blanchette B, Feng X, Singh BR (2007) Marine glutathione S-transferases. Marine Biotechnology 9:513-542

Blanchette BN, Singh BR (1999) Purification and characterization of the glutathione Stransferases from the northern quahog Mercinaria mercinaria. Mar Biotechnol $1: 74-80$

Blanchette BN, Singh BR (2002) Induction of glutathione S-transferase in the Northern quahog Mercenaria mercenaria after exposure to the polychlorinated biphenyl (PCB) mixture Aroclor 1248. J Protein Chem 21:489-494

Blanchette BN, Singh BR (2003) An enzyme based dechlorination of a polychlorinated biphenyl (PCB) mixture, Aroclor 1248, using glutathione S-transferases from the northern quahog Mercenaria mercenaria. J Protein Chem 2003:377-386

Block JH (1974) Marine sterols from some gorgonians. Steroids 23:421-424

Bogaards JJ, Venekamp JC, van Bladeren PJ (1997) Stereoselective conjugation of prostaglandin A2 and prostaglandin $\mathrm{J} 2$ with glutathione, catalyzed by the human glutathione S-transferases A1-1, A2-2, M1a-1a, and P1-1. Chem Res Toxicol $10: 310-317$

Borst P, Evers R, Kool M, Wijnholds J (2000) A family of drug transporters: the multidrug resistance-associated proteins. Journal of the National Cancer Institute 92:1295-1302 
Boutet I, Tanguy A, Moraga D (2004) Characterisation and epression of four mRNA sequences encoding glutatione S-transferases pi, mu, omega and sigma classes in the Pacific oyster Crassostrea gigas exposed to hydrocarbons and pesticides. Marine Biology 146:53-64

Boyle R, McLean S, Foley WJ, Davies NW (1999) Comparative metabolism of dietary terpene, p-cymeme, in generalist and specialist folivorous marsupials. Journal of Chemical Ecology 25:2109-2126

Brattsten LB (1992a) Metabolic defenses against plant allelochemicals. In: Rosenthal GA, Berenbaum MR (eds) Herbivores: their interactions with secondary plant metabolites. Academic Press, New York, p 175-242

Brattsten LB, Evans CK, Bonetti S, Zalkow LH (1984) Induction by carrot allelochemicals of insecticide-metabolising enzymes in the southern armyworm (Spodoptera eridania). Comp Biochem Physiol C 77:29-37

Brattsten VJ (1992b) Metabolic defenses against plant allelochemicals. In: Rosenthal G, Berenbaum M (eds) Herbivores: Their interactions with secondary metabolites, Vol 2. Academic Press, San Diego, p 175-242

Brown DJ, Clark GC, Van Beneden RJ (1998) A new cytochrome P450 (CYP30) family identified in the clam, Mercenaria mercenaria. Comp Biochem Physiol $121 \mathrm{C}: 351-360$

Canova S, Degan P, Peters LD, Livingstone DR, Voltan R, Venier P (1998) Tissue dose, DNA adducts, oxidative DNA damage and CYP1A-immunopositive proteins in mussels exposed to waterborne benzo[a]pyrene. Mutat Res 399:17-30

Chambers TC, Raynor RL, Kuo JF (1993) Multidrug resistant human KB carcinoma cells are highly resistant to the protein phosphatase inhibitors okadaic acid and calyculin A. Analysis of potential mechanisms involved in toxin resistance. Int $\mathbf{J}$ Cancer 53:323-327

Chaty S, Rodius F, Vasseur P (2004) A comparative study of the expression of CYP1A and CYP4 genes in aquatic invertebrate (freshwater mussel, Unio tumidus) and vertebrate (rainbow trout, Oncorhynchus mykiss). Aquatic Toxicology 69:81-93

Cheung CC, Zheng GJ, Li AM, Richardson BJ, Lam PK (2001) Relationships between tissue concentrations of polycyclic aromatic hydrocarbons and antioxidative responses of marine mussels, Perna viridis. Aquatic Toxicology 52:189-203

Chiappone M, Dienes H, Swanson DW, Miller SL (2003) Density and gorgonian hostoccupation patterns by flamingo tongue snails (Cyphoma gibbosum) in the Florida Keys. Caribbean Journal of Science 39:116-127 
Cimino G, De Rosa S, De Stefano S, Sodano G (1984) 18-Hydroxy steroids from the Mediterranean gorgonian Leptogorgia sarmentosa. Experientia 40:246-248

Cimino G, Desiderio B, De Stefano S, Sodano G (1979) Chemistry of Mediterranean gorgonians: Pregna-dien-ol-one acetate; novel steroid from gorgonian Eunicella cavolini. Experientia 35:442-443

Cohen MB, Berenbaum MR, Schuler MA (1989) Induction of cytochrome P-450mediated detoxification of xanthotoxin in the black swallowtail. Journal of Chemical Ecology 15:2347-2355

Cohen MB, Berenbaum MR, Schuler MA (1990) Immunochemical analysis of cytochrome P450 monooxygenase diversity in the black swallowtail caterpillar, Papilio polyxenes. Insect Biochemistry 8:777-783

Cohen MB, Schuler MA, Berenbaum MR (1992) A host-inducible cytochrome P-450 from a host-specific catepillar: Molecular cloning and evolution. PNAS 89:1092010924

Coll JC (1992) The chemistry and chemical ecology of octocorals (Coelenterata, Anthozoa, Octocorallia). Chemical Reviews 92:613-631

Collett A, Tanianis-Hughes J, Warhurst G (2004) Rapid induction of P-glycoprotein expression by high permeability compounds in colonic cells in vitro: a possible source of transporter mediated drug interactions. Biochemical Pharmacology 68:783-790

Cornwall R, Toomey BH, Bard SM, Bacon C, Jarman WM, Epel D (1995) Characterization of multixenobiotic/multidrug transport in the gills of the mussel Mytilus californianus and identification of environmental substrates. Aquatic Toxicology 31:277-296

Cronin G, Hay ME, Fenical W, Lindquist N (1995) Distribution, density, and sequestration of host chemical defenses by the specialist nudibranch Tritonia hamnerorum found at high densities on the sea fan Gorgonia ventalina. Marine Ecology Progress Series 119:177-189

Croop JM (1998) Evolutionary relationships among ABC transporters. Methods in Enzymology 292:101-116

Danielson PB, MacIntyre RJ, Fogleman JC (1997) Molecular cloning of a family of xenobiotic-inducible drosophilid cytochrome P450s: Evidence for involvement in host-plant allelochemical resistance. Proceedings of the National Acadmey of Sciences 94:10797-10802 
David P, Dauphin-Villemant C, Mesneau A, Meyran JC (2003) Molecular approach to aquatic environmental bioreporting: differential response to environmental inducers of cytochrome P450 monooxygenase genes in the detritivorous subalpine planktonic Crustacea, Daphnia pulex. Molecular Ecology 12:2473-2481

Dean M (2002) The human ATP-binding cassette (ABC) transporter superfamily. NCBI

DeBusk BC, Chimote SS, Rimoldi JM, Schenk D (2000) Effect of the dietary brominated phenol, lanasol, on chemical biotransformation enzymes in the gumboot chiton Cryptochiton stelleri (Middendorf, 1846). Comparative Biochemistry and Physiology Part C 127:133-142

Ding Y, Ortelli F, Rossiter LC, Hemingway J, Ranson H (2003) The Anopheles gambiae glutathione transferase supergene family: annotation, phylogeny and expression profiles. BMC Genomics 4:1-16

Doyen P, Bigot A, Vasseur P, Rodius F (2008) Molecular cloning and expression study of pi-class glutathione S-transferase (pi-GST) and selenium-dependent glutathione peroxidase (Se-GPx) transcripts in the freshwater bivalve Dreissena polymorpha. Comp Biochem Physiol C Toxicol Pharmacol 147:69-77

Doyen P, Vasser P, Rodius F (2005) cDNA cloning and expression pattern of pi-class glutathione $S$-transferase in freshwater bivalves Unio tumidus and Corbicula fluminea. Comparative Biochemistry and Physiology 140C:300-308

Duffy JE, Hay ME (2001) Ecology and Evolution of Marine Consumer-Prey Interactions. In: Bertness MD, Hay ME, Gaines SD (eds) Marine Community Ecology. Sinauer Associates, Sunderland, MA, p 131-157

Eisner T (1970) Chemical defense against predation in arthropods, Vol. Academic Press, New York

Endicott JA, Ling V (1989) The biochemistry of P-glycoprotein-mediated multidrug resistance. Annual Review of Biochemistry 58:137-171

Epel D (1998) Use of multidrug transporters as first lines of defense against toxins in aquatic organisms. Comparative Biochemistry and Physiology Part A 120:23-28

Eufemia N, Clerte S, Girshick S, Epel D (2002) Algal products as naturally occurring substrates for p-glycoprotein in Mytilus californianus. Marine Biology 140:343353

Eufemia NA, Epel D (2000) Induction of the mulixenobiotic defense mechanism (MXR), P-glycoprotein, in the mussel Mytilus californianus as a general cellular response to environmental stresses. Aquatic Toxicology 49:89-100 
Evers R, Cnubben NHP, Wijnholds J, van Deemeter L, van Bladeren P, Borst P (1997) Transport of glutathione prostaglandin A conjugates by the multidrug resistance protein. FEBS Lett 419:112-116

Evers R, Zaman GJ, van Deemeter L, Jansen H, Calafat J, Oomen LC, Elferink O, Borst P, Schinkel AH (1996) Basolateral localization and export activity of the human multidrug resistance-associated protein in polarized pig kidney cells. J Clin Invest 97:1211-1218

Faulkner DJ (1992) Chemical defenses in marine molluscs. In: Paul VJ (ed) Ecological roles of marine natural products. Cornell University Press, Ithaca, p 119-163

Faulkner DJ, Ghiselin MT (1983) Chemical defense and evolutionary ecology of dorid nudibranchs and some other opisthobranch gastropods. Marine Ecology Progress Series 13:295-301

Feeny P (1992) The evolution of chemical ecology: Contributions from the study of herbivorous insects. In: Rosenthal GA, Berenbaum MR (eds) Herbivores: their interactions with secondary plant metabolites, Vol 2. Academic Press, Inc., San Diego, p 1-44

Feldstein T, Nelson N, Mokady O (2006) Cloning and expression of MDR transporters from marine bivalves, and their potential use in biomonitoring. Marine Environmental Research 62 Suppl.:S118-121

Fenical W, Pawlik JR (1991) Defensive properties of secondary metabolites from the Caribbean gorgonian coral Erythropodium caribaeorum. Marine Ecology Progress Series 75:1-8

Fitzpatrick PJ, Krag TOB, Hojrup P, Sheehan D (1995) Characterization of a glutathione S-transferase and a related glutathione-binding protein from the gill of the blue musel, Mytilus edulis. Biochem J 305:145-150

Fitzpatrick PJ, O'Halloran J, Sheehan D, Walsh DR (1997) Assessment of a glutathione S-transferase and related proteins in the gill and digestive gland of Mytilus edulis (L)as a potential organic pollution biomarker. Biomarkers 2:51-56

Fitzpatrick PJ, Sheehan D (1993) Separation of multiple forms of glutathione Stransferase from the blue mussel, Mytilus edulis. Xenobiotica 23:851-861

Francis F, Haubruge E, Gaspar C, Dierickx PJ (2001) Glutathione S-transferases of Aulacorthum solani and Acyrthosiphon pisum: partial purification and characterization. Comparative Biochemistry and Physiology Part B 129:165-171 
Franco JL, Trivella DBB, Trevisan R, Dinslaken DF, Marques MRF, Bainy ACD, Dafre AL (2006) Antioxidant status and stress proteins in the brown mussel Perna perna exposed to zinc. Chemico-Biological Interactions 160:232-240

Franzellitti S, Fabbri E (2006) Cytoprotective responses in the Mediterranean mussel exposed to $\mathrm{Hg}_{2}{ }^{+}$and $\mathrm{CH}_{3} \mathrm{Hg}^{+}$. Biochemical and Biophysical Research Communications 351:719-725

Galgani F, Cornwall R, Holland-Toomey B, Epel D (1996) Interaction of environmental xenobiotics with a multixenobiotic defense mechanism in the bay mussel Mytilus galloprovincialis from the coast of California. Environmental Toxicology and Chemistry 15:325-331

Gerhart DJ (1984) Prostaglandin A2: An agent of chemical defense in the Caribbean gorgonian Plexaura homomalla. Marine Ecology Progress Series 19:181-187

Gerhart DJ (1986) Prostaglandin $A_{2}$ in the caribbean gorgonian Plexaura homomalla: Evidence against allelopathic and antifouling roles. Biochemical Systematics and Ecology 14:417-421

Gerhart DJ (1991) Emesis, learned aversion, and chemical defense in octocorals: a central role for prostaglandins? Am J Physiol Regul Integr Comp Physiol 260:R839R843

Goldberg WM (1973) The ecology of the coral-octocoral communities off the southeast Florida coast: geomorphology, species composition, and zonation. Bull Mar Sci $23: 465-488$

Gonzalez FJ (1989) The molecular biology of cytochrome P450s. Pharm Rev 40:243-288

Gonzalez FJ, Nebert DW (1990) Evolution of the P450 gene superfamily: animal-plant 'warfare', molecular drive and human genetic differences in drug oxidation. Trends in Genetics 6:182-186

Gowlan BT, McIntosh AD, Davies IM, Moffat CF, Webster L (2002) Implications from a field study regarding the relationship between polycyclic aromatic hydrocarbons and glutathione S-transferase activity in mussels. Mar Environ Res 54:231-235

Graham-Lorence SE, Peterson JA (1996) Structural alignments of P450s and extrapolations to the unknown. Methods in Enzymology 272:315-326

Harper MK, Bugni TS, Copp BR, James RD, Lindsay BS, Richardson AD, Schnabel PC, Tasdemir D, VanWagoner RM, Verbitski SM, Ireland CM (2001) Introduction to the chemical ecology of marine natural products. In: McClintock JB, Baker BJ (eds) Marine Chemical Ecology. CRC Press, Boca Raton, p 3-70 
Harrison T, Zangerl AR, Schuler MA, Berenbaum MR (2001) Developmental variation in cytochrome P-450 expression in Papilio polyxenes. Arch Insect Biochem Physiol 48:179-189

Harvell CD, Fenical W, Greene CH (1988) Chemical and structural defenses of Caribbean gorgonians (Pseudopterogorgia spp.) I. Development of an in situ feeding assay. Marine Ecology Progress Series 49:287-294

Harvell CD, Suchanek TH (1987) Partial predation on tropical gorgonians by Cyphoma gibbosum. Marine Ecology Progress Series 38:37-44

Hay ME (1991) Marine-Terrestrial Contrasts in the Ecology of Plant Chemical Defenses Against Herbivores. TRENDS in Ecology and Evolution 6:362-365

Hay ME (1992) The role of seaweed chemical defenses in the evolution of feeding specialization and in the mediation of complex interactions. In: Paul VJ (ed) Ecological roles of marine natural products. Cornell University Press, Ithaca, $p$ 93-118

Hay ME (1996) Marine chemical ecology: what's known and what's next? Journal of Experimental Marine Biology and Ecology 200:103-134

Hay ME, Fenical W (1988) Marine plant-herbivore interactions: the ecology of chemical defense. Annu Rev Ecol Syst 19:111-145

Hayes JD, Flanagan JU, Jowsey IR (2005) Glutathione transferases. Annu Rev Pharmacol Toxicol 45:51-88

Hipfner DR, Deeley RG, Cole SP (1999) Structural, mechanistic and clinical aspects of MRP1. Biochim Biophys Acta 1461:359-376

Hoarau P, Damiens G, Romeo M, Gnassia-Barelli M, Bebianno MJ (2006) Cloning and expression of a GST-pi gene in Mytilus galloprovincialis. Attempt to use the GST-pi transcript as a biomarker of pollution. Comp Biochem Physiol C Toxicol Pharmacol 143:196-203

Hoarau P, Garello G, Gnassia-Barelli M, Romeo M, Girard JP (2002) Purification and partial characterization of seven glutathione S-transferase isoforms from the clam Ruditapes decussatus. Eur J Biochem 269:4359-4366

Hoarau P, Gnassia-Barelli M, Romeo M, Girard JP (2001) Differential induction of glutathione S-transferases in the clam Ruditapes decussatus exposed to organic compounds. Environ Toxicol Chem 20:523-529 
Ishikawa T, Akimaru K, Nakanishi M, Tomokiyo K, Furuta K, Suzuki M, Noyori R (1998) Anti-cancer prostaglandin-induced cell cycle arrest and its modulation by an inhibitor of the ATP dependent glutathione S-conjugate export pump. Biochem J 336:569-576

Jonsson H, Viken Sandnes K, Schiedek D, Schneider R, Grosvik BE, Goksoyr A (2004) Development of two novel CYP-antibodies and their use in a PCB exposure experiment with Mytilus edulis. Marine Environmental Research 58:655-658

Juliano RL, Ling V (1976) A surface glycoprotein modulating drug permeability in Chinese hamster ovary cell mutants. Biochim Biophys Acta 455:152-162

Kaaya A, Najimi S, Ribera D, Narbonne JF, Moukrim A (1999) Characterization of glutathione S-transferase (GST) activities in Perna perna and Mytilus galloprovincialis used as a biomarker of pollution in the Agadir marine bay (south of Morocco). Bull Environ Contam Toxicol 62:623-629

Kawamoto Y, Nakamura Y, Naito Y, Torii Y, Kumagai T, Osawa T, Ohigashi H, Satoh $\mathrm{K}$, Imagawa M, Uchida K (2000) Cyclopentenone prostaglandins as potential inducers of phase II detoxification enzymes. The Journal of Biological Chemistry 275:11291-11299

Keppler C, Ringwood AH (2001) Expression of P-glycoprotein in the gills of oysters, Crassostrea virginica: seasonal and pollutant related effects. Aquatic Toxicology 54:195-204

Khessiba A, Hoarau P, Gnassia-Barelli M, Aissa P, Romeo M (2001) Biochemical response of the mussel Mytilus galloprovincialis from Bizerta (Tunisia) to chemical exposure. Arch Environ Contam Toxicol 40:222-229

Kikuta Y, Kusunose E, Kusunose M (2002) Prostaglandin and leukotriene omegahydroxylases. Prostaglandins \& other Lipid Mediators 68-69:345-362

Kingtong S, Chitramvong Y, Janvilisri T (2007) ATP-binding cassette multidrug transporters in Indian-rock oyster Saccostrea forskali and their role in the export of an environmental organic pollutant tributyltin. Aquatic Toxicology 85:124-132

Kogan JD, Sell K, Stinner RE, Bradley JR, Kogan M (1978) A bibliography of Heliothis zea (Boddie) and H. virescens (F.) (Lepidoptera:Noctuidae), International Agricultural Publication, Urbana, Illinois

Kohler A, Lauritzen B, Jansen D, Bottcher P, Teguiwa L, Kruner G, Broeg K (1998) Detection of P-glycoprotein mediated MDR/MXR in Carcinus maenas hepatopancreas by immuno-gold-silver labeling. Mar Environ Res 48:411-414 
Kuhajek JM, Schlenk D (2003) Effects of the brominated phenol, lanosol, on cytochrome P450 and glutathione transferase activities in Haliotis rufescens and Katharina tunicata. Comparative Biochemistry and Physiology Part C 134:473-479

Kurata K, Taniguchii K (1997) Feeding-deterrent bromophenols from Odonthalia corymbifera. Phytochemistry 45:1185-1188

Kurelec B (1995) Reversion of the multixenobiotic resistance mechanism in gills of a marine mussel Mytilus galloprovincialis by a model inhibitor and environmental modulators of P170-glycoprotein. Aquatic Toxicology 33:93-103

Lasker HR (1985) Prey preferences and browsing pressure of the butterflyfish Chaetodon capistratus on Caribbean gorgonians. Marine Ecology Progress Series 21:213-220

Lasker HR, Coffroth MA (1983) Octocoral distributions at Carrie Bow Cay, Belize. Marine Ecology Progress Series 13:21-28

Lasker HR, Coffroth MA, Fitzgerald LM (1988) Foraging patterns of Cyphoma gibbosum on octocorals: the roles of host choice and feeding preference. Biological Bulletin $174: 254-266$

Le Pennec G, Le Pennec M (2003) Induction of glutathione S-transferases in primary cultured digestive gland acini from the mollusk bivalve Pecten maximus (L.): application of a new cellular model in biomonitoring studies. Aquatic Toxicology 2003:131-142

Lee RF (1988) Glutathione S-transferase in marine invertebrates from Langesundfjord. Marine Ecology Progress Series 46:33-36

Lee RF, Keeran WS, Pickwell GV (1988) Marine invertebrate glutathione transferases: purification, characterization and induction. Marine Environmental Research 24:97-100

Li W, Schuler MA, Berenbaum MR (2003) Diversification of furanocoumarinmetabolizing cytochrome P450 monooxygenases in two papilionids: Specificity and substrate encounter rate. PNAS 100:14593-14598

Li X, Baudry J, Berenbaum MR, Schuler MA (2004) Structural and functional divergence of insect CYP6B proteins: From specialist to generalist cytochrome P450. Proc Natl Acad Sci 101:2939-2944

Li X, Schuler MA, Berenbaum M (2007) Molecular mechanisms of metabolic resistance to synthetic and natural xenobiotics. Annu Rev Entomol 52:231-253 
Litman T, Druley TE, Stein WD, Bates SE (2001) From MDR to MXR: new understanding of multidrug resistance systems, their properties and clinical significance. Cellular and Molecular Life Sciences 58:931-959

Livingstone DR, Nasci C, Sole M, Da Ros L, O'Hara SCM, Peters LD, Fossato V, Wootton AN, Goldfarb PS (1997) Apparent induction of a cytochrome P450 with immunochemical similarities to CYP1A in digestive gland of the common mussel (Mytilus galloprovincialis L.) with exposure to 2,2',3,4,4',5'-hexachlorobiphenyl and Arochlor 1254. Aquatic Toxicology 38:205-296

Livingstone DR (1998) The fate of organic xenobiotics in aquatic ecosystems: quantitative and qualitative differences in biotransformation by invertebrates and fish. Comparative Biochemistry and Physiology Part A 120:43-49

Loe DW, Deeley RG, Cole SP (1998) Characterization of vincristine transport by M(r) 190,000 multidrug resistance protein (MRP): evidence for cotransport with reduced glutathione. Cancer Res 58:5130-5136

Luckenbach T, Epel D (2008) ABCB and ABCC type transporters confer multixenobiotic resistance and form an environment-tissue barrier in bivalve gills. Am J Physiol Regul Integr Comp Physiol (In press)

Luedeking A, Kohler A (2002) Identification of six mRNA sequences of genes related to multixenobiotic resistance (MXR) and biotransformation in Mytilus edulis. Marine Ecology Progress Series 238:115-124

Luedeking A, Van Noorden CJF, Koehler A (2005) Identification and characterisation of a multidrug resistance-related protein mRNA in the blue mussel Mytilus edulis. Marine Ecology Progress Series 286:167-175

Ma R, Cohen MB, Berenbaum MR, Schuler MA (1994) Black swallowtail (Papilio polyxenes) alleles encode cytochrome P-450s that selectively metabolize linear furanocoumarins. Arch Biochem Biophys 310:332-340

Mansuy D (1998) The great diversity of reactions catalyzed by cytochromes P450. Comparative Biochemistry and Physiology Part C 121:5-14

Matsubara S, Yamamoto S, Sogawa K, Yokotani N, Fujii-Kuriyama Y, Haniu M, Shively JE, Gotoh O, Kusunose E, Kusunose M (1987) cDNA cloning and inducible expression during pregnancy of the mRNA for rabbit pulmonary prostaglandin $\omega$ hydroxylase (cytochrome P-450-p-2). J Biol Chem 262:13366-13371

Minier C, Akcha F, Galgani F (1993) P-glycoprotein expression in Crassostrea gigas and Mytilus edulis in polluted seawater. Comparative Biochemistry and Physiology 106B:1029-1036 
Minier C, Moore MN (1996) Rhodamine B accumulation and MXR protein expression in mussel blood cells: effects of exposure to vincristine. Marine Ecology Progress Series 142:165-173

Myrnes B, Nilsen IW (2007) Glutathione S-transferase from the Icelandic scallop (Chlamys islandica): isolation and partial characterization. Comp Biochem Physiol C Toxicol Pharmacol 144:403-407

Nelson DR (1998) Metazoan cytochrome P450 evolution. Comparative Biochemistry and Physiology Part C 121:15-22

Nelson DR, Kamataki T, Waxman DJ, et al. (1993) The P450 superfamily: update on new sequences, gene mapping, accession numbers, early trival names, and nomenclature. DNA Cell Biology 12:1-51

Nowlis JP (1993) Mate and oviposition-influenced host preferences in the coral-feeding snail Cyphoma gibbosum. Ecology 74:1959-1969

O'Connor TP (2002) National distribution of chemical concentrations in mussels and oysters in the USA. Marine Environmental Research 53:117-143

O'Neal W, Pawlik JR (2002) A reappraisal of the chemical and physical defenses of Caribbean gorgonian corals against predatory fishes. Marine Ecology Progress Series 240:117-126

Okita RT, Okita JR (2001 ) Cytochrome P450 4A fatty acid omega hydroxylases. Current Drug Metabolism 2:265-281

Omura T (1999) Forty years of cytochrome P450. Biochemical and Biophysical Research Communications 266:690-698

Ortelli F, Rossiter LC, Vontas J, Ranson H, Hemingway J (2003) Heterologous expression of four glutathione transferase genes genetically linked to a major insecticide-resistance locus from the malaria vector Anophele gambiae. Biochem J 373:957-963

Parkinson A (2001) Biotransformation of Xenobiotics. In: Klaassen CD (ed) Casarett and Doull's toxicology: the basic science of poisons. McGraw-Hill, New York, p 133224

Pass GJ, McLean S (2002) Inhibition of the microsomal metabolism of 1,8-cineole in the common brushtail possum (Trichosurus vulpecula) by terpenes and other chemicals. Xenobiotica 32:1109-1126 
Paul VJ (1992) Chemical defenses of benthic marine invertebrates. In: Paul VJ (ed) Ecological Roles of Marine Natural Products. Comstock and Publishing Associates, London, p 164-188

Paul VJ, Cruz-Rivera E, Thacker RW (2001) Chemical mediation of macroalgalherbivore interactions: ecological and evolutionary perspectives. In: McClintock JB, Baker BJ (eds) Marine Chemical Ecology. CRC Press, Boca Raton, p 227-266

Paul VJ, Puglisi MP (2004) Chemical mediation of interactions among marine organisms. Natural Product Reports 21:189-209

Pawlik JR (2000) Marine chemical ecology. Marine Ecology Progress Series 207:225226

Pawlik JR, Burch MT, Fenical W (1987) Patterns of chemical defense among Caribbean gorgonian corals: a preliminary survey. Journal of Experimental Marine Biology and Ecology 108:55-66

Pawlik JR, Chanas B, Toonen RJ, Fenical W (1995) Defenses of Caribbean sponges against predatory reef fish. I. Chemical deterrency. Marine Ecology Progress Series 127:183-194

Pawlik JR, Fenical W (1989) A re-evaluation of the ichthyodeterrent role of prostaglandins in the Caribbean gorgonian coral Plexaura homomalla. Marine Ecology Progress Series 52:95-98

Pawlik JR, Fenical W (1992) Chemical defense of Pterogorgia anceps, a Caribbean gorgonian coral. Marine Ecology Progress Series 87:183-188

Pemble SE, Taylor JB (1992) An evolutionary perspective on glutathione S-transferase inferred from class-theta glutathione transferase cDNA sequences. Biochem $\mathrm{J}$ 287:957-963

Pennings SC, Paul VJ (1993) Sequestration of dietary secondary metabolites by three species of sea hares: location, specificity and dynamics. Marine Biology 117:535546

Peters LD, Nasci C, Livingstone DR (1998a) Immunochemical investigations of cytochrome P450 forms/epitopes (CYP1A, 2B, 2E, 3A and 4A) in digestive gland of Mytilus sp. Comparative Biochemistry and Physiology 121C:361-369

Peters LD, Nasci C, Livingstone DR (1998b) Variation in levels of cytochrome P4501A, 2B, 2E, 3A and 4A-immunopositive proteins in digestive glands of indigenous and transplanted mussel Mytilus galloprovincialis in Venice Lagoon, Italy. Mar Environ Res 46:295-299 
Petersen RA, Niamsup H, Berenbaum MR, Schuler MA (2003) Transcriptional response elements in the promoter of CYP6B1, an insect P450 gene regulated by plant chemicals. Biochimica et Biophysica Acta 1619:269-282

Petersen RA, Zangerl AR, Berenbaum MR, Schuler MA (2001) Expression of CYP6B1 and CYP6B3 cytochrome P450 monooxygenases and furanocoumarin metabolism in different tissues of Papilio polyxenes (Lepidoptera: Papilionidae). Insect Biochemistry and Molecular Biology 31:679-690

Petushok N, Gabryelak T, Palecz D, Zavodnik L, Szollosi V, Deer KA (2002) Comparative study of the xenobiotic metabolising system in the digestive gland of the bivalve molluses in different aquatic ecosystems and in aquaria experiments. Aquatic Toxicology 61:65-72

Proksch P (1994) Defensive roles for secondary metabolites from marine sponges and sponge feeding nudibranchs. Toxicon 32:639-655

Quesada AR, Gravalos MD, Puentes JL (1996) Polyaromatic alkaloids from marine invertebrates as cytotoxic compounds and inhibitors of multidrug resistance caused by P-glycoprotein. Br J Cancer 74:677-682

Rappa G, Lorico A, Flavell RA, Sartorelli AC (1997) Evidence that the multidrug resistance protein (MRP) functions as a co-transporter of glutathione and natural product toxins. Cancer Res 57:5232-5237

Rebelo MF, Moreira JC (2003) Is there a CYP1A1 in marine bivalves? Expressed sequences related to cytochrome $\mathrm{P} 450$ in Crassostrea rhizophorae. Comments on Toxicology 9:279-287

Rewitz KF, Styrishae B, Lobner-Olesen A, Andersen O (2006) Marine invertebrate cytochrome P450: emerging insights from vertebrate and insect analogies. Comp Biochem Physiol C Toxicol Pharmacol 143:363-381

Rho J, Lee H-S, Seo Y, Cho KW, Shin J (2000) New bioactive steroids from the gorgonian Acalycigorgia inermis. Bulletin of the Korean Chemical Society 21:518-520

Ritz V, Marwitz J, Richter E, Ziemann C, Quentin I, Steinfelder HJ (1997) Characterization of two pituitary GH3 cell sublines partially resistant to apoptosis induction by okadaic acid. Biochem Pharmacol 54:967-971

Rodriguez AD (1995) The natural products chemistry of west indian gorgonian octocorals. Tetrahedron 51:4571-4618 
Ruesink JL, Harvell CD (1990) Specialist predation on the Caribbean gorgonian Plexaurella spp. by Cyphoma signatum. Marine Ecology Progress Series 65:265272

Sawicki R, Singh SP, Mondal AK, Benes H, Zimniak P (2003) Cloning, expression and biochemical characterization of one Epsilon-class (GST-3) and ten Delta-class (GST-1) glutathione S-transferases from Drosophila melanogaster, and identification of additional nine members of the Epsilon class. Biochem J 370:661-669

Schlenk D, Buhler DR (1988) Cytochrome P450 and phase II activities in the gumboot chiton Cryptochiton stelleri. Aquatic Toxicology 13:167-182

Schroder HC, Badria FA, Ayyad SN, Batel R, Wiens M, Hassanein HMA, Kurelec B, Muller WEG (1998) Inhibitory effects of extracts from the marine alga Caulerpa taxifolia and of toxin from Caulerpa racemosa on multixenobiotic resistance in the marine sponge Geodia cydonium. Environmental Toxicology and Pharmacology 5:119-126

Scott JG, Liu N, Wen Z (1998) Insect cytochromes P450: diversity, insecticide resistance and tolerance to plant toxins. Comparative Biochemistry and Physiology Part C $121: 147-155$

Sharma RK, Doig MV, Lewis DFV, Gibson GG (1989) Role of hepatic and renal cytochrome P-450 IVA1 in the metabolism of lipid substrates. Biochem Pharmac 38:3621-3629

Shaw JP, Large AT, Chipman JK, Livingstone DR, Peters LD (2000) Seasonal variation in mussel Mytilus edulis digestive gland cytochrome P4501A- and 2Eimmunoidentified protein levels and DNA strand breaks (Comet assay). Mar Environ Res 50:405-409

Sheehan D, Meade G, Foley VM, Dowd CA (2001) Structure, function and evolution of glutathione transferases: implications for classification of non-mammalian members of an ancient enzyme superfamily. Biochemical Journal 360:1-16

Simpson A (1997) The cytochrome P450 4 (CYP4) Family. Gen Pharmac 28:351-359

Slattery M, Avila C, Starmer J, Paul VJ (1998) A sequestered soft coral diterpene in the aeolid nudibranch Phyllodesmium guamensis, Avila, Ballesteros, Slattery, Starmer and Paul. Journal of Experimental Marine Biology and Ecology 226:3349 
Smital T, Kurelec B (1997) Inhibitors of the multixenobiotic resistance mechanism in natural waters: in vivo demonstration of their effects. Environ Toxicol Chem $16: 2164-2170$

Smital T, Luckenbach T, Sauerborn R, Hamdoun AM, Vega RL, Epel D (2004)

Emerging contaminants - pesticides, PPCPs, microbial degradation products and natural substances as inhibitors of multixenobiotic defense in aquatic organisms. Mutat Res 552:101-117

Smital T, Sauerborn R, Hackenberger BK (2003) Inducibility of the P-glycoprotein transport activity in the marine mussel Mytilus galloprovincialis and the freshwater mussel Dreissena polymorpha. Aquatic Toxicology 65:443-465

Smital T, Sauerborn R, Pivcevic B, Krca S, Kurelec B (2000) Interspecies differences in P-glycoprotein mediated activity of multixenobiotic resistance mechanisms in several marine and freshwater invertebrates. Comparative Biochemistry and Physiology 126C:175-186

Svensson S, Sarngren A, Forlin L (2003) Mussel blood cells, resistant to the cytotoxic effects of okadaic acid, do not express cell membrane p-glycoprotein activity (multixenobiotic resistanc). Aquatic Toxicology 65:27-37

Snyder MJ (1998) CYP4 cytochrome P450 enzymes belonging to the CYP4 family from marine invertebrates. Biochem Biophys Res Commun 249:187-190

Snyder MJ (2000) Cytochrome P450 enzymes in aquatic invertebrates: recent advances and future directions. Aquatic Toxicology 48:529-547

Snyder MJ, Champagne DE, Cohen MB, Howard JJ (1998) Effects of plant diet on detoxification enzyme activities of two grasshoppers, Melanoplus differentialis and Taeniopoda eques. Journal of Chemical Ecology 24:2151-2165

Snyder MJ, Walding JK, Feyereisen R (1995) Glutathione S-transferase from larval Manduca sexta midgut: sequence of two cDNAs and enzyme induction. Insect Biochem Molec Biol 25:455-465

Sotka EE, Whalen KE (2008) Herbivore offense in the sea: the detoxificaiton and transport of secondary metabolites. In: Amsler C (ed) Algal Chemical Ecology. Springer, New York, p 203-221

Stachowicz JJ (2001) Chemical Ecology of Mobile Benthic Invertebrates: Predators and Prey, Allies and Competitors. In: McClintock JB, Baker BJ (eds) Marine Chemical Ecology. CRC Press, Boca Raton, p 157-194 
Stien X, Percic P, Gnassia-Barelli M, Romeo M, Lafaurie M (1998) Evaluation of biomarkers in caged fishes and mussels to assess the quality of waters in a bay of the NW Mediterranean sea. Environ Pollut 99:339-345

Strode C, Wondji CS, David JP, Hawkes NJ, Lumjuan N, Nelson DR, Drane DR, Karunaratne S, Hemingway J, Black WC, Ranson H (2008) Genomic analysis of detoxification genes in the mosquito Aedes aegypti. Insect Biochemistry and Molecular Biology 38:113-123

Suganuma M, Fujiki H, Suguri H, Yoshizawa S, Hirota M, Nakayasu M, Ojika M, Wakamatus K, Yamada K, Sugimur T (1988) Okadaic acid: an additional nonphorbol-12-tetradecanoate-13-acetate-type tumor promoter. Proceedings of the National Academy of Sciences of the USA 85:1768-1771

Svensson S, Sarngren A, Forlin L (2003) Mussel blood cells, resistant to the cytotoxic effects of okadaic acid, do not express cell membrane p-glycoprotein activity (multixenobiotic resistanc). Aquatic Toxicology 65:27-37

Tanaka J, Trianto A, Musman M, Issa HH, Ohtani I, Ichiba T, Higa T, Yoshida W, Scheuer PJ (2002) New polyoxygenated steroids exhibiting reversal of multidrug resistance from the gorgonian Isis hippuris. Tetrahedron 58:6259-6266

Targett NM (1979) Gastropod tentacle withdrawal: a screening procedure for biological activity in marine macroalgae. Bot Mar 22:543-545

Targett NM, Arnold TM (2001) Effects of secondary metabolites on digestion in marine herbivores. In: McClintock JB, Baker BJ (eds) Marine Chemical Ecology. CRC Press, Boca Raton, p 391-411

Targett NM, Targett TE, Vrolijk NH, Ogden JC (1986) The effect of macrophyte secondary metabolites on feeding preference of the herbivorous parrotfish Sparisoma radians. Mar Biol 92:141-148

Teunissen Y, Geraerts WPM, van Heerikhuizen H, Planta RJ, Joosse J (1992) Molecular cloning of a cDNA encoding a member of a novel cytochrome $\mathrm{P} 450$ family in the mollusc Lymnaea stagnalis. J Biochem 112:249-252

Thiebaut T, Tsuruo T, Hamada H, M.M. G, Pastan I, Willingham MC (1987) Cellular localization of the multidrug resistance gene product in normal human tissues. Proceedings of the National Academy of Sciences of the USA 84:7735-7738

Thomson RH (1971) Naturally occurring quinones, Vol. Academic Press, New York

Thornton RS, Kerr RG (2002) Induction of pseudopterosin biosynthesis in the gorgonian Pseudopterogorgia elisabethae. Journal of Chemical Ecology 28:2083-2090 
Tohda H, Yasui A, Yasumoto T, Nakayasu M, Shima H, Nagao M, Sugimura T (1994) Chinese Hamster ovary cells resistant to okadaic acid express a multidrug resistant phenotype. Biochem Biophys Res Commun 203:1210-1216

Toledo-Silva GD, Siebert MN, Medeiros ID, Sincero TC, Moraes MO (2008) Cloning a new cytochrome P450 isoform (CYP356A1) from oyster Crassostrea gigas. Marine Environmental Research Epub ahead of print

Tomarev SI, Zinovieva RD, Guo K, Piatigorsky J (1993) Squid glutathione S-transferase relationships with other glutathione S-transferases and S-crystallins of cephalopods. Journal of Biological Chemistry 268:4534-4542

Tomarev SI, Zinovieva RD, Piatigorsky J (1991) Crystallins of the octopus lens. Recruitment from detoxification enzymes. J Biological Chemistry 266:2422624231

Vasconcelos VM, Wiegand C, Pflugmacher S (2007) Dynamics of glutathione Stransferase in Mytilus galloprovincialis exposed to toxic Microcystis aeruginosa cells, extracts and pure toxins. Toxicon 50:740-745

Vidal ML, Narbonne JF (2000) Characterization of glutathione S-transferase activity in the Asiatic clam Corbicula fluminea. Bull Environ Contam Toxicol 64:455-462

Vreeland HV, Lasker HR (1989) Selective feeding of the polychaete Hermodice carunculata on Caribbean gorgonians. J Exp Mar Biol Ecol 129:265-277

Vuilleumier S (1997) Bacterial glutathione S-transferases. What are they good for? J Bacteriol 179:1431-1441

Waldmann P, Pivcevic B, Muller WE, Zahn RK, Kurelec B (1995) Increased genotoxicity of acetylaminofluorene by modulators of multixenobiotic resistance mechanism: studies with the fresh water clam Corbicula fluminea. Mutat Res 342:113-123

Watkins PB (1997) The barrier function of CPY3A4 and P-glycoprotein: implications for drug delivery and activity in cancer chemotherapy. Mol Carcinog 13:129-134

Weinheimer AJ, Spraggins RL (1969) The occurrence of two new prostaglandin derivatives (15-epi-PGA 2 and its acetate methyl ester) in the gorgonian Plexaura homomalla. Tetrahedron Lett 59:5185-5189

Werck-Reichhart D, Feyereisen R (2000) Cytochromes P450: a success story. Genome Biology 1:1-9 
Whitlock JP (1986) The regulation of cytochrome P450 gene expression. Annu Rev Pharmacol Toxicol 26:333-369

Williams AB, Jacobs RS (1993) A marine natural product, patellamide D, reverses multidrug resistance in a human leukemic cell line. Cancer Lett 71:97-102

Williams RT (1959) Detoxication Mechanisms, Vol. Chapman \& Hall, London

Wootton AN, Goldfarb PS, Lemaire P, O'Hara SCM, Livingstone DR (1996) Characterization of the presence and seasonal variation of a CYP1A-like enzyme in digestive gland of the common mussel, Mytilus edulis. Marine Environmental Research 42:297-301

Wootton AN, Herring C, Spry JA, Wiseman A, Livingstone DR, Goldfarb PS (1995) Evidence for the existence of cytochrome P450 gene families (CYP1A, 3A, 4A, 11A) and modulation of gene expression (CYP1A) in the mussel Mytilus spp. Marine Environmental Research 39:21-26

Yamamoto S, Kusonose E, Ogita K, Kaku M, Ichihara K, Kusunose M (1984) Role of cytochrome P450 in co-hydroxylation of prostaglandins. J Biochem 96:593-603

Yang H-L, Zeng Q-Y, Li E-Q, Zhu S-G, Zhou X-W (2004) Molecular cloning, expression and characterization of glutathione S-transferase from Mytilus edulis. Comparative Biochemistry and Physiology 139:175-182

Yang H, Nie L, Zhu S, Zhou X (2002) Purification and characterization of a novel glutathione S-transferase from Asaphis dichotoma. Archives of Biochemistry and Biophysics 403:202-208

Yu SJ (1982) Host plant induction of glutathione S-transferases in the fall armyworm. Pest Biochem Physiol 19:101-106

Yu SJ (1983) Induction of detoxifying enzymes by allelochemicals and host plants in the fall armyworm. Pestic Biochem Physiol 19:330-336

Yu SJ (1984) Interactions of allelochemicals with detoxification enzymes of insecticidesusceptible and resistant fall armyworms. Pestic Biochem Physiol 22:60-68

Yu SJ (1986) Consequences of induced foreign compound-metabolizing enzymes in insects. In: Brattsten LB, Ahmad S (eds) Molecular aspects of insect-plant associations. Plenum, New York, p 153-174

Yu SJ (1989) Purification and characterization of gluathione S-transferase from five phytophagous Lepidoptera. Pest Biochem Physiol 35:97-105 
Yu SJ (1992) Plant allelochemical-adapted glutathione transferases in Lepidoptera. In: Mullin CA, Scott JG (eds) Molecular Mechanisms of Resistance to Herbivorous Pests to Natural, Synthetic and Bioengineering Control Agents. Plenum Publ., New York, p 174-190

Zhou ZH, Syvanen M (1997) A complex gluthathione S-transferase gene family in the housefly Musca domestica. Mol Gen Genet 256:187-194 


\section{Chapter II}

Proteomic identification, cDNA cloning, and enzymatic activity of glutathione $S$ transferases from the generalist marine gastropod, Cyphoma gibbosum 


\begin{abstract}
Glutathione S-transferases (GST) are key detoxification enzymes involved in the biotransformation and excretion of reactive electrophilic compounds including natural products. GSTs were characterized from the digestive gland of the tropical gastropod, Cyphoma gibbosum, to investigate the possible role of these enzymes in conferring resistance to allelochemicals present in this consumer's gorgonian coral diet. I identified the collection of expressed cytosolic GST classes in C. gibbosum using a proteomic approach involving affinity chromatography, high performance liquid chromatography, electrophoresis, nanospray liquid chromatography-tandem mass spectrometry (LCMS/MS) and MS/MS sequencing. Two major GST subunits, constitutively expressed in digestive gland tissues, were identified as putative mu-class GSTs most closely related to GSTs from abalone and oyster. One minor GST subunit was identified as a putative theta-class GST, apparently the first theta-class GST identified from a molluscan source. Two mu-class GST cDNAs, CgGSTM1 and CgGSTM2, were isolated by RT-PCR using primers derived from peptide sequences. The full-length cDNA sequences encode proteins of 215 amino acids in length that share $78 \%$ amino acid identity. Phylogenetic analysis establishes these as mu-class GSTs and reveals a mollusc-specific subclass of the GST-mu clade. Homology of C. gibbosum digestive gland GSTs to mammalian and bacterial isoforms suggests a possible role in the biotransformation of gorgonian natural products such as organohalogens and prostaglandins. These results provide new insights into metazoan GST diversity and the biochemical mechanisms used by marine animals to cope with their chemically defended prey.
\end{abstract}




\section{Introduction}

Glutathione S-transferases (GSTs, EC 2.5.1.18) form a large superfamily of multifunctional enzymes capable of conjugating a broad range of toxic electrophilic xenobiotics with glutathione (Sheehan et al. 2001). GSTs function primarily as detoxification enzymes, generally rendering the resultant products more water soluble (nonreactive conjugate), thereby facilitating excretion. The catalytic versatility and diversity of GSTs can be attributed to the nonspecific nature of the hydrophobic substrate binding site (H-site) and the extensive gene duplication and divergence that have occurred in this superfamily (Ivarsson et al. 2003, Pearson 2005). The soluble GSTs in metazoans are divided into seven classes (alpha, mu, pi, theta, sigma, zeta, and omega) based on sequence identity, immunological and kinetic properties (Sheehan et al. 2001, Nebert \& Vasiliou 2004, Hayes et al. 2005). While the majority of GST enzymatic characterization has focused on mammalian forms, non-vertebrate models offer an exciting opportunity to examine the evolution of GSTs and their adaptive responses to environmental chemicals, including natural products.

Biochemical adaptations involving xenobiotic response genes, such as GSTs, may help explain consumer resistance to dietary chemical threats, providing insight into enzymatic mechanisms underlying consumer foraging patterns. For example, the ability of terrestrial invertebrates (insects) to tolerate naturally occurring dietary toxins (i.e. allelochemicals in their host plants) has been linked in part to high constitutive activity of GSTs (reviewed in Li et al. 2007). The induction of GSTs in response to dietary host allelochemicals may serve as an additional adaptive mechanism to protect against toxicity. While the role of GSTs in plant-herbivore interactions has clearly influenced the 
ecology of terrestrial consumers, far less is known about the detoxification enzymes that allow marine invertebrates to exploit allelochemically defended prey.

Only a few studies have addressed the induction of GSTs upon exposure to allelochemicals in marine invertebrates (Vrolijk \& Targett 1992, DeBusk et al. 2000, Kuhajek \& Schlenk 2003). One such study (Vrolijk \& Targett 1992) examined GST activity in the digestive gland of a generalist gastropod, Cyphoma gibbosum, which exclusively feeds on several families of chemically defended gorgonian corals. The authors reported significantly higher GST activity in field-collected C. gibbosum feeding on gorgonians Gorgonia ventalina and Briareum asbestinum, suggesting that GST expression varies in response to different suites of gorgonian allelochemicals. Additionally, GST activity from C. gibbosum cytosolic preparations was among the highest ever reported from a molluscan digestive gland and was similar to values described from Papilio polyxenes, a specialist insect that feeds solely on chemically defended plants (Lee 1991, Lee \& Berenbaum 1992). In a subsequent study (Cronin et al. 1995), thin-layer chromatographic profiles of nonpolar tissue extracts from $C$. gibbosum feeding on G. ventalina did not mirror those of its octocoral prey, lending further support to the idea that this gastropod predator has the capacity to biotransform dietary compounds to readily excretable metabolites. However, the GST isoforms responsible for the detoxification of gorgonian allelochemicals are not known; and in general GST diversity in molluscs - including gastropods - is poorly understood.

GST cDNA sequences representing alpha, mu, pi, omega, and sigma GST classes have been identified in molluscs. The majority of sequences are grouped within the pi class, with representatives from cephalopods (squid, octopus), and seven bivalve species 
(Tomarev et al. 1991, Tomarev et al. 1993, Boutet et al. 2004, Yang et al. 2004, Doyen et al. 2005, Hoarau et al. 2006, Munasinghe et al. 2006, Myrnes \& Nilsen 2007, GenBank ${ }^{\circledR}$ Accession No. EF194203, EF520700, DQ530213, DQ530212). The endogenous function of pi-class GSTs in molluscs has yet to be defined; however, studies in mammalian systems indicate that pi GSTs are more participatory than other GST classes in the detoxification of prostaglandins and other electrophilic $\alpha, \beta$-unsaturated carbonyl compounds (Berhane et al. 1994, Bogaards et al. 1997). Prostaglandins are potent signaling molecules involved in the production of pain and fever (Malan \& Porreca 2005), the regulation of blood pressure/coagulation (Egan \& FitzGerald 2006) and reproduction (Goldberg \& Ramwell 1975). The highest concentrations of prostaglandins in nature have been found in Caribbean gorgonians (Weinheimer \& Spraggins 1969), where the acetoxy acids, hydroxyl methyl esters and hydroxyl acids of prostaglandin $A_{2}$ function as feeding deterrents against generalist reef fish (Gerhart 1984, Pawlik \& Fenical 1989). Prostaglandins in the A series especially can significantly induce GST activity in mammalian cells (Uchida 2000). I hypothesize that C. gibbosum GSTs may conjugate gorgonian allelochemicals, like prostaglandins, potentially alleviating their toxicity.

The objective of the present study was to isolate and characterize the GSTs in $C$. gibbosum digestive gland that may protect this marine consumer from allelochemicals found in its prey. Initially, I targeted pi-class GSTs because of their role in prostaglandin metabolism. However, attempts to obtain pi-class GSTs from C. gibbosum using RTPCR with degenerate primers designed from an alignment of molluscan GST pi cDNA sequences (Doyen et al. 2005) failed to yield any GST sequences. Therefore, I initiated a 
proteomic approach involving affinity chromatography coupled with HPLC and mass spectrometry to provide an unbiased assessment of GST protein diversity in the digestive gland of C. gibbosum. Here I report the identification of several mu-class GST proteins in C. gibbosum digestive gland, the cloning and phylogenetic characterization of two complete mu-class GST cDNAs and partial peptide sequences of a theta-class GST, apparently the first member of this class identified from a mollusc. These results contribute to a better understanding of GST diversity in molluscs and of the biochemical resistance mechanisms used by marine consumers to cope with chemical defenses in their prey, providing insight into patterns of predation and herbivory in the marine environment.

\section{Materials and Methods}

\section{Reagents}

CDNB, dithiothreitol (DTT), potassium phosphate, potassium chloride, EDTA, protease inhibitor cocktail (4-(2-aminoethyl)benzenesulfonyl fluoride, aprotinin, bestatin hydrochloride, E-64, leupeptin, pepstatin A), SDS, boric acid, $\mathrm{NaCl}$, sodium acetate, GSH, GSH-agarose were purchased from Sigma (St. Louis, MO). Bradford reagents and molecular weight standards for protein gels were purchased from BioRad (Hercules, CA). Novex ${ }^{\circledR}$ Tris-glycine gels and Sample Treatment Buffer were purchased from Invitrogen (Carlsbad, CA). Silver SNAP ${ }^{\circledR}$ Stain for Mass Spectrometry was purchased from Pierce (Rockford, IL). 


\section{Animals}

Adult Cyphoma gibbosum (ca 2-3 cm length) were collected from five shallow reefs $(<20 \mathrm{~m})$ near the Perry Institute of Marine Science (PIMS), Lee Stocking Island, Exuma Cays, Bahamas in January 2006 and transported to wet laboratory facilities provided by PIMS. The feeding assays are described in detail in Chapter 3. Individuals were allowed to feed on a control diet (e.g. alginic acid and freeze-dried squid paste (O'Neal \& Pawlik 2002) or one of six gorgonian diets (Briareum asbestinum, Eunicea mammosa, Gorgonia ventalina, Pseudopterogorgia acerosa, Pseudopterogorgia americana, Plexaura homomalla) for four days. The length (4 days) of the feeding assay was chosen based upon two previous studies that measured C. gibbosum mean residence time on gorgonian colonies (Harvell \& Suchanek 1987, Ruesink \& Harvell 1990) and the induction/decay kinetics of GST expression (Pickett et al. 1982). Upon completion of the feeding assay the digestive glands were immediately dissected and either preserved in RNALater ${ }^{\circledR}$ (Ambion, Austin, TX) or frozen in liquid nitrogen and transported back to the Woods Hole Oceanographic Institution. Tissues were maintained at $-80^{\circ} \mathrm{C}$ until further analysis.

\section{Enzyme purification}

Individual digestive glands $(\mathrm{n}=42)$ were homogenized 1:4 $(\mathrm{w} / \mathrm{v})$ in ice-cold homogenization buffer $(0.1 \mathrm{M}$ potassium phosphate, $1 \mathrm{mM}$ EDTA, $1 \mathrm{mM}$ DTT, $1.15 \%$ potassium chloride, protease inhibitor cocktail (1X); pH 7.5) with an IKA Ultra Turrax T8 homogenizer (Wilmington, NC) for $30 \mathrm{sec}$ on ice. All subsequent steps were carried out at $4{ }^{\circ} \mathrm{C}$. Cytosol was isolated by centrifugation of the crude homogenate at $750 \mathrm{xg}$ 
for 10 min then, without stopping, at 12,000 $\mathrm{x}$ for 10 min using a Beckman J2-21 centrifuge (Fullerton, CA). The supernatant was carefully removed, avoiding both the fatty layer and the pellet and transferred to an ultracentrifuge tube and centrifuged at $100,000 \mathrm{x} g$ for 70 min using a Beckman L8-60M ultracentrifuge (Fullerton, CA). An aliquot of the supernatant was taken for cytosolic protein determination using the BCA protein assay method (Smith et al. 1985) with BSA as the standard and the remaining cytosol was flash frozen in liquid nitrogen until further analysis. Samples were stored for several months in this manner suffered no apparent loss of enzymatic activity.

GSTs were purified using size exclusion chromatography, affinity chromatography and HPLC following a modified method from (Donham et al. 2005) . Cytosolic samples from individual snail digestive glands were purified separately. Initially, a subset of cytosol samples $(n=8)$ were used to determine the optimal buffer conditions and volumes for GST purification. Eluted 1-mL fractions from both sizeexclusion and affinity columns were sampled for activity towards CDNB and assayed for protein using the Bradford assay (Bradford 1976). These results helped streamline the GST purification process for the remaining cytosol samples.

A PD-10 desalting column (bed volume $8.3 \mathrm{~mL}$, bed height $5 \mathrm{~cm}, 5 \mathrm{~K} \mathrm{NMWL}$ ) (GE Healthcare, Piscataway, NJ) containing Sephadex G-25 matrix was equilibrated in Buffer A (50 mM Tris buffer, $1 \mathrm{mM}$ EDTA, $1 \mathrm{mM}$ DTT; $\mathrm{pH}$ 6.0) and $2.5 \mathrm{~mL}$ of crude cytosol were applied to the column. Cytosolic samples less than $2.5 \mathrm{~mL}$ were brought up to this volume with Buffer A and then applied to the column. GST proteins were eluted by gravity with Buffer A and fractions containing GST activity were combined (approx. 6 $\mathrm{mL}$ of elute) and then applied to a GSH-agarose affinity column (bed volume $0.5 \mathrm{~mL}, 0.8$ 
$x 4 \mathrm{~cm}$ i.d.) equilibrated in Buffer A. The affinity column was washed with $7 \mathrm{~mL}$ of Buffer B (Buffer A $+0.5 \mathrm{M} \mathrm{NaCl}$ ) to rinse away non-specific proteins. Retained GSTs were then eluted with $5 \mathrm{~mL}$ of Buffer C (50 mM Tris-base, $1 \mathrm{mM}$ EDTA, $1 \mathrm{mM}$ DTT, $0.5 \mathrm{M} \mathrm{NaCl}, 50 \mathrm{mM}$ glutathione; $\mathrm{pH} 9.5$ ) and fractions containing GST activity were then combined, buffer exchanged to low salt concentration, and concentrated with Amicon Ultra-4 centrifugational filters (5K NMWL membrane; Millipore, Billerica, MA). Protein concentrations of Amicon concentrates were determined with the NanoOrange protein quantitation kit (Molecular Probes, Eugene, OR).

Affinity-purified GSTs from individuals feeding on the same diet were pooled (100 $\mu \mathrm{L}$ injection volume) and injected onto a reverse phase Vydac protein/peptide column (model \#218 TP 52; C18 $\mu \mathrm{m} 250 \mathrm{~mm} \times 2.1 \mathrm{~mm}$ ) and separated on a Waters 600 MultiSolvent Delivery System, with a flow rate of $0.5 \mathrm{~mL} / \mathrm{min}$. Peaks were detected using a Waters 2487 Dual Wavelength Absorbance Detector $(\lambda=214 \mathrm{~nm})$. Mobile phase A consisted of $38 \%$ acetonitrile, $62 \%$ water and $0.1 \%$ trifluoroacetic acid (TFA). Mobile phase B consisted of $80 \%$ acetonitrile, $20 \%$ water and $0.1 \%$ TFA. The initial mobile phase consisted of $100 \%$ A. GST subunits were separated using a linear gradient from 0 to $40 \% \mathrm{~B}$ in $22 \mathrm{~min}$, and 40 to $100 \% \mathrm{~B}$ in $37 \mathrm{~min}$. Peaks were hand-collected, centrifugally evaporated to dryness, resuspended in $1 \mathrm{X}$ sample treatment buffer and separated by $12 \%$ Novex ${ }^{\circledR}$ Tris-glycine SDS-PAGE gel electrophoresis according to manufacturer's instructions (Invitrogen, Carlsbad, CA). Bands were visualized using the SilverSNAP ${ }^{\circledR}$ staining kit for mass spectrometry, excised from the gel and delivered to the UC-Davis Proteomics Facility, Davis, CA for in-gel digestion and LC-MS/MS analysis. 


\section{Protein in-gel digestion}

Protein bands were reduced and alkylated according to (Shevchenko et al. 1996). Proteins were reduced with $10 \mathrm{mM}$ DTT in $100 \mathrm{mM} \mathrm{NH}_{4} \mathrm{HCO}_{3}\left(\mathrm{pH} 8,55^{\circ} \mathrm{C}\right)$ for $1 \mathrm{~h}$, then alkylated with $55 \mathrm{mM}$ iodoacetamide in $100 \mathrm{mM} \mathrm{NH}_{4} \mathrm{HCO}_{3}$ for $45 \mathrm{~min}$ in the dark at room temperature. Excess reagent was removed, and gel pieces were washed with 100 $\mathrm{mM} \mathrm{NH}_{4} \mathrm{HCO}_{3}$ and partially dehydrated with acetonitrile; complete dehydration was then performed in vacuo. Finally, proteins were digested in $50 \% \mathrm{NH}_{4} \mathrm{HCO}_{3}$ containing sequence grade trypsin (Promega, Madison, WI) at a final concentration range of 10-25 ng $\mu \mathrm{L}^{-1}\left(37^{\circ} \mathrm{C}\right)$ for $17 \mathrm{~h}$. Peptides were extracted once with $0.1 \%$ TFA in water and once with $5 \%$ formic acid:acetonitrile (1:1). The extraction volume was carefully controlled to never exceed $50 \mu \mathrm{L}$ for mass spectrometric analysis.

\section{Nanospray LC-MS/MS and database analysis}

The trypsin-digested samples were analyzed using a Eksigent Nano LC 2-D system (Eksigent, Dublin, CA) coupled to an LTQ ion trap mass spectrometer (ThermoFisher, San Jose, CA) interfaced with a New Objective Picoview Nano-spray ionization source (Woburn, MA) to identify peptide fragments. Digested peptides were loaded on a reverse-phase Agilent Nano-trap (Zorbax 300SB-C18, 300Å, Agilent Technologies, Santa Clara, CA) at a loading flow rate of $5 \mu \mathrm{L} / \mathrm{min}$ for $10 \mathrm{~min}$. The buffers used for the reverse-phase chromatography were $0.1 \%$ formic acid in water (solvent A) and $95 \%$ acetonitrile in $0.1 \%$ formic acid in water (solvent B). Peptides were eluted from the trap and chromatographically separated on a reverse-phase capillary column (Pico Frit, $75 \mu \mathrm{m}$ x $15 \mathrm{~cm}$, tip $5 \mu \mathrm{m}$ : New Objective) packed in-house with Magic C18 AQ (3 $\mu \mathrm{m}$, 


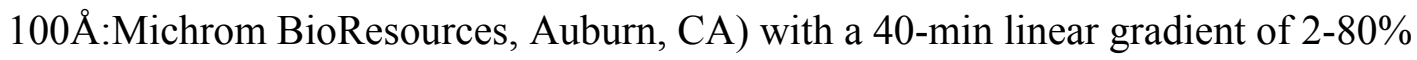
solvent B (as described below) at a flow rate of $300 \mathrm{~nL} \min ^{-1}$. The LTQ parameters were as follows: electrospray potential, $1.8 \mathrm{kV}$; source temperature, $180^{\circ}$; collision energy, $35 \%$; dynamic exclusion duration, $1 \mathrm{~min}$. The MS survey scan followed by ten MS/MS scans were consecutively acquired over the LC gradient. Upon completion of an LCMS/MS run, the MS/MS spectra from each survey were charge state deconvoluted and searched against the non-redundant NCBI protein database using BioWorks version 3.3 (Thermo Scientific, Waltham, MA) and MASCOT (Matrix Science, London, UK) and against the MSDB database (Imperial College, London, UK) using GPM software (http://www.thegpm.org). Protein fragments with significant hits to eukaryotic GSTs were then manually validated.

\section{GST activity assay}

Enzyme activity was measured using CDNB as a substrate by the method of (Habig et al. 1974) optimized for C. gibbosum (Vrolijk \& Targett 1992) in a microplate format. The reaction mixture (in a final volume of $200 \mu \mathrm{L}$ ) contained $0.1 \mathrm{M}$ potassium phosphate buffer, 1.0 mM EDTA, pH 7.5, $1 \mathrm{mM} \mathrm{CDNB}, 1 \mathrm{mM}$ reduced glutathione (GSH) and $2 \mu \mathrm{g}$ of protein. CDNB was solubilized in ethanol and constituted $1 \%$ of the final reaction mixture volume. The reaction incubated at $25^{\circ} \mathrm{C}$ was initiated by the addition of CDNB and performed in triplicate. The conjugation of CDNB with GSH was measured as the increase in absorbance at $340 \mathrm{~nm}\left(\Delta \varepsilon_{340} 0.00503 \mu \mathrm{M}^{-1} \mathrm{~cm}^{-1}\right)$ using a tunable microplate reader (Versamax, Molecular Devices, Sunnyvale, CA). Activity was 
calculated using protein concentrations determined via the Bradford assay with BSA as a standard.

\section{$R N A$ isolation and $c D N A$ synthesis}

Total RNA was purified from C. gibbosum digestive glands using the RNeasy Maxi Kit and DNAse treated using a RNase-free DNAse Kit (Qiagen, Valencia, CA) following the manufacturer's instructions. The integrity of each RNA sample was checked by electrophoresis on 1\% agarose-formaldehyde gel in MOPS buffer and visualized with ethidium bromide under UV light. Total RNA concentration was determined using a Nanodrop spectrophotometer (Wilmington, DE). Poly(A)+ RNA was isolated using the MicroPoly(A)Purist mRNA purification kit (Ambion, Austin, TX) according to the manufacturer's instructions. Poly(A)+ RNA was pooled from seven individuals feeding on either a control diet or one of six gorgonian species $(0.14 \mu \mathrm{g}$ poly(A) RNA/individual) to ensure representation of all GSTs expressed under various dietary conditions. One microgram of pooled RNA was primed with modified oligo (dT) primers and used to create an adaptor-ligated ds cDNA library synthesized using the Marathon cDNA Amplification Kit (BD Biosciences, Palo Alto, CA) according to the manufacturer's instructions.

\section{Primer design, RACE-PCR, cloning, sequencing}

Degenerate primers were designed to C. gibbosum GST peptide sequences identified from LC-MS/MS with homology to mu-class GSTs from abalone (Haliotis discus discus) and oyster (Crassostrea gigas) (GSTm_R10) (Table 1), and theta-class 
GSTs from sea bream (Pagrus major, Sparus aurata), plaice (Pleuronectes platessa) and bass (Micropterus salmoides) (primers not shown). Primers were obtained from Sigma Genosys (St. Louis, MO). PCR products were generated by rapid amplification of cDNA ends (RACE) using GST degenerate primers in combination with specific oligonucleotides designed to adaptor sequences located on the 3' and 5' ends of the cDNA. Amplification of PCR products was carried out according to the Advantage 2 PCR Enzyme Kit (Clontech, Mountain View, CA) and cycling parameters were as follows: $94^{\circ} \mathrm{C}$ for $30 \mathrm{sec} ; 30$ cycles of $94^{\circ} \mathrm{C}$ for $5 \mathrm{sec}$, annealing at $55^{\circ} \mathrm{C}$ for $30 \mathrm{sec}$, extension at $68^{\circ} \mathrm{C}$ for $2 \mathrm{~min}$. Primers were used at the following concentrations: $10 \mu \mathrm{M}$ of adaptor primer and $100 \mu \mathrm{M}$ of degenerate primer in a $50 \mu \mathrm{L}$ reaction. Sequences obtained by RACE were then used to design specific primers (GSTm_F13 and GSTm_F15) to clone full-length C. gibbosum GST cDNAs. PCR products were cloned into pGEM-T (Promega, Madison, WI) and sequenced in both directions using an ABI 3730XL capillary sequencer at the Keck facility of the Josephine Bay Paul Center for Comparative Molecular Biology \& Evolution at the Marine Biological Laboratory (Woods Hole, MA). A minimum of twelve clones were sequenced for each PCR fragment.

\section{Sequence analysis}

Clones were grouped based on similar nucleotide sequence using Sequencher (Gene Codes Co., Ann Arbor, MI) and used to generate a consensus sequence that was compared to known GST coding sequences using BLASTX. Multiple alignments of deduced amino acid sequences were performed using ClustalW (Thompson et al. 1994). 
Ambiguous alignment positions were excluded from further analyses. Phylogenetic relationships were investigated using Bayesian techniques as implemented in the computer program MrBayes (v 3.1.2; Ronquist \& Huelsenbeck 2003). MrBayes estimates posterior probabilities using Metropolis-Hastings coupled Monte Carlo Markov chains $\left(\mathrm{MC}^{3}\right) \cdot \mathrm{MC}^{3}$ estimates were performed with uninformative prior probabilities using the WAG model of amino acid substitution (Whelan \& Goldman 2001) and prior uniform gamma distributions approximated with four categories $(\mathrm{WAG}+\mathrm{I}+\Gamma)$. Four incrementally heated, randomly seeded Markov chains were run for $3 \times 10^{6}$ generations, and topologies were sampled every $100^{\text {th }}$ generation. The $\mathrm{MC}^{3}$ burnin values were conservatively set at $1 \times 10^{6}$ generations. Posterior probabilities of topologies and clades were estimated from the sampled topologies after removal of the initial $\mathrm{MC}^{3}$ burnin.

\section{Results}

\section{GST purification and activity}

Cytosol was isolated from the digestive glands of individual C. gibbosum feeding for four days on one of six gorgonian diets ( $n=4-7$ snails per gorgonian diet) or a control $\operatorname{diet}(n=13$ snails $)$, resulting in a mean total protein yield of $125.6 \pm 52.8 \mathrm{mg} \mathrm{g}^{-1}$ digestive gland wet weight. C. gibbosum digestive glands collected for this study averaged $0.22 \pm 0.11 \mathrm{~g} \mathrm{snail}^{-1}(\mathrm{n}=42$; mean $\pm \mathrm{SD})$. Glutathione transferase activity of crude cytosol ranged from 0.57 to $5.82 \mathrm{U} \mathrm{mg}^{-1}$ protein, with an average of $2.67 \pm 1.27 \mathrm{U}$ $m g \operatorname{protein}^{-1}(\mathrm{n}=42)$, using CDNB as a substrate. Following size exclusion chromatography and affinity purification of the GSTs from C. gibbosum digestive gland, an average of $25 \pm 14 \mu \mathrm{g}$ of GST protein was collected from each digestive gland ( $\mathrm{n}=$ 
36 ), representing approximately $0.2 \%$ of the total cytosolic protein. A 220 -fold

purification of GST protein was obtained using size-exclusion and affinity

chromatography (Table 2). Representative GST elution profiles from the Sephadex G-25

column and the GSH-agarose columns are presented in Figure 1.

\section{Gel electrophoresis and GST identification}

To provide an initial characterization of affinity-purified proteins, bound protein fractions obtained from GSH-agarose affinity columns from two individuals (feeding either on P. americana or the control diet) were concentrated, combined, and $15 \mu \mathrm{L}$ of the pooled sample was analyzed on a $12 \%$ Novex ${ }^{\circledR}$ Tris-glycine SDS-PAGE gel (Figure 2). Three distinct bands ranging in size from 21 to $24 \mathrm{kDa}$ were detected by silver staining and excised from the gel for identification via LC-MS/MS. All three bands contained peptide sequences that closely matched those of mu-class GSTs in the database (Table 3). This pooled GST affinity-purified fraction was used as standard for subsequent SDS-PAGE gels.

\section{HPLC and LC-MS/MS based GST identification}

Affinity-purified fractions from individual digestive glands were concentrated and then equal volumes of affinity-purified GSTs were pooled within each snail diet for further HPLC separation of GST subunits. HPLC analysis of affinity-purified GSTs pooled within snail diet identified a total of fourteen unique ( 2 major and 12 minor) peaks. The relationship between snail diet and GST subunit expression will be described elsewhere (Chapter 4). Here, I present the proteomic characterization of HPLC separated 
GST subunits. Figure 3 shows a representative HPLC separation of digestive gland GST subunits from four C. gibbosum feeding on B. asbestinum. For peak collection purposes, the fourteen peaks were grouped into seven fractions (B-H; A= injection peak) (Figure 3).

The HPLC fractions were separated on 12\% Tris-glycine SDS-PAGE gels (Figure 4) and bands were excised for proteomic analysis. Peptide sequences were determined for fractions B-H using nanospray LC-MS/MS and identified by comparison to proteins in the Genbank ${ }^{\circledR}$ database. Fractions D and F, with elution times of 18 and 22 minutes, respectively, represent the two major GST subunits. Both of these fractions yielded peptides that closely matched mu-class GSTs (Table 3; Figure 5). Peptides in the remaining fractions also matched GST mu-class proteins, with the exception of fraction B, which yielded eight peptides that matched theta-class GSTs from fish (Table 3; Figure 6). Manual validation of LC-MS/MS spectra verified five of the C. gibbosum peptide sequences as identical to the fish GST-theta peptides (Table 3).

\section{C. gibbosum cDNA cloning and sequence analysis}

To obtain full-length cDNA sequences for $C$. gibbosum GSTs, polypeptides identified by mass spectrometry were used to design degenerate primers. The mu-class GST degenerate primer (GSTm_R10), designed to the peptide sequence AYMASDK, yielded two 600-bp fragments that were confirmed by BLAST searches to be partial cDNAs encoding mu-class GSTs. Complete cDNA sequences were generated by 3' RACE, revealing open reading frames encoding predicted proteins of 215 amino acids each. The predicted proteins displayed $61 \%$ and $62 \%$ amino acid identity to Pacific oyster GST mu for transcript 1 (CgGSTM1; GenBank ${ }^{\circledR}$ Accession No. EU008563) and 
transcript 2 (CgGSTM2; GenBank ${ }^{\circledR}$ Accession No. EU008562), respectively. The two C. gibbosum GST mu cDNAs are $78 \%$ identical and $88 \%$ similar (BLOSUM62) to each other at the protein level. Translated nucleotide sequences predict a molecular mass of 25.0 $\mathrm{kDa}$ for CgGSTM1 and $25.2 \mathrm{kDa}$ for CgGSTM2. Figure 5 shows an alignment of these two sequences with several invertebrate and vertebrate mu-class GST sequences. Amino acid residues involved in glutathione binding as determined using the Pfam database (Marchler-Bauer et al. 2007) are entirely conserved among C. gibbosum, vertebrate and invertebrate sequences included in the alignment, while substrate binding sites are poorly conserved.

Two C. gibbosum tryptic peptides identified in the LC-MS/MS analysis (ITQSN AILR and AYMASDK), were found to be identical to corresponding C. gibbosum GST translated nucleotide sequences (nucleotides 583-603 in CgGSTM1 and CgGSTM2; and 205-231 in CgGSTM1, respectively) (Table 3).

To infer relationships between $C$. gibbosum predicted protein sequences and other GST sequences, a phylogenetic tree was constructed using Bayesian techniques. Cyphoma GSTM1 and GSTM2 clearly group within the mu-class GST clade and appear most closely related to other molluscan mu GSTs, which together form a strongly supported subgroup within this clade (Figure 7).

\section{Discussion}

Dietary toxins present physiological challenges to marine consumers, such as Cyphoma gibbosum, that feed solely on chemically defended gorgonian prey. The high concentration of allelochemicals in gorgonian corals (Paul 1992, O'Neal \& Pawlik 2002), 
coupled with the findings that digestive glands of C. gibbosum - which feed exclusively on gorgonians - contain high levels of GST activity (Vrolijk \& Targett 1992), prompted an investigation to identify and biochemically characterize those GST enzymes possibly responsible for detoxifying gorgonian allelochemicals.

The levels of cytosolic GST activities in C. gibbosum digestive gland (Table 2 and Vrolijk \& Targett 1992) are among the highest recorded for any molluscan tissue (reviewed in Vrolijk \& Targett 1992, Le Pennec \& Le Pennec 2003). The majority of studies reporting GST activity from molluscs have used GST activity measurements as an indicator of pollutant exposure (Sheehan et al. 1995, Fitzpatrick et al. 1997, Kaaya et al. 1999, Hoarau et al. 2006, Verlecar et al. 2006). Although the level of GST activity in $C$. gibbosum is high even in comparison to that of molluscs exposed to pollutants known to induce GST expression (Boryslawskyj et al. 1988, Lee 1988, Fitzpatrick et al. 1995), this high activity is unlikely to be a response to anthropogenic contamination, given the remote site of collection. Rather, the high GST activity may reflect an adaptation that facilitates consumption of allelochemical-rich prey. Whether high GST activity is common among marine species that feed exclusively on chemically defended food is unknown, and may depend upon the specific suite of allelochemicals present in the diet. Regardless of its origin, the high GST activity in C. gibbosum suggested that this species would be a rich source of GST enzyme(s), enabling proteomic studies to further characterize GSTs potentially involved in allelochemical metabolism.

The results of the proteomic and molecular analyses in the present study clearly show that the predominant cytosolic GSTs expressed in C. gibbosum digestive gland are mu-class GSTs. These include the major HPLC peaks (fractions D and F) as well as 
several minor peaks. According to the current system of GST classification, GSTs sharing greater than $60 \%$ identity fall within the same class, while those with less than $30 \%$ identity are assigned to separate classes (Sheehan et al. 2001). The classification of C. gibbosum GSTs as members of the mu class is supported by both the homology searches of C. gibbosum tryptic peptides (Table 3) and the phylogenetic analysis of translated C. gibbosum GST cDNAs (Figure 7). The presence of mu-class GSTs in molluscs had been predicted based on immunoblot analysis (Sheehan et al. 1995, Vidal et al. 2002, Hoarau et al. 2004), but only recently have molluscan GST mu nucleotide sequences been determined (Boutet et al. 2004, Myrnes \& Nilsen 2007; Genbank ${ }^{\circledR}$ Accession No. ABF67506). Our identification of two GST cDNAs in C. gibbosum provide the first published description of GST-mu forms from gastropods. Phylogenetic analysis reveals a mollusc-specific subclass within the GST-mu clade.

Proteomic results indicate the possibility of additional GST mu subunits beyond the two cDNAs identified here. Only two of the twelve Cyphoma tryptic peptides identified as matching abalone and oyster mu-class GSTs were found to be encoded by the two cDNA clones isolated from C. gibbosum. Not surprisingly these peptides corresponded to fairly conserved regions of the GST protein. However, three peptides (KAAYFEALPAK; SFLGDQQFFAGSK; and IMQPGSLDAFPTLLAFMGRIEALPAIK) identified as matching abalone GSTM are quite divergent from the translated $C$. gibbosum sequences, indicating that at least one, and possibly as many as three, additional GST mu subunits are present in Cyphoma. HPLC analysis of affinity-purified extracts suggests that there may be additional muclass subunits, perhaps as many as thirteen (represented by the 13 peaks in fractions $\mathrm{C}-\mathrm{H}$, 
Figure 3), the majority of which are minor components. In addition, visualization of hand-collected HPLC fractions by SDS-PAGE and silver staining (Figure 4) revealed the major peak in fraction F to be a composite of two separate GST subunits that were unresolvable by HPLC. Peak F from affinity-purified extracts from each of the seven diets gave this similar double banding pattern (data not shown), indicating that both subunits are universally expressed regardless of snail diet. Both bands were later confirmed to be mu-class GSTs by LC-MS/MS, thus increasing the count of potential mu-class subunits identified by HPLC analysis to fourteen. Whether the HPLC peaks represent truly unique subunits or HPLC-resolved post-translationally modified variants of the same subunit remains unclear. Multiple GST mu subunits in a single species are not uncommon; five distinct mu-class subunits have been identified from humans (Sheehan et al. 2001). Overall, our results provide conclusive evidence for at least three distinct GST-mu isoforms, and perhaps more, in C. gibbosum. Interestingly, mu-class GST subunits are capable of forming heterodimers (Hayes \& Pulford 1995). Whether Cyphoma GST subunits form heterodimers is unknown, but the formation of heterodimeric GSTs has been suggested as a way of increasing the range of substrates that might be acted on by a limited set of GST isoforms (Sheehan et al. 2001).

In this study, I identified a theta-class GST from C. gibbosum digestive gland and by manual validation confirmed the sequence of five peptides to be identical to theta and theta-class-related GSTs from fish. The HPLC fraction B shows a single peak, suggesting that only one subunit is expressed. Several attempts to amplify theta-like GSTs from C. gibbosum digestive gland mRNA with degenerate primers designed to these peptide sequences were not successful. 
The identification of putative a theta-class GST in C. gibbosum was unexpected. To the best of our knowledge, no theta-like GSTs have been identified previously in a molluscan species, although theta-class GSTs exist in vertebrates, arthropods, polychaetes, algae and bacteria (Pemble \& Taylor 1992, Rhee et al. 2007). Theta-class GSTs in general have been notoriously hard to identify because they normally do not bind to affinity matrices such as GSH-agarose (Sheehan et al. 2001). In addition, most lack detectable activity toward CDNB, and thus can be missed if GST activity is the only means of GST isolation (Comstock et al. 1994, Lopez et al. 1994). The unique activity of theta-class GSTs can be traced to the presence of the essential Ser-11, responsible for glutathione deprotonation and activation, in place of the tyrosine found in the alpha, mu, and pi class GSTs (Landi 2000). Theta-class GSTs can be further distinguished from alpha/mu/pi class isoforms because of their high affinity for glutathione (high $\mathrm{K}_{\mathrm{m}}$ ), but low affinity for glutathione-conjugates. The diminished product retention in the active site of theta GSTs favors increased substrate turnover in comparison to alpha/mu/pi forms, which have a greater capacity to sequester conjugated products (Landi 2000). Generally, it is believed that the theta-class GSTs gave rise to the alpha/mu/pi classes via gene duplication events (Pemble \& Taylor 1992); however, this has been called into question more recently (Blanchette et al. 2007). In this study, I identified a theta-like GST from C. gibbosum digestive gland and by manual validation confirmed the sequence of five peptides to be identical to theta and theta-class related GSTs from fish. The HPLC fraction B shows a single peak, suggesting that only one subunit is expressed. Attempts to amplify theta-like GSTs from C. gibbosum digestive gland mRNA with 
degenerate primers (not shown) designed to these peptide sequences have not yet succeeded.

It is interesting to note that Cyphoma theta-like peptides matched only theta-class GSTs from fish rather than those from terrestrial invertebrates. Using phylogenetic relationships inferred from Bayesian analyses, Lee et al. (2006) found that theta class GSTs formed two distinct, well-supported clades, one ("theta A") containing only fish representatives, which includes the related rho-class GSTs, and the other ("theta B") including theta-class GSTs from mammals, fish, birds, and invertebrates. Recent evidence has confirmed the deeply rooted nature of the "theta A" clade by the identification of a rho-GST in a primitive cephalochordate (Fan et al. 2007) once thought to be a fish-specific class (Lee et al. 2006). The Cyphoma GST theta-like peptides matched both rho- and theta-class fish sequences in the "theta A" clade, providing the first evidence for invertebrate members within group.

Several natural compounds, including alpha-tocopherol, coumarin, and indole-3carbinol, have been identified as potent inducers of mammalian theta GSTs. However, it is the dehalogenase activity of theta-class GSTs that makes this class of enzymes so unique (Landi 2000). For example, both bacterial and mammalian theta-class GSTs are capable of metabolizing dichloromethane (DCM) to formaldehyde (Gisi et al. 1999). The oceans are the largest source of organohalogens (Gribble 2003), with representatives from cnidarians including briarane diterpenes (Kubota et al. 2006), bromo-, chloro- and indo-vulones, clavulones and punaglandins (related to mammalian prostaglandins) (Baker \& Scheuer 1994, Rezanka \& Dembitsky 2003, Rowley et al. 2005), and chlorinated 
sterols (Iwashima et al. 2001). It is possible that C. gibbosum theta-like GSTs may have evolved to protect this consumer against halogenated compounds from its gorgonian host.

Numerous studies have begun to identify allelochemical substrates for invertebrate GSTs (reviewed in Li et al. 2007). Many plant allelochemicals and marine natural products contain the appropriate functional groups that can be directly conjugated with GSH (Schlenk \& Buhler 1988, Brattsten 1992). Cyphoma gibbosum regularly feeds on the gorgonian Plexaura homomalla, which contains high concentrations (up to $8 \%$ of the dry weight) of prostaglandins (15(R)-PGA $)$ (Weinheimer \& Spraggins 1969, Dominguez et al. 1980). Prostaglandins are known to suppress cell proliferation and overexpression of mu-class GSTs resulting in increased conjugation of prostaglandins may inhibit the antiproliferative effects of these compounds (Tsuchilda \& Sato 1992). Naturally occurring prostaglandins $\left(\mathrm{PGA}_{2}\right.$ and $\left.\mathrm{PGJ}_{2}\right)$ undergo enzymatic conjugation by purified human GSTM1a-1a (Bogaards et al. 1997). Thus, high expression of GST mu isoforms may allow $C$. gibbosum to tolerate the chemical defenses of its host gorgonian and subsequently feed longer than would otherwise be possible. Preliminary studies have demonstrated that prostaglandins found in gorgonians significantly inhibit Cyphoma GST activity in vitro (Chapter 4), consistent with the idea that gorgonian prostaglandins may be substrates for Cyphoma GSTs.

In summary, a proteomic approach was successful at identifying peptides representing the collection of expressed GST subunits in C. gibbosum digestive gland. This technique is a valuable alternative to designing degenerate primers to all of the GST classes suspected of being expressed in the sample. Using proteomics, I was able to identify several mu-class GSTs and one theta-class GST subunit(s), the latter class 
identified for the first time in a mollusc. The manually validated GST peptides were used to design primers to amplify two full-length $C$. gibbosum mu-class GST cDNAs. Future studies will focus on identifying gorgonian allelochemicals that are substrates for $C$. gibbosum GSTs using a bioassay-guided fractionation approach; expression of recombinant proteins will allow further characterization of individual GST isoforms. The high GST activity and diversity of GST isoforms in C. gibbosum may protect this generalist predator against dietary chemicals while conferring a selective advantage over other consumers that avoid chemically defended prey.

\section{References Cited}

Baker BJ, Scheuer PJ (1994) The punaglandins: 10-chloroprostanoids from the octocoral Telesto riisei. Journal of Natural Products 57:1346-1353

Berhane K, Widersten M, Engstrom A, Kozarich JW, Mannervik B (1994) Detoxication of base propenals and other $\alpha, \beta$-unsaturated aldehyde products of radical reactions and lipid peroxidation by human glutathione transferases. PNAS 91:1480-1484

Blanchette B, Feng X, Singh BR (2007) Marine glutathione S-transferases. Marine Biotechnology 9:513-542

Bogaards JJ, Venekamp JC, van Bladeren PJ (1997) Stereoselective conjugation of prostaglandin $\mathrm{A} 2$ and prostaglandin $\mathrm{J} 2$ with glutathione, catalyzed by the human glutathione S-transferases A1-1, A2-2, M1a-1a, and P1-1. Chem Res Toxicol 10:310-317

Boryslawskyj M, Garrood AC, Pearson JT (1988) Elevation of glutathione S-transferase activity as a stress response to organochlorine compounds in the freshwater mussel, Sphaerium corneum. Marine Environmental Research 24:101-104

Boutet I, Tanguy A, Moraga D (2004) Characterisation and epression of four mRNA sequences encoding glutatione S-transferases pi, mu, omega and sigma classes in the Pacific oyster Crassostrea gigas exposed to hydrocarbons and pesticides. Marine Biology 146:53-64

Bradford MM (1976) A rapid and sensitive method for quantitation of microgram quantities of protein utilizing principle of protein-dye binding. Analytical Biochemistry 72:248-254 
Brattsten LB (1992) Metabolic defenses against plant allelochemicals. In: Rosenthal GA, Berenbaum MR (eds) Herbivores: their interactions with secondary plant metabolites. Academic Press, New York, p 175-242

Comstock KE, Widersten M, Hao X-Y, Henner D, Mannervik B (1994) A comparison of the enzymatic and physicochemical properties of human glutathione transferase M4-4 and three other human mu class enzymes. Archives of Biochemistry and Biophysics 311:487-495

Cronin G, Hay ME, Fenical W, Lindquist N (1995) Distribution, density, and sequestration of host chemical defenses by the specialist nudibranch Tritonia hamnerorum found at high densities on the sea fan Gorgonia ventalina. Marine Ecology Progress Series 119:177-189

DeBusk BC, Chimote SS, Rimoldi JM, Schenk D (2000) Effect of the dietary brominated phenol, lanasol, on chemical biotransformation enzymes in the gumboot chiton Cryptochiton stelleri (Middendorf, 1846). Comparative Biochemistry and Physiology Part C 127:133-142

Dominguez JN, Adams DR, Famerich J (1980) Isolation of prostaglandins from the gorgonian Plexaura homomalla collected off the Venezuelan coast. Rev Latinoam Quim 11:56-58

Donham RT, Morin D, Jewell WT, Burns SA, Mitchell AE, Lame MW, Segall HJ, Tjeerdema RS (2005) Characterization of glutathione S-transferases in juvenile white sturgeon. Aquatic Toxicology 71:203-214

Doyen P, Vasser P, Rodius F (2005) cDNA cloning and expression pattern of pi-class glutathione $S$-transferase in freshwater bivalves Unio tumidus and Corbicula fluminea. Comparative Biochemistry and Physiology Part C 140:300-308

Egan K, FitzGerald GA (2006) Eicosanoids and the vascular endothelium. Handb Exp Pharmacol 176:189-211

Fan C, Zhang S, Liu Z, Li L, Luan J, Saren G (2007) Identification and expression of a novel class of glutathione-S-transferase from amphioxus Branchiostoma belcheri with implications to the origin of vertebrate liver. The International Journal of Biochemistry and Cell Biology 39:450-461

Fitzpatrick PJ, O'Halloran J, Sheehan D, Walsh DR (1997) Assessment of a glutathione S-transferase and related proteins in the gill and digestive gland of Mytilus edulis (L)as a potential organic pollution biomarker. Biomarkers 2:51-56

Fitzpatrick PJ, Sheehan D, Livingstone DR (1995) Studies on isoenzymes of glutathione S-transferase in the digestive gland of Mytilus galloprovincialis with exposure to pollution. Marine Environmental Research 39:241-244 
Gerhart DJ (1984) Prostaglandin A2: An agent of chemical defense in the Caribbean gorgonian Plexaura homomalla. Marine Ecology Progress Series 19:181-187

Gisi D, Leisinger T, Vuilleumier S (1999) Enzyme-mediated dichloromethane toxicity and mutagenicity of bacterial and mammalian dichloromethane-active glutathione S-transferases. Archives of Toxicology 73:71-79

Goldberg VJ, Ramwell PW (1975) Role of prostaglandins in reproduction. Physiological Reviews 55:325-351

Gribble GW (2003) The diversity of naturally produced organohalogens. Chemosphere 52:289-297

Habig WH, Pabst MJ, Jakoby WB (1974) Glutathione S-transferases. Journal of Biological Chemistry 249:7130-7139

Harvell CD, Suchanek TH (1987) Partial predation on tropical gorgonians by Cyphoma gibbosum. Marine Ecology Progress Series 38:37-44

Hayes JD, Flanagan JU, Jowsey IR (2005) Glutathione transferases. Annu Rev Pharmacol Toxicol 45:51-88

Hayes JD, Pulford DJ (1995) The glutathione S-transferase supergene family: regulation of GST and the contribution of the isoenzymes to cancer chemoprotection and drug resistance. Crit Rev Biochem Mol Biol 30:445-600

Hoarau P, Damiens G, Romeo M, Gnassia-Barelli M, Bebianno MJ (2006) Cloning and expression of a GST-pi gene in Mytilus galloprovincialis. Attempt to use the GST-pi transcript as a biomarker of pollution. Comp Biochem Physiol C Toxicol Pharmacol 143:196-203

Hoarau P, Garello G, Bnassia-Barelli M, Romeo M, Girard J-P (2004) Effect of three xenobiotic compounds on glutathione S-transferase in the clam Ruditapes decussatus. Aquatic Toxicology 68:87-94

Ivarsson Y, Mackey AJ, Edalat M, Pearson WR, Mannervik B (2003) Identification of residues in glutathione transferase capable of driving functional diversification in evolution. J Biol Chem 278:8733-8738

Iwashima M, Nara K, Nakamichi Y, Iguchi K (2001) Three new chlorinated marine steroids, yonarasterols G, $\mathrm{H}$ and I, isolated from the Okinawan soft coral, Clavularia viridis. Steroids 66:25-32

Kaaya A, Najimi S, Ribera D, Narbonne JF, Moukrim A (1999) Characterization of glutathione S-transferase (GST) activities in Perna perna and Mytilus galloprovincialis used as a biomarker of pollution in the Agadir marine bay (south of Morocco). Bull Environ Contam Toxicol 62:623-629 
Kubota NK, Kobayashi Y, Iwamoto H, Fukazawa Y, Uchio Y (2006) Two new halogenated briarane diterpenes from the papuan gorgonian coral Junceella fragilis. Bulletin of the Chemical Society of Japan 79:634-636

Kuhajek JM, Schlenk D (2003) Effects of the brominated phenol, lanosol, on cytochrome P450 and glutathione transferase activities in Haliotis rufescens and Katharina tunicata. Comparative Biochemistry and Physiology Part C 134:473-479

Landi S (2000) Mammalian class theta GST and differential susceptibility to carcinogens: a review. Mutation Research 463:247-283

Le Pennec G, Le Pennec M (2003) Induction of glutathione S-transferases in primary cultured digestive gland acini from the mollusk bivalve Pecten maximus (L.): application of a new cellular model in biomonitoring studies. Aquatic Toxicology 2003:131-142

Lee K (1991) Glutathione S-transferase activities in phytophagous insects: induction and inhibition by plant phototoxins and phenols. Insect Biochem 21:353-361

Lee K, Berenbaum M (1992) Ecological aspects of antioxidant enzymes and glutathione S-transferases in three Papilio species. Biochem Syst Ecol 20:197-207

Lee RF (1988) Glutathione S-transferase in marine invertebrates from Langesundfjord. Marine Ecology Progress Series 46:33-36

Lee Y-M, Soo Seo J, Jung S-O, Kim I-C, Lee J-S (2006) Molecular cloning and characterization of theta-class glutathione S-transferase (GST-T) from the hermaphorditic fish Rivulus marmoratus and biochemical comparisons with alpha-class glutathione S-transferase (GST-A). Biochemical and Biophysical Research Communications 346:1053-1061

Li X, Schuler MA, Berenbaum M (2007) Molecular mechanisms of metabolic resistance to synthetic and natural xenobiotics. Annu Rev Entomol 52:231-253

Lopez MF, Patton WF, Sawlivich WB, Erdjument-Bromage H, Barry P, Gmyrek K, Hines T, Tempst P, Skea WM (1994) A glutathione S-transferase (GST) isozyme from broccoli with significant sequence homology to the mammalian theta-class of GSTs. Biochem Biophys Acta 1205:29-38

Malan TP, Porreca F (2005) Lipid mediators regulating pain sensitivity. Prostaglandins \& Other Mediators 77:123-130

Marchler-Bauer A, Anderson J, Derbyshire M, DeWeese-Scott C, Gonzales NR, Gwadz M, Hao L, He S, Hurwitz DI, Jackson JD, Ke Z, Krylov D, Lanczycki CJ, Liebert CA, Liu C, Lu F, Lu S, Marchler GH, Mullokandov M, Song JS, Thanki N, Yamashita RA, Yin JJ, Zhang D, SH. B (2007) CDD: a conserved domain database for interactive domain family analysis. Nucleic Acids Research 35:237240 
Munasinghe H, Kang HS, Lee J (2006) Analysis of digestive gland expressed sequence tag library from the disk abalone, Haliotis discus discus. Journal of the World Aquaculture Society 37:96-106

Myrnes B, Nilsen IW (2007) Glutathione S-transferase from the Icelandic scallop (Chlamys islandica): isolation and partial characterization. Comp Biochem Physiol C Toxicol Pharmacol 144:403-407

Nebert DW, Vasiliou V (2004) Analysis of the glutathione S-transferase (GST) gene family. Hum Genomics 1:460-464

O'Neal W, Pawlik JR (2002) A reappraisal of the chemical and physical defenses of Caribbean gorgonian corals against predatory fishes. Marine Ecology Progress Series 240:117-126

Paul VJ (1992) Chemical defenses of benthic marine invertebrates. In: Paul VJ (ed) Ecological Roles of Marine Natural Products. Comstock and Publishing Associates, London, p 164-188

Pawlik JR, Fenical W (1989) A re-evaluation of the ichthyodeterrent role of prostaglandins in the Caribbean gorgonian coral Plexaura homomalla. Marine Ecology Progress Series 52:95-98

Pearson WR (2005) Phylogenies of glutathione transferase families. Methods Enzymol 401:186-204

Pemble SE, Taylor JB (1992) An evolutionary perspective on glutathione S-transferase inferred from class-theta glutathione transferase cDNA sequences. Biochem $\mathrm{J}$ 287:957-963

Pickett CB, Donohue AM, Lu AYH, Hales BF (1982) Rat liver glutathione S-transferase $B$ : the funtional mRNAs specific for the $Y a$ and $Y c$ subunits are induced differentially by phenobarbital. Archives of Biochemistry and Biophysics 215:539-543

Rezanka T, Dembitsky VM (2003) Brominated oxylipins and oxylipin glycosides from Red Sea corals. Eur J Org Chem:309-316

Rhee J-S, Lee Y-M, Hwang D-S, Won E-J, Raisuddin S, Shin K-H, Lee J-S (2007) Molecular cloning, expression, biochemical characteristics, and biomarker potential of theta class glutathione S-transferase (GST-T) from the polychaete Neanthes succinea. Aquatic Toxicology 83:104-115

Ronquist F, Huelsenbeck JP (2003) MrBayes 3: Bayesian phylogenetic inference under mixed models. Bioinformatics 19:1572-1574 
Rowley AF, Vogan CL, Taylor GW, Clare AS (2005) Prostaglandins in non-insectan invertebrates: recent insights and unsolved problems. The Journal of Experimental Biology 208:3-14

Ruesink JL, Harvell CD (1990) Specialist predation on the Caribbean gorgonian Plexaurella spp. by Cyphoma signatum. Marine Ecology Progress Series 65:265272

Schlenk D, Buhler DR (1988) Cytochrome P450 and phase II activities in the gumboot chiton Cryptochiton stelleri. Aquatic Toxicology 13:167-182

Sheehan D, McIntosh J, Power A, Fitzpatrick PJ (1995) Drug metabolizing enzymes of mussels as bioindicators of chemical pollution. Biochem Soc Trans 23:419-422

Sheehan D, Meade G, Foley VM, Dowd CA (2001) Structure, function and evolution of glutathione transferases: implications for classification of non-mammalian members of an ancient enzyme superfamily. Biochemical Journal 360:1-16

Shevchenko A, Wilm M, Mann M (1996) Mass spectrometric sequencing of proteins from silver stained polyacrylamide gels. Anal Chem 68:850-858

Smith PK, Krohn RI, Hermanson GT, Mallia AK, Gartner FH, Provenzano MDea (1985) Measurement of protein using bicinchonicic acid. Analytical Biochemistry $150: 76-85$

Thompson JD, Higgins DG, Gibson TJ (1994) CLUSTAL W: improving the sensitivity of progressive multiple sequence alignment through sequence weighting, position-specific gap penalties and weight matrix choice. Nucleic Acids Res $22: 4673-4680$

Tomarev SI, Zinovieva RD, Guo K, Piatigorsky J (1993) Squid glutathione S-transferase relationships with other glutathione S-transferases and S-crystallins of cephalopods. Journal of Biological Chemistry 268:4534-4542

Tomarev SI, Zinovieva RD, Piatigorsky J (1991) Crystallins of the octopus lens. Recruitment from detoxification enzymes. J Biological Chemistry 266:2422624231

Tsuchilda S, Sato K (1992) Glutathione transferases and cancer. CRC Crit Rev Biochem Mol Biol 27:337-384

Uchida K (2000) Induction of glutathione S-transferase by prostaglandins. Mechanisms of Ageing and Development 116:135-140

Verlecar XN, Pereira N, Desae SR, Jena KB, Singdha (2006) Marine pollution detection through biomarkers in marine bivalves. Current Science 91:1153-1157 
Vidal M-L, Rouimi P, Debrauwer L, Narbonne J-F (2002) Purification and characterisation of glutathione S-transferases from the freshwater clam Corbicula fluminea. Comp Biochem Physiol C Toxicol Pharmacol 131:477-489

Vrolijk NH, Targett NM (1992) Biotransformation enzymes in Cyphoma gibbosum: implications for detoxification of gorgonian allelochemicals. Marine Ecology Progress Series 88:237-246

Weinheimer AJ, Spraggins RL (1969) The occurrence of two new prostaglandin derivatives (15-epi-PGA 2 and its acetate methyl ester) in the gorgonian Plexaura homomalla. Tetrahedron Lett 59:5185-5189

Whelan S, Goldman N (2001) A general empirical model of protein evolution derived from multiple protein families using a maximum-likelihood approach. Mol Biol Evol 18:691-699

Yang H-L, Zeng Q-Y, Li E-Q, Zhu S-G, Zhou X-W (2004) Molecular cloning, expression and characterization of glutathione S-transferase from Mytilus edulis. Comparative Biochemistry and Physiology Part B 139:175-182 


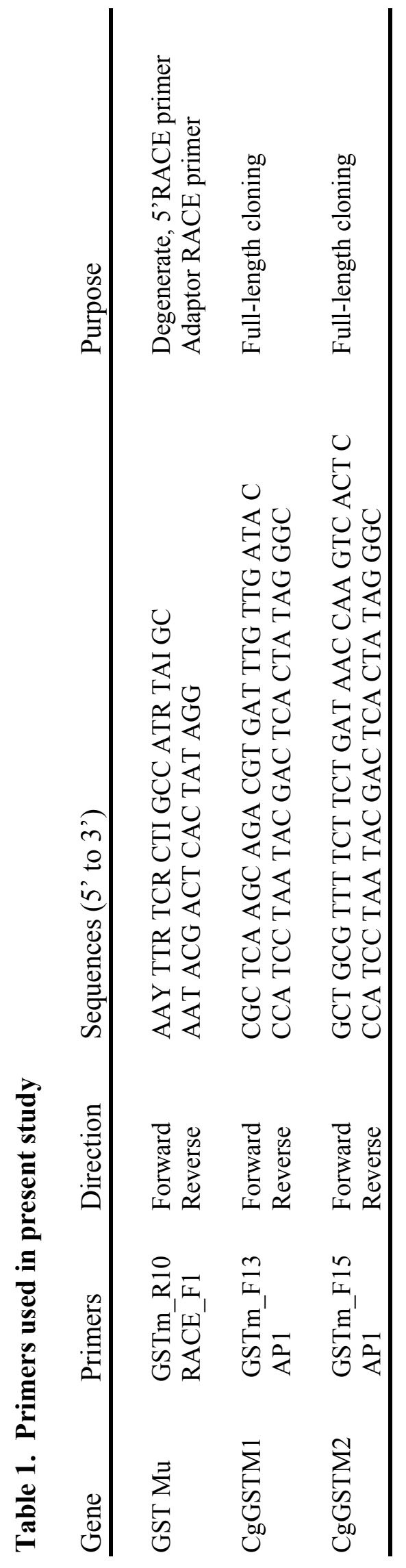




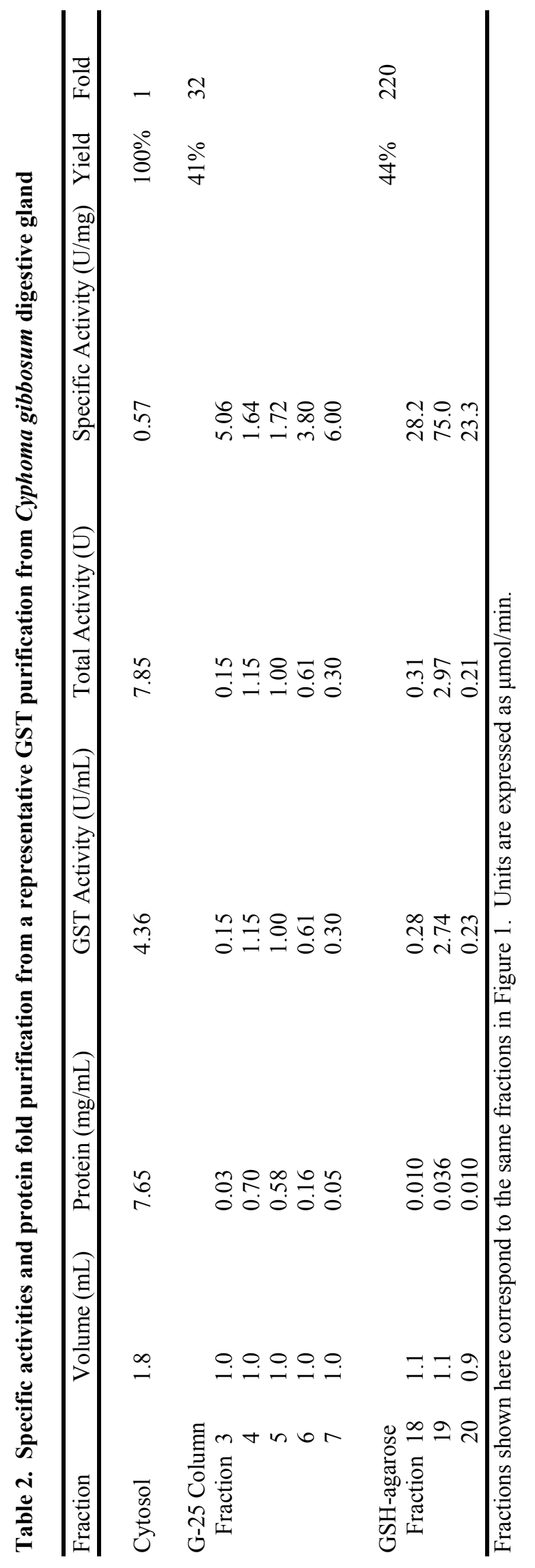




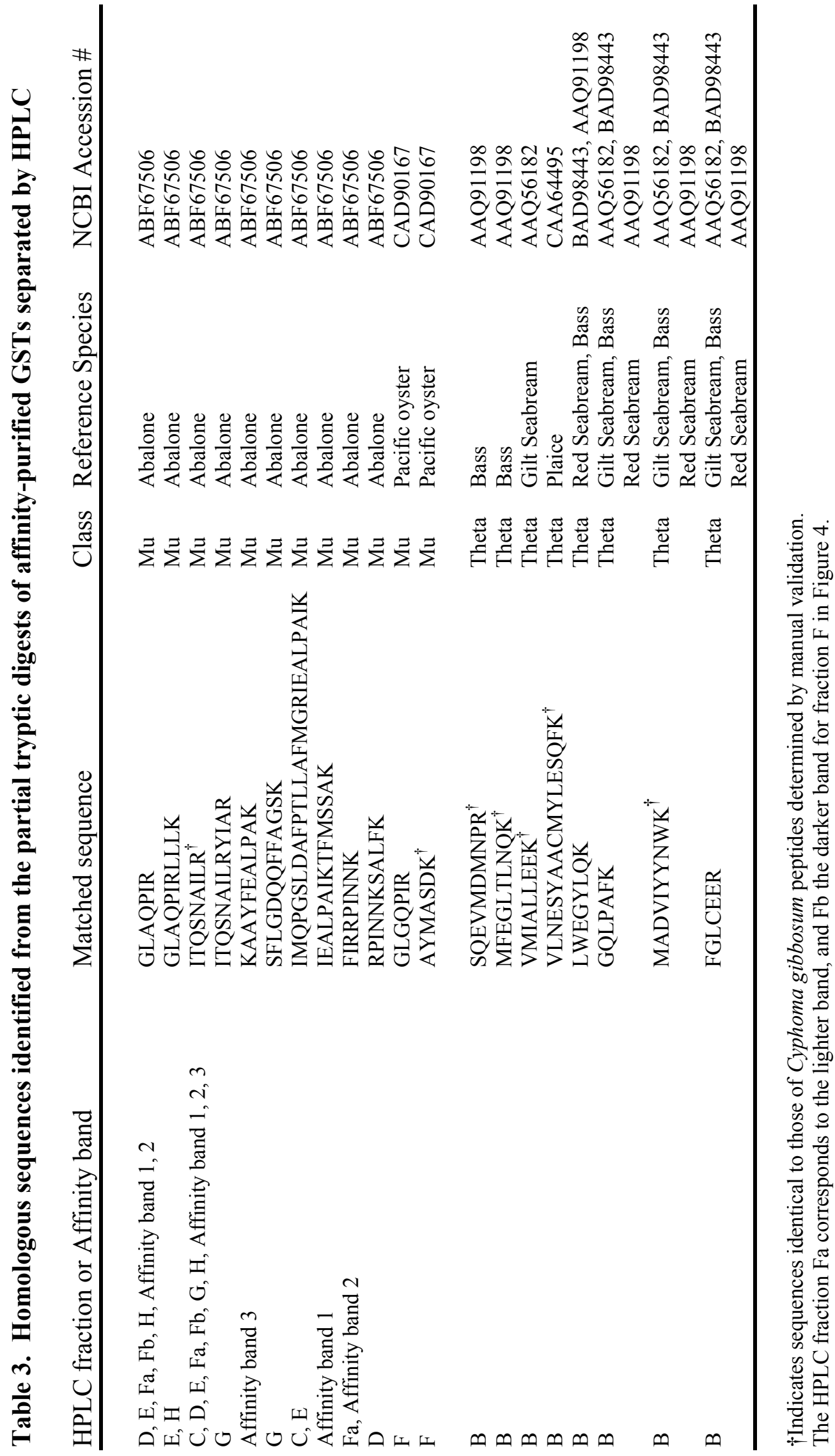



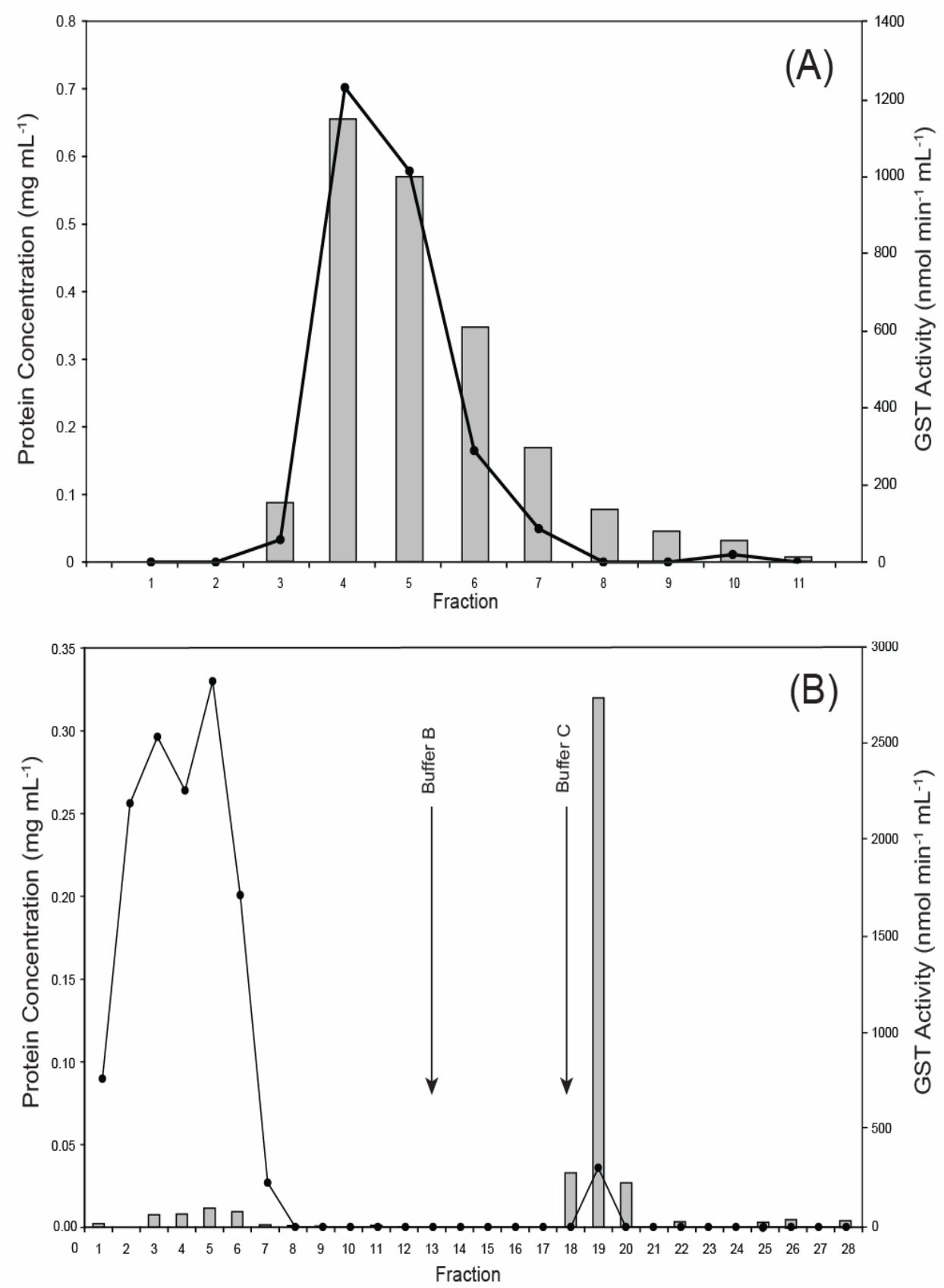

Figure 1. Purification of cytosolic GSTs from $\boldsymbol{C}$. gibbosum digestive gland. (A) The crude cytosol (2.5 $\mathrm{mL}$ ) from one individual was applied to a size exclusion PD-10 desalting column (bed volume $8.3 \mathrm{~mL}, 5$ $\mathrm{cm}$ height) containing Sephadex G-25 matrix $(85-260 \mu \mathrm{m})$ equilibrated in $50 \mathrm{mM}$ Tris buffer, $1 \mathrm{mM}$ EDTA, 1mM DTT at pH 6.0 (Buffer A). Fractions were collected in $1.2 \mathrm{~mL}$ aliquots by gravity at a flow rate of $1 \mathrm{~mL} \mathrm{~min}{ }^{-1}$. Fractions $3-7$ were pooled for further purification. (B) The pooled fractions (approx. $6 \mathrm{~mL}$ ) from the size exclusion column were applied to the GSH-agarose (sulfur to epoxide-activiated 4\% cross-lined beaded agarose) affinity column (bed volume $0.5 \mathrm{~mL}, 0.8 \times 4 \mathrm{~cm}$ i.d.) equilibrated in Buffer A. The affinity column was first rinsed with $6 \mathrm{~mL}$ of Buffer A and then $7 \mathrm{~mL}$ of Buffer B (Buffer A $+0.5 \mathrm{M}$ $\mathrm{NaCl}$ ) to rinse away non-specific proteins. GSTs were eluted with Buffer C (Buffer B $+50 \mathrm{mM} \mathrm{GSH}, \mathrm{pH}$ $9.5)$ in $1 \mathrm{~mL}$ aliquots at a flow rate of $0.5 \mathrm{~mL} \mathrm{~min}^{-1}$. Fractions $18-20$ were collected and pooled for further separation by HPLC. GST activity (bars) was measured as the increase in absorbance at $340 \mathrm{~nm}$ and protein concentration $(\bullet)$ was estimated by absorbance at $595 \mathrm{~nm}$. 


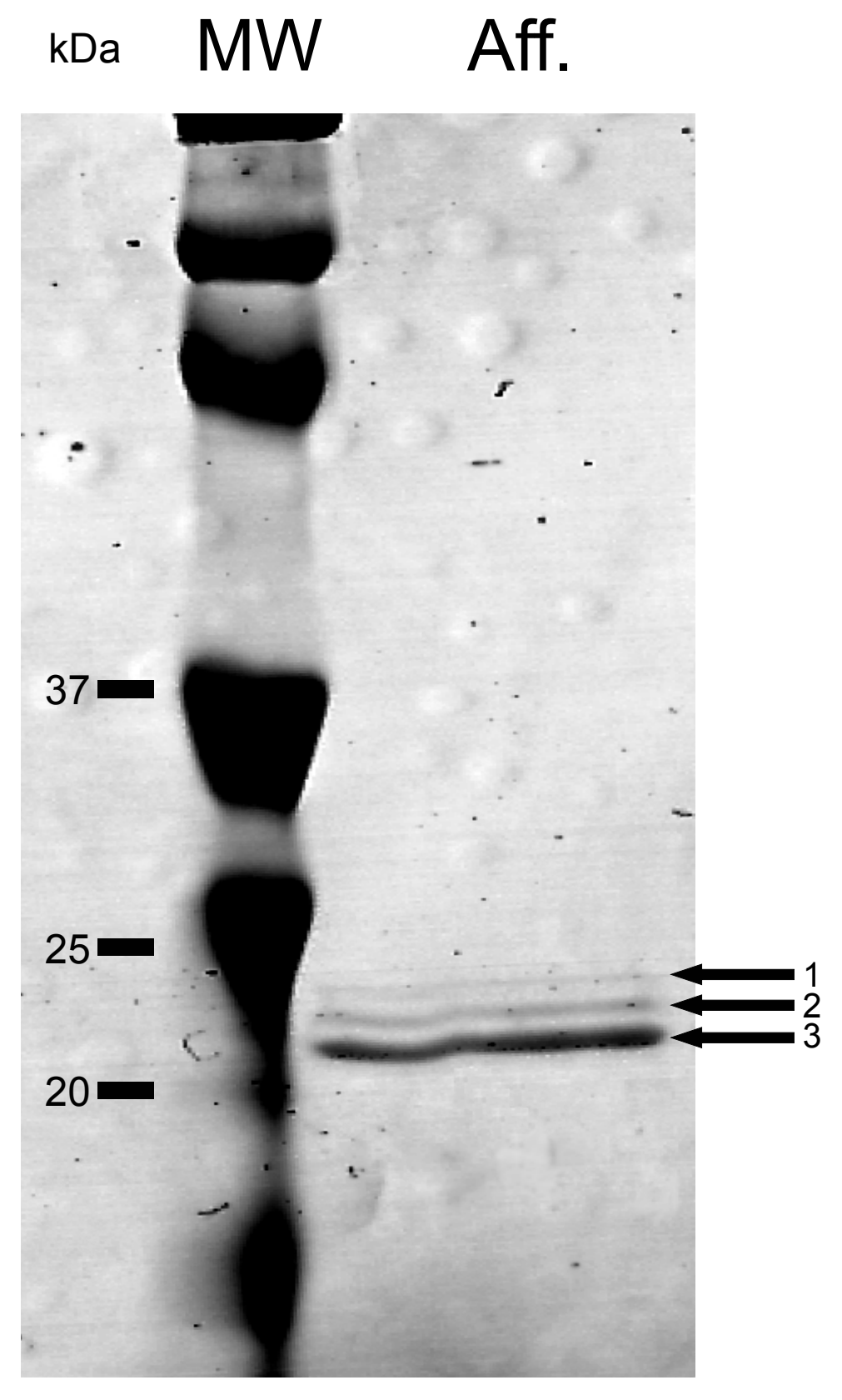

Figure 2. SDS-PAGE of affinity purified GSTs from $C$. gibbosum digestive gland SDS-PAGE of affinity-purified extract from $C$. gibbosum digestive gland obtained from size exclusion and affinity chromatography. Lane M, Bio-Rad Kaleidoscope protein standards; lane Aff., affinity-purified extract. Bands visualized by silver staining. 


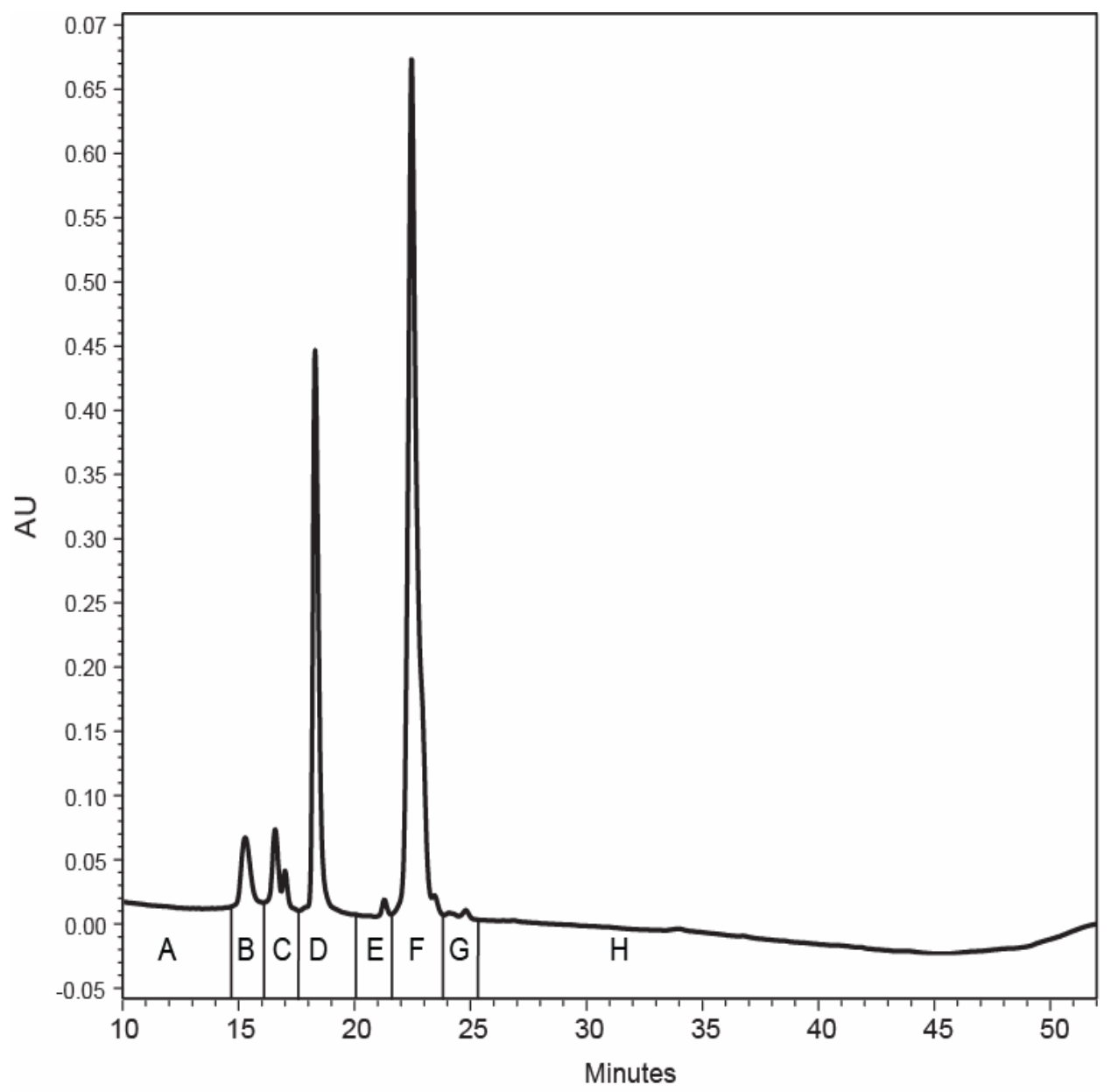

Figure 3. HPLC spectrum of GST subunits. Representative HPLC spectrum of pooled affinity-purified extracts from $C$. gibbosum feeding on B. asbestinum. GST subunits were separated on a reverse phase VYDAC protein/peptide column $(\mathrm{C} 18 \mu \mathrm{m} 250 \mathrm{~mm}$ x $2.1 \mathrm{~mm}$ ) with a flow rate of $0.5 \mathrm{~mL} \mathrm{~min}^{-1}$. Mobile phase A consisted of acetonitrile/water/TFA (38:62:0.1, v/v) and mobile phase B consisted of acetonitrile/water/TFA (80:20:0.1, v/v). GST subunits were separated using a linear gradient from 0 to $40 \% \mathrm{~B}$ in $22 \mathrm{~min}$, and 40 to $100 \% \mathrm{~B}$ in $37 \mathrm{~min}$ and visualized at 214 $\mathrm{nm}$. Fourteen unique peaks were identified (not all visible in representative HPLC spectrum) and grouped into fractions B-H. Fraction A consisted of the injection peak (not shown); fraction B was identified as a theta-like GST; fractions $\mathrm{C}-\mathrm{H}$ were identified as mu-class GSTs. 


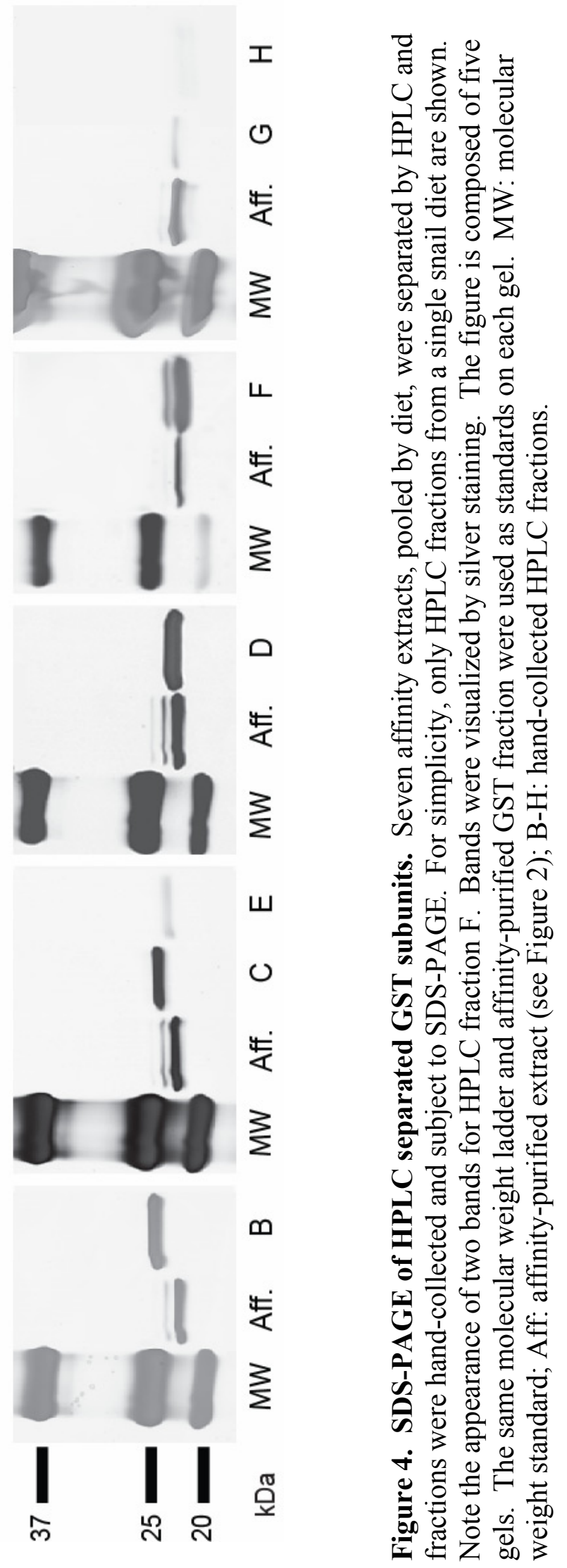




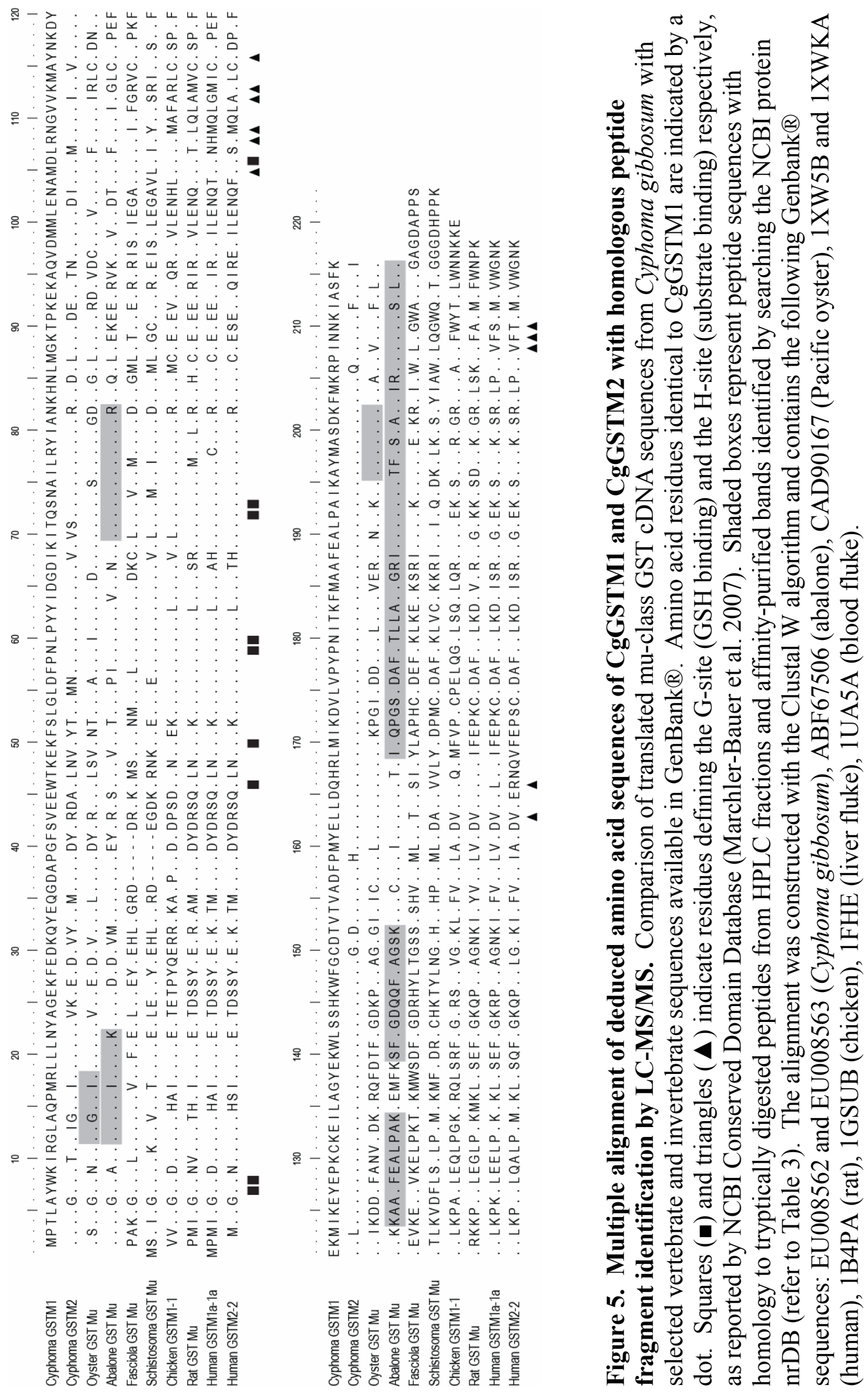




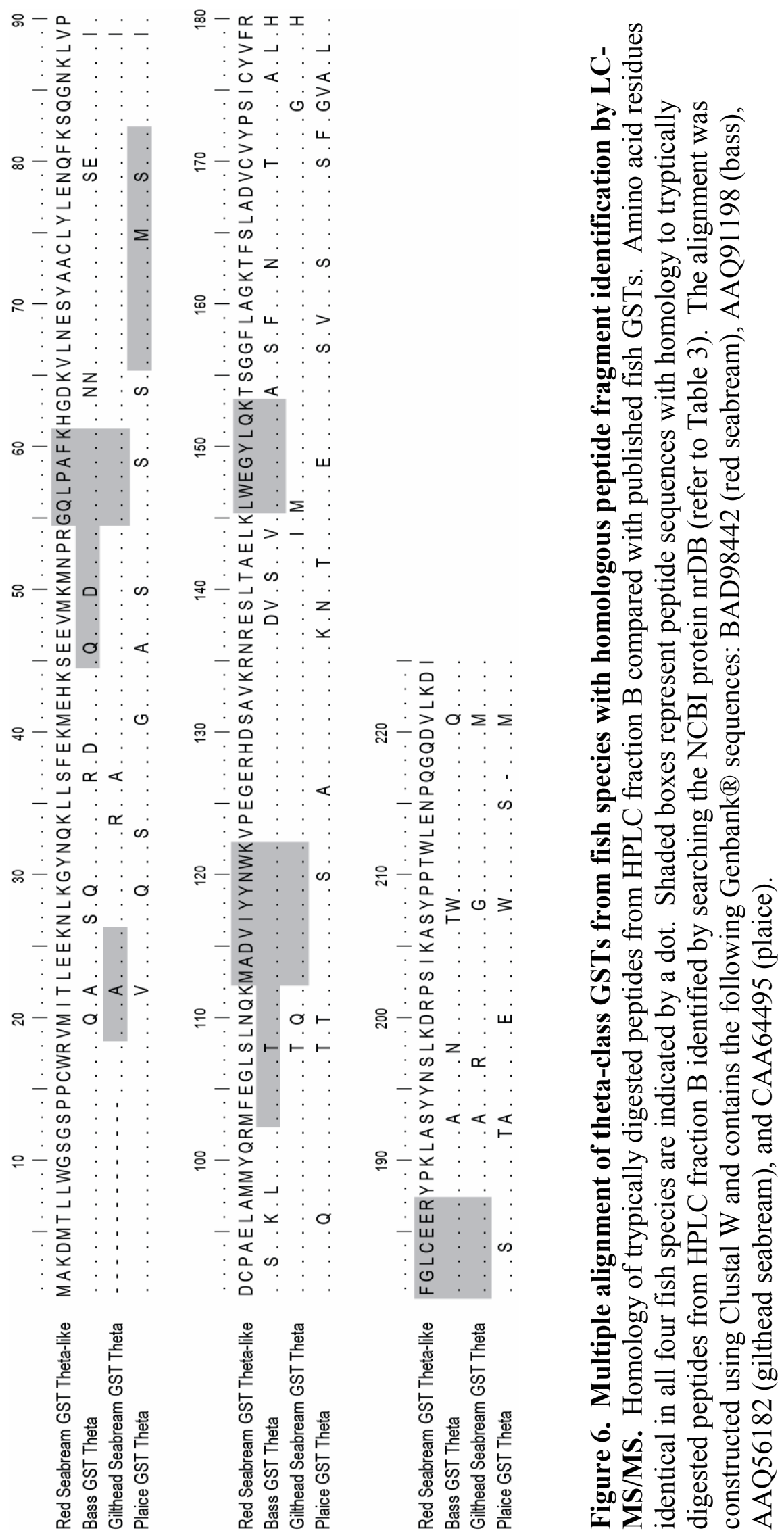


Figure 7. Phylogenetic tree depicting the relationship of Cyphoma gibbosum muclass GSTs with other invertebrate and vertebrate GSTs.

Tree was constructed using MrBayes. Fruitfly, Housefly and Honeybee sigma-GSTs were defined as an outgroup. Values at branch points are posterior probabilities derived from $3 \mathrm{e} 6$ generations (see methods). Note the clustering of Cyphoma GSTMs (bold) with other molluscan GSTMs. The tree contains the following JGI and Genbank accession nos: Apis mellifera (XP_624682), Boophilus microplus (AAD15991), Caenorhabditis elegans (NP_499006, NP_503889), Corbicula fluminea (AAX20374), Crassostrea gigas (CAD90167), Cyphoma gibbosum (EU008563 and EU008562), Danio rerio (XP_690427), Drosophila melanogaster (NP_725653), Fasciola hepatica (P56598), Haliotis discus discus (ABF67506, ABF67507), Haemaphysalis longicornis (AAQ74441), Homo sapiens (NP_665683, AAV38750, NP_000840, NP_000841, NP_000843), Lottia gigantea (JGI scaffold_43000011), Monodelphis domestica (P46437), Mytilus edulis (AAS60226), Mus musculus (P13745, NP_038569, NP_034488), Strongylocentrotus purpuratus (XP_795664, XP_785553), Sarcoptes scabiei (AAO15607), Tetraodon nigroviridis (CAF91521), Unio tumidus (AAX20373), Xenopus tropicalis (NP_001004964). Tree construction performed by J. Goldstone. 


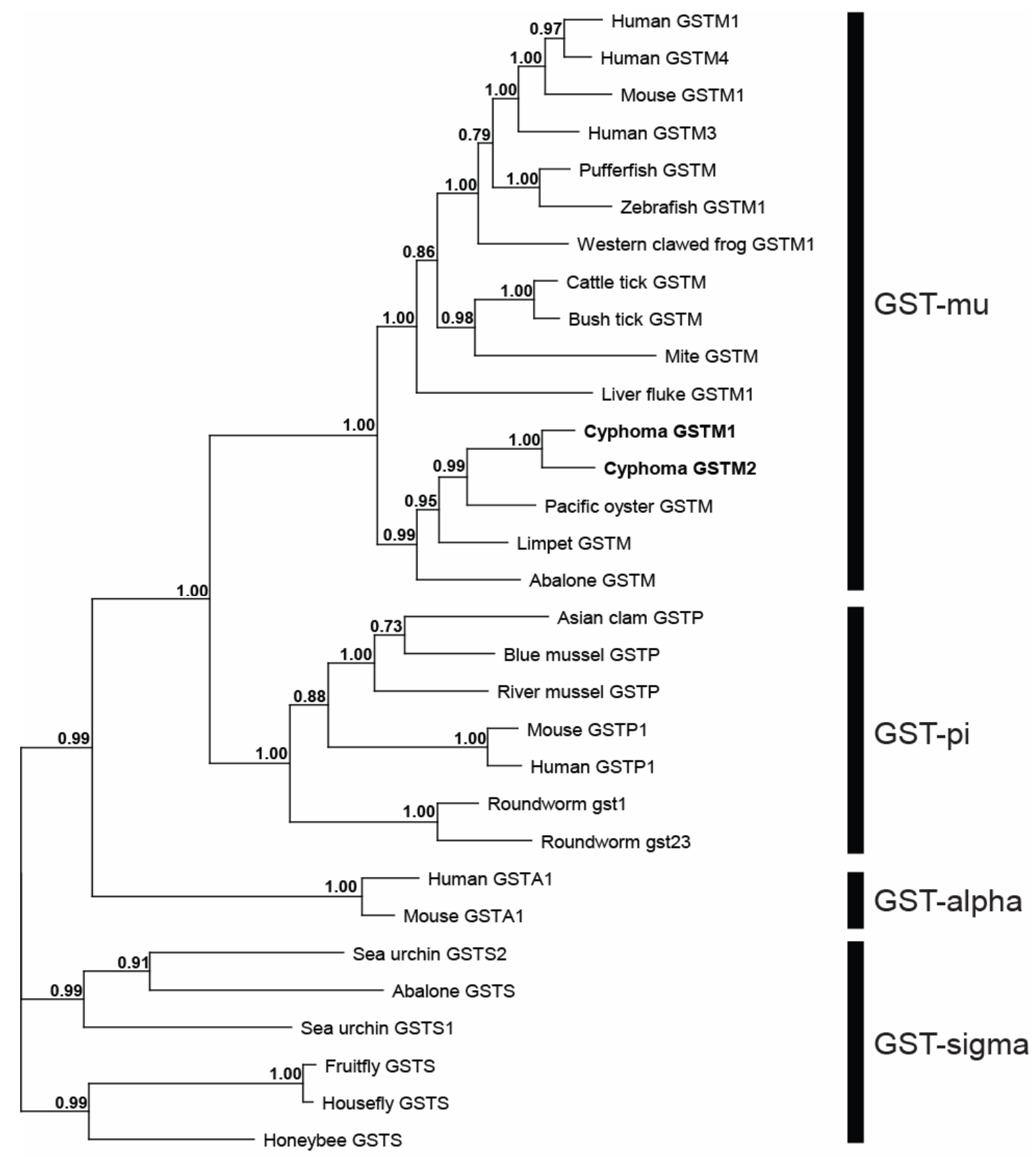

0.1 


\section{Chapter III}

Gorgonian host-inducible cytochrome P450s from Cyphoma gibbosum: molecular cloning, diversity and function 


\section{Abstract}

The production of chemical defenses by marine organisms limits predation and herbivory by most potential consumers. However, there are some marine consumers that can tolerate allelochemicals produced by their prey/hosts seemingly without deleterious effects. The induction of biochemical resistance mechanisms, such as cytochrome P450s (P450s), have been proposed to mediate allelochemical detoxification in these consumers, yet compelling evidence for these claims are generally lacking. Here, I use the generalist marine gastropod Cyphoma gibbosum, which feeds exclusively on chemical defended gorgonians, as a model to investigate the diversity, transcriptional response and enzymatic activity of putative allelochemical detoxification P450s in marine consumers. Using an adaptor-ligated cDNA library combined with specific and degenerate primers targeted to cytochrome P450 (CYP) Family 4, twelve new CYP4 genes were identified from the digestive gland of $C$. gibbosum. In controlled laboratory-based feeding studies with C. gibbosum, a 2.7- to 5.1-fold induction of CYP4-2 (CYP4BK) and CYP4-3 (CYP4BL) transcripts was observed following dietary exposure to the gorgonian Plexaura homomalla. This gorgonian species is known to contain high concentrations of ichthyodeterrent prostaglandins. Phylogenetic analysis reveals C. gibbosum CYP4-2 and CYP4-3 closest vertebrate relatives include CYP4A and CYP4F genes, whose roles entail metabolic inactivation of pathophysiologically important fatty acid derivatives, including prostaglandins. Examination of fatty acid hydroxylase activity in Cyphoma microsomes and allelochemically-responsive recombinant Cyphoma P450s indicates a possible role in eicosanoid (e.g., leukotriene $\mathrm{B}_{4}$ ) metabolism. Sequence analysis further demonstrates that $C$. gibbosum $\mathrm{CYP} 4$ s share identical amino acid residues with vertebrate $4 \mathrm{~A}$ and $4 \mathrm{~F}$ 
forms at key positions within the active site or sites responsible for maintaining the correct orientation of the fatty acid within the access channel, further alluding to their possible role in prostaglandin metabolism. These results are the first to describe the differential regulation of specific P450 transcripts in a marine consumer in response to a diet rich in allelochemicals. This work has important implications for understanding the molecular basis of the biochemical resistance strategy marine consumers use to cope with their chemically defended prey, and the ancestral history and evolutionary progression of allelochemical metabolizing genes within the P450 superfamily.

\section{Introduction}

Gorgonian corals (Phylum: Cnidaria; Subclass: Octocorallia; Order Gorgonacea) are the most conspicuous group of invertebrates on Caribbean coral reefs (Goldberg 1973, Lasker \& Coffroth 1983); however, they are rarely consumed despite their abundance and the intense predation in these ecosystems (O'Neal \& Pawlik 2002). The dominance of gorgonians can be attributed, in part, to the variety of defensive secondary metabolites they produce, commonly referred to as allelochemicals (Pawlik et al. 1987, O'Neal \& Pawlik 2002, Paul \& Puglisi 2004). An allelochemical is a "chemical produced by an organism that is toxic to, or inhibits the growth of, other organisms" (Despres et al. 2007). Octocorals, in particular, produce a diverse array of terpenoid derivatives that have been shown to have antipredatory properties (Rodriguez 1995, Katz \& Adamczeski 2000, Paul \& Puglisi 2004). Although these chemical defenses limit the predation by most potential consumers, the ovulid gastropod Cyphoma gibbosum thrives solely on a diet of allelochemically-rich octocorals and is considered the principle consumer of 
gorgonians on Caribbean coral reefs (Birkeland \& Gregory 1975, Burkepile \& Hay 2007). High levels of predation by this mollusc have also been shown to significantly increase production of the ichthyodeterrent terpenoids in in situ caging studies (Thornton \& Kerr 2002). The mechanisms by which C. gibbosum can tolerate these and other dietary allelochemicals at natural or elevated concentrations are unknown.

A wealth of literature describes the diversity of gorgonian allelochemicals and their effects on consumers (Gerhart 1984, Pawlik et al. 1987, Harvell et al. 1988, Pawlik \& Fenical 1989, Fenical \& Pawlik 1991, Pawlik \& Fenical 1992, Gerhart \& Coll 1993, O'Neal \& Pawlik 2002; reviewed in Harper et al. 2001); yet, relatively little is known about the mechanisms marine consumers have evolved to overcome the chemical defenses of their hosts/prey. While avoidance of toxic prey (Gerhart 1991, Long \& Hay 2006), diet-mixing (Harvell \& Suchanek 1987), sequestration (Proksch 1994, Cimino \& Ghiselin 1999) and target-site mutation conferring insensitivity (Bricelj et al. 2005) have been described in marine systems, few studies have investigated allelochemical detoxification as a mechanism by which marine consumers may use to cope with noxious dietary compounds.

In comparison to consumer-prey dynamics in marine ecosystems, insect-plant allelochemical interactions are better understood and provide a conceptual framework for investigating how marine consumers respond to toxins both on a behavioral and cellular/biochemical level. In terrestrial ecosystems, metabolic resistance to host plant toxins is attributed, in part, to an arsenal of inducible detoxification enzymes termed cytochrome P450 monooxygenases (P450s), capable of protecting the consumer from dietary intoxication (Schuler 1996). Furthermore, much of the apparent diversity of P450 
isoforms in insects may be the result of the co-evolutionary 'arms race' between prey chemical defenses and predator detoxification mechanisms (Gonzalez \& Nebert 1990). According to this view, multiple duplication and divergence events among P450 genes have allowed isoforms to gain new functions and presumably to increase the pool of allelochemical substrates upon which they act (Li et al. 2003), while still allowing some isoforms to retain their ancestral metabolic capabilities (Li et al. 2002a). A similar diversification of P450s genes may have occurred in marine invertebrates feeding on chemically-defended prey, providing consumers like C. gibbosum with protection against the continuous barrage of defensive compounds they may encounter.

Vrolijk and Targett (Vrolijk \& Targett 1992) were the first to measure P450 content and activity from field-collected C. gibbosum feeding on four species of gorgonian corals (Briareum asbestinum, Gorgonian ventalina, Plexaura homomalla, and Pseudopterogorgia americana). The specific content of cytochrome P450 in the digestive gland was low and only quantifiable in $C$. gibbosum collected from $P$. americana. The authors suggested that the low specific content may have resulted from denatured P450 protein, which was confirmed by the presence of $420 \mathrm{~nm}$ peaks in the CO-difference spectra. Additionally, two spectrofluorometric assays (methoxyresorufin O-deethylase (MROD) and ethoxyresorufin O-deethylase (EROD)) used to detect P450 activity in C. gibbosum digestive gland microsomes were negative. MROD and EROD assays have classically been used to detect subfamily specific P450 activity (i.e. CYP1A) in vertebrates exposed to pollutants (e.g. planar halogenated and polycyclic aromatic hydrocarbons) (Stegeman \& Hahn 1994). While evidence of deuterostome (e.g. tunicate and sea urchin) CYP1A-like and CYP1-like genes exists (Goldstone et al. 2007), to date 
no full-length CYP1-like sequences have been reported for molluscs (Rewitz et al. 2006) or any other protostome, further suggesting that the CYP1 family may be deuterostome specific. Recent work by Grosvik et al. (2006) strengthens this argument by calling into question immunochemical evidence suggesting the presence of a CYP1A-like protein in molluscs. Therefore, it is not entirely surprising that $C$. gibbosum digestive gland tissues lack CYP1A-like enzyme activity, which does not preclude the possibility of other xenobiotic detoxifying CYPs being responsible for allelochemical resistance.

Members of the P450 (CYP) family 4 represent a substantial portion of the cDNA sequences identified to date in molluscan species (Snyder 1998, Chaty et al. 2004). This family is considered one of the most ancient P450 families, having evolved from the steroid-synthesizing P450s and since diverged into an array of subfamilies whose substrates may be more diverse than previously realized. In vertebrates, CYP4 genes are recognized as the predominant fatty acid $\omega$-hydroxylases, preventing lipotoxicity by hydroxylating eicosanoids, including prostaglandins (Kikuta et al. 2002, Hsu et al. 2007). Prostaglandins are potent signaling molecules, known as regulators of fever, inflammation, and pain response in human biology. In marine systems, prostaglandins are known to function as feeding deterrents and can comprise up to $8 \%$ of the dry weight of some gorgonian species (reviewed by Stanley 2000). Yet the diversity of CYP4 substrates extends beyond fatty acid derivatives.

The ability of P450s to metabolize terpenes is of particular interest here due to the predominance of both diterpenoid and sesquiterpenoid compounds across all members of the Octocorallia (Coll 1992). Terpene derivatives, including the sesquiterpene farnesol as well as sesquiterpenoid epoxide juvenile hormone III, are 
substrates for the cockroach CYP4C7 (Sutherland et al. 1998, Sutherland et al. 2000). CYP4D10 isolated from the Sonoran Desert endemic Drosophilia mettleri was significantly induced in response to exposure to defensive isoquinoline alkaloids specific to its host the saguaro cactus, suggesting that this CYP may be responsible for their detoxification (Danielson et al. 1998). Allelochemical resistance in this species of insect may also involve cooperative action among multiple P450 isoforms, possibility within the same family, allowing this generalist to exploit a broader range of plants with structurally similar defensive compounds. Evidence from these and other studies of insect allelochemical metabolism highlight the relative importance of both P450 diversification and modulation of transcript expression in explaining consumer patterns of host plant utilization. Whether C. gibbosum possesses a similar diversity of allelochemically responsive CYP4 genes is the focus of this investigation.

Vrolijk and Targett (1992) originally hypothesized that the ability of C. gibbosum to tolerate dietary allelochemicals may involve biochemical resistance mechanisms, such as inducible cytochrome P450s. Here, I explore this hypothesis further by using a molecular approach to identify CYP4 genes in C. gibbosum and examine their transcriptional response following exposure to variety of gorgonian allelochemicals in a series of feeding assays. Once allelochemically-responsive CYP4 genes were identified, representative forms were heterologously expressed and their ability to metabolize diagnostic substrates was examined. Evidence presented here emphasizes the role of P450 genes in the adaptation of marine consumers to their chemically defended prey. 


\section{Materials and Methods}

Animal collection and feeding assay design

A total of 151 adult Cyphoma gibbosum (ca 2-3 cm length) were collected from five shallow reefs $(<20 \mathrm{~m})\left(\mathrm{Big}\right.$ Point $-23^{\circ} 47.383^{\prime} \mathrm{N}, 7^{\circ} 8.113^{\prime} \mathrm{W}$; North Normans $23^{\circ} 47.383^{\prime} \mathrm{N}, 76^{\circ} 8.264^{\prime} \mathrm{W}$; Rainbow Gardens $-23^{\circ} 47.792^{\prime} \mathrm{N}, 76^{\circ} 8.787^{\prime} \mathrm{W}$; Shark Rock $23^{\circ} 45.075^{\prime} \mathrm{N}, 76^{\circ} 7.475^{\prime} \mathrm{W}$; Sugar Blue Holes $\left.-23^{\circ} 41.910^{\prime} \mathrm{N}, 76^{\circ} 0.23^{\prime} \mathrm{W}\right)$ near the Perry Institute of Marine Science (PIMS), Lee Stocking Island, Exuma Cays, Bahamas (Figure 1) in January 2006. Snails were immediately transported to wet laboratory facilities provided by PIMS where a series of feeding assays were conducted with seven gorgonian species (Briareum asbestinum, Eunicea mammosa, Gorgonia ventalina, Pseudopterogorgia acerosa, Pseudopterogorgia americana, Pseudopterogorgia elisabethae, Plexaura homomalla) observed to serve as hosts for C. gibbosum in the field. Individual snails were housed separately in 3-L polycarbonate tanks which were placed in a 12' x 20 ” raceway supplied with filtered, continuous-flow seawater. This design allowed for a common water source to feed each tank but prevented mixing between tanks. Snails collected from the same reefs were housed separately in the same raceways. Snails collected from each reef were randomly assigned to one of nine groups: one of seven gorgonian diets, a control diet, or a time-zero group at the start of the feeding assays. Snails in the time zero groups ( $\mathrm{n}=6$ or 7 snails/reef location) were dissected within two hours after field collection and digestive glands were preserved in RNA Later ${ }^{\circledR}$ (Ambion) and stored at $-80^{\circ} \mathrm{C}$. These time-zero snails provide baseline information about the CYPs expressed in a population of C. gibbosum on a particular reef at the time of collection. The remaining snails were included in the feeding assay and 
maintained on their respective diet (gorgonian or control) for a total of four days. A single feeding assay consisted of two raceways, each holding ten tanks - seven tanks containing one $C$. gibbosum feeding on one of seven gorgonian diets and three tanks each containing one $C$. gibbosum feeding on the control diet. This design accommodated 20 snails feeding at any one time. Snails within each raceway were collected from the same reef and each four-day feeding assay (2 raceways) was repeated a total of six times (Figure 2). Upon completion of the $4 \mathrm{~d}$ feeding assay, the digestive glands were immediately dissected, weighed, preserved in RNA Later ${ }^{\circledR}$ at $-80^{\circ} \mathrm{C}$ for real-time quantitative PCR expression analysis and transported back to the Woods Hole Oceanographic Institution. Tissues were maintained at $-80^{\circ} \mathrm{C}$ until further analysis.

Running in parallel with the first set of feeding assays was a second set of feeding assays. Digestive gland tissues collected during the second feeding assays were used to investigate enzymatic activity of $C$. gibbosum digestive gland microsomes (described below) and cytosolic fractions (described in Chapter 2). The design of the second feeding assay was exactly as described above, except one raceway with ten tanks each holding a single snail was used. Snails within the raceway were collected from the same reef, and each $4 \mathrm{~d}$ assay was repeated four times (Figure 3). A total of 39 snails were collected from four reefs (Big Point, Rainbow Gardens, Shark Rock and Sugar Blue Holes) and randomly assigned to either a control diet or one of six gorgonian diets $(B$. asbestinum, E. mammosa, G. ventalina, P. acerosa, P. americana, P. homomalla). Following the completion of the $4 \mathrm{~d}$ feeding assay digestive glands were immediately dissected, weighed, and frozen in liquid nitrogen and transported to the Woods Hole Oceanographic Institution. Tissues were maintained at $-80^{\circ} \mathrm{C}$ until further analysis. 
Table 1 provides a summary of digestive gland samples collected from both feeding assays and processed for RNA and protein analysis.

A minimum of ten colonies for each gorgonian species were collected from shallow reefs $(<20 \mathrm{~m})$ surrounding PIMS and housed in separate raceways prior to introduction into the tanks containing $C$. gibbosum. The maximum amount of time between gorgonian field collection and introduction into the feeding assay was 12 hours. Gorgonian colonies were cut into 2-3 inch pieces and allowed to 'heal' for four hours before addition to $C$. gibbosum tanks. The control diet, which closely approximated the nutritional quality of gorgonian tissue, consisted of a combination of alginic acid and freeze-dried squid powder prepared by the method of (O'Neal \& Pawlik 2002) with some modification. The squid-alginate paste was pressed into sixteen 3-mm deep wells which had been drilled into a 3" x 1" piece of Formica ${ }^{\circledR}$ resembling a domino. The domino was then placed into a $0.25 \mathrm{M}$ calcium chloride solution allowing the squid-aliginate paste to harden. Theoretically, snails feeding on the control diet devoid of gorgonian compounds should experience no induction of allelochemically-responsive CYPs. Both control and gorgonian diets were replaced each day for four days and feeding activity was monitored by the presence of feeding scars on their gorgonian prey and empty wells on control dominos.

The length ( $4 \mathrm{~d}$ ) of the feeding assay was decided based upon previous studies that measured C. gibbosum residence time on gorgonian colonies (Harvell \& Suchanek 1987) and known detoxification enzyme induction times in other invertebrates (DeBusk et al. 2000, Li et al. 2000, Li et al. 2002c, Kuhajek \& Schlenk 2003, Rewitz et al. 2004) (David et al. 2006). Studies examining the half lives of CYP mRNA have found that 
most decline rapidly within 24 hours (Daujat et al. 1991, Kloepper-Sams \& Stegeman 1994, Lekas et al. 2000) - some as little as two hours in terrestrial invertebrates (Sutherland et al. 2000) when the chemical stimulus is removed. Therefore, any CYP mRNA induction we observe in C. gibbosum digestive glands should be attributed to the xenobiotics in their most recent diet.

\section{Initial RNA extraction and RT-PCR}

In 2004, a preliminary series of feeding assays with 15 adult $C$. gibbosum and four gorgonian species (Briareum asbestinum, Gorgonia ventalina, Pseudopterogorgia acerosa, Pseudopterogorgia americana) provided tissue for the initial cloning of CYP4 fragments. Digestive gland samples were stored in RNALater ${ }^{\circledR}$ at $-80^{\circ} \mathrm{C}$ until further processing. Total RNA was isolated from pooled digestive glands using RNA STAT-60 (Tel-Test B, Inc., Friendswood, TX) according to the manufacturer's protocol. The integrity of the RNA sample was checked by electrophoresis on a $1 \%$ agaroseformaldehyde gel in MOPS buffer and visualized with ethidium bromide under UV light. Total RNA concentration was determined using a Nanodrop spectrophotometer (Wilmington, DE). Poly(A)+ RNA was purified using the MicroPoly(A)Purist mRNA purification kit (Ambion, Austin, TX) according to the manufacturer's instructions. Firststrand cDNA was reverse transcribed from $2 \mu \mathrm{g}$ poly(A)+ RNA using OmniScript reverse transcriptase (OmniScript RT kit, Qiagen) with random hexamer primers. PCR was performed using AmpliTaq Gold DNA polymerase (Applied Biosystems) under the following conditions: $94^{\circ} \mathrm{C}$ for $10 \mathrm{~min}$; $\left(94^{\circ} \mathrm{C}\right.$ for $15 \mathrm{sec}, 52^{\circ} \mathrm{C}$ for $\left.30 \mathrm{sec}\right)$ for $35 \mathrm{cycles}$; $72^{\circ} \mathrm{C}$ for 7 min with pairs of degenerate primers (CYP4_F1/ CYP4_R3), (CYP4_F2/ 
CYP4_R3) (see Table 2) designed against the conserved CYP4 P450 fingerprint region. Primers were obtained from Sigma Genosys (St. Louis, MO). PCR products were visualized on agarose gels, gel purified (Gene Clean II, Bio 101, Inc.), ligated into pGEM-T Easy@ plasmid vector (Promega, Madison, WI), and transformed into JM109 cells (Promega). PCR products were sequenced in both directions using an ABI 3730XL capillary sequencer at the Keck facility of the Josephine Bay Paul Center for Comparative Molecular Biology \& Evolution at the Marine Biological Laboratory (Woods Hole, MA). A minimum of twelve clones were sequenced for each PCR fragment. Clones were initially clustered based on nucleotide sequence identity $(>80 \%)$ with Sequencher 4.6 (Gene Codes Corp., Ann Arbor, MI) and a consensus sequence was generated and examined by NCBI/GenBank BLASTx for gene identification (Altschul et al. 1997).

Rapid amplification of cDNA ends (RACE)

Digestive gland total RNA was purified from seven C. gibbosum individuals collected during the January 2006 feeding assays using the RNeasy Maxi Kit and DNAse treated using a RNase-free DNAse Kit (Qiagen, Valencia, CA) following the manufacturer's instructions. The integrity and concentration of total RNA was determined as described in Chapter 2, Methods. Poly(A)+ RNA was isolated using the MicroPoly(A) Purist mRNA purification kit according to the manufacturer's instructions. Poly(A)+ RNA was pooled from seven snails feeding either on a control diet or one of six gorgonian species $(0.14 \mu \mathrm{g}$ poly(A)+ RNA/individual) to ensure representation of all CYPs expressed under various dietary conditions. One microgram of pooled 
poly(A)+RNA was primed with modified oligo (dT) primers and used to create an adaptor-ligated double-stranded cDNA library synthesized using the Marathon cDNA Amplification Kit (BD Biosciences, Palo Alto, CA) according to the manufacturer's instructions.

Gene specific primers designed to the three partial cDNA sequences (Table 2) obtained in the initial RT-PCR experiment were used in combination with adaptorspecific primers to obtain full-length CYP sequences by 5' and 3' RACE-PCR. Primers were obtained from Sigma Genosys (St. Louis, MO). Amplification of PCR products was carried out according to the Advantage 2 PCR Enzyme Kit (Clontech, Mountain View, CA) and cycling parameters were as follows: $94^{\circ} \mathrm{C}$ for $30 \mathrm{sec} ;\left(94^{\circ} \mathrm{C}\right.$ for $5 \mathrm{sec}$, $72^{\circ} \mathrm{C}$ for $\left.2.5 \mathrm{~min}\right)$ for 5 cycles; $\left(94^{\circ} \mathrm{C}\right.$ for $5 \mathrm{sec}, 70^{\circ} \mathrm{C}$ for $\left.2.5 \mathrm{~min}\right)$ for 5 cycles; $\left(94^{\circ} \mathrm{C}\right.$ for $5 \mathrm{sec}, 68^{\circ} \mathrm{C}$ for $2.5 \mathrm{~min}$ ) for $25 \mathrm{cycles} ; 68^{\circ} \mathrm{C}$ for $5 \mathrm{~min}$ with the following specific primer pairs (RACE_1_F/ CYP4_A12_R ), (RACE_1_F/ CYP4_D09_F), (RACE_1_F/ CYP4_F11_R), (RACE_1_F/CYP4_F1), and (AP1/CYP4-3_R1). Once the start and stop codons had been obtained, primers were designed immediately up or down stream, respectively, to amplify full-length cDNA. Full-length products were amplified with PfuUltra $^{\mathrm{TM}}$ Fusion HS DNA Polymerase (Stratagene, La Jolla, CA) and cycling parameters were as follows: $95^{\circ} \mathrm{C}$ for $1 \mathrm{~min} ;\left(95^{\circ} \mathrm{C}\right.$ for $20 \mathrm{sec}, 63^{\circ} \mathrm{C}$ for $20 \mathrm{sec}, 72^{\circ} \mathrm{C}$ for 1min) for 40 cycles; $72^{\circ} \mathrm{C}$ for 3 min with specific primers pairs CYP4-3_F3/ CYP4-3_R6, and CYP4-2_F1/CYP4-2_R1. All PCR products were sequenced and analyzed as described above. 
Sequence analysis and structural alignments

Partial and full-length CYP4 nucleotide sequences were clustered by Sequencher 4.6 based on nucleotide identity ( $>80 \%$ identity), aligned using ClustalX (Thompson et al. 1994) and this alignment was used to construct maxium parsimony trees using PAUP*4.0b10 (Swofford 1998) from which the number of possible distinct CYP4 loci were inferred. Trees were visualized and manipulated using FigTree v1.1(Rambaut 2007). Sequences within each cluster were then grouped according to maximum parsimony tree results, and consensus nucleotide and deduced amino acid sequences were generated from these groupings in BioEdit v7.0.5.2 (Hall 1999).

Multiple alignments of Cyphoma deduced amino acid sequences and other invertebrate and vertebrate full-length CYP4 gene sequences were performed by ClustalX for phylogenetic analysis by Bayesian and maximum likelihood methods. Ambiguous alignment positions were excluded from further analyses. Bayesian phylogenetic relationships were investigated using the computer program MrBayes (v 3.1.2; Ronquist \& Huelsenbeck 2003). MrBayes estimates posterior probabilities using MetropolisHastings coupled Monte Carlo Markov chains (MC3). MC3 estimates with uninformative prior probabilities were performed using the WAG model of amino acid substitution (Whelan \& Goldman 2001) and prior uniform gamma distributions approximated with four categories (WAG+I+gamma). Four incrementally heated, randomly seeded Markov chains were run for $3 \times 10^{6}$ generations, and topologies were sampled every 100th generation. The MC3 burnin values were conservatively set at $1 \times 10^{6}$ generations. Posterior probabilities of topologies and clades were estimated from the sampled topologies after removal of the initial MC3 burnin. Maximum likelihood phylogenetic 
relationships were calculated with the Pthreads version of RAxML v7.0.0 (Stamatakis 2006, Ott et al. 2007) using the WAG+gamma model of amino acid substitution. Multiple initial ML searches were performed from random starting points and bootstrap support was estimated for the best ML tree.

Identification of putative substrate recognition sites (SRSs) of Cyphoma CYPs was accomplished by using the bacterial CYP102 (Ravichandran et al. 1993) as a template to highlight (putative) active site residues. Bacterial CYPs have often been used convincingly as templates for eukaryotic P450 homology modeling studies (Chang et al. 1996). ClustalX was used to align full-length Cyphoma deduced amino acid sequences with CYP102 and selective mammalian CYPs whose SRSs have previously been determined (Gotoh 1992, Loughran et al. 2000, Kalsotra et al. 2004). Alignments were visualized in BioEdit v7.0.5.2 (Hall 1999) and structurally conserved regions (e.g., helices and $\beta$-structures) and SRS for Cyphoma CYPs were generated by copying the backbone coordinates from CYP102.

\section{Real-time quantitative RT-PCR}

DNAse-treated poly(A)+ RNA $(0.2 \mu \mathrm{g})$ from the digestive gland of snails participating in the 2006 feeding assay $(n=141$, Table 1$)$ was used to synthesize cDNA using a blend of oligo (dT) and random hexamers as decribed by the iScript ${ }^{\mathrm{TM}} \mathrm{cDNA}$ Synthesis Kit (Bio-Rad, Hercules, CA). The quantity of poly(A)+RNA for cDNA synthesis was chosen based on an experiment comparing the product yield (e.g. target gene expression) versus input concentration of poly(A)+RNA (Figure 4). PCR reactions were performed using iQ SYBR Green Supermix (Bio-Rad) using an iCycler MyiQ Real- 
Time PCR Detection System (Bio-Rad). Sequence-specific primers for quantitative PCR analysis of CYP mRNA expression are listed in Table 3. In addition, a representative group of poly(A)+ RNA samples was used to perform control cDNA synthesis experiments without reverse transcriptase to check for contamination by genomic DNA. The PCR conditions were as follows: $95^{\circ} \mathrm{C}$ for $3 \mathrm{~min} ;\left(95^{\circ} \mathrm{C}\right.$ for $15 \mathrm{sec}, 64^{\circ} \mathrm{C}$ or $62^{\circ} \mathrm{C}$ for 1 min) for 40 cycles. PCR product specificity from each primer pair was confirmed by melt curve analysis to ensure that only a single product was amplified. A standard curve was generated for each CYP grouping by serially diluting plasmids containing the fragment to be amplified. Each sample and standard was run in duplicate and the expression of $C$. gibbosum $\beta$-actin was used to control for differences in cDNA synthesis among samples. The molecule number per gene in each RNA sample was calculated from the standard curve.

\section{Data analysis of $R T-q P C R$ experiments}

To test whether cytochrome P450 gene expression differed between snails feeding on a control diet versus each gorgonian diet, a two way multivariate analysis of variance (MANOVA) was used with Diet (control vs. gorgonian diet) as a fixed factor and Reef (snail origin) as a random factor. The CYP4 genes were considered dependent variables. If Diet was found to be significant in the two-way MANOVA, univariate two-way ANOVAs were run for each CYP4 gene to determine which diet showed significant differences. In addition, a one-way MANOVA was used to examine the variability in CYP4 gene expression among reefs, where Reef was considered a random factor. This test was used to investigate reef-specific variation in transcript levels in time-zero snails, 
and to determine if any such variation persisted in snails collected from these same reefs after being fed a control diet for four days. The CYP4 genes were considered dependent variables.

P-values have been corrected for both MANOVA analyses using Bonferroni's adjustment (Sankoh et al. 1997). Data analysis was performed using SYSTAT® version 11 (Systat Software, Inc., San Jose, CA). Data reported as molecule numbers for each gene were log transformed to homogenize variances for MANOVA and ANOVA analysis.

Heterologous expression of Cyphoma CYPs in yeast

The open reading frame (ORF) of five CYPs, representing a diversity of the CYP4 sequences from Cyphoma $($ CYP4-2a $=$ clone 198_58; CYP4-2b = clone 198_27; CYP4-3a1 = clone 197_52; CYP4-3b1 = clone 197_48; CYP4-3b3 = clone 197_53), were amplified with custom primers (Table 4) and PCR fragments were ligated into pENTR/D/TOPO ${ }^{\circledR}$ according to the manufacturer's instructions (Invitrogen, Carlsbad, CA). PCR products were amplified using PfuUltra ${ }^{\mathrm{TM}}$ (Stratagene, La Jolla, CA) with the following conditions: $95^{\circ} \mathrm{C}$ for $2 \mathrm{~min} ;\left(95^{\circ} \mathrm{C}\right.$ for $20 \mathrm{sec}, 63.2^{\circ} \mathrm{C}$ for $20 \mathrm{sec}, 72^{\circ} \mathrm{C}$ for 30 sec) for 30 cycles; and $72^{\circ} \mathrm{C}$ for $3 \mathrm{~min}$ for final extension. Primers were used at $10 \mu \mathrm{M}$ in a $50 \mu \mathrm{L}$ reaction. PCR products were separated on a $1 \%$ agarose gel and discrete bands were excised and extracted with the Geneclean ${ }^{\circledR}$ kit (Qbiogene, Irvine, CA) according to the manufacturer's protocol.

ORFs for all five clones were transferred from the entry vector $\mathrm{pENTR/D/TOPO}$ to the destination vector pYESDEST52/V5-His using the TOPO Cloning Kit (Invitrogen) 
and provided protocol. A pYESDEST52 plasmid carrying the Arabidopsis $\beta$ glucuronidase (gus) gene was used as a transformation and expression control. Expression clone plasmids were purified from overnight $E$. coli culture and used for yeast transformation. Saccharomyces cerevisiae $\mathrm{W}(\mathrm{R})$ strain, which over-expresses the yeast NADPH-cytochrome P450 reductase under a galactose-inducible promoter, was a kind gift of Drs. D. Pompon and P. Urban (Center de Génétique Moléculaire, CNRS, Gif-surYvette, France) (Pompon et al. 1996). The W(R) yeast was made competent using the S.c. EasyComp ${ }^{\mathrm{TM}}$ transformation kit according to the manufacturer's instructions (Invitrogen) and separately transformed with the expression clones containing $C$. gibbosum P450s.

To achieve higher recombinant protein expression, yeast cells were initially grown to high density with glucose as the main carbon source; thereafter, galactose was added to induce expression. The production of recombinant CYP protein was as follows: a single transformed yeast colony was picked from a selective plate and used to inoculate $30 \mathrm{~mL}$ of SGI medium (containing per liter, $6.7 \mathrm{~g}$ yeast nitrogen base without amino acids, $1 \mathrm{~g}$ bactocasamino acids deficient for uracil, $40 \mathrm{mg}$ DL-tryptophan, $20 \mathrm{~g}$ glucose, $100 \mathrm{mg}$ adenine). The SGI culture was grown at $28^{\circ} \mathrm{C}$ with shaking at $130 \mathrm{rpm}$ overnight, then transferred $(10 \mathrm{~mL})$ to a 2-liter flask containing $500 \mathrm{~mL}$ of YPGE media (containing per liter, $10 \mathrm{~g}$ yeast extract, $10 \mathrm{~g}$ bactopeptone, $5 \mathrm{~g}$ glucose, $100 \mathrm{mg}$ adenine, $3 \%$ ethanol). The YPGE culture was grown overnight at $28^{\circ} \mathrm{C}$ with shaking at $130 \mathrm{rpm}$. Yeast cells were induced by the addition of $2 \%$ galactose for 8 or $15 \mathrm{hrs}$ at $28^{\circ} \mathrm{C}$ with shaking at 130rpm. Cells were harvested by centrifugation, washed with TES50 buffer 
(50 mM Tris- $\mathrm{HCl}, 1 \mathrm{mM}$ EDTA, $0.6 \mathrm{M}$ sorbitol; $\mathrm{pH}$ 7.4) and stored at $-80^{\circ} \mathrm{C}$ until microsomal preparation.

\section{Preparation of yeast microsomes}

Yeast cells were suspended in degassed TES50 buffer containing $1.0 \mathrm{mM}$ dithiothreitol (DTT) and protease inhibitor cocktail (1X) (Sigma) and mechanically disrupted using the BeadBeater (BioSpec Products, Inc., Bartlesville, OK). A $25 \mathrm{~mL}$ chamber containing about $50 \%$ glass beads $(0.5 \mathrm{~mm}$ diameter) and yeast cell slurry was cooled with an ice water/methanol (20\%) cooling jacket. Any air remaining in the chamber was displaced by adding TES50 buffer. The cells were disrupted by twenty 5-s BeadBeater cycles with 45-s resting (cooling) periods between cycles. This method of disruption has been shown to be effective at maintaining the sample temperature below $8^{\circ} \mathrm{C}$ during disruption and results in greater than $90 \%$ lysis of yeast cells (Chung et al. 2004).

All subsequent steps were carried out at $4^{\circ} \mathrm{C}$. Cell lysate was decanted and the beads remaining in the chamber were washed once with $2 \mathrm{~mL}$ of degassed buffer and combined with the cell lysate. The combined cell lysate was centrifuged at $750 \mathrm{xg}$ for 10 min then, without stopping, at 12,000 $\mathrm{x}$ g for 10 min using a Beckman J2-21 centrifuge (Fullerton, CA) to remove cell debris. The supernatant was carefully removed and centrifuged at 100,000 x g for 70 min using a Beckman L8-60M ultracentrifuge (Fullerton, CA) to collect the microsomal fraction. The resulting microsomal pellet was resuspended in 1 to $2 \mathrm{~mL}$ of TEG50 buffer (50 mM Tris-HCl, $1 \mathrm{mM}$ EDTA, 20\% glycerol (by vol.), 1 mM DTT; pH 7.4) by gentle hand homogenization using a Potter- 
Elvehjem homogenizer and microsomal suspensions were stored at $-80^{\circ} \mathrm{C}$ until use. An aliquot of suspension was taken for microsomal protein determination using the Bradford assay method (Bradford 1976) with BSA as the standard.

Preparation of Cyphoma digestive gland microsomes

Individual digestive glands $(\mathrm{n}=49)$ were homogenized 1:4 $(\mathrm{w} / \mathrm{v})$ in ice-cold homogenization buffer (0.1 M potassium phosphate, $1 \mathrm{mM}$ EDTA, $1 \mathrm{mM}$ DTT, $1.15 \%$ potassium chloride, protease inhibitor cocktail (1X); $\mathrm{pH} 7.5)$ with an IKA Ultra Turrax T8 homogenizer (Wilmington, NC) for $30 \mathrm{sec}$ on ice. All subsequent steps were carried out at $4{ }^{\circ} \mathrm{C}$. Cytosol was isolated by centrifugation of the crude homogenate at $750 \mathrm{xg}$ for 10 min then, without stopping, at 12,000 x $g$ for 10 min using a Beckman J2-21 centrifuge (Fullerton, CA). The supernatant was carefully removed, avoiding both the fatty layer and the pellet and transferred to an ultracentrifuge tube and centrifuged at $100,000 \times \mathrm{g}$ for 70 min using a Beckman L8-60M ultracentrifuge (Fullerton, CA). The microsomal pellet was resuspended in 0.2 to $0.8 \mathrm{~mL}$ of microsomal buffer $(0.1 \mathrm{M}$ potassium phosphate, $1 \mathrm{mM}$ EDTA, $1 \mathrm{mM}$ DTT, 20\% glycerol (by vol.); pH 7.5) and stored at $-80^{\circ} \mathrm{C}$ until use. An aliquot of suspension was taken for microsomal protein determination using the Bradford assay method (Bradford 1976) with BSA as the standard.

P450 content and enzymatic assays

Cytochrome P450 specific content of yeast and digestive gland microsomal samples was determined by the carbon monoxide difference spectrum $\left(\Delta \mathrm{OD}_{450-490}\right)$ of 
sodium dithionite-reduced samples $(1 \mathrm{mg} / \mathrm{mL})$ using an extinction coefficient of $91 \mathrm{mM}^{-}$ ${ }^{1} \mathrm{~cm}^{-1}$ by the method of (Omura \& Sato 1964). P450 reductase in both yeast and digestive gland microsomal samples was assayed by measuring NADPH-cytochrome $c$ reductase activity. The reaction mixture (in a final volume of $200 \mu \mathrm{L}$ ) contained $0.2 \mathrm{M}$ potassium phosphate buffer, $\mathrm{pH}$ 7.7, $80 \mu \mathrm{M}$ equine heart type III Cytochrome $c$ (Sigma), and 0.2 mM NADPH. NADPH was solubilized in TEG50 buffer. The rate of Cytochrome $c$ reduction was measured as the increase in absorbance at $550 \mathrm{~nm}\left(\Delta \varepsilon_{550} 21.1 \mathrm{mM}^{-1} \mathrm{~cm}^{-1}\right)$ using a UV-2401PC spectrophotomer (Shimadzu). One unit of reductase activity is defined as the amount of enzyme which can reduce $1 \mathrm{nmol}$ of Cytochrome $c$ per min. Lauric acid hydroxylase activity was determined by Discovery Labware (BD Biosciences, Woburn, MA) using the method described by (Crespi et al. 2005). The reaction mixture $(0.1 \mathrm{~mL}$ final volume) contained $20 \mu \mathrm{L}$ yeast microsomal protein (1.1$4.0 \mathrm{mg} / \mathrm{mL}$ ) expressing C. gibbosum P450s, $1.3 \mathrm{mM}$ NADP+, $3.3 \mathrm{mM}$ glucose-6phosphate, $0.4 \mathrm{U} / \mathrm{mL}$ glucose-6-phosphate dehydrogenase, $3.3 \mathrm{mM} \mathrm{MgCl}_{2}, 0.1 \mathrm{mM}$ [14C]-lauric acid in $100 \mathrm{mM}$ Tris buffer (pH 7.5). Human liver microsomes (HLM) (1.0 $\mathrm{mg} / \mathrm{mL}$ ) were used as a positive control. Yeast microsomes were incubated for $80 \mathrm{~min}$ at $25^{\circ} \mathrm{C}$ and $\mathrm{HLM}$ were incubated for $10 \mathrm{~min}$ at $37^{\circ} \mathrm{C}$. Negative control incubations consisting of the same reaction mixture without microsomal proteins were also performed. All samples were run in single determinations. The reactions were stopped by the addition of $50 \mu \mathrm{L}$ of $94 \%$ acetonitrile $/ 6 \%$ acetic acid, centrifuged at $10,000 \times \mathrm{g}$ for 3 min, and $75 \mu \mathrm{L}$ of supernatant was injected onto a C18 HPLC column $(5 \mu, 4.6 \mathrm{~mm} \mathrm{x}$ $250 \mathrm{~mm}$ ). The metabolites were separated at $45^{\circ} \mathrm{C}$ with methanol/acetonitrile/water (23:23:54) containing $1 \mathrm{mM}$ perchloric acid adjusted to $100 \%$ methanol over 35 min with 
a flow rate of $1.0 \mathrm{~mL} / \mathrm{min}$. Lauric acid and the $\omega$-hydroxylated metabolite were detected by liquid scintillation counting.

Leukotriene B4 ( $\left.\mathrm{LTB}_{4}\right)$ hydroxylase activity was determined by Discovery Labware (BD Biosciences). The conversion of $\mathrm{LTB}_{4}$ to its hydroxylated metabolites by recombinant CYP4 proteins and Cyphoma microsomes was performed by incubating 1.0 $\mathrm{mg} / \mathrm{mL}$ of snail microsomes or $2.0 \mathrm{mg} / \mathrm{mL}$ of yeast microsomes with $1.3 \mathrm{mM}$ NADP+, 3.3 mM glucose-6-phosphate, $0.4 \mathrm{U} / \mathrm{mL}$ glucose-6-phosphate dehydrogenase, $3.3 \mathrm{mM}$ magnesium chloride, $29.7 \mu \mathrm{M} \mathrm{LTB}_{4}$ in $100 \mathrm{mM} \mathrm{KPO}_{4}(0.1 \mathrm{~mL}$ final volume). Human liver microsomes $(0.5 \mathrm{mg} / \mathrm{mL})$ were used as a positive control. Snail microsomes were incubated for $60 \mathrm{mins}$ at $30^{\circ} \mathrm{C}$, and yeast microsomes were incubated for 120 mins at both $23^{\circ} \mathrm{C}$ and $30^{\circ} \mathrm{C}$. Reactions were terminated after 120 mins by the addition of $25 \mu \mathrm{L}$ of $94 \%$ acetonitrile $/ 6 \%$ glacial acetic acid. Incubations were centrifuged at $10,000 \mathrm{x}$ g for 3 min. and $80 \mu \mathrm{L}$ of the supernatant was injected onto a C18 HPLC column $(5 \mu, 4.6 \mathrm{~mm} \mathrm{x}$ $250 \mathrm{~mm}$ ) and separated with an initial mobile phase consisting of $30 \%$ acetonitrile with 1 $\mathrm{mM}$ perchloric acid in water changing to $70 \%$ methanol over 20 minutes at a flow rate of $1.0 \mathrm{~mL} / \mathrm{min}$. Products were detected by monitoring absorbance at $270 \mathrm{~nm}$ and compared to known standards. Control reactions without microsomal protein, without NADPH and without incubation were performed with a 'global control' sample made by separately pooling all of the yeast microsomal samples and the snail microsomal samples. 


\section{Results}

Identification of Cyphoma CYP4 genes

When an RT-PCR cloning approach was used with pooled digestive gland mRNA samples and degenerate primers designed to the conserved I-helix and heme-binding region, three partial CYP4 cDNAs approximately 396 base pairs (bp) in length were identified. The resultant sequences, which shared $41-54 \%$ amino acid identify, were separated into three clusters designated CYP4-1, CYP4-2, and CYP4-3. Specific primers designed to each of the three CYP4 clusters were used in 5' and 3' RACE reactions to obtain full-length sequences. In total, RACE and RT-PCR cloning efforts generated 352 cDNA clones. The cDNA clones within each cluster were aligned using ClustalX and used to construct three maximum parsimony trees to assist in the further identification of groups and subgroups of sequences within each cluster. These analyses were used to help infer the number of possible distinct CYP4 genes.

Based on current $\mathrm{P} 450$ Nomenclature rules, proteins that share $\geq 40 \%$ identity are assigned to the same family; proteins sharing $\geq 55 \%$ identity are grouped within the same subfamily; and allelic variants of the same gene are classified as having $\leq 3 \%$ divergence, unless functional differences (catalytic activities) can be demonstrated (Nelson 2006). The criteria established for P450 nomenclature, based on somewhat arbitrary cut-off values, does not take into account the phylogenetic relationships among species, whereby P450s sharing the same enzymatic function may be assigned to separate subfamilies because they fall below the arbitrary cut-off value (Nelson et al. 2004). Additionally, there are examples of distinct genes sharing greater than $97 \%$ amino acid identitiy, further complicating allelic variant vs. distinct loci assignment when genomic 
information is lacking (Nebert et al. 1989). These caveats were considered here when classifying the CYP4 sequences identified from Cyphoma. Sequence analysis revealed fifteen full-length CYP4 cDNAs encoding twelve distinct CYP4 proteins, (CYP4-1, CYP4-2a, CYP4-2b, CYP4-3a1, CYP4-3a2, CYP4-3b1, CYP4-3b2, CYP4-3b3_clone 1, CYP4-3b3_clone 2, CYP4-3b3_clone 3, CYP4-3b3_clone 4, CYP4-3b3_clone 5, and CYP4-3c). ClustalX alignments indicate that the Cyphoma CYP4 protein sequences share identities ranging from 26.3\% (CYP4-3a1v2 - CYP4-1v2) to 99.2\% (CYP43b2_clone4 - CYP4-3b3/CYP4-3b2_clone5) (Figure 5).

CYP4-1 cluster. Maximum parsimony analysis (Figure 6) identified one CYP4 gene with several allelic variants. Upon further analysis two distinct groupings of variants were identified designated CYP4-1v1 and CYP4-1v2, which share 98.8\% amino acid identity. CYP4-1v2 differ by a 15 bp insertion at 1201 bp position, resulting in an open reading frame of $1551 \mathrm{bp}$ encoding a 517 amino acid protein rather than the 512 a.a. protein as seen in CYP4-1v1 (Figure 7). In addition, five of the 65 clones within the CYP4-1 group contained a 68 bp deletion at nucleotide position 1066 causing a frame shift to occur resulting in a premature stop codon. These clones likely represent a low frequency nonfunctional allele because this mutation would delete a signification portion of the CYP4, including the conserved cysteine residue in the P450 active site.

CYP4-2 cluster. This grouping is likely represented by two distinct genes, which share $93.5 \%$ amino acid identity and are designated here as CYP4-2a and CYP4-2b. The CYP4-2a subgroup is represented by only four of 121 possible clones, yet these sequences clearly form a distinct group as visualized by the unrooted maximum parsimony cluster analysis (Figure 8). The remaining clones grouped within the CYP4- 
$2 \mathrm{~b}$ cluster likely represent two allelic variants within this subgroup, evidenced by a minor branch extending from the main CYP4-2b cluster in Figure 8. The nucleotide sequences of CYP4-2a and CYP4-2b are 1527 and 1545 bp, respectively, encoding proteins of 508 and 514 amino acids in length (Figure 9). The difference in length between the two cDNAs is due to an 18 bp addition to the 3' end of CYP4-2b. Both the CYP4-2a and CYP4-2b sequences contain this additional sequence; however, in the CYP4-2a group, a mutation at position 1527 leads to stop codon, truncating the protein six amino acids upstream of CYP4-2b stop codon. The highly similar UTRs suggest that CYP4-2a and CYP4-2b arose from a recent duplication event, followed by a diversification of both forms; however, which sequence is representative of the ancestral form is not known. CYP4-3 cluster. The CYP4-3 cluster (the most diverse) includes 166 clones that may correspond to as many as nine distinct loci. An alignment of deduced amino acid sequences indicates that these group members share sequence identities ranging from $89.2 \%$ to $99.2 \%$ (Figure 5). Relationships among members of the CYP4-3 cluster were visualized by a maximum parsimony cluster analysis (Figure 10), indicating three separate groups (CYP4-3a, $-3 b,-3 c$ ) within the CYP4-3 members. The CYP4-3a group is likely represented by one gene with at least three allelic variants (CYP4-3a1v1, CYP43a1v2, and CYP4-3a2) which share $>99 \%$ amino acid identity when positions common to all three variants are compared. The full-length CYP4-3a1v1, CYP4-3a1v2 and CYP4$3 \mathrm{a} 2$ sequences are 1563,1500 and $1602 \mathrm{bp}$ in length encoding proteins of 520, 499 and 533 amino acids, respectively (Figure 11, 12). One variant in particular designated CYP4-3a1v2, contains an inframe deletion of 63 bp (21 a.a.) causing the entire F helix and the majority of the SRS-2 region to be removed, resulting in a protein of 499 amino 
acids. With the exception of this deletion, the protein coding sequences of CYP4-3a1v1 and CYP4-3a1v2 are identical. CYP4-3a2, represented by two clones, is $97.3 \%$ and 93.4\% similar at the protein level to CYP4-3a1v1 and CYP4-3a1v2; however, if you disregard positions containing insertions/deletions, the similarity increases to $99.7 \%$ between all three variants. The most obvious difference between CYP4-3a1 and CYP4$3 \mathrm{a} 2$ sequences is the addition of 13 residues at the C-terminal end of CYP4-3a2, resulting from a single nucleotide substitution in the corresponding stop codon in CYP4-3a1.

Amino acid sequence identities between CYP4-3b members range from $95.0 \%$ to 99.2\% and all encode proteins of 530 amino acids in length (Figures 11, 12). The CYP4$3 \mathrm{~b}$ sequences can be further subdivided into one of three additional subgroupings (CYP4$3 \mathrm{~b} 1,-3 \mathrm{~b} 2,-3 \mathrm{~b} 3$ ) supported by the maximum parsimony analysis (Figure 10). Protein identities range from 95.0 to $99.2 \%$ between CYP4-3b members (Figure 5). While consensus nucleotide sequences could be easily generated for CYP4-3b1 and CYP4-3b3 members so that at least one clone matched the consensus nucleotide sequence, this proved impossible for sequences within the CYP4-3b2 subgroup. Due to the extensive variation among CYP4-3b2 members, illustrated by the lack of clustering among clones in the MP analysis (Figure 10, Part B), five full-length clones (CYP4-3b2_clone 1 thru 5) were selected to represent the range of CYP4-3b2 diversity in lieu of generating a consensus nucleotide sequence with no physical representatives. Protein identities among the CYP4-3b2 subgroup members range between 96.1 to $99.2 \%$. The greater than 97\% amino acid identity among some subgroup members would suggest multiple allelic variants are a possibility. 
The full-length CYP4-3c sequence is $1563 \mathrm{bp}$ in length and encodes a protein of 520 amino acids. CYP4-3c sequences represent members that appear to be a hybrid ${ }^{1}$ between CYP4-3a and CYP4-3b groups (Figures 11, 12), with amino acid identities ranging from $94.6 \%$ to $98.0 \%$ (CYP4-3c and CYP4-3a) and 94.2\% to 96.9\% (CYP4-3c and CYP4-3b). Percent identities increase even further if you restrict the region of comparison to the N-terminal half of CYP4-3c which is nearly identical to that of CYP43a, whereas the same can be said of the C-terminal half of CYP4-3c with CYP4-3b3.

A list of putative Cyphoma CYP4 genes, described here with their corresponding names assigned by the P450 Nomenclature Committee, can be found in Table 5. An amino acid alignment of the 15 full-length CYP4 cDNAs generated from nucleotide consensus sequences is shown in Figure 12.

\section{Sequence analysis}

BlastX searches with full-length cDNA sequences and phylogenetic analysis using both Bayesian and Maximum Likelihood methods (Figures 13, 14) confirmed that all of the Cyphoma sequences identified here belong to the cytochrome P450 4 clan and should be placed within the CYP4 family of sequences (Nelson et al. 2004). The CYP4 family is one of the oldest, most diverse families within the P450 superfamily (Simpson 1997). Because of this ancient lineage, the addition of new members in this family has blurred the definition of what constitutes a CYP family leading to 'family creep' or the inclusion of invertebrate members with less than $40 \%$ identity due to the reluctance to

\footnotetext{
${ }^{1}$ The term hybrid refers to a cDNA sharing identical blocks of sequence with two or more distinct cDNAs and does not imply a specific mechanism used to generate the hybrid cDNA
} 
create new CYP families and the recognition that phylogenetic relationships need to be considered (Nelson et al. 2004).

Serial duplication events appear to have occurred within both the CYP4-2 (CYP4BK) and CYP4-3 (CYP4BL) lineages. The paralogous CYP4-2 and CYP4-3 Cyphoma sequences share less than $40 \%$ amino acid sequence identity with full-length vertebrate CYP4 members, and cluster within an apparently invertebrate-specific clade whose most closely related vertebrate homologs are found within CYP4 subfamilies A, B, F, T, X, Z (Figure 13). Top scores from BlastX searches indicate that Cyphoma CYP4-2 and CYP4-3 cDNAs are more similar to mammalian CYP4F members than to other non-mammalian CYP4F members or other vertebrate CYP4 subfamilies, suggesting possible convergent evolution between Cyphoma CYP4s and mammalian CYP4F forms, or the retention of residues reflecting a more ancestral form and indicating possible shared substrates between these two groups. A comparison of Cyphoma CYP4-2a, CYP4-2b to vertebrate CYP4 members found that Cyphoma cDNAs were most similar to mouse CYP4F13 (GenBank Accession \# NP_570952.1) with amino acid identity ranging from 37.8 to $38.0 \%$, compared to 32.9 to $33.0 \%$ with Dicentrarchus labrax CYP4F7 (seabass, GenBank Accession \# AAD32564). Identities between Cyphoma CYP4-3 sequences and mouse CYP4F39 (GenBank Accession \# AA145756.1) ranged from 36.4 to $37.3 \%$, compared to 30.9 to $33.0 \%$ with D. labrax CYP4F7.

Cyphoma CYP4-1 (CYP4V10) sequences, however, do share $>40 \%$ protein identity with other vertebrate CYP4V amino acid sequences, including 47.5-47.9\% with zebrafish CYP4V2 (GenBank Accession \# AAI25969) and 45.5-45.9\% with human CYP4V2 (GenBank Accession \# Q6ZWL3). Cyphoma CYP4-1 sequences also share 
$>40 \%$ identity with invertebrate sequences formally designated within the CYP4C subfamily that have recently been moved into the CYP4V subfamily and include 45.245.6\% with Carcinus maenas CYP4V16 formally CYP4C39 (green crab, GenBank Accession \# JC8026), and 41.3-41.7\% with Orconectes limosus CYP4V11 - formally CYP4C15 (crayfish, GenBank Accession \# AAF09264).

Several conserved domains are present within all of the Cyphoma CYP4 proteins. Beginning at the N-terminal portion, eukaryotic CYPs carry a sequence of amino acids responsible for targeting the $\mathrm{P} 450$ protein to the correct subcellular location in the membrane, which is absent in soluble bacterial P450 proteins (Figure 12). The highly conserved WXXXR domain towards the N-terminus is located in the center of the Chelix and neutralizes the charge of one of the propionate side chains of the heme group by the tryptophan nitrogen and the basic arginine (Graham \& Peterson 2002). The I-helix, or P450 fingerprint region, is one of the most highly conserved domains among P450s. All of the Cyphoma CYP4 sequences contain the conserved threonine residue, located within the I helix, which is thought to aid in the protonation of the reduced oxygen intermediate (Williams et al. 2000a). The conserved EXXR domain found within the Khelix and located on the proximal side of the heme, may assist in stabilizing the heme core. Located just before the L-helix is the P450 consensus sequence (FXXGXRXCXG) containing the absolutely conserved cysteine serving as the fifth ligand to the heme iron (Werck-Reichhart \& Feyereisen 2000). 


\section{Quantitative RT-PCR analysis of CYP4 expression}

Quantitative RT-PCR analysis was used to investigate the constitutive and inducible expression of CYP4 forms in Cyphoma after dietary exposure to several gorgonian species with varying allelochemical profiles. Adult Cyphoma were allowed to feed ad libitum for $4 \mathrm{~d}$ on one of seven gorgonian diets or a control diet devoid of gorgonian allelochemicals. CYP4 transcripts were measured by quantitative RT-PCR from mRNA extracted from the digestive glands of either control or allelochemicallyexposed snails using general and specific gene primers ${ }^{2}$. Digestive gland expression of CYP4 transcripts was monitored using general-cyp4-1, general-cyp4-2, general-cyp4-3 oligonucleotide primers and two additional primer pairs specific for a subset (A and B) of CYP4-3 sequences (Table 3). Figure 15 maps the location of those CYP4-3 clones that would be detected by CYP4-3 (sub A) $_{\text {and CYP4-3 }}$ (sub B) primers. Control amplifications were performed with cDNAs to confirm the specificity of the primers (data not shown).

Initially, CYP4 expression analysis was performed using only general-cyp4-1, general-cyp4-2, and the subset-specific CYP4-3 ${ }_{(\text {sub A) }}$ and CYP4-3 $3_{(\text {sub B) }}$ quantitative PCR primers (Figure 16). Subsequently, it was determined that CYP4-3 (subA) and CYP4-3(sub B) primers did not detect some transcripts and the expression analysis was repeated with general-cyp4-3 primers for control snails and snails consuming the gorgonian $\operatorname{diet} P$. homomalla for which a significant induction of CYP4-3 gene subsets was seen (Figure 17).

\footnotetext{
${ }^{2}$ Three sets of general primers were designed to each of the three Cyphoma CYP4 clusters (CYP4-1, CYP4-2, CYP4-3) and were used to detect the expression of all sequences within the cluster. Two sets of specific primers, designated CYP4-3(sub A) and CYP4-3(sub B), were designed to pick up selected subsets of sequences within the CYP4-3 cluster only.
} 
Significant differences in CYP4 expression between control and gorgonian diets were found for three gorgonian species (MANOVA, G. ventalina $\mathrm{F}_{4,33}=18.99, \mathrm{p}<$ 0.001; P. americana $\mathrm{F}_{4,32}=6.653, \mathrm{p}<0.001 ;$ P. homomalla $\mathrm{F}_{5,30}=7.479, \mathrm{p}<0.001$; Table 6). However, for two of the two gorgonian diets a significant Diet $\mathrm{x}$ Reef interaction was observed (MANOVA, G. ventalina $\mathrm{F}_{16,101}=6.392, \mathrm{p}<0.001 ; P$. homomalla $\mathrm{F}_{15,66}=2.429, \mathrm{p}<0.001$, Table 6 ), indicating that CYP4 expression in snails inhabiting particular reefs were of high influence. ANOVA analysis further revealed that the significant Diet $\mathrm{x}$ Reef interaction in snails feeding on G. ventalina and P. homomalla could be traced to significant differences in CYP4-3 $3_{(\mathrm{subA})}$ expression among reefs (Table 7). Two snails collected from N. Normans out of 13 feeding on G. ventalina and one snail collected from Shark Rock out of 11 feeding on P. homomalla, showed negligible expression of CYP4-3 $3_{(s u b A)}$ transcripts, accounting for the significance of the interaction term. Interestingly, all three of these snails did express transcripts detected by subsetspecific CYP4-3 (subB) primers at levels similar to other snails feeding on the same diet. In addition, when the entire complement of CYP4-3 transcript expression was measured in control and $P$. homomalla fed snails using general-cyp4-3 primers, the single snail from the Shark Rock collection feeding on $P$. homomalla, originally showing anomalous gene expression for CYP4-3 (sub A), displayed induced CYP4-3 transcript expression compared to reef controls. This finding may indicate that sequences detected by CYP4-3(subA) primers represent alternative splice variants or alleles that may not be expressed within certain subpopulations of snails. Sequences that are detected by CYP4-3(subA) primers are contained within the CYP4-3b1/CYP4-3b3/CYP4-3c groups defined by maximum parsimony analysis (Figure 15), all of which contain clones that are highly homologous to 
each other at the C-terminal end. However, CYP4-3b1, CYP4-3b3, and CYP4-3c share between 94.2 and $96.9 \%$ protein identity, which falls below the $97 \%$ cut-off suggesting they are distinct genes. It is possible that these distinct loci may be inducible by specific compounds rather than structurally similar classes of allelochemicals produced by $P$. homomalla, and natural variability in allelochemical content among gorgonian colonies may account for differences in transcript expression.

In light of this information, the data were reanalyzed for both gorgonian diets excluding those reefs containing snails with the anomalously low CYP4-3 (subA) expression values. As expected, there were no significant differences in CYP4 gene expression among snails feeding on G. ventalina (data not shown), but gene expression was still significantly different in snails feeding on $P$. homomalla compared to controls (MANOVA, $\mathrm{F}_{5,24}=7.606, \mathrm{p}<0.001$, Table 6). There was significant induction (ANOVA, p < 0.001, Table 7) of CYP4-2 (2.7-fold), CYP4-3 (2.7-fold), and CYP4$3_{\text {(subA) }}(5.1$-fold) gene expression in snails fed $P$. homomalla compared to controls (Figure 17) and the significant differences among $P$. homomalla-fed snails were limited to diet effects only. In addition, significant differences in CYP4 expression in P. americana-fed snails (MANOVA) were found not to be significant in ANOVA comparisons after pvalues were Bonferroni adjusted (Table 7).

CYP4 gene expression did differ significantly among time-zero group snails collected from different reefs (MANOVA, $\mathrm{F}_{20,70}=1.739, \mathrm{p}=0.047$, Table 8, Figure 18). However, CYP4 gene expression did not vary among snails from different reefs fed a control diet for 4 days (MANOVA, $\mathrm{F}_{20,80}=1.367, \mathrm{p}=0.164$, Table 8, Figure 18). These results demonstrate that gene expression is highly variable among snails collected from 
different reefs, possibility reflecting the variability of gorgonian diets at each reef

location. If one considers the time-zero group as a proxy for the natural variation of gene expression in individuals on different reefs, then four days feeding on a control diet is enough to allow gene expression to return to some constitutive level, no matter reef origin, once the allelochemical stimulus is removed. Therefore, these results support the use of control snail gene expression as the true baseline, representing the nonallelochemically induced state of CYP4 gene expression in Cyphoma.

Running in parallel to the four day feeding assays was a longer term (14d) feeding assay used to investigate CYP4 gene expression in individuals exposed to the same gorgonian host almost five times longer than would be expected based on observations of residence time in the field (Harvell \& Suchanek 1987). The design of the long term feeding assay was the same as described above, except one raceway contained ten tanks, each holding a single snail feeding on either a control diet $(\mathrm{n}=2$ snails) or one of seven gorgonian diets ( $\mathrm{n}=7$ snails) for $14 \mathrm{~d}$. All nine snails were collected from the same reef (i.e., North Normans). The mean CYP4 expression of two snails feeding on the control diet for 14d was no different from snails feeding on control diets for 4d (Figure 19). While the CYP4 expression results in snails feeding on a gorgonian diet are limited to one observation per gorgonian species, snails feeding on B. asbestinum, E. mammosa, G. ventalina, P. acerosa, P. americana, and P. elisabethae displayed CYP4 expression patterns similar to that of the paired controls (data not shown). Based on the four day feeding assays we expected to see sustained induction of CYP4-2, CYP4-3 and CYP4$3_{\text {(subA) }}$ genes in the individual feeding on $P$. homomalla for 14d; there was higher CYP4$3_{\text {(subA) }}$ gene expression in this snail compared to the control individuals, but expression of 
CYP4-2 and CYP4-3 was similar to that of controls (Figure 19). However, feeding records indicate that the individual feeding on $P$. homomalla ceased feeding six days prior to the end of the $14 \mathrm{~d}$, which may explain the lack of CYP4 induction in this individual.

\section{Identification of putative substrate recognition sites}

Allelochemically-responsive Cyphoma CYP4 protein sequences were compared with characterized vertebrate fatty acid hydroxylases to help define the possible function and range of substrates for Cyphoma CYP4 forms by comparing key conserved residues among both groups. Cyphoma CYP4 proteins were also aligned with the crystal structure coordinates of bacterial fatty acid monooxygenase CYP102 (CYPBM3) (Ravichandran et al. 1993) and CYP2 forms described in (Gotoh 1992) to better define putative SRS regions and highlight differences between active site and substrate binding residues among Cyphoma P450 forms.

The bacterial CYP102 was used as a template to align Cyphoma CYP4-2 and CYP4-3 forms. In addition, human CYP4F3, CYP4F11 and rabbit CYP4A4, CYP4A5, CYP4A6, CYP4A7 were included in the alignment to aid in comparing previously annotated active site residues between mammalian fatty acid hydroxylases and Cyphoma CYP4 proteins (Figure 20). Amino acid identity between bacterial CYP102 and Cyphoma CYP4-2 and CYP4-3 sequences ranged between 16.6-21.5\%. The bacterial CYP102 was used in place of one of the many crystallized eukaryote P450 forms (e.g., rabbit CYP2C5) because the CYP102 alignment with Cyphoma CYP4 genes resulted in 
the highest percent identity (data not shown). Therefore, the bacterial CYP102 backbone was used as the template to define putative SRSs within the Cyphoma CYP4 proteins.

Even though Cyphoma CYP4 sequences are highly similar to one another within the clusters defined here, variation among even one residue can have a profound effect on enzymatic function (Lindberg \& Negishi 1989). An alignment of the deduced amino acid sequences of both CYP4-2a and CYP4-2b indicates that the sequence variations are limited to 27 out of a possible 508 positions, not including the additional 6 residues at the C-terminal end of CYP4-2b. Seven of the 27 residues fall within five of the six substrate recognition sites (SRSs) which are critical for defining substrate specificity and activity in both vertebrate and invertebrate CYPs (Gotoh 1992, Pan et al. 2004). A similar deduced amino acid alignment constructed for all sequences found in the CYP4-3 group, indicated that sequence variation was limited to 40 out of 520 positions, with 13 substitutions occurring within SRSs. If we narrow our comparison to just the seven sequences representing the highly similar CYP4-3b subgroup (95.0 to $99.2 \%$ a.a. identity), 32 out of 520 possible positions contain amino acid variations, 13 of which are located in one of the six SRS regions.

The great diversity of P450 reactions stems from the structural arrangement of the P450 protein, allowing for the discrimination and orientation of substrates in close proximity to the activated oxygen species located in the heme core. Rigorous homology modeling of human CYP4A11 with bacterial fatty acid hydroxylase CYP102 coupled with site-directed mutational analysis has highlighted key resides in the binding pocket and substrate access channel influencing substrate specificity and hydroxylation position (Chang \& Loew 1999). Table 9 contains a listing of these residues from CYP102 and 
CYP4A11 with the corresponding residues from the Cyphoma CYP4-2 and CYP4-3 group of sequences. The order of residues listed in the table is based on their proximity to the heme core (upper - region nearest to the surface of the protein; middle - region buried in the middle located at distance from the ferryl oxygen; lower - region containing residues with $7 \AA$ from the ferryl oxygen and site of metabolic activity). Despite the low sequence similarity overall, half of the residues within the lower substrate channel are absolutely conserved between the bacterial, human, and Cyphoma proteins, including T260, F261, G265, T268, A328 from CYP102. Three of the four remaining residues near the heme core in CYP102 (L75, A264, and A328) are replaced by bulkier residues in human CYP4A11 (Y120, E321, V386), which control the entrance and depth of substrate penetration within the active site and favor terminal carbon hydroxylation by restricting only the $\omega$ methyl group to come within proximity to the ferryl oxygen (Chang \& Loew 1999). Cyphoma CYP4-2 and CYP4-3 forms also contain the same bulky residues as CYP4A11 within their active sites (Table 9), suggesting terminal hydroxylation would be favored.

In addition, within the active site of CYP4A, CYP4B, and CYP4F forms, a glutamate residue (E321 in CYP4A11 in Table 9) binds to the heme positioning the fatty acid into a position favoring $\omega$-hydroxylation (Stark et al. 2005). Mutating this position to an alanine results in the reduction of terminal carbon hydroxylation ( $\omega: \omega-1)$ from 20:1 to 5:1, or the complete elimination of $\omega$-hydroxylation all together (Dierks et al. 1998a, Dierks et al. 1998b) and reduced fatty acid hydroxylation (Zheng et al. 2003). Cyphoma CYP4-2b contains the less bulky alanine at the position equivalent to E321 in CYP4A11, 
which would predict reduced hydroxylase activity and a substrate orientation favoring non-terminal $\omega$ hydroxylation for this cDNA.

Modeling studies of mammalian CYP4A (Chang \& Loew 1999, Loughran et al. 2000) indicate that residues falling outside of the prescribed SRSs regions (Gotoh 1992) still play critical roles in substrate binding and activity (Figure 20). Many of these residues correspond to polymorphic sites within Cyphoma CYP4-2 and CYP4-3 proteins. For example, residues 81 and 91, forward of the first SRS region in the Cyphoma CYP43 cluster, are highly polymorphic and correspond to positions located at the mouth of the substrate access channel in CYP4A7 (R88) and CYP102 (Y51), responsible for anchoring the terminal carboxylic group on the fatty acid to the protein (Loughran et al. 2000). In general, Cyphoma CYP4-2 and CYP4-3 proteins seem to contain a majority of residues with small side chains at these positions (alanine, glycine, valine), suggesting that the opening of the substrate access channel may be able to accommodate larger fatty acids.

Further work by (Loughran et al. 2000) identified two additional residues (Y204 and F252) in rabbit CYP4A4, one of which is located outside of putative Cyphoma SRS sites defined here, that influence $\mathrm{PGE}_{1}$ hydroxylase activity (Figure 20). These residues have been replaced by H206 and S255 in CYP4A7, which shows substantially less turnover of $\mathrm{PGE}_{1}$ in comparison to CYP4A4. Cyphoma CYP4-2 proteins share the same residues at both corresponding positions in CYP4A4 (Y200 and F248), highlighting their potential role as prostaglandin (i.e., $\mathrm{PGE}_{1}$ ) hydroxylases. Cyphoma CYP4-3 proteins share either tyrosine $(\mathrm{Y})$ or histidine $(\mathrm{H})$ at the first position corresponding to Y206 in CYP4A4, and contain a tryptophan (W) at the second position, corresponding to a conservative substitution from a similar aromatic phenylalanine (F) in CYP4A4. 
Homology models of CYP4F3 and CYP4F11 based on bacterial (CYP102) and eukaryotic P450 crystal structure coordinates agree, for the most part, with our putative SRS assignments made for Cyphoma CYP4s based on our alignment to CYP102 (Kalsotra et al. 2004) (Figure 20). The exception is the SRS-2 region, which is slightly offset in comparison to Cyphoma CYP4 SRS-2, possibly due to the highly gapped nature of the author's alignment resulting from the variability seen among P450s within the F-G loop region (Peterson \& Graham-Lorence 1995). The positioning, length and polarity of the F-G loop is thought to dictate the accessibility of the substrate to the access channel (Peterson \& Graham-Lorence 1995, Williams et al. 2000b). The F-G loop in Cyphoma CYP4-2 and CYP4-3 is predicted to be substantially larger, containing 19 additional residues within the $\mathrm{G}$ helix, in comparison to CYP102. Interestingly, almost the entire Fhelix has been removed from sequence CYP4-3a1v2, likely altering the substrate profile for this variant. Additionally, the putative SRS-1, -2 sites suggested here are different from those defined by (Loughran et al. 2000) for CYP4A members. It is likely that Cyphoma allelochemically-responsive CYPs share properties of both vertebrate CYP4A/F groups because of their evolutionary history and probable shared function. To date, no crystal structure has been determined for any eukaryotic CYP4 protein, further complicating the definitive identification of key residues for this family of proteins.

In summary, a majority of the amino acid substitution patterns among Cyphoma CYP4-2 (15 out of 27) and CYP4-3 (22 of 40) sequences cluster within SRS or near (within 2 residues) positions identified as being involved in the positioning of the substrate within the access channel or the active site. Although SRS-1 and 2 sites may shift somewhat depending on the species and subfamily used for comparison, these 
patterns suggest that amino acid replacement differences are targeted within domains affecting substrate recognition.

\section{Results of enzymatic assays}

P450 content and reductase activity. The P450 content of Cyphoma microsomal proteins and recombinant yeast microsomes containing selected CYP4 cDNAs (Figures $21,22)$ was investigated by the method of (Omura \& Sato 1964). The characteristic P450 spectral peak was not detected in Cyphoma digestive gland microsomal preparations nor was a peak at $420 \mathrm{~nm}$ indicating the presence of degraded protein. Cytochrome P450 was consistently detected in recombinant microsomes from yeast induced for $8 \mathrm{hrs}$ on galactose-containing media (27.4 pmol P450 mg protein $^{-1}-118.7$ pmol P450 mg protein ${ }^{-}$ ${ }^{1}$ ), but not in yeast induced for $15 \mathrm{hrs}$. No $420 \mathrm{~nm}$ peak was ever observed in any yeast microsomal preparations. The lack of chromophore detection at $450 \mathrm{~nm}$ with spectrophotometry in some yeast samples does not preclude NADPH-dependent enzymatic activities in these yeast microsomes. For example, recombinant yeast expression of ovine CYP4F21 yielded no P450 spectra, but yeast microsomes containing CYP4F21 metabolized three stable $\mathrm{PGH}_{2}$ analogues and $\mathrm{PGE}_{2}$ to their respective 20hydroxy metabolites, whereas control microsomes lacked such activity (Bylund 2000, Bylund \& Oliw 2001). NADPH-cytochrome P450 reductase activity was also confirmed to be strongly induced in galactose-induced yeast microsomal samples $(\sim 5000 \mathrm{nmol} \mathrm{min}$

$\left.{ }^{1} \mathrm{mg}_{\text {protein }}{ }^{-1}\right)$ and highly expressed in the one snail digestive gland examined (631 nmol $\min ^{-1} \mathrm{mg}$ protein $\left.{ }^{-1}\right)$ 
Fatty acid hydroxylase activity. Yeast microsomes containing Cyphoma CYP4-2 and CYP4-3 (Figure 22) proteins were surveyed for both lauric acid and leukotriene B4 $\left(\mathrm{LTB}_{4}\right)$ hydoxylase activity to define a range of possible fatty acid substrates for Cyphoma CYP4 proteins. Recombinant yeast microsomes, isolated from 8- and 15-hr induced cultures expressing either CYP4-2a, CYP4-2b, CYP4-3a1, CYP4-3b1, or CYP43b3, were incubated with $0.1 \mathrm{mM}$ lauric acid or $29.7 \mu \mathrm{M} \mathrm{LTB} 4$ and the production of hydroxylated metabolites was analyzed by HPLC or liquid scintillation detection. Yeast microsomes containing recombinant CYP4 protein did not metabolize lauric acid to any detectable metabolites; however, leukotriene B4 hydroxylase activity was detected in recombinant yeast microsomes (Table 10, Figure 23 ). $\mathrm{LTB}_{4}$ activity was present only in yeast expressing CYP4-3a1 and CYP4-3b3 ranging from $0.017-0.299 \mathrm{pmol} \mathrm{mg}^{-1} \mathrm{~min}^{-1}$ and was greater in samples incubated at $30^{\circ} \mathrm{C}$ then at $23^{\circ} \mathrm{C}$. In addition, $\mathrm{LTB}_{4}$ hydroxylase activity was detected in the digestive gland of three of the four snails feeding on $P$. homomalla, while only one of the ten snails feeding on the control diet exhibited detectable activity (Table 11). Human liver microsome samples were run in parallel experiments and showed typical activity and metabolic profile for this enzyme source.

\section{Discussion}

This study provides the first evidence linking the induction of specific P450 transcripts in a marine consumer to the chemistry of its gorgonian host. The diet of the generalist $C$. gibbosum includes a variety of gorgonian families with structurally diverse allelochemical profiles. Only snails feeding on the gorgonian Plexaura homomalla 
displayed significant induction (2.7- to 5.1-fold) of digestive gland CYP4 transcripts in comparison to individuals feeding on a control diet devoid of gorgonian allelochemicals.

The suite of allelochemicals produced by $P$. homomalla is unique to this genus of Caribbean coral and includes high tissue concentrations of prostaglandins (1 to $8 \%$ of the dry tissue weight) (Weinheimer \& Spraggins 1969, Schneider et al. 1977a, Dominguez et al. 1980). In mammalian systems, prostaglandins behave as 'local' (i.e., autocrine or paracrine) lipid mediators, acting through G-protein-coupled receptors to stimulate the pro-inflammatory cascade after tissue injury, sensitize neurons to pain, stimulate smooth muscle contraction, regulate vasodilation, regulate temperature, and control ionic balance in the kidney (Funk 2001, Rowley et al. 2005). In invertebrates, prostaglandins play similar roles as modulators of ion transport and regulators of immune response and reproduction (Stanley 2000, 2006), but are most notable as prey chemical defenses in marine systems (Gerhart 1984, Di Marzo et al. 1991, Gerhart 1991, Marin et al. 1991).

The most abundant prostaglandin in P. homomalla is the fully esterified $\mathrm{PGA}_{2}$ form (averaging $1-2 \%$ of dry weight), followed by its hydroxy acid ( $0.2 \%$ of dry weight) (Weinheimer \& Spraggins 1969, Schneider et al. 1977a, Dominguez et al. 1980). Damage to gorgonian soft tissue can stimulate the lipase-mediated enzymatic hydrolysis of the acetoxy methyl ester of $\mathrm{PGA}_{2}$, resulting in the accumulation of the partially esterified $\mathrm{PGA}_{2}$ compounds (Schneider et al. 1977a, Valmsen et al. 2001). Palatability studies with a natural assemblage of reef fish have confirmed the ichthyodetterency of the crude extract of $P$. homomalla (O'Neal \& Pawlik 2002), the hydroxy acids of $\mathrm{PGA}_{2}$ (both $\mathrm{S}$ and $\mathrm{R}$ isomers), and both the hydroxyl methyl ester and acetoxy acid of $\mathrm{PGA}_{2}$ (Gerhart 1984, Pawlik \& Fenical 1989). Interestingly, the fully-esterified form of $\mathrm{PGA}_{2}$ did not 
deter consumption; however, esterified prostaglandins have been hypothesized to function as sources of inducible defenses, whereby damage to the coral may cause the innocuous acetoxy methyl esters to undergo hydrolysis to the noxious hydroxy acids over a period of several hours (Pawlik \& Fenical 1989). The esterification of prostaglandins may protect the gorgonian from self-intoxication, allowing for the high concentration of prostaglandin compounds to persist in gorgonian tissues. For less mobile predators, like C. gibbosum, feeding stimulated formation of the hydroxy acids of $\mathrm{PGA}_{2}$ in $P$. homomalla hosts and/or acidic hydrolysis of esterified $\mathrm{PGA}_{2}$ forms in the low-pH gastric environment could pose a significant threat to these obligate gorgonian predators, unless they possess orchestrated detoxification mechanisms capable of responding to their host allelochemicals.

Within the diverse P450 superfamily, family 4 monooxygenases (CYP4) contain the major fatty acid $\omega$-hydroxylases capable of preventing lipotoxicity (Hsu et al. 2007). Phylogenetic analysis of C. gibbosum $\mathrm{P} 450$ sequences revealed that those transcripts induced in response to dietary exposure of $P$. homomalla are most closely related to vertebrate CYP4A and CYP4F forms well known for their ability to metabolize prostaglandins, including $\mathrm{PGA}_{2}$ (Sawamura et al. 1993, Okita \& Okita 2001, Capdevila \& Falck 2002, Kikuta et al. 2002, Kalsotra \& Strobel 2006). In some cases the snail CYP4s share the same amino acid residues determined to be important in prostaglandin metabolism by vertebrate CYP4A/F forms. Allelochemical-responsive P450s in Cyphoma include both CYP4-2 and CYP4-3, which likely function in a cooperative fashion to mediate prostaglandin detoxification. The induction of P450 forms by gorgonian diets did not extend to all Cyphoma CYP4 forms. CYP4-1 (CYP4V10) was 
not induced, nor would this have been expected, since it falls within the CYP4C/V clade containing CYP forms whose roles have been postulated to include hormone-stimulated fatty acid oxidation during starvation (cockroach, CYP4C1) (Lu et al. 1996, 1999) and fatty acid metabolism in the retina in vertebrates (reviewed in Hsu et al. 2007).

P450 genes, in contrast to housekeeping genes, are often transcriptionally induced by substrates upon which they act (Whitlock 1986). A significant increase in mRNA for selected CYP4 transcripts was observed in snails following a $4 \mathrm{~d}$ dietary exposure to $P$. homomalla allelochemicals. Both CYP4-2 and CYP4-3 were constitutively expressed and induced to the same degree (2.7-fold). This combination of constitutive and inducible expression mirrors that of the CYP6B17 and related transcripts in Papilio glaucus, a generalist lepidopteran that feeds on a range of host plants and occasionally encounters toxic furanocoumarins in its diet ( $\mathrm{Li}$ et al. 2001). CYP6B17 is constitutively expressed in uninduced larvae and induced 3-fold in larvae exposed to the furanocoumarin xanthotoxin. For generalist species like $P$. glaucus and $C$. gibbosum, where the chance of encountering an allelochemically-rich diet is high, there may be a selective advantage to constitutively expressing select P450 forms. P. glaucus also expresses a second group of furanocoumarin metabolizing genes that are closely related to the CYP6B17 group. These transcripts within the CYP6B4 group are not constitutively expressed in unexposed larvae, but are highly inducible upon exposure to furanocoumarins ( $\mathrm{Li}$ et al. 2001). In contrast, all of the allelochemically-responsive genes had some measurable level of constitutive expression in control-fed snails; however, additional quantitative PCR analysis of a subset of Cyphoma CYP4-3 genes revealed CYP4-3 $3_{(\text {sub A) }}$ transcripts exhibited a greater fold induction (5.1-fold) and lower 
basal expression in comparison to the CYP4-3 cluster as a whole. This result suggests selective CYP4-3 forms have different patterns of inducibility, perhaps to respond to different suites of compounds produced by P. homomalla.

Since their initial discovery of prostaglandins in gorgonians by Weinheimer and Spraggins in 1969, the synthesis (Valmsen et al. 2001, Valmsen et al. 2004), structural diversity (Spraggins 1972, Schneider et al. 1977b, Agalias et al. 2000, Schneider et al. 2002, Schneider et al. 1972, Light \& Samuelsson 1972, Schneider et al. 1977a, Groweiss \& Fenical 1990) and bioactivity of these compounds (Honda et al. 1987, Bhakuni \& Rawat 2005, Chiang et al. 2006, Roberts et al. 2003) have been studied intensively. Prostaglandins in the A series (i.e., $\mathrm{PGA}_{2}$ ) dominate the bulk of the crude extract of Plexaura homomalla (Schneider et al. 1977a). The 15(R) form of $\mathrm{PGA}_{2}$ is typically found in Florida Keys populations, whereas the typical mammalian 15(S) form is found in colonies collected in the Bahamas, Cayman Islands and Curaçao (Schneider et al. 1977b, Ciereszko et al. 1985, Gerhart 1986, Schneider et al. 2002). Generally, individual P. homomalla colonies produce either the $\mathrm{R}$ and $\mathrm{S}$ configurations, but mixtures within the same colony have been reported (Schneider \& Morge 1971, Schneider et al. 1977a). Several $\mathrm{PGA}_{2}$ analogues of minor abundance have also been described; these include 5,6trans-PGA 2 (5-15\% of the $\mathrm{PGA}_{2}$ fraction) (Schneider et al. 1977a), and 13,14-dihydroand 13,14-cis-PGA 2 derivatives (Schneider et al. 1977b). Bahamian P. homomalla populations have also been reported to contain the prostaglandin $\mathrm{E}_{2}\left(\mathrm{PGE}_{2}\right)$, methyl ester and 15 -acetate methyl ester at roughly $10 \%$ of the abundance of $\mathrm{PGA}_{2}$ esters (Schneider et al. 1972, Prince et al. 1973, Schneider et al. 2002) and prostaglandin $\mathrm{F}_{2 \alpha}\left(\mathrm{PGF}_{2 \alpha}\right)$ as both the acid and the acetate methyl ester $(0.6 \%$ of the chloroform extract) (Groweiss \& 
Fenical 1990). It is possible that the structurally diverse pool of prostaglandins found in gorgonian tissues may have necessitated the evolution of multiple prostaglandin metabolizing P450s, resulting in the diversity of closely related CYP4-3 transcripts identified here. Many of the amino acid differences (22/40) among members of the CYP4-3 group occur within, or near, the putative six SRS regions or residues lining the substrate access channel. Based on the location of these differences and knowledge gained from site-directed mutagenesis studies, it is likely that these variations will confer differences in catalytic activity and substrate specificity among these closely related proteins.

It is conceivable that ancestral Cyphoma P450s, whose function was to metabolize endogenous fatty acids, acquired new functions through strategic mutations allowing this predator to exploit prostaglandin-rich prey. One recent study suggests that the loss of host plant specialization in the Papilio lineage, favoring generalists like P. glaucus, may have evolved from only a small number of mutational changes within the SRS-6 region, allowing for the acquisition of novel catalytic activities while still retaining the ancestral furanocoumarin-metabolizing capability (Mao et al. 2007). This gradual accumulation of functionally significant replacements, often following a series of gene duplications (Wen et al. 2006), has been hypothesized as a means for enzymes to evolve in response to host selection (Mao et al. 2007). It would be interesting to explore whether the co-occurring specialist Cyphoma signatum, which feeds exclusively on Plexaurella spp., known only to contain the eicosanoid 11-R-hydroxy-5Z,8Z,12E,14Z-eicosateraenoic acid (11-RHETE) (Di Marzo et al. 1996) and not prostaglandins, retains a similar diversity CYP4 transcripts capable of responding to foreign dietary prostaglandins. Insect studies 
indicate that the constitutive expression, inducibility and catalytic versatility of herbivore P450s generally correspond to the frequency of ecological allelochemical exposure (Cohen et al. 1992, Li et al. 2001, Li et al. 2007). This theory would predict that while $C$. signatum may share similar CYP4 genes, C. gibbosum would be more efficient at metabolizing dietary prostaglandins.

The expansion of the CYP4-3 cluster relative to the other Cyphoma P450s identified in the present study suggests positive selection of this subfamily likely through repeated gene duplication events. In addition, alternative splicing of transcripts or the formation of chimeric CYPs from the splicing of pre-mRNA molecules can allow for the generation of novel genes with divergent catalytic functions. There is evidence for both of these scenarios within the P450 superfamily. For example, the human CYP4F3 gene has two different inducer specific 5' UTR transcriptional start sites capable of controlling the mutually exclusive splicing of either exon 3 or 4 , generating the tissue-specific expression of catalytically distinct CYP4F3A and CYP4F3B isoforms (Christmas et al. 1999, Christmas et al. 2001). In addition, chimeric RNA molecules have been identified for both CYP2C and CYP3A members (Finta \& Zaphiropoulos 2000, Finta \& Zaphiropoulos 2002). In this case, exons are joined together from distinct pre-mRNA molecules yielding chimeric mRNAs. Formation of hybrid mRNA, especially by transsplicing, allows detritus or solo exons to become functional even if they are dispersed in the genome (Bonen 1993). In both cases, exon shuffling or alternative splicing of distinct transcripts provides the opportunity for novel catalytic functions to emerge, further increasing the diversity of P450 genes. However, without specific knowledge of the 
genomic arrangement or exon-intron structure of Cyphoma CYP4 genes, we cannot distinguish between these and other possibilities.

The consensus amino acid sequence representing Cyphoma CYP4-3c (clones within this group share greater than $96.3 \%$ a.a. identity) is a hybrid of both the CYP4-3b and CYP4-3a groups, with individual clones spanning a range of identities between the $3 \mathrm{a}$ and $3 \mathrm{~b}$ nodes (Figure 10). This suggests the CYP4-3c locus defined here could be made up of multiple loci resulting from repeated duplication events, one locus with highly polymorphic alleles, or products of alternative splicing or trans-splicing. The same could also be said of the CYP4-3b2 subgroup represented by five unique clones. CYP4-3b2_clone 5 is a hybrid between CYP4-3b2_clone 3/CYP4-3b2_clone 4/CYP4$3 \mathrm{~b} 3$ (N-terminal) and CYP4-3a group (C-terminal). Alternatively, the hybrid nature of CYP4 forms here may have resulted from the combination of gene duplication events followed by gene conversions, resulting in the homogenization present among members of the CYP4-3 group. This scenario has been hypothesized to account for the nearly identical amino acid sequences in CYP6B gene paralogs in the moth, Helicoverpa zea (Li et al. 2002b). Additional studies such as genomic PCR or the construction of a BAC library would help precisely identify the number of distinct loci represented by the CYP4-3 cluster.

Multiple gene duplication events are common among CYP4 members, including human CYP4F genes (CYP4F2, CYP4F3(A/B), CYP4F8, CYP4F11, CYP4F12) (Nelson et al. 2004). While these genes share greater than $77 \%$ amino acid identity with each other, their enzymatic activities and substrate specificities can be strikingly different (reviewed by Kalsotra \& Strobel 2006). A closer examination of the substrate spectrum 
for vertebrate fatty acid hydroxylases suggests certain isoforms have narrow substrate specificity, which is a significant departure from those xenobiotic CYP families $(1,2,3)$ known for their broad substrate pool. Consequently, the lack of lauric acid hydroxylase activity or substantial $\mathrm{LTB}_{4}$ hydroxylase activity in recombinant yeast microsomes reported here does not preclude fatty acid hydroxylase activity of Cyphoma CYP4 proteins. For example, recombinant rabbit CYP4A4 can metabolize long chain fatty acids, including prostaglandins, yet shows little if any ability to metabolize lauric acid (reviewed in Okita \& Okita 2001). Mouse CYP4F14 catalyzes the $\omega$-hydroxylations of $\mathrm{LTB}_{4}$, lipoxin $\mathrm{A}_{4}$ and $\mathrm{PGA}_{1}$, but no activity towards lipoxin $\mathrm{B}_{4}$, lauric acid or arachidonic acid was detected (Kikuta et al. 2000). Similarly, not all $\mathrm{LTB}_{4} \omega$-hydroxylases catalyze prostaglandin hydroxylation. For example, human CYP4F3 shares $\mathrm{LTB}_{4} \omega$-hydroxylase activity with rodent CYP4F14, yet it does not catalyze the hydroxylation of $\mathrm{PGA}_{1}, \mathrm{PGE}_{1}$, or lauric acid (Kikuta et al. 1998). It is possible that the substrate specificities of allelochemically-responsive Cyphoma CYP4 forms might be finely tuned toward those fatty acids (primarily prostaglandins) found within its gorgonian diet. Even so, $\mathrm{LTB}_{4}$ hydroxylase activity measurements in Cyphoma microsomes suggests those snails exposed to prostaglandin-rich gorgonian diets have a greater ability to metabolize fatty acids in comparison to snails feeding on control diets, and it is likely that this enhanced enzymatic activity is due to the induction of allelochemically-responsive CYP4s. In vitro studies will be needed in order to directly demonstrate that ecologically relevant prostaglandins can serve as substrates for C. gibbosum P450s; nevertheless, this study provides the most compelling evidence thus far for the involvement of P450s in allelochemical metabolism in marine consumers. 


\section{References}

Agalias A, Mihopoulos N, Tsoukatou M, Marinos L, Vagias C, Harvala C, Roussis V (2000) New prostaglandins from the chemically defended soft coral Plexaura nina. Z Naturforsch 55c:425-430

Altschul SF, Madden TL, Schaffer AA, Zhang J, Zhang Z, Miller W, Lipman DJ (1997) Gapped BLAST and PSI-BLAST: a new generation of protein database search programs. Nucleic Acids Research 25:3389-3402

Bhakuni DS, Rawat DS (2005) Marine prostaglandins, Vol. Springer, New York

Birkeland C, Gregory B (1975) Foraging behavior and rates of feeding of the gastropod, Cyphoma gibbosum. Bull Nat Hist Mus Los Angeles Co 20:57-67

Bonen L (1993) Trans-splicing of pre-mRNA in plants, animals and protists. FASEB J 7:40-46

Bradford MM (1976) A rapid and sensitive method for quantitation of microgram quantities of protein utilizing principle of protein-dye binding. Analytical Biochemistry 72:248-254

Bricelj VM, Connell L, Konoki K, MacQuarrie SP, Scheuer T, Catterall WA, Trainer VL (2005) Sodium channel mutation leading to saxitoxin resistance in clams increases risk of PSP. Nature 2005:763-767

Burkepile DE, Hay ME (2007) Predator release of the gastropod Cyphoma gibbosum increases predation on gorgonian corals. Oecologia 154:167-173

Bylund J (2000) Cytochrome P450 enzymes in oxygenation of prostaglandin endoperoxides and arachidonic acid. Uppsala University

Bylund J, Oliw EH (2001) Cloning and characterization of CYP4F21: a prostaglandin E2 20-hydroxylase of ram seminal vesicles. Archives of Biochemistry and Biophysics 389:123-129

Capdevila JH, Falck JR (2002) Biochemical and molecular properties of the cytochrome P450 arachidonic acid monooxygenases. Prostaglandins \& Other Lipid Mediators 68-69:325-344

Chang Y-T, Loew GH (1999) Homology modeling and substrate binding study of human CYP4A11 enzyme. Proteins: structure, function and genetics 34:403-415

Chang YT, Stiffelman OB, Loew GH (1996) Computer modeling of 3D structures of cytochrome P450s. Biochimie 78:771-779 
Chaty S, Rodius F, Vasseur P (2004) A comparative study of the expression of CYP1A and CYP4 genes in aquatic invertebrate (freshwater mussel, Unio tumidus) and vertebrate (rainbow trout, Oncorhynchus mykiss). Aquatic Toxicology 69:81-93

Chiang PC, Kung FL, Huang DM, Li TK, Fan JR, Pan SL, Shen YC, Guh JH (2006) Induction of Fas clustering and apoptosis by coral prostanoid in human hormoneresistant prostate cancer cells. Eur J Pharmacol 542:22-30

Christmas P, Jones JP, Patten CJ, Rock DA, Zheng Y, Cheng SM, al. e (2001) Alternative splicing determines the function of CYP4F3 by switching substrate specificity. Journal of Biological Chemistry 276:38166-38172

Christmas P, Ursino SR, Fox JW, Soberman RJ (1999) Expression of the CYP4F3 gene. Journal of Biological Chemistry 274:21191-21199

Chung W-G, Sen A, Wang-Buhler J-L, Yang Y-H, Lopez N, Merrill GF, Miranda CL, $\mathrm{Hu}$ C-H, Buhler DR (2004) cDNA-directed expression of a functional zebrafish CYP1A in yeast. Aquatic Toxicology 70:111-121

Ciereszko LS, Gopichand Y, Schmitz FJ, Schneider WP, Bundy GL (1985) Prostglandin (15S)-PGA2 derivatives in the gorgonian Plexaura homomalla (Esper) forma kukenthali. Cellular and Molecular Life Sciences 41:37-38

Cimino G, Ghiselin MT (1999) Chemical defense and evolutionary trends in biosynthetic capacity among dorid nudibranchs (Mollusca: Gastropoda: Opisthobranchia). Chemoecology 9:187-207

Cohen MB, Schuler MA, Berenbaum MR (1992) A host-inducible cytochrome P-450 from a host-specific catepillar: Molecular cloning and evolution. PNAS 89:1092010924

Coll JC (1992) The chemistry and chemical ecology of octocorals (Coelenterata, Anthozoa, Octocorallia). Chemical Reviews 92:613-631

Crespi CL, Chang TKH, Waxman DJ (2005) Determination of CYP4A-11 catalyzed lauric acid 12-hydroxylation by high performance liquid chromatography with radiometric detection. In: Phillips IR, Shephard EA (eds) Methods in Molecular Biology, Vol 320. Humana Press, Inc., Totowa, NJ, p 143-147

Danielson PB, Foster JLM, McMahill MM, Smith MK, Fogleman JC (1998) Induction by alkaloids and phenobarbital of Family 4 cytochrome P450s in Drosophila: evidence for involvement in host plant utilization. Mole Gen Genet 259:54-59

Daujat M, Clair P, Astier C, Fabre I, Pineau T, Yerle M, Gellin J, Maurel P (1991) Induction, regulation and messenger half-life cytochromes P450 IA1, IA2 and IIIA6 in primary cultures of rabbit hepatocytes. . Eur J Biochem 200:501-510 
David JP, Boyer S, Mesneau A, Ball A, Ranson H, Dauphin-Villemant C (2006) Involvement of cytochrome P450 monooxygenases in the response of mosquito larvae to dietary plant xenobiotics. Insect Biochemistry and Molecular Biology $36: 410-420$

DeBusk BC, Chimote SS, Rimoldi JM, Schenk D (2000) Effect of the dietary brominated phenol, lanasol, on chemical biotransformation enzymes in the gumboot chiton Cryptochiton stelleri (Middendorf, 1846). Comparative Biochemistry and Physiology Part C 127:133-142

Despres L, David J-P, Gallet C (2007) The evolutionary ecology of insect resistance to plant chemicals. TRENDS in Ecology and Evolution 22:298-307

Di Marzo V, Cimino G, Crispino A, Minardi C, Sodano G, Spinella A (1991) A novel multifunctional metabolic pathway in a marine mollusc leads to unprecedented prostaglandin derivatives (prostaglandin 1,15-lactones). Biochemical Journal 273:593-600

Di Marzo V, Ventriglia M, Mollo E, Mosca M, Cimino G (1996) Occurrence and biosynthesis of 11(R)-hydroxy-eicosatetraenoic acid (11-R-HETE) in the Caribbean soft coral Plexaurella dichotoma. Experientia 52:834-838

Dierks EA, Davis SC, Ortiz de Montellano PR (1998a) Glu-320 and Asp-323 are determinants of the CYP4A1 hydroxylation regiospecificity and resistance to inactivation by 1-aminobenzotriazole. Biochemistry 37:1839-1847

Dierks EA, Zhang Z, Johnson EF, Ortiz de Montellano PR (1998b) The catalytic site of cytochrome P450 4A11 (CYP4A11) and its L131F mutant. Journal of Biological Chemistry 273:23055-23061

Dominguez JN, Adams DR, Famerich J (1980) Isolation of prostaglandins from the gorgonian Plexaura homomalla collected off the Venezuelan coast. Rev Latinoam Quim 11:56-58

Fenical W, Pawlik JR (1991) Defensive properties of secondary metabolites from the Caribbean gorgonian coral Erythropodium caribaeorum. Marine Ecology Progress Series 75:1-8

Finta C, Zaphiropoulos PG (2000) The human CYP2C locus: a prototype for intergenic and exon repetition splicing events. Genomics 63:433-438

Finta C, Zaphiropoulos PG (2002) Intergenic mRNA molecules resulting from transsplicing. Journal of Biological Chemistry 277:5882-5890

Funk CD (2001) Prostaglandins and leukotrienes: advances in eicosanoid biology. Science 294:1871-1875 
Gerhart DJ (1984) Prostaglandin A2: An agent of chemical defense in the Caribbean gorgonian Plexaura homomalla. Marine Ecology Progress Series 19:181-187

Gerhart DJ (1986) Gregariousness in the gorgonian-eating gastropod Cyphoma gibbosum: tests of several possible causes. Marine Ecology Progress Series $31: 255-263$

Gerhart DJ (1991) Emesis, learned aversion, and chemical defense in octocorals: a central role for prostaglandins? Am J Physiol Regul Integr Comp Physiol 260:R839R843

Gerhart DJ, Coll JC (1993) Pukalide, a widely distributed octocoral diterpenoid, induces vomiting in fish. Journal of Chemical Ecology 19:2697-2704

Goldberg WM (1973) The ecology of the coral-octocoral communities off the southeast Florida coast: geomorphology, species composition, and zonation. Bull Mar Sci $23: 465-488$

Goldstone JV, Goldstone HMH, Morrison AM, Tarrant A, Kern SE, Woodin BR, Stegeman JJ (2007) Cytochrome P450 genes in early deuterostomes (tunicates and sea urchins) and vertebrates (chicken and frog): origin and diversification of the CYP1 gene family. Molecular Biology and Evolution 24:2619-2631

Gonzalez FJ, Nebert DW (1990) Evolution of the P450 gene superfamily: animal-plant 'warfare', molecular drive and human genetic differences in drug oxidation. Trends in Genetics 6:182-186

Gotoh O (1992) Substrate recognition sites in cytochrome P450 family 2 (CYP2) proteins inferred from comparative analyses of amino acid and coding nucleotide sequences. Journal of Biological Chemistry 267:83-90

Graham SE, Peterson JA (2002) Sequence alignments, variabilities, and vagaries. Methods Enzymol 357:15-28

Grosvik BE, Jonsson H, Rodriguez-Ortega MJ, Roepstorff P, Goksoyr A (2006) CYP1Aimmunopositive proteins in bivalves identified as cytoskeletal and major vault proteins. Aquatic Toxicology 79:334-340

Groweiss A, Fenical W (1990) PGF2alpha -9-0-acetate methyl ester, a minor naturally occurring prostaglandin from the gorgonian coral Plexura homomalla. Journal of Natural Products 53:222-223

Hall TA (1999) BioEdit: a user-friendly biological sequence alignment editor and analysis program for Windows 95/98/NT. Nucl Acids Symp Ser 41:95-98

Harper MK, Bugni TS, Copp BR, James RD, Lindsay BS, Richardson AD, Schnabel PC, Tasdemir D, VanWagoner RM, Verbitski SM, Ireland CM (2001) Introduction to 
the chemical ecology of marine natural products. In: McClintock JB, Baker BJ (eds) Marine Chemical Ecology. CRC Press, Boca Raton, p 3-70

Harvell CD, Fenical W, Greene CH (1988) Chemical and structural defenses of Caribbean gorgonians (Pseudopterogorgia spp.) I. Development of an in situ feeding assay. Marine Ecology Progress Series 49:287-294

Harvell CD, Suchanek TH (1987) Partial predation on tropical gorgonians by Cyphoma gibbosum. Marine Ecology Progress Series 38:37-44

Honda A, Mori Y, Iguchi K, Yamada Y (1987) Antiproliferative and cytotoxic effects of newly discovered halogenated coral prostanodis from the Japanese stolonifer Clavularia viridis on human myeloid leukemia cells in culture. Molecular Pharmacology 32:530-535

Hsu M-H, Savas U, Griffin KJ, Johnson EF (2007) Human cytochrome P450 family 4 enzymes: function, genetic variation and regulation. Drug Metabolism Reviews 39:515-538

Kalsotra A, Strobel HW (2006) Cytochrome P450 4F subfamily: At the crossroads of eicosanoid and drug metabolism. Pharmacology \& Therapeutics 112:589-611

Kalsotra A, Turman CM, Kikuta Y, Strobel HW (2004) Expression and characterization of human cytochrome P450 4F11: Putative role in the metabolism of therapeutic drugs and eicosanoids. Toxicol Appl Pharmacol 199:295-304

Katz E, Adamczeski M (2000) Organic chemistry and biological activity of metabolites derived from marine sea plumes, Pseudopterogorgia species of gorgonian octocorals. Studies in Natural Products Chemistry 23:153-184

Kikuta Y, Kasyu H, Kusunose E, Kusunose M (2000) Expression and catalytic activity of mouse leukotriene B4 omega-hydroxylase, CYP4F14. Archives of Biochemistry and Biophysics 383:225-232

Kikuta Y, Kusunose E, Kusunose M (2002) Prostaglandin and leukotriene omegahydroxylases. Prostaglandins \& other Lipid Mediators 68-69:345-362

Kikuta Y, Kusunose E, Sumimoto H, Mizukami Y, Takeshige K, Sakaki T, Yabusaki Y, Kusunose M (1998) Purification and characterization of recombinant human neutrophil leukotriene B4 omega-hydroxylase (Cytochrome P450 4F3). Archives of Biochemistry and Biophysics 355:201-205

Kloepper-Sams PJ, Stegeman JJ (1994) Turnover of hepatic microsomal cytochrome P4501A protein and heme in beta-naphthoflavone-induced Fundulus heteroclitus. Mol Mar Biol Biotechnol 3:171-183 
Kuhajek JM, Schlenk D (2003) Effects of the brominated phenol, lanosol, on cytochrome P450 and glutathione transferase activities in Haliotis rufescens and Katharina tunicata. Comparative Biochemistry and Physiology Part C 134:473-479

Lasker HR, Coffroth MA (1983) Octocoral distributions at Carrie Bow Cay, Belize. Marine Ecology Progress Series 13:21-28

Lekas P, Tin KT, Lee C, Prokipcak RD (2000) The human cytochrome P450 1A1 mRNA is rapidly degraded in HepG2 cells. Archives of Biochemistry and Biophysics 384:311-318

Li W, Berenbaum M, Schuler MA (2001) Molecular analysis of multiple CYP6B genes from polyphagus Papilio species. Insect Biochemistry and Molecular Biology 31:999-1011

Li W, Petersen RA, Schuler MA, Berenbaum M (2002a) CYP6B cytochrome P450 monooxygenases from Papilio canadensis and Papilio glaucus: potential contributions of sequence divergence to host plant associations. Insect Molecular Biology 11:543-551

Li W, Schuler MA, Berenbaum MR (2003) Diversification of furanocoumarinmetabolizing cytochrome P450 monooxygenases in two papilionids: Specificity and substrate encounter rate. PNAS 100:14593-14598

Li X, Berenbaum M, Schuler MA (2002b) Cytochrome P450 and actin genes expressed in Helicoverpa zea and Helicoverpa armigera: paralogy/orthology identification, gene conversion and evolution. Insect Biochemistry and Molecular Biology $32: 331-320$

Li X, Berenbaum MR, Schuler MA (2000) Molecular cloning and expression of CYP6B8: a xanthotoxin-inducible cytochrome P450 cDNA from Helicoverpa zea. Insect Biochem Mol Biol 30:75-84

Li X, Schuler MA, Berenbaum M (2007) Molecular mechanisms of metabolic resistance to synthetic and natural xenobiotics. Annu Rev Entomol 52:231-253

Li X, Schuler MA, Berenbaum MR (2002c) Jasmonate and salicylate induce expression of herbivore cytochrome P450 genes. Nature 419:712-715

Light RJ, Samuelsson B (1972) Identification of prostaglandins in the gorgonian, Plexaura homomalla. Eur J Biochem 28:232-240

Lindberg RLP, Negishi M (1989) Alteration of mouse cytochrome P450coh substrate specificity by mutation of a single amino-acid residue. Nature 339:632-634

Long JD, Hay ME (2006) Fishes learn aversion to a nudibranch's chemical defense. Marine Ecology Progress Series 307:199-208 
Loughran PA, Roman LJ, Aitken AE, Miller T, Masters BSS (2000) Identification of unique amino acids that modulate CYP4A7 activity. Biochemistry 39:1511015120

Lu K-H, Bradfield JY, Keeley LL (1996) Age and starvation effects on hypertrehalosemic hormone-dependent gene expression of cytochrome P4504C1 in cockroach, Blaberus discoidalis. Journal of Insect Physiology 42:925-930

Lu K-H, Bradfield JY, Keeley LL (1999) Juvenile hormone inhibition of gene expression for cytochrome P4504C1 in adult females of the cockroach, Blaberus discoidalis. Insect Biochemistry and Molecular Biology 29:667-673

Mao W, Schuler MA, Berenbaum MR (2007) Cytochrome P450s in Papilio multicaudatus and the transition from oligophagy to polyphagy in the Papilionidae. Insect Molecular Biology 16:481-490

Marin A, Di Marzo V, Cimino G (1991) A histological and chemical study of the cerata of the opisthobranch mollusc Tethys fimbria. Marine Biology 111:353-358

Nebert DW, Nelson DR, Adesnik M, Coon MJ, Estabrook RW, Gonzalez FJ, Guengerich FP, Gunsalus IC, Johnson EF, Kemper B, Levin W, Phillips IR, Sato R, Waterman MR (1989) The P450 Superfamily: updated listing of all genes and recommended nomenclature for chrosomal loci. DNA 8:1-13

Nelson DR (2006) Cytochrome P450 nomenclature, 2004. Methods Mol Biol 320:1-10

Nelson DR, Zeldin DC, Hoffman SMG, Maltais LJ, Wain HM, Nebert DW (2004) Comparison of cytochrome P450 (CYP) genes from the mouse and human genomes, including nomenclature recommendations for genes, pseudogenes and alternative-splice variants. Pharmacogenetics 14

O'Neal W, Pawlik JR (2002) A reappraisal of the chemical and physical defenses of Caribbean gorgonian corals against predatory fishes. Marine Ecology Progress Series 240:117-126

Okita RT, Okita JR (2001 ) Cytochrome P450 4A fatty acid omega hydroxylases. Current Drug Metabolism 2:265-281

Omura T, Sato R (1964) The carbon monoxide-binding pigment of liver microsomes. Journal of Biological Chemistry 239:2370

Ott M, Zola J, Aluru S, Stamatakis A (2007) Large-scale maximum likelihood-based phyloenetic analysis on the IBM BlueGene/L ACM/IEEE Supercomputing conference 2007

Pan L, Wen Z, Baudry J, Berenbaum M, Schuler MA (2004) Identification of variable amino acids in the SRS1 region of CYP6B1 modulating furanocoumarin metabolism. Archives of Biochemistry and Biophysics 422:31-41 
Paul VJ, Puglisi MP (2004) Chemical mediation of interactions among marine organisms. Natural Product Reports 21:189-209

Pawlik JR, Burch MT, Fenical W (1987) Patterns of chemical defense among Caribbean gorgonian corals: a preliminary survey. Journal of Experimental Marine Biology and Ecology 108:55-66

Pawlik JR, Fenical W (1989) A re-evaluation of the ichthyodeterrent role of prostaglandins in the Caribbean gorgonian coral Plexaura homomalla. Marine Ecology Progress Series 52:95-98

Pawlik JR, Fenical W (1992) Chemical defense of Pterogorgia anceps, a Caribbean gorgonian coral. Marine Ecology Progress Series 87:183-188

Peterson JA, Graham-Lorence SE (1995) Cytochrome P450: structure, mechanism, and biochemistry, Vol. Plenum, New York

Pompon D, Louerat B, Bronine A, Urban P (1996) Yeast expression of animal and plant P450s in optimized redox environments. Methods Enzymol 272:51-64

Prince A, Alvarez FS, Young J (1973) Preparation of prostaglandins A2, E2, and 11-epiE2 from their acetate methyl esters using an endogenous enzyme system present in Plexaura homomalla. Prostaglandins 3:531-535

Proksch P (1994) Defensive roles for secondary metabolites from marine sponges and sponge feeding nudibranchs. Toxicon 32:639-655

Rambaut A (2007) Fig Tree

Ravichandran KG, Boddupalli SS, Hasemann CA, Peterson JA, Deisenhofer J (1993) Crystal structure of hemoprotein domain of P450BM-3, a prototype for microsomal P450's. Science 261:731-736

Rewitz KF, Kjellerup C, Jorgensen A, Petersen C, Andersen O (2004) Identification of two Nereis virens (Annelida: Polychaeta) cytochromes P450 and induction by xenobiotics. Comparative Biochemistry and Physiology 138C:89-96

Rewitz KF, Styrishae B, Lobner-Olesen A, Andersen O (2006) Marine invertebrate cytochrome P450: emerging insights from vertebrate and insect analogies. Comp Biochem Physiol C Toxicol Pharmacol 143:363-381

Roberts SM, Santoro MG, Sickle ES (2003) The emergence of cyclopentenone prostaglandins as important biologically active compounds. ChemInform 34

Rodriguez AD (1995) The natural products chemistry of west indian gorgonian octocorals. Tetrahedron 51:4571-4618 
Ronquist F, Huelsenbeck JP (2003) MrBayes 3: Bayesian phylogenetic inference under mixed models. Bioinformatics 19:1572-1574

Rowley AF, Vogan CL, Taylor GW, Clare AS (2005) Prostaglandins in non-insectan invertebrates: recent insights and unsolved problems. The Journal of Experimental Biology 208:3-14

Sankoh AJ, Huque MF, Dubey SD (1997) Some comments on frequently used multiple endpoint adjustments methods in clinical trials. Statistics in Medicine 16:25292542

Sawamura A, Kusunose E, Satouchi K, Kusunose M (1993) Catalytic properties of rabbit kidney fatty acid omega-hydroxylase cytochrome P450ka2 (CYP4A7). Biochem Biophys Acta 1168:30-36

Schneider C, Manier L, Hachey D, Brash AR (2002) Detection of the 15-acetate of prostaglandin E2 methyl ester as a prominent component of the prostaglandins in the gorgonian coral Plexaura homomalla. Lipids 37:217-221

Schneider WP, Bundy GL, Lincoln FH, Daniels EG, Pike JE (1977a) Isolation and chemical conversions of prostaglandins from Plexaura homomalla: preparation of prostaglandin E2, prostaglandin F2, and their 5,6-trans isomers. Journal of the American Chemical Society 99:1222-1232

Schneider WP, Hamilton RD, Rhuland LE (1972) Occurrence of esters of (15S)prostaglandin A2 and E2 in coral. Journal of the American Chemical Society 94:2122-2123

Schneider WP, Morge RA (1971) Search for prostaglandins in marine specimens from American and African waters, Upjohn Technical Report, Upjohn Co., Kalamazoo, Michigan

Schneider WP, Morge RA, Henson BE (1977b) The occurrence of 13, 14-dihydro and 13, 14-cis-unsaturated prostaglandins in the coral, Plexaura homomalla. Synthesis of 13, 14-cis-prostaglandin E2, 15-acetate methyl ester, and the 13, 14-cis analogues of prostaglandin F2alpha and prostaglandin F2beta. Journal of the American Chemical Society 99:6062-6066

Schuler MA (1996) The role of cytochrome P450 monooxygenases in plant-insect interactions. Plant Physiol 112:1411-1419

Simpson A (1997) The cytochrome P450 4 (CYP4) Family. Gen Pharmac 28:351-359

Snyder MJ (1998) CYP4 cytochrome P450 enzymes belonging to the CYP4 family from marine invertebrates. Biochem Biophys Res Commun 249:187-190

Spraggins RL (1972) $\mathrm{PGA}_{2}$ and isomers from coral prostaglandins. Tetrahedron Letters 42:4343-4346 
Stamatakis A (2006) Maximum likelihood-based phylogenetic analyses with thousands of taxa and mixed models. Bioinformatics 22:2688-2690

Stanley DW (2000) Eicosanoids in invertebrate signal transduction systems, Vol. Princeton University Press, Princeton, NJ

Stanley DW (2006) Prostaglandins and other eicosanodis in insects: Biological significance. Annu Rev Entomol 51:25-44

Stark K, Wongsud B, Burman R, Oliw EH (2005) Oxygenation of polyunsaturated long chain fatty acids by recombinant CYP4F8 and CYP4F12 and catalytic importance of Tyr-125 and Gly-328 of CYP4F8. Archives of Biochemistry and Biophysics 441:174-181

Stegeman JJ, Hahn ME (1994) Biochemistry and molecular biology of monooxygenases: current perspectives on forms, functions, and regulation of cytochrome P450 in aquatic species. In: Malins DC, Ostrander GK (eds) Aquatic Toxicology: Molecular, Biochemical and Cellular Perspectives. CRC Press, Boca Raton, FL, p $87-206$

Sutherland TD, G.C. U, Feyereisen R (2000) Terpenoid hydroxylase (CYP4C7) messenger RNA levels in the corpora allata: a marker for ovarian control of juvenile hormone synthesis in Diploptera punctata. Journal of Insect Physiology 46:1219-1227

Sutherland TD, Unnithan GC, Andersen JF, Evans PH, Murataliev MB, Szabo LZ, Mash EA, Bowers WS, Feyereisen R (1998) A cytochrome P450 terpenoid hydroxylase linked to the suppression of insect juvenile hormone synthesis. Proceedings of the National Academy of Sciences of the USA 95:12884-12889

Swofford DL (1998) PAUP*, Phylogenetic Analysis Using Parsimony (*and Other Methods). Sinauer Associates, Sunderland, MA

Thompson JD, Higgins DG, Gibson TJ (1994) CLUSTAL W: improving the sensitivity of progressive multiple sequence alignment through sequence weighting, position-specific gap penalties and weight matrix choice. Nucleic Acids Res $22: 4673-4680$

Thornton RS, Kerr RG (2002) Induction of pseudopterosin biosynthesis in the gorgonian Pseudopterogorgia elisabethae. Journal of Chemical Ecology 28:2083-2090

Valmsen K, Boeglin WE, Jarving I, Schneider C, Varvas K, Brash AR, Samel N (2004) Structural and functional comparison of 15S- and 15R-specific cyclooxygenases from the coral Plexaura homomalla. Eur J Biochem 271:3533-3538

Valmsen K, Jarving I, Boeglin WE, Varvas K, Koljak R, Pehk T, Brash A, Samel N (2001) The origin of 15R-prostaglandins in the Caribbean coral Plexaura 
homomalla: Molecular cloning and expression of a novel cyclooxygenase. PNAS 98:770-7705

Vrolijk NH, Targett NM (1992) Biotransformation enzymes in Cyphoma gibbosum: implications for detoxification of gorgonian allelochemicals. Marine Ecology Progress Series 88:237-246

Weinheimer AJ, Spraggins RL (1969) The occurrence of two new prostaglandin derivatives (15-epi-PGA 2 and its acetate methyl ester) in the gorgonian Plexaura homomalla. Tetrahedron Lett 59:5185-5189

Wen Z, Rupasinghe S, Niu G, Berenbaum M, Schuler MA (2006) CYP6B1 and CYP6B3 of the Black Swallowtail (Papilio polyxenes): Adaptive evolution through Subfunctionalization. Mol Biol Evol 23:2434-2443

Werck-Reichhart D, Feyereisen R (2000) Cytochromes P450: a success story. Genome Biology 1:1-9

Whelan S, Goldman N (2001) A general empirical model of protein evolution derived from multiple protein families using a maximum-likelihood approach. Mol Biol Evol 18:691-699

Whitlock JP (1986) The regulation of cytochrome P450 gene expression. Annu Rev Pharmacol Toxicol 26:333-369

Williams PA, Cosme J, Sridhar V, Johnson EF, McRee DE (2000a) Mammalian microsomal cytochrome P450 monooxygenase: structural adaptations for membrane binding and functional diversity. Molecular Cell 5:121-131

Williams PA, Cosme J, Sridhar V, Johnson EF, McRee DE (2000b) Microsomal cytochrome P450 2C5: comparison to microbial P450s and unique features. Journal of Inorganic Biochemistry 81:183-190

Zheng Y-M, Baer BR, Kneller B, Henne KR, Kunze KL, Rettie AE (2003) Covalent heme binding to CYP4B1 via Glu310 and a carbocation porphyrin intermediate. Biochemistry 42:4601-4606 


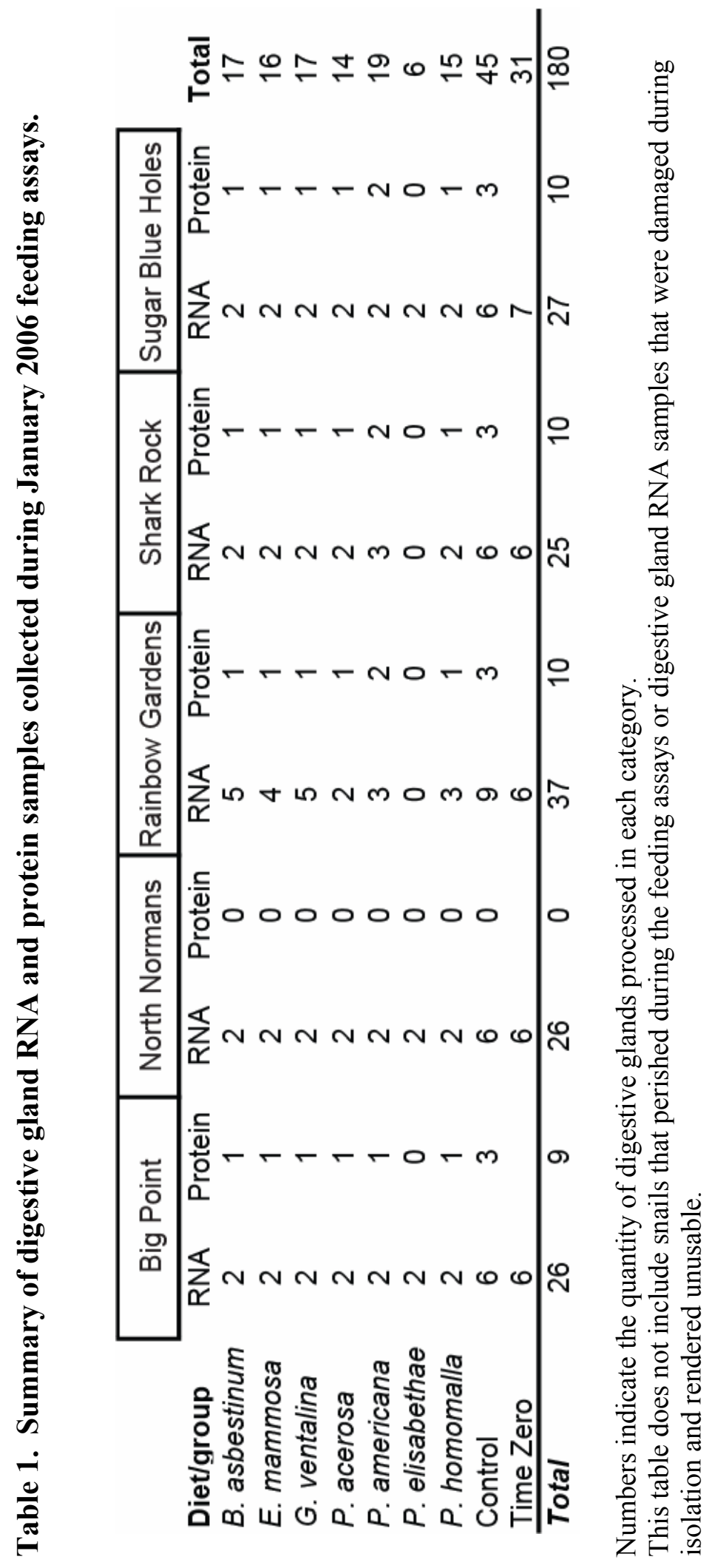




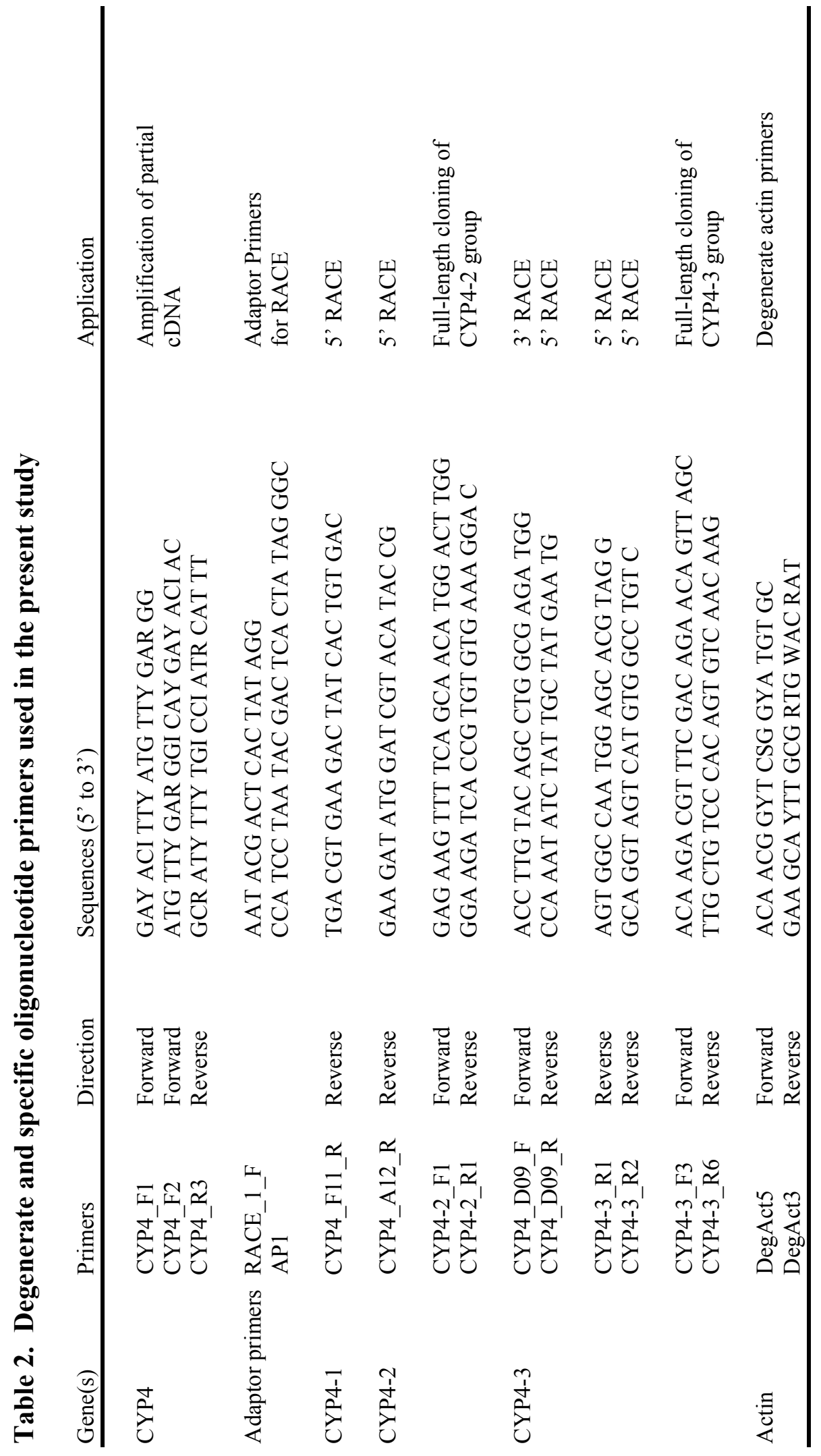




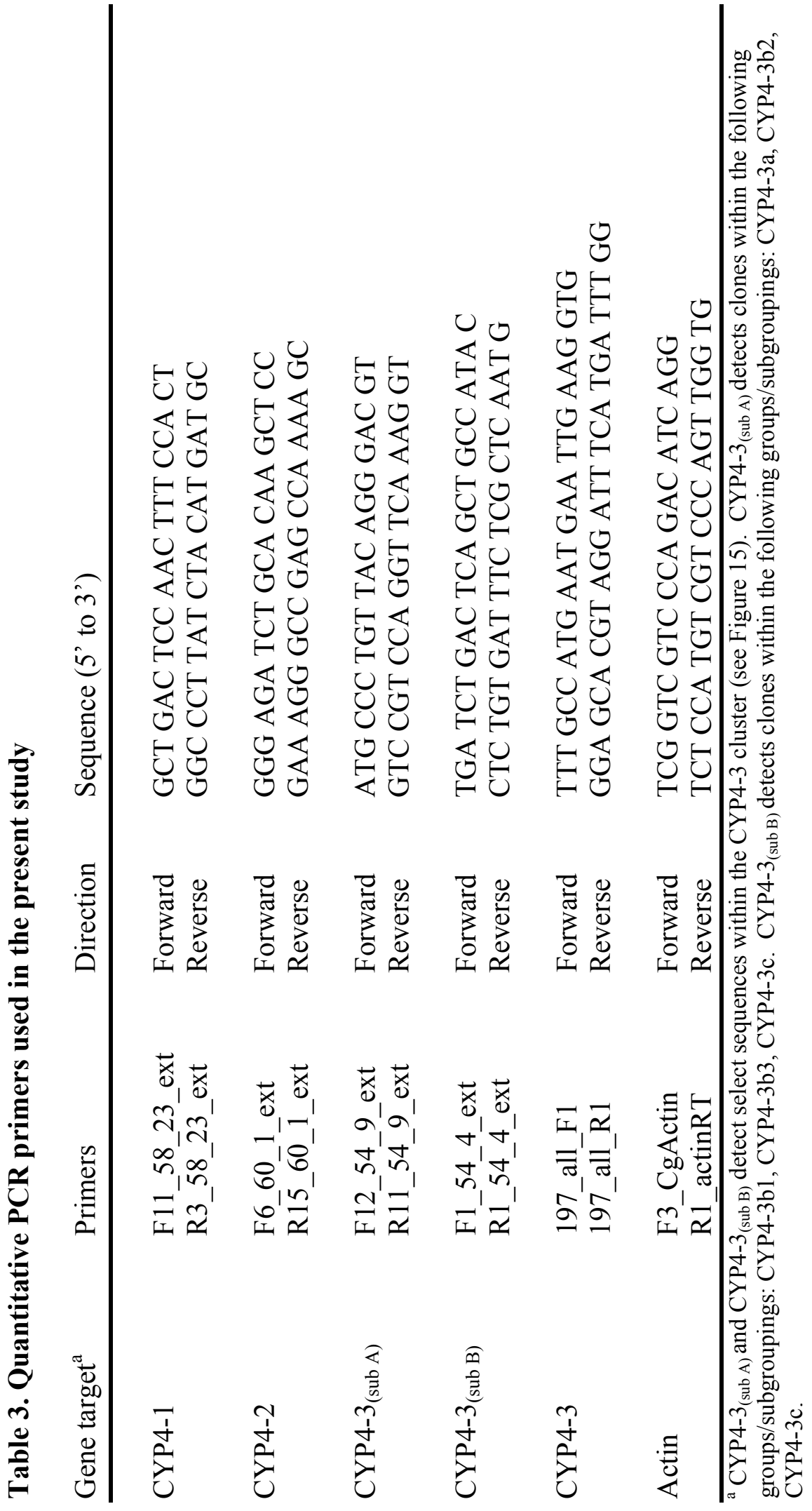




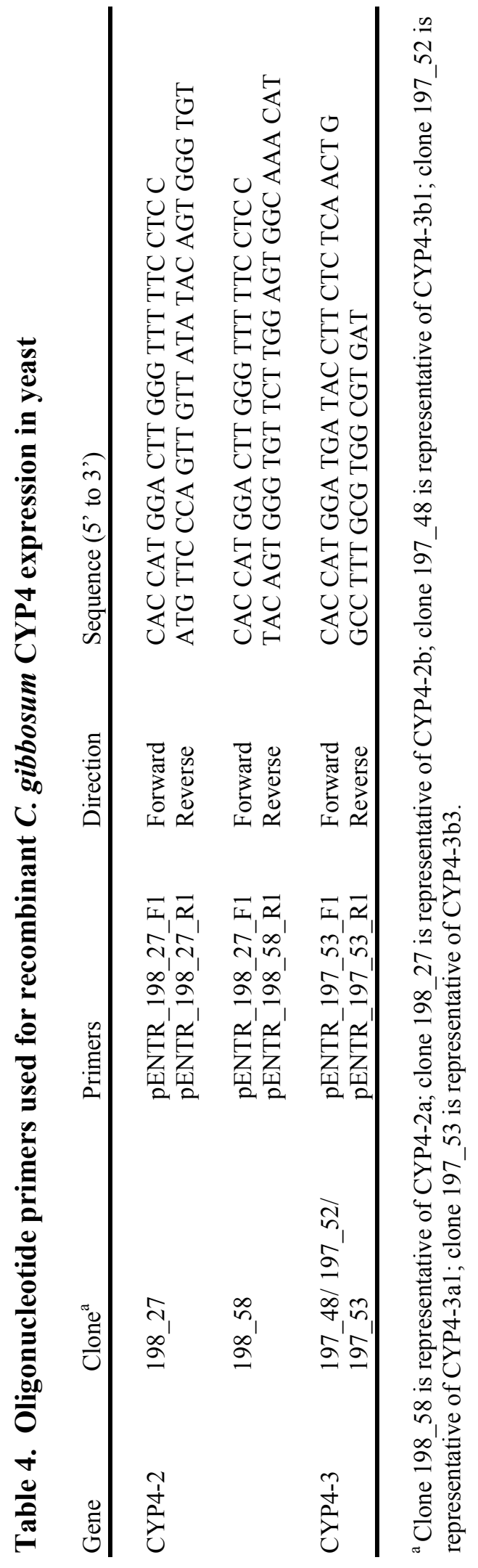




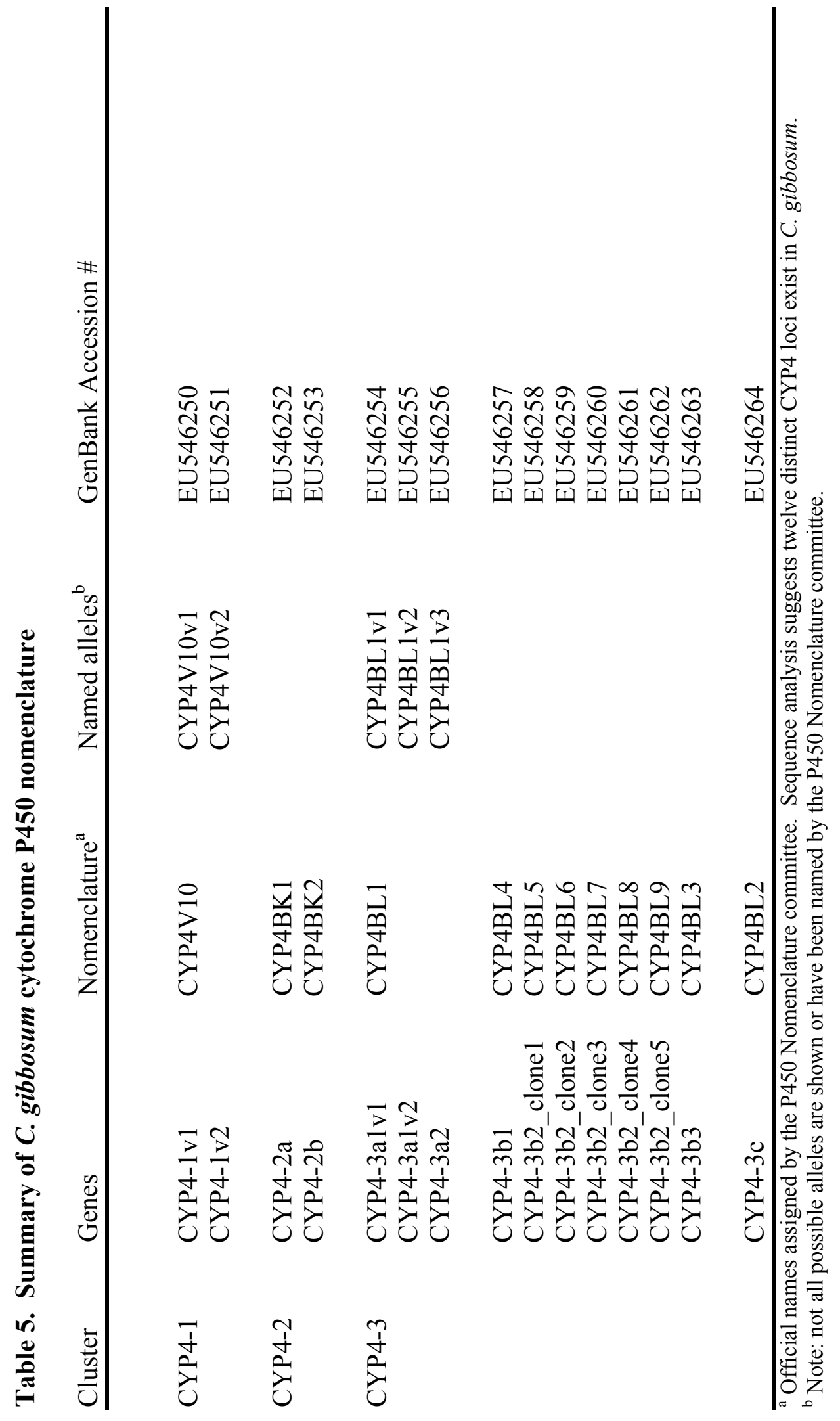


Table 6. Results of a two-way MANOVA investigating differences in digestive gland CYP4 gene expression in $C$. gibbosum feeding on control versus gorgonian diets.

\begin{tabular}{lrrrl} 
Factors & df & Wilks' $\Lambda$ & $F$ & $\mathrm{p}$ \\
\hline Control vs. B. asbestinum & & & & \\
Diet & 4,33 & 0.933 & 0.590 & 0.672 \\
Reef & 16,101 & 0.536 & 1.435 & 0.140 \\
Diet x Reef & 16,101 & 0.744 & 0.644 & 0.840
\end{tabular}

Control vs. E. mammosa

$\begin{array}{lrrrr}\text { Diet } & 4,33 & 0.887 & 1.015 & 0.414 \\ \text { Reef } & 16,98 & 0.598 & 1.127 & 0.341 \\ \text { Diet } x \text { Reef } & 16,98 & 0.594 & 1.142 & 0.329\end{array}$

Control vs. G. ventalina

Diet

$\begin{array}{cccc}4,33 & 0.303 & 18.99 & <\mathbf{0 . 0 0 1} \\ 16,101 & 0.116 & 6.476 & <\mathbf{0 . 0 0 1} \\ 16,101 & 0.118 & 6.392 & <\mathbf{0 . 0 0 1}\end{array}$

Control vs. P. acerosa

$\begin{array}{lrrrr}\text { Diet } & 4,30 & 0.816 & 1.682 & 0.180 \\ \text { Reef } & 16,92 & 0.470 & 1.615 & 0.080 \\ \text { Diet } x \text { Reef } & 16,92 & 0.580 & 1.126 & 0.344\end{array}$

Control vs. P. americana

$\begin{array}{lrrrr}\text { Diet } & 4,32 & 0.546 & 6.653 & <\mathbf{0 . 0 0 1} \\ \text { Reef } & 16,98 & 0.574 & 1.227 & 0.261 \\ \text { Diet x Reef } & 16,98 & 0.586 & 1.175 & 0.301\end{array}$

Control vs. P. elisabethae

$\begin{array}{lllll}\text { Diet } & 4,15 & 0.480 & 4.067 & 0.019 \\ \text { Reef } & 8,30 & 0.381 & 2.328 & 0.045 \\ \text { Diet } x \text { Reef } & 8,30 & 0.619 & 1.017 & 0.444\end{array}$

Control vs. $P$. homomalla (All reefs included)

$\begin{array}{lcccc}\text { Diet } & 5,30 & 0.445 & 7.479 & <\mathbf{0 . 0 0 1} \\ \text { Reef } & 20,100 & 0.279 & 2.355 & <\mathbf{0 . 0 0 1} \\ \text { Diet x Reef } & 20,100 & 0.270 & 2.429 & <\mathbf{0 . 0 0 1}\end{array}$

Control vs. $P$. homomalla (deletion of Shark Rock individuals)

$\begin{array}{lrrrr}\text { Diet } & 5,24 & 0.387 & 7.606 & <\mathbf{0 . 0 0 1} \\ \text { Reef } & 15,66 & 0.439 & 1.542 & 0.115 \\ \text { Diet } x \text { Reef } & 15,66 & 0.421 & 1.632 & 0.089\end{array}$

A $p \leq 0.002$ should be accepted as significant (Bonferroni adjusted). Significant values in bold. 
Table 7. Results of ANOVA comparisons (Univariate F-tests) of diet- and reef-specific mean CYP4 gene expression in $C$. gibbosum feeding on control vs. gorgonian diets.

\begin{tabular}{|c|c|c|c|c|c|}
\hline Diet comparisons & & df & MS & $\mathrm{F}$ & $\mathrm{p}$ \\
\hline Control vs. G. ventali & & & & & \\
\hline Diet & CYP4-1 & 1,36 & 0.016 & 0.050 & 0.825 \\
\hline & CYP4-2 & 1,36 & 0.030 & 0.550 & 0.464 \\
\hline & CYP4-3 (subA) & 1,36 & 6.070 & 46.339 & $<0.001$ \\
\hline & CYP4-3 (subB) & 1,36 & 0.010 & 1.368 & 0.250 \\
\hline Reef & CYP4-1 & 4,36 & 0.069 & 0.211 & 0.931 \\
\hline & CYP4-2 & 4,36 & 0.054 & 0.989 & 0.426 \\
\hline & CYP4-3 (subA) & 4,36 & 3.127 & 23.869 & $<\mathbf{0 . 0 0 1}$ \\
\hline & CYP4-3 (subB) & 4,36 & 0.124 & 1.710 & 0.169 \\
\hline Diet x Reef & CYP4-1 & 4,36 & 0.280 & 0.850 & 0.503 \\
\hline & CYP4-2 & 4,36 & 0.034 & 0.629 & 0.645 \\
\hline & CYP4-3 (subA) & 4,36 & 3.555 & 27.137 & $<\mathbf{0 . 0 0 1}$ \\
\hline & CYP4-3 (subB) & 4,36 & 0.032 & 0.447 & 0.774 \\
\hline Control vs. $P$. americe & & & & & \\
\hline Diet & CYP4-1 & 1,35 & 0.037 & 0.114 & 0.738 \\
\hline & CYP4-2 & 1,35 & 0.035 & 0.871 & 0.357 \\
\hline & CYP4-3 (subA) & 1,35 & 0.948 & 6.681 & 0.014 \\
\hline & CYP4-3 (subB) & 1,35 & 0.354 & 5.667 & 0.023 \\
\hline Control vs. $P$. homom & (All reefs inclu & & & & \\
\hline Diet & CYP4-1 & 1,34 & 0.162 & 0.442 & 0.511 \\
\hline & CYP4-2 & 1,34 & 1.557 & 36.592 & $<0.001$ \\
\hline & CYP4-3 (subA) & 1,34 & 0.394 & 1.316 & 0.259 \\
\hline & CYP4-3 (subB) & 1,34 & 0.494 & 8.210 & 0.007 \\
\hline & CYP4-3 & 1,34 & 1.678 & 19.924 & $<\mathbf{0 . 0 0 1}$ \\
\hline Reef & CYP4-1 & 4,34 & 0.643 & 1.756 & 0.161 \\
\hline & CYP4-2 & 4,34 & 0.043 & 1.017 & 0.412 \\
\hline & CYP4-3 (subA) & 4,34 & 3.200 & 10.698 & $<\mathbf{0 . 0 0 1}$ \\
\hline & CYP4-3 (subB) & 4,34 & 0.041 & 0.688 & 0.605 \\
\hline & CYP4-3 & 4,34 & 0.078 & 0.925 & 0.461 \\
\hline Diet x Reef & CYP4-1 & 4,34 & 0.053 & 0.144 & 0.965 \\
\hline & CYP4-2 & 4,34 & 0.090 & 2.113 & 0.101 \\
\hline & CYP4-3 (subA) & 4,34 & 2.354 & 7.870 & $<\mathbf{0 . 0 0 1}$ \\
\hline & CYP4-3 (subB) & 4,34 & 0.036 & 0.592 & 0.670 \\
\hline & CYP4-3 & 4,34 & 0.144 & 1.713 & 0.170 \\
\hline Control vs. $P$. homom & (deletion of $\mathrm{Sh}$ & Rock & & & \\
\hline Diet & CYP4-1 & 1,28 & 0.097 & 0.488 & 0.490 \\
\hline & CYP4-2 & 1,28 & 1.530 & 32.658 & $<\mathbf{0 . 0 0 1}$ \\
\hline & CYP4-3 (subA) & 1,28 & 3.877 & 27.577 & $<\mathbf{0 . 0 0 1}$ \\
\hline & CYP4-3 (subB) & 1,28 & 0.509 & 7.610 & 0.010 \\
\hline & CYP4-3 & 1,28 & 1.765 & 18.754 & $<\mathbf{0 . 0 0 1}$ \\
\hline
\end{tabular}

A $p \leq 0.007$ should be accepted as significant (Bonferroni adjusted). Significant values in bold. 
Table 8. Results of a one-way MANOVA investigating CYP4 gene expression variability among reefs for time-zero and control-fed $\boldsymbol{C}$. gibbosum. Reefs were considered random factors.

\begin{tabular}{lllll} 
Factors & df & Wilks' $\Lambda$ & $F$ & $\mathrm{p}$ \\
\hline $\begin{array}{c}\text { Reef (Experiment 1) } \\
\text { Control diet }\end{array}$ & 20,80 & 0.163 & 1.367 & 0.164 \\
$\begin{array}{c}\text { Reef (Experiment 2) } \\
\text { Time-zero group }\end{array}$ & 20,70 & 0.265 & 1.739 & $\mathbf{0 . 0 4 7}$
\end{tabular}




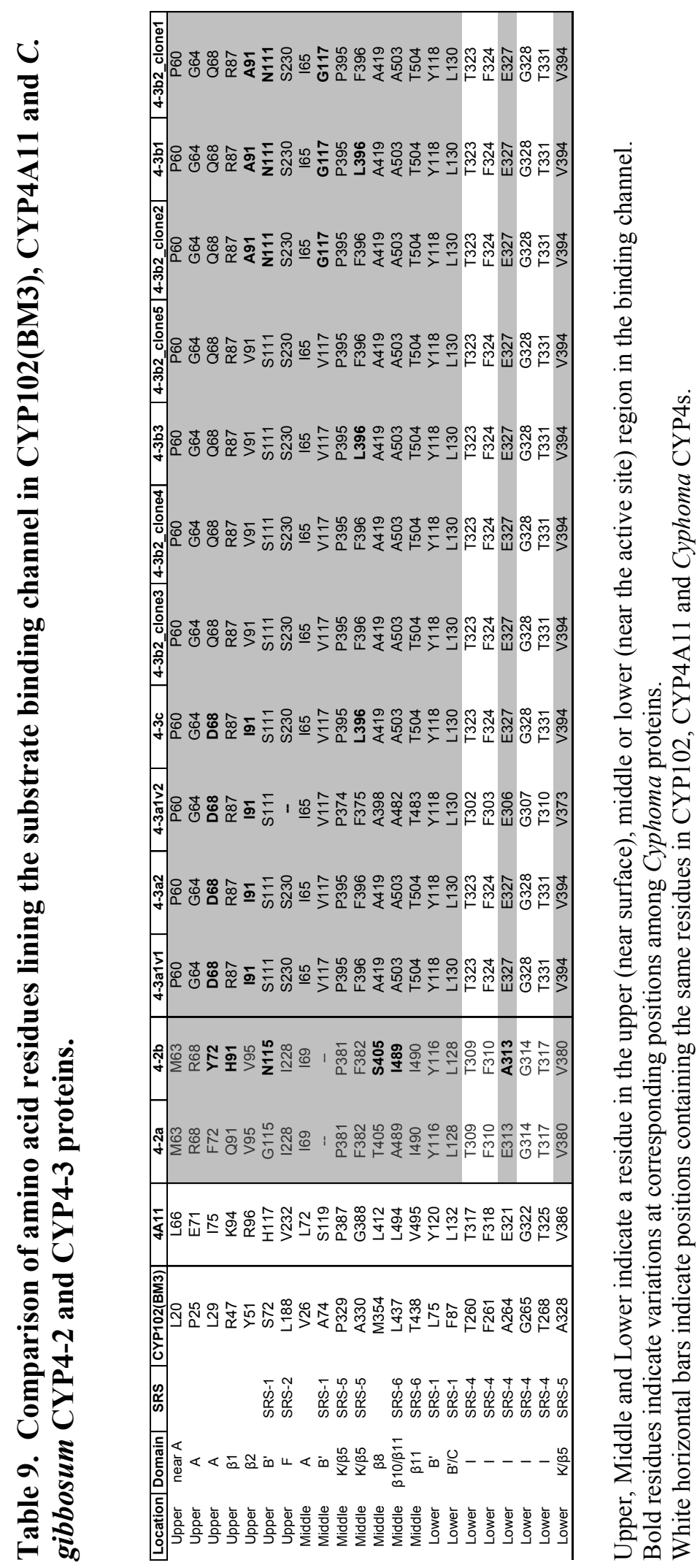




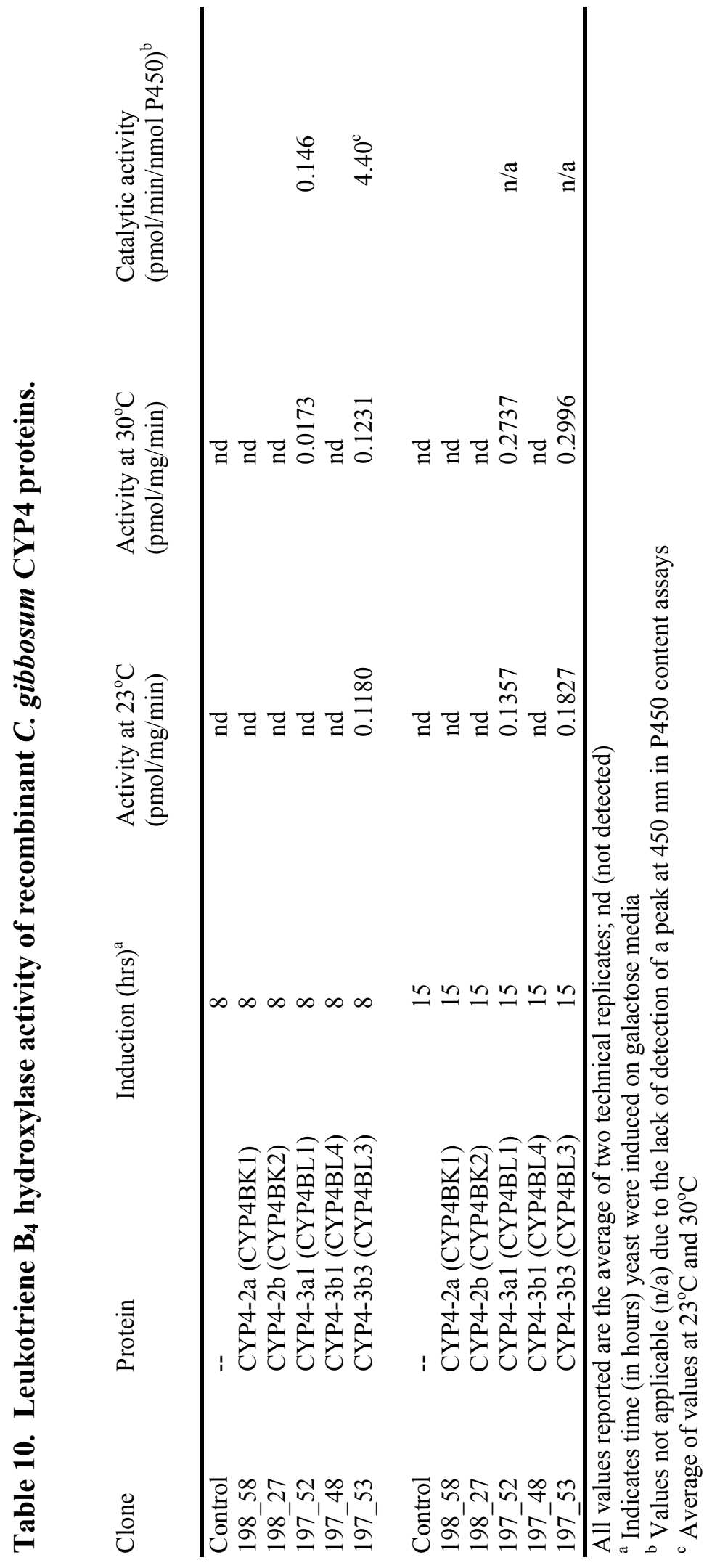




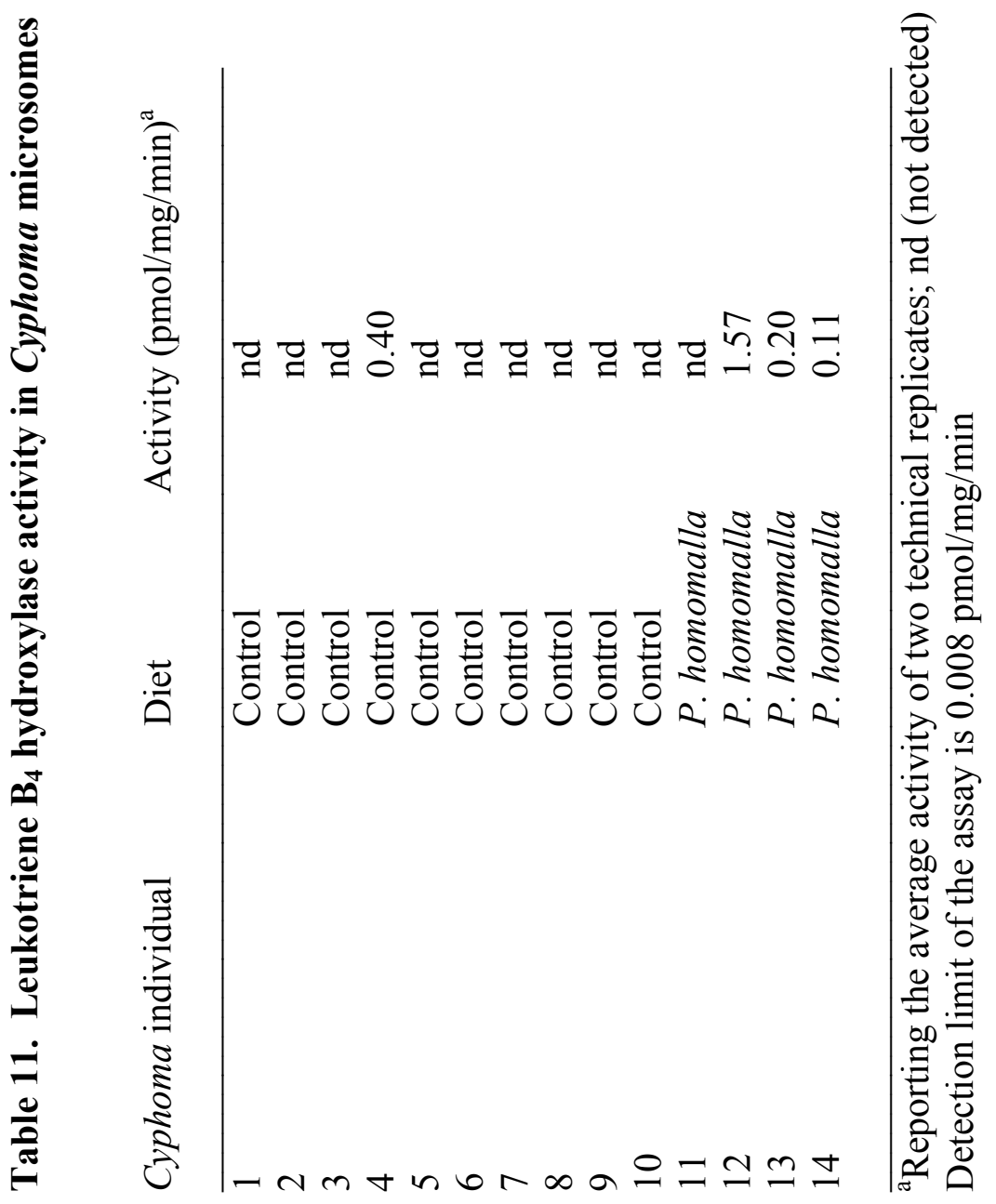




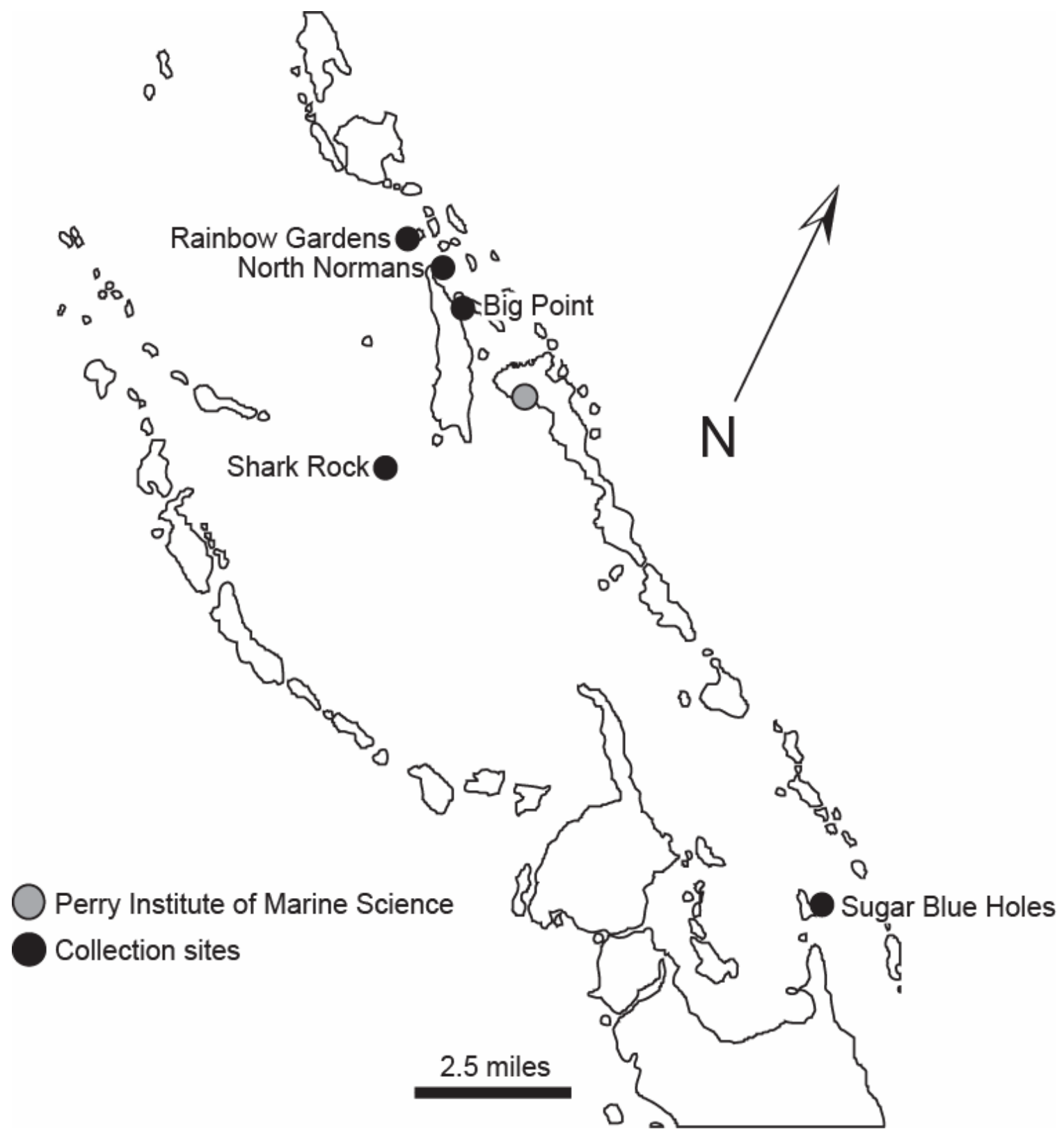

Figure 1. Cyphoma gibbosum and gorgonian sampling location in the Exuma Keys, Bahamas. Black circles indicate the locations of reefs where $C$. gibbosum and gorgonian colonies were collected for feeding assays in January of 2004 and 2006. 

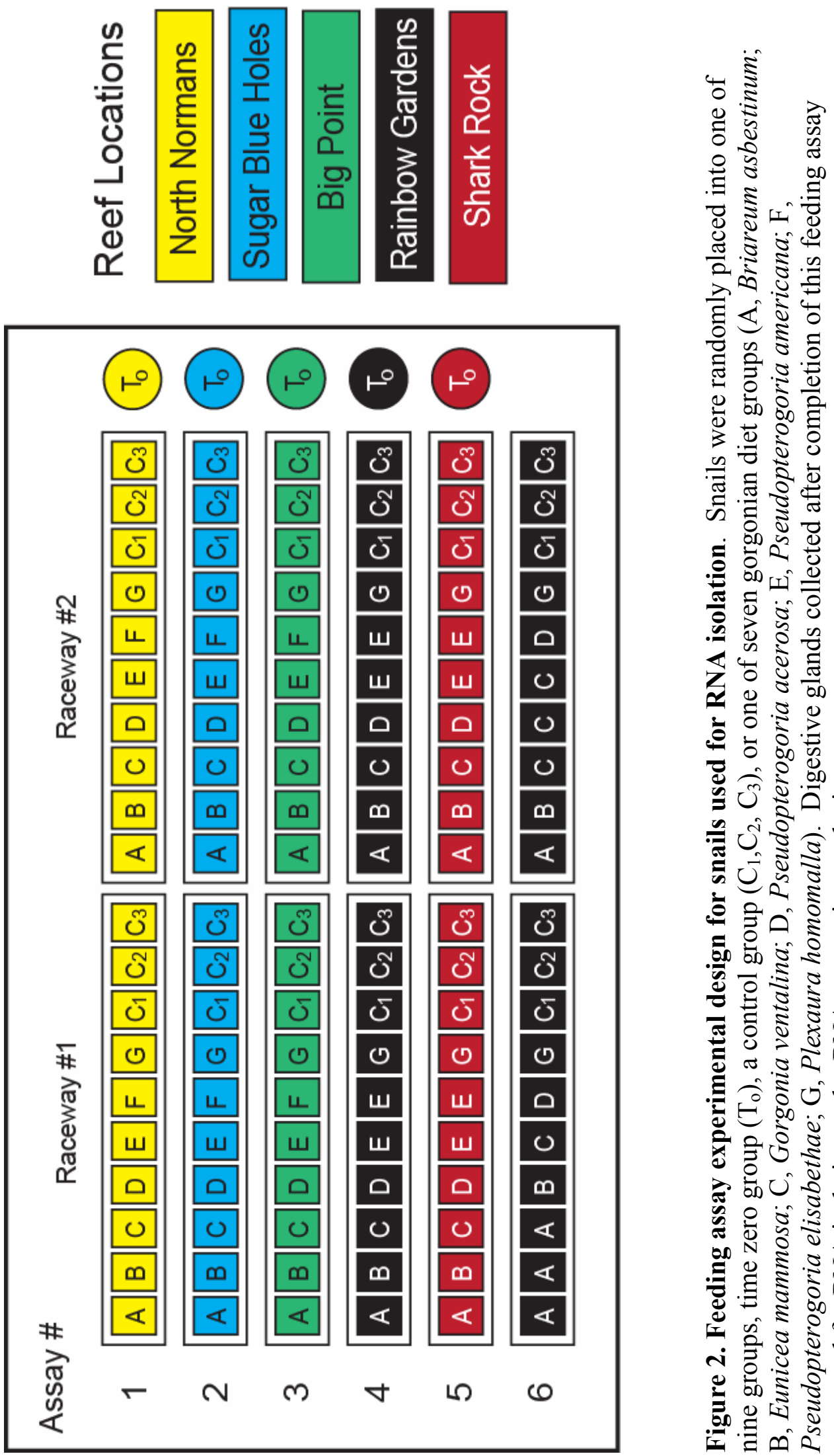

द्वे

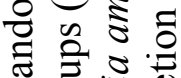

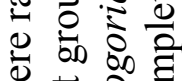

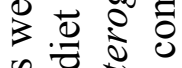

寻 売

की

อี

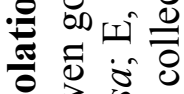

文 0

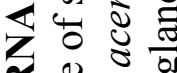

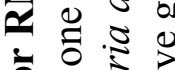

อี

उ. 0

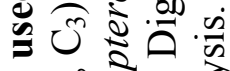

๘லি

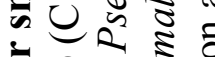

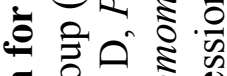

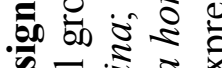

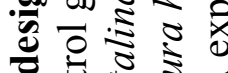

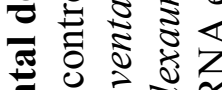

ฮี ๘

กิ

능

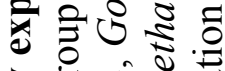

त की

幺ิ

का

.

ఫू छ

की है

ن

० कू इ ?

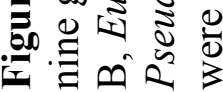



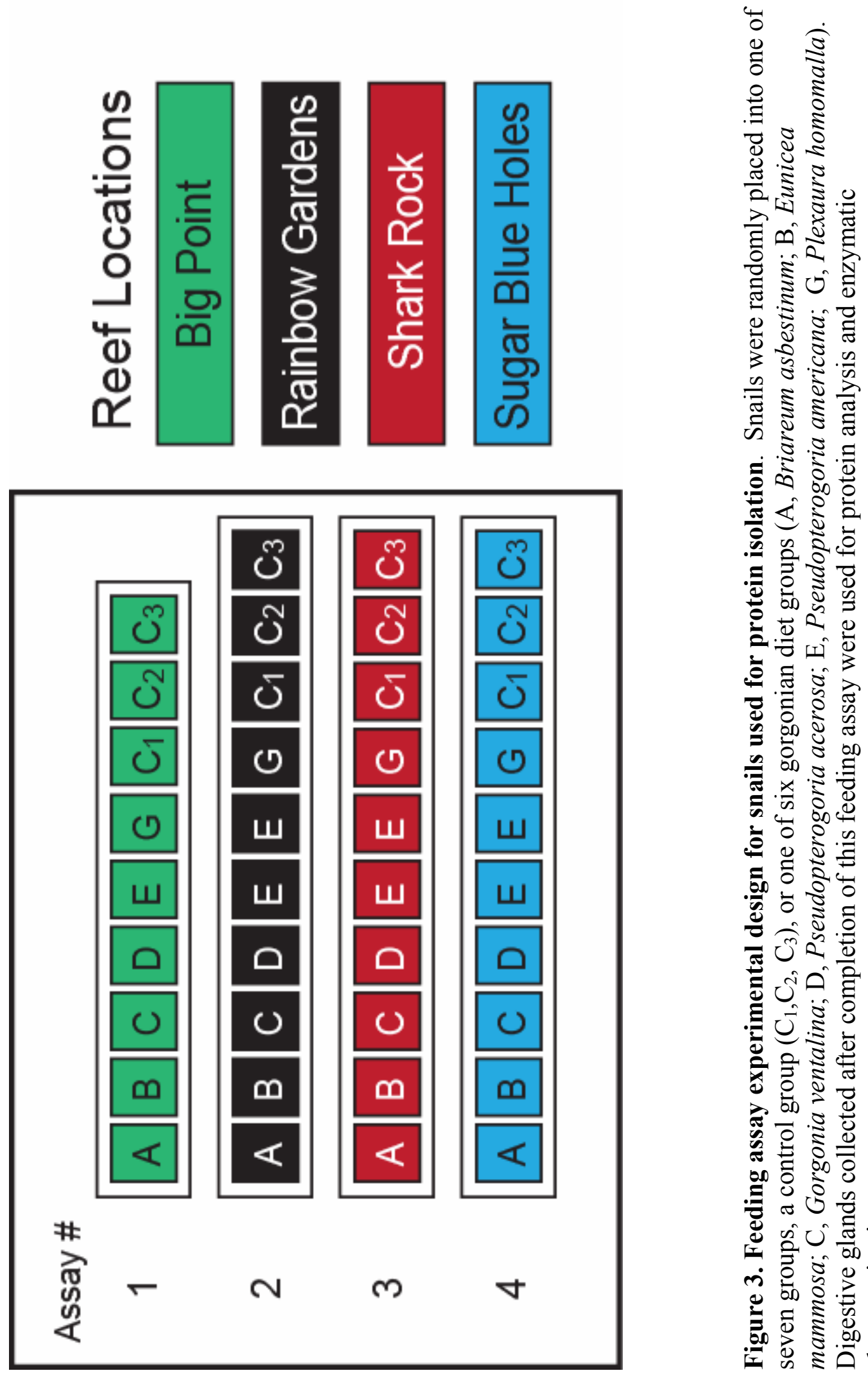

范范

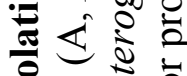

\& 0

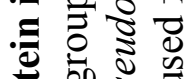

के को

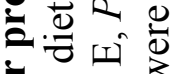

迄

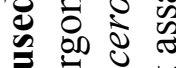

品

जี

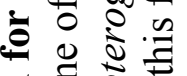

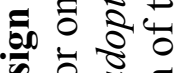

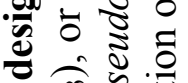

สิि

ฮै ชิ ڤิ

जि ठ0

过

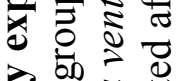

에

至

on 00

.

ฮิ่

地

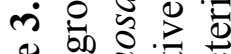

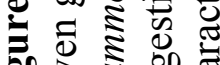

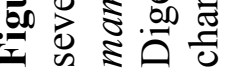




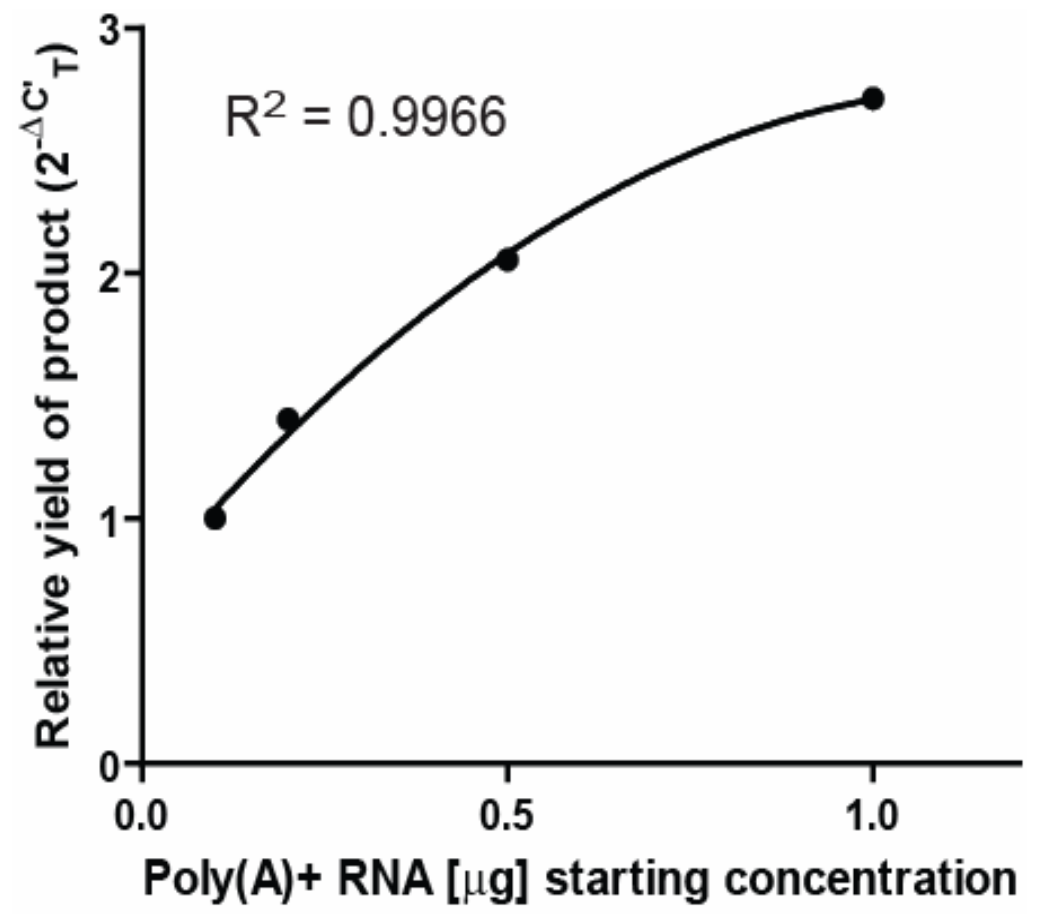

Figure 4. Quantifying relative yield of a target gene by real-time quantitative PCR (qPCR) versus input poly(A)+ RNA concentration. Four concentrations of poly(A)+RNA isolated from a single individual were reverse transcribed to cDNA as described in the methods. Quantitative PCR was performed with CYP4-3 (subB) primers as described in the methods. The average $\Delta \mathrm{C}_{\mathrm{T}}$ was calculated from duplicate qPCR wells for each poly(A)+ RNA concentration and subtracted from the $\Delta \mathrm{C}_{\mathrm{T}}$ obtained with $1.0 \mu \mathrm{g}$ poly(A)+RNA yielding $\Delta \Delta \mathrm{C}_{\mathrm{T}}$. The $\Delta \Delta \mathrm{C}_{\mathrm{T}}$ were then backtransformed $\left(2^{-\Delta \Delta \mathrm{CT}}\right)$ to calculate relative abundance of each sample. A five-fold increase in poly(A)+RNA $(0.2$ $\mu \mathrm{g} \rightarrow 1.0 \mu \mathrm{g}$ ) quantity affords less than a $1.25 \mathrm{x}$ increase in product yield. It was decided to use $0.2 \mu \mathrm{g}$ of poly (A)+RNA in subsequent qPCR experiments to maximize the yield of cDNA using the least amount of starting poly(A)+RNA. 


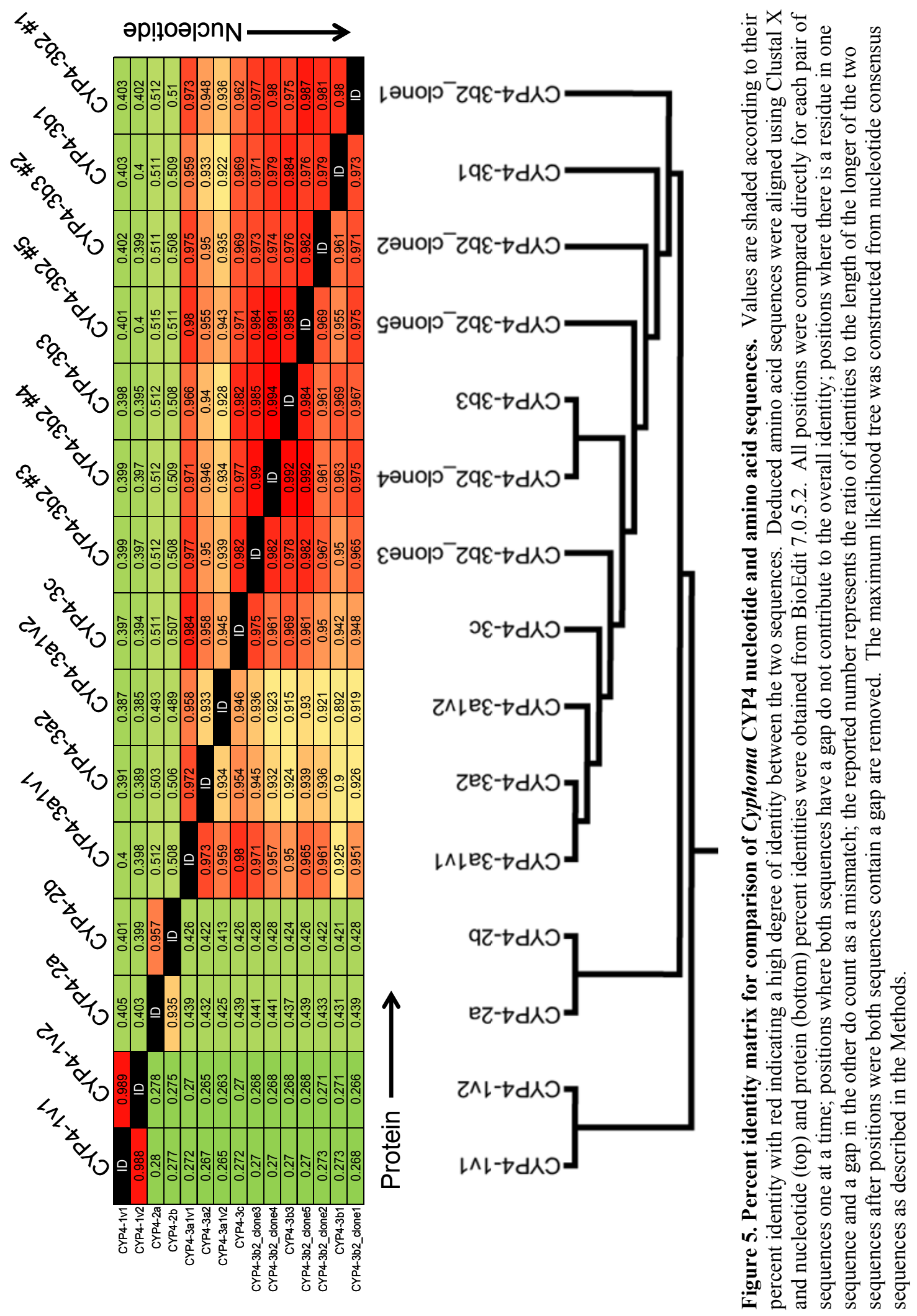




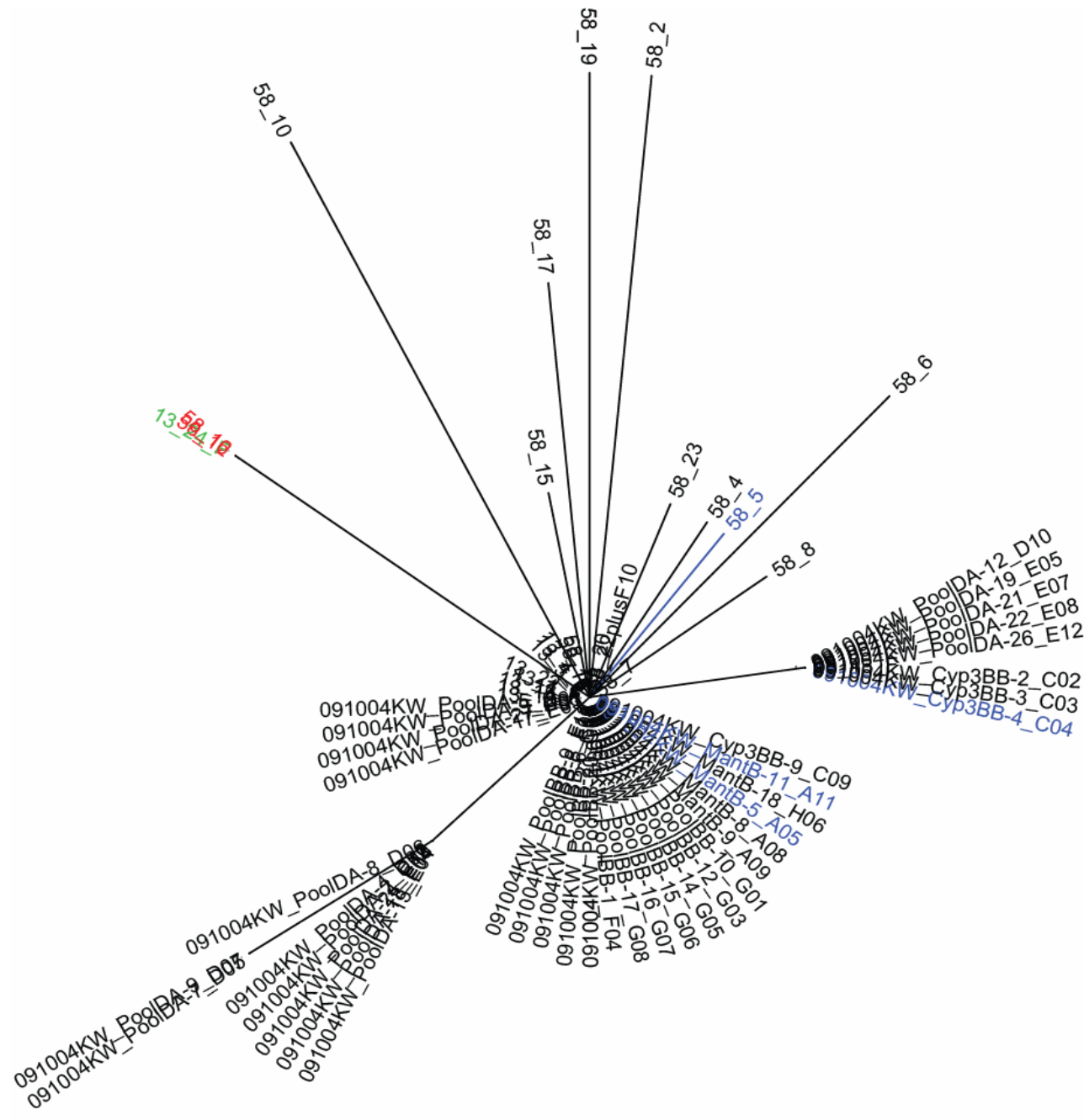

0.5

Figure 6. Cluster analysis of CYP4-1 clones visualized by an unrooted maximum parsimony tree. Nucleotide sequences were aligned using ClustalX (Thompson et al., 1997) and the alignment was used to construct a maximum parsimony tree using PAUP*4.0b10 (Swofford 1998). Trees were visualized and manipulated using FigTree v1.1 (Rambaut 2008). Each operational taxonomic unit (OTU) represents the consensus sequence of an individual clone sequenced in both directions. Black OTUs correspond to CYP41v1. Red OTUs correspond to CYP4-1v2 and indicate clones with an insertion of 15bp at nucleotide position 1201. Blue OTUs indicate clones with a $68 \mathrm{bp}$ deletion at nucleotide position 1066 causing a frame shift resulting in a premature stop codon likely resulting in a non-functional protein; no designation was given. The green OTU denotes a single clone found to have both the $15 \mathrm{bp}$ insertion and $68 \mathrm{bp}$ deletion. Scale bar indicates the number of nucleotide base changes. 
으 \&8

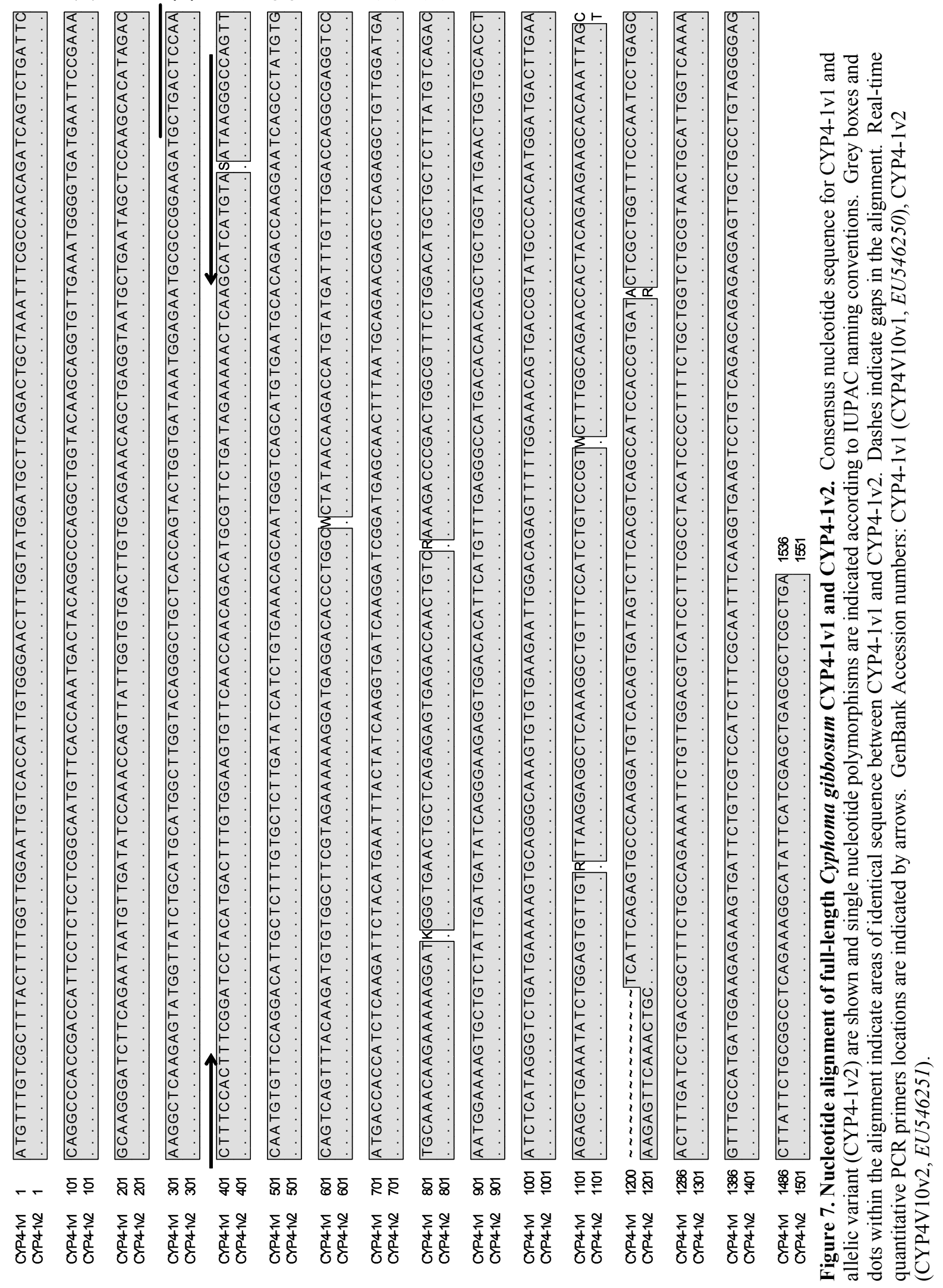




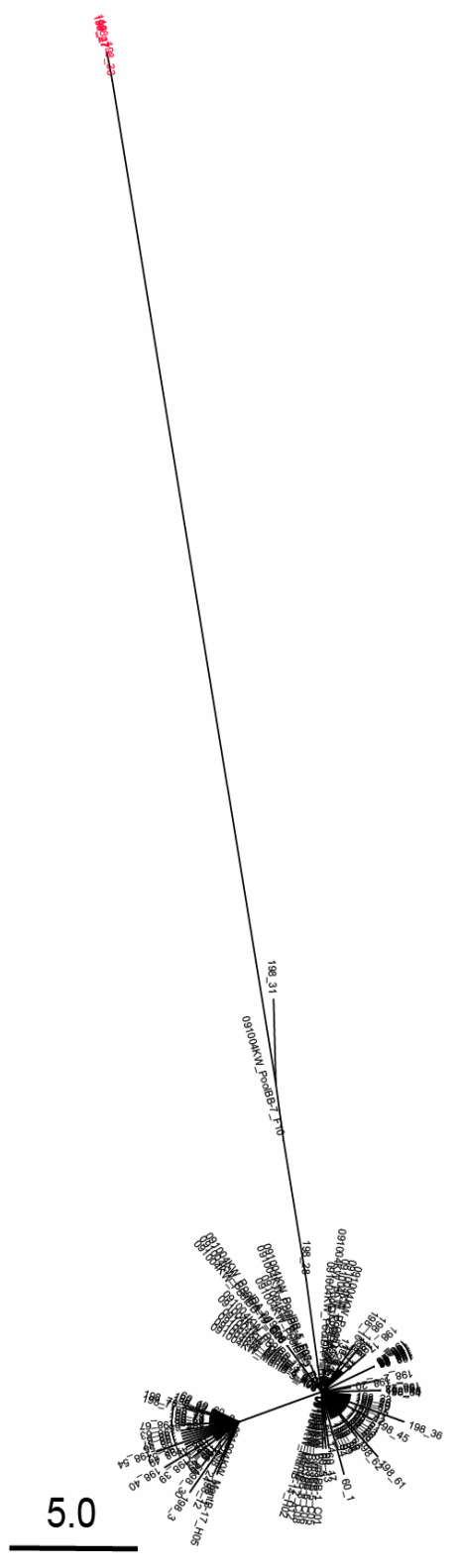

Figure 8. Cluster analysis of CYP4-2 clones visualized by an unrooted maximum parsimony tree. Nucleotide sequences were aligned using ClustalX (Thompson et al., 1997) and the alignment was used to construct a maximum parsimony tree using PAUP*4.0b10 (Swofford 1998). Trees were visualized and manipulated using FigTree v1.1 (Rambaut 2008). Each operational taxonomic unit (OTU) represents the consensus sequence of an individual clone sequenced in both directions. Black OTUs correspond to CYP4-2b cDNAs and red OTUs (4 clones) correspond to CYP4-2a cDNAs. Scale bar indicates the number of nucleotide base changes. 


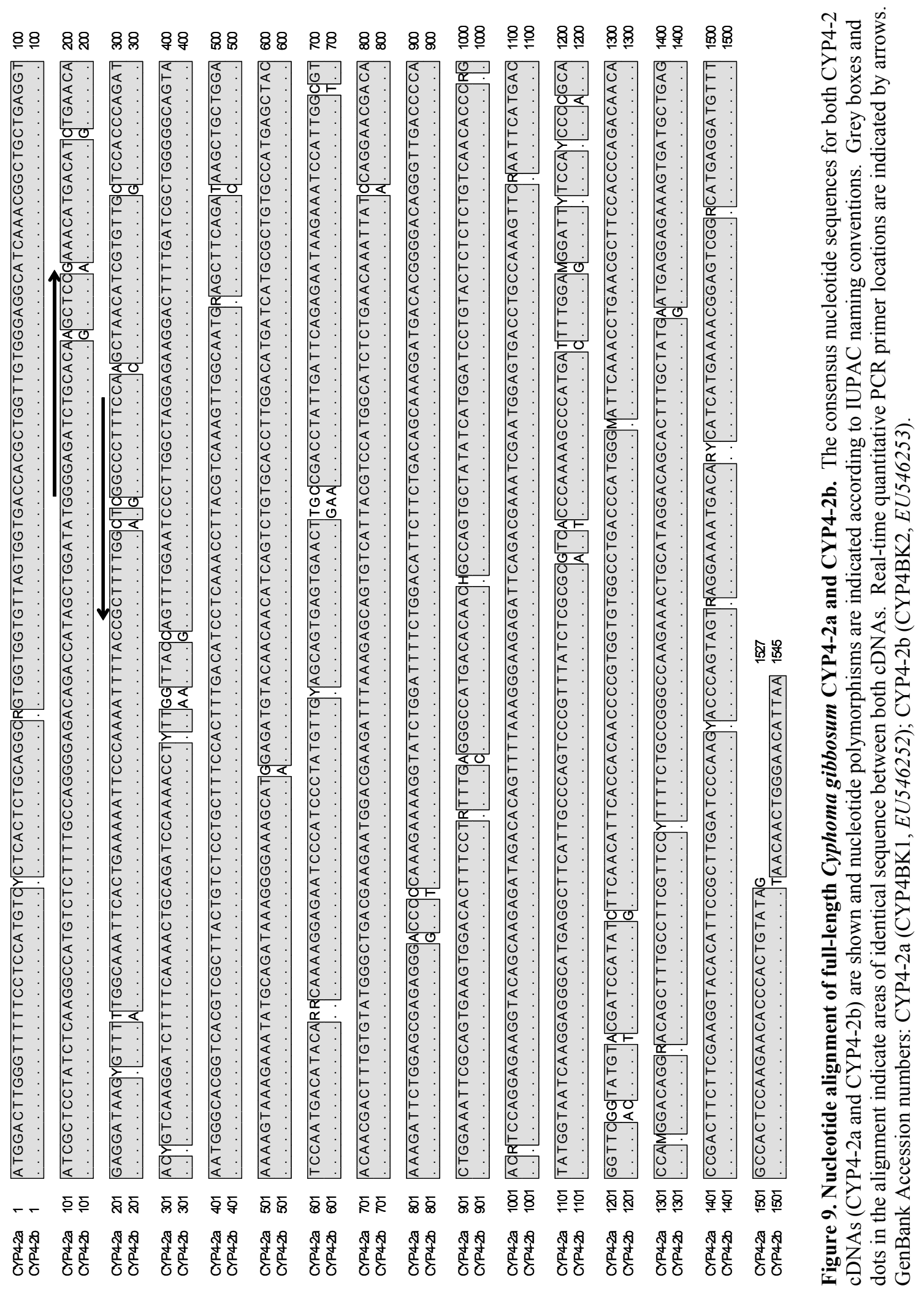




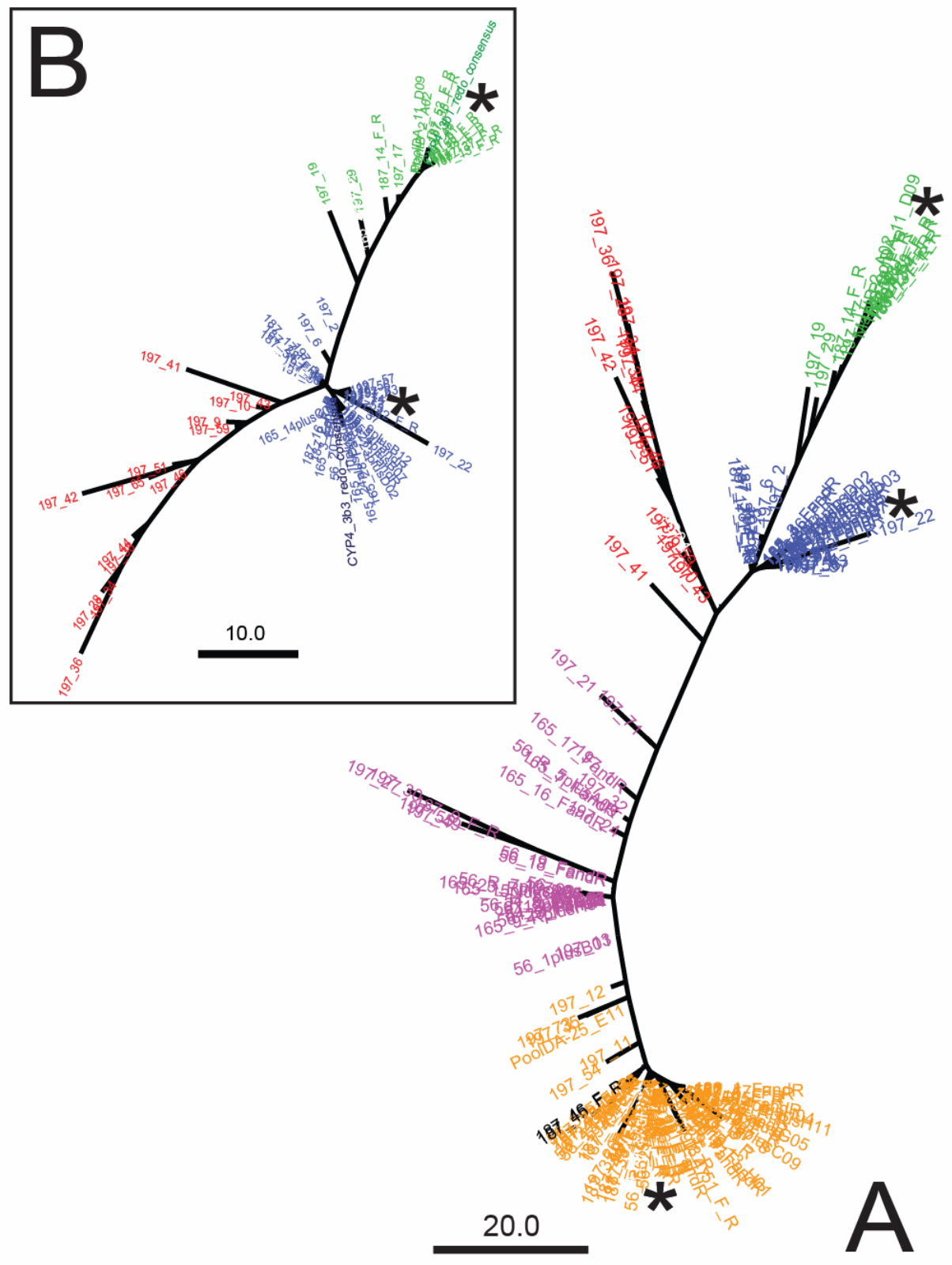

Figure 10. Cluster analysis of CYP4-3 clones visualized by an unrooted maximum parsimony tree. Nucleotide sequences were aligned using ClustalX (Thompson et al., 1997) and the alignment was used to construct a maximum parsimony tree using PAUP*4.0b10 (Swofford 1998). Trees were visualized and manipulated using FigTree v1.1 (Rambaut 2008). Each operational taxonomic unit (OTU) represents the consensus sequence of an individual clone sequenced in both directions. The color of the OTU indicates further groupings denoting possible distinct loci. Part (A) depicts all clones within the CYP4-3 grouping; CYP4-3a1=orange, CYP4-3a2=black, CYP4-3b1=green, CYP4-3b2=red, CYP4-3b3=blue, CYP4$3 \mathrm{c}=$ purple. Part (B) is an expanded view of the CYP4-3b node. Clones used in yeast heterologous expression experiments are indicated by an asterisk. Scale bar indicates the number of nucleotide base changes. 
Figure 11. Nucleotide alignment of eleven full-length Cyphoma gibbosum CYP4-3 cDNA sequences. The consensus nucleotide sequences for all eleven cDNAs, including possible allelic variants, are shown. Nucleotide polymorphisms are indicated according to IUPAC naming conventions. CYP4-3a sequences are represented three allelic variants. CYP4-3b2 sequences are represented by five individual clones because no 'physical' clones could be supported by the consensus sequence generated for the CYP4-3b2 subgroup. Identical bases are indicated with a "•" and are shaded grey. Real-time quantitative PCR primer locations are indicated by arrows; solid arrows correspond to all CYP4-3 sequences; dashed arrows correspond to CYP4-3 (sub A) sequences; dotted arrows correspond to CYP4-3 (sub B) sequences. GenBank Accession numbers: CYP4-3a1v1 (CYP4BL1v1, EU546254); CYP4-3a1v2 (CYP4BL1v2, EU546255); CYP4-3a2 (CYP4BL1v3, EU546256); CYP4-3b1 (CYP4BL4, EU546257); CYP4-3b2_clone1 (CYP4BL5, EU546258); CYP4-3b2_clone2 (CYP4BL6, EU546259); CYP4-3b2_clone3 (CYP4BL7, EU546260); CYP4-3b2_clone4 (CYP4BL8, EU546261); CYP4-3b2_clone5 (CYP4BL9, EU546262); CYP4-3b3 (CYP4BL3, EU546263). 


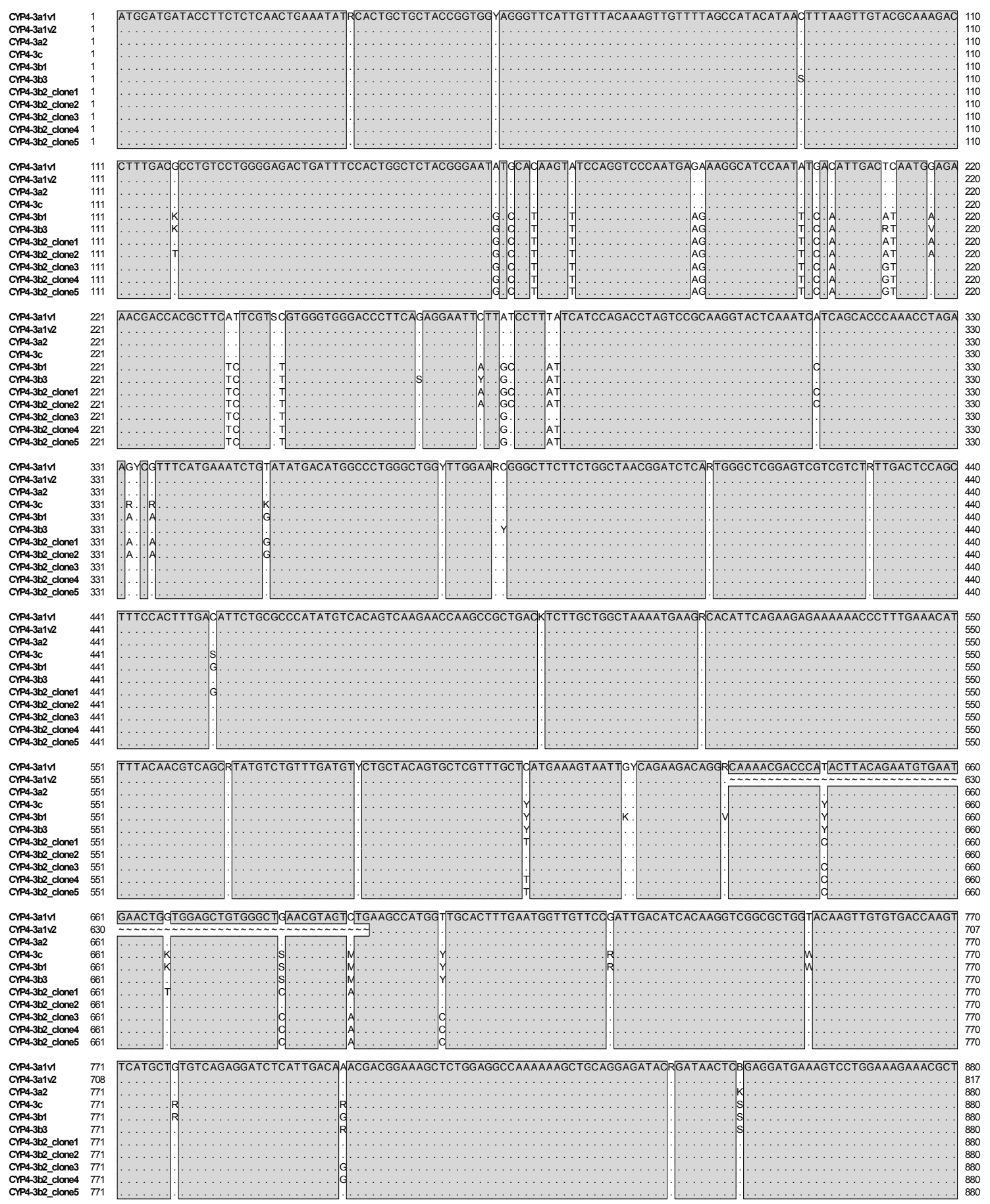




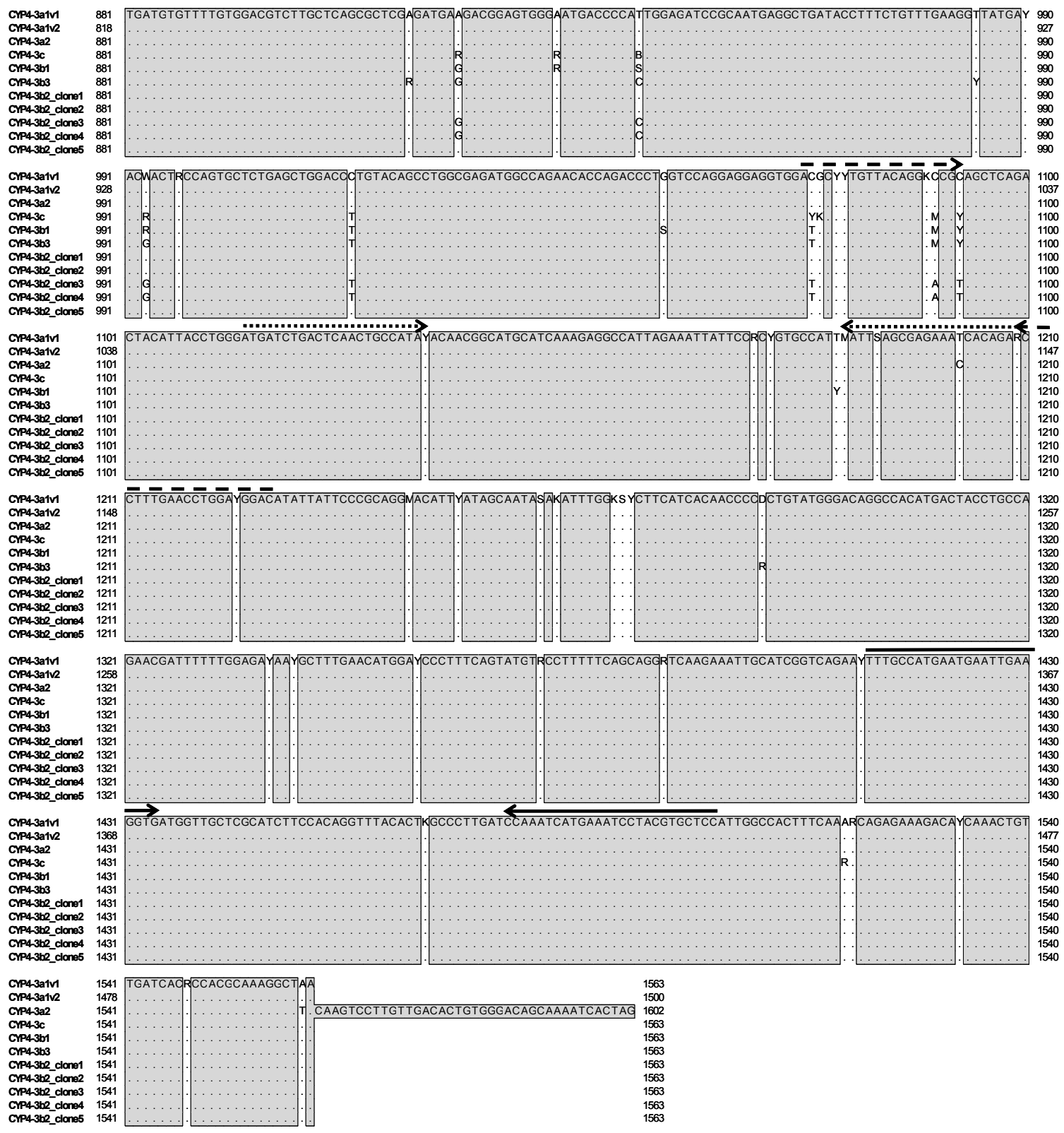




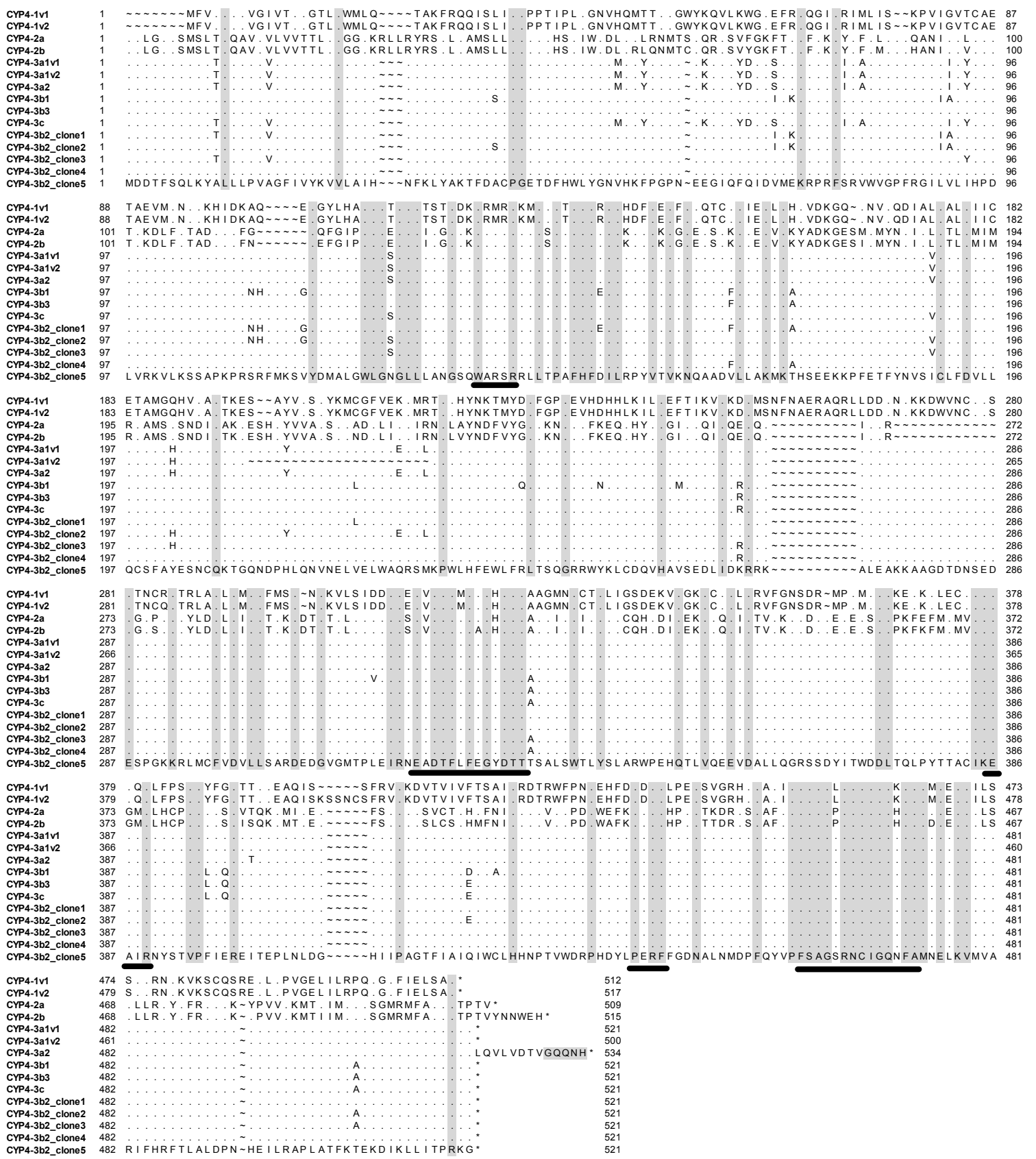

Figure 12. Deduced amino acid alignment of $C$. gibbosum CYP4-1, CYP-4-2, and CYP4-3 consensus sequences. Amino acid sequences were generated from consensus nucleotide sequences and aligned using ClustalX. Grey boxes indicate areas of identical sequence among all cDNAs. Amino acid residues identical to CYP4-3b2_clone 5 are indicated by a "•" and gaps by a “ $"$ ". The stop codon is denoted by an asterisk. The conserved WXXXR, I-helix, EXXR, PXRF, and heme-binding domains, in order, are indicated by black lines under the sequence alignment. 
Figure 13. Phylogenetic relationships of Cyphoma gibbosum CYP4 proteins with other invertebrate and vertebrate CYP4s. Bayesian and Maximum Likelihood (ML) trees were constructed as described in the Methods. Both trees resulted in the same topology, and the Bayesian tree is depicted here. Sequences from C. gibbosum are highlighted in red. Values at branch points represent posterior probabilities derived from $3 \times 10^{6}$ generations and ML bootstrap values calculated with 1000 replications. Predicted sequences are labeled with an asterisk. Sequences include: Abalone CYP4V13 formally CYP4C17 (H. rufescens, AAC32833), Anemone (N. vectensis, JGI \# 194368), Anemone (N. vectensis, JGI \# 86714), Cockroach CYP4C7 (D. punctata, AAC69184), Crayfish CYP4V11 formally CYP4C15 (O. limosus, AAF09264), Fly CYP4C3 (D. melanogaster, FlyBase FBpp0085074), Frog CYP4F42 (X. laevis, BAD02914.1), Green crab CYP4V16 formally CYP4C39 (C. maenas, JC8026), Hard clam CYP30 (M. mercenaria, AAB66556), Human CYP4A11 (NP_000769.2), Human CYP4A22 (NP_001010969.2), Human CYP4B1 (NP_000770.2), Hüman CYP4F11 (NP_067010.2), Human CYP4F12 (NP_076433.2), Human CYP4F2 (XP_001172541.1), Human CYP4F22 (NP_775754.2), Human CYP4F3 (NP_000887.2), Human CYP4F8 (NP_009184.1), Human CYP4V2 (NP_997235.2), Human CYP4X1 (NP_828847.1), Human CYP4Z1 (NP_835235.1), Limpet (L. gigantea, JGI\# 122078), Limpet (L. gigantea, JGI\# 154296), Limpet (L. gigantea, JGI\# 178560), Limpet (L. gigantea, JGI\# 206515), Limpet (L. gigantea, JGI\# 211775), Limpet (L. gigantea, JGI\# 237658), Mouse CYP4A12a (NP_803125.2), Mouse CYP4A12b (NP 758510.2), Mouse CYP4A14 (NP_031848.1), Mouse CYP4B1 (NP_031849.1), Mouse CYP4F13 (NP_570952.1), Mouse CYP4F14 (NP_071879.1), Mouse CYP4F15 (NP_598888.1), Mouse CYP4F16 (NP_077762.1), Mouse CYP4F18 (NP_077764.1), Mouse CYP4F37 (NP_001093657.1), Mouse CYP4F39 (AAI45756), Mouse CYP4F40 (NP_001095058.1), Mussel CYP4Y1 (M. galloprovincialis, AAC32835), Polychaete worm (Capitella sp. JGI\# 130691), Polychaete worm (Capitella sp. JGI\# 144012), Polychaete worm (Capitella sp. JGI\# 162759), Polychaete worm (Capitella sp. JGI\# 181976), Polychaete worm CYP4AT1 (C. capitata, AAS87604), Sand worm CYP4BB1 (N. virens, AAR88241), Sea urchin (S. purpuratus, J. Goldstone predicted, GLEAN3_05931), Sea urchin (S. purpuratus, J. Goldstone predicted, GLEAN3_20229), Seabass (D. labrax, AAD32564), Silkworm CYP4M9 (B. mandarina, ABK27872.1), Tunicate (C. intestinalis, JGI\# Sc78), Water flea CYP4C34 (D. pulex, BQ703383), Zebrafish CYP 4T (D. rerio, Ensembl ENSDART00000013654), Zebrafish CYP4F13 (D. rerio, Ensembl ENSDART00000063442), Zebrafish CYP4V2 (D. rerio, Ensembl ENSDART00000089480), Zebrafish CYP4V7(D. rerio, Ensembl ENSDART00000087976). Phylogenetic tree construction by J. Goldstone. 


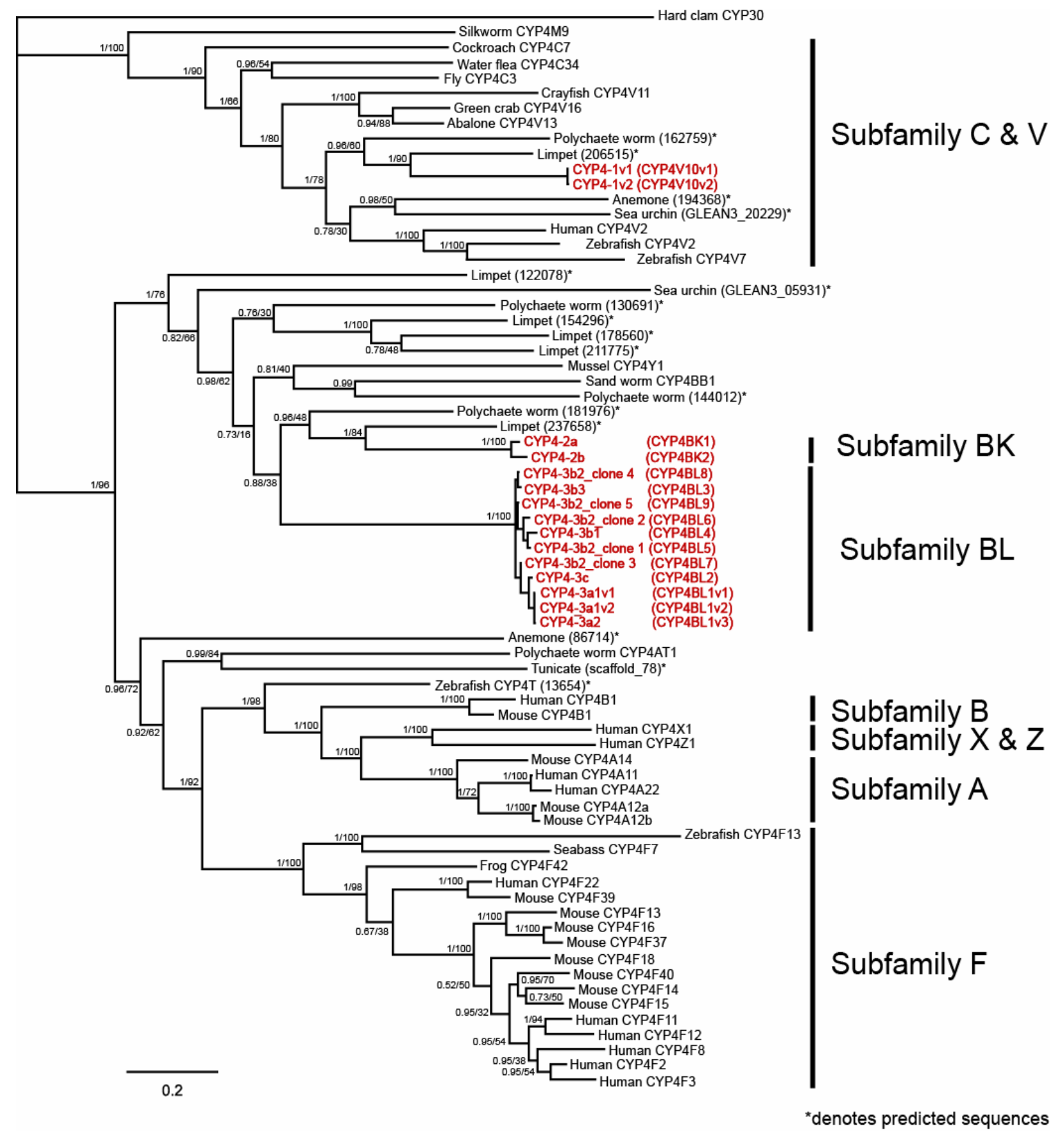




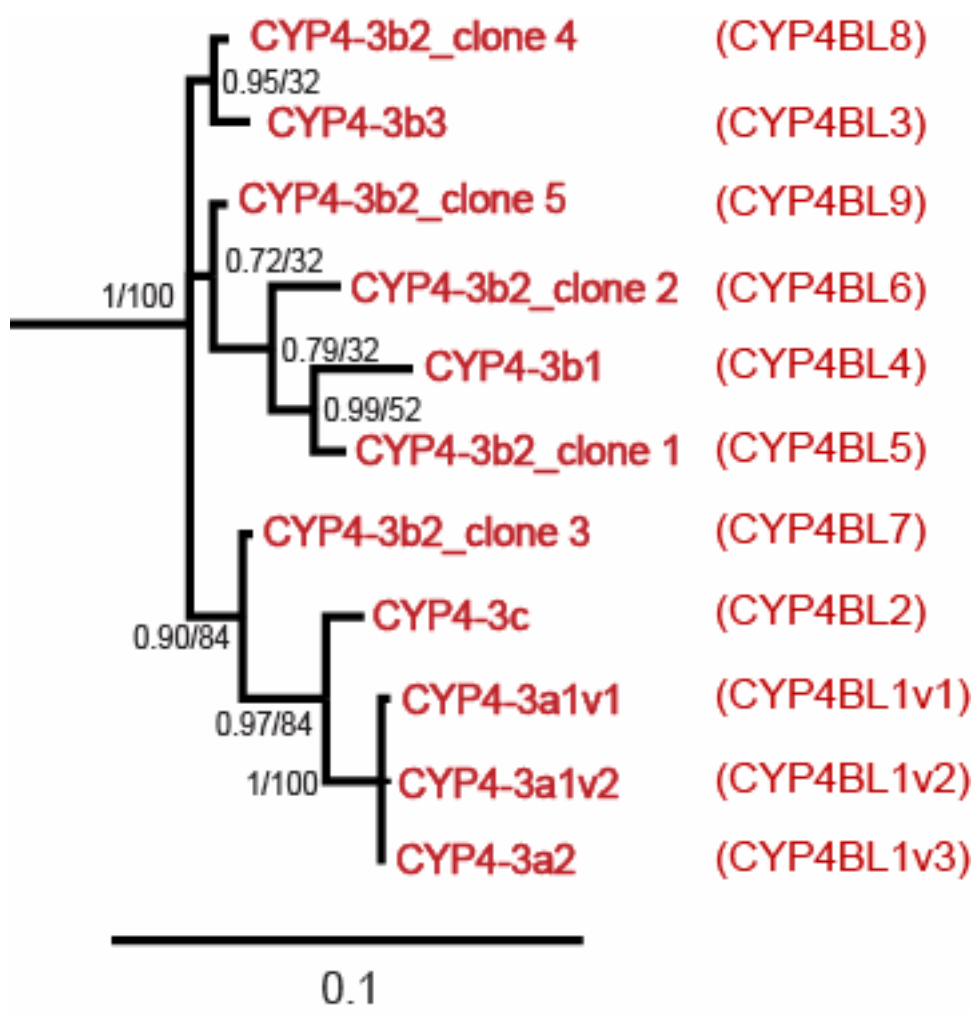

Figure 14. Phylogenetic relationships among Cyphoma gibbosum CYP4-3 proteins. Partial tree representing an expanded view of the CYP4-3 node from Figure 13. Values at branch points represent posterior probabilities derived from $3 \times 10^{6}$ generations and maximum likelihood bootstrap values calculated with 1000 replications. Gene designations assigned by the P450 Nomenclature Committee are indicated to the right of the tree. Phylogenetic tree construction by J. Goldstone. 

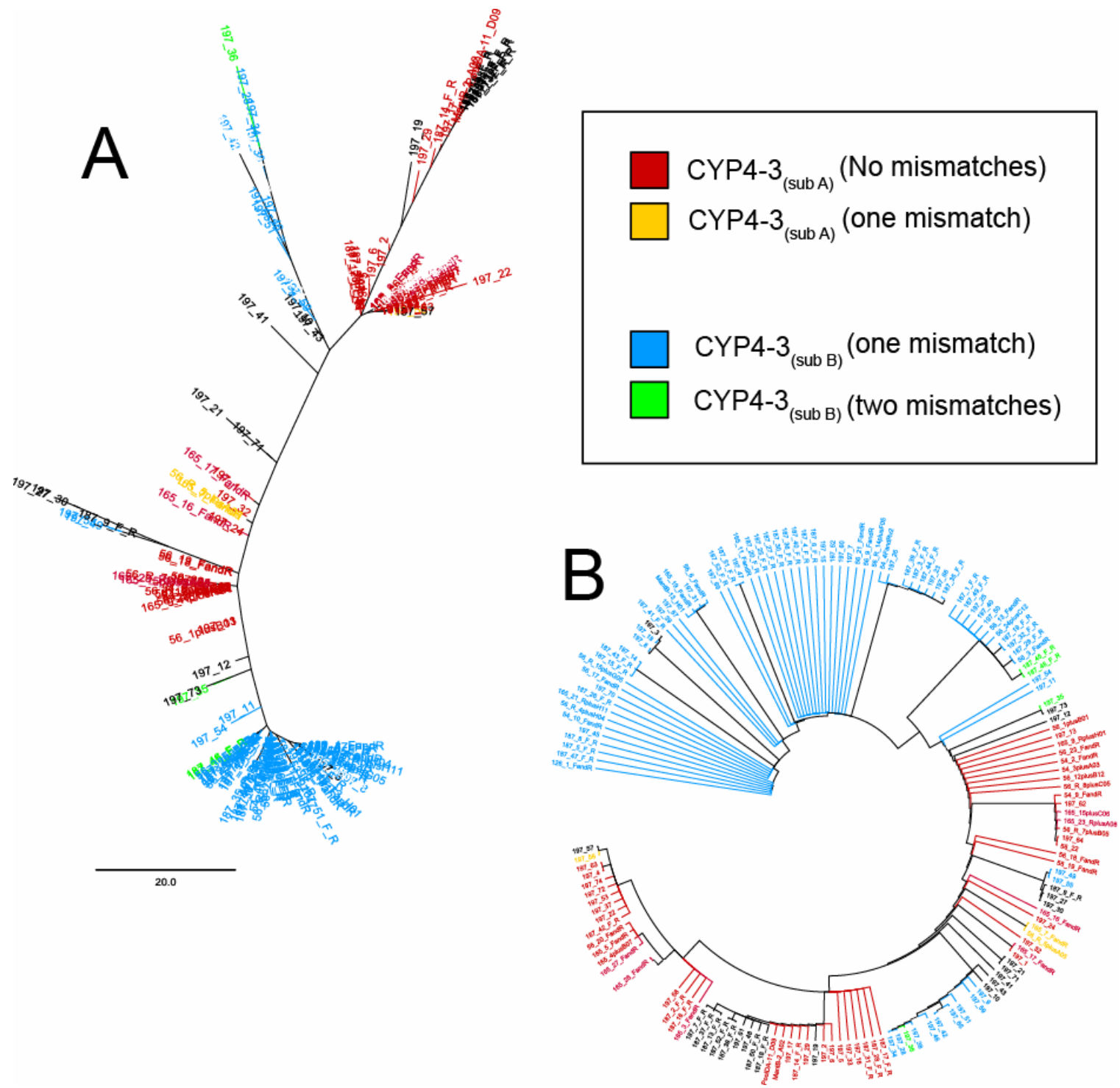

Figure 15. Maximum parsimony trees depicting transcripts recognized by $\mathrm{CYP4-3}_{(\mathrm{sub} A)}$ and CYP4$\mathbf{3}_{\text {(sub B) }}$ quantitative RT-PCR primers. Each taxon represents the consensus sequence of an individual clone sequenced in both directions. The qPCR primer set used to detect clone-specific abundance is indicated by operational taxonomic unit (OTU) color. OTUs in red and orange denote those clones that are picked up by CYP4-3 (sub A) qPCR primers. Red OTUs indicate clones that contain no nucleotide mismatches with qPCR primers. Orange OTUs $(\mathrm{n}=3)$ indicate clones with a one base pair mismatch in the forward primer, not within three base pairs of the 3' end. OTUs in blue and green denote those clones that are picked up by CYP4-3 (sub B) $\mathrm{qPCR}$ primers. Blue OTUs indicate clones that contain a one base pair mismatch in the forward primer ten base pairs from the 3'end. Green OTUs $(\mathrm{n}=4)$ indicate clones with a one base pair mismatch in both the forward and reverse primers not within ten base pairs of the 3 ' end. Black OTUs denote clones that would not be picked up by either primer set. Partial sequences not covered by the qPCR primer pairs described here were deleted from the above trees. The (A) unrooted maximum parsimony tree (see Figure X) was proportionally transformed into a circular tree (B) using FigTree v1.1 (Rambaut 2008). The scale bar in (A) indicates the number of nucleotide base changes. 


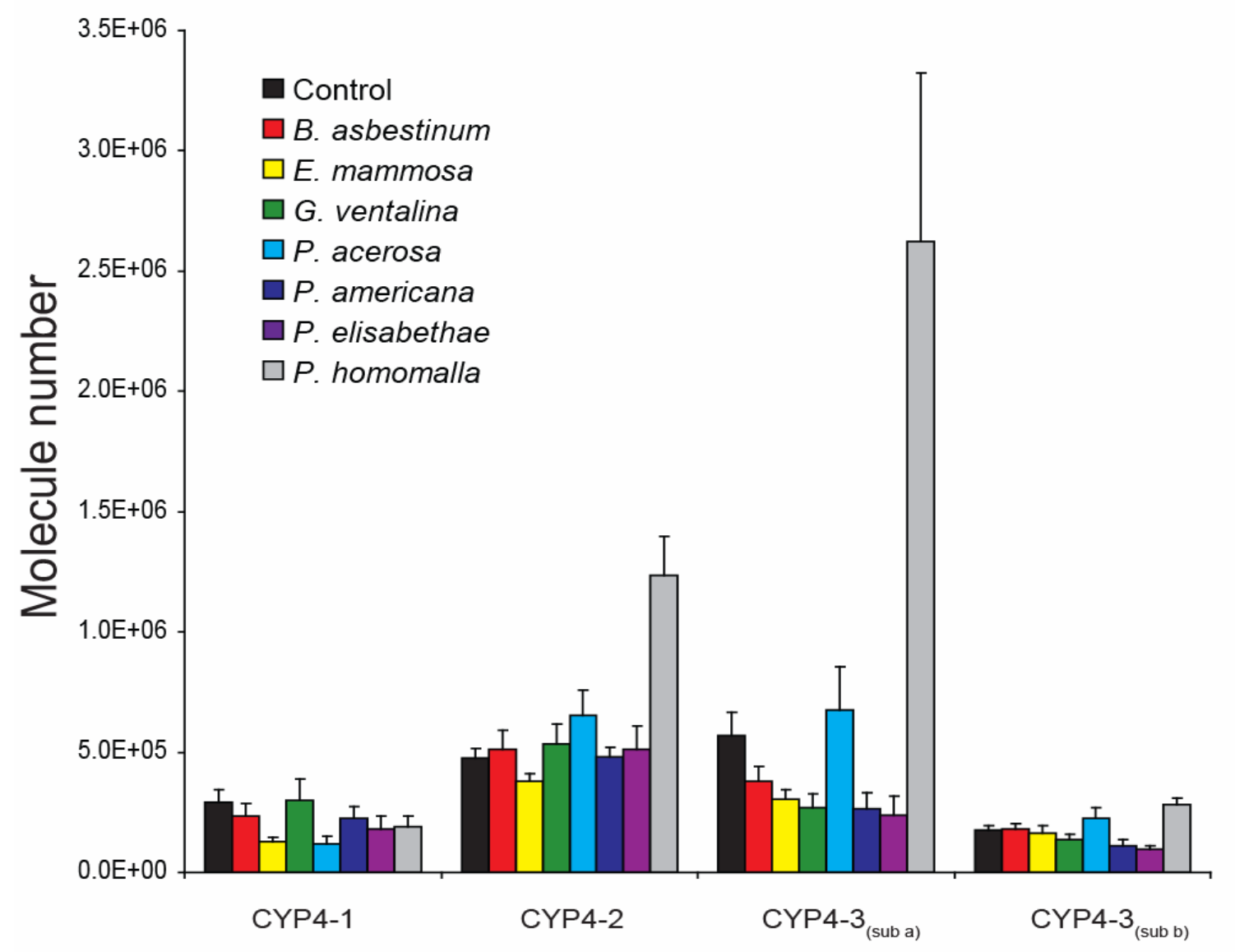

Figure 16. Mean CYP4 gene expression among $C$. gibbosum feeding on gorgonian and control diets for four days. Bars represent the mean CYP4 gene expression $( \pm \mathrm{SE})$ of snails feeding on $B$. asbestinum $(\mathrm{n}=13)$, E. mammosa $(\mathrm{n}=12)$, G. ventalina $(\mathrm{n}=13)$, P. acerosa $(\mathrm{n}=10), P$. americana $(\mathrm{n}=12), P$. elisabethae $(\mathrm{n}=6), P$. homomalla $(\mathrm{n}=11)$ and the control diet $(\mathrm{n}=33)$. Results from snails collected from all five reefs are shown. Real-time quantitative PCR was performed and the number of molecules per $0.2 \mu \mathrm{g}$ of polyA+ RNA was calculated from the standard curve and normalized by a $\beta$-actin correction factor. 


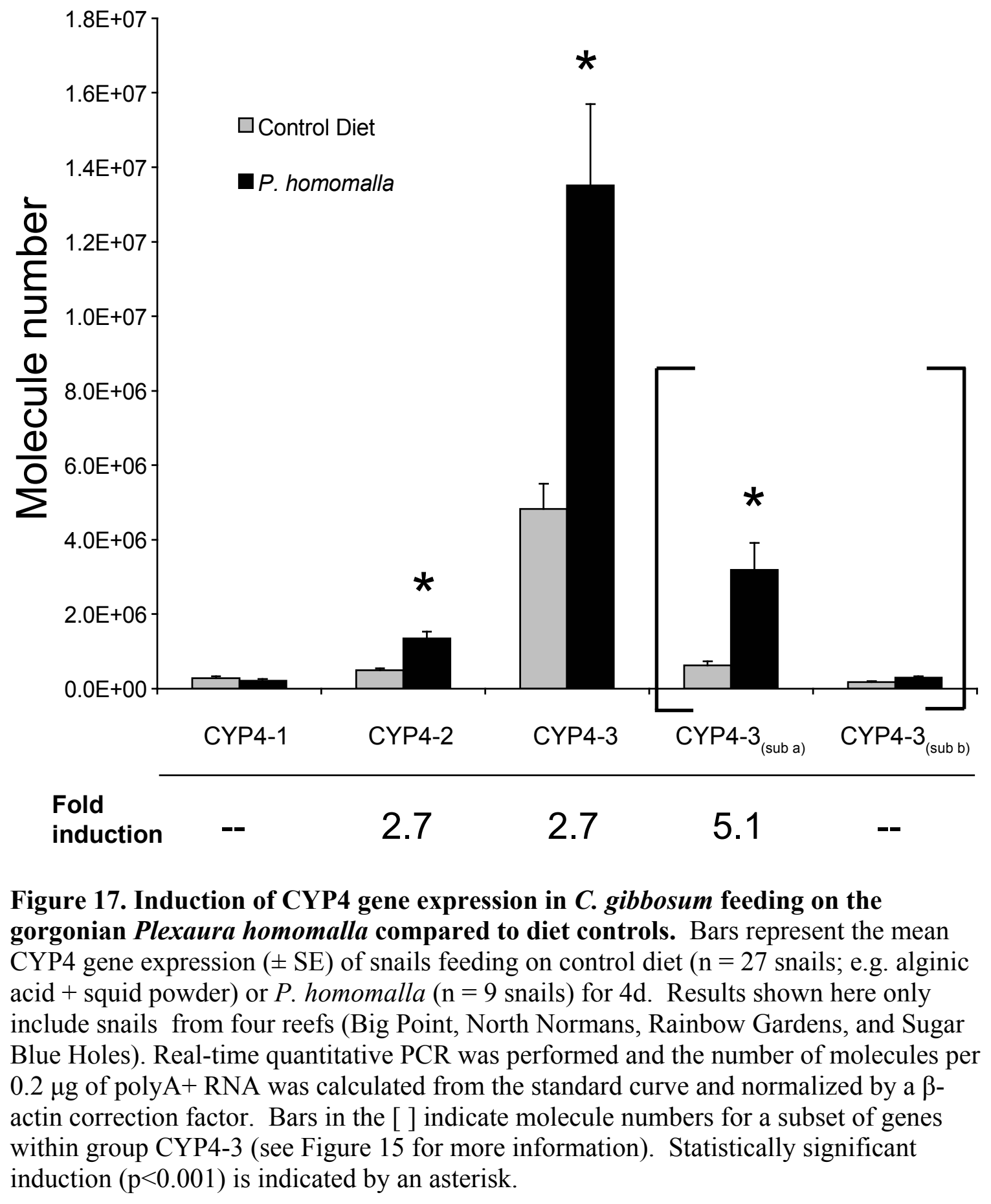



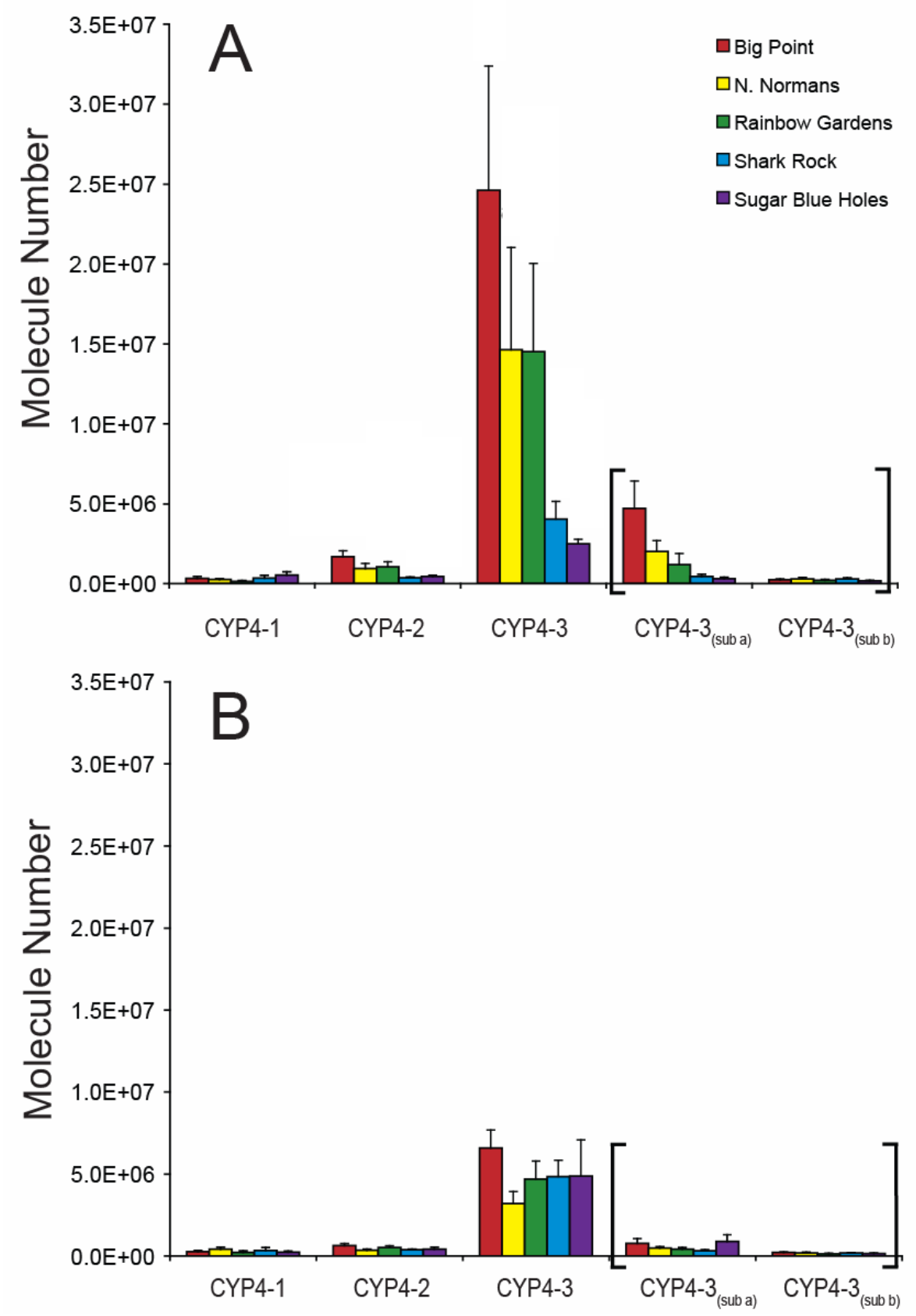

Figure 18. Comparing CYP4 expression levels among time-zero and $4 \mathrm{~d}$ control-fed $C$. gibbosum snails collected from five reefs. (A) Control snails; Bars represent mean CYP4 expression ( \pm SE) in snails $(\mathrm{n}=33)$ collected from five reefs and fed a control diet (e.g. alginic acid + squid powder) for four days. (B) Time-zero snails; Bars represent mean CYP4 expression $( \pm \mathrm{SE})$ in snails $(\mathrm{n}=30)$ collected from five reefs and immediately dissected to preserve reef-specific gene expression signals. Real-time quantitative PCR was performed and the number of molecules per $0.2 \mu \mathrm{g}$ of polyA+ RNA was calculated from the standard curve and normalized by a $\beta$-actin correction factor. Bars in the [ ] indicate molecule numbers for a subset of genes within group CYP4-3. 


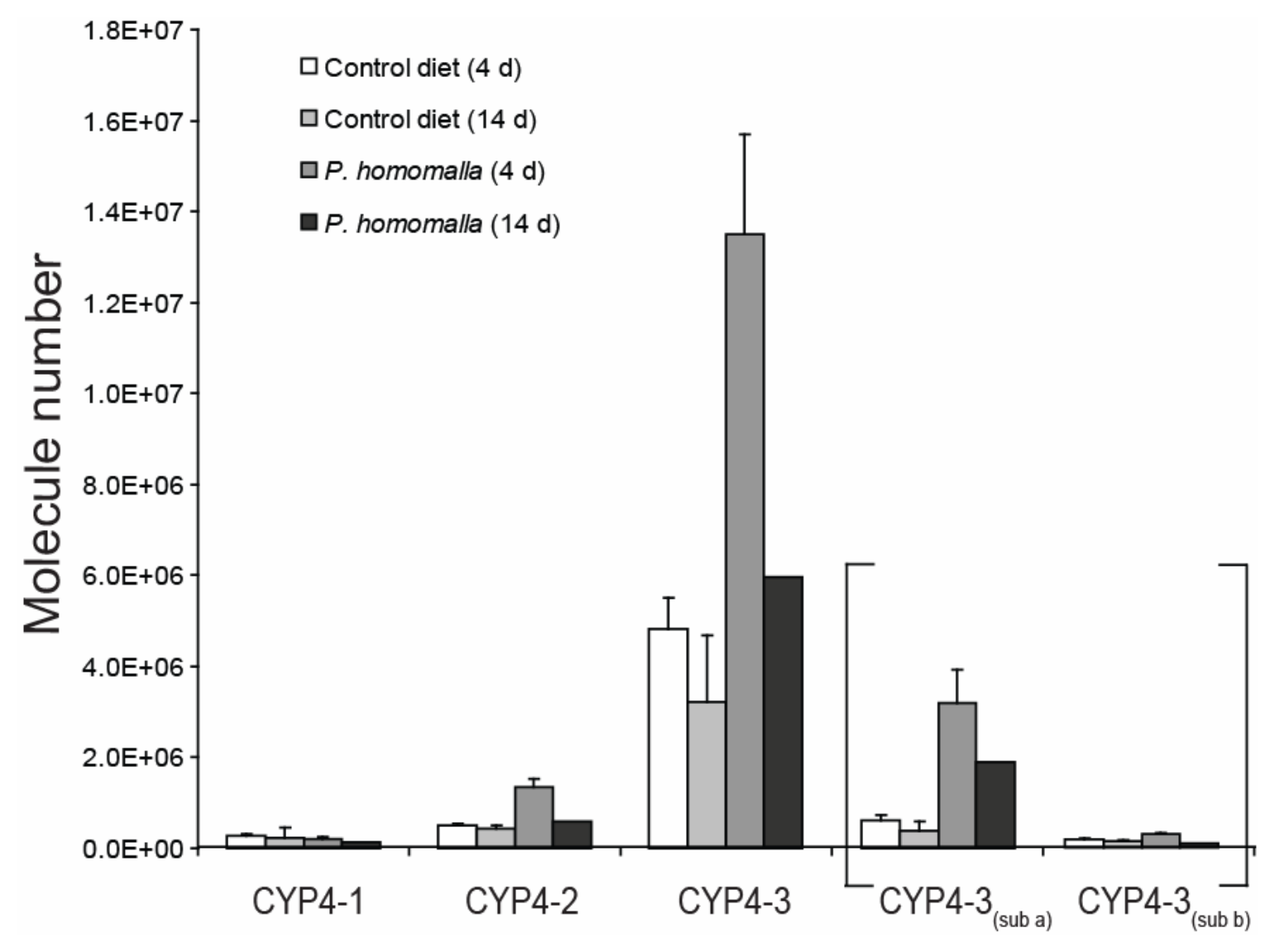

Figure 19. Comparison of CYP4 gene expression in snails feeding on control or $P$. homomalla diet for $4 \mathbf{d}$ or greater. Bars represent the mean CYP4 gene expression ( \pm $\mathrm{SE})$ of snails feeding on control diet $(\mathrm{n}=27$ snails; e.g. alginic acid + squid powder $)$ or $P$. homomalla $(\mathrm{n}=9$ snails) for $4 \mathrm{~d}$. Results shown here only include snails from four reefs (Big Point, North Normans, Rainbow Gardens, and Sugar Blue Holes). Run in parallel to the four day feeding assays was a series of long term feeding assays used to examine the induction of CYP4 in C. gibbosum. Adult C. gibbosum collected from North Normans were allowed to feed on control $(\mathrm{n}=2)$ or P. homomalla $(\mathrm{n}=1)$ for $14 \mathrm{~d}$ and mean CYP4 gene expression ( \pm SE) is shown for each $14 \mathrm{~d}$ diet group . Real-time quantitative PCR was performed and the number of molecules per $0.2 \mu \mathrm{g}$ of polyA+ RNA was calculated from the standard curve and normalized by a $\beta$-actin correction factor. Bars in the [ ] indicate molecule numbers for a subset of genes within group CYP4-3. 
Figure 20. Amino acid alignment for defining putative residues involved in substrate recognition and catalytic activity in allelochemically-responsive Cyphoma CYP4-2 and CYP4-3 deduced amino acid sequences. In order to identify key amino acid residues, Cyphoma CYP4s were aligned to selected human CYP4Fs and rabbit CYP4As, whose substrate recognition sites (SRSs) have been identified in Loughran et al. (2000) and Kalsotra et al. (2004). The crystallized bacterial CYP102 provided a structural template and secondary structural elements (helices A-L and $\beta$-sheets 1-12) described in Ravichandran et al. (1993) were copied onto this alignment. Putative SRSs were also identified by aligning Cyphoma CYP4 deduced amino acid sequences with mammalian CYP2s from Gotoh (1992) (CYP2 sequences not included here). Residues identical to CYP4-3b2_clone 5 are indicated by a dot within the alignment. Boxed regions represent the six SRSs. Residues shaded in grey are identical in all 20 CYP sequences. The Nterminal membrane anchor region is indicated by a dotted line above the alignment. Residues lining the substrate binding channel as described in Chang and Lowe (1999) are indicated by a black dot below the alignment. Residues affecting fatty acid hydroxylase activity in rabbit CYP4A isoforms as described in Loughran et al. (2000) are indicated by a red dot below the alignment. The blue shaded boxes indicate SRS-1 and SRS-2 in rabbit CYP4A sequences defined by Loughran et al. (2000). The yellow shaded box indicates SRS-2 in human CYP4F sequences defined by Kalsotra et al. (2004). Gaps within the alignment are indicated by $(\sim)$ and $(-)$. Protein sequences used in the alignment include: bacterial CYP102 (2HPD), CYP4A4 (rabbit, P10611), CYP4A5 (rabbit, P14579), CYP4A6 (rabbit, P14580), CYP4A7 (rabbit, P14581), CYP4F3 (human, Q08477), CYP4F11 (human, Q9HBI6). 


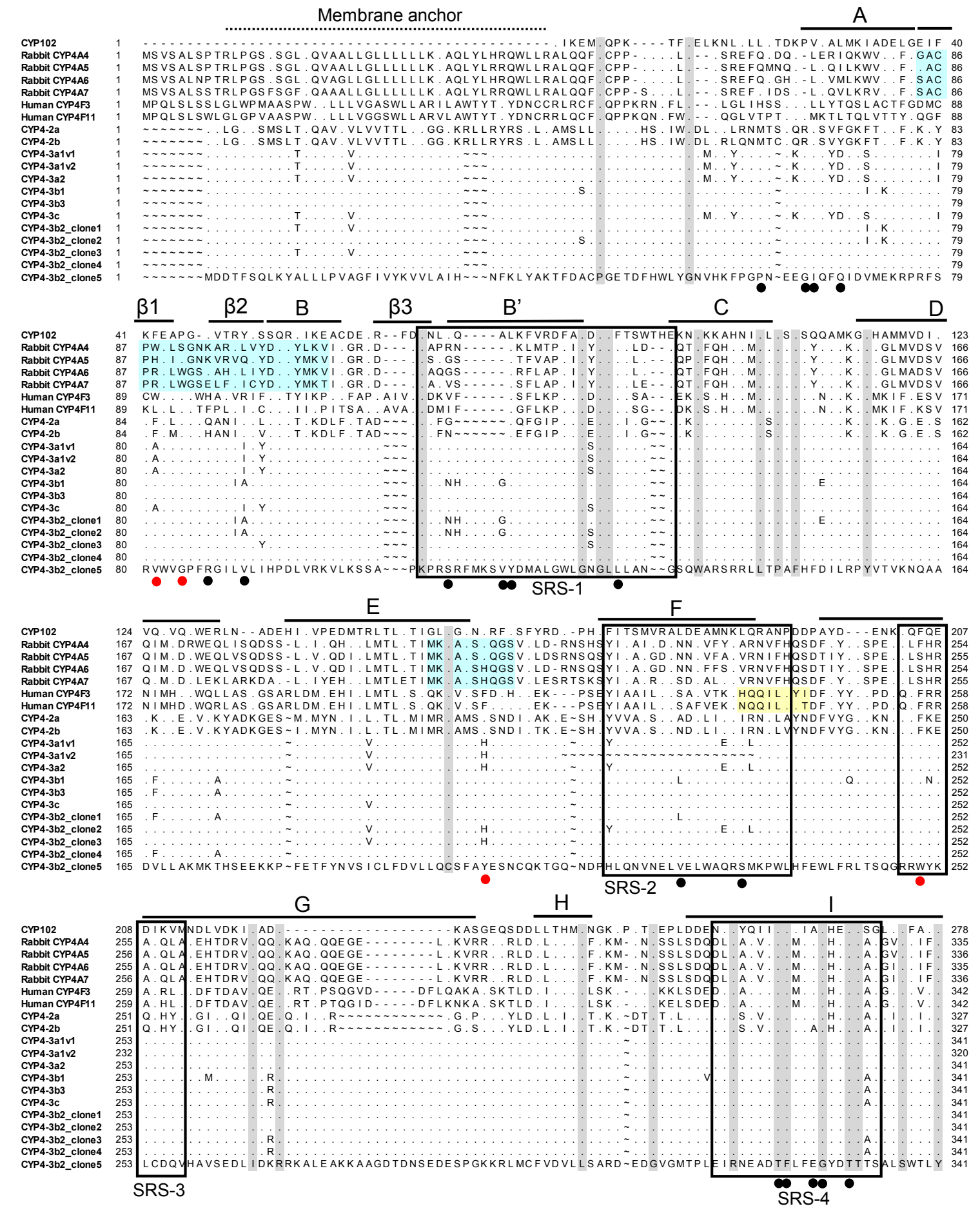



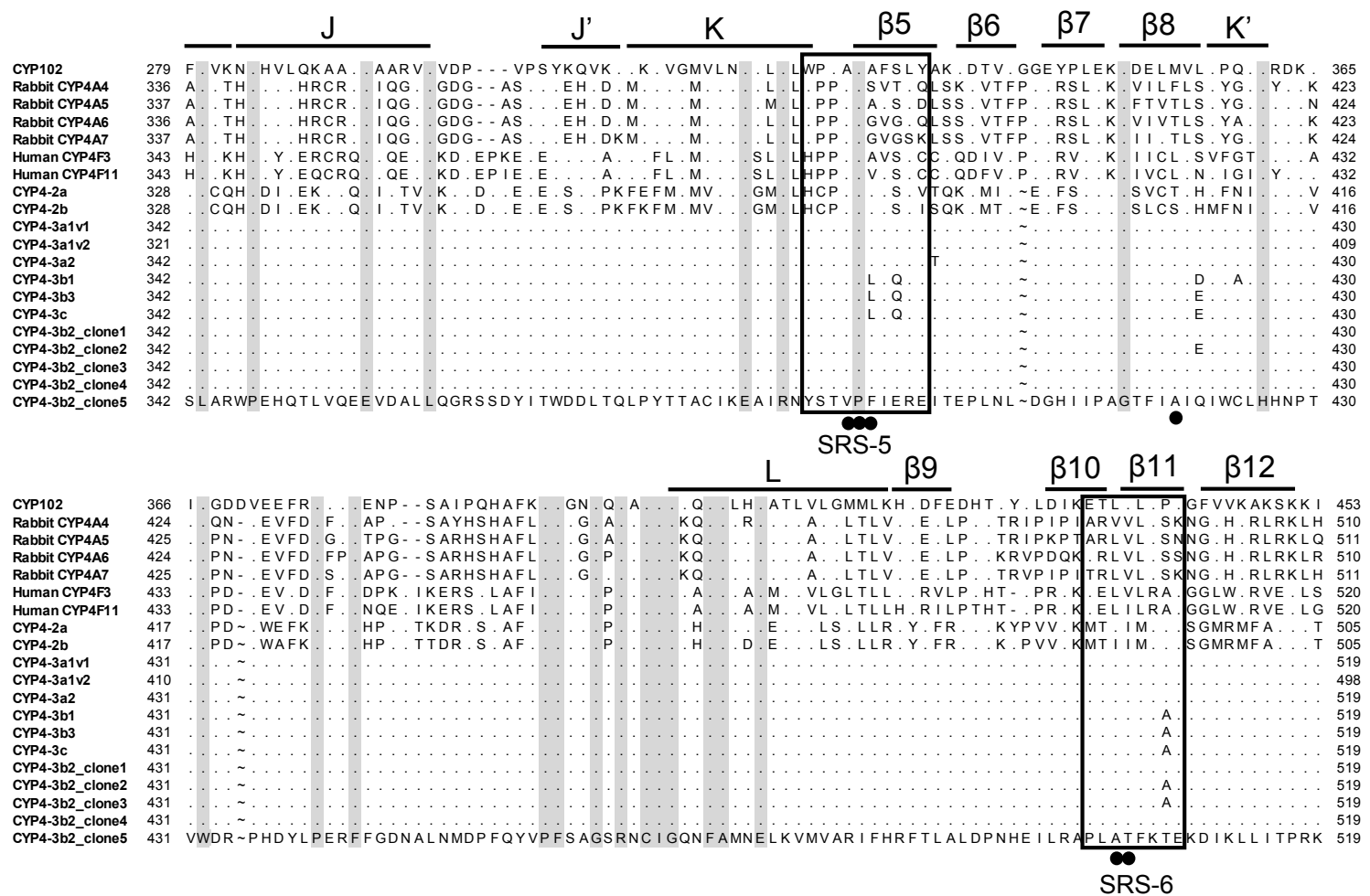

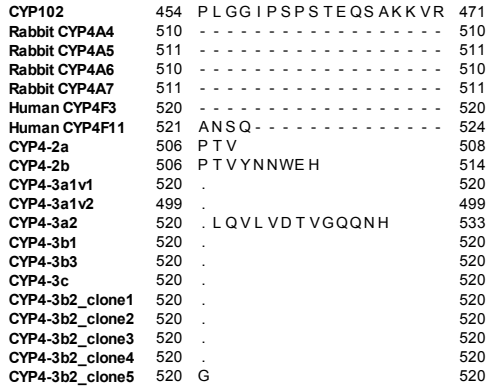




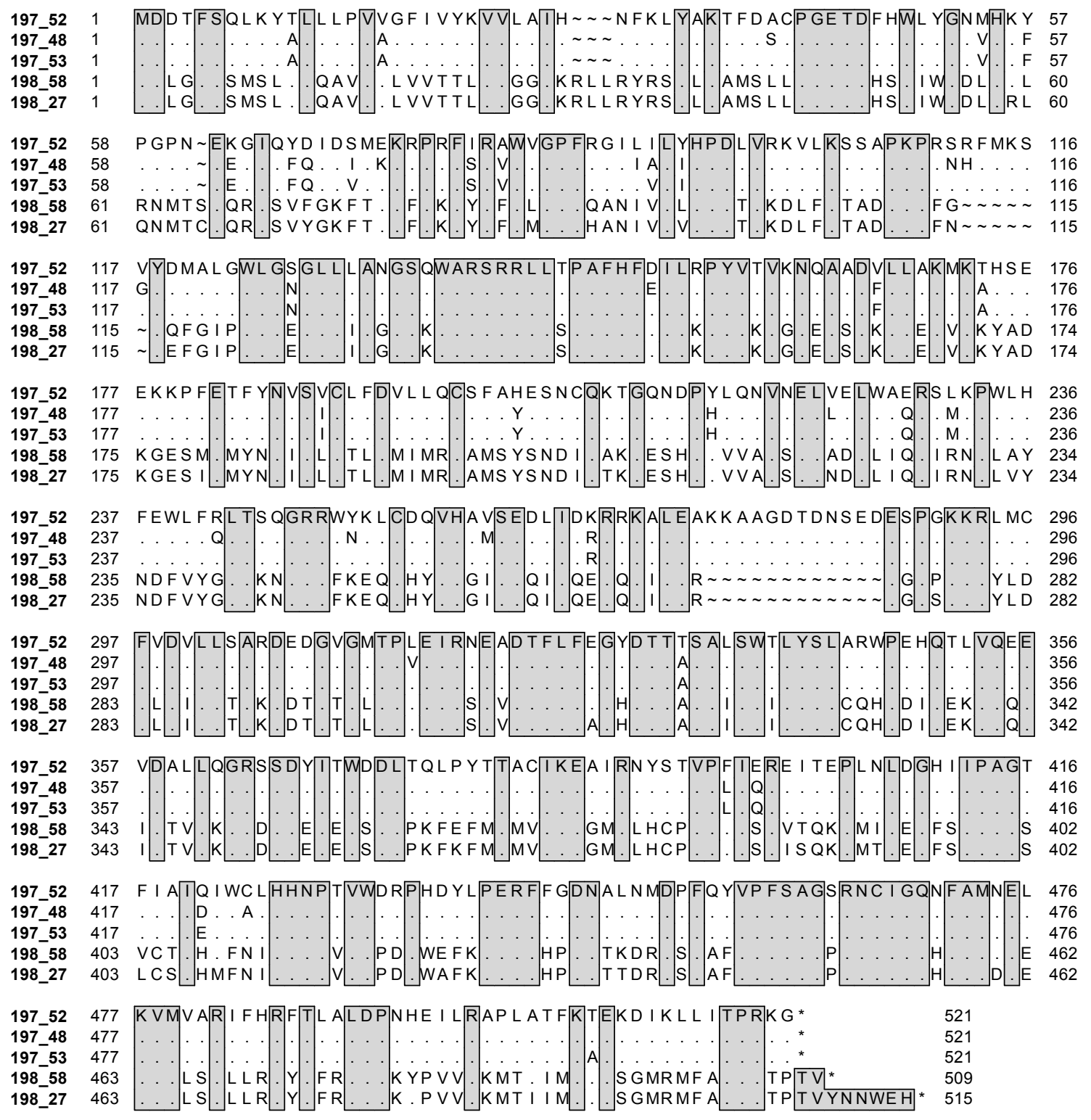

\section{Figure 21. Cyphoma CYP4-2 and CYP4-3 clones selected for heterologous}

expression in yeast. CYP4-2a and CYP4-2b are represented by clones 198_58 and 198_27, respectively. CYP4-3a1, CYP4-3b1, CYP4-3b3 are represented by clones 197_52, 197_48, and 197_53, respectively. Deduced amino acid sequences were aligned using ClustalX. Grey boxes indicate areas of identical sequence among all clones. Amino acid residues identical to clone 197_52 are indicated by a "•". Stop codons and gaps are indicated by "*”" and " $\sim$ ", respectively. 

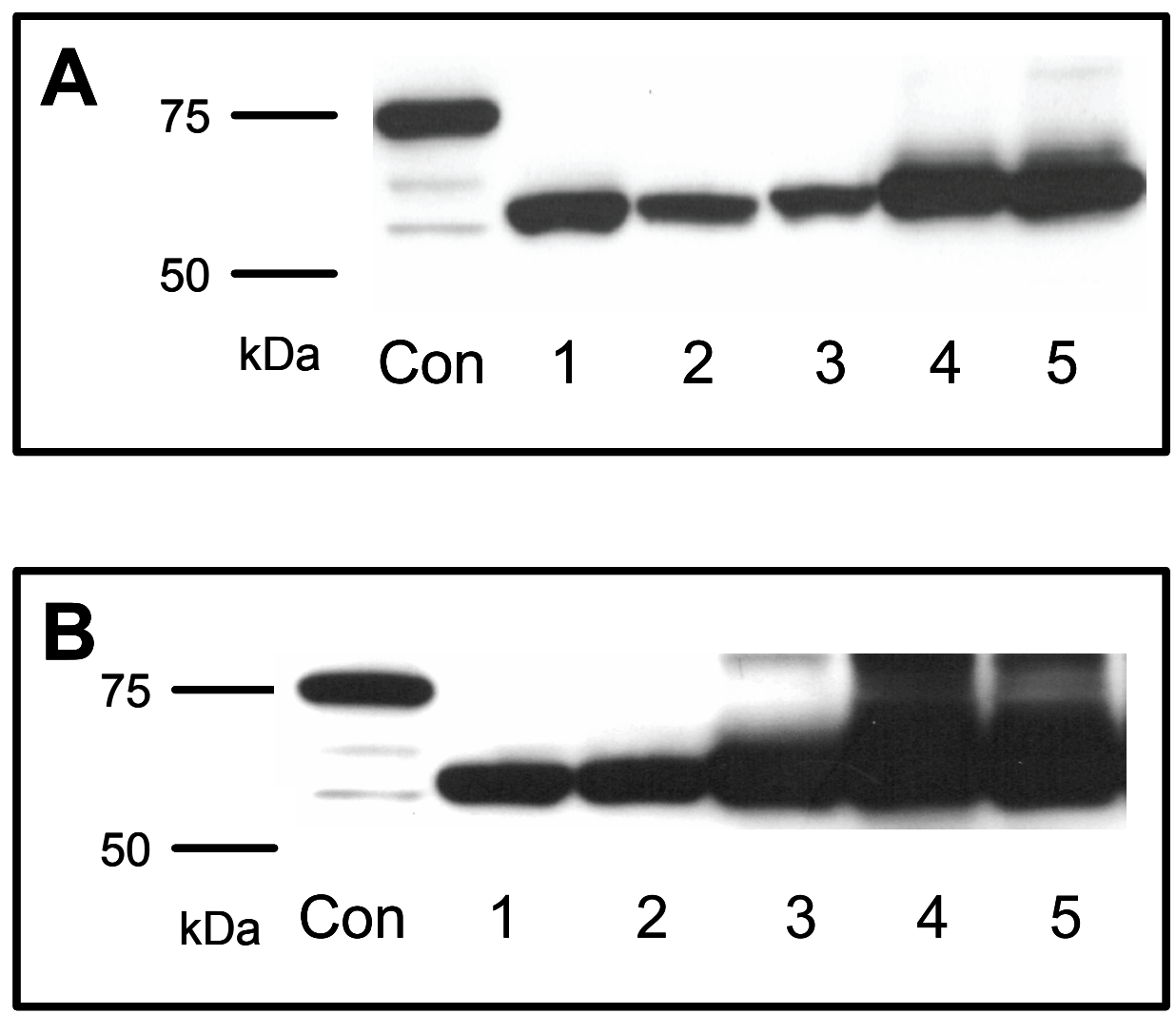

Figure 22. Recombinant expression of selected Cyphoma gibbosum CYPs in Saccharomyces cerevisiae. The W(R) strain of yeast that over-expresses NADPHreductase was transformed with $C$. gibbosum CYPs under the control of a galactose inducible promoter. (A) After 8 hours (B) or 15 hours of induction in YPGE media containing 2\% galactose, CYP expression is visualized by Western blotting with anti-V5HRP. Each lane contains $20 \mu \mathrm{g}$ of protein. (lanes - Con, positive control gene expression (Arabidopsis $\beta$-glucuronidase); lane 1, $198 \_58$; lane 2, $198 \_27$; lane 3, 197_52; lane 4, 197_48; lane 5, 197-53). 
Figure 23. High pressure liquid chromatograms of leukotriene $B_{4}$ metabolites formed by recombinant yeast expressing $C$. gibbosum CYP4 proteins. Structure of metabolites formed in LTB4 hydroxylase assays are shown in (A). Human liver microsomes (HLM) $(0.5 \mathrm{mg} / \mathrm{mL}$ protein) $(\mathbf{B})$ and yeast microsomes $(2.0 \mathrm{mg} / \mathrm{mL})$ containing $C$. gibbosum CYP4 proteins $(\mathbf{C})$ and were incubated with $29.7 \mu \mathrm{M} \mathrm{LTB}_{4}, 1.3$ $\mathrm{mM}$ NADP+, $3.3 \mathrm{mM}$ glucose-6-phosphate, $0.4 \mathrm{U} / \mathrm{mL}$ glucose-6-phosphate dehydrogenase, $3.3 \mathrm{mM}$ magnesium chloride in $100 \mathrm{mM} \mathrm{KPO}_{4}$ buffer at $23^{\circ} \mathrm{C}$ and $30^{\circ} \mathrm{C}$ for $120 \mathrm{~min}$. Substrate and metabolites analyzed by reverse phase HPLC and separated initially with $30 \%$ acetonitrile with $1 \mathrm{mM}$ perchloric acid in water changing to $70 \%$ methanol over $20 \mathrm{~min}$ (flow rate $=1.0 \mathrm{~mL} / \mathrm{min}$ ). $\mathrm{LTB}_{4}$ hydroxylase activity was detected with recombinant $C$. gibbosum microsomes (D), but not in three control incubations (i.e., no protein control incubation; a 'global control' pooled yeast sample incubation without NADPH cofactor or without incubation $=$ time zero $(\mathbf{E})$ ). 
(A)

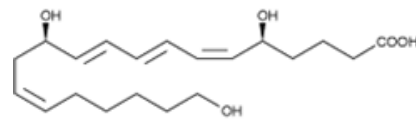

20-hydroxy $\mathrm{LTB}_{4}$

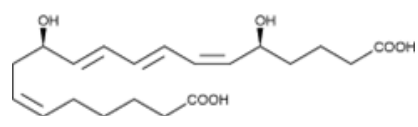

20-carboxy $\mathrm{LTB}_{4}$

(B) Human Liver Microsomes

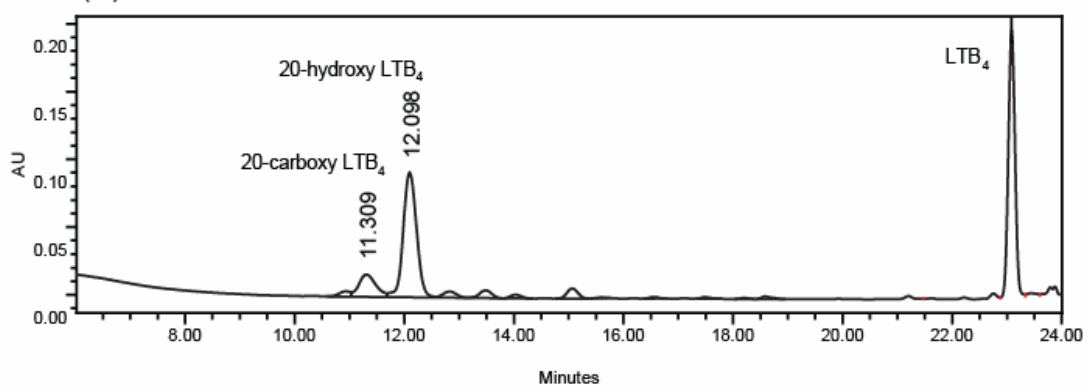

(C) Recombiant yeast expressing 197_53

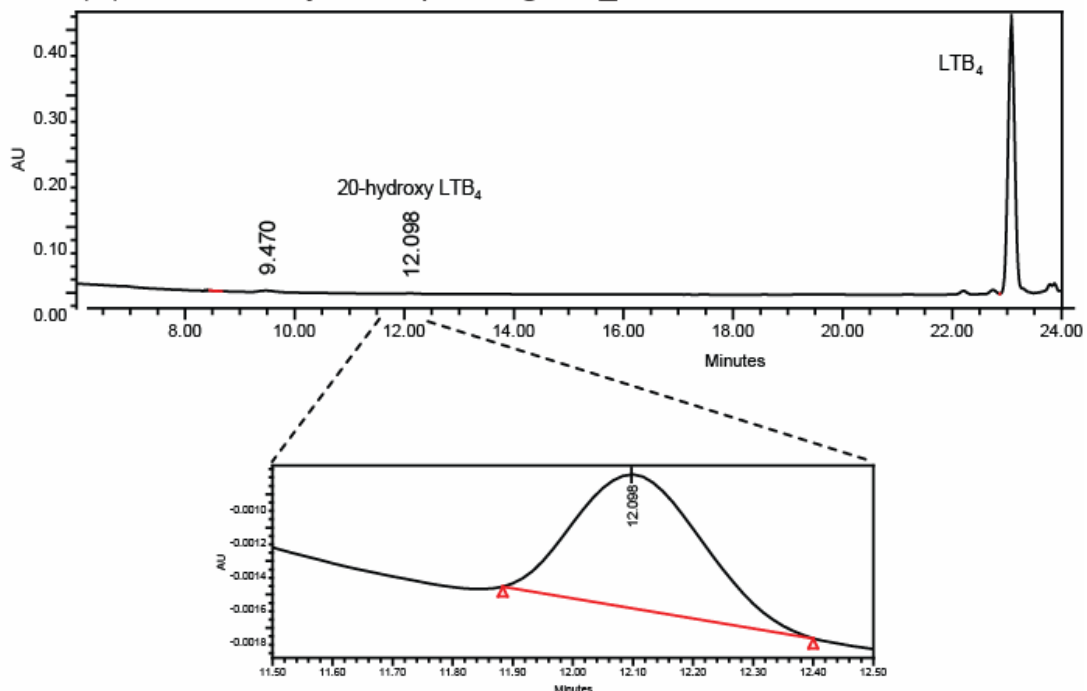

(D) 120 min incubation

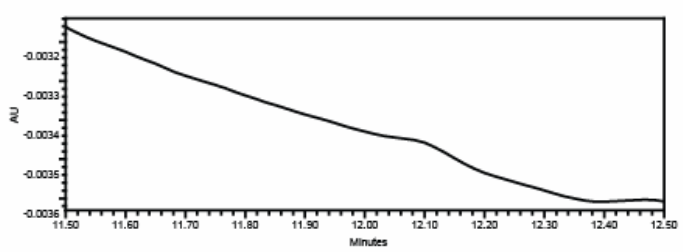

(E) Time zero incubation 


\section{Chapter IV}

Influence of gorgonian diet on the activity and expression of Cyphoma gibbosum glutathione $S$-transferases (GSTs): evidence that ecologically relevant prostaglandins are substrates for molluscan GSTs. 


\begin{abstract}
Despite the profound variation in tolerance of allelochemically-rich foods among marine consumers, few studies have addressed the proximate mechanisms underlying this variation. Under continual exposure to naturally occurring prey toxins, associated predators have likely evolved glutathione $S$-transferases capable of metabolizing and/or sequestering a wide range of structurally diverse compounds. GSTs were isolated from the digestive gland of the obligate gorgonian predator, Cyphoma gibbosum, and were studied for their sensitivity to inhibition by gorgonian extracts and commercially available prostaglandins that resemble known gorgonian allelochemicals. All gorgonian extracts examined were potent inhibitors of GST activity, suggesting that the $\operatorname{diet}$ of $C$. gibbosum may contain high concentrations of GST substrates. In particular, the chloroform-soluble extract from Plexaura homomalla substantially inhibited Cyphoma GST activity and was found to primarily contain prostaglandin $\mathrm{A}_{2}$, a known gorgonian feeding deterrent. Further screening of commercially available prostaglandins in series $\mathrm{A}, \mathrm{E}$, and $\mathrm{F}$ revealed those prostaglandins most abundant in gorgonian tissues with highly reactive $\alpha, \beta$-unsaturated carbonyls $\left(\mathrm{PGA}_{2}\right)$ were the most potent inhibitors. Kinetic studies of GST inhibition showed that $\mathrm{PGA}_{2}$ was a competitive inhibitor of 1-chloro-2,4dinitrobenzene (CDNB) conjugation by Cyphoma GSTs, suggesting that $\mathrm{PGA}_{2}$ is a substrate for Cyphoma mu-class GSTs. In vivo estimates of $\mathrm{PGA}_{2}$ concentration in digestive gland tissues calculated from snail grazing rates suggest that Cyphoma GSTs would be saturated with respect to $\mathrm{PGA}_{2}$ and operating at or near physiological capacity. The high concentrations of putative substrates and inhibitors of GSTs present in all
\end{abstract}


gorgonian extracts may explain why Cyphoma digestive gland GSTs are highly expressed constitutively, i.e., regardless of the nature of the allelochemical diet. It is likely that GSTs operate as 'all-purpose' detoxification enzymes in this marine generalist, capable of conjugating or sequestering a broad range of gorgonian allelochemicals, potentially providing a competitive dietary advantage for this species.

\section{Introduction}

Glutathione S-transferases (GSTs, EC 2.5.1.18) comprise a large superfamily of enzymes whose soluble members function primarily as detoxification enzymes, facilitating the conjugation of a diverse array of hydrophobic electrophilic xenobiotics by the nucelophilic attack of glutathione (Parkinson 2001). GSTs have long been known as important components of cellular defense mechanisms in mammalian systems (Hayes et al. 2005) and now numerous studies are revealing their significance in mediating allelochemical tolerance in invertebrate-host interactions (reviewed in Li et al. 2007).

In terrestrial herbivores, both the diversity of GST forms and their allelochemical detoxification capabilities is likely a result of the co-evolution of these enzymes in response to host-plant allelochemicals (Wadleigh \& Yu 1988, Bolton \& Ahokas 1997). GST forms from polyphagous herbivores are able to metabolize a broader range of allelochemicals in comparison to those from specialists, consistent with the host range differences of these herbivores (Wadleigh \& Yu 1987, 1988, Yu \& Abo-Elghar 2000), suggesting that the evolution of generalist GST forms favors promiscuous catalytic activity presumably needed to cope with the breadth of dietary toxins encountered. 
Additionally, the degree of polyphagy has also been correlated with the number of expressed GST isoforms. GST isoforms purified from five lepidopterans revealed that specialists expressed only one major isoform, while generalists expressed multiple forms (Yu 1989). In addition to the increased diversity and relaxed substrate specificity of generalist detoxification enzymes, the inducibility of GST forms and activity in insects exposed to allelochemicals and host plant foliage suggests that some consumers also have the ability to mount a defense against dietary toxins through changes in GST expression (Yu 1982, 1989, Brattsten 1992, Snyder et al. 1995, Yu 1999, Feng et al. 2001, Francis et al. 2001, Fang et al. 2005, Francis et al. 2005). For generalist consumers that regularly encounter unpredictable host chemistry, a combination of diverse, catalytically versatile, allelochemically-responsive GSTs would confer a selective advantage and have substantial influence in determining dietary preference among herbivores.

Like their terrestrial counterparts, marine consumers that regularly feed on allelochemically-rich prey may have evolved a parallel suite of biochemical resistance mechanisms (reviewed in Sotka \& Whalen 2008). The induction or high constitutive activity of GSTs seen in several marine molluscs after exposure to allelochemical treatment or diet has been suggested as a protective mechanism against dietary intoxication (Lee et al. 1988, Vrolijk \& Targett 1992, Regoli et al. 1997, DeBusk et al. 2000, Kuhajek \& Schlenk 2003, Vasconcelos et al. 2007). For example, the generalist marine gastropod Cyphoma gibbosum, which feeds entirely on a diet of chemicallydefended gorgonians (O'Neal \& Pawlik 2002), contains highly expressed cytosolic GST forms in its digestive gland (Vrolijk \& Targett 1992), with activities rivaling those of 
terrestrial invertebrates that feed solely on allelochemically-rich prey (Lee 1991, Lee \& Berenbaum 1992). Vrolijk \& Targett (1992) noted differences in GST activity from field-collected C. gibbosum feeding on different gorgonian diets, suggesting that GST activity is induced in response to different suites of gorgonian allelochemicals.

The gorgonian Plexaura homomalla, in particular, has been suggested to be a preferred diet of C. gibbosum (Harvell \& Suchanek 1987, Lasker et al. 1988) even though this gorgonian contains impressive quantities of the cyclopentenone prostaglandins $\left(\mathrm{PGA}_{2}\right)$ (Weinheimer \& Spraggins 1969, Schneider et al. 1972, Spraggins 1972, Schneider et al. 1977, Ciereszko et al. 1985), known to serve as a feeding deterrent against generalist reef predators (Gerhart 1984, Pawlik \& Fenical 1989, Gerhart 1991). Aside from their icythodetterent properties in marine systems, the cytotoxic effects of cyclopentenone prostaglandins (cyPGs) (e.g., induction of apoptosis and inhibition of cell growth) are believed to stem from their reactive $\alpha, \beta$-unsaturated carbonyl group in the cyclopentenone ring, which can undergo nucleophilic addition with electrophilic moieties resulting in protein and DNA adduct formation (Noyori \& Suzuki 1993, Bogaards et al. 1997, Chen et al. 1999, Sanchez-Gomez et al. 2007). Cyclopentenone prostaglandins of the $\mathrm{A}$ and $\mathrm{J}$ series have been shown to be inducers of GST activity and mRNA/protein expression in mammalian (Kawamoto et al. 2000, Uchida 2000) and invertebrate cell lines (Stanley et al. 2008). Furthermore, select vertebrate alpha-, mu- and pi-class GSTs were found to enhance $\mathrm{PGA}_{2}$ conjugation with glutathione, suggesting that the overexpression of GST forms could modulate the cytotoxic effects of cyPGs (Bogaards et al. 1997). Given that $C$. gibbosum neither avoids $P$. homomalla nor adjusts its feeding 
rates to reduce toxin exposure (Lasker et al. 1988), this snail likely possesses effective detoxification mechanisms, possibility GST-mediated, to contend with the high concentrations of dietary prostaglandins.

In a previous study, proteomic analysis confirmed the expression of two major GST mu-class isoforms responsible for the high GST activity observed in the digestive gland of C. gibbosum (Chapter 2). Here, I present the results of a controlled laboratory feeding study that was used to examine the influence of gorgonian diet on GST activity and subunit expression in C. gibbosum digestive gland. Results indicate that GST subunit composition was invariant and activity was consistently high regardless of snail diet, suggesting that constitutive GST expression in C. gibbosum may afford this consumer greater protection if gorgonian diets examined were to contain GST substrates. To identify possible substrates for Cyphoma GSTs, gorgonian extracts were screened using a bioassay-guided fractionation approach. These studies revealed that moderately hydrophobic fractions from all gorgonians examined inhibited GST activity, suggesting that the putative substrates/inhibitors for Cyphoma GSTs are ubiquitous among all gorgonian species. In addition, selected prostaglandins representing a range of eicosanoids previously described from $P$. homomalla were examined for their ability to inhibit GST activity. Kinetic analyses revealed cyclopentenone prostaglandins to be high affinity competitive inhibitors - and thus likely substrates - for C. gibbosum GSTs, with apparent affinity values comparable to $\mathrm{K}_{\mathrm{m}}$ values described for prostaglandin-conjugating vertebrate GSTs. 


\section{Materials and Methods}

Reagents

1-chloro-2,4-dinitrobenzene (CDNB), dithiothreitol (DTT), potassium phosphate, potassium chloride, EDTA, protease inhibitor cocktail mix, glutathione (GSH), and GSHagarose were purchased from Sigma (St. Louis, MO). PD-10 desalting columns were purchased from GE Healthcare (Piscataway, NJ). Bradford reagents were purchased from BioRad (Hercules, CA). Prostaglandins 15(S)-PGA 2 , 15(R)-15-methyl PGA 2 , 15(S)-PGE $2,15(\mathrm{R})-\mathrm{PGE}_{2}, 15(\mathrm{~S})-\mathrm{PGE}_{2}$-methyl ester, 15(S)-PGF $2 \alpha, 15(\mathrm{R})-\mathrm{PGF}_{2 \alpha}, 15(\mathrm{~S})-$ $\mathrm{PGF}_{2 \alpha}$-methyl ester were purchased from Cayman Chemical (Ann Arbor, MI).

\section{Animal collection and feeding assay design}

Feeding assays with adult Cyphoma gibbosum (ca 2-3 cm length) and six species of gorgonian (Briareum asbestinum, Eunicea mammosa, Gorgonia ventalina, Pseudopterogorgia acerosa, Pseudopterogorgia americana, Plexaura homomalla) were performed as described in Chapter 3, Materials and Methods. Briefly, a total of 39 snails were collected from four shallow reefs (Big Point $-23^{\circ} 47.383^{\prime} \mathrm{N}, 76^{\circ} 8.113^{\prime} \mathrm{W}$; North Normans $-23^{\circ} 47.383^{\prime} \mathrm{N}, 76^{\circ} 8.264^{\prime} \mathrm{W}$; Rainbow Gardens $-23^{\circ} 47.792^{\prime} \mathrm{N}, 7^{\circ} 8.787^{\prime} \mathrm{W}$; Shark Rock $-23^{\circ} 45.075^{\prime} \mathrm{N}, 76^{\circ} 7.475^{\prime} \mathrm{W}$; Sugar Blue Holes $-23^{\circ} 41.910^{\prime} \mathrm{N}, 76^{\circ} 0.23^{\prime} \mathrm{W}$ ) surrounding Lee Stocking Island, Exuma Cays, Bahamas and allowed to feed ad. libum on either a control diet or one of six gorgonian diets for $4 \mathrm{~d}$. Following the completion of the feeding assay digestive glands were immediately dissected, weighed, frozen in liquid nitrogen and maintained at $-80^{\circ} \mathrm{C}$ until further processing. Table 1 and Figure 3 in 
Chapter 3 provide a summary of the feeding assay design and summary of the digestive gland samples collected for protein analysis.

\section{GST purification and HPLC analysis subunits}

Cytosolic and affinity-purified GSTs were isolated from Cyphoma digestive gland samples as described in Chapter 2, Materials and Methods. Briefly, cytosolic GSTs were isolated by homogenizing digestive glands $(\mathrm{n}=39)$ separately in buffer $(0.1 \mathrm{M}$ potassium phosphate, $1 \mathrm{mM}$ EDTA, $1 \mathrm{mM}$ DTT, 1.15\% potassium chloride, protease inhibitor cocktail (1X); $\mathrm{pH} 7.5)$ and differentially centrifuging the homogenates to obtain the cytosolic fraction containing the soluble GST pool. Individual cytosolic GST fractions were then applied to both a PD-10 size exclusion and GSH-agarose affinity column in series to obtain affinity-purified GSTs as described in Chapter 2, Materials and Methods. GST fractions were buffer exchanged to low salt concentration and concentrated with Amicon Ultra-4 centrifugational filters (5K NMWL membrane; Millipore, Billerica, MA). Protein concentrations of Amicon concentrates were determined using the NanoOrange protein quantitation kit (Molecular Probes, Eugene, OR).

A $30 \mu \mathrm{L}$ aliquot of the affinity-purified GST concentrate from each of the 39 digestive gland samples was injected onto a reverse phase Vydac protein/peptide column (model \#218 TP 52; C18 $\mu \mathrm{m} 250 \mathrm{~mm}$ x $2.1 \mathrm{~mm}$ ) and separated using a Waters 600 MultiSolvent Delivery System, with a flow rate of $0.5 \mathrm{~mL} / \mathrm{min}$. Peaks were detected using a Waters 2487 Dual Wavelength Absorbance Detector $(\lambda=214 \mathrm{~nm})$. Mobile phase A consisted of $38 \%$ acetonitrile, $62 \%$ water and $0.1 \%$ trifluoroacetic acid (TFA). Mobile 
phase B consisted of $80 \%$ acetonitrile, $20 \%$ water and $0.1 \%$ TFA. The initial mobile phase consisted of $100 \%$ A. GST subunits were separated using a linear gradient from 0 to $40 \% \mathrm{~B}$ in $22 \mathrm{~min}$, and 40 to $100 \% \mathrm{~B}$ in $37 \mathrm{~min}$. The column was re-equilibrated with $100 \% \mathrm{~A}$ from $37-50$ mins prior to the next injection. Integration of peak area was achieved using the Empower 2 Chromatography Data Software package (Waters, Milford, MA) and converted to GST subunit percent composition for each digestive gland sample.

\section{GST activity assay}

Enzyme activity was measured using CDNB as a substrate by the method of (Habig et al. 1974) optimized for C. gibbosum (Vrolijk \& Targett 1992) in a microplate format. The reaction mixture (in a final volume of $200 \mu \mathrm{L}$ ) contained $0.1 \mathrm{M}$ potassium phosphate buffer, 1.0 mM EDTA, pH 7.5, 1 mM CDNB, $1 \mathrm{mM}$ reduced glutathione (GSH) and $2 \mu \mathrm{g}$ of cytosolic protein or $3.3-6.4 \mathrm{ng}$ of affinity-purified GST sample. CDNB was solubilized in ethanol and constituted $1 \%$ of the final reaction mixture volume. The reaction was incubated at $25^{\circ} \mathrm{C}$ and initiated by the addition of CDNB. All reactions were performed in triplicate. The conjugation of CDNB with GSH was measured as the increase in absorbance at $340 \mathrm{~nm}\left(\Delta \varepsilon_{340} 0.00503 \mu \mathrm{M}^{-1} \mathrm{~cm}^{-1}\right)$ using a tunable microplate reader (Versamax, Molecular Devices, Sunnyvale, CA). Activity was calculated using protein concentrations determined via the Bradford assay with BSA as a standard. 


\section{Extraction and isolation of gorgonian compounds}

A minimum of ten colonies for each gorgonian species were collected from shallow reefs $(<20 \mathrm{~m})$ surrounding Lee Stocking Island, Exuma Cays, Bahamas and used in the feeding assays described above. A portion of the gorgonian colonies, prior to their introduction into the feeding assay, was immediately removed after field collection and immersed in seawater to determine volumetric displacement, frozen at $-80^{\circ} \mathrm{C}$, and lyophilized for subsequent chemical extraction. Pseudopterogoria blanquillensis was also collected for chemical analysis; however, this gorgonian species did not participate in the feeding assays. A $50 \mathrm{~mL}$ equivalent pool of gorgonian tissue for each of the eight species was extracted twice in $250 \mathrm{~mL}$ reagent grade acetone overnight with agitation.

Resulting extracts were vacuum-filtered through celite, dried down by rotary evaporation, and recombined into a $20 \mathrm{~mL}$ scintillation vial using a minimum volume of solvent. Extracts were then completely dried using a vacuum concentrator. The crude extracts were assayed at $1 / 20^{\text {th }}$ natural concentration by volume (i.e., the extract from $0.05 \mathrm{~mL}$ of gorgonian was diluted into $1 \mathrm{~mL}$ of assay buffer) for the ability to inhibit Cyphoma cytosolic GST activity as described above, and inhibitory fractions were subjected to further fractionation using a bioassay-guided fractionation approach.

Gorgonian crude organic extracts were separated by partition between hexane and methanol-water (9:1) followed by partition of the methanol-water fraction (adjusted to 6:4) against chloroform. All three fractions were reduced in vacuo and assayed for their ability to inhibit cytosolic GST activity. The chloroform fractions from all eight gorgonian species showed the most inhibition and were further separated on a reverse- 
phase semi-prep Zorbax SB-C18 column $(5 \mu \mathrm{m}, 9.4 \mathrm{~mm} \times 2.5 \mathrm{~cm})$ attached to a Waters Breeze HPLC system (515 pump) with a Waters 2487 UV detector at 215 and $254 \mathrm{~nm}$. Compounds were eluted over $33 \mathrm{mins}$ at a flow rate of $3 \mathrm{~mL} / \mathrm{min}$ with methanol/water (9:1) with linear ramping to $100 \%$ methanol. HPLC fractions were hand collected at three minute intervals over 33 min, yielding ten fractions per gorgonian species. Each fraction was assayed for GST inhibition at $1 / 10^{\text {th }}$ natural concentration by volume. Fractions yielding $100 \%$ inhibition were further assayed at $1 / 200^{\text {th }}$ natural volumetric concentrations.

\section{Inhibition assays}

GST activity measurements were performed as described above. The reaction mixture (in a final volume of $200 \mu \mathrm{L}$ ) contained $0.1 \mathrm{M}$ potassium phosphate buffer, 1.0 mM EDTA, pH 7.5, $1 \mathrm{mM} \mathrm{CDNB}, 1 \mathrm{mM}$ reduced GSH and either $2 \mu \mathrm{g}$ of cytosolic GST preparations or 3.3 - $6.4 \mathrm{ng}$ of affinity-purified GSTs. Gorgonian extracts were dissolved in appropriate solvents (e.g., acetone, $n$-propanol, or methanol), HPLC fractions were dissolved in methanol, and prostaglandins were dissolved in DMSO. Solvent concentrations did not exceed 5\% of the experimental volume and had no effect on GST activity when compared to non-solvent controls (data not shown). Immediately prior to the start of the assay, inhibitor solutions were added to the buffer/GSH mixture and homogenized to ensure equal distribution of inhibitor in all microplate wells. The data were corrected for the non-enzymatic reaction rates and the effect of the inhibitors on 
catalytic activity was measured by comparing the initial rate of reaction in the presence and absence of the inhibitor.

Initially, eight prostaglandins (15(S)-PGA $2,15(\mathrm{R})-15$-methyl $\mathrm{PGA}_{2}, 15(\mathrm{~S})-\mathrm{PGE}_{2}$, 15(R)-PGE 2 , 15(S)-PGE 2 -methyl ester, 15(S)-PGF $2 \alpha, 15(\mathrm{R})-\mathrm{PGF}_{2 \alpha}, 15(\mathrm{~S})-\mathrm{PGF}_{2 \alpha}$-methyl

ester) were screened at $600 \mu \mathrm{M}$ for their potential to inhibit cytosolic GST activity. From this initial screening, only those prostaglandin compounds that demonstrated an ability to reduce GST activity by $50 \%$ or greater were further evaluated at a range of concentrations $(0.2-2000 \mu \mathrm{M})$ in order to estimate the concentration producing $50 \%$ inhibition of enzyme activity $\left(\mathrm{IC}_{50}\right)$. Prostaglandin $\mathrm{IC}_{50}$ values were calculated and $95 \%$ confidence intervals were estimated using Prism 5.0 software (GraphPad) by fitting the $\log$ transformation of the response variable by nonlinear regression to the variable slope equation (1) and constraining the bottom to zero while allowing the Hill Slope to vary. The variable slope equation is:

$$
\mathrm{Y}=\frac{\text { Bottom }+(\text { Top }- \text { Bottom })}{1+10\left(\left(\operatorname{LogIC}_{50}-[\mathrm{I}]\right) * \text { Hillslope }\right)}
$$

where Top is the maximum percent GST activity remaining, Bottom was constrained to zero, $\mathrm{IC}_{50}$ is the concentration of inhibitor that produces inhibition half-way between the Top and Bottom, and [I] is the logarithmic concentration of the inhibitor.

\section{Determining inhibition type and kinetic constants}

In order to determine the type of inhibition, initial-rate measurements with 15(S)$\mathrm{PGA}_{2}$ and GSH using CDNB as the concentration-variable substrate were performed with 
an affinity-purified GST sample at $25^{\circ} \mathrm{C}$ in $0.1 \mathrm{M}$ potassium phosphate buffer, $1.0 \mathrm{mM}$ EDTA, pH 7.5, containing 4\% (v/v) DMSO. Data were corrected for the non-enzymatic reaction rates and globally fitted to equations for competitive (Eq. (2)), noncompetitive (Eq. (3)), and uncompetitive (Eq. (4)) using a single substrate-single inhibitor model with Prism 5.0 software. The equations used were:

$$
\begin{gathered}
v_{\mathrm{o}}=\frac{\mathrm{V}_{\max }[\mathrm{S}]}{\mathrm{K}_{m}\left(1+[\mathrm{I}] / \mathrm{K}_{i}\right)+[\mathrm{S}]} \\
v_{\mathrm{o}}=\frac{\mathrm{V}_{\max }[\mathrm{S}]}{\mathrm{K}_{m}\left(1+[\mathrm{I}] / \mathrm{K}_{i}\right)+[\mathrm{S}]\left(1+[\mathrm{I}] / \mathrm{K}_{i}{ }^{\prime}\right)} \\
v_{\mathrm{o}}=\frac{\mathrm{V}_{\max }[\mathrm{S}]}{\mathrm{K}_{m}+[\mathrm{S}]\left(1+[\mathrm{I}] / \mathrm{K}_{i}{ }^{\prime}\right)}
\end{gathered}
$$

where $v$ is the initial rate of product formation, $\mathrm{V}_{\max }$ is the maximal rate of product formation, $\mathrm{K}_{\mathrm{m}}$ is the Michaelis-Menten constant, [S] is the substrate concentration, [I] is the inhibitor concentration, $\mathrm{K}_{i}$ is the equilibrium dissociation constant for the enzymeinhibitor complex, and $\mathrm{K}_{i}{ }^{\prime}$ is the equilibrium dissociation constant for the inhibitor from the enzyme-substrate-inhibitor complex.

The appropriate model of inhibition was chosen based on how well the data supported each model (goodness-of-fit), given the number of parameters and sample size, using both the Akaike information criterion (AIC) (Akaike 1986) and the extra-sum-ofsquares ( $F$-test) tests. In paired model comparisons (i.e., Eq. (2) versus Eq. (3)) performed by Prism 5.0, the resulting $\Delta \mathrm{AIC}_{\mathrm{c}}$ values were used to calculate the probability 
that each model was correct given the available data and AIC results were compared to $F$-test results to select the most appropriate inhibition model. In no case did the two test results (Akaike and extra-sum-of-squares) differ from one another. The data were then fitted to the most appropriate model and used to estimate an apparent Michaelis-Menten constant $\left(\mathrm{K}_{\mathrm{m}}\right)$ and maximal velocity $\left(\mathrm{V}_{\max }\right)$. Double reciprocal plots of the inhibition data were used to examine the inhibition patterns.

Because the $\mathrm{IC}_{50}$ depends on the substrate concentration used in the experiment, this value is only useful for comparing inhibitors within experiments and not between laboratories unless identical assay conditions were used. However, calculated $\mathrm{K}_{\mathrm{i}}$ values (the dissociation constant of the enzyme-inhibitor complex) can be used to directly compare inhibitor affinity for the enzyme between studies. Once $15(\mathrm{~S})-\mathrm{PGA}_{2}$ was confirmed to be a competitive inhibitor of $C$. gibbosum GST activity, the $\mathrm{K}_{\mathrm{i}}$ was calculated using the $\mathrm{IC}_{50}$ values obtained for $15(\mathrm{~S})-\mathrm{PGA}_{2}, 15(\mathrm{R})-15$-methyl $\mathrm{PGA}_{2}, 15(\mathrm{~S})$ $\mathrm{PGE}_{2}, 15(\mathrm{~S})-\mathrm{PGF}_{2 \alpha}$ with the Cheng-Prusoff equation (Eq. 5), where $\mathrm{IC}_{50}, \mathrm{~K}_{\mathrm{m}}, \mathrm{S}$, and $\mathrm{K}_{\mathrm{i}}$ are defined above.

$$
\mathrm{IC}_{50}=\mathrm{K}_{\mathrm{i}}\left(1+\frac{\mathrm{S}}{\mathrm{K}_{\mathrm{m}}}\right)
$$

\section{Results}

Dietary influence on GST activity and protein composition

Cytosol was isolated from the digestive glands of 39 individual C. gibbosum feeding on one of six gorgonian diets $(n=27)$ or a control diet $(n=12)$ for four days. GST specific activity levels measured from individual crude cytosolic preparations were 
grouped by snail diet and ranged from 1930 to $2957 \mathrm{nmol} \mathrm{\textrm {min } ^ { - 1 } \mathrm { mg } \text { protein }}{ }^{-1}$. GST activity values were within the range reported by Vrolijk and Targett (1992) but did not differ significantly between snail diets (Figure 1). Cytosolic GSTs were further purified (approximately 200-fold) by size-exclusion and affinity chromatography (see Chapter 2, Results) and separated by reverse-phase HPLC in order to quantify the relative abundance of GST subunits from each digestive gland sample (Figure 2). HPLC separation identified fourteen unique peaks, with two major peaks ( 4 and 8 ) representing on average $25 \%$ and $68 \%$ of the relative composition of GST subunits among all digestive gland samples, respectively (Figure 3). HPLC peak (1) and peaks (2 - 14) were previously identified as theta- and mu-class GSTs, respectively (Chapter 2, Results). The relative amounts of each GST form did not differ significantly as a function of gorgonian diet when expressed either as a percent of all subunits present (Figure 3) or when normalized to the amount of affinity-purified GST sample injected on to the HPLC column (Figure 4). These results indicate that, while GST activity is constitutively expressed at high levels in Cyphoma digestive gland, both GST activity and subunit abundance are unaffected by gorgonian diet.

\section{Inhibition of GST activity by gorgonian extracts}

Crude organic extracts were prepared from eight species of gorgonian ( $B$. asbestinum, E. mammosa, G. ventalina, P. acerosa, P. americana, P. blanquillensis, $P$. elisabethae, and $P$. homomalla) and tested at $1 / 20^{\text {th }}$ natural volumetric concentrations for inhibition of Cyphoma GST activity (Figure 5). Extracts from both P. acerosa and $P$. 
homomalla completely inhibited GST activity, while extracts from the remaining gorgonian species inhibited $\geq 70 \%$ of GST activity compared to solvent controls. Crude extracts were then partitioned into three fractions (e.g., hexane, chloroform, and aqueous) of increasing polarity. The chloroform soluble fractions from all gorgonian species consistently showed $\geq 80 \%$ inhibition of GST activity compared to controls. Aqueous fractions displayed minor inhibitory effects with the exception of fractions from $P$. aceros $a$ and $P$. homomalla, which inhibited GST activity by 85 and 99\%, respectively. Hexane fractions exhibited intermediate and wide-ranging inhibitory effects depending on gorgonian species. It was decided to further separate the chloroform soluble fraction by HPLC because of the consistency of inhibition seen for this fraction among all gorgonian extracts surveyed.

Chloroform soluble fractions were separated using reverse-phase HPLC. For all gorgonian species examined, compounds eluting between 3 to 6 min (fraction 1) consistently inhibited affinity-purified GST activity by $>80 \%$ at $1 / 10^{\text {th }}$ natural volumetric concentrations compared to paired solvent controls (Figure 6). Inspection of HPLC traces suggests that fraction 1 for all gorgonian species examined consists of a mixture of compounds. HPLC fraction 1 was further diluted to $1 / 200^{\text {th }}$ natural volumetric concentrations for those gorgonian species (B. asbestinum, E. mammosa, P. acerosa, P. homomalla) exhibiting $>93 \%$ inhibition of GST activity. Diluting fraction 1 decreased the inhibitory effect of the compound(s); however, in all cases diluted fractions still retained the ability to inhibit $>65 \%$ GST activity compared to solvent controls. 
The highly inhibitory chloroform fraction 1 from P. homomalla was further analyzed by Amy Lane at the Georgia Institute of Technology by high-performance separation techniques coupled with spectroscopic methods such as mass spectrometry (MS) and nuclear magnetic resonance (NMR) to provide additional structurally informative data. LC-MS analysis of $P$. homomalla chloroform-soluble fraction 1 revealed the presence of three peaks $(\mathrm{m} / \mathrm{z}=271,315,333)$, which are diagnostic of the free hydroxy acid of $\mathrm{PGA}_{2}$ (Figure 7). Further comparison of the ${ }^{1} \mathrm{H}$ NMR spectra of $P$. homomalla (fraction 1) and the $\mathrm{PGA}_{2}$ standard (Figure 8) confirmed the presence of $\mathrm{PGA}_{2}$ in the gorgonian tissue and indicated that the free hydroxy acid of $\mathrm{PGA}_{2}$ was a major component of the chloroform-soluble fraction. A dilution series of the $\mathrm{PGA}_{2}$ standard was subjected to LC-MS analysis and used to quantify the amount of $\mathrm{PGA}_{2}$ in $P$. homomalla tissue $(1.6 \mathrm{mM})$ based on an extrapolation from the standard curve. Further analysis of $P$. homomalla HPLC fractions 1 and 2 by LC-MS and NMR also suggested the presence of additional prostaglandins, possibly $\mathrm{PGA}_{2}$ analogs (data not shown).

\section{Inhibition of GST activity by prostaglandins}

Eight commercially available prostaglandins representing a diversity of forms present in gorgonian tissue (i.e., $\mathrm{PGA}_{2}, \mathrm{PGE}_{2}, \mathrm{PGF}_{2 \alpha}$ ), including both enantiomers ( $\mathrm{R}$ and S) forms when possible, were screened at $600 \mu \mathrm{M}$ for their ability to inhibit CDNBconjugating activity of crude cytosolic Cyphoma GSTs (Figure 9). Prostaglandins containing a cyclopentenone ring $\left(\mathrm{PGA}_{2}\right)$ caused the greatest inhibition of GST activity, while the methyl ester forms of $\mathrm{PGE}_{2}$ and $\mathrm{PGF}_{2 \alpha}$ displayed little to no inhibitory activity. 
In general, prostaglandin series with the greatest inhibitory activities (i.e., $\mathrm{PGA}_{2}$ ) were those reported to be found in the greatest abundance in gorgonian tissues. The potencies of the four most inhibitory prostaglandins (15(S)-PGA $2,15(\mathrm{R})-15$-methyl $\mathrm{PGA}_{2}, 15(\mathrm{~S})$ $\left.\mathrm{PGE}_{2}, 15(\mathrm{~S})-\mathrm{PGF}_{2 \alpha}\right)$ were evaluated at a range of concentrations $(0.2-2000 \mu \mathrm{M})($ Figure 10). All displayed concentration-dependent inhibition of enzyme activities with $\mathrm{IC}_{50}$ values ranging from $75.4 \mu \mathrm{M}$ for $15(\mathrm{~S})-\mathrm{PGA}_{2}$ to $334.6 \mu \mathrm{M}$ for $15(\mathrm{~S})-\mathrm{PGF}_{2 \alpha}$ (Table 1).

The inhibitory effect of $15(\mathrm{~S})-\mathrm{PGA}_{2}$ was studied in greater detail by examining CDNB concentration-dependent GST conjugating activity in the presence of two concentrations of inhibitor. Apparent kinetic constants $\left(\mathrm{K}_{\mathrm{m}}\right.$ and $\left.\mathrm{V}_{\max }\right)$ for CDNB in the presence and absence of $15(\mathrm{~S})-\mathrm{PGA}_{2}$ (Table 2) were obtained by fitting the data to the Michaelis-Menten equation by non-linear regression. $\mathrm{V}_{\max }$ values for CDNB in the presence and absence of inhibitor did not differ significantly from one another (Extra sum-of-squares $\mathrm{F}$ test, Experiment 1, $\mathrm{F}_{1,32}=2.462, \mathrm{p}=0.13$; Experiment 2, $\mathrm{F}_{1,31}=2.471$, $\mathrm{p}=0.13$ ); however, precise determination of this parameter proved difficult due to the high variability in GST activity measurements at high concentrations of CDNB (Figure 11, part A, B), due to the limited solubility of this substrate at concentrations greater than $3 \mathrm{mM}$.

To determine the type of inhibition caused by $\mathrm{PGA}_{2}$, the data were fit to three inhibition models (competitive, noncompetitive, and uncompetitive) in a series of pairwise comparisons (Table 3,4). Both the Akaike's information criterion and the extra-sum-of-square F test were in agreement that competitive inhibition was statistically superior for describing the data. The competitive inhibition model was, therefore, used to 
calculate kinetic constants for CDNB $\left(\mathrm{K}_{\mathrm{m}}=0.25-0.47 \mathrm{mM}\right)$ and $15(\mathrm{~S})-\mathrm{PGA}_{2}\left(\mathrm{~K}_{\mathrm{i}}=15.6\right.$ $-24.2 \mu \mathrm{M})$ (Table 5). The Cheng-Prusoff equation for competitive inhibition was also used to calculate the corresponding $\mathrm{K}_{\mathrm{i}}$ values for $15(\mathrm{~S})-\mathrm{PGA}_{2}, 15(\mathrm{R})-15$-methyl $\mathrm{PGA}_{2}$, 15(S)-PGE 2 , and 15(S)-PGF ${ }_{2 \alpha}$ using the $\mathrm{IC}_{50}$ values listed in Table 1. The average $\mathrm{K}_{\mathrm{i}}$ value for $15(\mathrm{~S})-\mathrm{PGA}_{2}$ derived from the competitive inhibition equation $\left(\mathrm{K}_{\mathrm{i}}=19.9 \mu \mathrm{M}\right.$, Table 5) exactly matched the calculated $\mathrm{K}_{\mathrm{i}}$ value obtained using the $\mathrm{IC}_{50}$ values obtained for $15(\mathrm{~S})-\mathrm{PGA}_{2}\left(\mathrm{~K}_{\mathrm{i}}=19.9 \mu \mathrm{M}\right.$, Table 1$)$.

Lineweaver-Burk plots of $1 / \mathrm{V}$ versus $1 /[\mathrm{CDNB}]$ for $15(\mathrm{~S})-\mathrm{PGA}_{2}$ inhibition of affinity-purified GSTs did not converge on the y-axis as expected for competitive inhibition, suggesting mixed (competitive and noncompetitive) inhibition (Figure 11, part C, D). Because inhibition assays were not performed on single GST isoform preparations but rather on affinity-purified GST fractions containing multiple GST isoforms, it is possible that $\mathrm{PGA}_{2}$ could interact differently with select GST isoforms. In addition, the variability of the data, likely a result of the insolubility of CDNB at concentrations above $3 \mathrm{mM}$, could substantially influence the trajectory of the regression analysis. In contrast to the Lineweaver-Burke plots, the weight of evidence from the more statistically valid nonlinear regression analysis suggests that $\mathrm{PGA}_{2}$ is a competitive inhibitor and putative substrate for Cyphoma GSTs.

\section{Discussion}

It is likely that the exploitation of allelochemically-defended gorgonian corals by the co-evolved predator, Cyphoma gibbosum, is facilitated by this predator's ability to 
biotransform or sequester dietary allelochemicals using detoxification enzymes such as soluble glutathione $S$-transferases. GSTs are integral components of the cellular xenobiotic defense system (Strange et al. 2000) and have been documented to mediate allelochemical tolerance in terrestrial consumers (Wadleigh \& Yu 1987, 1988, Yu \& Abo-Elghar 2000). Here, I investigated the influence of gorgonian diet on the expression, activity and inhibition of Cyphoma GSTs.

Cyphoma cytosolic digestive gland preparations contained high GST activity; however, contrary to previous reports (Vrolijk \& Targett 1992), GST activity did not significantly vary with respect to gorgonian diet. The apparent differences likely lie in the basic experimental design between the two studies. Vrolijk \& Targett (1992) noted differences in GST activity among field-collected individuals where no data were available on the residence time of snails on their respective hosts. In contrast, snails in the present study were subject to controlled $4 \mathrm{~d}$ feeding assays. It is possible that GST enzymes could show significant levels of induction if snails were allowed to feed on gorgonian diets longer than four days. However, it seems unlikely that our design, which included those gorgonian species examined by Vrolijk \& Targett (1992), would have missed significant induction of GSTs because the length of the assay should have provided sufficient time for protein induction based on GST induction studies in polyphagous insects exposed for two days to dietary allelochemicals (Wadleigh \& Yu 1988, Yu 1999). Additionally, snails could extend their exposure to the same suite of allelochemicals beyond the average 3.3 day residence time predicted by (Harvell \& Suchanek 1987), if snails migrated to another colony of the same species. This scenario 
would be favored if the proportion of B. asbestinum and G. ventalina, the two gorgonian diets eliciting increased GST activity in Vrolijk \& Targett (1992), were in higher abundance on reefs because prey selection by $C$. gibbosum is in proportion to gorgonian species abundance (Harvell \& Suchanek 1987). Alternatively, geographical (Rodriguez 1995) and within colony differences in allelochemical content (Harvell \& Fenical 1989) could account for the differences between the two studies.

Although GST activity did not vary by gorgonian diet, cytosolic digestive gland GSTs were further purified by affinity chromatography to investigate if GST subunit composition was influenced by allelochemical exposure. Cyphoma GST subunits were separated by HPLC resulting in the identification of two major mu-class GST subunits accounting for $93 \%$ of the total GST subunit abundance. Quantification of GST subunit composition indicated that the relative abundance of GST subunits did not differ among snails feeding on different gorgonian diets. Interestingly, GST activity was maintained at a high level and subunit composition did not vary in snails fed control diets devoid of allelochemicals as compared to snails fed gorgonian diets. The presence of high GST activity in control-fed snails could indicate that some lipophilic gorgonian compounds and/or their metabolites may persist in snail tissues even after feeding has ceased, causing the expression of GSTs to be maintained. Alternatively, Cyphoma GSTs could be expressed constitutively at high levels or regulated by an allelochemical-independent mechanism. Having a constant supply of 'all-purpose' GST enzymes may prove advantageous for predators that consistently feed on prey containing allelochemical GST substrates. 
To determine the prevalence of gorgonian species containing putative GST substrates, gorgonian extracts and semi-pure fractions were screened for their ability to inhibit the CDNB-conjugating activity of Cyphoma GSTs. The ability of compounds to inhibit GST activity was used as an indirect measure of their potential to act as GST substrates. Crude extracts from all eight gorgonian species were effective at inhibiting GST activity by greater than $70 \%$ at $1 / 8^{\text {th }}$ natural volumetric concentrations compared to controls. In general, substrates for GST enzymes are classified as hydrophobic compounds able to react with the thiol moiety of glutathione (Hayes et al. 2005). Upon further separation of the crude extract, the chloroform-soluble fraction was identified as containing the bulk of the inhibitory compounds. Efforts are underway to determine if the chloroform-soluble fractions contain electrophilic compounds with internal leaving groups (e.g., epoxides, $\alpha, \beta$-unsaturated ketones, halogenated hydrocarbons, etc.) (van Bladeren 2000) capable of serving as sites for the nucleophilic addition of glutathione. In addition to containing potential GST substrates, gorgonian extracts may also contain electrophilic compounds that could act as potent GST inhibitors, binding to free cysteine residues on the protein, resulting in enzyme inactivation (van Iersel et al. 1999). The presence of high affinity GST inhibitors in gorgonian tissues may represent specific counter-adaptations of prey to thwart consumer GST-mediated metabolism of cooccurring allelochemicals (Lee 1991, Li et al. 2007). Although the high-throughput screening approach of gorgonian extracts was not able to distinguish between GST substrates and inhibitors, this result did substantiate the hypothesis that all gorgonian species contained significant quantities of compounds capable of interacting with 
Cyphoma GSTs, which could account for the high constitutive activity of digestive gland GSTs identified here and in (Vrolijk \& Targett 1992).

In this study, I also examined the chemistry of specific gorgonian diets that contain classes of compounds recognized to be substrates/inhibitors for vertebrate GSTs (Cagen et al. 1975, van Iersel et al. 1999, Beuckmann et al. 2000, Kawamoto et al. 2000, Uchida 2000, Murphy \& Zarini 2002, Sanchez-Gomez et al. 2007). The gorgonian Plexaura homomalla, once under intense study because of the unusually high concentration of prostaglandins isolated from its tissues, can account for nearly $50 \%$ of the biomass on some Caribbean reefs (Bayer \& Weinheimer 1974) and has been suggested to be a favored diet of C. gibbosum (Harvell \& Suchanek 1987, Lasker et al. 1988, Chiappone et al. 2003). The potential importance of this particular gorgonian species' allelochemicals in the co-evolution of $C$. gibbosum detoxification enzymes coupled with the interesting ecological and biological activities of eicosanoids, were motivating factors in determining if prostaglandins could serve as substrates for $C$. gibbosum GSTs.

P. homomalla tissues predominately contain the fully esterified form of $\mathrm{PGA}_{2}(\sim$ $2 \%$ dry weight of the gorgonian) (Weinheimer \& Spraggins 1969), which is related to a larger group of eicosanoids that includes the coral-derived halogenated marine clavulones (Honda et al. 1987, Iguchi et al. 1987) and puniglandins (Fukushima \& Kato 1985, Baker $\&$ Scheuer 1994), all of which display cytotoxic activities thought to be related to the presence of a reactive $\alpha, \beta$-unsaturated ketone (Honn \& Marnett 1985, Kato et al. 1986). While the exact mechanism of toxicity is unknown, the prostaglandins are transported 
into the nucleus (Narumiya \& Fukushima 1986, Narumiya et al. 1987, Narumiya et al. 1988) where the electrophilic $\alpha, \beta$-unsaturated carbonyl is free to bind with nucleophilic sulfhydryl residues on target proteins, unless rapidly conjugated by cytosolic GSH and exported out of the cell by glutathione-conjugate transporters (Atsmon et al. 1990). In this study, the $\alpha, \beta$-unsaturated carbonyl-containing prostaglandins (15(R)-15-methyl $\mathrm{PGA}_{2}$ and $\left.15(\mathrm{~S})-\mathrm{PGA}_{2}\right)$ were the most potent inhibitors of CDNB conjugating activity of Cyphoma GSTs in both the initial screening of eight prostaglandin compounds and upon comparison of $\mathrm{IC}_{50}$ values, establishing the order of potency of prostaglandins to be 15(S)-PGA $2>15(\mathrm{R})-15$-methyl $\mathrm{PGA}_{2}>>15(\mathrm{~S})-\mathrm{PGE}_{2} \approx 15(\mathrm{~S})-\mathrm{PGF}_{2 \alpha}$. The $\mathrm{K}_{\mathrm{i}}$ values for cyclopentenone-containing prostaglandin A series were also 2.3- to 4-fold lower (greater affinities) for Cyphoma GSTs in comparison to those of either $\mathrm{PGE}_{2}$ or $\mathrm{PGF}_{2 \alpha}$. In addition, subsequent structural analysis confirmed that the inhibitory $P$. homomalla chloroform-soluble fractions predominantly contained high concentrations of the potent $\mathrm{PGA}_{2}$ and $\mathrm{PGA}_{2}$-analogs, likely accounting for the bulk of the observed inhibition for these particular HPLC fractions.

Statistical comparison of the goodness-of-fit of the data among different models of inhibition using both Akaike information criterion and extra-sum-of-squares test suggest that $\mathrm{PGA}_{2}$ is a competitive inhibitor of $\mathrm{CDNB}$, and likely a substrate for $C$. gibbosum GST(s). Because $\mathrm{PGA}_{2}$ acts as a competitive inhibitor of GST activity, likely binding with high affinity in the active site (H-site) once occupied by $\mathrm{CDNB}$, it is reasonable to compare $\mathrm{K}_{\mathrm{i}}$ values (i.e., apparent $\mathrm{K}_{\mathrm{m}}$ for $\mathrm{PGA}_{2}$ ) obtained here to $\mathrm{K}_{\mathrm{m}}$ values for $\mathrm{PGA}_{2}$ cited in other studies. The apparent $\mathrm{K}_{\mathrm{m}}(\sim 19.9 \mu \mathrm{M})$ for $15(\mathrm{~S})-\mathrm{PGA}_{2}$ described 
here is in line with the $\mathrm{K}_{\mathrm{m}}$ value identified for the conversion of $\mathrm{PGA}_{2}$ to its glutathione conjugate by human mu-class GST M1a-a (26 $\mu \mathrm{M})$ (Bogaards et al. 1997) and $\mathrm{K}_{\mathrm{m}}$ values for $\mathrm{PGA}_{2}$ for rat alpha-class GST A4-4 (12 $\left.\mu \mathrm{M}\right)$ and human mu-class GST M2-2 (7.6 $\mu \mathrm{M})$ (Hubatsch et al. 2002). The similarity between kinetic constants further supports the conclusion that $\mathrm{PGA}_{2}$ is a substrate for Cyphoma GSTs. The rank order of affinity of Cyphoma GSTs for prostaglandins (15(S)-PGA $2>15(\mathrm{R})-15$-methyl $\mathrm{PGA}_{2}>15(\mathrm{~S})-\mathrm{PGE}_{2}$ $\left.>15(\mathrm{~S})-\mathrm{PGF}_{2 \alpha}\right)$, also is positively correlated with the abundance of each prostaglandin series in P. homomalla tissues, suggesting that Cyphoma GSTs may have evolved to efficiently catalyze those prostaglandin series found in the greatest abundance in its diet $\left(\mathrm{PGA}_{2}\right)$, yet still retain a broad enough substrate specificity to conjugate additional forms $\left(\mathrm{PGE}_{2}, \mathrm{PGF}_{2 \alpha}\right)$.

The apparent $\mathrm{K}_{\mathrm{m}}$ values reported here indicate that dietary prostaglandins would be high affinity substrates of Cyphoma digestive gland GSTs in vivo. However, the physiological relevance of GSTs for prostaglandin biotranformation depends on the concentrations of prostaglandins occurring in the digestive glands of Cyphoma feeding on prostaglandin-containing gorgonians. To obtain an estimate of these concentrations, I first calculated the volume of $P$. homomalla tissue consumed per snail per day based on feeding scar measurements reported in (Harvell \& Suchanek 1987). Cyphoma feeding scars on $P$. homomalla colonies averaged $12 \mathrm{~cm}$ in length $(\mathrm{n}=21$ snails $)$, did not exceed $1 \mathrm{~cm}$ in width, and penetrated to the gorgonian skeleton $66 \%$ of the time (Harvell \& Suchanek 1987). Therefore, conservative estimates of scar volume averaged $1.44 \mathrm{~cm}^{3}$ per snail (or $1.44 \mathrm{~mL}$ ) (length $\mathrm{x}$ width $\mathrm{x}$ depth; $12 \mathrm{~cm} \mathrm{x} 0.4 \mathrm{~cm} \times 0.4 \mathrm{~cm}$ ). This tissue 
volume was divided by the mean residence time of snails feeding on P. homomalla (2.9 $\mathrm{d}, \mathrm{n}=50$ snails) (Harvell \& Suchanek 1987) to yield an estimate for the volume of $P$. homomalla tissue consumed by each snail per day $(0.66 \mathrm{~mL} / \mathrm{snail} /$ day). (Pawlik \& Fenical 1989) determined that $1 \mathrm{~mL}$ of wet $P$. homomalla tissue (excluding the gorgonian axial skeleton) was equal to $0.86 \mathrm{~g}$ of dry gorgonian tissue. If $2 \%$ of the dry weight of the gorgonian is prostaglandins (Weinheimer \& Spraggins 1969), then $0.66 \mathrm{~mL}$ of gorgonian tissue would contain $0.011 \mathrm{~g}$ of prostaglandins. Assuming the majority of the prostaglandins are in the $\mathrm{PGA}_{2}(\mathrm{FW}=348.5 \mathrm{~g} / \mathrm{mol})$ form and are completely retained within the digestive gland upon ingestion (ave. dig. gland weight $=0.25 \mathrm{~g}(\mathrm{n}=96$ snails) with a density comparable to human liver $\sim 1 \mathrm{~g} / \mathrm{mL}$ ), then the upper limit of $\mathrm{PGA}_{2}$ concentrations in digestive gland would be $0.13 \mathrm{M}$. The single day grazing rates of $P$. homomalla colonies by C. gibbosum reported in (Lasker et al. 1988) were used to obtain a lower bound of tissue consumption; their average feeding rates of $0.17 \mathrm{~mL} / \mathrm{snail} / \mathrm{day}$ lead to an estimated $\mathrm{PGA}_{2}$ concentration of 0.03 M. Ciereszko \& Schneider (1987) reported the fecal pellets of $C$. gibbosum contain no appreciable amounts of recognizable prostaglandins, suggesting that the majority of prostaglandins are being metabolized or sequestered in the snail. If we conservatively assume only $1 \%$ of the ingested prostaglandins are retained within the digestive gland during feeding (e.g., $1 \%$ concentration of $\mathrm{PGA}_{2} \sim 0.3-1.3 \mathrm{mM} \mathrm{PGA}_{2}$ ), the in vivo concentration of prostaglandins in this tissue would still be 15 - to 65 -fold higher than the apparent $\mathrm{K}_{\mathrm{m}}$ $(15.6-24.2 \mu \mathrm{M})$ obtained for $\mathrm{PGA}_{2}$ (Table 5). Even at the lower bound of in vivo $\mathrm{PGA}_{2}$ 
concentration $(\sim 0.3 \mathrm{mM})$, Cyphoma GSTs would be nearing their physiological capacity $(>95 \%)$ according to fractional velocity $\left(\mathrm{v} / \mathrm{V}_{\max }\right)$ calculations.

The $\mathrm{K}_{\mathrm{m}}$ for CDNB calculated here (ave. $0.36 \mathrm{mM}$ ) was substantially lower than the $\mathrm{K}_{\mathrm{m}}$ value (ave. $1.49 \mathrm{mM}$ ) reported for Cyphoma by Vrolijk and Targett (1992), indicating that CDNB has a higher affinity for Cyphoma GSTs than previously thought. The apparent differences between kinetic constants is likely a result of measurements made using different protein sources - affinity-purified GSTs used in this study as opposed to crude cytosolic preparations used in Vrolijk and Targett (1992). If CDNB readily interacts with non-GST proteins in a sample, effectively decreasing the freeCDNB concentration, this could result in higher apparent $\mathrm{K}_{\mathrm{m}}$ values reported by Vrolijk and Targett (1992).

GSTs have gained considerable attention for their conjugating ability to conjugate electrophilic toxicants. However, their lesser known ability to bind non-substrate ligands by acting as 'xenobiotic sponges', capable of soaking up and sequestering excess intracellular xenobiotics, may be as important of a protective mechanism (Ketley et al. 1975, Kostaropoulos et al. 2001). Select human GST isoforms have also been shown to exert their protective effects through this ligandin-like behavior by binding with high affinity to inhibitory prostaglandins (e.g., $\mathrm{PGJ}_{2}$ ), effectively sequestering them in the cytosol away from target nuclear proteins and preventing gene regulation (Paumi et al. 2004, Sanchez-Gomez et al. 2007). Lineweaver-Burke plots indicate that $\mathrm{PGA}_{2}$ is a mixed inhibitor of Cyphoma GST activity, suggesting that this prostaglandin can bind to both the substrate active site and other sites on Cyphoma GSTs. This additional binding 
capacity of $\mathrm{PGA}_{2}$ to non-active site residues may indicate that sequestration of cyPGs by Cyphoma GSTs may be an important protective mechanism, and that over expression of GST forms could afford additional protection against prostaglandin-induced cytotoxicity.

The potential of GST to bind non-substrates has also been hypothesized to help protect consumers that regularly feed on allelochemical-rich prey. A comprehensive screening of allelochemicals from plants found that many inhibit the GSTs found in generalist lepidopterans (Yu \& Abo-Elghar 2000), and over expression of GST enzymes in these consumers may play an important role in non-enzymatic cellular defense against dietary electrophilic chemical defenses. In marine systems, the chiton Cryptochiton stelleri regularly feeds on a red algal diet known to contain high concentrations of the feeding deterrent lanosol (DeBusk et al. 2000). Lanosol was found to be a noncompetitive inhibitor of $C$. stelleri GST activity, suggesting that while this feeding deterrent is not a substrate, overexpression of GSTs may serve as a detoxification strategy if GST enzymes can sequester the compound. Like C. stelleri, high constitutive GST activity was observed in Cyphoma independent of allelochemical diet and all of the gorgonian extracts examined contained potent inhibitory compounds. While the type of inhibition was not quantified for the gorgonian extracts, it is likely that gorgonian diets contain both substrates (i.e., $\mathrm{PGA}_{2}$ ) and non-substrate ligands. Therefore, constitutive expression of GSTs may be indicative of a more general biochemical resistance strategy that is capable of responding to a diversity of compounds in the diet of a generalist consumer. 
The results of this study provide the first comprehensive evaluation of the influence of dietary allelochemicals on the expression and function of glutathione transferases in a generalist marine consumer. Controlled feeding assays showed that Cyphoma digestive gland GST composition and activity did not vary with gorgonian diet. This result, in combination with evidence from in vitro inhibition studies with Cyphoma GSTs by gorgonian extracts, suggests the high constitutive expression of GST enzymes in Cyphoma digestive gland may be necessitated by the presence of numerous potent inhibitors/substrates in their gorgonian diets. Furthermore, all three prostaglandin series (A, E, F) found in the gorgonian P. homomalla were able to inhibit Cyphoma CDNBconjugating GST activity, with relative potencies positively correlated with their abundance in gorgonian tissues. Kinetic analysis also demonstrated that inhibition of Cyphoma GSTs by prostaglandin $\mathrm{A}_{2}$ was competitive toward CDNB and that its $\mathrm{K}_{\mathrm{i}}$ (apparent $\mathrm{K}_{\mathrm{m}}$ ) values were similar to $\mathrm{K}_{\mathrm{m}}$ values from known prostaglandin-conjugating vertebrate GSTs, suggesting that this allelochemical is a substrate for Cyphoma mu-class GSTs. Together, these findings suggest $C$. gibbosum detoxification enzymes have evolved to enable the detoxification of a broad range of electrophilic allelochemicals resulting from its close association with diverse gorgonian diets. Given the importance of allelochemicals in shaping patterns of predation and herbivory in marine systems, these findings suggest that co-evolved marine consumers have the capacity to detoxify allelochemicals in their prey, providing these consumers with a competitive advantage in ecosystems where allelochemically-rich prey species abound. 


\section{References}

Akaike A (1986) An information criterion (AIC). Math Sci 14:5-9

Atsmon J, Freeman ML, Meredith MJ, Sweetman BJ, Roberts II LJ (1990) Conjugation of 9-deoxy-delta-9-delta-12(E)-prostaglandin $\mathrm{D}_{2}$, with intracellular glutathione and enchancement of its antiproliferative activity by glutathione depletion. Cancer Research 50:1879-1885

Baker BJ, Scheuer PJ (1994) The punaglandins: 10-chloroprostanoids from the octocoral Telesto riisei. Journal of Natural Products 57:1346-1353

Bayer FM, Weinheimer AJ (1974) Prostaglandins from Plexaura homomalla: ecology, utilization and conservation of a major medical marine resource. University of Miami Press, Coral Gables, Florida, 165 pp.

Beuckmann CT, Fujimori K, Urade Y, Hayaishi O (2000) Identification of Mu-class glutathione transferases M2-2 and M3-3 as cytosolic prostaglandin E synthases in the human brain. Neurochemical Research 25:733-738

Bogaards JJ, Venekamp JC, van Bladeren PJ (1997) Stereoselective conjugation of prostaglandin A2 and prostaglandin J2 with glutathione, catalyzed by the human glutathione S-transferases A1-1, A2-2, M1a-1a, and P1-1. Chemical Research in Toxicology 10:310-317

Bolton RM, Ahokas JT (1997) Purification and characterisation of hepatic glutathione transferases from a herbivorous marsupial, the brushtail possum (Trichosurus vulpecula). Comparative Biochemistry and Physiology Part B 116:467-475

Brattsten VJ (1992) Metabolic defenses against plant allelochemicals. In: Rosenthal G, Berenbaum M (eds) Herbivores: Their interactions with secondary metabolites, Vol 2. Academic Press, San Diego, p 175-242

Cagen LM, Pisano JJ, Ketley JN, Habig WH, Jakoby WB (1975) The conjugation of prostaglandin A1 and glutathione catalyzed by homogenous glutathione Stransferases from human and rat liver. Biochimica et Biophysica Acta - Lipids and Lipid Metabolism 398:205-208

Chen Y, Morrow JD, Roberts II LJ (1999) Formation of reactive cyclopentenone compounds in vivo as products of the isoprostane pathway. Journal of Biological Chemistry 274:10863-10868

Chiappone M, Dienes H, Swanson DW, Miller SL (2003) Density and gorgonian hostoccupation patterns by flamingo tongue snails (Cyphoma gibbosum) in the Florida Keys. Caribbean Journal of Science 39:116-127 
Ciereszko LS, Gopichand Y, Schmitz FJ, Schneider WP, Bundy GL (1985) Prostglandin (15S)-PGA 2 derivatives in the gorgonian Plexaura homomalla (Esper) forma kukenthali. Cellular and Molecular Life Sciences 41:37-38

Ciereszko LS, Schneider WP (1987) Conversion of the prostaglandin (15S)-PGA2 to (15S)-PGB2 in the flamingo tongue snail Cyphoma gibbosum (L.). Bulletin of Marine Science 41:634

DeBusk BC, Chimote SS, Rimoldi JM, Schenk D (2000) Effect of the dietary brominated phenol, lanasol, on chemical biotransformation enzymes in the gumboot chiton Cryptochiton stelleri (Middendorf, 1846). Comparative Biochemistry and Physiology Part C 127:133-142

Fang T, Pei L, Xiwu G (2005) Tissue-specific expression of glutathione S-transferases induced by 2-tridecanone or quercetin in cotton bollworms, Helicoverpa armigera. Progress in Natural Science 15:988-992

Feng Q-L, Davey KG, Pang ASD, Ladd TR, Retnakaran A, Tomkins BL, Zheng S, Palli SR (2001) Developmental expression and stress induction of glutathione Stransferase in the spruce budworm, Choristoneura fumiferana. Journal of Insect Physiology 47:1-10

Francis F, Haubruge E, Gaspar C, Dierickx PJ (2001) Glutathione S-transferases of Aulacorthum solani and Acyrthosiphon pisum: partial purification and characterization. Comparative Biochemistry and Physiology Part B 129:165-171

Francis F, Vanhaelen N, Haubruge E (2005) Glutathione S-transferase in the adaptation to plant secondary metabolites in Myzus persicae aphid. Archives of Insect Biochemistry and Physiology 58:166-174

Fukushima M, Kato T (1985) Antitumor marine eicosanoids: clavulones and punaglandins. Adv Prostaglandin Thromboxane Leukotriene Res 15:415-418

Gerhart DJ (1984) Prostaglandin $\mathrm{A}_{2}$ : An agent of chemical defense in the Caribbean gorgonian Plexaura homomalla. Marine Ecology Progress Series 19:181-187

Gerhart DJ (1991) Emesis, learned aversion, and chemical defense in octocorals: a central role for prostaglandins? Am J Physiol Regul Integr Comp Physiol 260:R839R843

Habig WH, Pabst MJ, Jakoby WB (1974) Glutathione S-transferases. Journal of Biological Chemistry 249:7130-7139 
Harvell CD, Fenical W (1989) Chemical and structural defenses of Caribbean gorgonians (Pseudopterogorgia sp.): intracolony localization of defense. Limnology and Oceanography 34:382-389

Harvell CD, Suchanek TH (1987) Partial predation on tropical gorgonians by Cyphoma gibbosum. Marine Ecology Progress Series 38:37-44

Hayes JD, Flanagan JU, Jowsey IR (2005) Glutathione transferases. Annu Rev Pharmacol Toxicol 45:51-88

Honda A, Mori Y, Iguchi K, Yamada Y (1987) Antiproliferative and cytotoxic effects of newly discovered halogenated coral prostanodis from the Japanese stolonifer Clavularia viridis on human myeloid leukemia cells in culture. Molecular Pharmacology 32:530-535

Honn KV, Marnett LJ (1985) Requirement of a reactive $\alpha, \beta$-unsaturated carbonyl for inhibition of tumor growth and induction of differentiation by "A" series prostaglandins. Biochem Biophys Res Commun 129:34-40

Hubatsch I, Mannervik B, Gao L, Roberts LJ, Chen Y, Morrow JD (2002) The cyclopentenone product of lipid peroxidation 15-A2t-isoprostane (8isoprostaglandin A2), is efficiently conjugated with glutathione by human and rat glutathione transferase A4-4. Chem Res Toxicol 15:1114-1118

Iguchi K, Kaneta S, Mori K, Yamada Y (1987) A new marine epoxy prostanoid with an antiproliferative activity from the stolonifer Clavularia viridis Quoy and Gaimard. Chem Pharm Bull 35:4375-4376

Kato T, Fukushima M, Kurozumi S, Noyori T (1986) Antitumor activity of prostaglandin A1 and delta,12-prostaglandin J2 in vitro and in vivo. Cancer Research 46:35383542

Kawamoto Y, Nakamura Y, Naito Y, Torii Y, Kumagai T, Osawa T, Ohigashi H, Satoh K, Imagawa M, Uchida K (2000) Cyclopentenone prostaglandins as potential inducers of phase II detoxification enzymes. The Journal of Biological Chemistry 275:11291-11299

Ketley JN, Habig WH, Jakoby WB (1975) Binding of nonsubstrate ligands to the glutathione S-transferases. Journal of Biological Chemistry 250:8670-8673

Kostaropoulos I, Papadopoulos AI, Metaxakis A, Boukouvala E, PapadopoulouMourkidou E (2001) Glutathione S-transferase in the defence against pyrethroids in insects. Insect Biochemistry and Molecular Biology 31:313-319 
Kuhajek JM, Schlenk D (2003) Effects of the brominated phenol, lanosol, on cytochrome P450 and glutathione transferase activities in Haliotis rufescens and Katharina tunicata. Comparative Biochemistry and Physiology Part C 134:473-479

Lasker HR, Coffroth MA, Fitzgerald LM (1988) Foraging patterns of Cyphoma gibbosum on octocorals: the roles of host choice and feeding preference. Biological Bulletin $174: 254-266$

Lee K (1991) Glutathione S-transferase activities in phytophagous insects: induction and inhibition by plant phototoxins and phenols. Insect Biochem 21:353-361

Lee K, Berenbaum M (1992) Ecological aspects of antioxidant enzymes and glutathione S-transferases in three Papilio species. Biochem Syst Ecol 20:197-207

Lee RF, Keeran WS, Pickwell GV (1988) Marine invertebrate glutathione transferases: purification, characterization and induction. Marine Environmental Research 24:97-100

Li X, Schuler MA, Berenbaum M (2007) Molecular mechanisms of metabolic resistance to synthetic and natural xenobiotics. Annu Rev Entomol 52:231-253

Murphy RC, Zarini S (2002) Glutathione adducts of oxyeicosanoids. Prostaglandins \& Other Lipid Mediators 68-69:471-482

Narumiya S, Fukushima M (1986) Site and mechanism of growth inhibition by prostaglandins. I. Active transport and intracellular accumulations of cyclopentoenone prostaglandins, a reaction leading to growth inhibition. J Pharmacol Exp Ther 239:506-511

Narumiya S, Ohno K, Fujiwara M, Fukushima M (1987) Site and mechanism of growth inhibition by prostaglandins. II. Temperature-dependent transfer of a cyclopentoenone prostglandin to nuclei. J Pharmacol Exp Ther 239:506-511

Narumiya S, Ohno K, Fukushima M, Fujiwara M (1988) Site and mechanism of growth inhibition by prostaglandins. III. Distribution and binding of prostaglandin A2 and delta-12-prostaglandin J2 in nuclei. J Pharmacol Exp Ther 242:306-311

Noyori R, Suzuki M (1993) Organic synthesis of prostaglandins: advancing biology. Science 259:44-45

O'Neal W, Pawlik JR (2002) A reappraisal of the chemical and physical defenses of Caribbean gorgonian corals against predatory fishes. Marine Ecology Progress Series 240:117-126 
Parkinson A (2001) Biotransformation of Xenobiotics. In: Klaassen CD (ed) Casarett and Doull's toxicology: the basic science of poisons. McGraw-Hill, New York, p 133224

Paumi CM, Smitherman PK, Townsend AJ, Morrow CS (2004) Glutathione Stransferases (GSTs) inhibit transcriptional activation by the peroxisomal proliferator-activated receptor gamma (PPARgamma) ligand, 15-deoxy-12,14prostglandin J2 (15-d-PGJ2). Biochemistry 43:2345-2352

Pawlik JR, Fenical W (1989) A re-evaluation of the ichthyodeterrent role of prostaglandins in the Caribbean gorgonian coral Plexaura homomalla. Marine Ecology Progress Series 52:95-98

Regoli F, Nigro M, Bertoli E, Principato G, Orlando E (1997) Defenses against oxidative stress in the Antarctic scallop Adamussium colbecki and effects of acute exposure to metals. Hydrobiologia 355:139-144

Rodriguez AD (1995) The natural products chemistry of west indian gorgonian octocorals. Tetrahedron 51:4571-4618

Sanchez-Gomez FJ, Gayarre J, Avellano MI, Perez-Sala D (2007) Direct evidence for the covalent modification of glutathione S-transferase P1-1 by electrophilic prostaglandins: implications for enzyme inactivation and cell survival. Archives of Biochemistry and Biophysics 457:150-159

Schneider WP, Bundy GL, Lincoln FH, Daniels EG, Pike JE (1977) Isolation and chemical conversions of prostaglandins from Plexaura homomalla: preparation of prostaglandin $\mathrm{E}_{2}$, prostaglandin $\mathrm{F}_{2}$, and their 5,6-trans isomers. Journal of the American Chemical Society 99:1222-1232

Schneider WP, Hamilton RD, Rhuland LE (1972) Occurrence of esters of (15S)prostaglandin $\mathrm{A}_{2}$ and $\mathrm{E}_{2}$ in coral. Journal of the American Chemical Society 94:2122-2123

Snyder MJ, Walding JK, Feyereisen R (1995) Glutathione S-transferase from larval Manduca sexta midgut: sequence of two cDNAs and enzyme induction. Insect Biochem Molec Biol 25:455-465

Sotka EE, Whalen KE (2008) Herbivore offense in the sea: the detoxificaiton and transport of secondary metabolites. In: Amsler C (ed) Algal Chemical Ecology. Springer, New York, p 203-221

Spraggins RL (1972) $\mathrm{PGA}_{2}$ and isomers from coral prostaglandins. Tetrahedron Letters $42: 4343-4346$ 
Stanley DW, Goodman C, An S, McIntosh A, Song Q (2008) Prostaglandins $A_{1}$ and $E_{1}$ influence gene expression in an established insect cell line (BCIRL-HzAM1 cells). Insect Biochemistry and Molecular Biology 38:275-284

Strange RC, Jones PW, Fryer AA (2000) Glutathione S-transferases: genetics and role in toxicology. Toxicology Letters 112-113:357-363

Uchida K (2000) Induction of glutathione S-transferase by prostaglandins. Mechanisms of Ageing and Development 116:135-140

van Bladeren PJ (2000) Glutathione conjugation as a bioactivation reaction. ChemicoBiological Interactions 129:61-76

van Iersel MLPS, Cnubben NHP, Smink N, Koeman JH, van Bladeren PJ (1999) Interactions of prostaglandin $\mathrm{A}_{2}$ with the glutathione-mediated biotransformation system. Biochemical Pharmacology 57:1383-1390

Vasconcelos VM, Wiegand C, S. P (2007) Dynamics of glutathione-S-transferases in Mytilus galloprovincialis exposed to toxic Microcystis aeruginosa cells, extracts and pure toxins. Toxicon 50:740-750

Vrolijk NH, Targett NM (1992) Biotransformation enzymes in Cyphoma gibbosum: implications for detoxification of gorgonian allelochemicals. Marine Ecology Progress Series 88:237-246

Wadleigh RW, Yu SJ (1987) Glutathione transferase activity of fall armyworm larvae toward alpha-beta-unsaturated carbonyl allelochemicals and its induction by allelochemicals. Insect Biochem 17:759-764

Wadleigh RW, Yu SJ (1988) Detoxification of isothiocyante allelochemicals by glutathione transferase in three lepidopterous species. Journal of Chemical Ecology 14:1279-1288

Weinheimer AJ, Spraggins RL (1969) The occurrence of two new prostaglandin derivatives (15-epi-PGA 2 and its acetate methyl ester) in the gorgonian Plexaura homomalla. Tetrahedron Lett 59:5185-5189

Yu SJ (1982) Host plant induction of glutathione S-transferases in the fall armyworm. Pest Biochem Physiol 19:101-106

Yu SJ (1989) Purification and characterization of gluathione S-transferase from five phytophagous Lepidoptera. Pest Biochem Physiol 35:97-105

Yu SJ (1999) Induction of new glutathione S-transferases isozymes by allelochemicals in the fall armyworm. Pesticide Biochemistry and Physiology 63:163-171 
Yu SJ, Abo-Elghar OE (2000) Allelochemicals as inhibitors of glutathione S-transferases in the fall armyworm. Pestic Biochem Physiol 68:173-183 


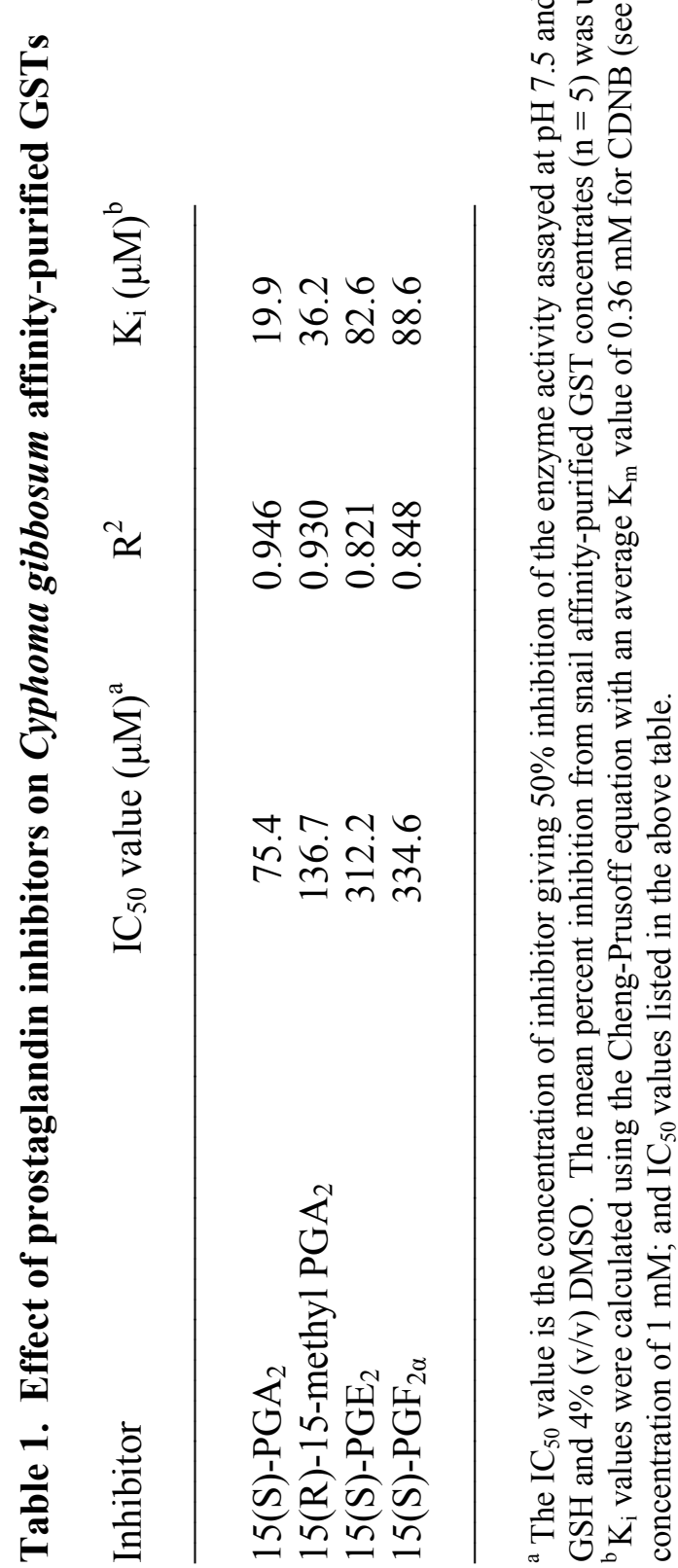




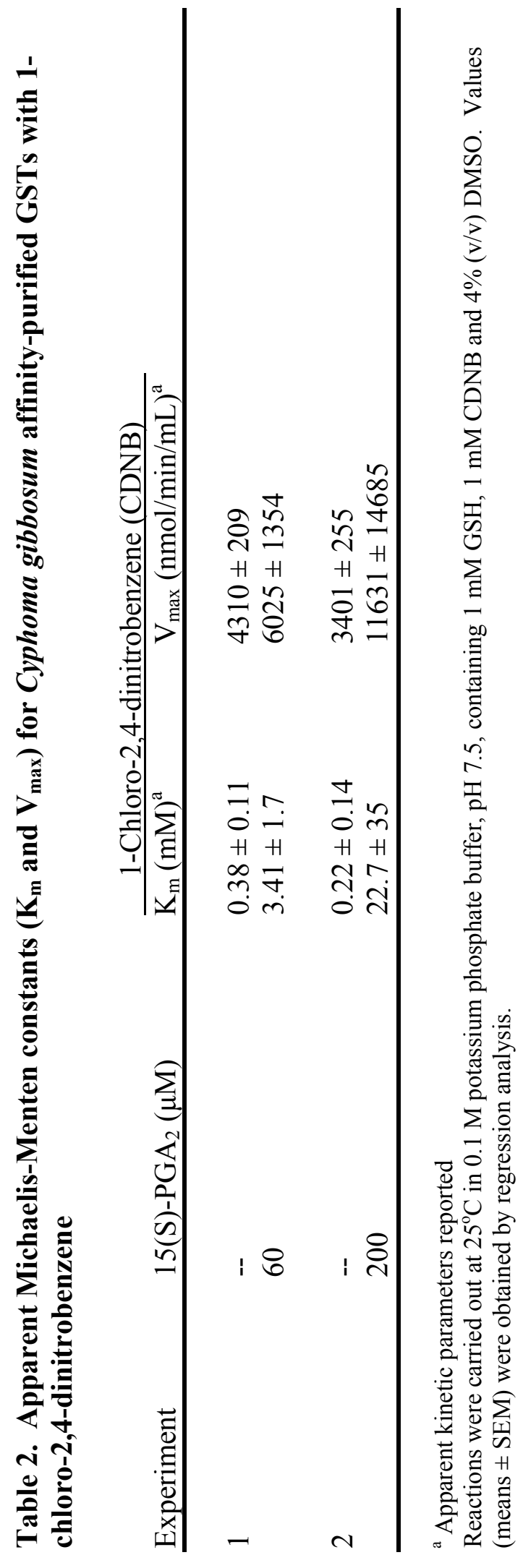




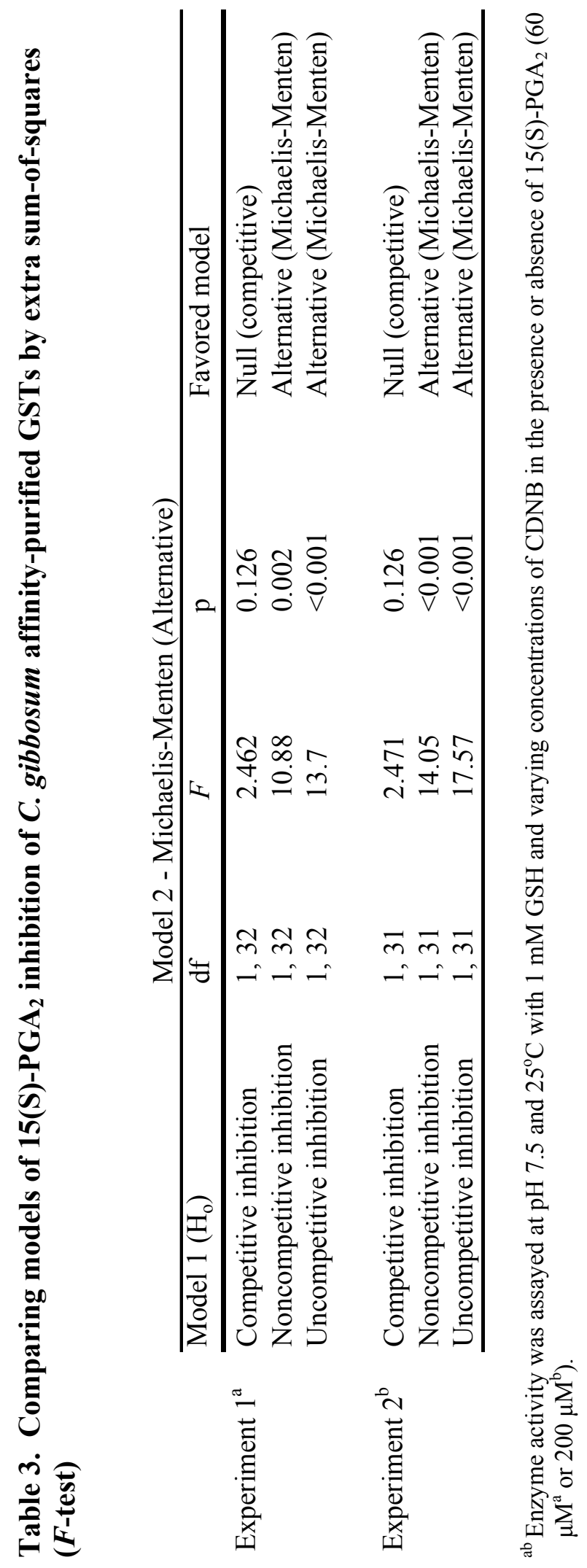




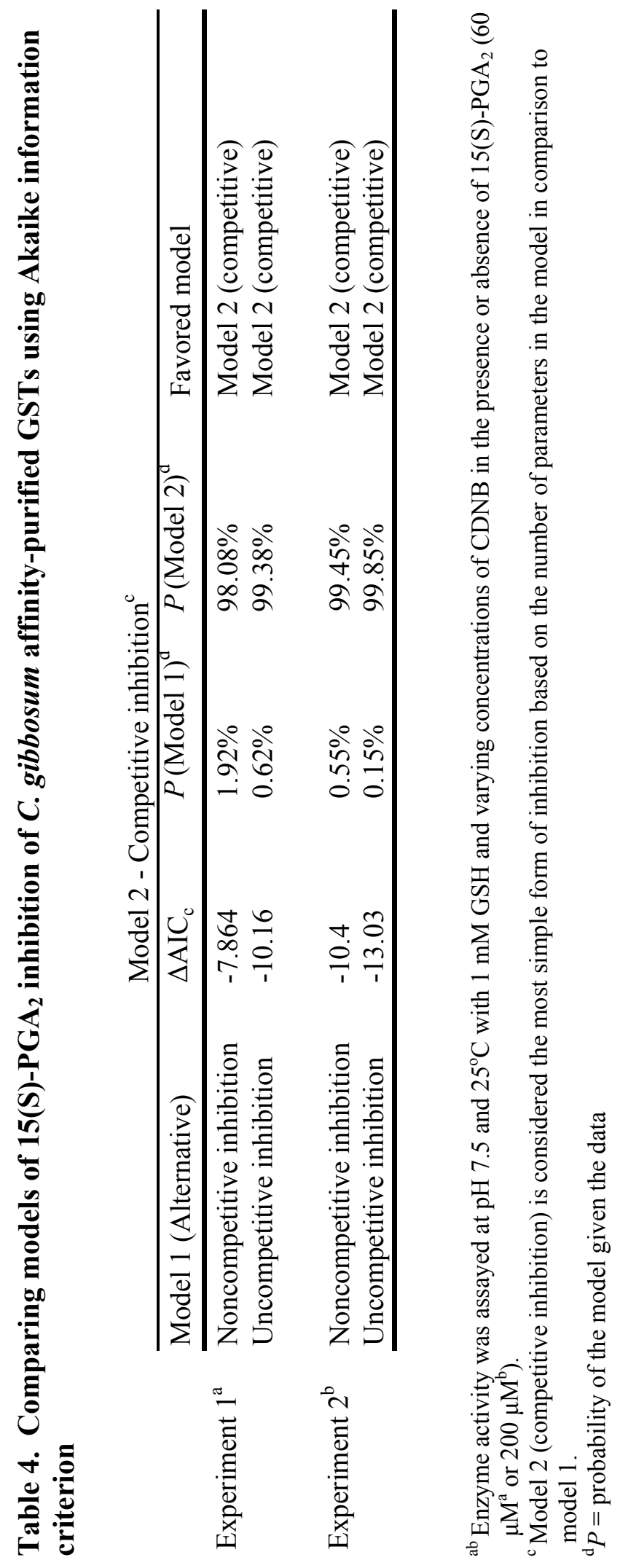




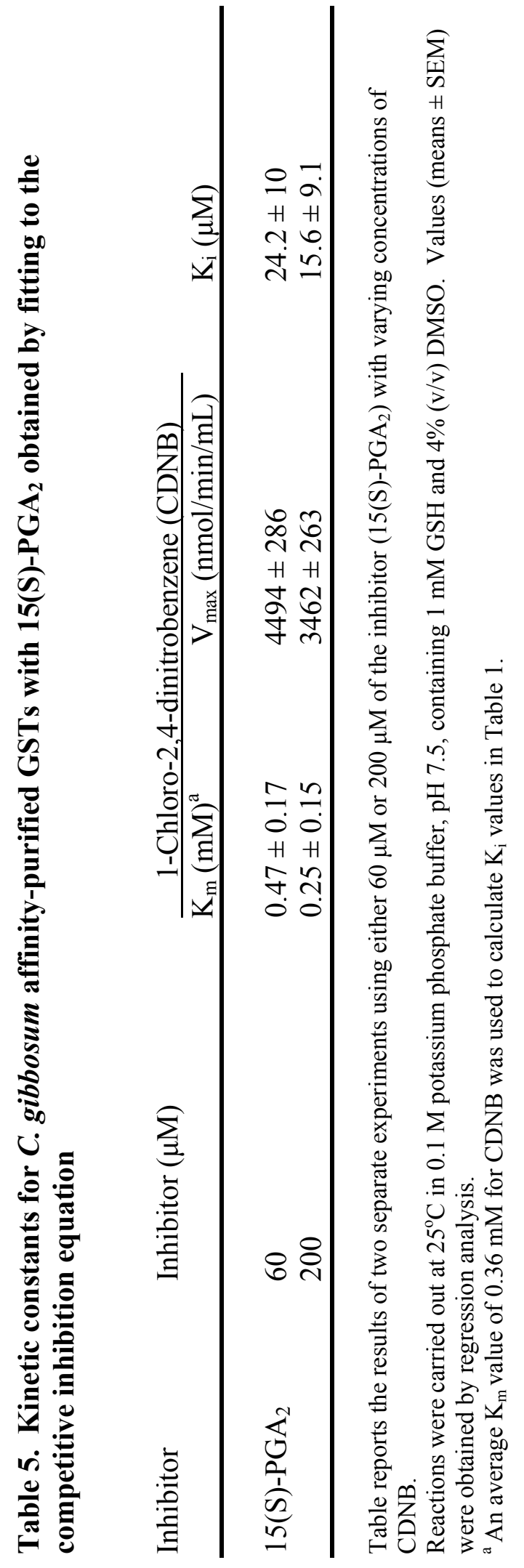




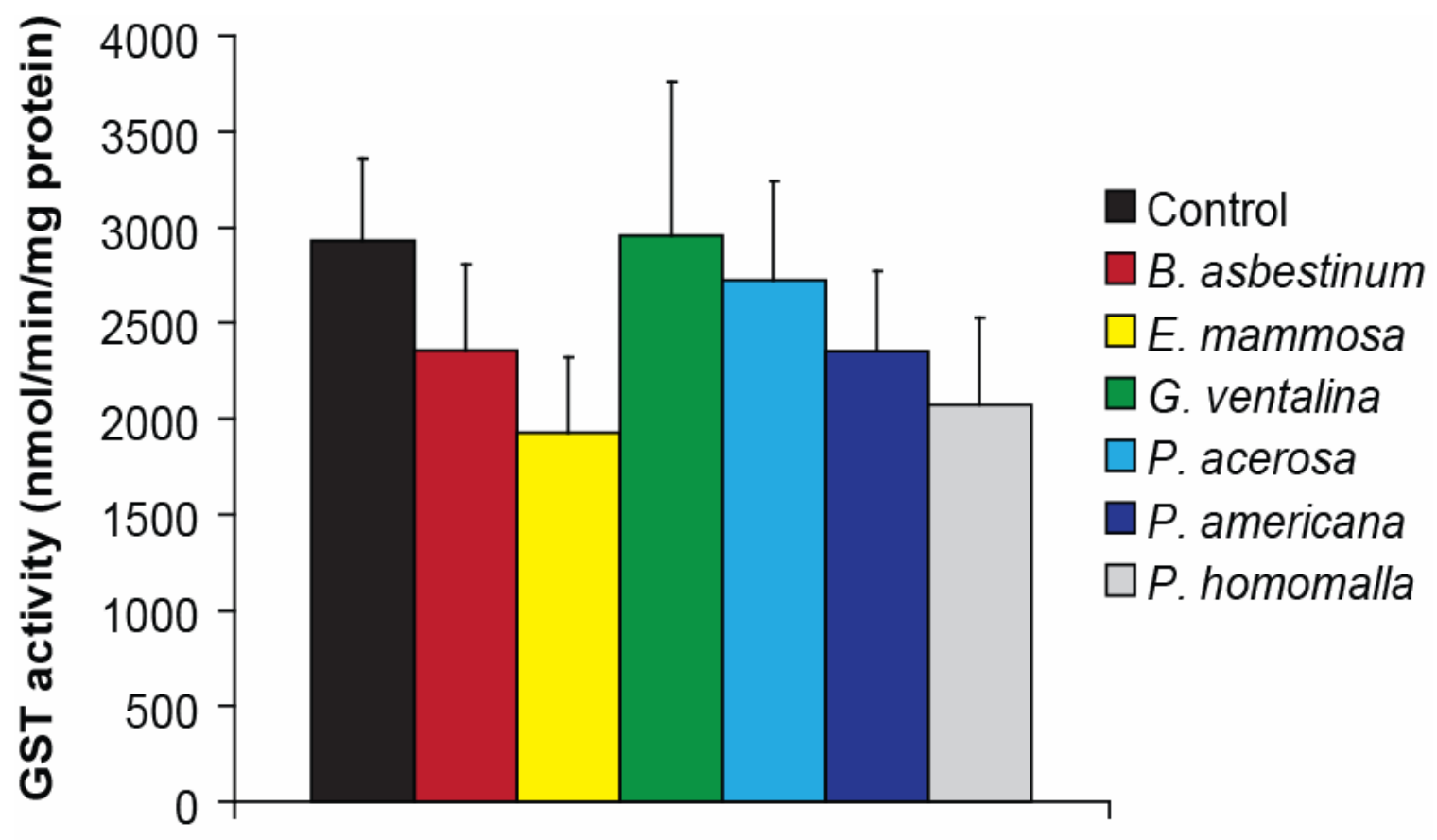

\section{Gorgonian diet}

Figure 1. GST activity levels from digestive gland cytosolic preparations of $C$. gibbosum feeding either on a control diet or six gorgonian diets in controlled $4 \mathrm{~d}$ feeding assays. Bars represent the mean GST activity $( \pm \mathrm{SE})$ of snails feeding on control $\operatorname{diet}(\mathrm{n}=12$ snails; e.g., alginic acid + squid powder) or one of six gorgonian diets $(B$. asbestinum, $\mathrm{n}=4 ;$ E. mammosa, $\mathrm{n}=4 ; G$. ventalina, $\mathrm{n}=4 ; P$. acerosa, $\mathrm{n}=4 ; P$. americana, $\mathrm{n}=7 ;$. homomalla, $\mathrm{n}=4$ ). The reaction mixture contained $2 \mu \mathrm{g}$ of cytosolic protein in $0.1 \mathrm{M}$ potassium phosphate buffer, $\mathrm{pH} 7.5$, containing $1 \mathrm{mM} \mathrm{GSH}$ and $1 \mathrm{mM} \mathrm{CDNB}$ at $25^{\circ} \mathrm{C}$. Results indicate that GST activity did not significantly differ among snail diets (ANOVA, $p=0.687$ ) or between snails collected from different reefs feeding on the control diet (ANOVA, $\mathrm{p}=0.109$ ). 


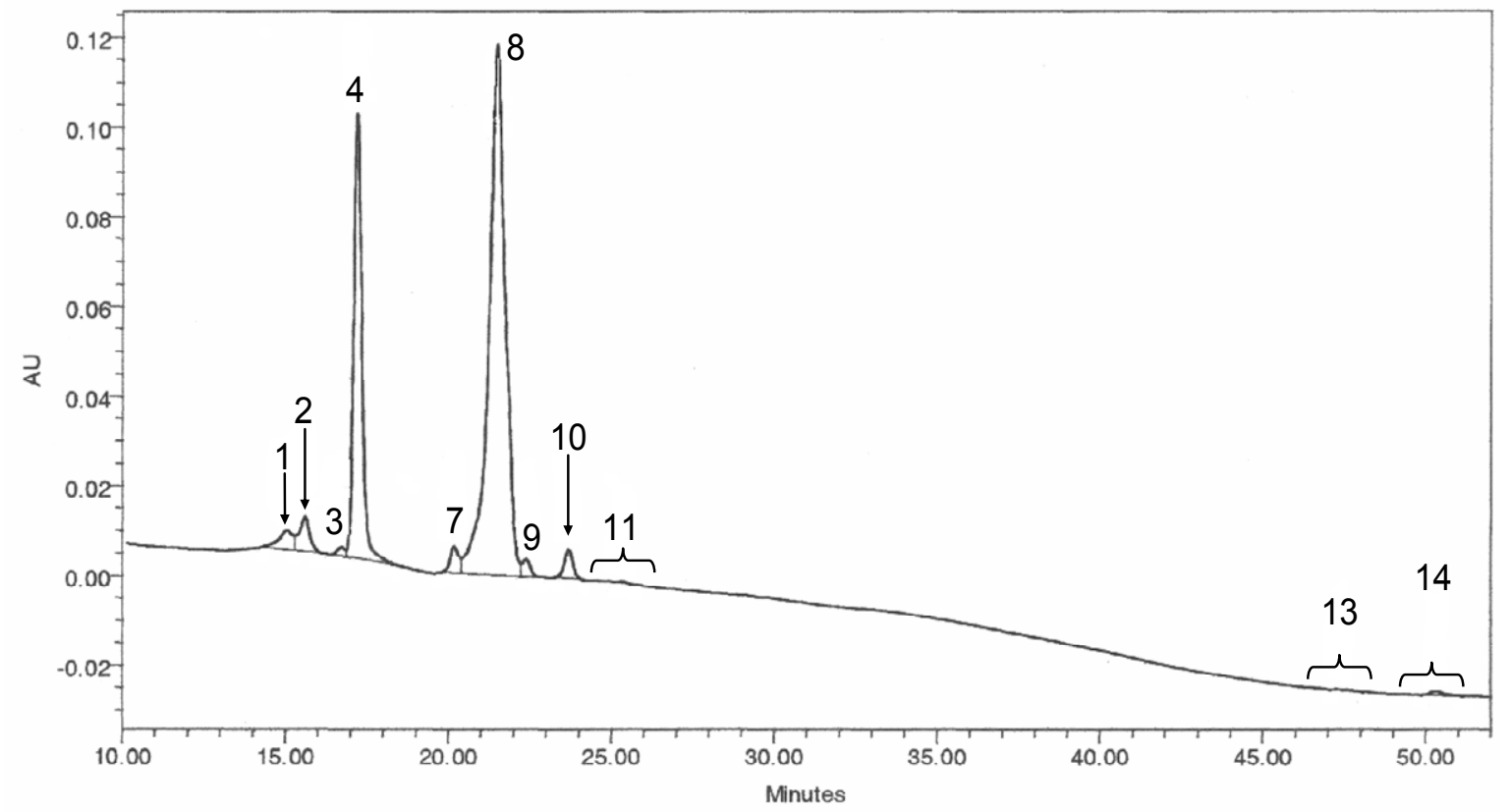

Figure 2. Representative HPLC separation of affinity-purified GST subunits from a C. gibbosum digestive gland. Representative HPLC separation of an affinity-purified extract from an individual $C$. gibbosum feeding on B. asbestinum. GST subunits were separated on a reverse phase VYDAC protein/peptide column $(\mathrm{C} 18 \mu \mathrm{m} 250 \mathrm{~mm} \times 2.1$ $\mathrm{mm}$ ) with a flow rate of $0.5 \mathrm{~mL} \mathrm{~min}^{-1}$. Mobile phase A consisted of acetonitrile/water/TFA (38:62:0.1, v/v) and mobile phase B consisted of acetonitrile/water/TFA (80:20:0.1, v/v). GST subunits were separated using a linear gradient from 0 to $40 \% \mathrm{~B}$ in $22 \mathrm{~min}$, and 40 to $100 \% \mathrm{~B}$ in $37 \mathrm{~min}$ and visualized at 214 $\mathrm{nm}$. Fourteen unique peaks were identified; however, not all were visible in one HPLC spectrum, therefore a representative spectrum was chosen. The position of HPLC peaks $1-4,7-11,13$ and 14 are labeled. 


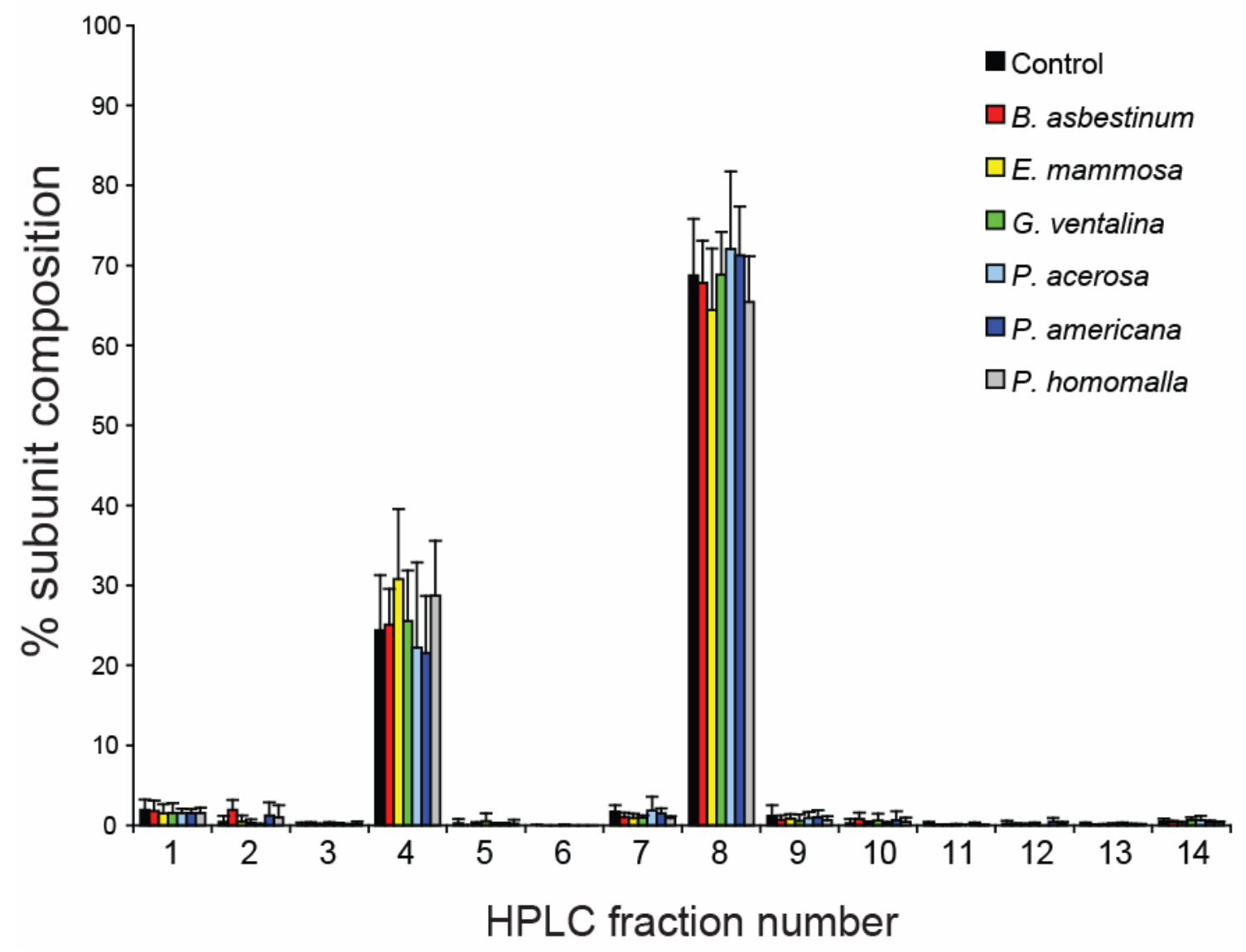

Figure 3. Average GST subunit percent composition as a function of snail diet. Bars represent the mean percent GST subunit composition $( \pm \mathrm{SD})$ in affinity-purified digestive gland preparations from snails grouped by diet; control diet $(\mathrm{n}=12$ snails $)$ and gorgonian diets (B. asbestinum, $\mathrm{n}=4 ;$ E. mammosa, $\mathrm{n}=4 ; G$. ventalina, $\mathrm{n}=4 ; P$. acerosa, $\mathrm{n}=4 ; P$. americana, $\mathrm{n}=7 ;$. homomalla, $\mathrm{n}=4$ ). Statistical analysis (ANOVA) indicated that GST subunit percent composition did not significantly differ among snail diets. 


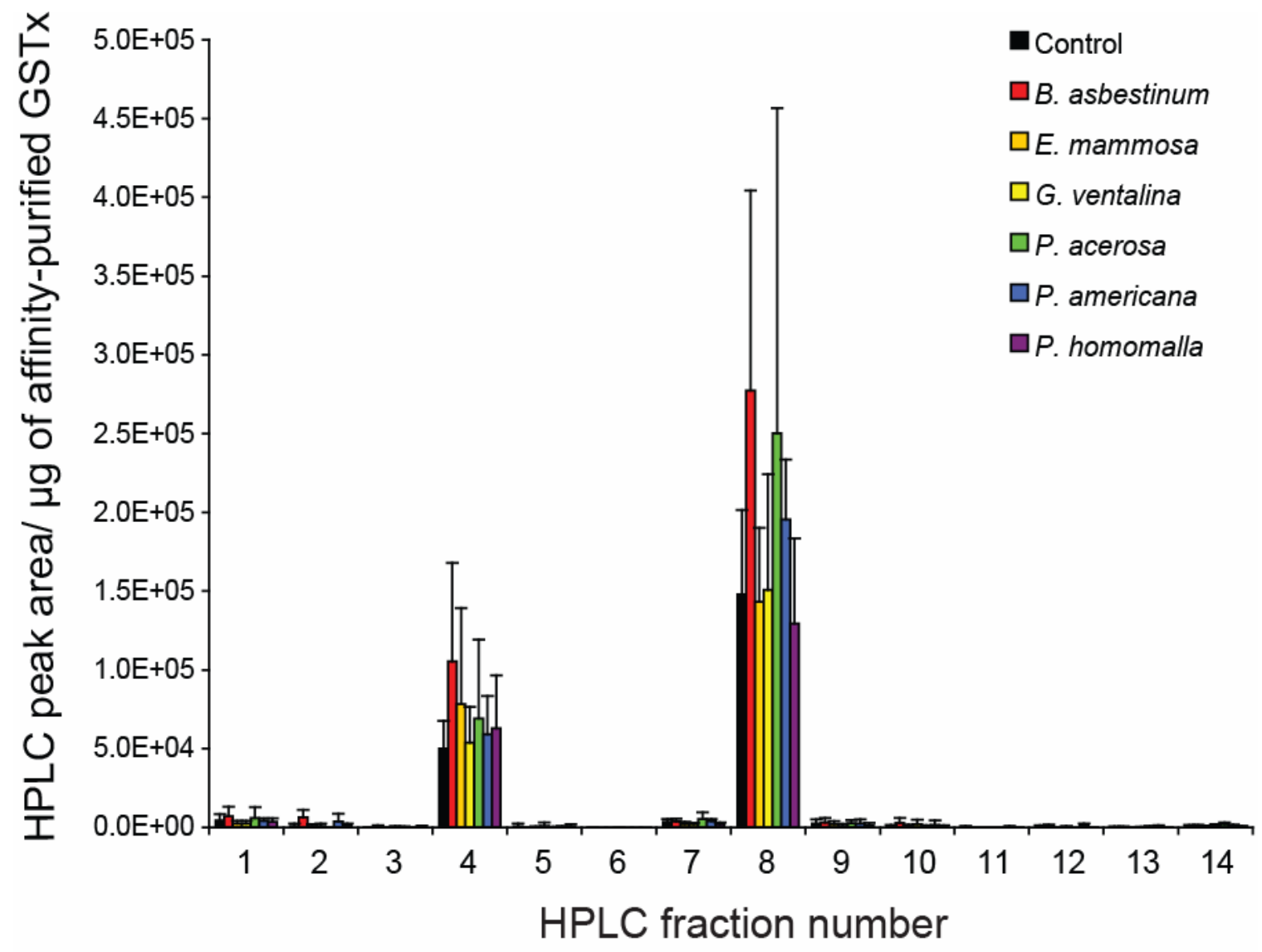

Figure 4. Peak area normalized to the amount of affinity-purified GST sample applied to the HPLC column. Bars represent the mean HPLC peak area normalized for the amount of GST protein applied to the HPLC column as a function of snail diet $( \pm$ $\mathrm{SE})$; control diet $(\mathrm{n}=12$ snails $)$ and gorgonian diets (B. asbestinum, $\mathrm{n}=4 ;$ E. mammosa, $\mathrm{n}=4 ;$ G. ventalina, $\mathrm{n}=4 ;$. acerosa, $\mathrm{n}=4 ;$ P. americana, $\mathrm{n}=7 ;$ P. homomalla, $\mathrm{n}=4)$. Statistical analysis (ANOVA) indicated the amount of starting material did not significantly affect GST subunit abundance among snail diets. 


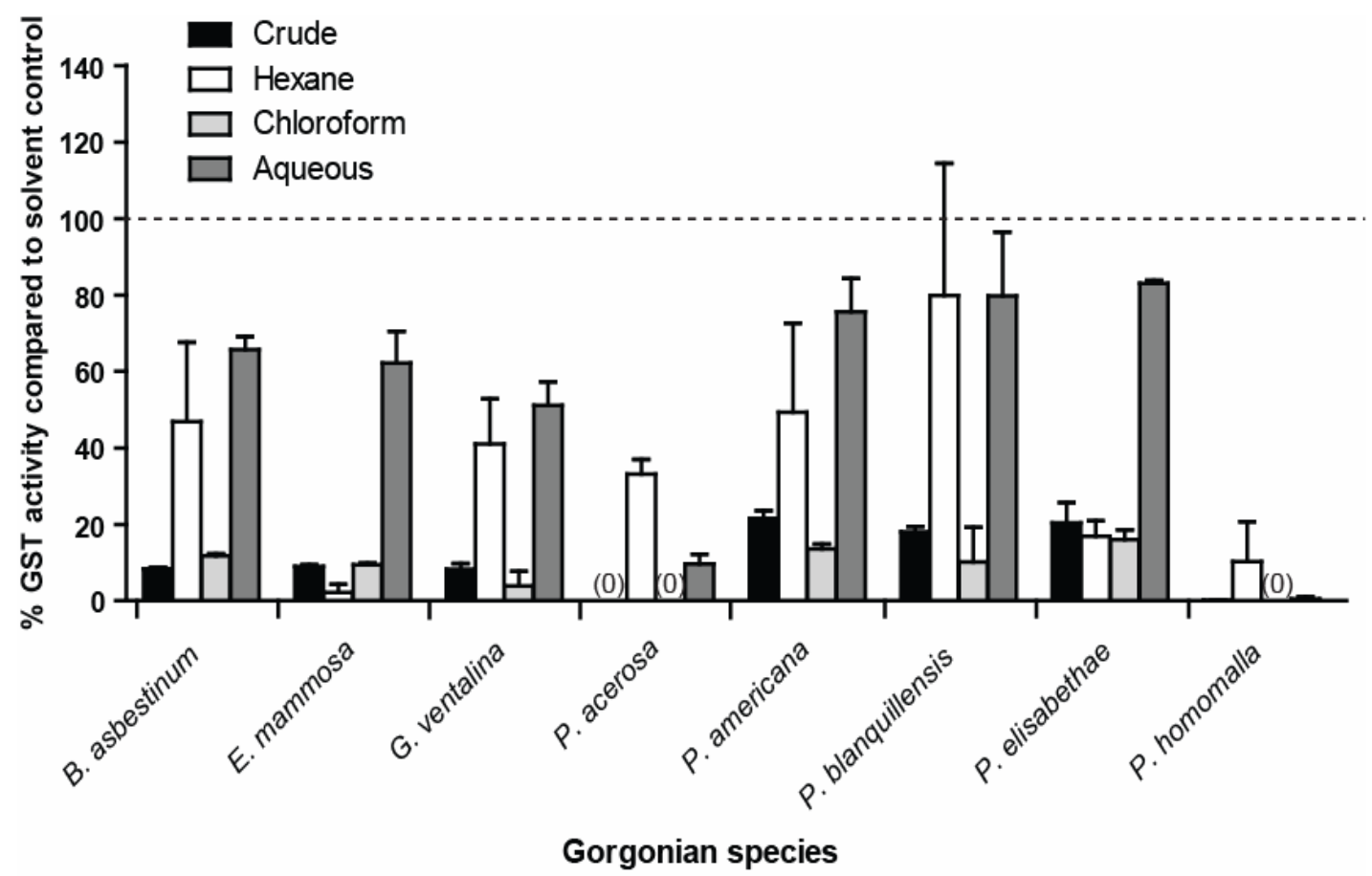

Figure 5. Inhibition of $C$. gibbosum GST activity by gorgonian crude and semipurified extracts. Bars represent the mean $( \pm \mathrm{SE})$ percent GST activity remaining after exposure to gorgonian compounds compared to solvent controls. Reaction mixture consisted of $2 \mu \mathrm{g}$ cytosolic protein in $0.1 \mathrm{M}$ potassium phosphate buffer, $\mathrm{pH} 7.5$, containing $1 \mathrm{mM} \mathrm{GSH}, 1 \mathrm{mM} \mathrm{CDNB}$ at $25^{\circ} \mathrm{C}$ with $<0.01 \%$ (v/v) solvent. Reactions were performed in duplicate with digestive gland crude cytosolic preparations from two snails. Crude extracts from eight gorgonian species were tested at $1 / 20^{\text {th }}$ natural volumetric concentration (NC) found in gorgonian tissues for their ability to inhibit crude cytosolic GST activity. Hexane and aqueous soluble extracts were tested at 1/4 x NC. Chloroform soluble fractions were tested at $1 / 4 \times \mathrm{NC}$ with the following exceptions: G. ventalina, $P$. acerosa, and $P$. homomalla were tested at $1 / 8 \times \mathrm{NC}$. A zero indicates complete inhibition of GST activity by the gorgonian extract or fraction. Bars approaching the dotted line indicate no difference from solvent controls. 
Figure 6. Inhibition of $C$. gibbosum GST activity by the chloroform-soluble HPLC fractions from eight gorgonian species. Chloroform partitions from eight gorgonian species ((A) B. asbestinum; (B) E. mammosa; (C) G. ventalina; (D) P. acerosa; (E) P. americana; (F) P. blanquillensis; (G) P. elisabethae; (H) P. homomalla) were separated into ten fractions (indicated by dotted lines) using a reverse-phase HPLC column (Zorbax SB-C18, 9.4mm x 2cm; solvent flow rate $=3 \mathrm{~mL} / \mathrm{min}$; injection volume $=500 \mu \mathrm{L}$ ). Mobile phase: methanol/water 9:1 from 0-5 mins; linear ramping to 100\% methanol from 5-18 min; 100\% methanol from 18-25 min; linear gradient to initial starting conditions of methanol/water 9:1 from 25-26 min; column flushed with methanol/water 9:1 from 26-33 min. Absorbance was monitored at 215 and $254 \mathrm{~nm}$ and fractions were collected every three minutes beginning at $t_{0}=3 \mathrm{~min}$. Overlaid on the HPLC absorbance spectra are the results GST inhibition assays with affinity-purified GST protein. The reaction mixture consisted of $6 \mathrm{ng}$ of affinity-purified GST protein in $0.1 \mathrm{M}$ potassium phosphate buffer, $\mathrm{pH} 7.5$, containing $1 \mathrm{mM} \mathrm{GSH}, 1 \mathrm{mM} \mathrm{CDNB}$ at $25^{\circ} \mathrm{C}$ with $2 \%(\mathrm{v} / \mathrm{v})$ methanol. An affinity-purified GST preparation from a single digestive gland was used as the protein source with a specific activity (mean $\pm \mathrm{SE}$ ) of $561 \pm 25 \mu \mathrm{mol} \mathrm{min}^{-1} \mathrm{mg}_{\text {protein }}{ }^{-1}$. HPLC fractions were tested at $1 / 10^{\text {th }}$ natural volumetric concentration, unless marked by an asterisk indicating samples were further tested at $1 / 200^{\text {th }}$ natural volumetric concentration. Each point ( $\boldsymbol{\square})$ represents the mean of two technical replicates. 


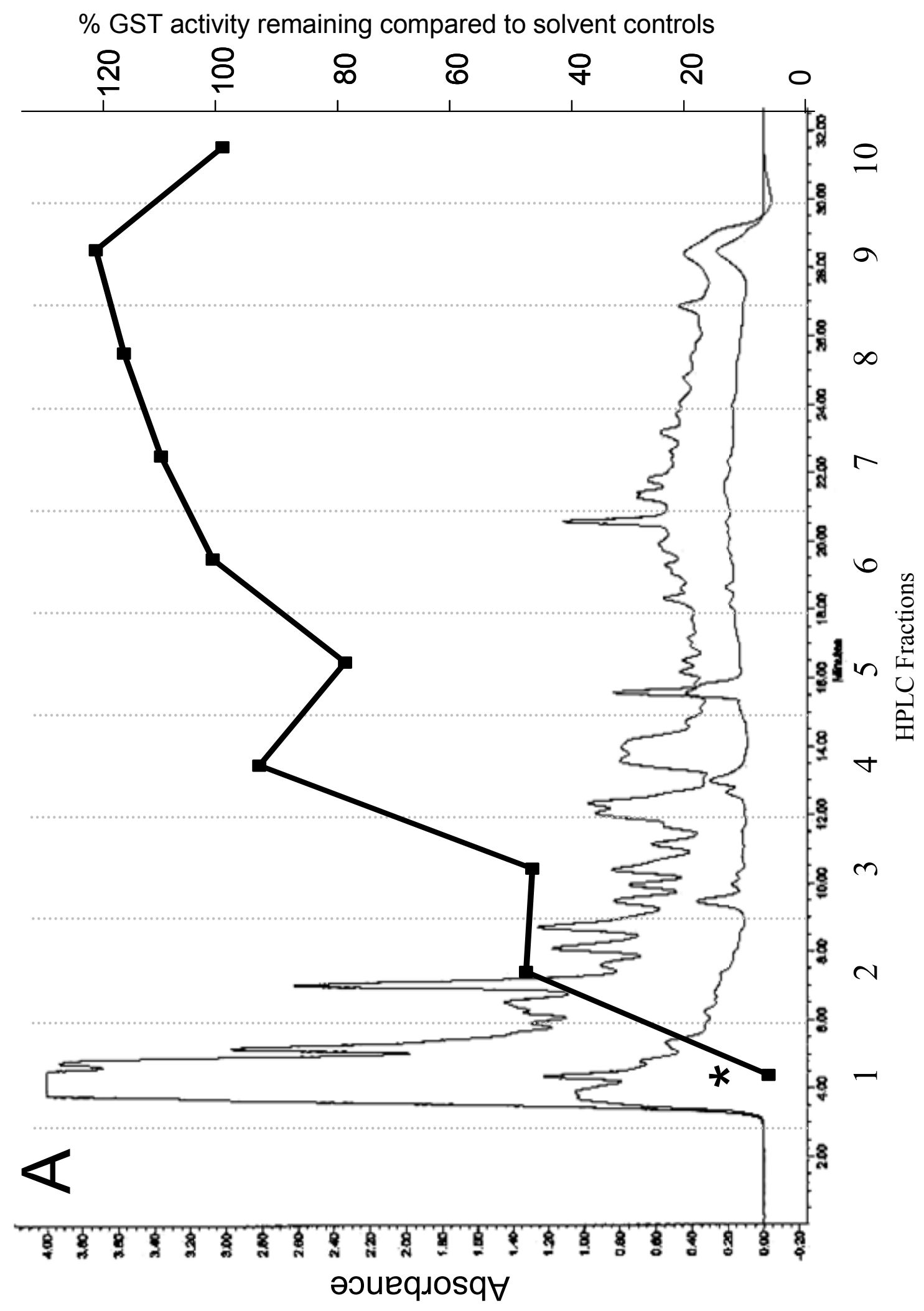




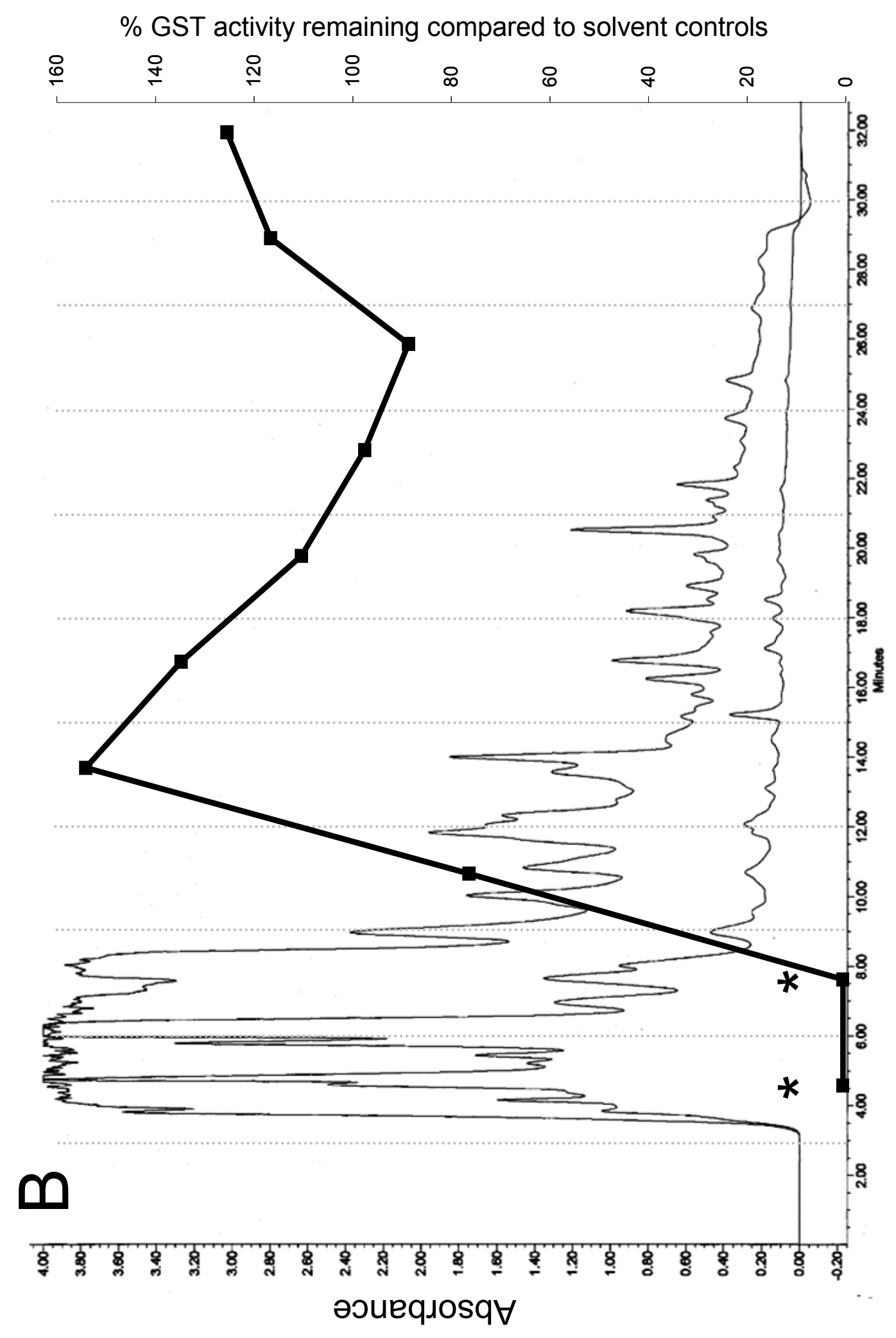




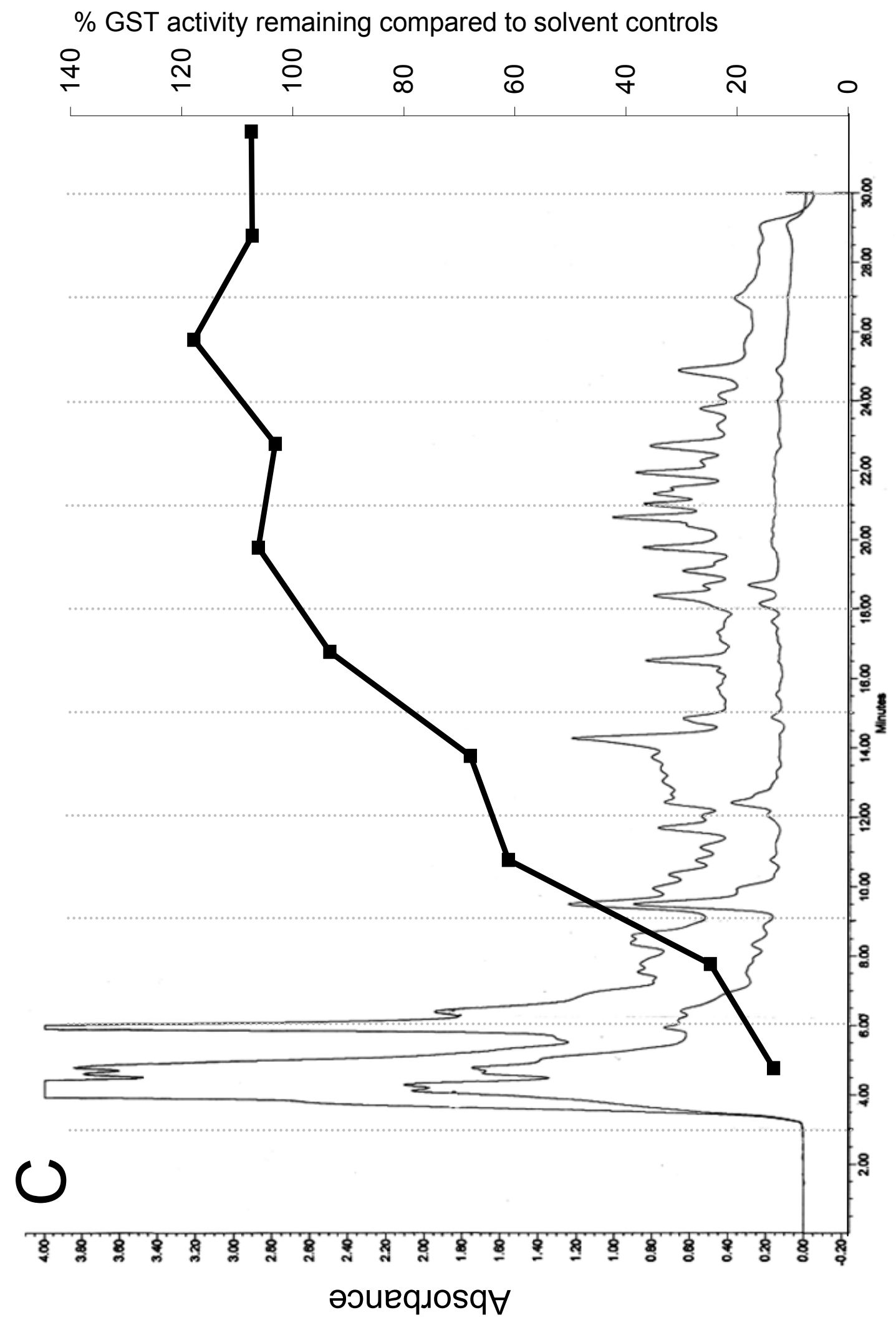




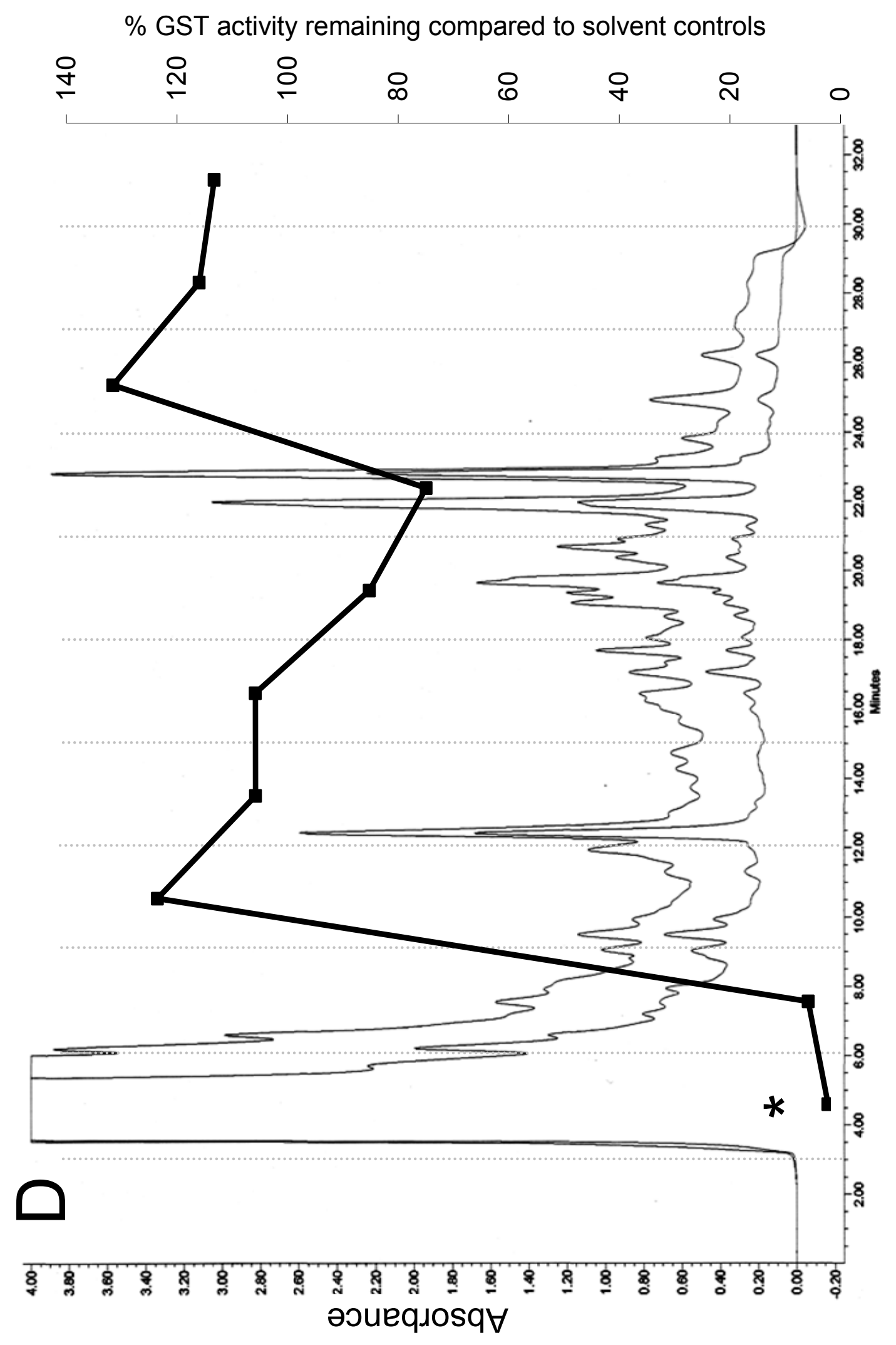




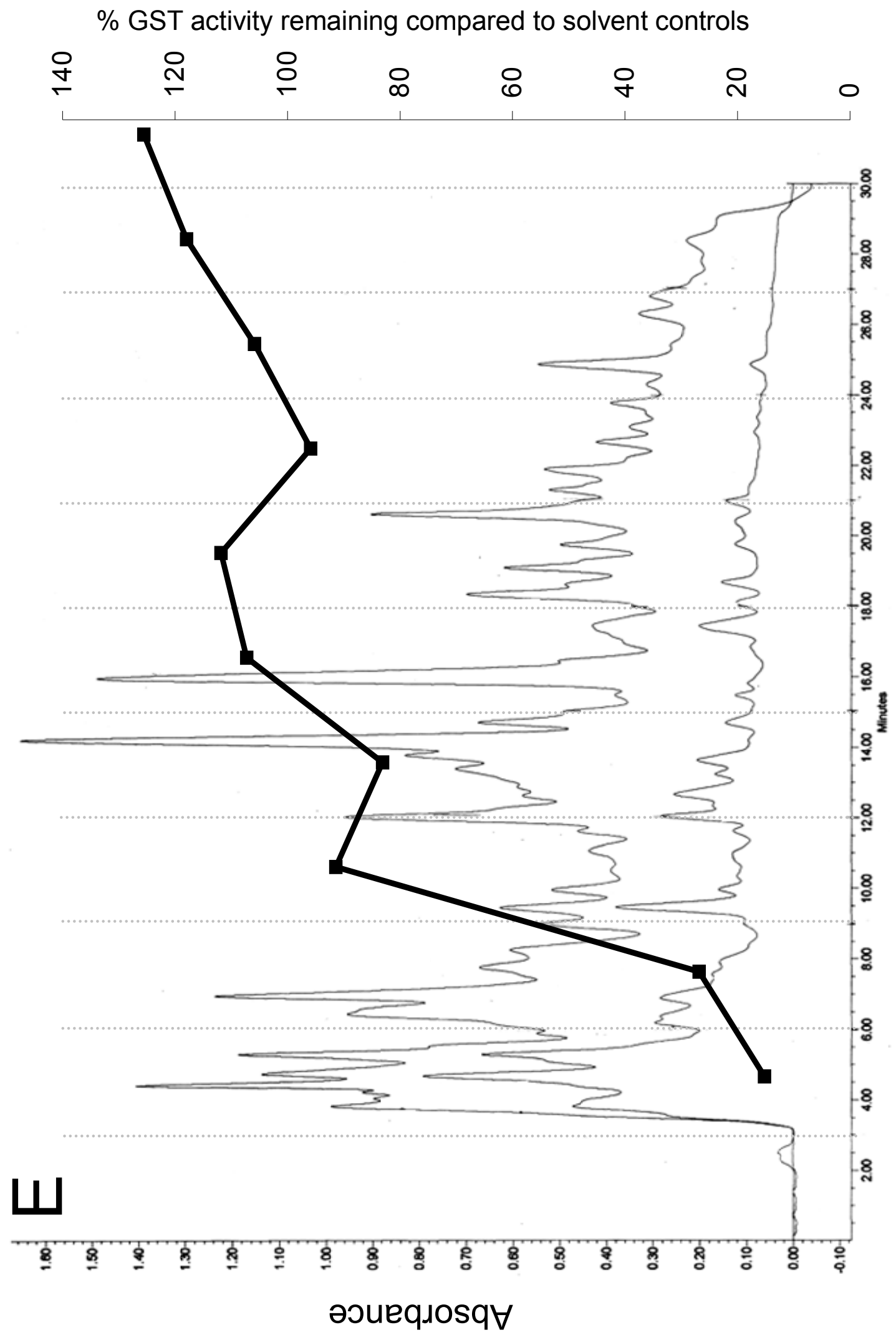




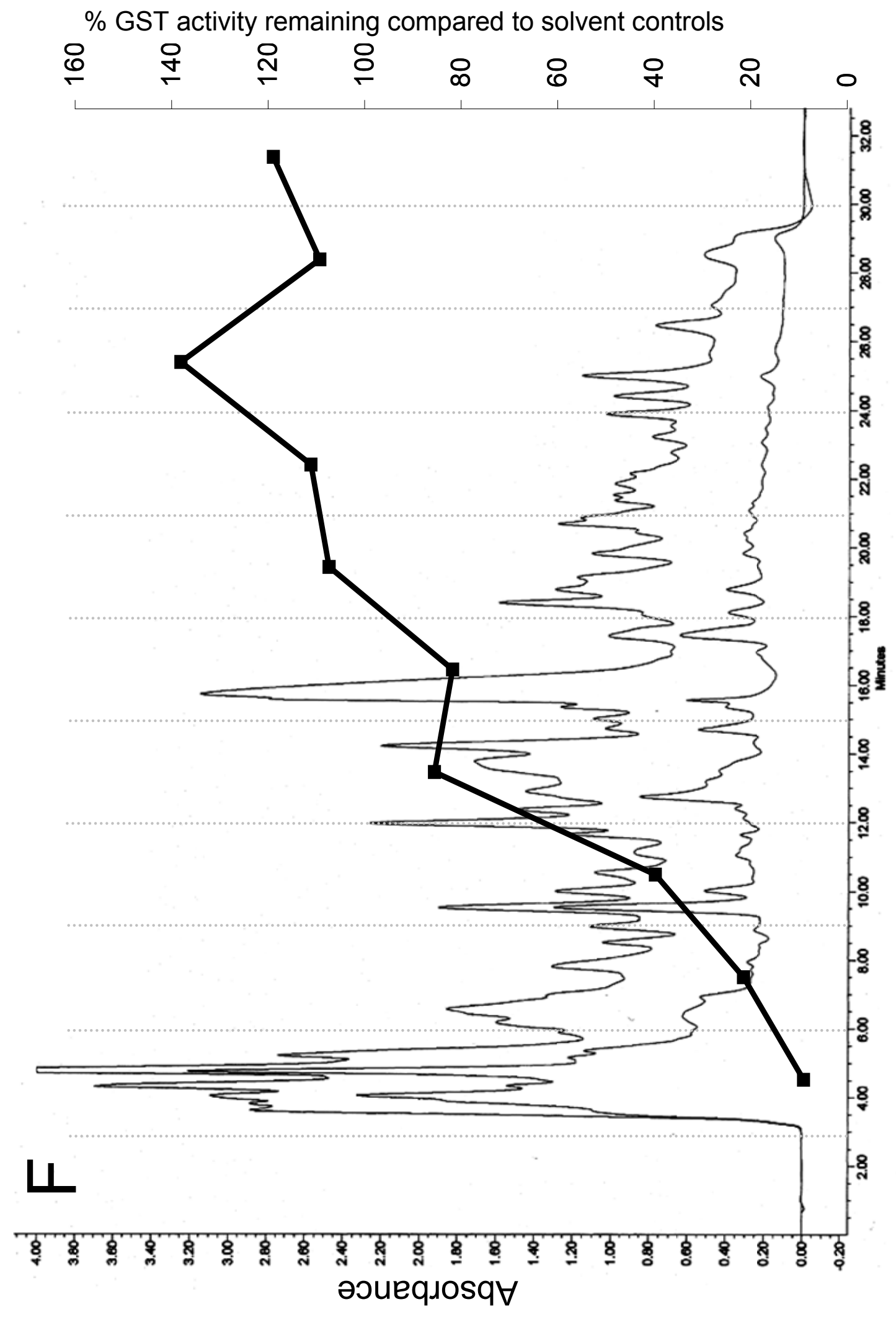




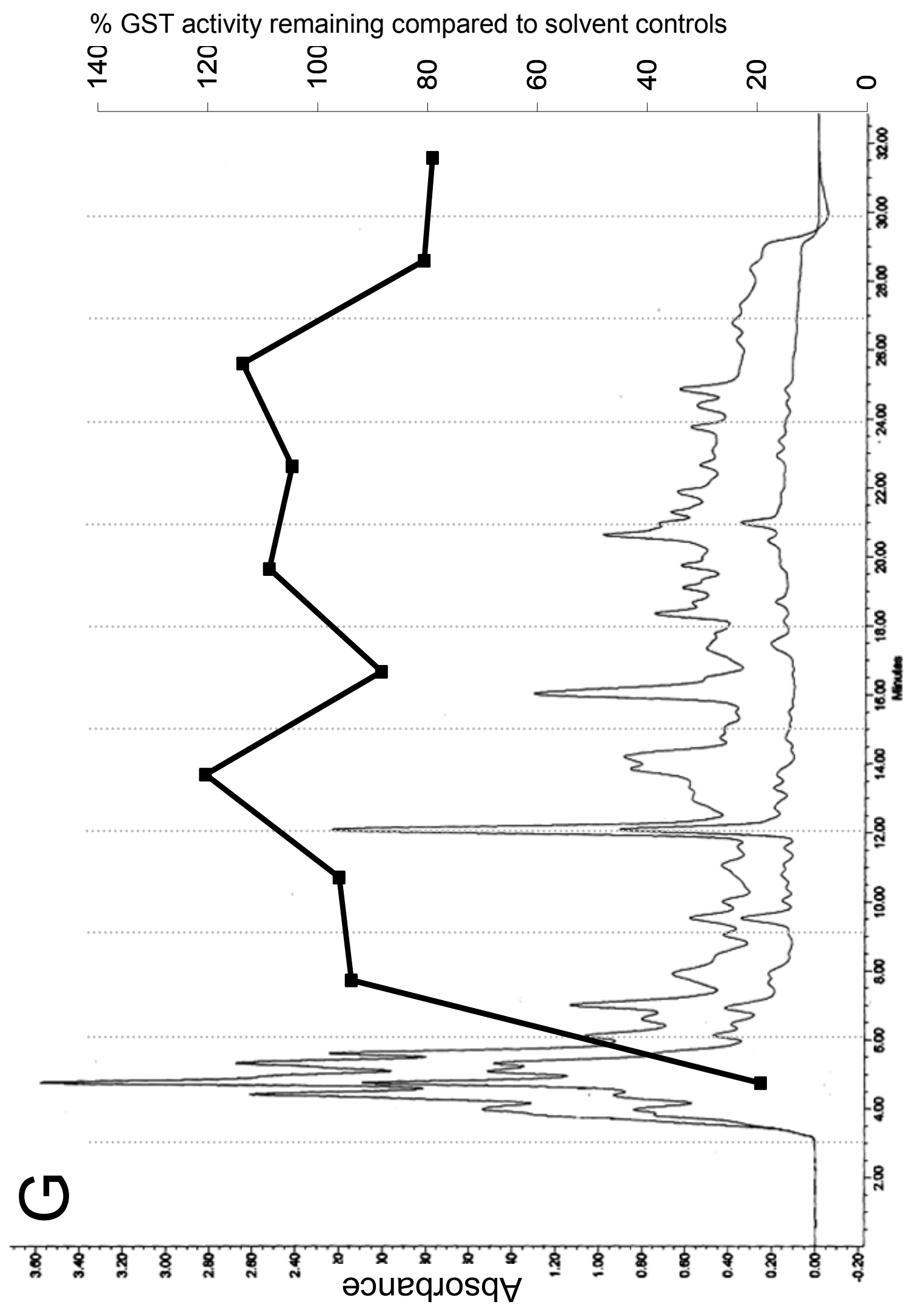




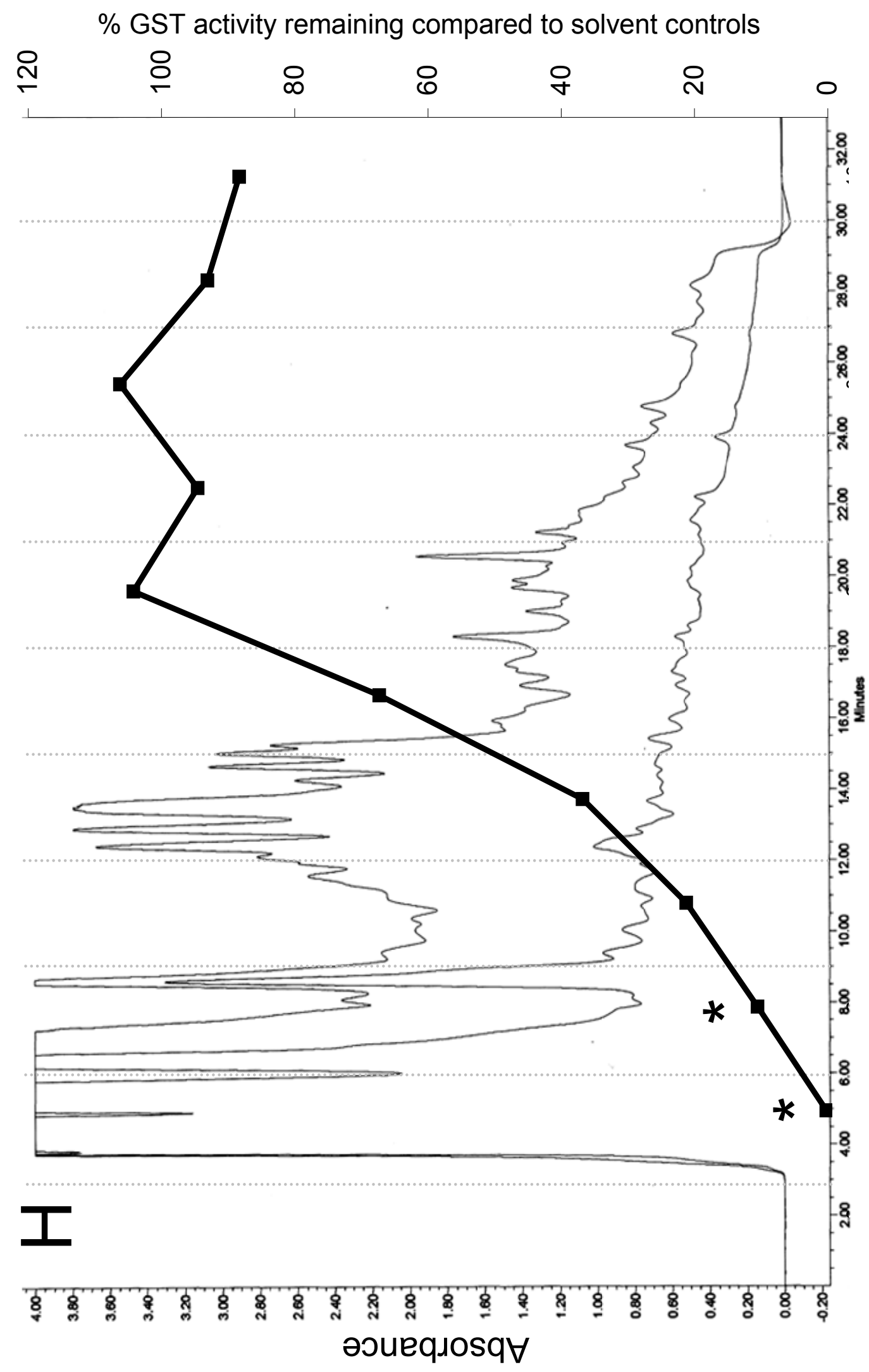




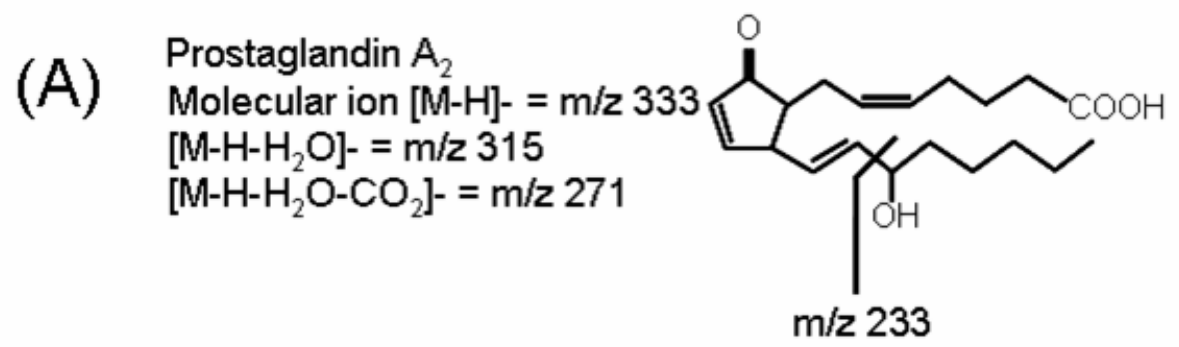

(B)

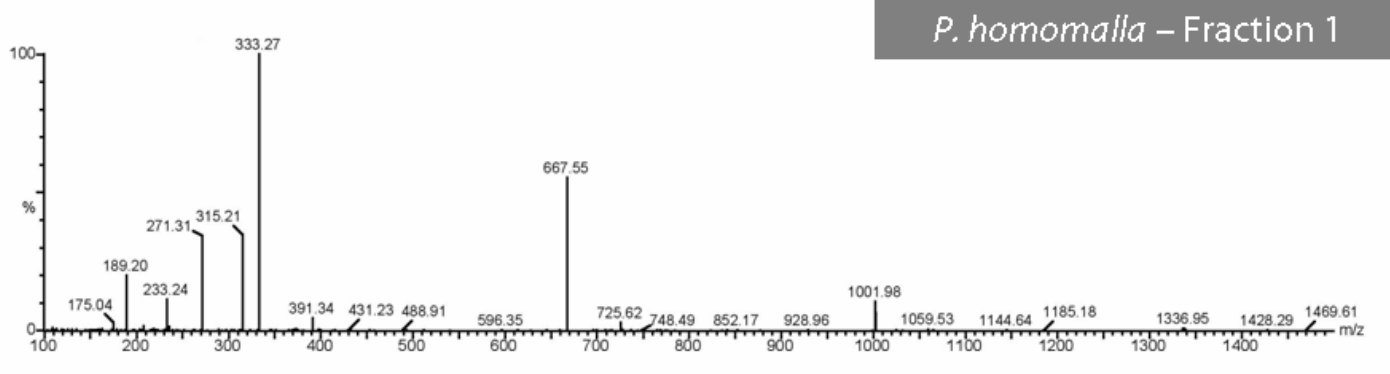

(C)

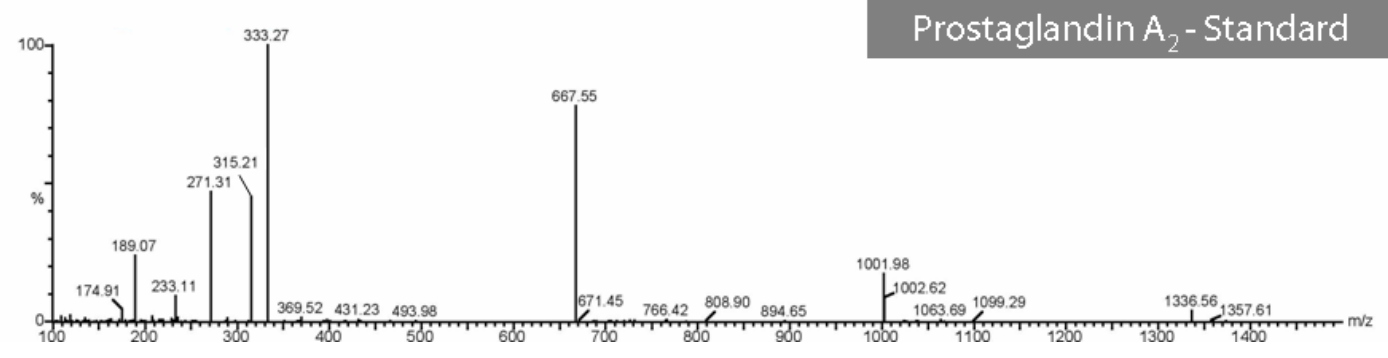

Figure 7. LC-MS identification of $\mathrm{PGA}_{2}$ in P. homomalla chloroform extracts. The fragmentation pattern of the free hydroxy acid of $\mathrm{PGA}_{2}$ is shown in (A). The similarity between the full-scan mass spectrum of $P$. homomalla fraction $1(\mathbf{B})$ and the $\mathrm{PGA}_{2}$ standard (mol wt 333) (C) indicates that the P. homomalla chloroform-soluble HPLC fraction 1 contains $\mathrm{PGA}_{2}$. 

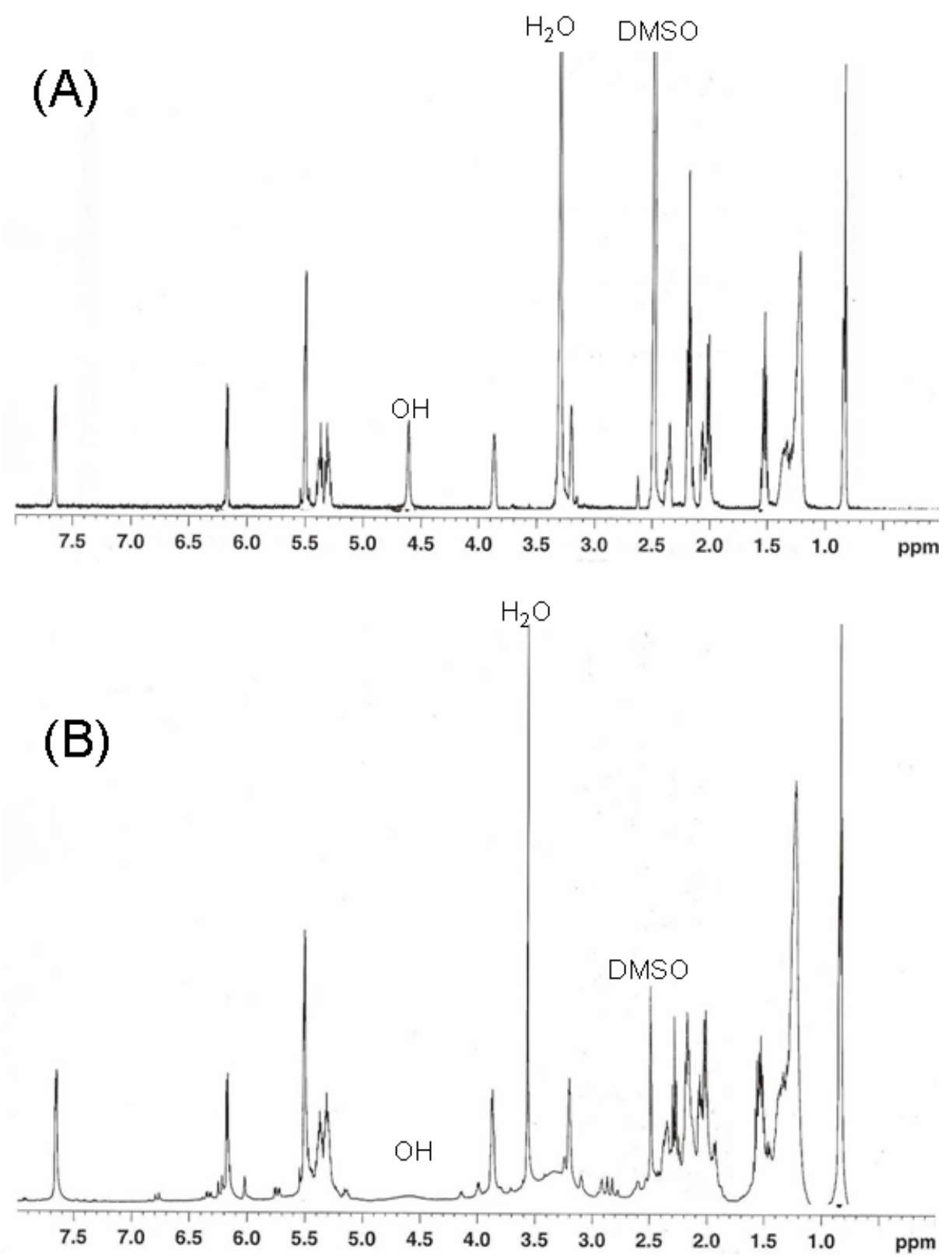

Figure 8. Comparison of ${ }^{1} \mathrm{H}$ NMR spectra from the PGA $\mathrm{A}_{2}$ standard (A) and the chloroform-soluble fraction 1 from $P$. homomalla (B). 
$\mathrm{PGA}_{2}$
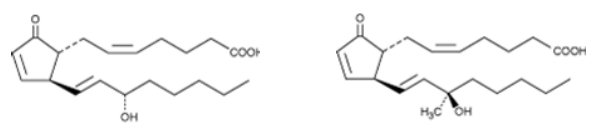

15(S)-Prostaglandin $A_{2}$

15(R)-15-methyl-Prostaglandin $A_{2}$
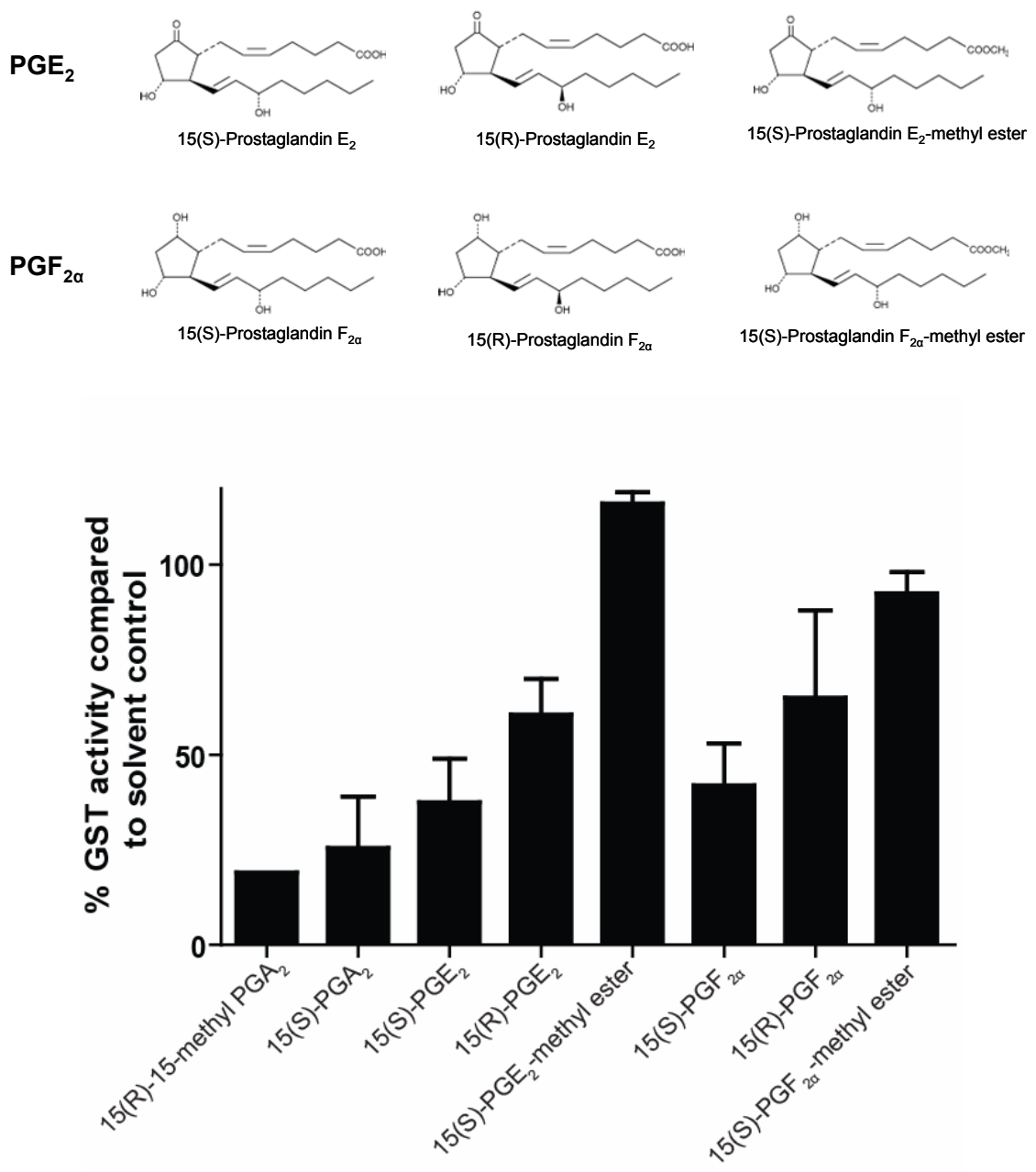

Prostaglandins $[600 \mu \mathrm{M}]$

Figure 9. Effect of prostaglandin A, E, and F series on cytosolic $C$. gibbosum GST activity. Eight commercially available prostaglandin compounds, representing a diversity of prostaglandin series present in gorgonian tissues, were screened for their ability to inhibit GST activity at $600 \mu \mathrm{M}$. Bars represent the mean $( \pm \mathrm{SE})$ percent GST activity remaining after prostaglandin exposure compared to solvent controls. The reaction mixture consisted of $2 \mu \mathrm{g}$ of cytosolic GST protein in $0.1 \mathrm{M}$ potassium phosphate buffer, $\mathrm{pH} 7.5$, containing $1 \mathrm{mM} \mathrm{GSH}, 1 \mathrm{mM} \mathrm{CDNB}$ at $25^{\circ} \mathrm{C}$ with $5 \%(\mathrm{v} / \mathrm{v})$ DMSO. Digestive gland cytosolic preparations from two snails were used as the enzyme source with specific activities of 5.8 and $5.1 \mu \mathrm{mol} \mathrm{min}^{-1} \mathrm{mg} \mathrm{protein}^{-1}$, respectively. 


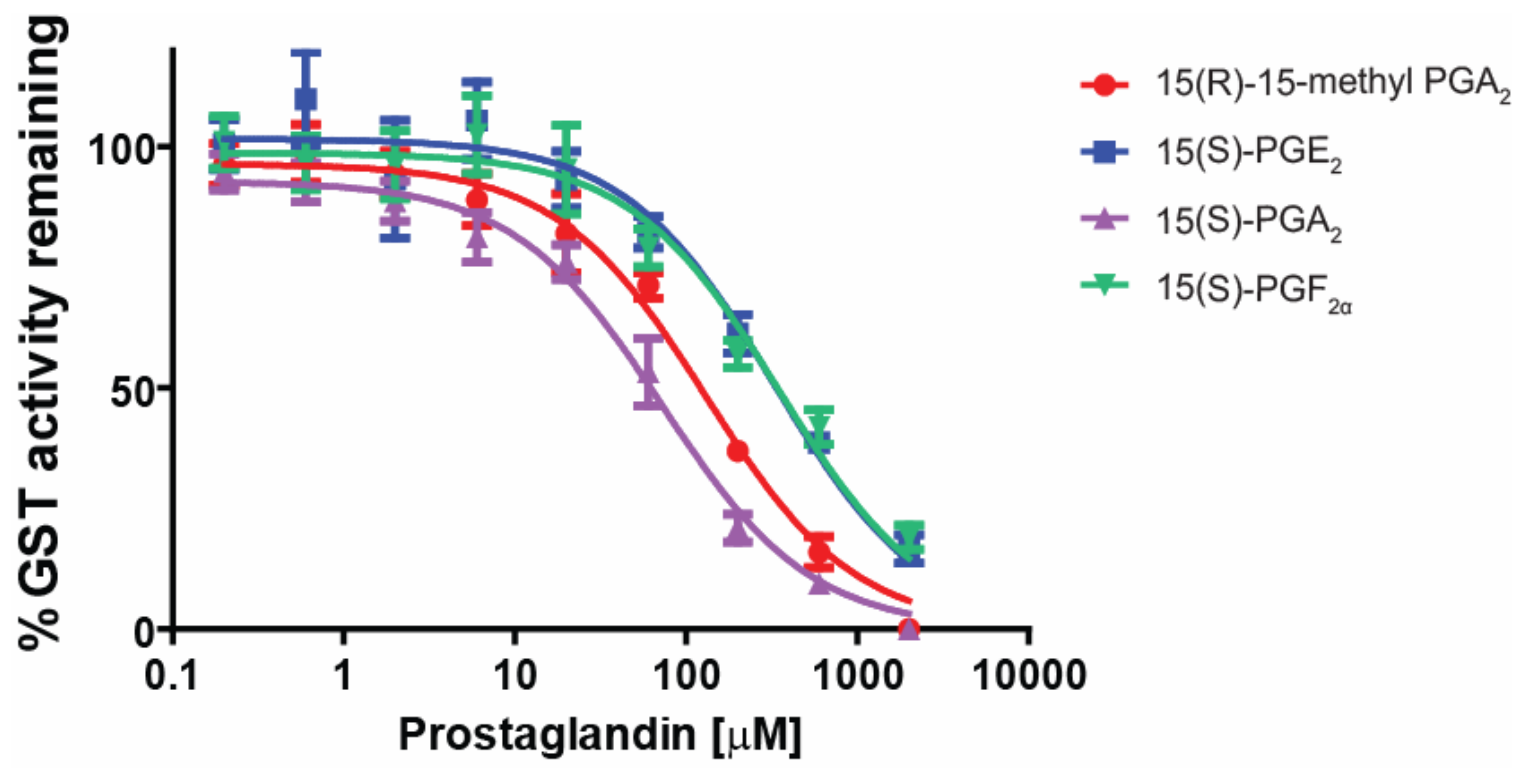

Figure 10. Inhibition of $C$. gibbosum affinity-purified GST activity by selected prostaglandins. Points represent the mean $( \pm \mathrm{SE})$ GST activity remaining compared to solvent controls after incubation with various concentrations $(0.2-2000 \mu \mathrm{M})$ of $15(\mathrm{R})$ 15-methyl $\mathrm{PGA}_{2}(\bullet), 15(\mathrm{~S})-\mathrm{PGE}_{2}(\boldsymbol{\bullet}), 15(\mathrm{~S})-\mathrm{PGA}_{2}(\boldsymbol{\Delta}), 15(\mathrm{~S})-\mathrm{PGF}_{2 \alpha}(\boldsymbol{\nabla})$. The reaction mixture consisted of $3.3-6.4 \mathrm{ng}$ of affinity-purified GST protein in $0.1 \mathrm{M}$ potassium phosphate buffer, $\mathrm{pH} 7.5$, containing $1 \mathrm{mM} \mathrm{GSH}, 1 \mathrm{mM} \mathrm{CDNB}$ at $25^{\circ} \mathrm{C}$ with $5 \%(\mathrm{v} / \mathrm{v})$ DMSO. Affinity-purified GST preparations from five snails were used as the enzyme source with specific activities of ranging from $290-582 \mu \mathrm{mol} \mathrm{min}^{-1} \mathrm{mg}_{\text {protein }}{ }^{-1}$. Plots were used to obtain the $\mathrm{IC}_{50}$ value for each prostaglandin using Prism software and are listed in Table 1. 

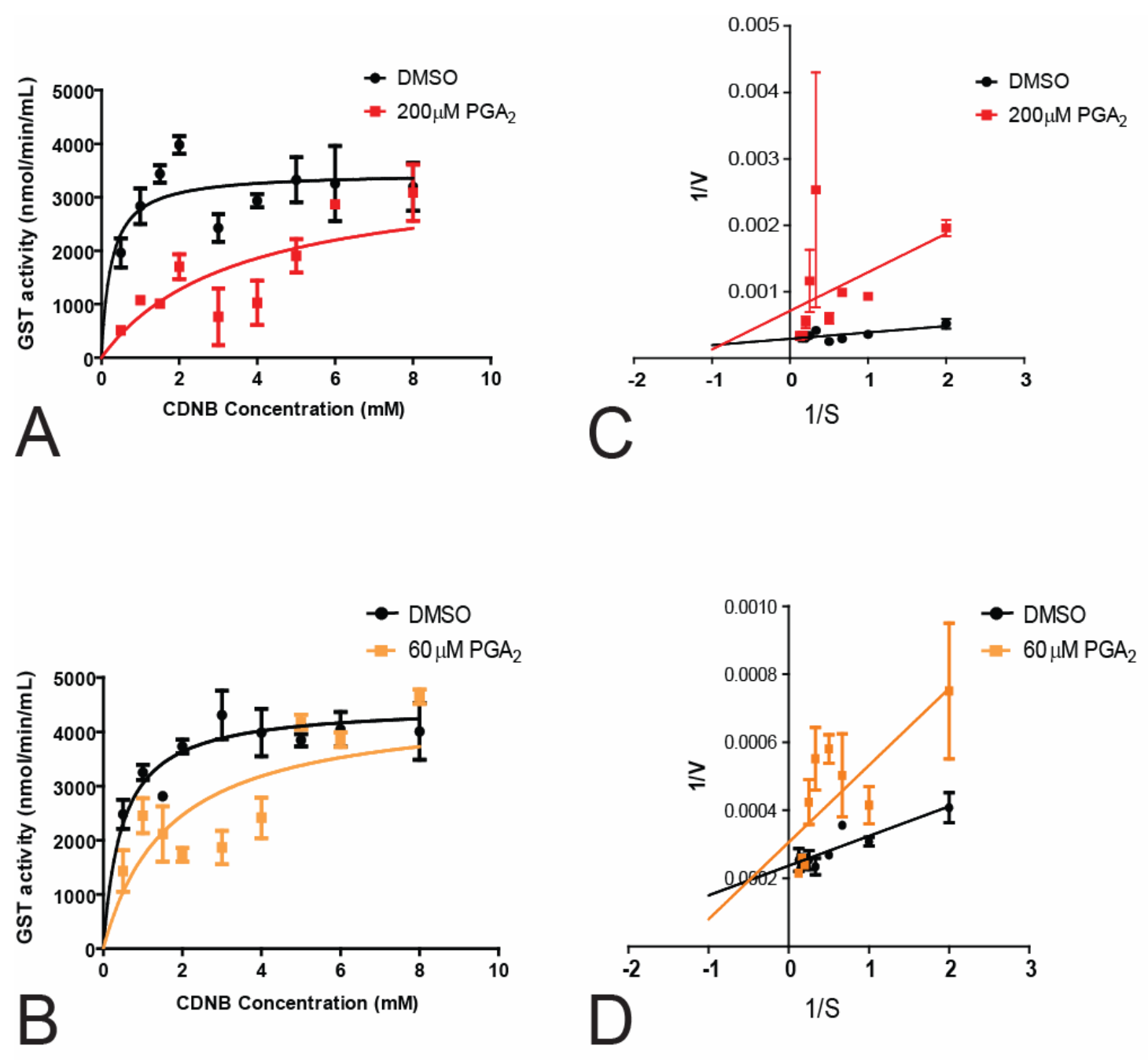

Figure 11. Lineweaver-Burke plots showing mixed inhibition of Cyphoma GSTs toward CDNB by 15(S)-PGA . GST activity was measured at varying concentrations of CDNB in the absence (DMSO) and presence of $200 \mu \mathrm{M}(\mathbf{A})$ and $60 \mu \mathrm{M}(\mathbf{B}) \mathrm{PGA}_{2}$. The reaction mixture consisted of varying concentrations of CDNB and $6 \mathrm{ng}$ of affinitypurified GST protein in $0.1 \mathrm{M}$ potassium phosphate buffer, $\mathrm{pH} 7.5$, containing $1 \mathrm{mM}$ $\mathrm{GSH}$ at $25^{\circ} \mathrm{C}$ with $5 \%(\mathrm{v} / \mathrm{v})$ DMSO. An affinity-purified GST preparation from a single digestive gland was used as the protein source with a specific activity of $561 \pm 25 \mu \mathrm{mol}$ $\min ^{-1} \mathrm{mg}$ protein ${ }^{-1}$. DMSO $(\bullet)$ and $\mathrm{PGA}_{2}(\boldsymbol{\bullet})$ values at each CDNB concentration represent the mean $( \pm \mathrm{SE})$ of two technical replicates. Lineweaver-Burke plots $(\mathbf{C}, \mathbf{D})$ of $1 / \mathrm{V}_{\max }$ versus CDNB concentration were constructed from data in part $\mathrm{A}$ and $\mathrm{B}$, respectively. Lineweaver-Burke plots indicated a mixed type of inhibition (i.e., competitive and noncompetitive inhibition). 


\section{Chapter V}

The role of multixenobiotic transporters in generalist and specialist molluscan predators as counter-defense mechanisms against dietary chemical stress 


\begin{abstract}
Multixenobiotic transporters have been extensively studied for their ability to modulate the absorption, metabolism, and toxicity of pharmacological agents. These transporters may also play critical roles in regulating the efflux or accumulation of natural dietary toxins in marine consumers, perhaps ultimately influencing dietary choice. This study presents functional and molecular evidence for multixenobiotic transportermediated efflux activity and expression in a generalist (Cyphoma gibbosum) and specialist (Tritonia hamnerorum) molluscan predator, both of which are obligate consumers of chemically defended gorgonian corals. Immunochemical analysis revealed that proteins with homology to the permeability glycoprotein (Pgp) subfamily of ABC transporters were not expressed in C. gibbosum digestive gland preparations or tissues, but were highly expressed in T. hamnerorum tissue homogenates. Pgp expression in $T$. hamnerorum was primarily localized to the apical tips of the gut epithelium, a region particularly vulnerable to dietary allelochemical exposure, suggesting these transporters may provide an effective means of protection against ingested environmental toxins. In vivo dye assays with $T$. hamnerorum indicated concentration-dependent inhibition of calcein-am efflux by specific inhibitors of Pgp and the multidrug resistance-associated protein (MRP), implying that both $\mathrm{ABC}$ protein subfamilies may facilitate allelochemical transport in this specialist predator. An adaptor-ligated cDNA library with degenerate and specific primers was used to clone eight cDNAs encoding two partial ABCB and two partial $\mathrm{ABCC}$ proteins from both $C$. gibbosum and T. hamnerorum. In addition, real-time quantitative PCR analysis demonstrated selected C. gibbosum MRP transcripts were
\end{abstract}


constitutively expressed in the digestive gland regardless of allelochemical diet. The constitutive expression of $C$. gibbosum MRP transporters with homology to mammalian glutathione-conjugate transporters may be explained by previous evidence suggesting that gorgonian diets contain high affinity substrates for phase II detoxification enzymes, whose conjugates may in turn be exported by MRPs. In summary, the foraging strategies of marine consumers may result in different expression patterns of related multixenobiotic transporters depending on diet chemistry and the requirements of the consumer; however, it is likely that both subfamilies of $\mathrm{ABC}$ transporters operate as effective allelochemical pumps, providing a physiological defense against environmental toxicants in both molluscan species.

\section{Introduction}

Soft-bodied benthic organisms produce a vast number of structurally diverse secondary metabolites, many of which function as feeding deterrents in marine systems (Hay \& Fenical 1988, Harvell \& Fenical 1989, Paul 1992, Hay 1996, Stachowicz 2001). For marine consumers, the consequences of ingesting chemically defended prey can be quite severe (Targett \& Arnold 2001), yet specialized consumers that solely feed on toxic prey can apparently tolerate these dietary compounds, and in some cases, even concentrate the defensive compounds for their own protection (Cimino et al. 1985, Cronin 2001). Few studies have explored the physiological targets of these compounds in generalist consumers and progress has been slow in understanding the mechanisms by which more specialized predators are able to cope with their toxic prey. 
For organisms that feed on toxin laden prey, multixenobiotic resistance transporters represent one mechanism by which predators may protect themselves against the toxicity of their prey, either by actively exporting allelochemicals out of cells or sequestering toxins within specialized cells or organelles, effectively compartmentalizing them away from vulnerable protein and DNA targets (Sorensen \& Dearing 2006). Those proteins involved in the transport of xenobiotics across membranes belong to the ATP Binding Cassette $(\mathrm{ABC})$ family, and likely provide consumers with a 'first line of defense' against the accumulation of dietary allelochemicals (Epel 1998). Several members of the ABCB (P-glycoprotein; Pgp or MDR) and ABCC (multidrug resistanceassociated protein or MRP) subfamilies function as highly promiscuous transporters, capable of trafficking a diverse array of moderately hydrophobic xenobiotics across cell membranes (Bodo et al. 2003). Together, the overexpression of both Pgp and MRP in tumor cell lines has long been known to mediate the ATP-dependent efflux of anticancer agents, conferring tumor resistance to natural product chemotherapeutic compounds (Deeley \& Cole 2006, Sarkadi et al. 2006). Only recently has it been suggested that ABC transporters are responsible for regulating the absorption of allelochemicals in the guts of consumers, and may therefore have a significant influence on the foraging patterns and ultimately diet choice of these organisms (Sorensen \& Dearing 2006, Sotka \& Whalen 2008).

The ubiquity of these multixenobiotic resistance proteins (MXRs) in aquatic organisms has been confirmed by immunological cross-reactivity studies, in vivo functional assays, competitive inhibition substrate binding assays (Bard 2000, Eufemia \& 
Epel 2000), and more recently by molecular evidence (Goldstone et al. 2007). The distribution of MXRs in tissues involved in absorption, secretion and barrier functions in aquatic invertebrates (Bard 2000) suggests that they may play a role in the prevention of dietary xenobiotic absorption. Several studies have also identified marine natural products from algae, tunicates, sea hares and gorgonians that may be substrates for multixenobiotic resistance proteins (Suganuma et al. 1988, Chambers et al. 1993, Williams \& Jacobs 1993, Aherne et al. 1996, Quesada et al. 1996, Schroder et al. 1998, Tanaka et al. 2002), suggesting that the pool of potential substrates in marine ecosystems may be extensive. Given this evidence, the constitutive or inducible expression of MXRs in marine consumers may serve a protective role against a range of allelochemically-rich prey.

Analogous to the reciprocal evolution of terrestrial consumer biotransformation enzymes in response to their toxic host plants (Li et al. 2004), marine consumers likely evolved multixenobiotic resistance mechanisms out of a similar need to mount a cellular defense against the escalating chemical attack produced by their prey/host(s). As a result of this chemical 'arms race', it is expected that many marine allelochemicals may be MXR substrates or potent inhibitors (Smital et al. 2004) - the latter likely functioning as counter-defense strategies of chemical defended prey to thwart the detoxification attempts by their consumers (Sorensen \& Dearing 2006). Eufemia et al. (2002) examined seaweed and phytoplankton extracts co-occurring with the filter feeder, Mytilus californianus, for their ability to act as chemosensitizers (substrates and/or inhibitors) for molluscan $\mathrm{ABC}$ transporters using competition-based fluorescent dye assays. Tissue 
accumulation of the fluorescent $\mathrm{ABC}$ transporter substrate (e.g., rhodamine) occurred if the test compound was a substrate (or inhibitor) of transport activity. Moderately hydrophobic fractions from five algal extracts caused the greatest accumulation of rhodamine dye in the gill tissue of M. californianus, suggesting the presence of Pglycoprotein substrates in algal species. In addition, polyphenolics (phlorotannins), known to be potent feeding deterrents in some marine ecosystems (Targett \& Arnold 2001), were also found to cause dye accumulation, suggesting they too are substrates or inhibitors for MXRs. Recent evidence also reveals that the unpalatability of newly invasive seaweeds may be linked in part to the liberation of potent MXR inhibitors (Smital et al. 2004). Extracts from the invasive green alga, Caulerpa taxifolia, resulted in the reversal of MXT activity in cell culture and in in vivo experiments with bivalves Dreissena polymorpha and Mytilus galloprovincialis (Smital et al. 1996, Schroder et al. 1998, Smital et al. 2004). Consumption of these algal species could pose severe threats to naïve consumers who may lack adequate adaptations to cope with the invasives. However, for those marine consumers that are regularly exposed to toxic allelochemicals in their diet, maintaining high levels of $\mathrm{ABC}$ transporter protein and/or activity in vulnerable tissues may allow these consumers to exploit an otherwise unattainable resource.

The objective of this study was to characterize the multixenobiotic resistance proteins potentially involved in dietary allelochemical resistance in two species of tropical gastropods that feed exclusively on allelochemically defended gorgonian corals. A combination of molecular, immunological and functional approaches were used to 
examine the expression and activity of molluscan $\mathrm{ABC}$ transporters in Tritonia hamnerorum, a specialist nudibranch that feeds on a single genus of gorgonian, and Cyphoma gibbosum, a generalist gastropod that includes multiple gorgonian families in its diet. Evidence from terrestrial chemical ecology studies suggests that generalists have likely evolved a greater diversity of catalytically versatile xenobiotic resistance mechanisms as a result of their chemically diverse diets, compared to specialists that feed on a reduced spectrum of allelochemicals due to their narrow foraging range (Li et al. 2004, Sorensen \& Dearing 2006). This study presents the initial characterization of those molluscan MXRs likely responsible for xenobiotic resistance, and will ultimately contribute to a more complete understanding of how generalists and specialists cope with their allelochemical $\operatorname{diet}(\mathrm{s})$.

Expression levels of select MXR transporters were compared between the two molluscan species to examine the relationship between MXR expression and diet specificity. Reverse transcription-polymerase chain reaction (RT-PCR) in combination with adaptor-specific and degenerate primers was used to perform targeted searches for $\mathrm{ABC}$ transporter genes and successfully identified two Pgp homologs and two MRP homologs from each molluscan species. To determine if MXR expression was influenced by the different allelochemical profiles of host gorgonians, quantitative RTPCR was used to measure the expression of selected $A B C$ transporter transcripts in digestive gland samples from C. gibbosum feeding on seven different gorgonian species. In addition, immunochemical analysis was used to characterize the expression and localization of Pgp in molluscan tissue homogenates and sections. Finally, quantification 
of MXR activity was measured using in vivo competitive-based fluorescent dye assays by examining the sensitivity of Tritonia transporters to model Pgp and MRP inhibitors. Together, these results indicate that both $\mathrm{ABC}$ protein subfamilies may play a significant role in defending molluscan predators against naturally occurring dietary toxins.

\section{Materials and Methods}

Animal collection

In January 2004, over 200 Tritonia hamnerorum, ranging in size from $3 \mathrm{~mm}$ to 15 $\mathrm{mm}$, were collected from shallow reefs surrounding the Perry Institute of Marine Science (PIMS), Lee Stocking Island, Exuma Cays, Bahamas. The purple sea fan, Gorgonia ventalina, was the only species of octocoral observed to serve as host for Tritonia hamnerorum at our study site. The density of Tritonia hamnerorum on individual sea fans ranged from two to over 500 individuals per sea fan. Nudibranchs were collected by removing the portion of sea fan housing them with scissors and transporting both the gorgonian and nudibranchs back to wet laboratory facilities provided by PIMS where they were maintained in flowing filtered seawater until further use. T. hamnerorum individuals used for RNA and protein isolation were removed from their host gorgonian, pooled, flash frozen and stored in liquid nitrogen until processing.

In a preliminary series of feeding assays conducted in January 2004, adult Cyphoma gibbosum were allowed to feed for four days on one of four gorgonian species (Briareum asbestinum, Gorgonia ventalina, Pseudopterogorgia acerosa, Pseudopterogorgia americana). A complete description of the feeding assay 
experimental set-up can be found in Chapter 3, Methods. Upon completion of the assays, digestive glands were immediately dissected and either frozen in liquid nitrogen $(n=2$ digestive glands) or stored in RNALater ${ }^{\circledR}$ at $-80^{\circ} \mathrm{C}(\mathrm{n}=15$ digestive glands $)$ until further processing.

\section{$R N A$ isolation and RT-PCR cloning}

Both Tritonia hamnerorum and Cyphoma gibbosum collected in 2004 provided tissue for initial ABC transporter cloning studies. Total RNA from a frozen, pooled sample of whole $T$. hamnerorum (267.9 $\mathrm{mg} ; \mathrm{n}>40$ individuals) was isolated with the RNeasy Maxi Kit (Qiagen, Valencia, CA) following the manufacturer's instructions. RNA isolation from pooled C. gibbosum digestive glands was performed as described in Chapter 3, Methods. The integrity of the RNA samples was checked by electrophoresis on a 1\% agarose-formaldehyde gel in MOPS buffer and visualized with ethidium bromide under UV light. Total RNA concentration was determined using a Nanodrop spectrophotometer (Wilmington, DE). Poly(A)+ RNA was purified using the MicroPoly(A)Purist mRNA purification kit (Ambion, Austin, TX) according to the manufacturer's instructions. First-strand cDNA was reverse transcribed from $2 \mu \mathrm{g}$ poly(A)+ RNA using OmniScript reverse transcriptase (OmniScript RT kit, Qiagen) with random hexamer primers. 
Initial cloning of C. gibbosum and T. hamnerorum MRP fragments.

PCR and nested PCR were performed using AmpliTaq Gold DNA polymerase (Applied Biosystems) under the following conditions: $94^{\circ} \mathrm{C}$ for $10 \mathrm{~min} ;\left(94^{\circ} \mathrm{C}\right.$ for $15 \mathrm{sec}$, $52^{\circ} \mathrm{C}$ for $30 \mathrm{sec}$ ) for 35 cycles; $72^{\circ} \mathrm{C}$ for $7 \mathrm{~min}$ and with degenerate primers pairs (MRP_F/MRP_R and nestMRP_F/nestMRP_R) (Table 1) designed against the conserved Walker A/B domains (Allikmets \& Dean 1998, Dean et al. 2001). Primers were a generous gift from David Epel and Amro Hamdoun, Hopkins Marine Station. PCR products were visualized on agarose gels, gel purified (Gene Clean II, Bio 101, Inc.), ligated into pGEM-T Easy@ plasmid vector (Promega, Madison, WI), and transformed into JM109 cells (Promega). PCR products were sequenced in both directions using an ABI 3730XL capillary sequencer at the Keck facility of the Josephine Bay Paul Center for Comparative Molecular Biology \& Evolution at the Marine Biological Laboratory (Woods Hole, MA). A minimum of twelve clones were sequenced for each PCR fragment. Clones were grouped based on nucleotide sequence with Sequencher 4.6 (Gene Codes Corp., Ann Arbor, MI) and a consensus sequence was generated and then examined by NCBI/GenBank BLASTx for gene identification (Altschul et al. 1997). BLASTx (NCBI) searches identified two partial sequences from C. gibbosum and two partial sequences from T. hamnerorum as having homology to MRP transporters. Gene specific primers (Table 1) were then designed to these cDNA fragments in order to obtain additional 5' and 3' sequence. 
Rapid amplification of cDNA ends (RACE)

Cyphoma RACE-PCR. Poly(A)+RNA isolated from the digestive glands of snails feeding on one of four gorgonian diets (see Chapter 3, Methods) (Briareum asbestinum, Gorgonia ventalina, Pseudopterogorgia acerosa, Pseudopterogorgia americana) was pooled and $1 \mu \mathrm{g}$ was primed with modified oligo (dT) primers and used to create an adaptor-ligated, double-stranded (ds) cDNA library using the Marathon cDNA Amplification Kit (BD Biosciences, Palo Alto, CA) according to the manufacturer's instructions. Gene specific primers were designed to both MRP cDNA fragments (CgMRP-1 and CgMRP-2) (Table 1) and were used in combination with adaptor-specific primers in nested 5' and 3' RACE reactions. All primers were obtained from Sigma Genosys (St. Louis, MO). Amplification of C. gibbosum MRP specific PCR products was carried out according to the Advantage 2 PCR Enzyme Kit (Clontech, Mountain View, CA) and cycling parameters were as follows: $94^{\circ} \mathrm{C}$ for $30 \mathrm{sec} ;\left(94^{\circ} \mathrm{C}\right.$ for $5 \mathrm{sec}, 72^{\circ} \mathrm{C}$ for $2.5 \mathrm{~min})$ for 5 cycles; $\left(94^{\circ} \mathrm{C}\right.$ for $5 \mathrm{sec}, 70^{\circ} \mathrm{C}$ for $\left.2.5 \mathrm{~min}\right)$ for 5 cycles; $\left(94^{\circ} \mathrm{C}\right.$ for $5 \mathrm{sec}$, $68^{\circ} \mathrm{C}$ for $2.5 \mathrm{~min}$ ) for 25 cycles; $68^{\circ} \mathrm{C}$ for $5 \mathrm{~min}$ with the following specific primers pairs (C. gibbosum MRP-1, 5' RACE; MRP-R1/RACE_1_F); or $94^{\circ} \mathrm{C}$ for $30 \mathrm{sec} ;\left(94^{\circ} \mathrm{C}\right.$ for 5 sec, $72^{\circ} \mathrm{C}$ for $\left.4 \mathrm{~min}\right)$ for 5 cycles; $\left(94^{\circ} \mathrm{C}\right.$ for $5 \mathrm{sec}, 70^{\circ} \mathrm{C}$ for $\left.4 \mathrm{~min}\right)$ for 5 cycles; $\left(94^{\circ} \mathrm{C}\right.$ for $5 \mathrm{sec}, 68^{\circ} \mathrm{C}$ for $4 \mathrm{~min}$ ) for 25 cycles with the following specific primer pairs (C. gibbosum MRP-1 -- CgMRP-1_F9/AP1 then CgMRP-1_F10/AP2; Cg_MRP-1_F10/AP1 then CgMRP-1_F8/AP2; CgMRP-1_R9/AP1 then CgMRP-1_R8/AP2; C. gibbosum MRP-2 -CgMRP-2_F7/AP1 then CgMRP-2_F6/AP2). 
The $C$. gibbosum adaptor-ligated ds cDNA library was also used to amplify partial Pgp cDNA sequences by RACE using degenerate primers designed to the conserved nucleotide binding domains. Nested-RACE was performed with the following degenerate primers pairs (Pgp_Bbox_F/RACE_1_F then Pgp_Cdomain_F/RACE_1_F) (Table 1) using the Advantage 2 PCR Enzyme Kit with the following cycling parameters: $94^{\circ} \mathrm{C}$ for $30 \mathrm{sec}$; $\left(94^{\circ} \mathrm{C}\right.$ for $5 \mathrm{sec}, 55^{\circ} \mathrm{C}$ for $30 \mathrm{sec}, 68^{\circ} \mathrm{C}$ for $2 \mathrm{~min}$ ) for 30 cycles. BLASTx searches identified the two partial sequences as having homology to Pgp. Gene specific primers were designed to both C. gibbosum Pgp-1 and Pgp-2 fragments and used in combination with adaptor-specific primers in nested 5' RACE reactions. PCR products were amplified with Advantage 2 polymerase with the following cycling parameters: $94^{\circ} \mathrm{C}$ for $30 \mathrm{sec}$; $\left(94^{\circ} \mathrm{C}\right.$ for $5 \mathrm{sec}, 72^{\circ} \mathrm{C}$ for $\left.3 \mathrm{~min}\right)$ for 5 cycles; $\left(94^{\circ} \mathrm{C}\right.$ for $5 \mathrm{sec}, 70^{\circ} \mathrm{C}$ for 3 $\min )$ for 5 cycles; $\left(94^{\circ} \mathrm{C}\right.$ for $5 \mathrm{sec}, 68^{\circ} \mathrm{C}$ for $\left.3 \mathrm{~min}\right)$ for 25 cycles with the following specific primer pairs (C. gibbosum Pgp-1 -- Pgp_R4/AP1; C.gibbosum Pgp-2 Pgp_R5/AP1 then Pgp_R6/AP2) (Table 1).

Tritonia RACE PCR. One microgram of poly(A)+RNA, isolated as described above, was used to created an adaptor-ligated ds cDNA library using the Marathon cDNA Amplification Kit according to the manufacturer's instructions. Gene specific primers were designed to both MRP cDNA fragments (ThMRP-1 and ThMRP-2) (Table 1) and were used in combination with adaptor-specific primers in nested 5' and 3' RACE reactions. T. hamnerorum MRP specific PCR products were amplified using the Advantage 2 PCR Enzyme Kit; cycling parameters were as follows: $94^{\circ} \mathrm{C}$ for $30 \mathrm{sec}$; $\left(94^{\circ} \mathrm{C}\right.$ for $5 \mathrm{sec}, 72^{\circ} \mathrm{C}$ for $\left.3 \mathrm{~min}\right)$ for 5 cycles; $\left(94^{\circ} \mathrm{C}\right.$ for $5 \mathrm{sec}, 70^{\circ} \mathrm{C}$ for $3 \mathrm{~min}$ ) for 5 
cycles; $\left(94^{\circ} \mathrm{C}\right.$ for $5 \mathrm{sec}, 68^{\circ} \mathrm{C}$ for $\left.3 \mathrm{~min}\right)$ for 25 cycles with the following specific primer pairs (T. hamnerorum MRP -1 - MRP_F4/AP1 then MRP_F5/AP2; MRP_R5/AP1 then MRP_R4/AP2; ThMRP-1_R6/AP1 then ThMRP-1_R7/AP2; ThMRP-1_F7/AP1 then ThMRP-1_F6/AP1; T. hamnerorum MRP-2 - MRP_R3/AP1 then MRP_R2/AP2; MRP_F2/AP1 then MRP_F3/AP2; ThMRP-2_R9/AP1 then ThMRP-2_R8/AP2; ThMRP-2_F11/AP1 then MRP_F3/AP2; ThMRP-2_F10/AP1 then MRP_F3/AP2).

The $T$. hamnerorum adaptor-ligated ds cDNA library was also used to initially amplify partial Pgp cDNA sequences by RACE using a combination of degenerate primers designed to the conserved nucleotide binding region and specific adaptor primers. Nested-RACE was performed with degenerate primer pairs (Pgp_Bbox_F/RACE_1_F then Pgp_Cdomain_F/RACE_1_F) (Table 1) using the Advantage 2 PCR Enzyme Kit with the following cycling parameters: $94^{\circ} \mathrm{C}$ for $30 \mathrm{sec}$; $\left(94^{\circ} \mathrm{C}\right.$ for $5 \mathrm{sec}, 61^{\circ} \mathrm{C}$ for $30 \mathrm{sec}, 68^{\circ} \mathrm{C}$ for $\left.2 \mathrm{~min}\right)$ for 5 cycles; $\left(94^{\circ} \mathrm{C}\right.$ for $5 \mathrm{sec}, 59^{\circ} \mathrm{C}$ for $30 \mathrm{sec}, 68^{\circ} \mathrm{C}$ for $\left.2 \mathrm{~min}\right)$ for 5 cycles; $\left(94^{\circ} \mathrm{C}\right.$ for $5 \mathrm{sec}, 57^{\circ} \mathrm{C}$ for $30 \mathrm{sec}, 68^{\circ} \mathrm{C}$ for $\left.2 \mathrm{~min}\right)$ for 20 cycles. BLASTx searches identified the two partial sequences as having homology to Pgp. Gene specific primers were designed to both T. hamnerorum Pgp-1 and Pgp-2 fragments and used in combination with adaptor-specific primers in nested RACE reactions. PCR products were amplified with Advantage 2 polymerase with the following cycling parameters: $94^{\circ} \mathrm{C}$ for $30 \mathrm{sec} ;\left(94^{\circ} \mathrm{C}\right.$ for $5 \mathrm{sec}, 72^{\circ} \mathrm{C}$ for $\left.3 \mathrm{~min}\right)$ for 5 cycles; $\left(94^{\circ} \mathrm{C}\right.$ for $5 \mathrm{sec}, 70^{\circ} \mathrm{C}$ for $\left.3 \mathrm{~min}\right)$ for 5 cycles; $\left(94^{\circ} \mathrm{C}\right.$ for $5 \mathrm{sec}, 68^{\circ} \mathrm{C}$ for $\left.3 \mathrm{~min}\right)$ for 25 cycles with the following specific primer pairs (T. hamnerorum Pgp-1 - ThPgp1_R8/AP1 then ThPgp-1_R7/AP2; ThPgp-1_R8/AP1 then ThPgp-1_R7; T. hamnerorum 
Pgp-2 - ThPgp-2_R10/AP1 then ThPgp-2_R9/AP2) (Table 1). PCR products obtained from C. gibbosum and T. hamnerorum RACE reactions were cloned, sequenced, and analyzed as described below.

Sequence analysis

Clones were initially grouped based on nucleotide sequence identity $(>80 \%)$ with Sequencher 4.6 (Gene Codes Corp., Ann Arbor, MI), and a consensus sequence was generated and examined by NCBI/GenBank BLASTx for gene identification (Altschul et al. 1997). Multiple alignments of molluscan deduced amino acid sequences were performed using ClustalW (Thompson et al. 1994). Human ABC gene subfamilies were aligned using Muscle v3.7 (Edgar 2004). In order to maintain the proper relationships between the incompletely sequenced $\mathrm{ABC}$ domains, $C$. gibbosum and T. hamnerorum Pgp and MRP sequences were aligned to each other separately and then to the human $\mathrm{ABCB}$ (containing Pgp) and $\mathrm{ABCC}$ (containing MRP) families using the profile-profile alignment settings of Muscle. Alignments were automatically masked using the alignment quality scores of Muscle; (cut-off score of 20). Maximum likelihood (ML) phylogenetic analyses were performed with RAxML (v7.0.0; Stamatakis 2006). Two types of analyses were performed: default rapid hill-climbing ML searches, starting from multiple different randomized maximum parsimony (MP) trees; or 100 replicates of rapid MP bootstrapping to find optimal start trees followed by rapid hill-climbing ML optimization. The PROTMIXWAG model of amino acid substitution was used in all analyses, which uses a category model of the WAG amino acid substitution matrix 
(Whelan \& Goldman 2001) during the hill-climbing ML search but a gamma distribution of substitution rates for a final tree optimization (Stamatakis 2006).

\section{Western blot for ABC-transporters}

Crude homogenates were prepared by homogenizing pooled C. gibbosum digestive glands and whole $T$. hamnerorum in $10 \mathrm{mM}$ potassium chloride, $1.5 \mathrm{mM}$ magnesium chloride, $10 \mathrm{mM}$ Tris-HCl, (pH 7.4), containing $2 \mathrm{mM} \mathrm{PMSF}$ and 5\% (by vol.) SDS at $4^{\circ} \mathrm{C}$. In addition, livers from Fundulus heteroclitus collected from New Bedford Harbor, MA, were also homogenized as described and used as a positive control (Bard et al. 2002). The crude homogenate was centrifuged at $14,000 \mathrm{x}$ g for 2 min at $4^{\circ} \mathrm{C}$, and the supernatant was stored at $-80^{\circ} \mathrm{C}$ until analysis. Protein concentrations were determined using the bicinchoninic acid (BCA) assay (Smith et al. 1985). Crude tissue homogenates were then diluted to $20 \mu \mathrm{g}$ total protein with standard SDS-PAGE sample buffer (50 mM Tris, pH 6.8, 2\% SDS, 10\% sucrose, $0.2 \% \beta$-mercaptoethanol, $0.001 \%$ bromphenol blue), denatured at $100^{\circ} \mathrm{C}$ for $3 \mathrm{~min}$, and loaded onto a $7.5 \%$ Tris-glycine gel using a 4\% stacking gel. Prestained molecular markers were purchased from Amersham (Full-range Rainbow MW Markers, GE Healthcare, Buckinghamshire, UK). Following electrophoresis, proteins were transferred onto a $0.45 \mu \mathrm{m}$ nitrocellulose membrane (Schleicher \& Schuell, Keene, NH) at $15 \mathrm{~V}$ for $54 \mathrm{~min}$. The membrane was blocked in $5 \%(\mathrm{wt} / \mathrm{vol})$ non-fat milk in Tris buffered saline-Tween $0.1 \%$ (TBST) for $1 \mathrm{hr}$ and then hybridized overnight with rocking at $4^{\circ} \mathrm{C}$ in TBST containing $0.4 \mu \mathrm{g} / \mathrm{mL}$ of the monoclonal antibody C219 (Signet Laboratories, Dedham, MA). The membrane was 
subsequently washed ( 3 x $10 \mathrm{~min}$ ) with TBST and incubated for $1 \mathrm{hr}$. with horseradish peroxidase-conjugated goat anti-mouse IgG (Jackson ImmunoResearch Inc., West Grove, PA) diluted 1:7000 in TBST. Detection of HRP activity was by enhanced chemoluminescence (ECL) onto Hyperfilm ECL (Amersham).

\section{Immunohistochemical analysis}

Live nudibranchs and snails were transferred to a $50 \mathrm{~mL}$ beaker containing filtered seawater and were relaxed by adding a few crystals of magnesium sulfate until they no longer recoiled to the touch. Digestive glands and mantle tissues from $C$. gibbosum $(\mathrm{n}=4)$ and whole $T$. hamnerorum individuals $(\mathrm{n}=2)$ were fixed for 2 hours at $4^{\circ} \mathrm{C}$ in a buffered seawater solution of $2 \%$ paraformaldehyde, $2.5 \%$ glutaraldehyde (Karnovsky’s Fixative) obtained from Electron Microscopy Sciences (Hatfield, PA). Tissue samples were then transferred to PBS and kept at $4^{\circ} \mathrm{C}$ till embedding. Paraffinembedded samples were sectioned at $5 \mu \mathrm{m}$ and mounted on Superfrost Plus (Fisher Scientific, St. Louis, MO) microscope slides, deparaffined, and then hydrated with normal mouse serum in $10 \mathrm{mM}$ phosphate buffered saline ( $\mathrm{pH} 7.5)$. Sections were incubated for $1 \mathrm{hr}$. at room temperature with the mAB C219 diluted $(2 \mu \mathrm{g} / \mathrm{mL})$ in Primary Antibody Diluent (Signet). Antibody binding was visualized with a commercial avidinbiotin-peroxidase kit using diaminobenzidine tetrahydrochlroide (DAB) as the chromogen (Vectastain ${ }^{\circledR}$ Elite ABC Kit, Vector Laboratories, Inc., Burlingame, CA) according to the manufacturer's instructions. Specific staining was evaluated by light microscopy by comparison of mAB C219 stained and unstained serial sections. 
In-vivo dye transport assays

Fluorophores and inhibitors. MK571 was purchased from Cayman Chemical (Ann Arbor, MI). Calcein-acetoxymethylester (C-AM) was purchased from Axxora (San Diego, CA). Calcein was purchased from Invitrogen (Carlsbad, CA). Verapamil was purchased from MP Biomedicals (Solon, OH). Concentrated stocks of MK571 and CAM were prepared in DMSO and were sufficiently concentrated so that the DMSO volume did not to exceed $0.5 \%$ of the experimental volume.

$\mathrm{ABC}$ transporter activity was measured by the accumulation of calcein in whole T. hamnerorum individuals. Calcein-AM (C-AM) is a non-fluorescent substrate for both MRP and Pgp. Any C-AM entering the cell, if not transported out immediately by either $\mathrm{ABC}$ transporter, is rapidly hydrolyzed by intracellular esterases to form calcein, a fluorescent membrane-impermeable molecule (Essodaigui et al. 1998). Therefore, exposure to inhibitors of $\mathrm{ABC}$ transporter activity results in high calcein accumulation and increased fluorescence, while reduced intracellular accumulation of calcein and fluorescence is observed when transporter activity is increased.

Nudibranchs maintained in the laboratory were removed from their host, $G$. ventalina, and allowed to depurate for four hours in a beaker of sterile-filtered seawater. Five similarly sized T. hamnerorum were placed in each well of a 24-well plate and incubated for two hours in $3 \mathrm{~mL}$ of $500 \mathrm{nM} \mathrm{C}$-AM resuspended in sterile-filtered seawater. Incubations were performed in the presence or absence of two inhibitors at two concentrations. MK571 specifically inhibits MRP transport activity, while verapamil 
inhibits Pgp transport activity. Nudibranchs were then rapidly washed two times with sterile-filtered seawater and homogenized for 30 seconds using an electric drill with a Teflon pestle in a $2 \mathrm{~mL}$ Wheaton glass homogenizer containing $125 \mu \mathrm{L}$ of ethanol. The homogenate $(\sim 175 \mu \mathrm{L})$ was transferred to a $1.5 \mathrm{~mL}$ tube and centrifuged at room temperature for $7 \mathrm{~min}$ at 6.1 relative centrifugal force $(\mathrm{RCF})$. Eighty-five microliters of supernatant was transferred to a 96-well black plate containing a clear bottom to minimize light scattering. The level of calcein in the resulting supernatant was measured fluorimetrically $\left(\lambda_{\mathrm{ex}}=485 \mathrm{~nm}, \lambda_{\mathrm{em}}=530 \mathrm{~nm}\right)$ using a Cytofluor 2300 plate reader (Millepore). A calcein standard curve was run alongside the supernatant readings to estimate the concentration of intracellular calcein. The ratio of intracellular calcein fluorescence in the absence and presence of MK571 or verapamil was used as a measure of the activity of T. hamnerorum MRP and Pgp transporters. Statistical analysis was performed using a two sample $t$ test of the means with a significance level of $5 \%$.

\section{Real-time quantitative RT-PCR and data analysis}

Total RNA and poly(A)+ RNA (n=141) were isolated as described in Chapter 3, Methods from the digestive glands of Cyphoma participating in the 2006 feeding assay. Sequence-specific primers for quantitative PCR analysis of C. gibbosum MRP-1 mRNA expression are listed in Table 1. PCR amplification conditions, control cDNA synthesis experiments, melt curve analysis and standard curve serial dilutions specific for the representative MRP-1 clone were performed as described in Chapter 3, Methods. Each sample and standard was run in duplicate and the expression of $C$. gibbosum $\beta$-actin was 
used to control for differences in cDNA synthesis among samples. Molecule number for each RNA sample was calculated from a standard curve dilution series.

To test whether Cyphoma MRP-1 gene expression differed between snails feeding on a control diet versus a gorgonian diet, a two way analysis of variance (ANOVA) was used with Diet (control vs. gorgonian diet) as a fixed factor and Reef (snail origin) as a random factor. The MRP-1 gene was considered a dependent variable. In addition, a one-way ANOVA was used to examine the variability in MRP-1 expression among reefs, where Reef was considered a random factor. This test was used to investigate reefspecific variation in transcript levels in time-zero snails, and to determine if any such variation persisted in snails collected from these same reefs after being fed a control diet for four days. P-values were corrected for the two-way ANOVA analysis using by Bonferroni adjustment (Sankoh et al. 1997). Data analysis was performed using SYSTAT ${ }^{\circledR}$ version 11 (Systat Software, Inc., San Jose, CA).

\section{Results}

Cloning of molluscan ABC transporter genes

An RT-PCR approach with pooled mRNA samples ${ }^{1}$ and degenerate oligonucleotide primers were used to identify initial Pgp and MRP fragments within the conserved nucleotide binding domain of $\mathrm{ABC}$ transporter genes from both Cyphoma gibbosum and Tritonia hamnerorum. BlastX (NCBI) comparison of translated cDNAs indicated homology to mammalian $\mathrm{ABCB}$ and $\mathrm{ABCC}$ proteins. Initial gene fragment

\footnotetext{
${ }^{1}$ Molluscan mRNA samples used for the initial cloning studies were made from pooled C. gibbosum digestive glands and pooled T. hamnerorum individuals.
} 
sizes were as follows: . gibbosum MRP-1 and MRP-2, 168 bp; C. gibbosum Pgp-1 and Pgp-2, 216 bp; T. hamnerorum MRP-1 and MRP-2, 170 bp; T. hamnerorum Pgp-1 and Pgp-2, 71 and 182 bp respectively. Specific oligonucleotide primers were designed to these initial fragments and were used in 5' and 3' RACE reactions to obtain the eight partial MXR sequences listed in Table 2 and depicted in Figures 1 thru 10.

Sequence analysis

Deduced amino acid alignments of the molluscan MRPs and Pgps generated from nucleotide consensus sequences are shown in Figures 5 and 10. MRP amino acid alignments with human $\mathrm{ABCC}$ sequences revealed nearly full-length coding sequence was obtained for ThMRP-1 with only a minimal portion of the 3' end missing. The partial sequence obtained for CgMRP-1 included the putative start codon and covered the first two transmembrane spanning domains and the nucleotide binding domain. Substantially less sequence was obtained for both CgMRP-2 and ThMRP-2, which align with the first nucleotide binding domain. An alignment of molluscan Pgp amino acid sequences with mouse ABCB1a revealed that both Tritonia Pgp sequences align with the first nucleotide binding domain, while Cyphoma Pgp sequences covered the second half of the protein and included the stop codon. In addition, Kyte and Doolittle (1982) hydrophobicity plots of $C$. gibbosum and $T$. hamnerorum $\mathrm{ABC}$ transporters with mouse $\mathrm{ABCB} 1 \mathrm{a}$ and human $\mathrm{ABCC} 3$ were nearly identical when aligned with each other (Figure $11,12)$, increasing confidence in the assignment of molluscan transmembrane and nucleotide binding domains. 
Phylogenetic analysis revealed homology of the molluscan $\mathrm{ABC}$ transporters to the human $\mathrm{ABCB}$ and $\mathrm{ABCC}$ subfamilies (Figure 13). Tritonia Pgp-1, Pgp-2 and Cyphoma Pgp-1, Pgp-2 were 63.5, 72.7, 55.5 and 55.9\% identical, respectively, with overlapping portions of human ABCB1. In addition, Tritonia MRP-1, MRP-2 and Cyphoma MRP-1, MRP-2 protein sequences were 34.3, 32.2, 35.8 and 24.8\% identical, respectively, with overlapping portions of human $\mathrm{ABCC} 1$. A second phylogenetic tree was constructed in order to better define the relationships among molluscan proteins and the human $\mathrm{ABCB}$ and $\mathrm{ABCC}$ subfamilies (Figure 14). This second tree suggested that two sets of paralogs exist for $\mathrm{ABCB}$ and $\mathrm{ABCC}$ proteins in Tritonia as a result of duplication events. The gene duplication resulting in ThMRP-1 and ThMRP-2 appears to have occurred prior to the Cyphoma/Tritonia speciation, while the duplication leading to ThPgp-1 and ThPgp-2 may have occurred after the Cyphoma/Tritonia speciation event. Overlapping portions of deduced amino acid sequences of Tritonia Pgp-1 and Pgp-2 are 67.4\% identical, while Tritonia MRP-1 and MRP-2 are 38.4\% identical. A similar comparison of Cyphoma proteins indicates that CgPgp-1 and CgPgp-2 (50.8\% a.a. identity) arose from a more recent duplication in comparison to CgMRP-1 and CgMRP-2 (34.5\% a.a. identity), which appear to be more deeply divergent, sharing a common ancestor basal to the clades containing $\mathrm{ABCC} 13$ and $\mathrm{ABCC} 4$.

Bootstrap values indicating strong support were used to assign molluscan genes to either a particular human ortholog, or when a strong relationship did not exist (bootstrap value $<80$ ), the assignment was made to a particular clade containing multiple subfamily members. Among ABCC proteins, only human ABCC5 and CgMRP-2 are indicated as 
possible orthologs; however, the bootstrap value on this pairing is very low $(50 \%$, see Figure 14), resulting in minimal confidence in this observation. Rather, CgMRP-2 should be considered an ortholog of all three human genes in this clade (ABCC5, $\mathrm{ABCC} 11$ and $\mathrm{ABCC} 12$ clade; i.e., the human genes are co-orthologs of CgMRP-2). CgMRP-1 and ThMRP-1 emerge as orthologs and together with ThMRP-2 appear to be most closely related to the human $\mathrm{ABCC} 1, \mathrm{ABCC} 2, \mathrm{ABCC} 3$ and $\mathrm{ABCC} 6$ members. Within the Pgp-related ABCB subfamily, significant bootstrap support exists for the molluscan Pgp/ABCB1/ABCB4/ABCB5/ABCB11 clade; however, more specific relationships can not be defined further because of low bootstrap support.

\section{Expression and localization of P-glycoproteins}

Expression of P-glycoprotein in Cyphoma digestive gland and whole Tritonia homogenates was examined by Western blot using the monoclonal antibody C219, which recognizes a highly conserved amino acid sequence within the nucleotide binding domain (VQ-E/A/V-ALD) (Georges et al. 1990). In Tritonia tissue homogenates, this antibody recognized a distinct band of expected size, $170 \mathrm{kDa}$ (Juliano \& Ling 1976), and two larger diffuse bands, $>200 \mathrm{kDa}$, possibility representing differentially glycosylated isoforms of Pgp (Schinkel et al. 1993) (Figure 15). However, similar immunoreactivity was absent for Cyphoma digestive gland homogenates. Based on deduced amino acid sequences, the lack of reactivity in Cyphoma homogenates is somewhat surprising considering that at least one of the Cyphoma proteins (CgPgp-1) contains the epitope VQEALD, among those recognized by C219. Although C219 recognizes this epitope 
containg Glu (E), it does so less strongly than the epitope containing Ala (A) (VQAALD) (Georges et al. 1990). The partial Tritonia Pgp-1 sequence contains the Ala at this position (VQAALD), which may explain the difference in reactivity between molluscan species. Alternatively, or in addition, there may be differences in Pgp expression that contribute to the differential recognition by $\mathrm{C} 219$ in these immunoblot studies.

The cellular localization of P-glycoprotein was examined in paraffin-embedded fixed tissue sections probed with C219. P-glycoprotein expression was detected in the apical tips of the ciliated columnar epithelia lining the lumen of the midgut in $T$. hamnerorum individuals (Figure 16 and 17). The midgut in nudibranchs is a centrally located sac anteriorly connected to the buccal cavity containing the radula and associated feeding organs by the esophagus and posterially connected to the tubular hindgut (Millott 1937). The midgut is also connected to the caecum and the surrounding digestive gland. Heavy ciliated cells within the anterior portion of the midgut are arranged in folds and contain elongated nuclei due to the compressed condition of the cells when the midgut is not distended (Millott 1937, Morse 1968). Immunohistochemical staining helps to accentuate the folded nature of the midgut epithelia (Figure 16). Faint staining was also noted in goblet-like cells found on the nudibranch's epidermis, possibly involved in mucus secretion (Figure 16). In contrast to the staining in Tritonia tissues, Pgp was not detected by immunohistochemistry in C. gibbosum mantle or digestive gland tissues. 
In vivo calcein efflux transport assay

In vivo examination of transporter activity in Tritonia was assessed using the calcein efflux assay. The calcein assay is a functional diagnostic method developed to quantify multixenobiotic transporter-mediated efflux activity in cells and tissues. Nonfluorescent calcein-AM rapidly traverses cell membranes where it can be converted to fluorescent calcein by non-specific esterases or extruded by Pgp and MRP before intracellular conversion to the non-MXR substrate. High levels of MXR transport activity can prevent the accumulation of free calcein in the cell, resulting in minimal fluorescent calcein accumulation. Transporter-specific MXR-mediated efflux can be measured by the use of specific MRP (MK571) and Pgp (verapamil) inhibitors. If transport activity is minimal, the transport inhibitor will have limited or no effect resulting in little increased cell fluorescence. However, if transport activity is significant, the presence of an inhibitor will increase calcein accumulation, as indicated by intracellular fluorescence, compared to incubations without the inhibitor present.

Live Tritonia were incubated in the presence of $500 \mathrm{nM}$ extracellular C-AM with and without varying concentrations of inhibitors. The addition of verapamil or MK571 to the seawater containing Tritonia significantly increased calcein accumulation compared to DMSO controls (Figure 18). These results indicate that MXR-mediated efflux activity prevents calcein accumulation in Tritonia tissues and that inhibiting this activity causes calcein-AM to be retained and hydrolyzed to calcein. Calcein accumulation varied depending on the inhibitor used and its concentration. Increasing verapamil concentration to $25 \mu \mathrm{M}$ did not cause a measurable increase in calcein accumulation 
compared to $5 \mu \mathrm{M}$ of verapamil, suggesting that the lower concentration of verapamil is sufficient to block the majority of Pgp transporters. In contrast, $30 \mu \mathrm{M} \mathrm{MK571} \mathrm{resulted}$ in a further $57 \%$ increase in calcein accumulation compared to that caused by $5 \mu \mathrm{M}$ MK571, and the calcein accumulation was greater than the maximal level obtained in the presence of verapamil. This difference in the absolute level of calcein accumulation suggests that MRP transporters are either more highly expressed or more efficient at exporting C-AM in Tritonia tissues and therefore may play a more active role in xenobiotic transport compared to Pgp.

Quantitative RT-PCR analysis of Cyphoma MRP-1 expression

Quantitative RT-PCR analysis was used to investigate the constitutive and inducible expression of MRP-1 forms in Cyphoma after dietary exposure to several gorgonian species with varying allelochemical profiles. Cyphoma MRP-1 was selected for expression analysis because of its homology to the human MRP1 (ABCC1), known for its ability to transport a range of glutathione-conjugated substrates. This is particularly relevant to the present study because Cyphoma digestive gland tissues constitutively express high levels of the glutathione-conjugating enzyme, glutathione $S$ transferase, likely necessitated by the presence of numerous potent inhibitors/substrates in its gorgonian diets (see Chapter 4). Thus, efflux of glutathione-conjugated allelochemicals from Cyphoma digestive gland may be mediated by MRP-1.

Adult Cyphoma were allowed to feed ad libitum for $4 \mathrm{~d}$ on one of seven gorgonian diets or a control diet devoid of gorgonian allelochemicals, as described in 
Chapter 3. Digestive gland levels of CgMRP-1 transcripts were measured by quantitative RT-PCR. MRP-1 transcripts were constitutively expressed in Cyphoma digestive gland and the expression was not affected by gorgonian diet (Table 3, Figure 19). MRP-1 transcript expression was also measured in time-zero individuals to determine if collection location could influence gene expression. MRP-1 expression was found to significantly differ in time-zero snails as a function of reef location (ANOVA, $\mathrm{F}_{4,26}=$ $2.74, p=0.05$, Table 4 , Figure 20), but did not significantly differ among snails allowed to feed on a control diet for four days (ANOVA, $\mathrm{F}_{4,28}=0.637, \mathrm{p}=0.640$ ).

\section{Discussion}

In aquatic systems, much of our knowledge of the function of $\mathrm{ABC}$ transporters in marine invertebrates is limited to the response of these proteins under anthropogenic stress conditions (Kurelec 1992, Minier et al. 1993, Smital et al. 2000, Smital et al. 2003, Kingtong et al. 2007). However, for marine consumers that regularly feed on prey/hosts laden with natural toxins, efflux transporters may play a critical role in regulating the absorption of allelochemicals, thereby dictating diet selection. This study is the first to examine the expression and activity of $\mathrm{ABC}$ transporters from two molluscan predators that feed solely on chemically defended prey.

\section{Molluscan P-glycoproteins}

Using a combination of molecular approaches, four partial Pgps related to multixenobiotic transporters in vertebrates were identified from the digestive gland of 
Cyphoma gibbosum (CgPgp-1, CgPgp-2) and whole Tritonia hamnerorum (ThPgp-1, ThPgp-2). All four molluscan Pgps encode transporters that cluster within a highly supported clade containing the human $\mathrm{ABCB} 1, \mathrm{ABCB} 4, \mathrm{ABCB} 5$ and $\mathrm{ABCB} 11$ genes. ABCB1 (MDR1 or Pgp1) is possibly the most well studied of all the multixenobiotic transporters and is known for its promiscuous transport of hydrophobic substrates, including xenobiotics, lipids, sterols, and chemotherapeutics derived from natural products (Choudhuri \& Klaassen 2006). ABCB4 (MDR3) and ABCB11 are both expressed in the liver and are involved in the secretion of bile acids (Gerloff et al. 1998, Oude Elferink \& Paulusma 2007), while ABCB5 is hypothesized to function as a drug resistance mediator, similar to $\mathrm{ABCB} 1$, and is primarily expressed in the epidermis (Frank et al. 2005). Acquisition of complete ABCB sequences would no doubt help to better define the relationships of the molluscan Pgps with particular ABCB members. Nevertheless, the phylogenetic analysis presented here clearly groups these molluscan transporters with those $\mathrm{ABCB}$ members known to mediate xenobiotic resistance.

Western blot analysis of molluscan tissues with the mAb C219, which recognizes both human MDR1 (ABCB1) and MDR3 (ABCB4) proteins (Van den Elsen et al. 1999), suggested that homologs of human MDR proteins are expressed in Tritonia tissues but not in Cyphoma digestive gland. The disparity in Pgp expression between both molluscan predators may reflect differences in their foraging behavior. Specialist herbivores that consume a diet rich in allelochemicals had a higher intestinal Pgp capacity in comparison to a sympatric generalists that are unable to tolerate the toxinladen diet (Green et al. 2004). While high Pgp protein expression does not necessarily 
translate to increased protein activity, these results do suggest that dietary toxins could be handled differently depending on consumer experience.

Deduced amino acid sequences from two partial Cyphoma Pgps indicate that at least one of the forms (CgPgp-1) contains the correct epitope (VQEALD) in its nucleotide binding domain and therefore would be recognized by C219 if expressed in the digestive gland. It is possible that CgPgp-1 is expressed in tissues other than the digestive gland; however, immunohistochemical analysis of whole Cyphoma sections with C219 did not detect any immunoreactive protein. Based on sequence data, multiple forms of Pgp are expressed in Cyphoma digestive gland, yet their detection may be limited by the reactivity of the antibody used here, suggesting that western blots should be interpreted with caution. In contrast, Tritonia tissue homogenates displayed a distinct band at $170 \mathrm{kDa}$, in agreement with human MDR proteins (Choudhuri \& Klaassen 2006) and two diffuse bands at $>200 \mathrm{kDa}$. Similar multiple banding patterns (i.e., $170 \mathrm{kDa}$, and $>200 \mathrm{kDa}$ banding) have also been observed in the gill tissue of mussels Mytilus californianus, M. galloprovincialis, and M. edulis and oysters Crassostrea gigas and $C$. virginica (i.e., > $200 \mathrm{kDa}$ ) (reviewed in Bard 2000). Protein bands $>200 \mathrm{kDa}$ may represent post-translational modifications or differential glycosylation states, not uncommon among mammalian P-glycoproteins (Schinkel et al. 1993).

Immunohistochemical staining of Tritonia tissues by C219 indicated that Pgp proteins were localized to the apical epithelial of the midgut and to a lesser extent in the epidermis. The location of Pgp in Tritonia digestive tissues is in agreement with the localization of mammalian $\mathrm{ABCB} 1$ on the apical (or luminal) surface of polarized 
epithelia of many tissues, such as the gastrointestinal tract, kidney proximal tubules and biliary heptocytes (Klein et al. 1999). Based on the location of mammalian ABCB1 in barrier tissues coupled with its function as a unidirectional transporter of a range of toxic substrates, it is likely that the physiological role of $\mathrm{ABCB} 1$ and its orthologs is to protect cells and ultimately organisms against toxic compounds (Schinkel et al. 1994, Schinkel et al. 1997). The two tissues types observed to exhibit the greatest Pgp expression in Tritonia, the gut epithelia and the epidermis, correspond to those tissues that would be exposed to the greatest concentration of gorgonian allelochemicals, due to the fact that Tritonia both resides on and consumes its gorgonian host.

Interestingly, this nudibranch is able to selectively sequester a furano-germacrene feeding deterrent from its gorgonian host, Gorgonia ventalina, and concentrate this chemical defense four-fold (dry mass basis) relative to the gorgonian (Cronin et al. 1995). While the exact mechanism of sequestration in nudibranch tissues is unknown, recent studies have demonstrated that mammalian MXR transporters can reduce the intracellular concentration of toxins by actively sequestering them in subcellular compartments, away from vulnerable cellular targets (Van Luyn et al. 1998, Molinari et al. 2002, Rajagopal \& Simon 2003, Ifergan et al. 2005). Furthermore, MXR members can have different activity profiles depending on membrane location (i.e., plasma membrane versus lysosomal membrane), which may be linked to the lipid environment or post-translational modification of the transporter that can occur within subcellular compartments (Rajagopal \& Simon 2003). This intracellular sequestration phenomenon has also been observed in mussel blood cells, whereby the intracellular accumulation of the fluorescent 
Pgp substrate Rhodamine B in lysosomes could be reversed if incubated with verapamil (Svensson et al. 2003). In addition, the MXR-mediated subcellular localization is suspected to be responsible for the sequestration of the marine toxin, okadaic acid in the mussel Mytilus edulis (Svensson et al. 2003). Transporters have also been suggested as a mechanism by which herbivorous insects can sequester unmetabolized host plant toxins in diverticular pouches, defensive glands or hemolymph (Sorensen \& Dearing 2006). Therefore, sequestration of dietary allelochemicals by $\mathrm{ABC}$ transporters may function as a protective mechanism against cytotoxicity, with the added advantage of providing the marine consumer with its own chemical protection.

The in vivo activity of MXR transporters was investigated in Tritonia using ABC subfamily specific transport inhibitors capable of blocking the Pgp- and MRP-mediated efflux of C-AM. Both inhibitors resulted in increased dye accumulation in Tritonia tissues, which is consistent with previous competitive dye transport assays reporting MXR-mediated transport activity in a variety of marine invertebrates (grass shrimp (Finley et al. 1998), worm (Toomey \& Epel 1993), sponge (Muller et al. 1996), oyster (Keppler 1997), mussel (McFadzen et al. 2000), sea urchin (Hamdoun et al. 2004)). Varying inhibitor concentration did not increase Pgp-mediated calcein accumulation, but did cause a substantial impact on MRP-mediated calcein accumulation. The greater level of calcein accumulation in Tritonia exposed to MRP inhibitor suggests that MRPmediated efflux may contribute more to xenobiotic resistance than Pgp in Tritonia. 


\section{Molluscan multixenobiotic resistance-associated proteins}

While both subfamilies of transporters confer multixenobiotic resistance, the substrate selectivities of Pgp and MRP differ markedly. Pgp transport neutral or mildly positive lipophilic compounds, while MRP substrates are lipophilic anions capable of transporting a range of substrates including glutathione (GSH), glucuronide, or sulfate conjugates of phase II detoxification reactions (Kruh \& Belinsky 2003). Phylogenetic analysis of molluscan MRP sequences obtained here indicate that CgMRP-1, ThMRP-1 and ThMRP-2 fall within a well-supported clade containing the mammalian ABCC1, $\mathrm{ABCC} 2, \mathrm{ABCC} 3$ and $\mathrm{ABCC} 6$ proteins, known for their ability to transport a variety of glutathione conjugates including natural product cancer drugs and prostaglandins (Evers et al. 1997, de Waart et al. 2006). The Caribbean gorgonian Plexaura homomalla is regularly consumed by Cyphoma despite the high concentration of prostaglandin $\mathrm{A}_{2}$ esters (Gerhart 1986), which function as potent feeding deterrents in this coral (Gerhart 1984, Pawlik \& Fenical 1989). Recent evidence suggests that Cyphoma may be able to tolerate dietary prostaglandins and other lipophilic gorgonian compounds by conjugation with glutathione $S$-transferases (GSTs). GSTs are highly expressed in the digestive gland of this predator, and a screening of gorgonian lipophilic extracts suggests all gorgonian diets may contain substrates for Cyphoma GSTs (Chapter 4). Therefore, the constitutive expression of MRP-1 in the digestive gland of Cyphoma may facilitate the efficient biliary excretion of putative glutathione-conjugates of prostaglandins and other lipophilic compounds (Evers et al. 1997, Paumi et al. 2003, de Waart et al. 2006). MRP-1 expression was also detected in the snails feeding on control diets devoid of gorgonian 
allelochemicals, suggesting that these transporters may also be responsible for the export of physiological substrates, in addition to their roles in multixenobiotic resistance. In contrast, MRP-1 expression significantly varied in time-zero snails as a function of reef location. While it is difficult to conclusively pin point the cause of this reef-specific variation, the length of snail foraging time on a single colony or the presence of additional gorgonian species not tested in our feeding assays may have had an effect on MRP-1 expression.

Phylogenetic analysis revealed that Cyphoma MRP-2 is significantly divergent from the other molluscan MRPs identified in this study and falls into the clade containing human $\mathrm{ABCC}$, $\mathrm{ABCC} 11$ and $\mathrm{ABCC} 12$. All three of these transporters are at the early stages of investigation and their physiological functions are unknown, yet studies indicate that they mediate the transport of antiretroviral nucleosides and lipophilic glutathioneconjugates (Wijnholds et al. 2000, Kruh et al. 2007).

Mounting evidence suggests that $\mathrm{ABC}$ transporters likely regulate the absorption and subsequent distribution of natural toxins in marine organisms (Toomey \& Epel 1993, Toomey et al. 1996, Keppler \& Ringwood 2001, Eufemia et al. 2002). The present work describes the first efforts to identify MXR genes that may protect marine invertebrates that have adapted to exclusively feed on allelochemically-rich prey. Messenger RNA encoding MXR transporters is expressed in both generalist and specialist molluscan species and share sequence and organizational structure similar to MXRs of distantly related organisms, indicating the likelihood of shared function as natural product transporters between mammalian and molluscan orthologs. A second piece of evidence 
supporting the role of MXR proteins as dietary allelochemical efflux pumps comes from the results of immunohistochemical analyses in Tritonia tissues, where Pgp expression was highest in the tissues most vulnerable to allelochemical exposure. Additionally, in vivo studies of MXR activity using ABC subfamily-specific inhibitors provided added support for the presence and function of MXR transporters in Tritonia. However, for organisms where in vivo dye assays may not be permitted, real-time qPCR provided a highly robust and sensitive method for quantifying MXR isoform-specific expression. Constitutive expression of selected promiscuous MXR transporters may be advantageous to a generalist predator with a chemically diverse diet. Support for this hypothesis may come from screening gorgonian extracts in competitive substrate inhibition assays with transfected cell lines or isolated membrane vesicles overexpressing molluscan MXRs of interest. This initial screening approach would facilitate comparisons of substrate breadth between MXRs from generalist and specialist consumers and allow one to begin to test predictions about whether generalist MXRs possess greater structural and functional flexibility in their substrate specificity compared to specialists (Li et al. 2004).

In summary, the elucidation of the molecular mechanisms underlying consumer tolerance is a prerequisite to understanding the foraging behavior of marine consumers. This study provides a much needed first step in identifying putative environmental chemical stress genes capable of ameliorating allelochemical-induced toxicity. It is likely that both MRP and Pgp play significant roles in natural toxicant efflux in marine consumers. Future work aimed at elucidating those marine natural products capable of 
interacting with substrate-binding sites on MXRs will provide valuable insight into the evolution of $\mathrm{ABC}$ transporter-mediated consumer counter-defense mechanisms.

\section{References}

Aherne GW, Hardcastle A, Valenti M, Bryant A, Rogers P, Pettit GR, Srirangam JK, Kelland LR (1996) Antitumour evaluation of dolastatins 10 and 15 and their measurement in plasma by radioimmunoassay. Chemother Pharmacol 38:225-232

Allikmets R, Dean M (1998) Cloning of novel ABC transporter genes. Methods in Enzymology 292:116-130

Altschul SF, Madden TL, Schaffer AA, Zhang J, Zhang Z, Miller W, Lipman DJ (1997) Gapped BLAST and PSI-BLAST: a new generation of protein database search programs. Nucleic Acids Research 25:3389-3402

Bard SM (2000) Multixenobiotic resistance as a cellular defense mechanism in aquatic organisms. Aquatic Toxicology 48:357-389

Bard SM, Bello SM, Hahn ME, Stegeman JJ (2002) Expression of P-glycoprotein in killifish (Fundulus heteroclitus) exposed to environmental xenobiotics. Aquatic Toxicology 59:237-251

Bodo A, Bakos E, Szeri F, Varadi A, Sarkadi B (2003) The role of multidrug transporters in drug availability, metabolism and toxicity. Toxicology Letters 140-141:133143

Chambers TC, Raynor RL, Kuo JF (1993) Multidrug resistant human KB carcinoma cells are highly resistant to the protein phosphatase inhibitors okadaic acid and calyculin A. Analysis of potential mechanisms involved in toxin resistance. Int $\mathbf{J}$ Cancer 53:323-327

Choudhuri S, Klaassen CD (2006) Structure, function, expression, genomic organization, and single nucleotide polymorphisms of human ABCB1 (MDR1), ABCC (MRP), and ABCG2 (BCRP) efflux transporters. International Journal of Toxicology 25:231-259

Cimino G, De Rosa S, De Stefano S, Morrone R, Sodano G (1985) The chemical defense of nudibranch molluscs: structure, biosynthetic origin and defensive properties of terpenoids from the dorid nudibranch Dendrodoris grandiflora. Tetrahedron 41:1093-1100 
Cronin G (2001) Resource allocation in seaweeds and marine invertebrates: chemical defense patterns in relation to defense theories. In: McClintock JB, Baker BJ (eds) Marine Chemical Ecology. CRC Press, Boca Raton, FL, p 325-353

Cronin G, Hay ME, Fenical W, Lindquist N (1995) Distribution, density, and sequestration of host chemical defenses by the specialist nudibranch Tritonia hamnerorum found at high densities on the sea fan Gorgonia ventalina. Marine Ecology Progress Series 119:177-189

de Waart DR, Paulusma CC, Kunne C, Oude Elferink RP (2006) Multidrug resistance associated protein 2 mediates transport of prostaglandin E2. Liver International $26: 362-368$

Dean M, Rzhetsky A, Allikmets R (2001) The human ATP-binding cassette (ABC) transporter superfamily. Genome Research 11:1156-1166

Deeley RG, Cole SP (2006) Substrate recognition and transport by multidrug resistance protein 1 (ABCC1). FEBS Lett 580:1103-1111

Edgar RC (2004) MUSCLE: multiple sequence alignment with high accuracy and high throughput. Nucleic Acids Res 32:1792-1797

Epel D (1998) Use of multidrug transporters as first lines of defense against toxins in aquatic organisms. Comparative Biochemistry and Physiology Part A 120:23-28

Essodaigui M, Broxterman HJ, Garnier-Suillerot A (1998) Kinetic analysis of calcein and calcein-acetoxymethylester efflux mediated by the multidrug resistance protein and p-glycoprotein. Biochemistry 37:2243-2250

Eufemia N, Clerte S, Girshick S, Epel D (2002) Algal products as naturally occurring substrates for p-glycoprotein in Mytilus californianus. Marine Biology 140:343353

Eufemia NA, Epel D (2000) Induction of the mulixenobiotic defense mechanism (MXR), P-glycoprotein, in the mussel Mytilus californianus as a general cellular response to environmental stresses. Aquatic Toxicology 49:89-100

Evers R, Cnubben NHP, Wijnholds J, van Deemeter L, van Bladeren P, Borst P (1997) Transport of glutathione prostaglandin A conjugates by the multidrug resistance protein. FEBS Lett 419:112-116

Finley DB, Scott GI, Karnaky K (1998) Investigation of the presence and function of a putative multidrug transporter in the grass shrimp, Palaemonetes pugio. Society of Environmental Toxicology and Chemistry, 19th Annual Meeting, Charlotte, $\mathrm{NC}$ 
Frank NY, Margaryan A, Huang Y, Schatton T, Waaga-Gasser AM, Gasser M, Sayegh MH, Sadee W, Frank MH (2005) ABCB5-Mediated doxorubicin transport and chemoresistance in human malignant melanoma. Cancer Research 65:4320-4333

Georges E, Bradley G, Gariepy J, Ling V (1990) Detection of P-glycoprotein isoforms by gene-specific monoclonal antibodies. Proc Natl Acad Sci 87:152-156

Gerhart DJ (1984) Prostaglandin A2: An agent of chemical defense in the Caribbean gorgonian Plexaura homomalla. Marine Ecology Progress Series 19:181-187

Gerhart DJ (1986) Gregariousness in the gorgonian-eating gastropod Cyphoma gibbosum: tests of several possible causes. Marine Ecology Progress Series 31:255-263

Gerloff T, Stieger B, Hagenbuch B, Madon J, Landmann L, Roth J, Hofmann AF, Meier PJ (1998) The sister of P-glycoprotein represents the canalicular bile salt export pump of mammalian liver. Journal of Biological Chemistry 273:10046-10050

Goldstone JV, Goldstone HMH, Morrison AM, Tarrant A, Kern SE, Woodin BR, Stegeman JJ (2007) Cytochrome P450 genes in early deuterostomes (tunicates and sea urchins) and vertebrates (chicken and frog): origin and diversification of the CYP1 gene family. Molecular Biology and Evolution 24:2619-2631

Green AK, Haley SL, Dearing MD, Barnes DM, Karasov WH (2004) Intestinal capacity of P-glycoprotein is higher in the juniper specialist, Neotoma stephensi, than the sympatric generalist, Neotoma albigula. Comparative Biochemistry and Physiology, Part A 139:325-333

Hamdoun AM, Cherr GN, Roepke TA, Epel D (2004) Activation of multidrug efflux transporter activity at fertilization in sea urchin embryos (Strongylocentrotus purpuratus). Developmental Biology 276:452-462

Harvell CD, Fenical W (1989) Chemical and structural defenses of Caribbean gorgonians (Pseudopterogorgia sp.): intracolony localization of defense. Limnology and Oceanography 34:382-389

Hay ME (1996) Marine chemical ecology: what's known and what's next? Journal of Experimental Marine Biology and Ecology 200:103-134

Hay ME, Fenical W (1988) Marine plant-herbivore interactions: the ecology of chemical defense. Annu Rev Ecol Syst 19:111-145

Ifergan I, Scheffer GL, Assaraf YG (2005) Novel extracellular vesicles mediate an ABCG2-dependent anticancer drug sequestration and resistance. Cancer Research 65:10952-10958 
Juliano RL, Ling V (1976) A surface glycoprotein modulating drug permeability in Chinese hamster ovary cell mutants. Biochim Biophys Acta 455:152-162

Keppler C (1997) Expression of multixenobiotic resistance proteins and total proteins and total proteins in gills of the oyster Crassostrea virginica. College of Charleston, Thesis

Keppler C, Ringwood AH (2001) Expression of P-glycoprotein in the gills of oysters, Crassostrea virginica: seasonal and pollutant related effects. Aquatic Toxicology 54:195-204

Kingtong S, Chitramvong Y, Janvilisri T (2007) ATP-binding cassette multidrug transporters in Indian-rock oyster Saccostrea forskali and their role in the export of an environmental organic pollutant tributyltin. Aquatic Toxicology 85:124-132

Klein I, Sarkadi B, Varadi A (1999) An inventory of the human ABC proteins. Biochimica et Biophysica Acta 1461:237-262

Kruh GD, Belinsky MG (2003) The MRP family of drug efflux pumps. Oncogene 22:7537-7552

Kruh GD, Guo Y, Hopper-Borge E, Belinsky MG, Chen ZS (2007) ABCC10, ABCC11, and ABCC12. Pflugers Arch 453:675-684

Kurelec B (1992) The multixenobiotic resistance mechanism in aquatic organisms: ecotoxic consequences. Sci Total Environ 171:197-204

Kyte J, Doolittle RF (1982) A simple method for displaying the hydropathic character of a protein. Journal of Molecular Biology 157:105-132

Li X, Baudry J, Berenbaum MR, Schuler MA (2004) Structural and functional divergence of insect CYP6B proteins: From specialist to generalist cytochrome P450. Proc Natl Acad Sci 101:2939-2944

Marchler-Bauer A, Anderson J, Derbyshire M, DeWeese-Scott C, Gonzales NR, Gwadz M, Hao L, He S, Hurwitz DI, Jackson JD, Ke Z, Krylov D, Lanczycki CJ, Liebert CA, Liu C, Lu F, Lu S, Marchler GH, Mullokandov M, Song JS, Thanki N, Yamashita RA, Yin JJ, Zhang D, SH. B (2007) CDD: a conserved domain database for interactive domain family analysis. Nucleic Acids Research 35:237240

McFadzen I, Eufemia NA, Heath C, Epel D, Moore M, Lowe D (2000) Multidrug resistance in the embryos and larvae of the mussel Mytilus edulis. Marine Environmental Research 50:319-323 
Millott N (1937) On the morphology of the alimentary canal, process of feeding, and physiology of digestion of the nudibranch mollusc Jorunna tomentosa (Cuvier). Philosophical Transactions of the Royal Society of London Series B Biological Sciences 228:173-217

Minier C, Akcha F, Galgani F (1993) P-glycoprotein expression in Crassostrea gigas and Mytilus edulis in polluted seawater. Comparative Biochemistry and Physiology 106B:1029-1036

Molinari A, Calcabrini A, Meschini S, Stringaro A, Crateri P, Toccacieli L, Marra M, Colone M, Cianfriglia M, Arancia G (2002) Subcellular detection and localization of the drug transporter P-glycoprotein in cultured tumor cells. Curr Protein Pept Sci 3:653-670

Morse MP (1968) Functional morphology of the digestive system of the nudibranch mollusc Acanthodoris pilosa. Biological Bulletin 134:305-319

Muller WEG, Steffen R, Rinkevich B, Matranga V, Kurelec B (1996) The multixenobiotic resistance mechanism in the marine sponge Suberites domuncula: its potential applicability for the evaluation of environmental pollution by toxic compounds. Marine Biology 125:165-170

Oude Elferink RP, Paulusma CC (2007) Function and pathophysiological importance of ABCB4 (MDR3 P-glycoprotein). Pflugers Arch 453:601-610

Paul VJ (1992) Chemical defenses of benthic marine invertebrates. In: Paul VJ (ed) Ecological Roles of Marine Natural Products. Comstock and Publishing Associates, London, p 164-188

Paumi CM, Wright M, Townsend AJ, Morrow CS (2003) Multidrug resistance protein (MRP) 1 and MRP3 attenuate cytotoxic and transactivating effects of the cyclopentenone prostaglandin, 15-deoxy-delta-12,14-prostaglandin J2 in MCF7 breast cancer cells. Biochemistry 42:5429-5437

Pawlik JR, Fenical W (1989) A re-evaluation of the ichthyodeterrent role of prostaglandins in the Caribbean gorgonian coral Plexaura homomalla. Marine Ecology Progress Series 52:95-98

Quesada AR, Gravalos MD, Puentes JL (1996) Polyaromatic alkaloids from marine invertebrates as cytotoxic compounds and inhibitors of multidrug resistance caused by P-glycoprotein. Br J Cancer 74:677-682

Rajagopal A, Simon SM (2003) Subcellular localization and activity of multidrug resistance proteins. Molecular Biology of the Cell 14:3389-3399 
Sankoh AJ, Huque MF, Dubey SD (1997) Some comments on frequently used multiple endpoint adjustments methods in clinical trials. Statistics in Medicine 16:25292542

Sarkadi B, Homolya L, Szakacs G, Varadi A (2006) Human multidrug resistance ABCB and ABCG transporters: participation in a chemoimmunity defense system. Physiol Rev 86:1179-1236

Schinkel AH, Kemp S, Dolle M, Rudenko G, Wagenaar E (1993) N-glycosylation and deletion mutants of the human MDR1 P-glycoprotein. Journal of Biological Chemistry 268:7474-7481

Schinkel AH, Mayer U, Wagenaar E, Mol CA, van Deemter L, Smit JJ, van der Valk MA, Voordouw AC, Spits H, van Tellingen O, Zijlmans JM, Fibbe WE, Borst P (1997) Normal viability and altered pharmacokinetics in mice lacking mdr1-type (drug-transporting) P-glycoproteins. Proc Natl Acad Sci 94:4028-4033

Schinkel AH, Smit JJ, van Tellingen O, Beijnen JH, Wagenaar E, van Deemter L, Mol CA, van der Valk MA, Robanus-Maandag EC, te Riele HP, al. e (1994) Disruption of the mouse mdrla P-glycoprotein gene leads to a deficiency in the blood-brain barrier and to increased sensitivity to drugs. Cell 77:491-502

Schroder HC, Badria FA, Ayyad SN, Batel R, Wiens M, Hassanein HMA, Kurelec B, Muller WEG (1998) Inhibitory effects of extracts from the marine alga Caulerpa taxifolia and of toxin from Caulerpa racemosa on multixenobiotic resistance in the marine sponge Geodia cydonium. Environmental Toxicology and Pharmacology 5:119-126

Smital T, Luckenbach T, Sauerborn R, Hamdoun AM, Vega RL, Epel D (2004) Emerging contaminants - pesticides, PPCPs, microbial degradation products and natural substances as inhibitors of multixenobiotic defense in aquatic organisms. Mutat Res 552:101-117

Smital T, Pivcevic B, Kurelec B (1996) Reversal of multidrug resistance by extract from the marine alga Caulerpa taxifolia. Period Biol 98:1197-1203

Smital T, Sauerborn R, Hackenberger BK (2003) Inducibility of the P-glycoprotein transport activity in the marine mussel Mytilus galloprovincialis and the freshwater mussel Dreissena polymorpha. Aquatic Toxicology 65:443-465

Smital T, Sauerborn R, Pivcevic B, Krca S, Kurelec B (2000) Interspecies differences in P-glycoprotein mediated activity of multixenobiotic resistance mechanisms in several marine and freshwater invertebrates. Comparative Biochemistry and Physiology 126C:175-186 
Smith PK, Krohn RI, Hermanson GT, Mallia AK, Gartner FH, Provenzano MDea (1985) Measurement of protein using bicinchonicic acid. Analytical Biochemistry $150: 76-85$

Sorensen JS, Dearing MD (2006) Efflux transporters as a novel herbivore countermechanism to plant chemical defenses. Journal of Chemical Ecology 32:1181-1196

Sotka EE, Whalen KE (2008) Herbivore offense in the sea: the detoxification and transport of secondary metabolites. In: Amsler C (ed) Algal Chemical Ecology. Springer, New York, p 203-221

Stachowicz JJ (2001) Chemical Ecology of Mobile Benthic Invertebrates: Predators and Prey, Allies and Competitors. In: McClintock JB, Baker BJ (eds) Marine Chemical Ecology. CRC Press, Boca Raton, p 157-194

Stamatakis A (2006) Maximum likelihood-based phylogenetic analyses with thousands of taxa and mixed models. Bioinformatics 22:2688-2690

Suganuma M, Fujiki H, Suguri H, Yoshizawa S, Hirota M, Nakayasu M, Ojika M, Wakamatus K, Yamada K, Sugimur T (1988) Okadaic acid: an additional nonphorbol-12-tetradecanoate-13-acetate-type tumor promoter. Proceedings of the National Academy of Sciences of the USA 85:1768-1771

Svensson S, Sarngren A, Forlin L (2003) Mussel blood cells, resistant to the cytotoxic effects of okadaic acid, do not express cell membrane p-glycoprotein activity (multixenobiotic resistanc). Aquatic Toxicology 65:27-37

Tanaka J, Trianto A, Musman M, Issa HH, Ohtani I, Ichiba T, Higa T, Yoshida W, Scheuer PJ (2002) New polyoxygenated steroids exhibiting reversal of multidrug resistance from the gorgonian Isis hippuris. Tetrahedron 58:6259-6266

Targett NM, Arnold TM (2001) Effects of secondary metabolites on digestion in marine herbivores. In: McClintock JB, Baker BJ (eds) Marine Chemical Ecology. CRC Press, Boca Raton, p 391-411

Thompson JD, Higgins DG, Gibson TJ (1994) CLUSTAL W: improving the sensitivity of progressive multiple sequence alignment through sequence weighting, position-specific gap penalties and weight matrix choice. Nucleic Acids Res $22: 4673-4680$

Toomey BH, Epel D (1993) Multixenobiotic resistance in Urechis caupo embryos: protection from environmental toxins. Biological Bulletin 185:355-364 
Toomey BH, Kaufman MR, Epel D (1996) Marine bacteria produce compounds that modulate multixenobiotic transport activity in Urechis caupo embryos. Marine Environmental Research 42:393-397

Van den Elsen JMH, Kuntz DA, Hoedemaeker FJ, Rose DR (1999) Antibody C219 recognizes an alpha-helical epitope on P-glycoprotein. Proc Natl Acad Sci 96:13679-13684

Van Luyn MJA, Muller M, Renes J, Meijer C, Scheper RJ, Nienhuis EF, Mulder NH, Jansen PLM, De Vries GE (1998) Transport of glutathione conjugates into secretory vesicles is mediated by the multidrug-resistance protein 1 . International Journal of Cancer 76:55-62

Whelan S, Goldman N (2001) A general empirical model of protein evolution derived from multiple protein families using a maximum-likelihood approach. Mol Biol Evol 18:691-699

Wijnholds J, Mol CA, van Deemter L, de Haas M, Scheffer GL, Baas F, Beijnen JH, Scheper RJ, Hatse S, De Clercq E, Balzarini J, Borst P (2000) Multidrugresistance protein 5 is a multispecific organic anion transporter able to transport nucleotide analogs. Proc Natl Acad Sci 97:7476-7481

Williams AB, Jacobs RS (1993) A marine natural product, patellamide D, reverses multidrug resistance in a human leukemic cell line. Cancer Lett 71:97-102 
Table 1. Primers used in the present study

\begin{tabular}{|c|c|c|c|}
\hline \multirow{2}{*}{$\begin{array}{l}\text { Gene } \\
\text { Degenerate }\end{array}$} & \multirow[t]{2}{*}{ Primers } & \multicolumn{2}{|c|}{ Direction Sequences (5' to 3') } \\
\hline & & & \\
\hline \multirow[t]{4}{*}{ MRP } & MRP_F & Forward & CTD GTD GCD GTD GTD GG \\
\hline & MRP_R & Reverse & RCT NAV NGC NSW NAR NGG NTC RCT \\
\hline & nest_MRP_F & Forward & CGG GAT CCA GRG ARA AYA THC TNT TTG G \\
\hline & nest_MRP_R & Reverse & CGG AAT TCN TCR TCH AGN AGR TAD ATR TC \\
\hline \multirow[t]{2}{*}{ P-gp } & Pgp_Bbox_F & Forward & GGI GGI CAG AAR CAR MGI ATI GC \\
\hline & Pgp_Cdomain_F & Forward & GAY GAR GCI ACI TCI GCI CTI G \\
\hline \multicolumn{4}{|l|}{ Specific } \\
\hline \multirow[t]{6}{*}{ Cyphoma MRP-1 } & MRP-R1 & Reverse & CCG GGC TAA ACT CAC TCT CTG TTT CTG G \\
\hline & CgMRP-1_R8 & Reverse & CAT CCA TGA CCT GAG AAG ATC TGG \\
\hline & CgMRP-1_R9 & Reverse & GGT TCA CAA ACT GCA ACA GGT CG \\
\hline & CgMRP-1_F8 & Forward & CCA GAA ACA GAG AGT GAG TTT AGC C \\
\hline & CgMRP-1 F9 & Forward & GAA TGG CAC CGT CAT CGT ACA GAG \\
\hline & CgMRP-1 F10 & Forward & ATT GAC GCC TGT GCC CTT CGC AC \\
\hline \multirow[t]{2}{*}{ Cyphoma MRP-2 } & CgMRP-2_F6 & Forward & GAG ACA TTT GGA GCT GGG GAC CAG \\
\hline & CgMRP-2_F7 & Forward & GTG TCA GCA TGC TGT CTG GAC AAA G \\
\hline Cурhота Pgp-1 & P-gp_R4 & Reverse & CCT CTG TCA CCA CAC CAT GTC G \\
\hline \multirow[t]{2}{*}{ Cyphoma Pgp-2 } & P-gp_R5 & Reverse & GTT GGC CAC AAA GCC AGC GTA GGC \\
\hline & P-gp_R6 & Reverse & CTC CAA CAC CTG ACC GTT CTC C \\
\hline \multirow[t]{8}{*}{ Tritonia MRP-1 } & MRP_F4 & Forward & CAA TCG GAT ATT GAC ATT CTC CCT GGC \\
\hline & MRP_F5 & Forward & GCT GTG TAC AGT GAC CAA GAC \\
\hline & MRP_R4 & Reverse & CAG GGA GAA TGT CAA TAT CCG ATT GG \\
\hline & MRP_R5 & Reverse & GTC TTG GTC ACT GTA CAC AGC \\
\hline & ThMRिP-1_F6 & Forward & AAA TGA CGT CCG CTG CTG GTG TCC \\
\hline & ThMRP-1 F7 & Forward & AGG CAT TTG GCT GAC GGA GTG GAC \\
\hline & ThMRP-1_R6 & Reverse & AAA CAT GGC CAC GCC TAG TTG GTC \\
\hline & ThMRP-1_R7 & Reverse & GGA AGT CTC ATC GCC AAT GCT GG \\
\hline \multirow[t]{8}{*}{ Tritonia MRP-2 } & MRP F2 & Forward & GGT CCA GAT CTG CAA ATG CTG \\
\hline & MRP_F3 & Forward & GCA AAT GCT GCC AGA TGG TGA TC \\
\hline & MRP_R2 & Reverse & CAG CAT TTG CAG ATC TGG ACC \\
\hline & MRP_R3 & Reverse & GAT CAC CAT CTG GCA GCA TTT GC \\
\hline & ThMRP-2 R9 & Reverse & GGA CTT GAC CAA ATT GCC CAG CC \\
\hline & ThMRP-2_R8 & Reverse & TGA CCC GTG AAG TGA AGC GCT ATC \\
\hline & ThMRP-2_F10 & Forward & GTG GAA GGG AGT GTT GTC ATG AGG \\
\hline & ThMRP-2_F11 & Forward & GAA TCA ACG TGA CGA TTC CAG ACC \\
\hline \multirow[t]{3}{*}{ Adaptor primers } & RACE_1_F & & AAT ACG ACT CAC TAT AGG \\
\hline & AP1 & & CCA TCC TAA TAC GAC TCA CTA TAG GGC \\
\hline & AP2 & & ACT CAC TAT AGG GCT CGA GCG GC \\
\hline Cyphoma MRP-1 & 136_1_F1 & Forward & ACG AGG AGC TGA TGT GTC ACG ATG G \\
\hline qPCR primers & 136_1_R1 & Reverse & GTC CTC CTC ATC CAC ATC TTC ATC G \\
\hline
\end{tabular}




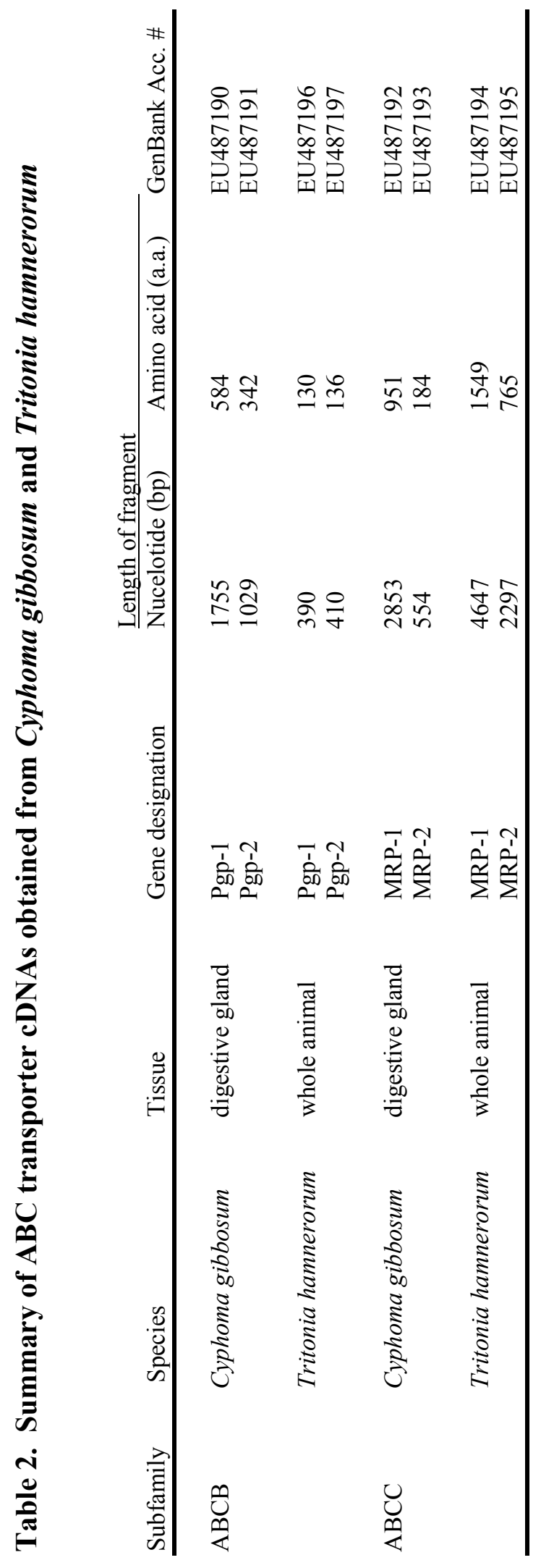


Table 3. Results of a two-way ANOVA investigating differences in MRP-1 gene expression in $C$. gibbosum feeding on control versus gorgonian diets.

\begin{tabular}{lrrrr} 
Factors & df & MS & $F$ & $\mathrm{p}$ \\
\hline Control vs. B. asbestinum & & & & \\
$\quad$ Diet & 1 & $5.3 \times 10^{9}$ & 0.797 & 0.422 \\
Reef & 4 & $1.4 \times 10^{10}$ & 0.423 & 0.791 \\
$\quad$ Diet x Reef & 4 & $6.6 \times 10^{9}$ & 0.204 & 0.935 \\
$\quad$ Error & 36 & $3.2 \times 10^{10}$ & & \\
Control vs. E. mammosa & & & & \\
$\quad$ Diet & 1 & $5.4 \times 10^{9}$ & 3.22 & 0.147 \\
Reef & 4 & $3.2 \times 10^{9}$ & 0.106 & 0.980 \\
Diet x Reef & 4 & $1.7 \times 10^{10}$ & 0.555 & 0.697 \\
Error & 35 & $3.0 \times 10^{10}$ & &
\end{tabular}

Control vs. G. ventalina

Diet

Reef

Diet x Reef

Error

1

4

4

35

$5.9 \times 10^{10}$
$1.4 \times 10^{10}$
$1.0 \times 10^{10}$
$3.2 \times 10^{10}$

Control vs. P. acerosa

Diet

Reef

Diet x Reef

Error

$2.0 \times 10^{10}$
$5.5 \times 10^{10}$
$2.1 \times 10^{10}$
$3.0 \times 10^{10}$

$$
1.9 \times 10^{10}
$$$$
2.5 \times 10^{10}
$$$$
1.9 \times 10^{10}
$$$$
2.9 \times 10^{10}
$$

5.91
0.432
0.313

0.072

0.785

0.867

$\begin{array}{rr}0.948 & 0.385 \\ 1.87 & 0.139 \\ 0.723 & 0.582\end{array}$

Control vs. $P$. americana

Diet

Reef

Diet x Reef

Error

\section{4}

4

35

Control vs. P. elisabethae

Diet

Reef

Diet x Reef

Error

$\begin{array}{rl}1 & 1.7 \times 10^{10} \\ 2 & 1.8 \times 10^{10} \\ 2 & 3.5 \times 10^{10} \\ 18 & 1.4 \times 10^{10}\end{array}$

Control vs. P. homomalla

Diet
Reef
Diet x Reef
Error

$\begin{array}{rrrr}1 & 6.4 \times 10^{10} & 9.66 & 0.036 \\ 4 & 4.5 \times 10^{9} & 0.157 & 0.958 \\ 4 & 6.6 \times 10^{9} & 0.230 & 0.920 \\ 34 & 2.9 \times 10^{10} & & \end{array}$

A $p \leq 0.007$ should be accepted as significant (Bonferroni adjusted) 
Table 4. Results of a one-way ANOVA investigating reef-dependent MRP-1 gene expression in time-zero and four day control fed $\boldsymbol{C}$. gibbosum. Reefs considered random factors.

\begin{tabular}{lllll} 
Factors & df & MS & F & p \\
\hline $\begin{array}{c}\text { Reef (Experiment 1) } \\
\text { Control diet }\end{array}$ & 4,28 & $2.1 \times 10^{10}$ & 0.637 & 0.640 \\
$\begin{array}{c}\text { Reef (Experiment 2) } \\
\text { Time-zero group }\end{array}$ & 4,26 & $3.1 \times 10^{10}$ & 2.74 & $\mathbf{0 . 0 5 0}$
\end{tabular}




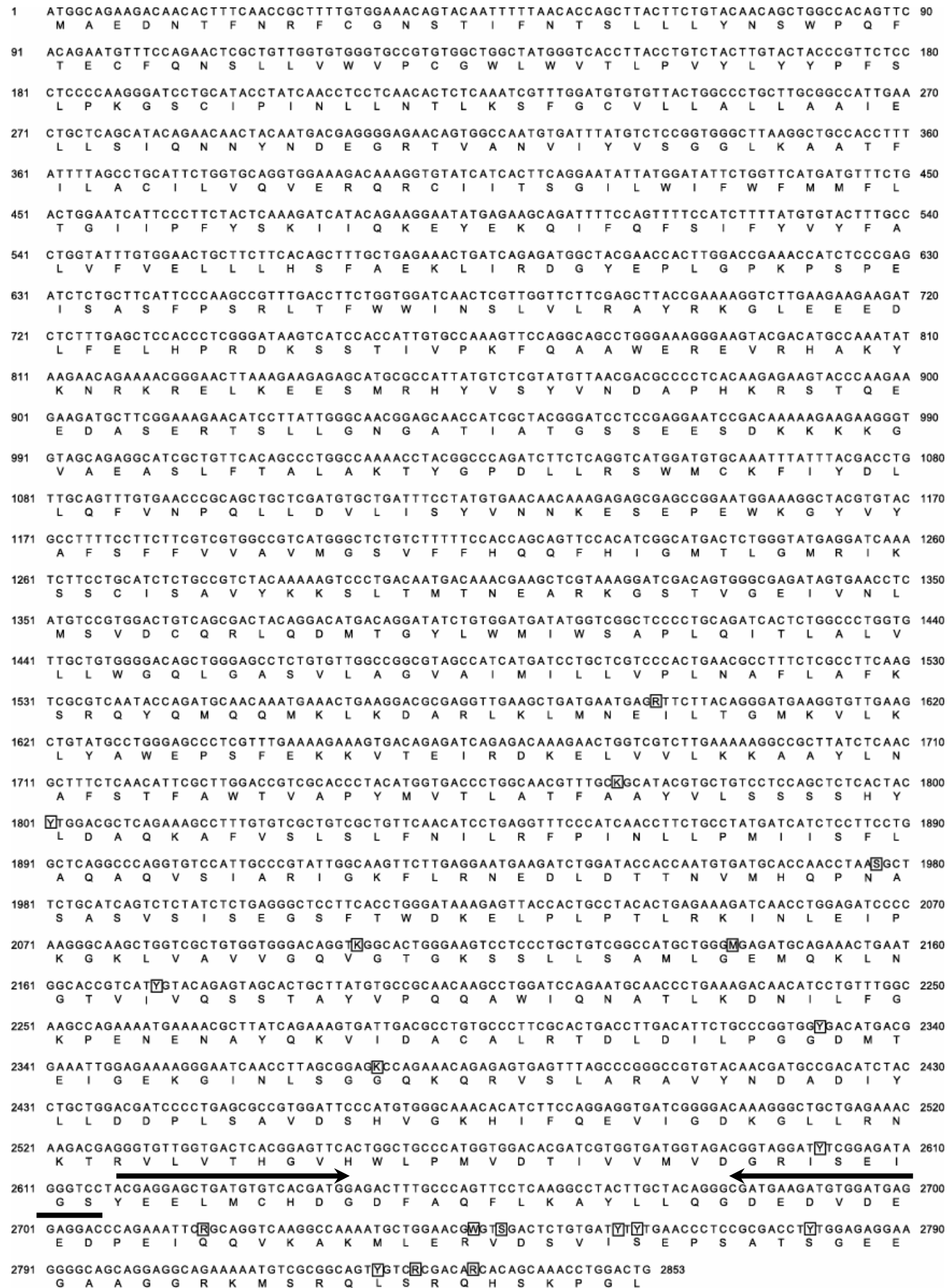

Figure 1. Partial nucleotide and deduced amino acid sequence of Cyphoma MRP-1 cDNA. The Cyphoma MRP-1 nucleotide polymorphisms (boxed) are indicated according to IUPAC naming conventions. Arrows indicate location of quantitative PCR primers. GenBank Accession number EU487192. 


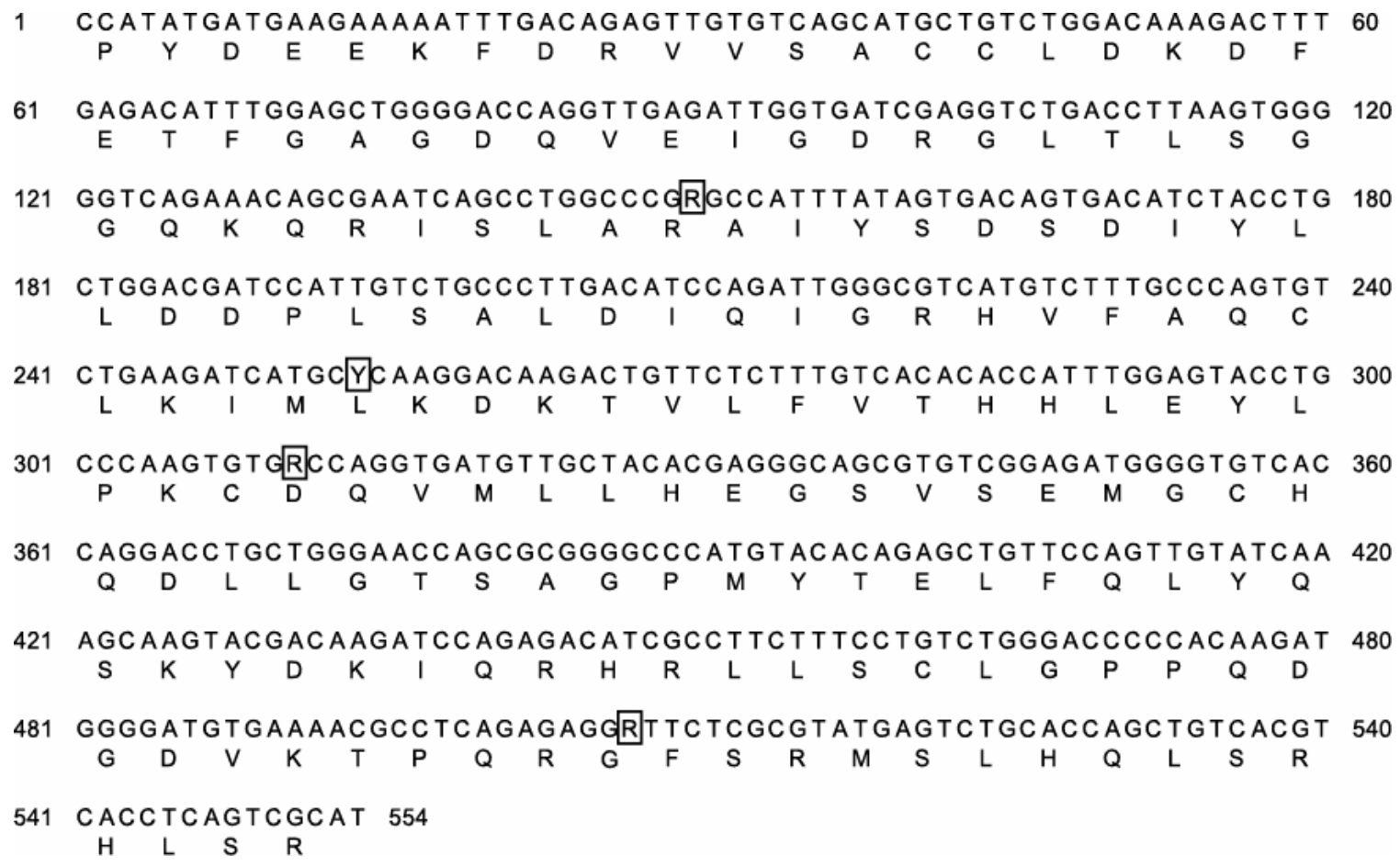

Figure 2. Partial nucleotide and deduced amino acid sequence of Cyphoma MRP-2 cDNA. The Cyphoma MRP-2 nucleotide polymorphisms (boxed) are indicated according to IUPAC naming conventions. GenBank Accession number EU487193. 
ATGGATTTCAACATCACCACAATGCAACAATCATCATCATCATCATCATCATCACCATCTTTGCTGGGGTTGAACACTACTACCACCACC 90 $\begin{array}{lllllllllllllllllllllllllllll}M & D & F & N & I & T & T & M & Q & Q & S & S & S & S & S & S & S & S & P & S & L & L & G & L & N & T & T & T & T\end{array}$ 91 ATTCACCCCAACAACATTACAACATTGGATCCTGACGAGGACCTCTCTAGTTTCGAAAAATTCTGCGGTGACTCTTCGTTTTGGGACACC 180 181 GATTTGTTGTRGATGCCCGTATCCAAAATCACCAAATTTTTCGAGAGGTGGCGTGGCATGGATCCCCTGCCTGATCTACCTGATG 270 D L L L D S P Y P K F T K C F R E V A L A W I P C L I Y L M

271 GGATGCCCTCTGTACTTTTACCACTTATCCAAAATGGCTTCAGTTCCGATACGAATCGGGATCGTCAATGTCGCCAAAACGATATGCGGT 360

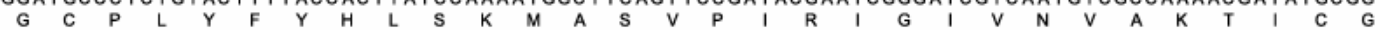

361 ATTTGTTTGGTTGGCATCACCATAGCAACGATCATCGTCCGGGTAGCGGACGACCGTGATGACACACCAGACGCTCTCTACGTGTCCGAG 450 I C L V G I T I A T I I V R V A D D R D D T P D A L Y V S E

451 GCATTCAAACTGGTTGCTTTATTCTGTCCCTTTTCATGAGTCAACAAGAGCGACGCAAAGgGTAGTTTCCTCCCCTGTCAACTGGTTG 540

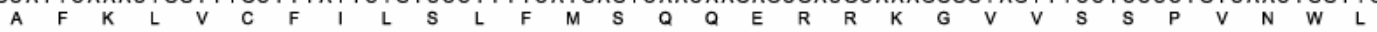

541 TTTTGGTTAGTTCTCTTCATCGTAGGCATTGTCCCCTTCTACAGCAACCTCAAGGAGGATACCCGTCATTCAGACAAGTTGGATTCATC 630

631 ATGTTCTATTTTACCACACGTTCATCCTTCTCTCCTTGATCATCGCCTCATTTGTGGAACCACGGTGTGAGGAATATCTGGATCTGTCT 720 $M$ F Y F Y H T F I L L S L I I A S F V E P R C E E Y L D L S

721 AAATCAAACTCTATGTATCATTACCCAAGTCCGGAAACCTCAGCGTCGTTTCCTAACCGCCTCTCCATTTGGTGGATGACAAGCCTGATA 810 $K S S N$ S M Y

811 ATCCTGGGGTTCAAGCGGAGTCTTGAAGAGGACGACATTTACGACCTTGAACCTGCGGACAGGAACACGAATCTCATGAAAAATTTCTC 900 I L G F K R S L E E D D I Y

901 GTCACTTGGGACAAAGAGAAAGCCAAAGTTGAGAATACAATCGGAAAGTGAAGTTCCTAATAAGCCAGTGTTTCAAGAACGAAACAAA 990

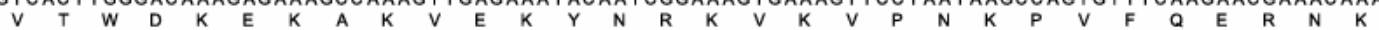

991 GACAAATGGGCAACAGAGTTTGACGAAAACACTCCGCTCATCGCAACGGTATCCAAGGCCAAATCAGAGAAGGAGGAGAACCCCACGTCA 1080 D K W A T E F D E N T P L I A T V S K A K S E K E E N P T S

1081 AAGAAATCTCCTTACAAGCAAGTGTCGGTCATGAAGGTTTTGCTCCTGGACCATGGCTACATGCTGTTACCTGCCCTGATGGCCAAGACA 1170 K K S P Y K Q V V S V M K V L L L D H G Y M L L P A L M A K T

1171 TGTTTCGACTTACTCCTGTTTGCCACTCCCAAAATTACAGAGGCACTTTTAGACTACATCACGTTTCGAGACCAGTACCATGAATGGAGA 1260 C $F$ D L L L

1261 GGTTATGCCCTGGCAGCATCCTATTTAGCTGTCAACTCTATAGCATCTGTTGGAGGGAATCAGGCTATATTCTACACCAAAAGGGCAGG 1350 $G$ Y A L A A S Y L A V N S I A S V G G N Q A I F Y T K R A G

1351 ATGAGAATGAAGGCTACCCTTATTAATGCCATTTACAGAAAATCTCTGACAGCCGCCAGCATTGGCGATGAGACTTCCAAAGGAGAGGTG 1440 $M \quad R \quad M \quad K$ A T L I N A I Y R K S L T A A S I G D E T S K G E V

1441 GTCAATCTGATGTCCGTGGATTGTCAGCGTATTGAAGATTAGCACAGTACATCAATTTGTTTTCTCTGCCCCTGGACAGATTATCCTA 1530 $V \quad N \quad L \quad M \quad S \quad V \quad D \quad C \quad Q \quad R \quad I \quad E$ D

1531 GCTCTAATCCTACTGTACGACCAACTAGGCGTGGCCATGTTTGCCGGCATTGGGGTTTTGTTTACTATCATCCCCATCAACGCTCTCATT 1620 A L I L L

1621 GGTTACTTCTTTCAAAAGTGGCAGAAATTGCAGATGAAATACAAAGATGATAGAATCAAGCTGCTCTCTGAGGTCTTGAATGGAATCAAG 1710

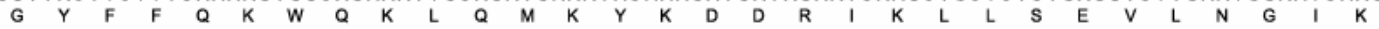

1711 GTCTTAAAACTTTATGCATGGGAAGGCTCGTTCCAGGAAAAGATTGGTGCCATTCGTCACATAGAGCTACGGATTATCAAGAACATCAGT 1800 $V$ L K L Y A W E G S F Q E K I G A I R H I E L R I I K N I S

1801 TTGCTTATTGCGTGTCTTCTGTATTTCTTCTTATCTCTACCAAATGTGGTTCAAGTGGTGTCCTACGGTGTGCATGTTGCAGACAAAGGC 1890

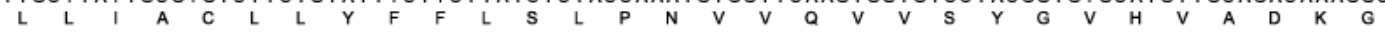

1891 TATCTCGACCCAACTGTGGCTTTTGTTCCTTACAGTTGTTAATATGCTGAACGGACCCTTGACCATCCTTCCCTTGTTATTCCTATT 1980

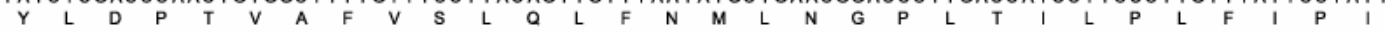

1981 GTCATTCAGTGTATAGTTTCCATAGCCCGTATCTCTGACTATCTCAGCAAGCCGGATATCAAGACAGATGTGGTCCATGTGGACAGACAT 2070 V I Q C I V S I A R I S D Y L S K P D I K T D V V H V D R H

2071 GCTAAAAATGCTATTTCCATTGAGAATGGCGACTTCACATGGACCCTGGATCAGCCTATATCAACTCTACGRAACATCAACTTAGAGATC 2160 A K N A I S I E N G D F T W T L D Q P I S T L R N I N L E I

2161 AAATCTGGCAGTCTGGTTGCTGTGGTTGG国ACGGTTGGGTGTGGAAATCATCTCTCATCTCRGCGCATTGGGGAAAGGAACGATT 2250

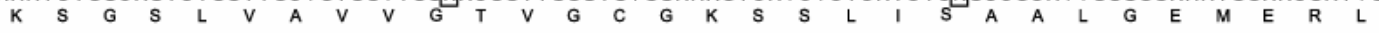

2251 GGAGGACGAGTCACCGTAAAGGGTTCCATTGCCTATGTACCGCAGGAAGCTTGGATCCAAAATGCTACCCYGAGAGACAATATCCTGTTT 2340 $G$ G R V T V K G S I A

2341 GGTAAAGACTACAGAGAACACATGTATAAAAAGATCATAGACGCTTGTGCTCTCCAATCGGATATTGAYATTCTCCCTGGCGGAGACAAG 2430

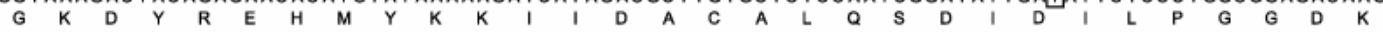

2431 ACAGAAATTGGAGAAAAGGGTATTAATGATCAGGTGGTCAGAAGCAGAGAGTTTCACTGGCCAGAGCTGTGTACAGTGACCAAGAYATT 2520 $T$ E I G E K G I N V S G G Q K Q R V S L A R A V Y S D Q D I

2521 TACCTCCTGGACGACCCACTGAGTGCCGTGGACAGTCACGTTGGAAAGCACATCTTCCAAGAGGTCATAGGTCAAAAAGGAGTTTAAAA 2610 Y L L D D P L S A V D S H V G K H I F Q E V I G Q K G V L K

2611 CACAAGACACGTTTATTAGTCACACACGGCATTCAGTGGCTCCCCCTGGTTGACAACATCTTTGTCGTGTCTAATGGAGAGATAAGTGAA 2700 H K T T L L V T H G I Q W L P L V D N I F V V S N G E I S E

2701 AAAGGCACATATACAGAGCTATTGGAAAAAGACGGCCATTTTGCTCAATTCATCAAGGAATATGCCCAAGAAAACAAGAATGACAGTGAC 2790 K G T Y T E L L E K D G H F A Q F I K E Y A Q E N K N D S D

2791 GAAGGAGAAGCCAAGCCTCTTTTTCAGCGCCAAGAGTCAGCGATATCAGGAGATTCTTCAGATTTTGGGACATCTTCACTGAGGAAGAGA 2880 E G E A K P L F Q R Q E S A I S G D S S D F G T S S L R K R

2881 AAATTGTCATATGCCCAACGACCCAGCACCGCCTCTCGAAGACACAGTGCTTGGGATGGTAACAGTCTGTTGGAAAAAAGTCTGGAAGCA 2970 $K$ L S Y A Q R 
2971 TCAAAAGCTGCAGCCAGGGCTGGAACAAAACTGACAGAGGATGAAGTTGGATTATCTGGCAAAGTGAAGCTTGAGATCTACCTTAAATAC 3060 3061 CTGAGAGAGCTTGGCGTAGCCACCTGTGTTGGCGCGTTTATTCTCTATGGATGCTGGGCTGGTTGTACCTGTTTGCAGGCATTTGGCTG 3150 3151 ACGGAGTGGACAGGTGATAGCTATCTACTGAATCTAAGCAACAAGGACACAGATAAATATGATGATGAGACAGACAAGTACTTGGGCGTT 3240 ACGGAGTGGACAGGTGATAGCTATCTACTGAATCTAAGCAACAAGGACACAGATAAATATGATGATGAGACAGACAAGTACTTGGGCGTT 3240 3241 TACGCTGCTGCCAGTATTTCACAGGGCTTATTCATCATGGTATTTTCCTTCATTGCTGCCTTTCAAATGACRTCCGCTGCTGGTGTCCTA 3330 3331 CACAATAGAATGCTCCATAAMG 3421 GACGTTGAAGTGCTGGACAACATTCTTCCACTCTCTATGAARCAGGTTATGAATGTGGGAGGCCAGGTGATCATCACCATCGTTAACATT 3510 3511 AGTTACGGGACCCCTATCTTCCTGGTGGCTCTGCTGCCATTGTCCATCATCTACATCGCTATTCAGCTTGYGTACATTCCTACATGCCGA 3600 3601 CAACTTCGTCGCATCAACTCCATTACGCGATCMYCGATATACGTACATTTCTCGGAAACACTGAGTGGAGCTTCATCTATTAGAGCTTAC 3690 3691 GGGATGCAAGAGAGGTTATAGAGGAGTCGATGAGGAGAATAGACCATAATGTCAAATTCTACTTTTCAAGTATTGCGGCAGCCAGCTGG 3780 $G M M Q G R F$

3781 TTATCCTTCCGACTCCAGTTCTTGGGCAACATGGTCATTTTTGCTGCTGCTATCTTTGCCGTGGCTGCCTCGGACATTGACCCCAGCGTC 3870

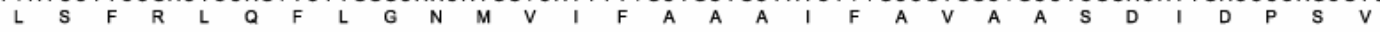
3871 GTTGGACTGTCTGTGTCTTATGCATCCATGATGACCAATGCTCTGGAGCAGCTCGTTAGTGTAATCAGTGAGACGGAGACCAATATCATC 3960 3961 TCTGTAGAACGATTGCAGGAATACACCAACGCTCCACAAGAGGCGGCTTGGATCTTGGATCATCACCGACCCAAACCAGACTGGCCAGAG 4050

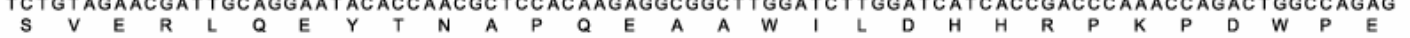
4051 AAGGGAACATTGTGTTTGATAATTATCAAACTAGGTATCGTCCTGGCCTTGACCTTGTCCTGCGTGATTTGACCTGCTCTATCAAGGGA 4140 K G N I V F F D N

4141 GGAGAAAGATTGGTATTGTGGGACGCACAGGGGCTGGCAAGTCTTCCATGACCGTGGCGTTGTTCCGAATCATTGAGGCTGCTGACGGT 4230 G E K I G I V G R T G A G K S S M T V A L F R I I E A A D G

4231 AAAATCATCATTGATGGAGAGGATGTGGCCAAGATGGGAATCCACGATCTCCGGAACAAAATCACCATTCTGCCGCAGGAACCTGTGATT 4320 4321 TTCTCTGGCACTTTGAGGATGAATCTGGATCCCTTCAACAAGTATACAGAGCCTGACATGTGGAACGCTCTAGAACATTCCTACTTGAAA 4410 $F$ S G T L R M N L D P F N K Y T E P D M W N A L E H S Y L K

4411 GAGTTTGGGAGGCCTCCCAGGGAATTGGACTATGAATGCGGGGAAGAAGGATCAAACTTGAGCGTTGGTCAGAGGCAGCTGGTTTGT 4500 E F V E G L P G K L D Y E C G E E G S N L S V G Q R Q L V C

4501 TTGGCCAGAACGCTTCTACGGAAAACCAAGATTCTAGTCCTGGATGAAGCCACAGCGGCTGTGGATATGGAAACAGATGATCTGATCCAG 4590 L A R T L L R K T K I L V L D E A T A A V D M E T D D L I Q

4591 GCCACCATCCGCACACAGTTTAAAGAATGCACGGTCTTGACCATTGCCCATCGTCTT 4647

Figure 3. Partial nucleotide and deduced amino acid sequence of Tritonia MRP-1 cDNA. The Tritonia MRP-1 nucleotide polymorphisms (boxed) are indicated according to IUPAC naming conventions. GenBank Accession number EU487194. 


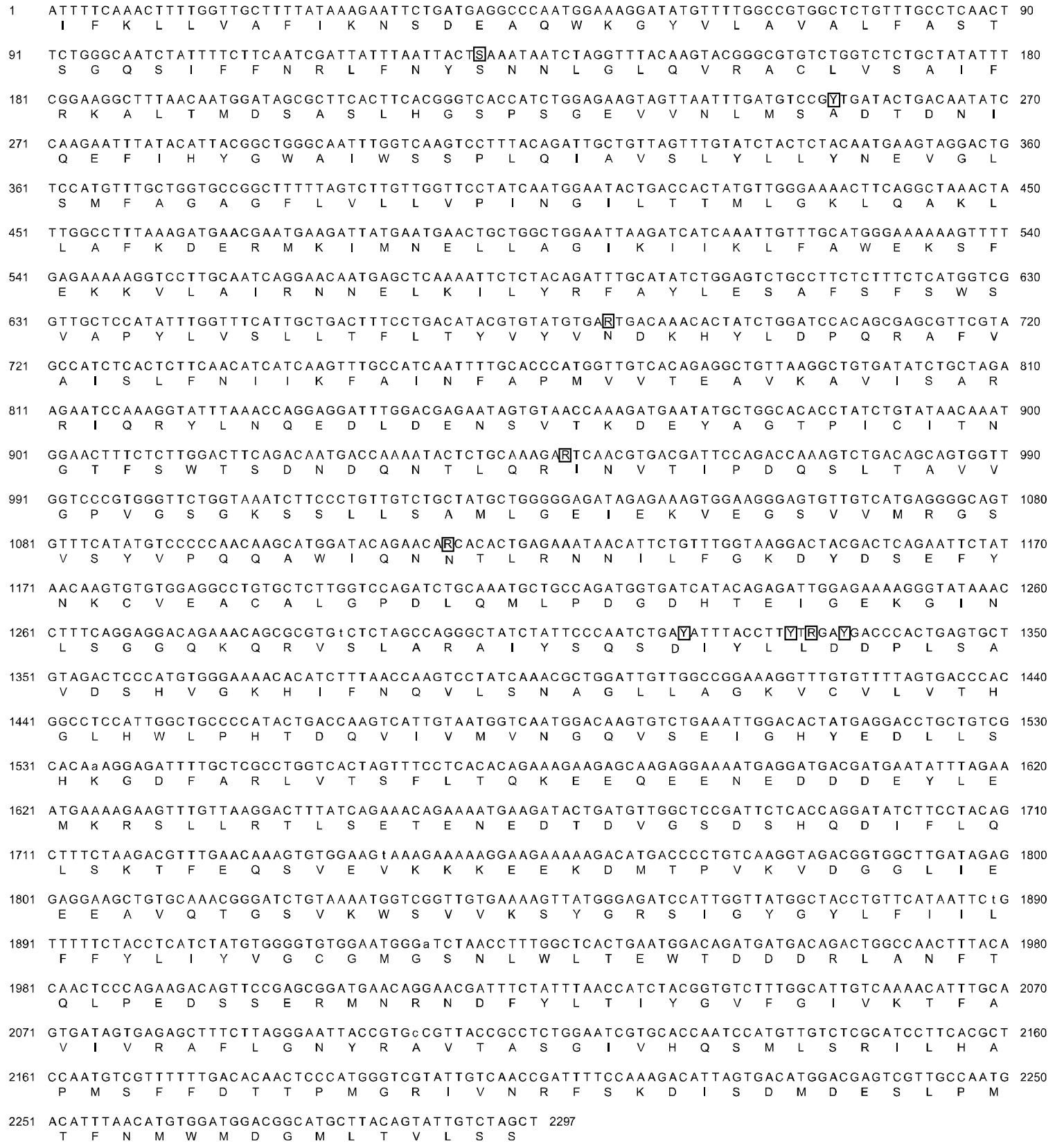

Figure 4. Partial nucleotide and deduced amino acid sequence of Tritonia MRP-2 cDNA. The Tritonia MRP-2 nucleotide polymorphisms (boxed) are indicated according to IUPAC naming conventions. GenBank Accession number EU487195. 


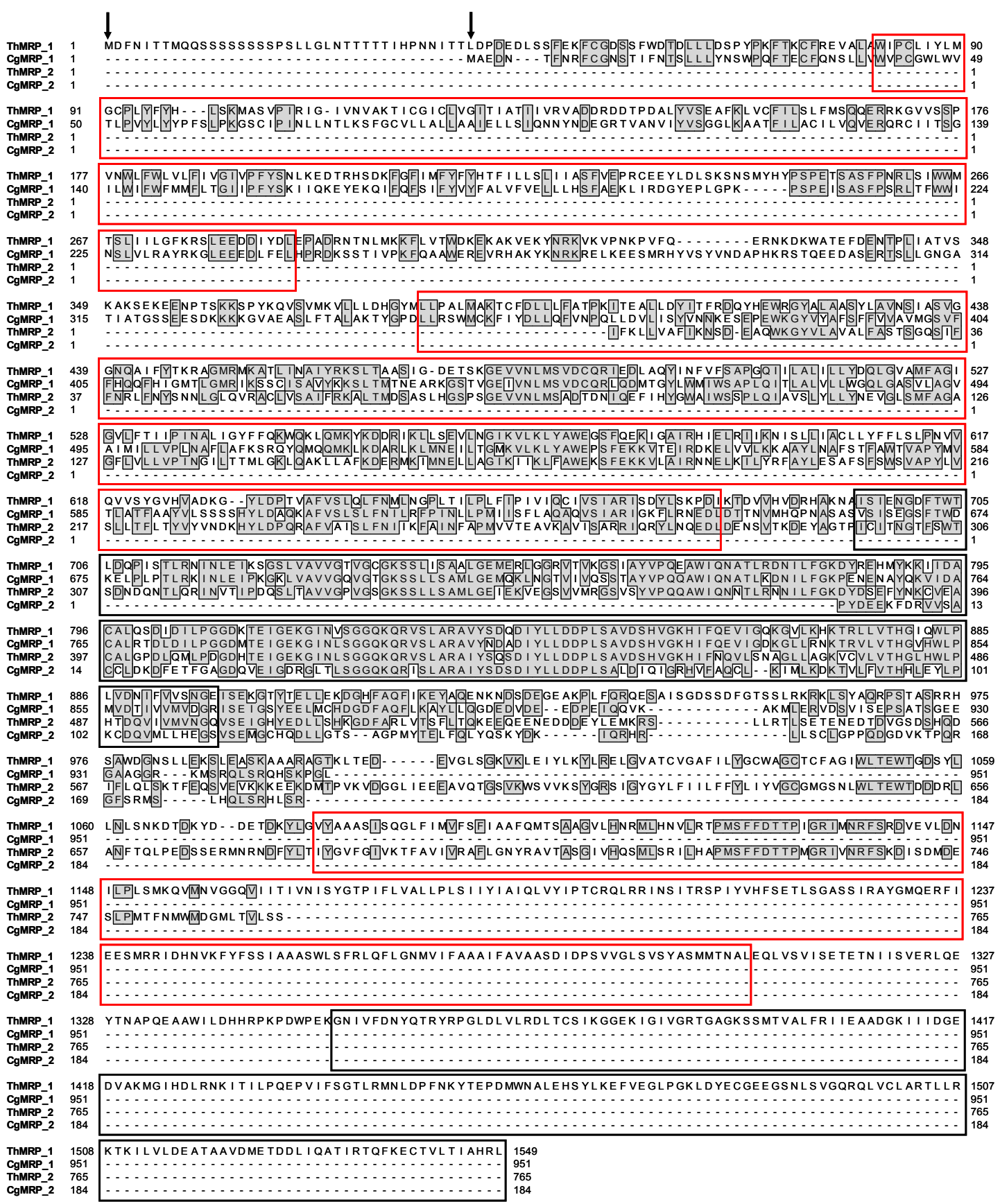

Figure 5. Alignment of deduced amino acid sequences of Cyphoma and Tritonia MRP proteins.

Molluscan deduced amino acids sequences were aligned using ClustalX. Identical residues in at least two sequences are shaded in grey. Black and red boxes represent the putative nucleotide binding domains and hydrophobic transmembrane domains, respectively. Domains were predicted using the algorithm of Kyte and Doolittle (1982) (window of 13 amino acids) and with NCBI Conserved Domain Database searches (Marchler-Bauer 2007). Predicted start codons for Cyphoma MRP-1 and Tritonia MRP-1 are indicated by a downward arrow above the alignment. A dash (-) indicates missing or gapped residues. GenBank sequences in the alignment include: Cyphoma MRP-1 (EU487192); Cyphoma MRP-2 (EU487193); Tritonia MRP-1 (EU487194); Tritonia MRP-2 (EU487195). 


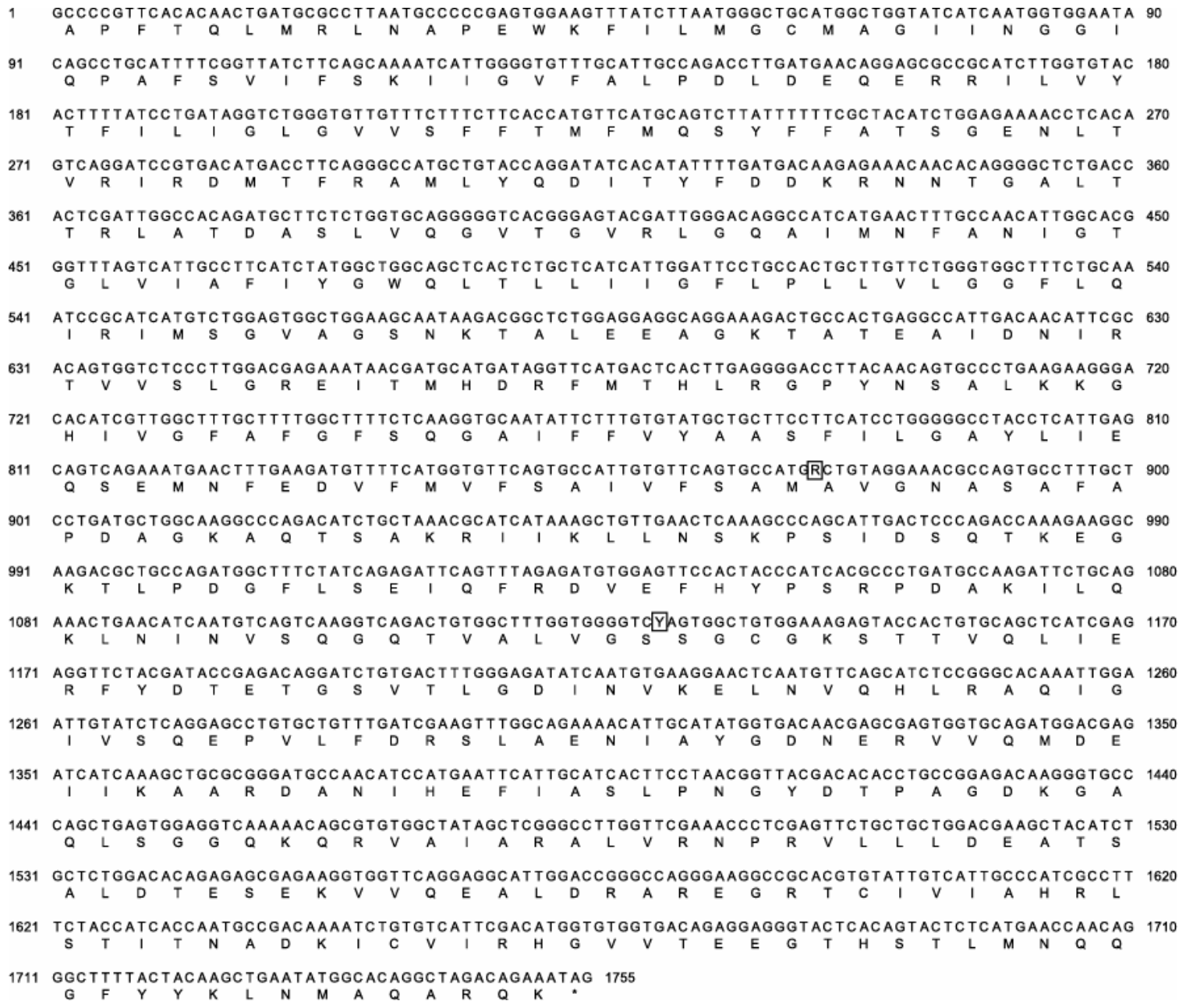

Figure 6. Partial nucleotide and deduced amino acid sequence of Cyphoma Pgp-1 cDNA. The Cyphoma Pgp-1 nucleotide polymorphisms (boxed) are indicated according to IUPAC naming conventions. The stop codon is indicated by an asterisk. GenBank Accession number EU487190. 


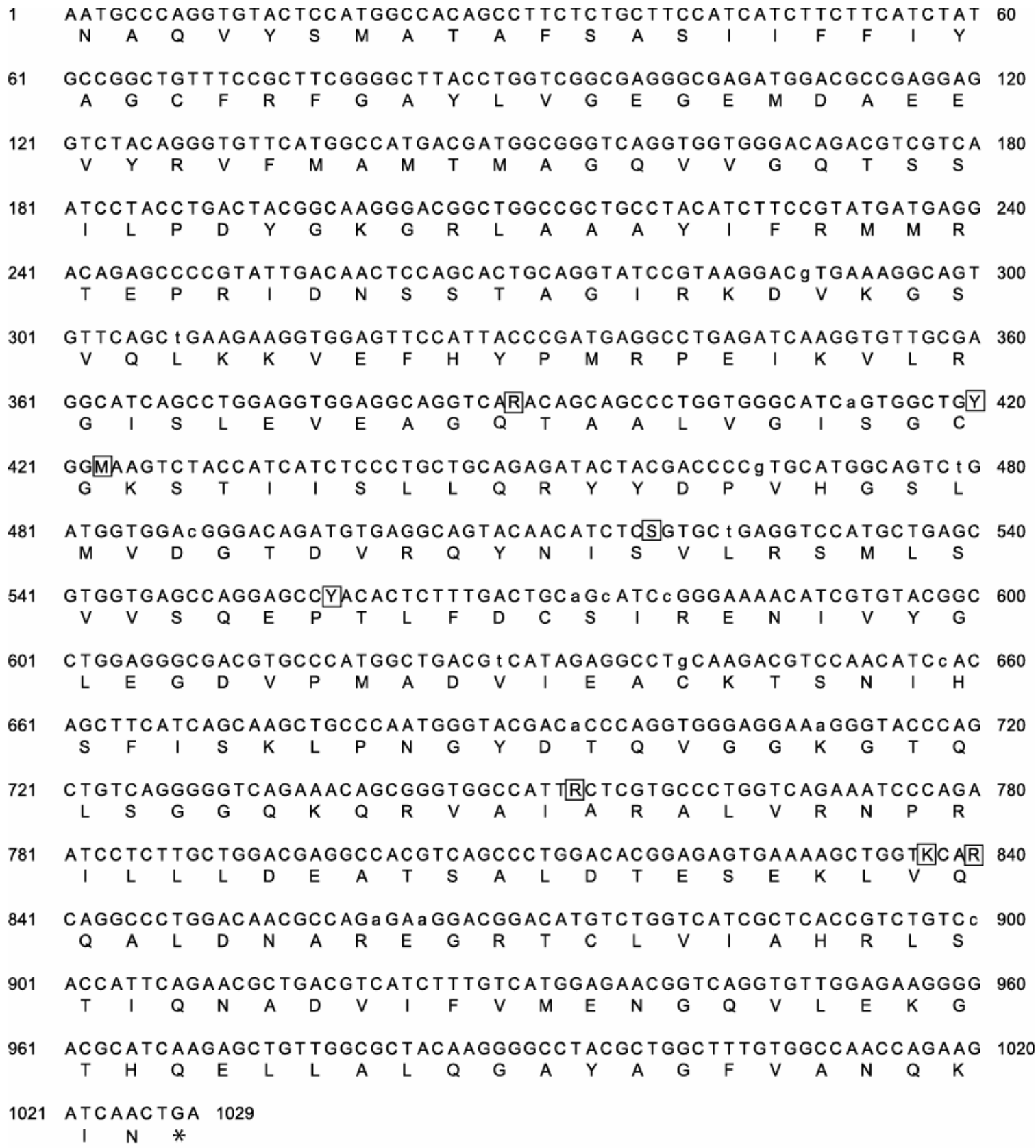

Figure 7. Partial nucleotide and deduced amino acid sequence of Cyphoma Pgp-2 cDNA. The Cyphoma Pgp-2 nucleotide polymorphisms (boxed) are indicated according to IUPAC naming conventions. The stop codon is indicated by an asterisk. GenBank Accession number EU487191. 


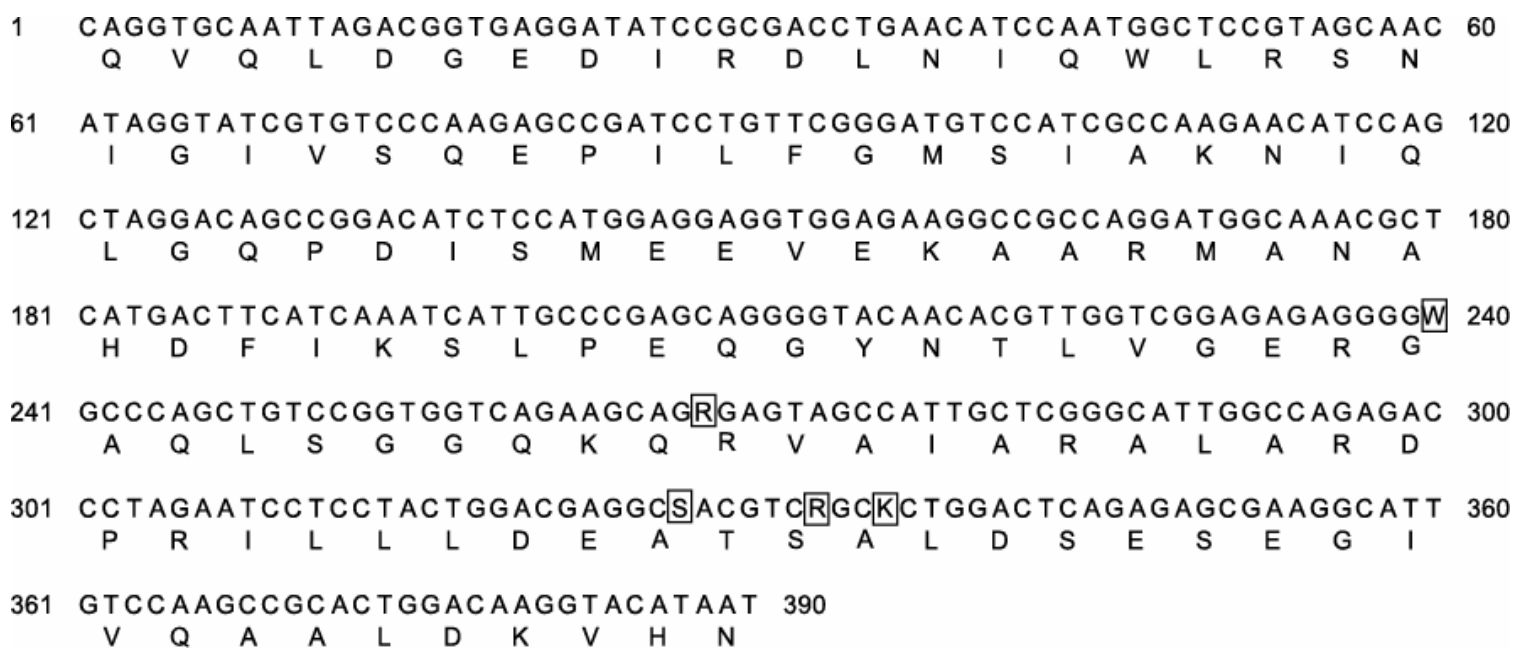

Figure 8. Partial nucleotide and deduced amino acid sequence of Tritonia Pgp-1

cDNA. The Tritonia Pgp-1 nucleotide polymorphisms (boxed) are indicated according to IUPAC naming conventions. GenBank Accession number EU487196. 


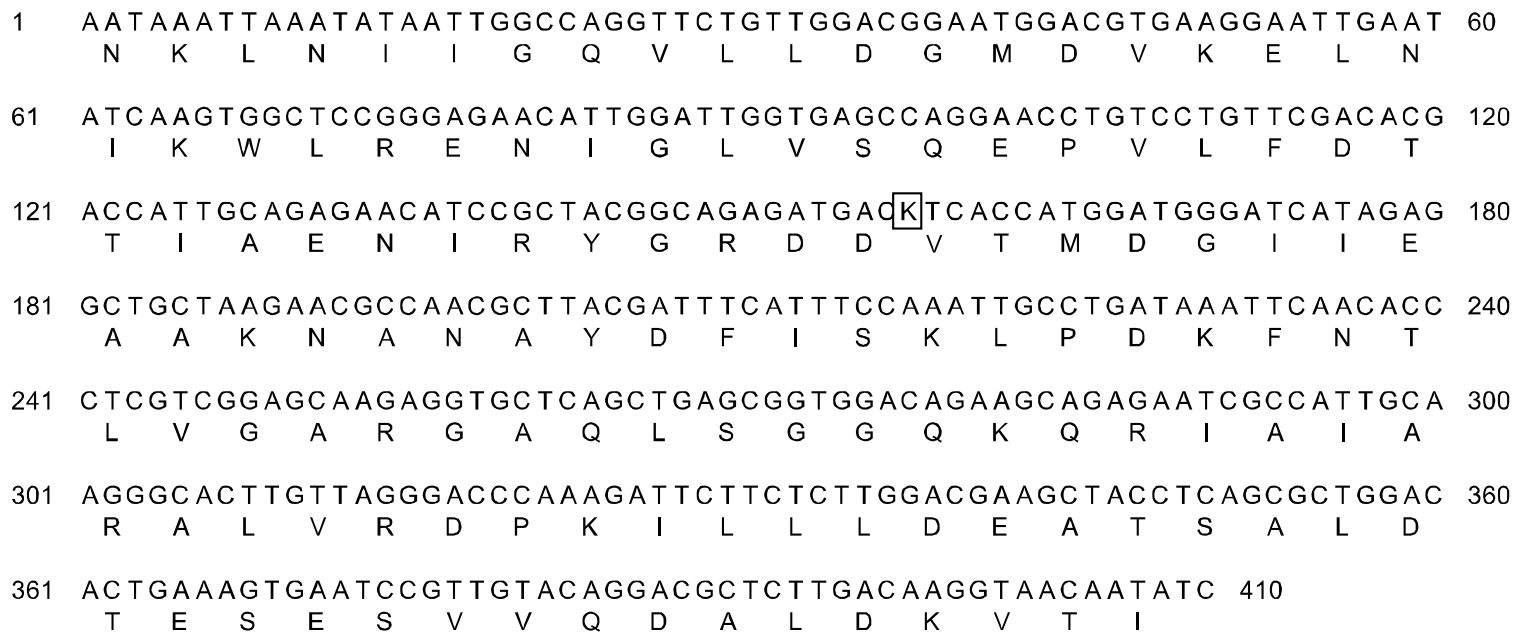

Figure 9. Partial nucleotide and deduced amino acid sequence of Tritonia Pgp-2

cDNA. The Tritonia Pgp-2 nucleotide polymorphisms (boxed) are indicated according to IUPAC naming conventions. GenBank Accession number EU487197. 


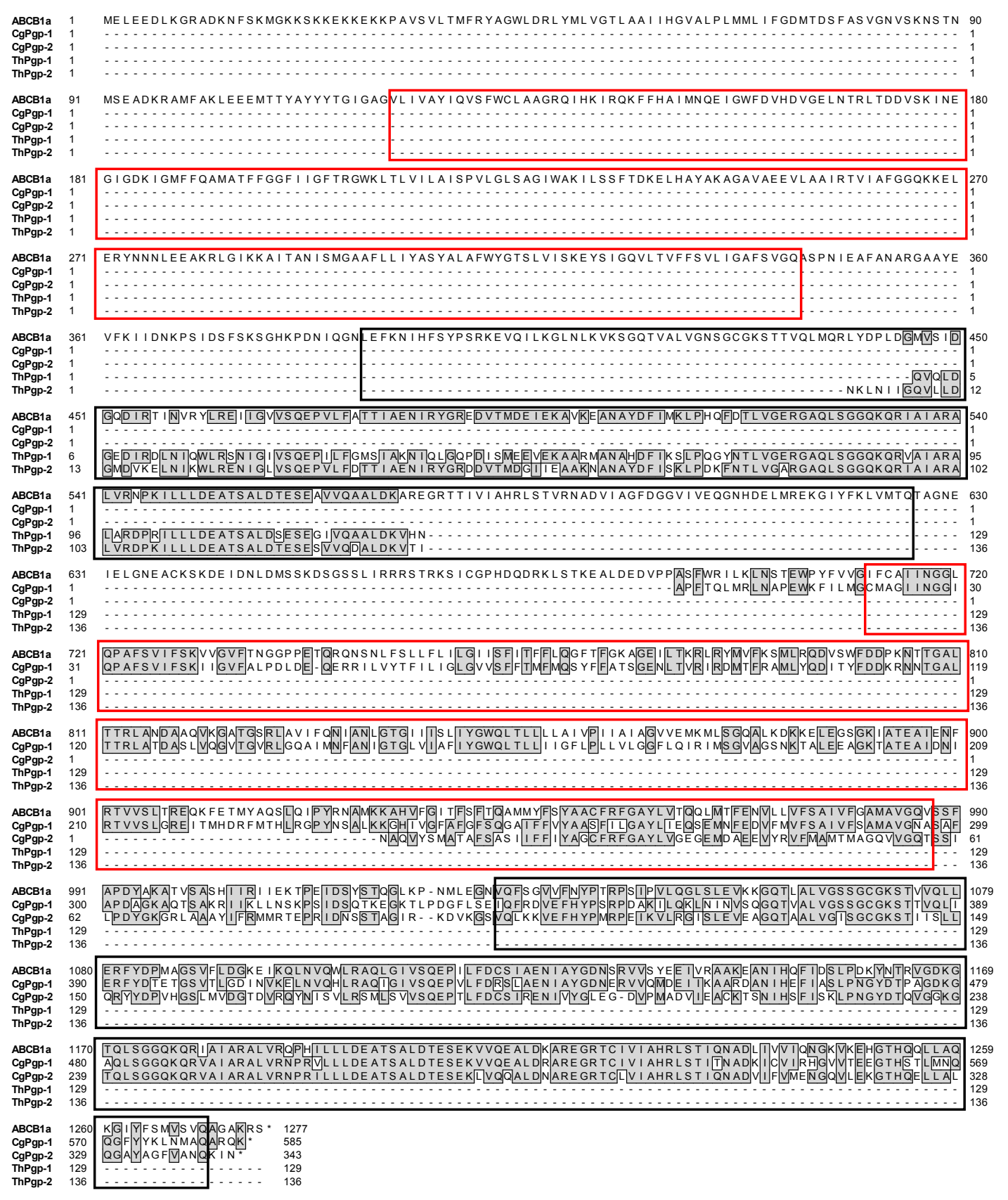

Figure 10. Alignment of deduced amino acid sequences of Cyphoma and Tritonia Pgp proteins with Mouse ABCB1a. Molluscan deduced amino acid sequences and mouse protein sequence were aligned using ClustalX. Identical residues are shaded in grey. Black and red boxes represent the putative nucleotide binding domains and hydrophobic transmembrane domains, respectively. Transmembrane and nucleotide binding domains were predicted using the algorithm of Kyte and Doolittle (1982) (window of 13 amino acids) and with NCBI Conserved Domain Database searches (Marchler-Bauer et al. 2007). An asterisk indicates a stop codon and a dash (-) indicates missing or gapped residues. GenBank sequences in the alignment include: mouse ABCB1a (M. musculus, NP_035206), C. gibbosum Pgp-1 (EU487190), C. gibbosum Pgp-2 (EU487191), T. hamnerorum Pgp-1 (EU487196), T. hamnerorum Pgp-2 (EU487197). 

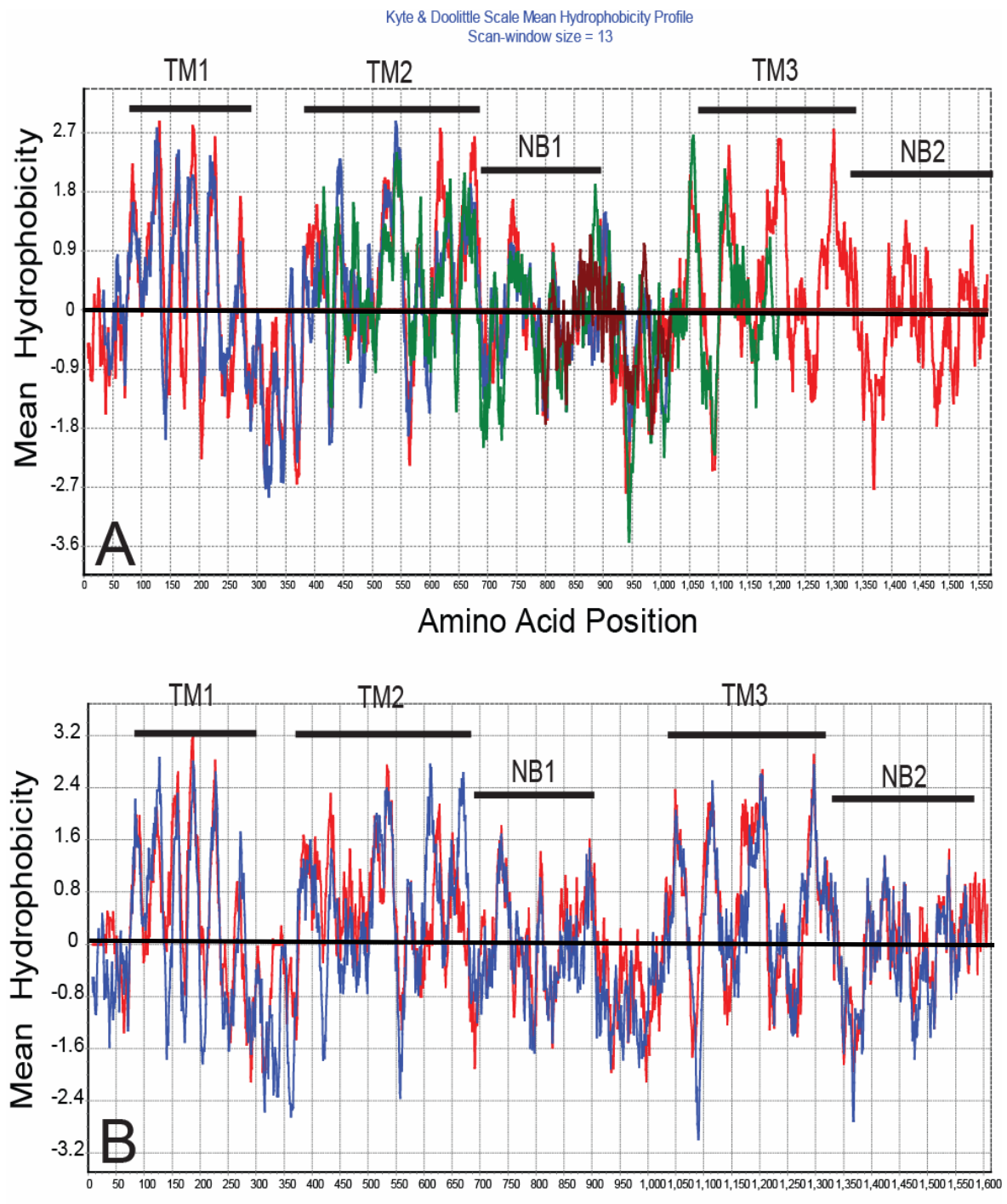

Amino Acid Position

Figure 11. Comparison of molluscan and human MRP hydropathy profiles. (A) Deduced amino acid sequences from Cyphoma and Tritonia MRP profiles were aligned using ClustalX. Tritonia MRP-1 plot is indicated by the red line and the Cyphoma MRP-1 (blue line), Tritonia MRP-2 (green line) and Cyphoma MRP-2 (maroon line) are layered on top. (B) Deduced amino acid sequence from Tritonia MRP-1 (blue line) was aligned with human $\mathrm{ABCC} 3$ (red line) using ClustalX. Black bars above the plots indicate positions of the three transmembrane regions (TM1, TM2, TM3) and nucleotide binding domains (NB1, NB2) in ABCC proteins. Values above and below the horizontal line indicate hydrophobic and hydrophilic regions, respectively. Hydrophobicity plots were generated using the Kyte-Doolittle algorithm (1982) with a window of 13 residues by BioEdit v7.0.5.2. GenBank sequences in the alignment include: human ABCC3 (NP_003777.2), C. gibbosum MRP-1 (EU487192), C. gibbosum MRP-2 (EU487193), $T$. hamnerorum MRP-1 (EU487194), T. hamnerorum MRP-2 (EU487195). 


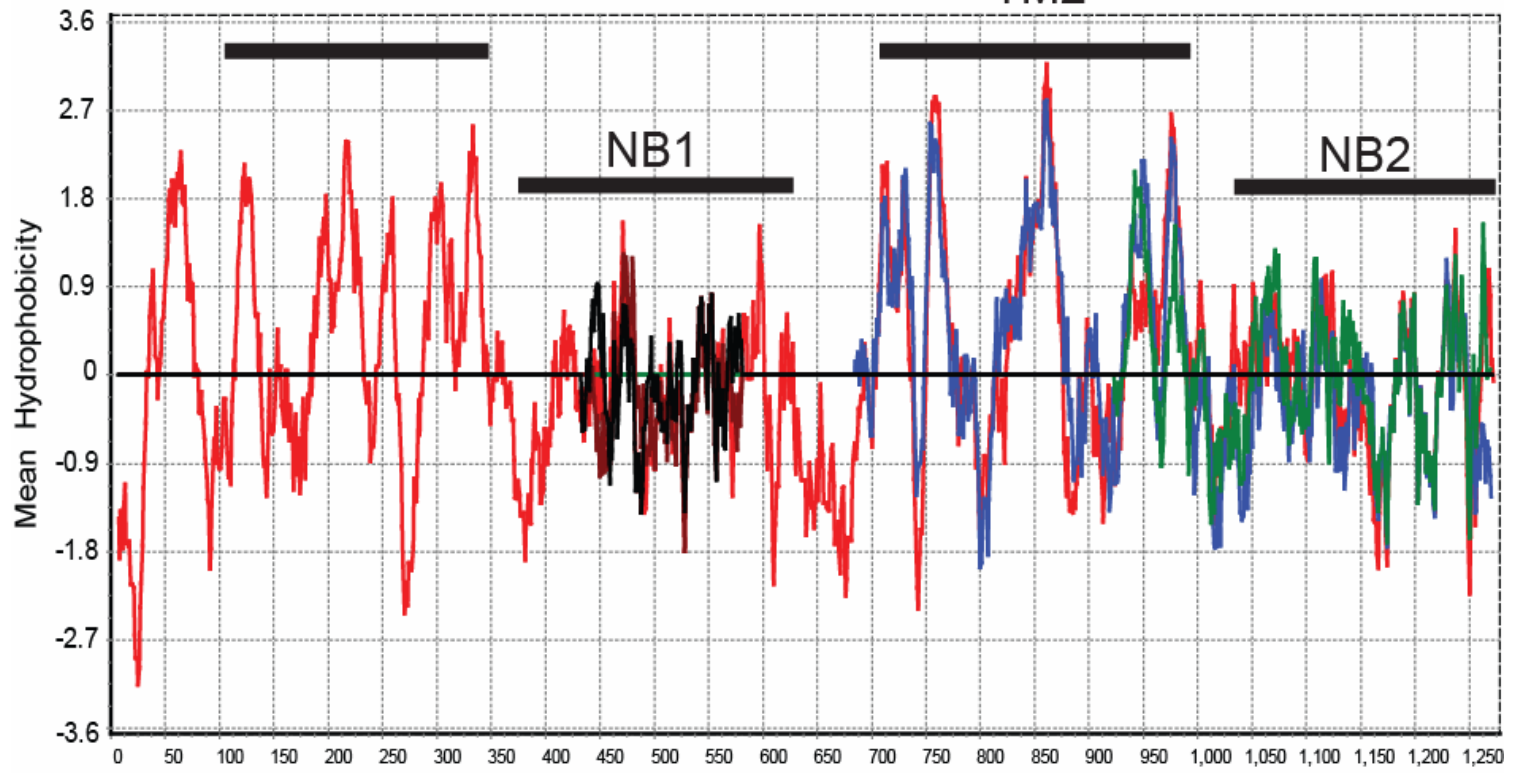

Amino Acid Position

Figure 12. Comparison of molluscan and mouse Pgp hydropathy profiles. Deduced amino acid sequences of Cyphoma and Tritonia P-glycoproteins were aligned to mouse ABCB1a using ClustalX. The mouse ABCB1a plot is indicated by the red line and is overlaid by Cyphoma Pgp-1 (blue line), Cyphoma Pgp-2 (green line), Tritonia Pgp-1 (maroon line), and Tritonia Pgp-2 (black line). Black bars above the plots indicate positions of the two transmembrane regions (TM1, TM2) and nucleotide binding domains (NB1, NB2) in ABCB proteins. Values above and below the horizontal line indicate hydrophobic and hydrophilic regions, respectively. Hydrophobicity plots were generated using the Kyte-Doolittle algorithm (1982) with a window of 13 residues by BioEdit v7.0.5.2. GenBank sequences in the alignment include: mouse ABCB1a (M. musculus, NP 035206), C. gibbosum Pgp-1 (EU487190), C. gibbosum Pgp-2 (EU487191), T. hamnerorum Pgp-1 (EU487196), T. hamnerorum Pgp-2 (EU487197). 
Figure 13. Phylogenetic relationships among Cyphoma, Tritonia and human $\mathrm{ABC}$ transporters. Maximum likelihood (ML) trees were constructed as described in the Methods. Out of a possible 3450 positions, 1821 positions (or 52.8\%) were used to construct the final tree. Molluscan sequences are highlighted in red. Values at branch points represent ML bootstrap values calculated with 100 replications. Triangles represent portions of the tree that were collapsed due to poor resolution of the taxa within each clade as evidenced by bootstrap analysis. GenBank sequences in the tree include: Human ABCA proteins (ABCA1, NP 005493.2; ABCA2, NP 001597.2; ABCA3, NP001080.2; ABCA4, NP 000341.2; ABCA5, NP 061142.2; ABCA6, NP 525023.2; ABCA7, NP 061985.2; ABCA8, NP 009099.1; ABCA9, NP_525022.2; ABCA10, NP 525021.3; ABCA12, NP 775099.2), human A $\bar{B} C B$ proteins (ABCB1, NP 000918.2; ABCB2, NP 000584.2; ABCB3, NP 000535.3; ABCB4, NP 000434.1; ABCB5, NP_848654.3; ABCB6, NP_005680.1; ABCB7, NP_004290.2; ABCB8, NP_009119.2; ABCB9, NP_982269.1; ABCB10, NP_036221.1; ABCB11, NP_003733.2), human A $\bar{B} C C$ proteins (ABCC1, NP_004987.2; ABCC2, NP 000383.1; ABCC3, NP 003777.2; ABCC4, NP 005836.2; ABCC5, NP_005679.2; ABCC6, NP_001162.3; ABCC8, NP_000343.2; ABCC9 a/b, NP_005682.2, NP 064693.2; $\mathrm{ABC} 10, \mathrm{NP} 258261.2 ; \mathrm{AB} C \mathrm{~B} 11, \mathrm{NP} \_115972.2 ; \overline{\mathrm{B} C C} 12, \mathrm{NP} 150229.2 ; \mathrm{ABCC} 13$, EAX10058.1), human $\mathrm{ABCD}$ (ABCD1, NP 000024.2; ABCD2, NP 005155.1; $\mathrm{ABCD} 3, \mathrm{NP}$ 002849.1, ABCD4, NP 005041.1), human ABCE (ABCE1, NP 002931.2), human ABCF (ABCF1, NP 001020262.1; ABCF2, NP_009120.1; ABCF3, NP_060828. 2), human ABCG (ABCG1, NP_997057.1; ABCG2, NP_004818.2; ABCG4, NP_071452.2; ABCG5, NP_071881.1; ABCG8, NP_071882.1), Cyphoma gibbosum MRP-1 (EU487192), MRP-2 (EU487193), Pgp-1 (EU487190), Pgp-2 (EU487191), Tritonia hamnerorum MRP-1 (EU487194), MRP-2 (EU487195), Pgp-1 (EU487196), Pgp-2 (EU487197). Analysis performed by J. Goldstone. 


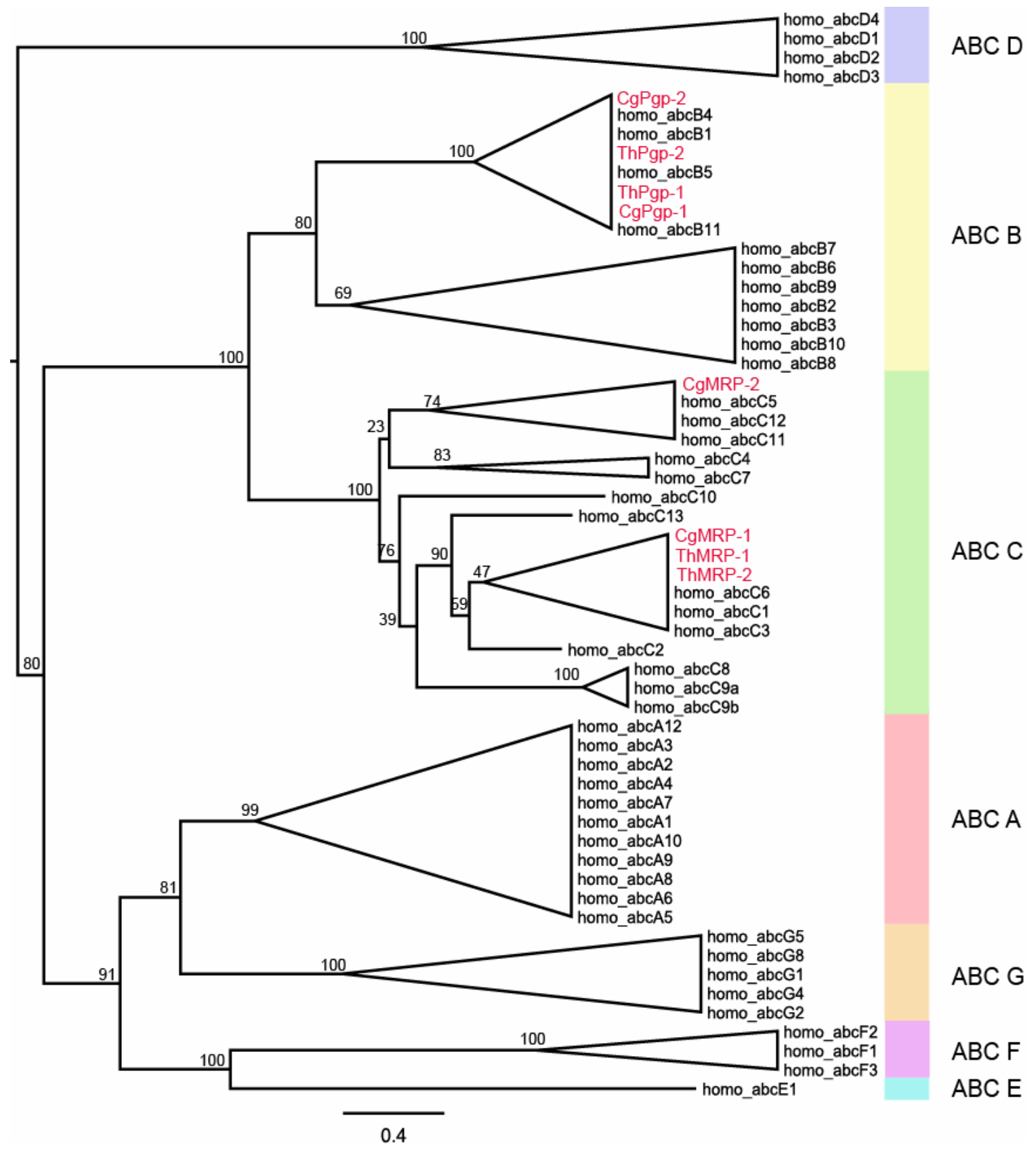




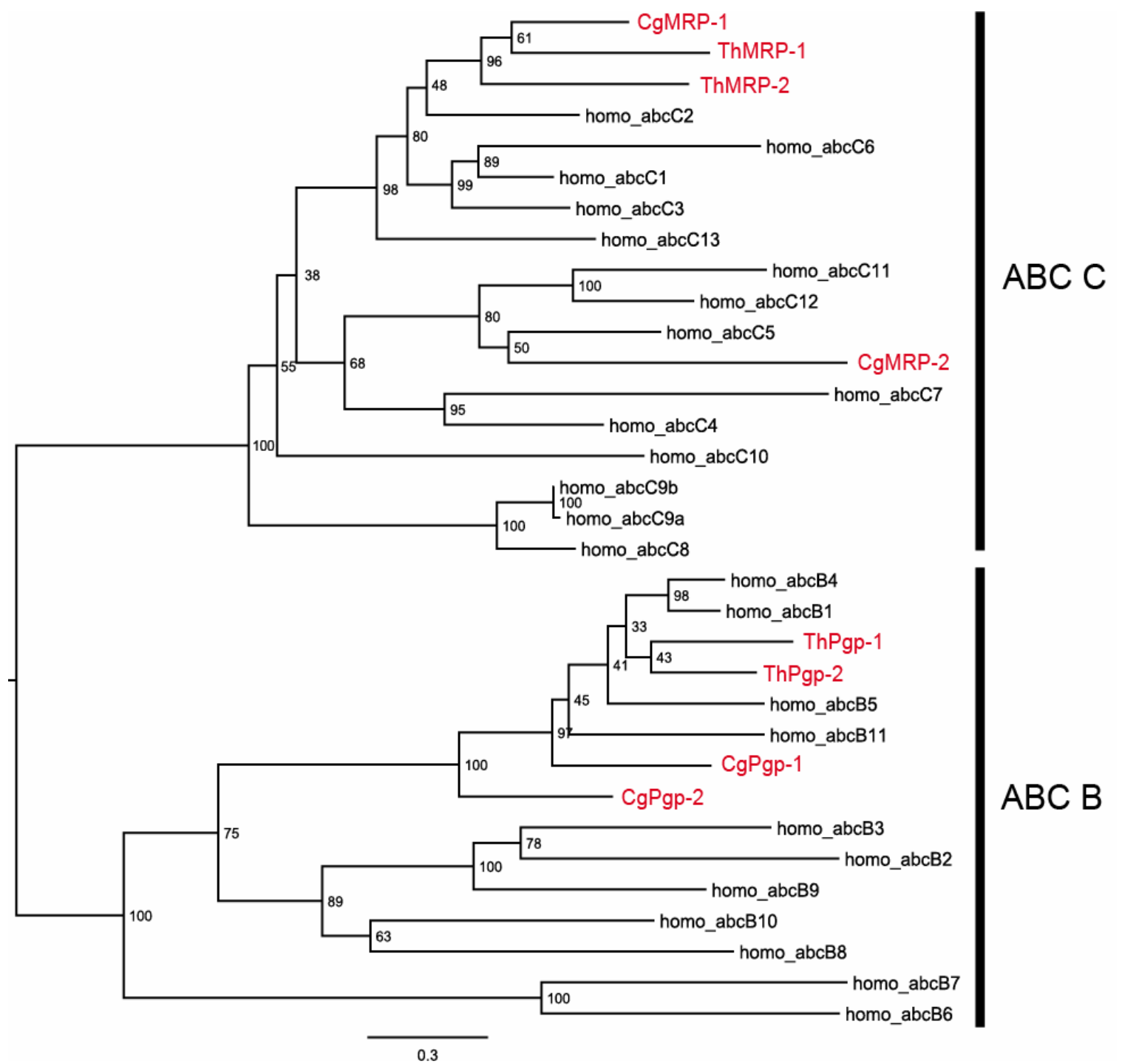

Figure 14. Phylogenetic relationships among Cyphoma, Tritonia and human $\mathrm{ABCB}$ and $\mathrm{ABCC}$

protein subfamilies. Maximum likelihood (ML) trees were constructed as described in the Methods. Out of a possible 2026 positions, 1402 positions (or $69.2 \%$ ) were used to construct the final tree. Molluscan sequences are highlighted in red. Values at branch points represent ML bootstrap values calculated with 100 replications. GenBank sequences in the tree include: Human ABCB proteins (ABCB1, NP_000918.2; ABCB2, NP 000584.2; ABCB3, NP 000535.3; ABCB4, NP 000434.1; ABCB5, NP 848654.3; ABCB6, NP_005680.1; ABCB7, NP_004290. 2 ; ABCB8, NP_009119.2; ABCB9, NP_982269. 1 ; ABCB10, NP_036221.1; ABCB11, NP_003733.2), human ABCC proteins (ABCC1, NP_004987.2; ABCC2, NP_000383.1; ABCC3, NP_003777.2; ABCC4, NP_005836.2; ABCC5, NP_005679.2; ABCC6, NP 001162.3; ABCC8, NP 000343.2; ABCC9 a/b, NP 005682.2, NP 064693.2; ABCC10, NP 258261.2;

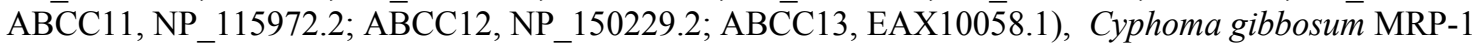
(EU487192), MRP-2 (EU487193), Pgp-1 (EU487190), Pgp-2 (EU487191), Tritonia hamnerorum MRP-1 (EU487194), MRP-2 (EU487195), Pgp-1 (EU487196), Pgp-2 (EU487197). Analysis performed by J.

Goldstone. 

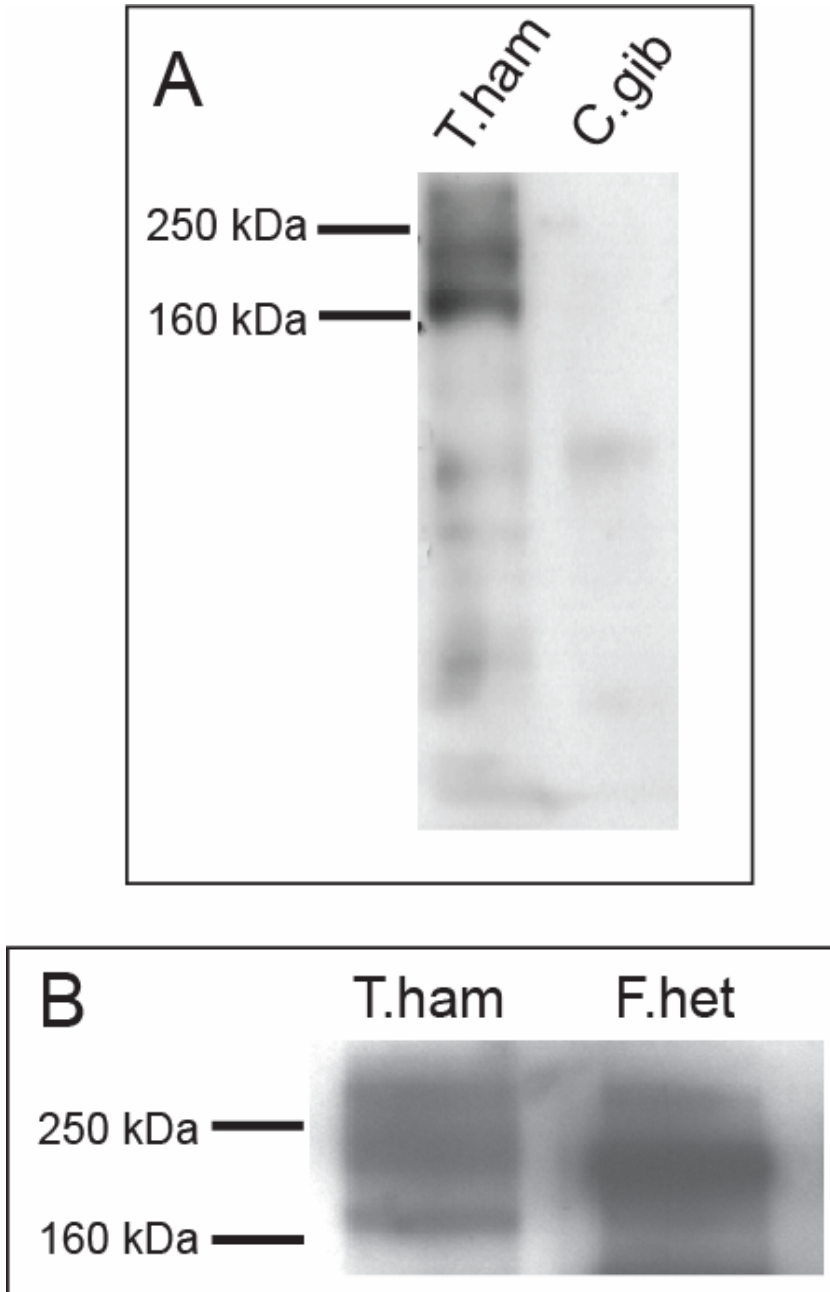

Figure 15. Detecting Pgp expression in molluscan tissue homogenates. Western blots were probed with anti-P-glycoprotein $\mathrm{mAb} C 219$ which reacted with (A) one sharp band at $170 \mathrm{kDa}$ and two diffuse bands at $>170 \mathrm{kDa}$ in T. hamnerorum whole cell homogenates. No immunopositive bands were detected in $C$. gibbosum digestive gland homogenates. (B) Fundulus heteroclitus liver cell lysates were used as a positive control. 

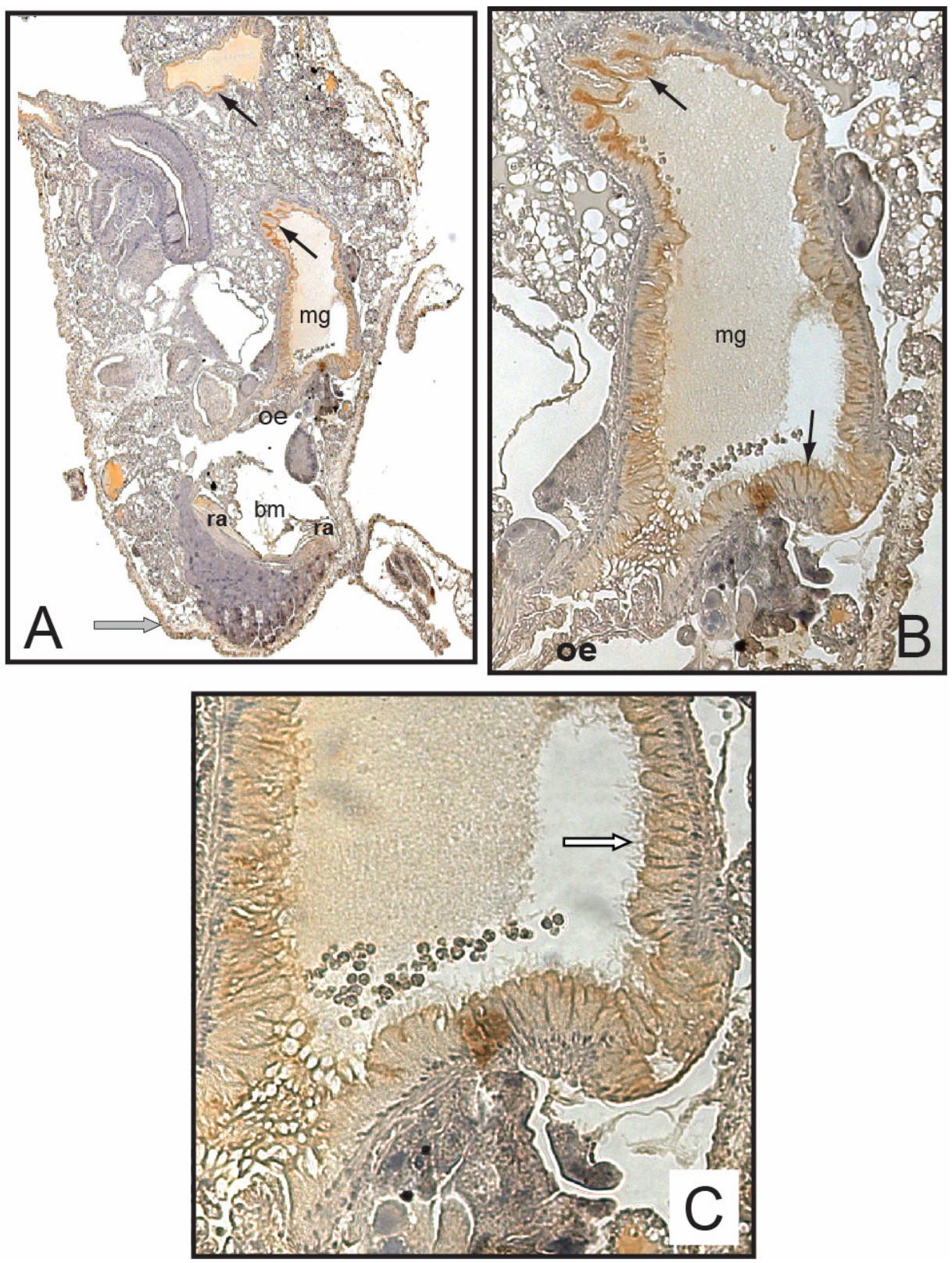

Figure 16. Immunolocalization of Pgp in T. hamnerorum tissues. Tangential sections of T. hamnerorum were probed with the anti-P-glycoprotein mAb C219. Orange-brown staining indicates immunoreactive protein. (A) Black arrows indicate intense staining by C219 along the apical tips of the gut epithelium; grey arrow indicates lighter staining by $\mathrm{C} 219$ along the epidermis; $\mathrm{bm}$. buccal mass; $\mathrm{mg}$. midgut; oe. esophagus; $r a$. radula; $(50 \mathrm{x})$. (B) Magnification (100x) of esophagus and midgut. (C) Further magnification (200x) of the ciliated columnar epithelia in the midgut; cilia indicated by white arrow. 

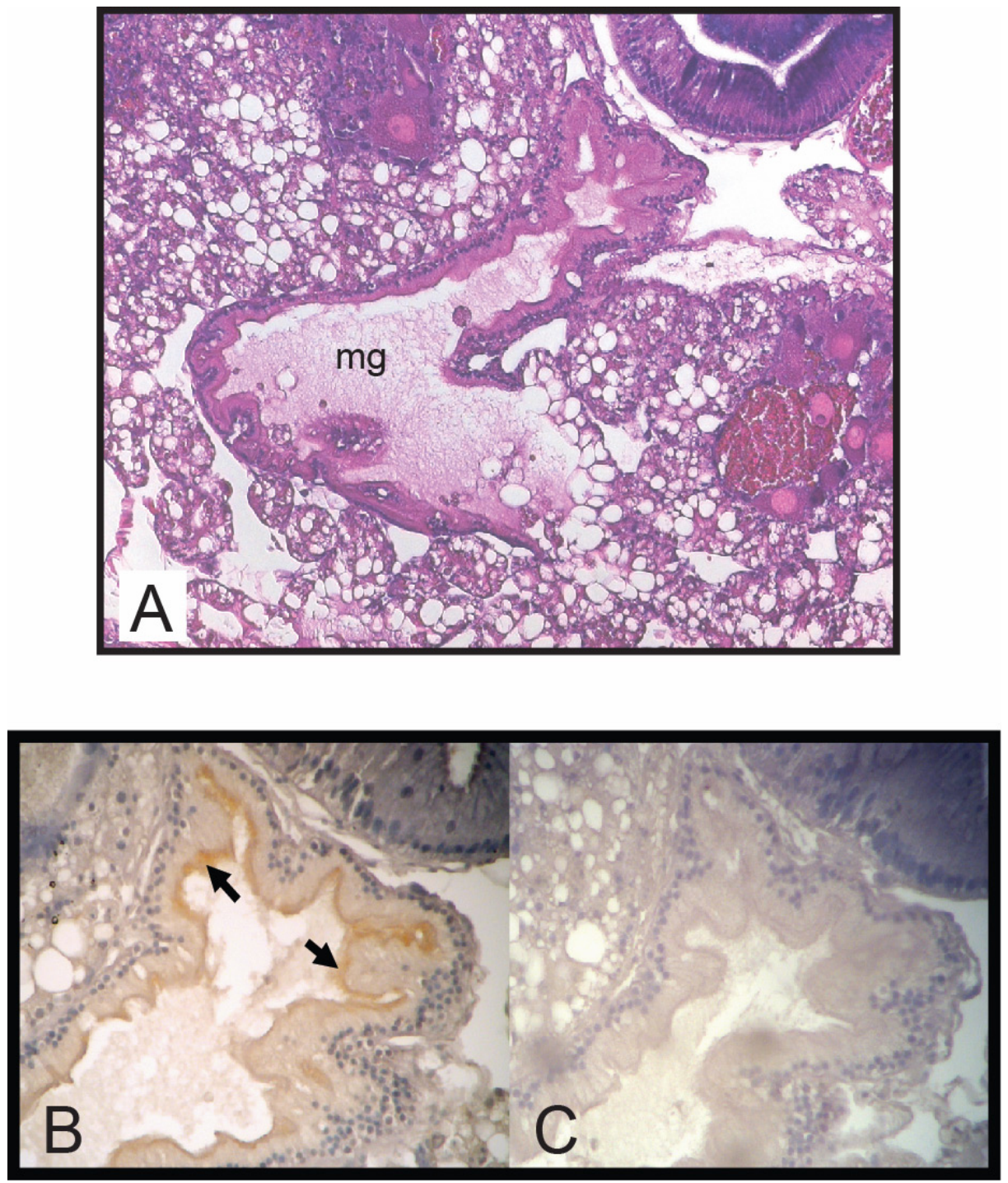

Figure 17. Immunolocalization of Pgp in T. hamnerorum tissues continued. (A) Hematoxylin and eosin stained section depicting the folded nature of T. hamnerorum midgut tissues; $m g$. midgut (100x). (B) C219 probed tissue section and (C) unlabeled serial section showing P-glycoprotein localized to the periphery of the midgut epithelium (indicated by black arrows) (200x) 


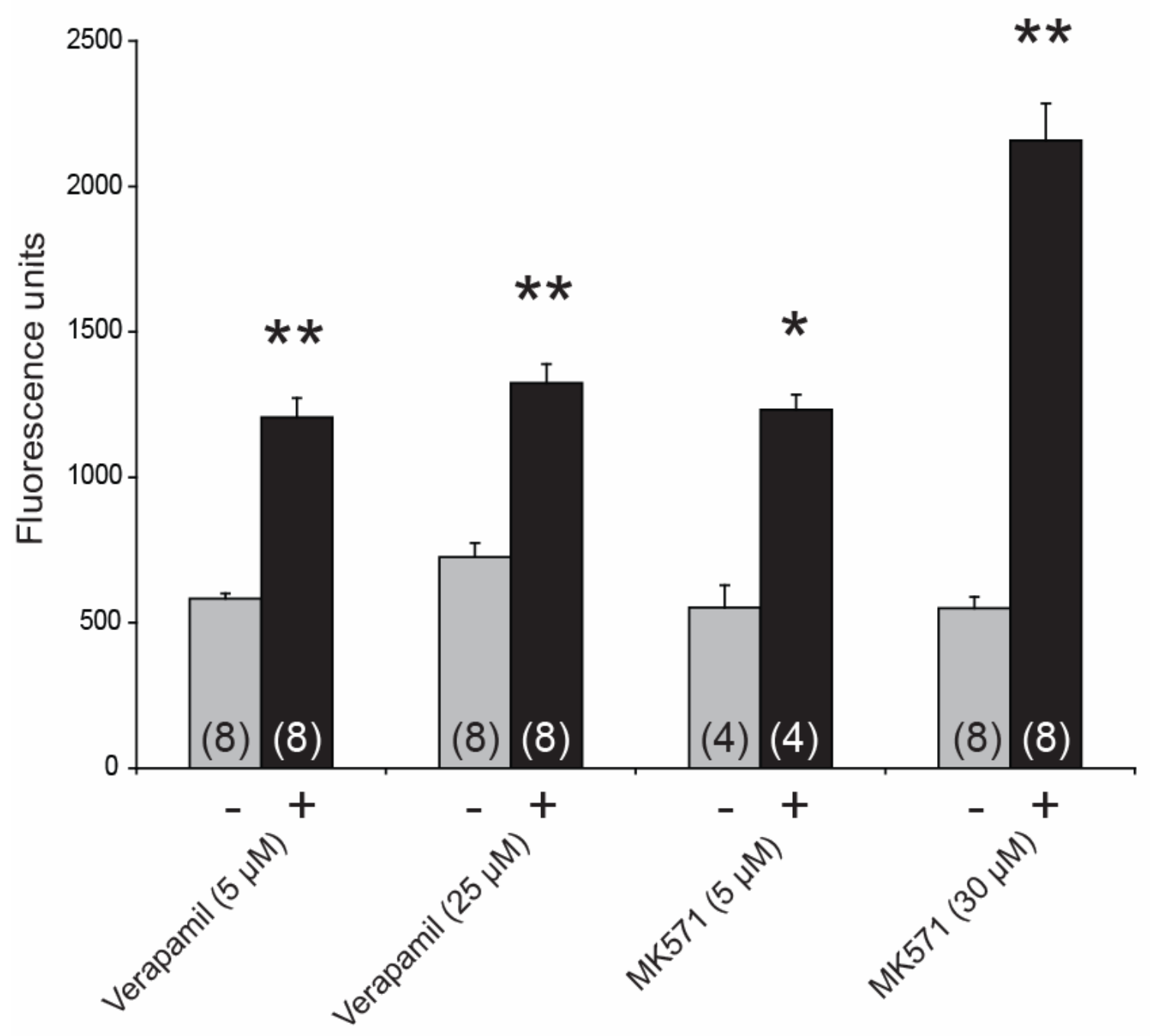

Figure 18. Change in intracellular fluorescence in $T$. hamnerorum incubated with MRP (MK571) and Pgp (verapamil) inhibitors compared to untreated controls. Bars represent mean fluorescence ( $\pm \mathrm{SE}$ ) of $T$. hamnerorum tissue homogenates from four or eight replicate wells (replicates indicated in parentheses). All inhibitor exposures resulted in a significant increase in calcein accumulation. MK571 at $30 \mu \mathrm{M}$ exposure resulted in the greatest inhibition of transport activity in T. hamnerorum. $\left({ }^{*} p=0.001\right.$, $* * p<0.001$, Two sample $t$ test) 


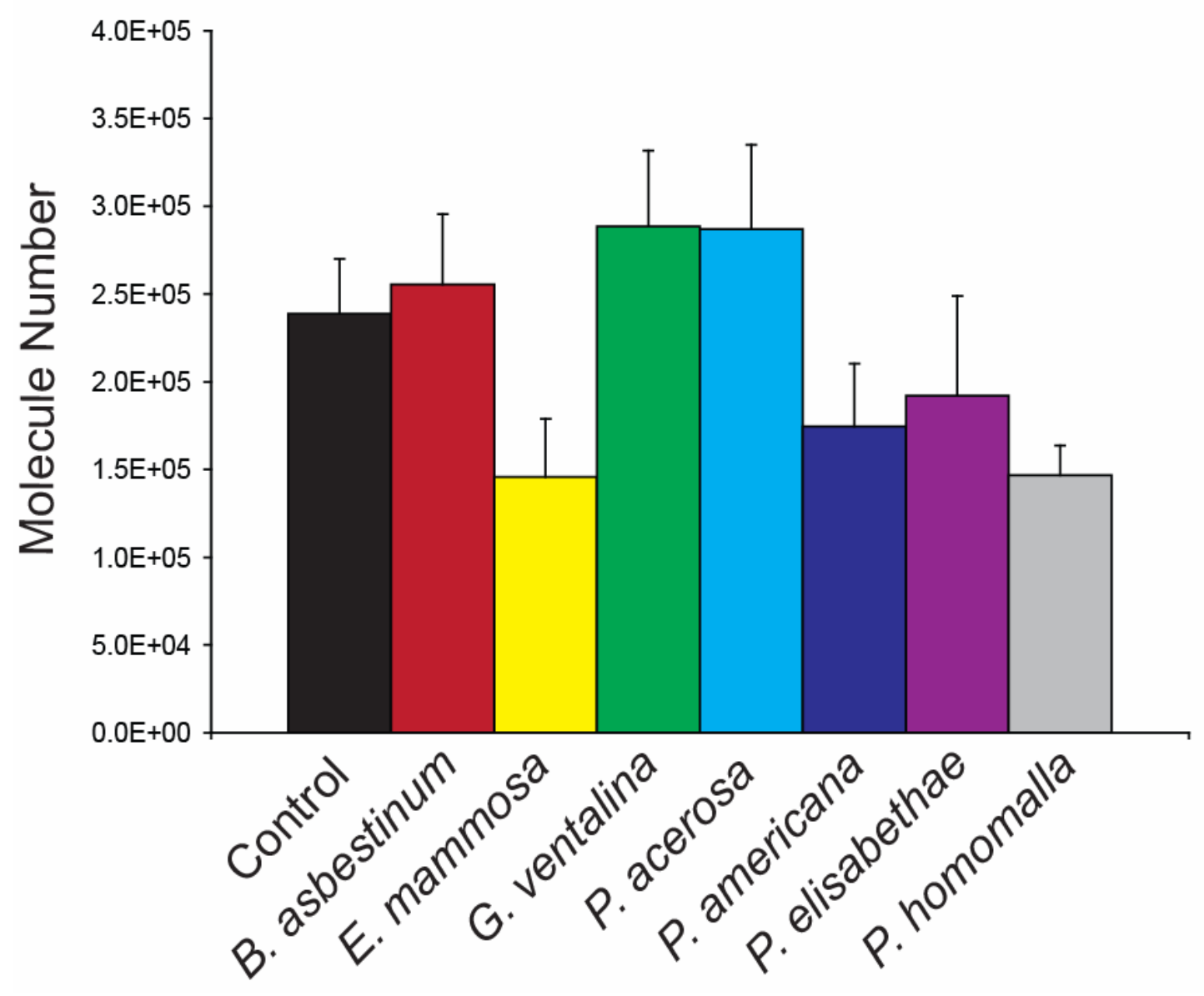

Figure 19. Mean MRP-1 transcript expression among $C$. gibbosum individuals feeding on a gorgonian or control diet for four days. Bars represent the mean MRP-1 transcript expression ( $\pm \mathrm{SE}$ ) of snails feeding on $B$. asbestinum (n $=13$ snails), $E$. mammosa $(\mathrm{n}=12), G$. ventalina $(\mathrm{n}=13), P$. acerosa $(\mathrm{n}=10), P$. americana $(\mathrm{n}=12), P$. elisabethae $(\mathrm{n}=6), P$. homomalla $(\mathrm{n}=11)$ or a control diet $(\mathrm{n}=33)$. Real-time quantitative PCR was performed and the number of transcript molecules per $0.2 \mu \mathrm{g}$ of poly(A)+ RNA was calculated from the standard curve and normalized by a $\beta$-actin correction factor. Results of a two-way ANOVA indicate no significant differences in MRP-1 expression in snails feeding on different diets. 

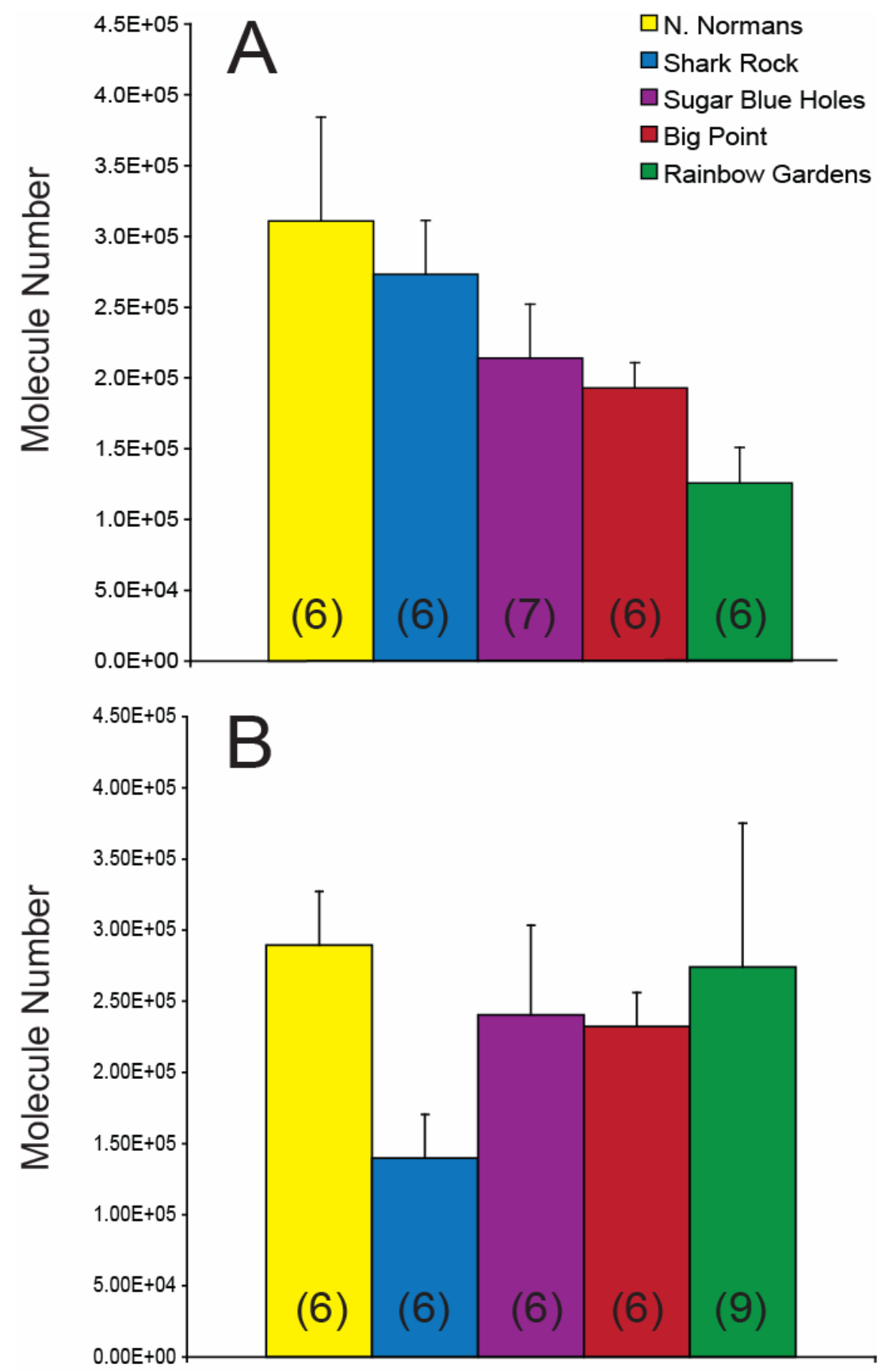

Figure 20. Mean MRP-1 transcript expression among time-zero and four day control diet fed $C$. gibbosum collected from five reefs. (A) Time-zero snails; mean MRP-1 transcript expression ( $\pm \mathrm{SE}$ ) in snails $(\mathrm{n}=31$ snails) collected from five reefs and immediately dissected to preserve reef-specific transcript expression signals. (B) Control snails; mean MRP-1 transcript expression $( \pm \mathrm{SE})$ in snails ( $\mathrm{n}=33$ snails) collected from five reefs and fed a control diet (e.g., alginic acid + squid powder) for four days. Values in parentheses indicate the number of replicate snails examined per reef. Real-time quantitative PCR was performed and the number of transcript molecules per $0.2 \mu \mathrm{g}$ of poly(A)+ RNA was calculated from the standard curve and normalized by a $\beta$-actin correction factor. 


\section{Chapter VI}

Conclusions and Future Directions 
The marriage between molecular/proteomic tools and traditional methods for the study of marine consumer-prey interactions holds considerable promise for the field of chemical ecology. Despite the tremendous progress in identifying the diversity, concentrations and distribution of allelochemicals and their effects on the behavior of marine consumers, few studies have addressed the proximate mechanisms underlying the profound variation in tolerance among these consumers for their chemically defended foods. The work presented in this thesis demonstrates the power of emerging technologies available to chemical ecologists to characterize for the first time those biochemical innovations postulated to lead to the adaptation of marine consumers to their allelochemically-defended prey. Elucidation of consumer environmental response genes encoding proteins involved in the detoxification and transport of natural products will undoubtedly ignite exciting science at the interface of pharmacology and marine ecology. Moreover, identifying the molecular underpinnings of organismal physiological response has broad implications for understanding the role of the environment in determining gene function in a co-evolutionary context. What follows in this chapter is the summation of a multidisciplinary study investigating the expression, activity and diversity of three dominant families of enzymes involved in xenobiotic resistance, providing the most comprehensive assessment thus far of biochemical resistance mechanisms used by marine consumers to cope with their chemically defended prey. 


\section{A Proteomic Approach to Chemical Ecology}

Glutathione $S$-transferases (GSTs) have long been known to play pivotal roles in xenobiotic resistance in insects and the high GST activity in the digestive gland of our model consumer, Cyphoma gibbosum (Vrolijk \& Targett 1992), further indicated their potential importance in allelochemical detoxification. However, information as to the diversity, isoform-specific expression, and relatedness of $C$. gibbosum GSTs to those of metazoans was lacking. After a molecular approach with degenerate primers designed to previously cloned molluscan GSTs failed to yield any GST sequences, efforts were redirected toward a proteomic approach that proved to be highly successful, facilitating the identification of the collection of expressed GSTs in C. gibbosum digestive gland. Peptide fragment analysis revealed that both mu- and theta-class GSTs were expressed in molluscan tissues - the latter being the first theta-class GST identified from a molluscan source. Mu-class GSTs are known to mediate the conjugation of electrophilic natural products, including prostaglandins (previously characterized as gorgonian feeding deterrents), while theta-class GSTs are unique in their ability to act as dehalogenases and may protect Cyphoma from a host of organohalogens found in its gorgonian diet.

RT-PCR and RACE cloning efforts with degenerate primers designed to homologous peptides obtained from proteomic analyses yielded two full-length mu-class GST cDNA sequences from C. gibbosum digestive gland. Comparative and phylogenetic analysis revealed that Cyphoma GST mu homologs share $78 \%$ amino acid identity and form a monophyletic group with other molluscan GST mu sequences. Attempts were made to further biochemically characterize individual Cyphoma mu-class GST isoforms 
by recombinant expression in yeast. While immunochemical analysis confirmed the expression of Cyphoma mu-class GSTs in yeast systems, GST activity was never observed with recombinant cytosolic fractions. It is possible the choice of expression system (yeast vs. E. coli) may have affected protein activity (e.g., inhibitor present), yet studies successfully expressing GSTs for functional characterization in both systems have been reported. Additional possibilities include the prevention of GST homodimer formation due to the presence of the C-terminal epitope tag used to visualize protein expression. Alternatively, Cyphoma GSTs may function as heterodimers, not uncommon among mu-class GSTs, and co-expression of both cDNAs would be necessary for GST activity to be restored. The potential of GST subunits to form heterodimers would likely increase the pool of potential substrates available for conjugation. Future optimization of recombinant Cyphoma GST expression systems will allow for further biochemical characterization of paralogous GST isoforms and permit the testing of hypotheses concerning possible subfunctionalization of specific GST isoforms following gene duplication and divergence events.

\section{Cyphoma GSTs: the role of constitutive biochemical defense mechanisms}

In contrast to most housekeeping genes, genes involved in xenobiotic metabolism often are strongly inducible by substrates upon which they act, accelerating the biotransformation and elimination of the substrate. Interestingly, Cyphoma digestive gland tissues constitutively express high levels of GST regardless of the diet of this consumer. Further, separation of Cyphoma GST proteins by HPLC revealed that GST 
subunits are expressed in the digestive gland in the same relative abundance in individuals feeding on different diets. These findings led me to test the hypothesis that the constitutive expression of GSTs may be advantageous to our generalist if the majority of gorgonian diets contain substrates for Cyphoma GSTs. A screen of crude extracts from eight species of gorgonian corals, commonly serving as hosts for Cyphoma in the field indicated that all extracts contained potent inhibitors of these enzymes, the most inhibitory of which were traced to the moderately hydrophobic, chloroform-soluble fractions. The sensitivity of Cyphoma GSTs to inhibition by these extracts suggests that gorgonian diets contain electrophilic substrates or inhibitors. GSTs are most notable for their ability to conjugate electrophilic substrates with glutathione; however, the ability of these enzymes to act as 'xenobiotic sponges' by sequestering non-substrate ligands (Ketley et al. 1975, Kostaropoulos et al. 2001) may serve as further protection against allelochemical toxicity. Additionally, the presence of inhibitors could represent counterdefense strategies employed by gorgonian hosts to block the GST-mediated metabolism of co-occurring allelochemicals by Cyphoma. Further studies at both the biochemical and organismal level would be needed to determine if potent gorgonian inhibitors could reduce the effectiveness of Cyphoma GSTs and thereby enhance toxicity.

Specific gorgonian compounds known for their ecological and biological activities were investigated for their ability to serve as substrates for Cyphoma GSTs. In mammals, prostaglandins are hormone-like fatty acids that exert their effects through Gprotein-coupled receptors and influence a variety of cellular processes including induction of apoptosis, inhibition of cell growth, activation of oxidative stress pathways 
and inflammation response. In marine systems, selected prostaglandin series $\left(\mathrm{PGA}_{2}\right.$, $\mathrm{PGE}_{2}$ and $\mathrm{PGF}_{2 \alpha}$ ) are found in unusually high concentrations in gorgonian tissue, where they function as antipredatory compounds. Some studies report that Cyphoma seems unaffected by the prostaglandins in its diet, preferring in some localities to reside on gorgonian species (e.g., Plexaura sp.) known to harbor high concentrations of prostaglandins. A screen of commercially available prostaglandins revealed that those in the A series, which are most abundant in gorgonians, were the most potent inhibitors of Cyphoma GST activity. Kinetic studies with affinity-purified GSTs indicated that 15(S)$\mathrm{PGA}_{2}$ was a competitive inhibitor, and likely a substrate for Cyphoma GSTs, with apparent affinity values comparable to $\mathrm{K}_{\mathrm{m}}$ constants described for vertebrate prostaglandin-conjugating GSTs. Estimates of the in vivo prostaglandin concentration experienced by Cyphoma when foraging suggests that GSTs would be saturated with respect to the $\mathrm{PGA}_{2}$ and would be operating near the enzyme's physiological limits. However, the prostaglandin-conjugating ability of Cyphoma GSTs will need to be substantiated in incubation experiments by demonstrating the formation of prostaglandinglutathione conjugates above non-enzymatic levels.

The results of Chapter 4 indicate that high, constitutive activity of Cyphoma gibbosum GSTs is likely necessitated by the ubiquitous presence of substrates/inhibitors in this consumer's gorgonian diet. Evidence from terrestrial insect-host studies also indicate that generalist counter-defense enzymes often have a broader substrate specificity than those of comparable specialists. The greater functional versatility of detoxification enzymes in generalists may facilitate the exploitation of a greater range of 
chemically diverse diets. Therefore, it would be interesting to compare GST expression and substrate metabolism profiles between the generalist Cyphoma gibbosum and the sympatric specialist Cyphoma signatum, which feeds solely on a single gorgonian species. It is possible that the success of the polyphagous foraging strategy of $C$. gibbosum is due to the constitutive expression of catalytically versatile GSTs that allow this consumer to cope with its chemically unpredictable prey.

Cyphoma P450s: gene specific induction in response to select suites of gorgonian allelochemicals

The majority of previous research assessing the response of marine consumer detoxification enzymes to allelochemical exposure has relied upon the use of enzymatic activity with diagnostic substrates or immunochemical detection with vertebrate-derived probes. While these methods are a good first step, often the selection of probes or diagnostic substrates has been biased toward vertebrate gene families or subfamilies involved in pharmacological or pollutant response, which may have little or no ecological relevance to allelochemical metabolism in the organism being studied. A more quantitative and sensitive approach to examine the tissue-specific level of putative allelochemical detoxification proteins involves quantitative PCR, which takes advantage of available molecular evidence and does not require first hand knowledge of protein function.

Cyphoma cytochrome P450 Family 4 (CYP4) members were originally targeted for expression analysis based on previous evidence in other organisms suggesting that 
classes of compounds analogous to those found in gorgonian tissues could be inducers and substrates of CYP4 proteins. Using molecular techniques, I identified several distinct CYP4 genes from Cyphoma digestive gland. Analysis of Cyphoma feeding on different diets revealed that mRNAs encoding specific CYP4 enzymes were regulated in a dietspecific manner. Select CYP4 transcripts were significantly induced in snails feeding on Plexaura homomalla, a gorgonian diet known to contain high concentrations of prostaglandins. Phylogenetic analysis of allelochemically-responsive molluscan CYP4 cDNAs indicated that the closest vertebrate relatives were those of the fatty acid metabolizing CYP4A and CYP4F subfamilies, both of which contain members with prostaglandin hydroxylase activity. A comparison of molluscan CYP4 genes with vertebrate fatty acid hydroxylase members revealed that molluscan enzymes share key amino acid residues within their substrate access channel and active site known to mediate prostaglandin hydroxylase activity in vertebrates. Heterologous expression of selected cDNAs indicated a possible role of Cyphoma CYP4s in eicosanoid metabolism. Furthermore, microsomal protein isolated from the digestive gland of snails feeding on $P$. homomlla had a greater propensity to metabolize the diagnostic fatty acid, leukotriene $\mathrm{B}_{4}$, in comparison to microsomes isolated from control snails. The increased eicosanoid metabolism in $P$. homomalla fed snails is consistent with the earlier observation that selected CYP4 enzymes are induced in snails feeding on this particular gorgonian diet, likely in response to the high concentrations of dietary prostaglandins.

The weight of evidence for Cyphoma CYP4s as prostaglandin metabolizing genes is striking. The next obvious step is to examine the metabolism of ecologically relevant 
prostaglandins by recombinant Cyphoma CYP4s. In addition, feeding assays with purified gorgonian prostaglandins incorporated into artificial diets offer a way to assess the rate and specificity of Cyphoma CYP4 transcript induction in response to specific allelochemical stressors. These additional studies will allow for a more complete description of the molecular and biochemical pathways likely responsible for mediating dietary prostaglandin tolerance in Cyphoma.

The results of this chapter have built a firm foundation from which to test additional hypotheses about the evolution and transcriptional regulation of environmental response genes in marine consumers. Molecular characterization of CYP4 transcripts expressed in C. gibbosum indicates that allelochemical-responsive CYP4 subfamilies have undergone extensive radiation in this generalist, likely driven in part by coevolutionary processes unique to the natural history of this consumer. Sequence variations have accrued in the coding regions, including substrate recognition sites, of these genes and this would suggest that despite their high degree of sequence similarity, these proteins may have significantly different metabolic capabilities and/or substrate specificities. The sequence diversity of allelochemically-responsive Cyphoma CYP4 subfamily members may reflect the enzymatic diversity required for generalists to metabolize the range of prostaglandin analogs in gorgonian tissues $\left(\mathrm{PGA}_{2}, \mathrm{PGE}_{2}\right.$ and $\left.\mathrm{PGF}_{2 \alpha}\right)$. Heterologous expression of polymorphic transcripts and subsequent analysis of prostaglandin metabolism would help define the key residue(s) required for metabolism of specific prostaglandin classes. 
In addition, promoter analysis of allelochemically-responsive CYP4 members is likely to identify a number of putative $c i s$-acting transcriptional response elements that are possible targets of regulation by gorgonian allelochemicals. Among the ligandactivated nuclear transcription factors known to regulate both CYP4 and GST expression are those in the peroxisome proliferator-activated receptor (PPAR) family, known for their roles in homeostasis, inflammation and wound repair. Cyclopentenone prostaglandins, including $\mathrm{PGA}_{2}$ series, are among the most potent of the natural PPAR agonists and it is likely that PPAR or related transcription factors orchestrate the induction of a battery of detoxification genes in Cyphoma in response to dietary prostaglandins. Sequencing of the sea urchin genome revealed two PPAR paralogs are present in invertebrate deuterostomes (Goldstone et al. 2006); however, little information exists as to the true number of nuclear receptors and their functions in molluscan species. Future work examining the ability of ecologically relevant prostaglandins to activate putative Cyphoma PPARs or related orphan nuclear receptors in cell-based reporter gene assays will help elucidate the molecular pathways responsible for gorgonian allelochemical detoxification. In sum, the work described in this chapter provides a framework for a more mechanistic understanding of the regulatory pathways mediating the expression of allelochemical metabolizing genes. 
Possible roles of efflux transporters as consumer counter-mechanisms to prey chemical defenses

Multixenobiotic resistance transporters (MXRs) are often considered an organism's first line of defense against environmental chemicals, yet they are frequently overlooked as possible allelochemical resistance mechanisms by many in the chemical ecology field. The multixenobiotic efflux phenotype has been described in several aquatic organisms, and numerous natural products - including marine examples - have been shown to inhibit the efflux of probe substrates for these transporters. The wide taxonomic distribution and broad substrate specificity of these transporters led me to hypothesize that MXRs may aid marine consumers in coping with dietary allelochemical stress. In addition to their efflux capabilities, MXRs have also been shown to facilitate the intracellular concentration of substrates in subcellular vesicles or organelles as another possible mechanism of reducing intracellular toxicity (Van Luyn et al. 1998, Molinari et al. 2002, Rajagopal \& Simon 2003, Ifergan et al. 2005). Some have suggested that the ability of specialist consumers to concentrate the dietary chemical defenses of their prey or host for their own protection may be facilitated by MXRmediated transport (Sorensen \& Dearing 2006). However, no specific transporters have yet been implicated in allelochemical sequestration. The objective of Chapter 5 was to improve our understanding of the diversity of putative allelochemical efflux transporters, their activity, and their expression in both generalist (Cyphoma gibbosum) and specialist (Tritonia hamnerorum) molluscan predators that are likely to process dietary allelochemicals in different ways based on the needs of each consumer. 
Molecular approaches yielded, from each molluscan species, four partial MXR fragments with homology to both human $\mathrm{ABCB}$ and $\mathrm{ABCC}$ subfamilies. Immunochemical analysis with a monoclonal antibody probe to P-glycoprotein (Pgp; ABCB1) detected immunoreactive proteins only in the tissue homogenates of Tritonia and not in the digestive gland homogenates of Cyphoma. Tritonia Pgp proteins were found to be associated with the apical tips of epithelia cells lining the gut lumen, a location consistent with a role in mediating dietary xenobiotic efflux. However, the lack of Pgp expression in Cyphoma homogenates and tissue sections was more ambiguous. Further inspection of partial deduced amino acid sequences of Cyphoma Pgps indicated that the disparity in protein expression may be due to lack of epitope recognition by the Pgp probe. These findings highlight the need for caution in interpreting immunochemical staining when probes developed in distantly related organisms are used.

Quantitative PCR is a more robust and sensitive approach for quantifying genespecific expression and, consequently, was used to investigate the influence of gorgonian diet on MXR expression in Cyphoma. I initially targeted Cyphoma multidrug resistance protein (MRP-1) because of its putative role in the ATP-dependent export of glutathione (GSH) conjugates, based on homology to known GSH-X efflux transporters. Quantitative PCR analysis revealed that MRP-1 was constitutively expressed in snails feeding on all gorgonian diets. This result coupled with the findings in Chapters 2 and 4 suggest that Cyphoma GSTs may play a significant role in the detoxification of hydrophobic gorgonian allelochemicals and resultant allelochemical glutathione conjugates could potentially be substrates for Cyphoma MRP-1 proteins. 
The in vivo activity of molluscan MXR transporters was assessed using a simple competitive dye efflux assay whereby MXR-specific inhibitors resulted in dye accumulation, implying the presence of MXR-mediated transport activity in Tritonia tissues. One question that was not addressed in studies in Chapter 5 was the ability of molluscan MXRs to transport (or sequester) gorgonian compounds. In the future, these same dye assays can be used to screen gorgonian extracts and pure compounds of interest using a bioassay-guided fractionation approach to identify substrates/inhibitors for molluscan MXR transporters both in in vivo and in vitro with selected heterologously expressed molluscan proteins. This screening approach can also be used to test hypotheses about the substrate flexibility of generalist MXRs that may allow these consumers to export a greater diversity of compounds, reflective of the chemically diverse and unpredictable diets they encounter, in comparison to specialist consumers.

Future work: genomic approaches to understanding allelochemical modes of action and consumer counter-defenses

The field of chemical ecology has entered a new era whereby advances in molecular biology are set to provide physiological ecologists with the most comprehensive view of how cells and ultimately organisms tolerate and respond to allelochemical stresses. Techniques such as transcriptome profiling using DNA microarrays will allow for the parallel analysis of the expression of thousands of genes, providing a complete picture of gene regulation occurring in response to dietary compounds. This method does not limit the researcher to simple single gene hypotheses 
rather, transcriptome profiling can be used to form a posteriori hypotheses about the mode of action of allelochemicals and consumer mechanisms of toxin resistance. The availability of genomic data from model marine organisms (e.g., anemone, sea urchin, sponge, oyster, limpet, polychaete, and tunicate) is rapidly expanding, and can be leveraged to investigate how small molecules can tranduce their effects through the genotype of an organism, ultimately affecting the phenotype and organism function. I am excited for the future of this field and the promise that genomic-enabled technology holds for rapidly advancing our understanding of allelochemical tolerance. Knowledge of how consumers respond and adapt to environmental chemical stressors on the molecular level will add volumes to our understanding of patterns of predation and herbivory in the marine environment.

\section{References Cited}

Goldstone JV, Hamdoun AM, Cole BJ, Howard-Ashby M, Nebert DW, Scally M, Dean M, Epel D, Hahn ME, Stegeman JJ (2006) The chemical defensome: Environmental sensing and response genes in the Strongylocentrotus purpuratus genome. Developmental Biology 300:366-384

Ifergan I, Scheffer GL, Assaraf YG (2005) Novel extracellular vesicles mediate an ABCG2-dependent anticancer drug sequestration and resistance. Cancer Research 65:10952-10958

Ketley JN, Habig WH, Jakoby WB (1975) Binding of nonsubstrate ligands to the glutathione S-transferases. Journal of Biological Chemistry 250:8670-8673

Kostaropoulos I, Papadopoulos AI, Metaxakis A, Boukouvala E, PapadopoulouMourkidou E (2001) Glutathione $S$-transferase in the defence against pyrethroids in insects. Insect Biochemistry and Molecular Biology 31:313-319

Molinari A, Calcabrini A, Meschini S, Stringaro A, Crateri P, Toccacieli L, Marra M, Colone M, Cianfriglia M, Arancia G (2002) Subcellular detection and localization of the drug transporter P-glycoprotein in cultured tumor cells. Curr Protein Pept Sci 3:653-670 
Rajagopal A, Simon SM (2003) Subcellular localization and activity of multidrug resistance proteins. Molecular Biology of the Cell 14:3389-3399

Sorensen JS, Dearing MD (2006) Efflux transporters as a novel herbivore countermechanism to plant chemical defenses. Journal of Chemical Ecology 32:1181-1196

Van Luyn MJA, Muller M, Renes J, Meijer C, Scheper RJ, Nienhuis EF, Mulder NH, Jansen PLM, De Vries GE (1998) Transport of glutathione conjugates into secretory vesicles is mediated by the multidrug-resistance protein 1 . International Journal of Cancer 76:55-62

Vrolijk NH, Targett NM (1992) Biotransformation enzymes in Cyphoma gibbosum: implications for detoxification of gorgonian allelochemicals. Marine Ecology Progress Series 88:237-246 
